\title{
INFORMAL SETTLERS, PERCEIVED SECURITY OF TENURE AND HOUSING CONSOLIDATION: CASE STUDIES FROM URBAN FIJI
}

\author{
By
}

Gabriel Luke Kiddle

\author{
A thesis \\ Submitted to the Victoria University of Wellington \\ in fulfilment of the requirements for the degree of \\ Doctor of Philosophy \\ in Geography
}

Victoria University of Wellington

2011 




\section{ABSTRACT}

The Pacific is an increasingly urban region. Accompanying this transformation has been the rapid growth of informal settlements in many Pacific nations. In Fiji, the site of the research, around 140,000 people are now living in informal settlements - often in poor quality housing, with inadequate service provision, in environmentally marginal areas, and with no legal security of tenure.

Emerging theory suggests that understandings of security of tenure need to move beyond a legal/illegal dichotomy and focus on perceived security of tenure. This perceived security of tenure approach accepts that a much wider continuum of land use rights typically exist and argues that households may engage in processes thought vital to addressing growing informality - such as 'self-help' housing investment (often termed 'housing consolidation') - in the absence of any legal security of tenure.

The research explores the nature of perceived security of tenure and housing consolidation in a unique context: a small-island state of dominant customary land. A mixed methods approach is taken, focusing on in-depth, semi-structured interviews with informal settlers in seven diverse case-study settlements across Fiji (on both state and native land). Ultimately the research seeks to inform a more nuanced understanding of Fijian informal settlements and suggest policy options for intervening amidst growing shelter informality.

Results suggest perceived security of tenure is more positive and housing consolidation is more prevalent than might be expected across the research case studies - although important differences are evident between indigenous Fijian and Indo-Fijian settlers. The research also reinforces the importance of the land tenure variable in the Fijian context particularly in influencing access arrangements to settlements, perceived security of tenure, and housing consolidation.

Perceived security of tenure approaches look to promote a wider package of policy options for improving tenure security for informal settlers. The current research supports an approach focusing on the in situ upgrading of current state land informal settlements (in contrast to the traditional focus on resettlement). It is also clear that ending evictions from state land areas - which unfortunately are still occurring, if not escalating, in Fiji - is 
the most important means of improving perceived security of tenure for current informal settlers on state land.

The research also focuses attention on informal settlements on native land - usually accessed by informal, or vakavanua, arrangements where new settlers negotiate a stay on the land directly with landowners. It is clear, however, that some of these arrangements - particularly for Indo-Fijian residents - leave settlers in precarious tenure situations. Informal settlements on native land also pose significant challenges as options for state intervention in these areas are limited. On the other hand, vakavanua arrangements do allow many low-income settlers to live affordably in central areas and thus reflect the resilience and flexibility of customary tenure which is so important in the Pacific. 


\section{ACKNOWLEDGEMENTS}

Many acknowledgements and sincere thanks are due to numerous people for their help and support in the four and a half years it has taken to produce this thesis. Firstly, I would like to thank my supervisor Professor John Overton for unwavering support and positivity that has encouraged me throughout - our discussions and your suggestions have added much to the process and final product. At Victoria University of Wellington I would also like to thank John McKinnon for early discussions and a final full read and comments, Professor Warwick Murray for some early suggestions, and Sophie Bond for review in the closing stages.

At universities elsewhere, I would particularly like to thank Professor Vijay Naidu at the University of the South Pacific (USP) for insight, help, encouragement, hospitality and friendship. Thank you also to all staff of the USP Development Studies Programme for help during my attachment. At USP I would also like to thank the many academics who gave their time in early discussions while refining the topic and searching for secondary resources. At the University of Wisconsin-Madison I would like to particularly thank Kurt Brown for kind hospitality and friendship, and Professor Harvey Jacobs for some stimulating discussions and new directions during my 2009 visit. At the Australian National University I would also like to particularly thank Dr. Charles Yala for some key advice in refining the research objectives.

Many people in Fiji helped to make the five-and-a-half-month fieldwork period in 2008 enjoyable, productive, rewarding and enriching. Firstly, a big vinaka vakalevu to all the residents of Lagilagi, Caubati Topline, Lakena Hill Two, Vunato, Tomuka, Tauvegavega and Bouma who were so welcoming, open and forthcoming during my community visits and interviews. I look forward to meeting again to feedback my key findings. Secondly, to all the individuals from government, civil society, and donor and international organisations who gave their time for interviews - thank you. I would also like to particularly acknowledge and thank Epeli Waqavonovono at the Fiji Islands Bureau of Statistics for willingness to share and prepare information from the 2007 census, as well as Father Kevin Barr and Semiti Qalowasa at the Ecumenical Centre for Research, Education \& Advocacy for aid in selecting case studies and facilitating introductions.

Thank you to my parents, Ed and Liz, my mother-in-law, Beryl McCormick, and sister-inlaw, Rhonda McCormick, for ongoing love, support and help with the children. Finally, I 
would like to thank my wife, Esther Kiddle, for ongoing encouragement, suggestions, and stirling editing skills (including at 40 weeks pregnant!). Certainly, when beginning this PhD I did not anticipate that submission would come three children, one marriage, and five city moves later! Esther, Ada, Sanne and Gabriel, this thesis is for you all.

The PhD was funded by a Victoria University of Wellington PhD scholarship and a PhD submission scholarship. 2008 Fieldwork costs were aided by a New Zealand Agency for International Development Postgraduate Field Research Award. Two grants from the School of Geography, Environment and Earth Science at Victoria University of Wellington enabled two early scoping and preparatory visits to Fiji. A JL and Kathleen Stewart Postgraduate Research Experience Travel Award helped to make a short period as visiting scholar to the Land Tenure Center at the University of Wisconsin-Madison in 2009 possible. Funding from the Australian National University also enabled attendance at the 2009 Asia-Pacific Week. A tertiary grant from the Masterton Trust Lands Trust was also gratefully received. All this financial support is acknowledged with sincere thanks. 
TABLE OF CONTENTS

\begin{tabular}{|c|c|}
\hline & Page \\
\hline List of Tables & viii \\
\hline List of Figures & $\mathrm{x}$ \\
\hline List of Acronyms and Symbols & $\mathrm{xi}$ \\
\hline Glossary of Fijian Terms Used & xiii \\
\hline CHAPTER 1: INTRODUCTION, CENTRAL RESEARCH QUESTION AND OBJECTIVES & 1 \\
\hline $\begin{array}{l}\text { CHAPTER 2: THE INTERNATIONAL CONTEXT - GLOBAL URBAN GROWTH, INFORMAL } \\
\text { SETTLEMENTS, HOUSING POLICY, AND SECURITY OF TENURE }\end{array}$ & 7 \\
\hline 2.1 Introduction & 7 \\
\hline 2.2 Global Urban Growth & 7 \\
\hline 2.3 Urban Poverty and the Challenges of Urbanisation & 11 \\
\hline 2.4 The Urban Built Environment for the Poor & 13 \\
\hline 2.5 International Housing Policy & 16 \\
\hline 2.6 Land Tenure Type and Security of Tenure & 30 \\
\hline 2.7 Summary & 32 \\
\hline CHAPTER 3: THE REGIONAL CONTEXT - AN INCREASINGLY URBAN PACIFIC & 35 \\
\hline 3.1 Introduction & 35 \\
\hline 3.2 Internal Migration and Urbanisation in the Pacific & 36 \\
\hline 3.3 Urban Management in the Pacific & 40 \\
\hline 3.4 The Pacific Land Tenure Debate & 42 \\
\hline 3.5 Security of Tenure and Housing Consolidation Research in the Pacific & 44 \\
\hline 3.6 Summary & 46 \\
\hline CHAPTER 4: THE FIJI CONTEXT & 47 \\
\hline 4.1 Introduction & 47 \\
\hline 4.2 Geography and Demography & 47 \\
\hline 4.3 Development Challenges & 50 \\
\hline 4.4 Fiji's Historical Legacy & 51 \\
\hline 4.5 Land Tenure in Fiji & 53 \\
\hline 4.6 The Fijian Economy & 62 \\
\hline 4.7 The Political Environment: A Legacy of Insecurity & 67 \\
\hline 4.8 The Poverty Profile and Coping Strategies & 70 \\
\hline 4.9 Notions of Security and Insecurity in Fiji & 74 \\
\hline 4.10 Summary & 75 \\
\hline CHAPTER 5: URBANISATION AND INFORMAL SETTLEMENTS IN FIJI & 77 \\
\hline 5.1 Introduction & 77 \\
\hline 5.2 Urbanisation in Fiji & 77 \\
\hline 5.3 The Emergence of Fijian Squatter/Informal Settlements & 85 \\
\hline 5.4 Summary & 105 \\
\hline $\begin{array}{l}\text { CHAPTER 6: INTERVENTION ACTIVITIES WITHIN THE FIJIAN LOW-INCOME HOUSING AND } \\
\text { INFORMAL SETTLEMENT SECTOR }\end{array}$ & 107 \\
\hline 6.1 Introduction & 107 \\
\hline 6.2 State Intervention & 107 \\
\hline
\end{tabular}




\begin{tabular}{|c|c|}
\hline 6.3 NGO Activities & 115 \\
\hline 6.4 Donor and International Organisations & 118 \\
\hline 6.5 Challenges to Intervention & 120 \\
\hline 6.6 Summary & 122 \\
\hline CHAPTER 7: RESEARCH METHODS & 125 \\
\hline 7.1 Introduction & 125 \\
\hline 7.2 Methodology and Epistemology & 126 \\
\hline 7.3 Methods & 128 \\
\hline 7.4 Limitations and Potential Biases & 133 \\
\hline 7.5 Summary & 136 \\
\hline CHAPTER 8: THE CASE STUDIES & 139 \\
\hline 8.1 Introduction & 139 \\
\hline 8.2 Lagilagi & 143 \\
\hline 8.3 Caubati Topline & 146 \\
\hline 8.4 Lakena Hill Two & 149 \\
\hline 8.5 Vunato & 152 \\
\hline 8.6 Tomuka & 155 \\
\hline 8.7 Tauvegavega & 158 \\
\hline 8.8 Bouma & 161 \\
\hline 8.9 Key Features of the Case Studies & 164 \\
\hline 8.10 Summary & 177 \\
\hline $\begin{array}{l}\text { CHAPTER 9: KEY RESULTS - SOCIO-ECONOMIC CHARACTERISTICS, MOVEMENT, ACCESS, } \\
\text { LIVELIHOODS, AND SERVICES AND AMENITIES }\end{array}$ & 181 \\
\hline 9.1 Introduction & 181 \\
\hline 9.2 Basic Socio-Economic Characteristics: Household Size and Average Incomes & 181 \\
\hline 9.3 Tenure Status and Length of Residence in Informal Settlements & 184 \\
\hline 9.4 The Nature of Movement & 185 \\
\hline 9.5 Access to Informal Settlements and Payments & 198 \\
\hline 9.6 Livelihoods in Informal Settlements & 208 \\
\hline 9.7 Services and Amenities in Informal Settlements & 214 \\
\hline 9.8 Summary & 215 \\
\hline $\begin{array}{l}\text { CHAPTER 10: KEY RESULTS - PERCEIVED SECURITY OF TENURE AND HOUSING } \\
\text { CONSOLIDATION }\end{array}$ & 217 \\
\hline 10.1 Introduction & 217 \\
\hline 10.2 Perceived Security of Tenure & 217 \\
\hline 10.3 Housing Consolidation & 239 \\
\hline 10.4 Summary & 254 \\
\hline $\begin{array}{l}\text { CHAPTER 11: DISCUSSION - THEMES, THE DYNAMICS OF PERCEIVED SECURITY OF TENURE } \\
\text { AND HOUSING CONSOLIDATION, RESEARCH NEEDS, AND POSSIBLE POLICY RESPONSES }\end{array}$ & 257 \\
\hline 11.1 Introduction & 257 \\
\hline 11.2 Key Themes from the Case Studies & 257 \\
\hline 11.3 Perceived Security of Tenure & 265 \\
\hline 11.4 Housing Consolidation & 276 \\
\hline $\begin{array}{l}11.5 \text { The Relationship between Perceived Security of Tenure and Housing } \\
\text { Consolidation }\end{array}$ & 280 \\
\hline 11.6 Limitations of the Current Study and Additional Future Research Neec & 284 \\
\hline
\end{tabular}




\begin{tabular}{|l|c|}
\hline 11.7 Possible Policy Responses & 287 \\
\hline 11.8 SUmmary & 295 \\
\hline CHAPTER 12: CONCLUSION & 297 \\
\hline & \\
\hline REFERENCES & 303 \\
\hline & \\
\hline APPENDICES & \\
\hline
\end{tabular}




\section{LIST OF TABLES}

\begin{tabular}{|c|c|}
\hline & Page \\
\hline Table 4.1. Primary Land Tenure in Fiji, 1970s, 1990s, and 2000s & 59 \\
\hline Table 4.2. Changes in Fijian Export Values (F\$ million), Key Sectors, 1985-2008 & 63 \\
\hline Table 4.3. Poverty in Fiji, 1977, 1990/91, 2002/03 & 71 \\
\hline $\begin{array}{l}\text { Table } 4.4 \text { Incidence of Poverty in Fiji (percentage of population with weekly per } \\
\text { capita income less than the poverty line), } 2002 / 03\end{array}$ & 72 \\
\hline $\begin{array}{l}\text { Table 4.5. Proportion of Own Production in Household Food Consumption, Fiji, } \\
2002 / 03\end{array}$ & 74 \\
\hline Table 5.1. Expiry and Renewal of ALTA Leases, 1997-2010 & 80 \\
\hline Table 5.2. Past and Projected Levels of Fiji Urbanisation, 1966-2030 & 82 \\
\hline Table 5.3. Divisional Population Distribution, Fiji, by Ethnicity, 1996 and 2007 & 84 \\
\hline Table 5.4. Squatter Households by Division and Ethnicity, 2003, HSRU Data & 96 \\
\hline Table 5.5. Squatter Households by Division and Ethnicity, 2007, HSRU Data & 97 \\
\hline $\begin{array}{l}\text { Table 5.6. Squatter Population and Households by Division and Ethnicity, } 2007 \\
\text { Census Data }\end{array}$ & 98 \\
\hline Table 8.1. Key Summary Basic Data: All Communities & 142 \\
\hline Table 9.1. Average Household Size, All Case Studies, Research Sample & 182 \\
\hline $\begin{array}{l}\text { Table 9.2. Average Household Size, Lagilagi, Caubati Topline, Lakena Hill Two, } \\
\text { Tomuka, Tauvegavega and all Fiji, } 2007 \text { Census Information }\end{array}$ & 182 \\
\hline $\begin{array}{l}\text { Table 9.3. Average Household Monthly Income, Fijian Dollars, All Case Studies, } \\
\text { Research Sample }\end{array}$ & 183 \\
\hline $\begin{array}{l}\text { Table 9.4. Average Household Income Per Person Per Day, Fijian Dollars, All Case } \\
\text { Studies, Research Sample }\end{array}$ & 183 \\
\hline $\begin{array}{l}\text { Table 9.5. Average Monthly Household Incomes, Fijian Dollars, 2002/2003 HIES } \\
\text { Data }\end{array}$ & 184 \\
\hline $\begin{array}{l}\text { Table 9.6. Average Length of Community Residence (Primary Interviewee or } \\
\text { Partner), All Case Studies, Research Sample }\end{array}$ & 185 \\
\hline Table 9.7. Previous Tenure Status, All Case Studies, Research Sample & 188 \\
\hline Table 9.8. Principal Reason for Location, All Case Studies, Research Sample & 190 \\
\hline $\begin{array}{l}\text { Table 9.9. Population by Locality of Birth, Lagilagi, Caubati Topline, Lakena Hill } \\
\text { Two and Tauvegavega, } 2007 \text { Census Information }\end{array}$ & 191 \\
\hline $\begin{array}{l}\text { Table 9.10. Population by Locality in 2002, Lagilagi, Caubati Topline, Lakena Hill } \\
\text { Two and Tauvegavega, } 2007 \text { Census Information }\end{array}$ & 192 \\
\hline $\begin{array}{l}\text { Table 9.1 1. Previous Connections to the Community, All Case Studies, Research } \\
\text { Sample }\end{array}$ & 198 \\
\hline Table 9.12. House Built or Obtained, All Case Studies, Research Sample & 199 \\
\hline $\begin{array}{l}\text { Table 9.13. Principal Means of Community Access, All Case Studies, Research } \\
\text { Sample }\end{array}$ & 201 \\
\hline $\begin{array}{l}\text { Table 9.14. Principal Method of Payment to Facilitate Community Access (if any), } \\
\text { All Case Studies, Research Sample }\end{array}$ & 201 \\
\hline
\end{tabular}




\begin{tabular}{|c|c|}
\hline Table 9.15. Main Household Income Source, All Case Stu & 209 \\
\hline $\begin{array}{l}\text { Table 9.16. Average Household Food Spend per Week, Fijian Dollars, All Case } \\
\text { Studies, Research Sample }\end{array}$ & 211 \\
\hline $\begin{array}{l}\text { Table 9.17. Percentage of Average Household Income Spent on Food, All Case } \\
\text { Studies, Research Sample }\end{array}$ & 211 \\
\hline $\begin{array}{l}\text { Table 9.18. Presence of Household Food Gardens, All Case Studies, Research } \\
\text { Sample }\end{array}$ & 212 \\
\hline $\begin{array}{l}\text { Table 10.1. Responses to the Question 'Do You Feel Threatened By Eviction?', } \\
\text { Research Sample }\end{array}$ & 218 \\
\hline $\begin{array}{l}\text { Table 10.2. Responses to the Question 'Has Anyone Tried To Make You Move?', } \\
\text { Research Sample }\end{array}$ & 219 \\
\hline $\begin{array}{l}\text { Table 10.3. Positive Responses to the Question 'Have You Ever Had Any Problems } \\
\text { With The Owner Of The House Or Land?', Research Sample }\end{array}$ & 222 \\
\hline $\begin{array}{l}\text { Table } 10.4 \text { Responses to the Question 'Do You Feel Secure or Insecure?', Research } \\
\text { Sample }\end{array}$ & 227 \\
\hline $\begin{array}{l}\text { Table 10.5. Security of Tenure on a Ten-Point Scale(Weighted Score Average), } \\
\text { Research Sample }\end{array}$ & 231 \\
\hline Table 10.6. Perceived Security of Tenure, Author's Analysis, Research Sample & 233 \\
\hline $\begin{array}{l}\text { Table 10.7. Perceived Security of Tenure by Primary Land Tenure, All Ethnic } \\
\text { Groups, Research Sample }\end{array}$ & 234 \\
\hline $\begin{array}{l}\text { Table 10.8. Perceived Security of Tenure by Primary Land Tenure, Indigenous Fijian } \\
\text { and Indo-Fijian Participants, Research Sample }\end{array}$ & 234 \\
\hline $\begin{array}{l}\text { Table 10.9. Construction of Dwelling Walls, All National Squatter Households, Total } \\
\text { Numbers, } 2007 \text { Census Information }\end{array}$ & 240 \\
\hline $\begin{array}{l}\text { Table 10.10. Construction of Dwelling Walls, Lagilagi, Caubati Topline, Lakena Hill } \\
\text { Two, Tomuka and Tauvegavega, Total Numbers and Percentage of all } \\
\text { Households in Community, } 2007 \text { Census Information }\end{array}$ & 241 \\
\hline $\begin{array}{l}\text { Table 10.11. Wall Quality, Lagilagi, Caubati Topline, Lakena Hill Two and } \\
\text { Tauvegavega, } 2007 \text { Census Information }\end{array}$ & 242 \\
\hline Table 10.12. Housing Investment in Last Five Years (2003-2008), Research Sample & 243 \\
\hline $\begin{array}{l}\text { Table 10.13. Housing Investment in Last Five Years (2003-2008), by Primary Land } \\
\text { Tenure, Indigenous Fijian and Indo-Fijian Participants and all Ethnic Groups }\end{array}$ & 244 \\
\hline Table 10.14. Average Number of Dwelling Rooms, Research Sample & 246 \\
\hline Table 10.15. Principal Reason for No Housing Consolidation, Research Sample & 250 \\
\hline Table 10.16. Access to Formal Credit, Research Sample & 252 \\
\hline $\begin{array}{l}\text { Table 1 1.1. Perceived Security of Tenure, Fiji Informal Settlers, Current Research } \\
\text { and Walsh, } 1978\end{array}$ & 267 \\
\hline $\begin{array}{l}\text { Table 11.2. Perceived Security of Tenure and Housing Consolidation, Research } \\
\text { Sample }\end{array}$ & 281 \\
\hline $\begin{array}{l}\text { Table 11.3. Average Length of Residence, Monthly Income, and Access to Credit } \\
\text { by Evidence of Housing Consolidation, Research Sample }\end{array}$ & 282 \\
\hline $\begin{array}{l}\text { Table 1 1.4. Evidence of Housing Consolidation by Category of Tenure Security, } \\
\text { Research Sample }\end{array}$ & 283 \\
\hline
\end{tabular}




\section{LIST OF FIGURES}

\begin{tabular}{|l|c|}
\hline & Page \\
\hline & \\
\hline Figure 2.1. Global Urban and Rural Population Trends, 1950-2050 & 8 \\
\hline Figure 2.2. The Positive Correlation Between Urbanisation and Economic & 10 \\
Development & 31 \\
\hline Figure 2.3. Urban Tenure Categories by Tenure Status & 35 \\
\hline Figure 3.1. Map of the Pacific & 48 \\
\hline Figure 4.1. Map of Fiji & 49 \\
\hline Figure 4.2. Principal Fijian Sugarcane Growing Areas & 60 \\
\hline Figure 4.3. Distribution of Land Tenure, Viti Levu, mid-1990s & 60 \\
\hline Figure 4.4. Distribution of Land Tenure, Vanua Levu and Taveuni, mid-1990s & 78 \\
\hline Figure 5.1. Map of Fiji with Main Urban Centres & 82 \\
\hline Figure 5.2. Map of Fiji Administrative Divisions & 95 \\
\hline Figure 5.3. Distribution of Squatter Settlements in Central Suva, mid-1980s & 139 \\
\hline Figure 8.1. National Location of Case Studies & 140 \\
\hline Figure 8.2. Location of the Greater Suva Case Studies & 144 \\
\hline Figure 8.3. Satellite Image of Lagilagi & 147 \\
\hline Figure 8.4. Satellite Image of Caubati Topline & 150 \\
\hline Figure 8.5. Satellite Image of Lakena Hill Two & 153 \\
\hline Figure 8.6. Satellite Image of Vunato & 156 \\
\hline Figure 8.7. Satellite Image of Tomuka & 159 \\
\hline Figure 8.8. Satellite Image of Tauvegavega & 162 \\
\hline Figure 8.9. Satellite Image of Bouma & 187 \\
\hline Figure 9.1. Location of Previous Residence, Urban Area within Province and Rural \\
Area by Division, All Case Studies, Research Sample & \\
\hline Figure 9.2. Location of Previous Residence, All Urban Areas and All Rural Areas, \\
All Case Studies, Research Sample & 187 \\
\hline Figure 9.3. Principal Reason for Location Decision, All Case Studies, Research \\
Sample & 189 \\
\hline Figure 11.1. Tenure Categories Within the Case-Study Settlements & 275 \\
\hline Figure 11.2. Evidence of Housing Consolidation by Category of Tenure Security, \\
Research Sample & 283 \\
\hline
\end{tabular}




\section{LIST OF ACRONYMS AND SYMBOLS}

\section{Acronyms}

\begin{tabular}{|c|c|}
\hline ACP & African, Caribbean and Pacific \\
\hline ADB & Asian Development Bank \\
\hline ALTA & Agricultural Landlord and Tenant Act \\
\hline ALTO & Agricultural Landlord and Tenant Ordinance \\
\hline AusAID & Australian Agency for International Development \\
\hline BNPL & Basic Needs Poverty Line \\
\hline CSR & Colonial Sugar Refinery \\
\hline ECREA & Ecumenical Centre for Research, Education and Advocacy \\
\hline EU & European Union \\
\hline FPL & Food Poverty Line \\
\hline FSC & Fiji Sugar Corporation \\
\hline GDP & Gross Domestic Product \\
\hline $\mathrm{HA}$ & Housing Authority \\
\hline HART & Housing and Relief Trust \\
\hline HFHF & Habitat for Humanity Fiji \\
\hline HIES & Household Income and Expenditure Survey \\
\hline HSRU & Housing and Squatter Resettlement Unit \\
\hline IRIN & United Nations Office for the Coordination of Humanitarian Affairs \\
\hline MDG & Millennium Development Goal \\
\hline NCBBF & National Council for Building a Better Fiji \\
\hline n.a. & not applicable \\
\hline n.d. & no date \\
\hline NLTB & Native Land Trust Board \\
\hline
\end{tabular}


NZAID New Zealand Agency for International Development (renamed the 'New Zealand Aid Programme' in 2009)

NZAP New Zealand Aid Programme

PCN Peoples' Community Network

PRB Public Rental Board

SDL

Soqosoqo Duavata Lewe Ni Vanua (Party)

UNDP

United Nations Development Programme

UNFPA

United Nations Population Fund

UN-Habitat

United Nations Human Settlement Programme

VKB

Vola Ni Kawa Bula (national register of all mataqali members)

$\underline{\text { Symbols }}$

$\cdot$.

no data

$F \$$

Fijian dollars (note as of November $2011 \mathrm{~F} \$ 1=\mathrm{NZ} \$ 0.69$ ) 


\section{GLOSSARY OF FIJIAN TERMS USED}

\begin{tabular}{|c|c|c|}
\hline Bele & ----------------------' & An edible shrub \\
\hline Bure & 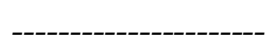 & A traditional Fijian thatched hut \\
\hline Dalo & 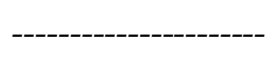 & Taro \\
\hline Galala & 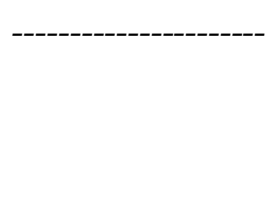 & $\begin{array}{l}\text { Regulations that made it expensive through } \\
\text { a colonial commutation tax for indigenous } \\
\text { Fijians to be away from villages and thus } \\
\text { exempt from communal obligations }\end{array}$ \\
\hline Girmit & -------------------- & $\begin{array}{l}\text { An agreement bringing Indian indentured } \\
\text { labourers to Fiji from } 1879 \text { to } 1916\end{array}$ \\
\hline Girmitiyas & --------------------- & $\begin{array}{l}\text { Those who came to Fiji under the } \\
\text { indentured labour system }\end{array}$ \\
\hline i taukei & 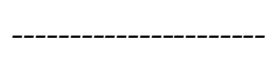 & Indigenous Fijians \\
\hline i tokatoka & ------------------- & $\begin{array}{l}\text { A smaller number group within the } \\
\text { village/mataqali }\end{array}$ \\
\hline Kerekere & 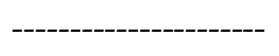 & To request \\
\hline Koro & 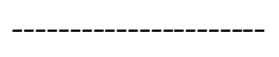 & Village \\
\hline Matanitu & 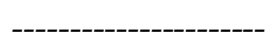 & A wide political alliance of vanua \\
\hline Mataqali & 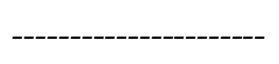 & Land owning tribal group/unit \\
\hline Rourou & & $\begin{array}{l}\text { Dalo leaves (often cooked with coconut } \\
\text { milk) }\end{array}$ \\
\hline Sevusevu & & $\begin{array}{l}\text { A ceremonial offering to the host (usually } \\
\text { accompanying a request) }\end{array}$ \\
\hline Soli & 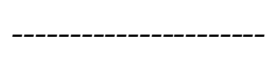 & Gift/collection \\
\hline Tabua & & $\begin{array}{l}\text { Whale's tooth (used predominantly for } \\
\text { ceremonial exchange) }\end{array}$ \\
\hline Tanoa & --------------------- & Kava bowl \\
\hline Tikana & 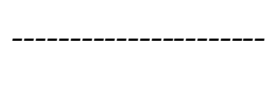 & $\begin{array}{l}\text { A Fijian administrative unit equivalent to } \\
\text { district }\end{array}$ \\
\hline Tiri & ---------------------- & Mangrove \\
\hline
\end{tabular}


Turaga

Vakadeitaki

Vakavanua

Vakavinavinaka

Vanua

Yaqona

Yavusa
Chief

Loosely translates as having some assurance that it is possible to stay on the land for as long as a household may want. It can be used to denote security of tenure

Cultural values or customary practices in the way of the land. Vakavanua agreements are informal arrangements used to allow the use of both rural and urban land

An expression of appreciation for being accorded a favour or to say thank you

A complex term referring most simply to land, people and custom

Piper methysticum (otherwise known as kava) - a plant the roots of which are prepared and used as a ceremonial and social drink

The widest tribal group comprising several mataqali 


\section{CHAPTER 1: INTRODUCTION, CENTRAL RESEARCH QUESTION AND OBJECTIVES}

In 2007, a major milestone was reached in human history; for the first time the world's urban population outnumbered those living in rural areas (United Nations Population Fund, 2007, p. 1). The next decades are expected to bring unprecedented population growth, concentrated in the urban areas of the developing world (Satterthwaite, 2007). The world's urban population is projected to grow from 3.4 billion in 2009 to 6.3 billion in 2050 (United Nations Department of Economic and Social Affairs, 2010, p. 1). The growth of slums, housing characterised by lack of water and sanitation, overcrowding, nondurable structures, and insecurity of land tenure (UN-Habitat, 2006, p. x-xi), have become synonymous, particularly in the developing world, with urban growth (ibid, $p$. viii). In 2007, another major global milestone was also reached when the number of urban slum dwellers passed the one billion mark (ibid) - a figure expected to rise to 1.4 billion by 2020 (ibid, p. x). In 2000, the international community committed to the Millennium Development Goals (MDGs), including MDG 7, Target 11: by 2020, to have improved the lives of 100 million slum dwellers. However, it is clear that the utility of this measure is rapidly decreasing with the enormous scale of continued global slum growth.

Security of tenure, defined by the United Nations Human Settlements Programme (UNHabitat) as the "rights of all individuals and groups to effective protection from the State against forced eviction" (2006, p. 94), is becoming increasingly precarious across the developing world - particularly when mass evictions are commonplace (ibid). While security of tenure is hard to measure on a global and local scale, evidence suggests that between $30-50 \%$ of the world's urban residents lack security of tenure (ibid, p. xi) proportions, unfortunately, that are only likely to worsen (UN-Habitat, 2007, p. 113).

The Pacific is also rapidly urbanising; transforming the social fabric of a region traditionally perceived as rural. If Papua New Guinea is excluded, around half of the region's population now live in urban areas (Australian Agency for International Development (AUSAID), 2008, p. 74). Urban growth is particularly pronounced in Melanesia where annual urban growth rates ${ }^{1}$ range from $1.5 \%$ and $2.8 \%$ in Fiji and Papua New Guinea to $4.0 \%$ and $4.2 \%$ in Vanuatu and Solomon Islands (Secretariat of the Pacific Community, 2010) - translating into urban population doubling times of approximately

\footnotetext{
1 From the most recent intercensal period.
} 
15-30 years (Haberkorn, 2006, p. 2). Difficulties in measuring security of tenure, coupled with a paucity of any reliable regional data, mean that indicators for MDG 7, Target 11 , are completely absent in the Pacific. However, it is certain that urban slums, usually known in the region as 'squatter settlements' but more appropriately termed 'informal settlements', are emerging as prominent features of the urban built environment in Papua New Guinea, Fiji, Vanuatu, Solomon Islands and Kiribati particularly. In Fiji, the site of the current research, 2007 census results show that more than $50 \%$ of the national population now live in urban areas (Fiji Islands Bureau of Statistics, 2008). 2007 census figures also reveal that just under 78,000 people now live in officially recognised squatter settlements. This is a very conservative figure, however, and more likely upwards of 140,000 people (or around $16.5 \%$ of the national population and $33 \%$ of the officially urban population) live in all types of informal settlements (McKinnon, Whitehead, Chung \& Taylor, 2007, p. ii). Legal security of tenure is absent for this very sizable group of Fiji's population. Poor quality housing, inadequate service provision and environmentally marginal locations also characterise informal settlements in Fiji. Urban poverty is also concentrated within Fijian informal settlements.

Theory influencing international low-income housing policy and intervention targeted towards informal settlements broadly fits within two major camps. Firstly, what are generally known as 'property rights approaches' largely extol the benefits of legalisation or formalisation (or titling) as the prime means of intervening, and increasing security of tenure, in the tide of growing informality. In contrast, 'perceived security of tenure approaches' or simply 'tenure security approaches' argue that tenure security is more complex than the formal/informal and legal/illegal dichotomies prevalent in property rights approaches suggest. This body of theory argues that perceived or de facto security of tenure, often operationalized as 'probability of eviction', is just as important as legal or de jure security of tenure. Perceived security of tenure approaches recognise that: (i) a more nuanced understanding of all variables that affect perceived security of tenure is needed; (ii) a broad range of tenure categories exist in any context as a continuum; and (iii) households may engage in processes thought vital to addressing further slum growth and escalating informality in the absence of any legal security of tenure (such as 'self-help' housing investment or incremental efforts by households themselves to improve their housing; often termed 'housing consolidation' in recent literature). These important recognitions are now reflected in leading shelter policy (such as that emanating from UN-Habitat) and have shaped the central research question, key objectives and methodology of the current study. 
Despite the emerging recognition of the importance of perceived security of tenure approaches, gaps in the literature still remain. Firstly, more needs to be known about the nature and nuances of perceived security of tenure (de Souza, 2001, p. 176; van Gelder, 2007, p. 219) including awareness of all its influencing variables and its variations in different contexts. Secondly, more also needs to be understood about the nature of the relationship between perceived security of tenure and housing consolidation (de Souza, 2001, p. 177; van Gelder, 2007, p. 219). Third, particularly upon the realisation of the continued global low-income housing crisis, recent calls have stressed the ongoing importance of self-help housing, or housing consolidation (which initially rose to policy prominence in the 1970s) (Breedenood \& van Lindert, 2010a \& 2010b). This literature makes a plea for re-evaluations of the role of self-help housing in effective housing policy as well as greater understandings of how it can be supported in different contexts (ibid). Finally, very little research has looked to investigate perceived security of tenure and housing consolidation within informal settlements in a small island state context of dominant customary land or within the Pacific region generally. These gaps thus present key avenues for the current study in Fiji; research that also looks, more generally, to address the "dearth of research on settlements [in the Pacific]" (Chand, 2007a, p. 32) and a need for more contextualised, multiple case-study research on informal settlements in Fiji (McKinnon et al., 2007, p. 16).

Given the above lacuna, the current study looks to address the following central research question: What is the nature of perceived security of tenure and housing consolidation in the urban informal settlements of Fiji? In investigating this question primary objectives are to:

1. explore the extent of perceived security of tenure in Fijian informal settlements

2. explore the key variables that influence perceived security of tenure in Fijian informal settlements

3. explore the extent of housing consolidation in Fijian informal settlements

4. begin to explore the relationship between perceived security of tenure and housing consolidation in Fijian informal settlements

The study will also: (i) document the recent growth of informal settlements in Fiji; (ii) review past, current, and planned intervention activities within the informal settlement/low-income housing sector in Fiji; and (iii) explore the variety of arrangements used to gain access to informal settlements - here particularly focusing on describing the nature of informal, or what are known locally as vakavanua, approaches used to gain 
access to native land on which to build. These form secondary objectives for the study and also address some critical documentation gaps within the literature. Seven informal settlements have been selected as case studies from across Fiji. The research also showcases socio-economic characteristics, livelihoods, and services and amenities within these communities, as well as exploring the type of movement towards these communities; thus helping to form a broader profile on informal settlements in Fiji. Ultimately, the research aims to inform a more nuanced understanding of the dynamics of Fijian informal settlements and to suggest policy options for intervening in the tide of growing Fijian housing informality. It is particularly hoped that policy options for increasing security of tenure in current settlements, promoting self-help housing investment, and improving access to land and housing for low-income urban residents and migrants can be suggested.

As mentioned, the research is positioned within a broader theoretical context often divided between property rights approaches and perceived security of tenure approaches. In addition, the research is also situated within a regional debate about whether traditional customary land tenures (which dominate land tenure in the Pacific) are appropriate as a vehicle for development or whether land reform should proceed (largely to privatise customary tenure to individual titles). The Pacific land tenure debate is summarised in Chapter 3, but suffice at this stage to state that the current research builds on, indeed embraces, the perspective that customary tenures form vital systems of resilience in the Pacific and should not be significantly altered by major land reform.

A rich tradition of geographic research has been concerned with land tenure in the Pacific. Geographers have also engaged in the Pacific land tenure debate introduced above and summarised in Chapter 3. The work of geographers on land tenure in the Pacific has, however, tended to focus on rural land and issues of agricultural productivity - with limited engagement with urban land tenure and security of tenure issues. Moreover, the more specific international literature looking at perceived security of tenure and housing consolidation in informal housing environments has largely drawn from a variety of fields outside of geography - including economics, urban studies, regional studies, architecture, and law. The very core idea central to the current research - that security of tenure can be distinguished by degrees of legality and degrees of perception - is very much absent from regional and indeed global human geography literature. Geographers need to be able to understand pertinent urban tenure issues in the Pacific and also the key distinction between legal and perceived 
security of tenure. Indeed, geographers need to be able to understand the influence that perceived security of tenure may have on housing consolidation and other processes thought vital to addressing escalating global housing informality. More broadly, insights gleamed from research focusing on urban tenure and security may inform wider understandings of the resilience of customary tenure and land-use in nonurban environments. It is perhaps surprising that human geography has not engaged extensively with perceived security of tenure theory - particularly as the concept of security of tenure is essentially rooted in relationships between people and the land on which they reside. Focusing on urban tenure and security and bringing perceived security of tenure theory fully into human geography thus form central orientations of this thesis.

This thesis is structured as follows: Chapter 2, forming the key international literature review, details global urban growth, early squatter settlement theory, evolving international low-income housing policy, and security of tenure debates. Chapter 3, the regional context, highlights an increasingly urban Pacific. Chapter 4 showcases the Fiji context of the research including the economic and political environment and Fijian land tenure. Chapter 5 details urbanisation and informal settlement growth in Fiji including a full review of available literature on Fijian informal settlements. Chapter 6 reviews intervention activities within Fijian informal settlements and the low-income housing sector generally. Chapter 7 discusses research methods. Chapter 8 introduces the seven research case studies and a number of central themes relevant to understanding informal settlements in Fiji. Chapter 9, the first of two key results chapters, presents key fieldwork findings showcasing socio-economic characteristics in, movement to, access to, livelihoods in, and services and amenities in the research case studies. Chapter 10, presenting the central fieldwork results, details the extent of perceived security of tenure and housing consolidation across the research sample. Chapter 11 discusses results; especially the key variables that influence perceived security of tenure, and the nature of the relationship between perceived security of tenure and housing consolidation. Chapter 12 concludes. 


\section{CHAPTER 2: THE INTERNATIONAL CONTEXT - GLOBAL URBAN GROWTH, INFORMAL SETTLEMENTS, HOUSING POLICY, AND SECURITY OF TENURE 2}

\subsection{Introduction}

This chapter introduces key theory situating and framing the research. Firstly, global urban growth is traced, before urban poverty and the challenges of urbanisation are summarised. Secondly, the urban built environment for the poor will be introduced including the five key determinants of urban slums (one of which is lack of secure tenure). The chapter thirdly focuses on showcasing the evolution of international housing policy shaping informal settlement intervention by introducing early influential theory, tracing key policy changes, and detailing recent debates within academic and policy circles. Finally, the chapter introduces different land tenure types - including the nature of customary tenures.

\subsection{Global Urban Growth}

As was noted in the previous chapter, 2007 was a milestone year; for the first time ever, the world's rural population was outnumbered by the 3.3 billion people living in cities and towns (United Nations Human Settlement Programme (UN-Habitat), 2006, p. viii; United Nations Population Fund (UNFPA), 2007, p. 1). As is shown in Figure 2.1 below, it is projected that the gap between the world's total urban and rural population will increasingly widen. Currently, around one in three global urban residents (or over a billion people) are living in slums - defined by the United Nations Human Settlement Programme (UN-Habitat) as housing characterised by lack of water, lack of sanitation, overcrowding, non-durable housing structures, and insecurity of land tenure (UN-Habitat, 2006, p. x). It is expected that the next few decades will bring unprecedented global urban growth - particularly notable in Africa and Asia where urban populations are expected to double between 2000 and 2030 (UNFPA, 2007, p. 1). Despite international efforts and the attention directed at Millennium Development Goal 7, Target 11, (to

2 Sections of this chapter have been published in the article: Kiddle, G.L. (2010) 'Key theory and evolving debates in international housing policy: From legalisation to perceived security of tenure approaches', Geography Compass, 4(7), pp. 881-892. 
have improved the lives of 100 million slum dwellers by 2020) the world's slum population is rapidly increasing; expected to reach 1.4 billion by 2020 (UN-Habitat, 2006, p. x).

Figure 2.1. Global Urban and Rural Population Trends, 1950-2050

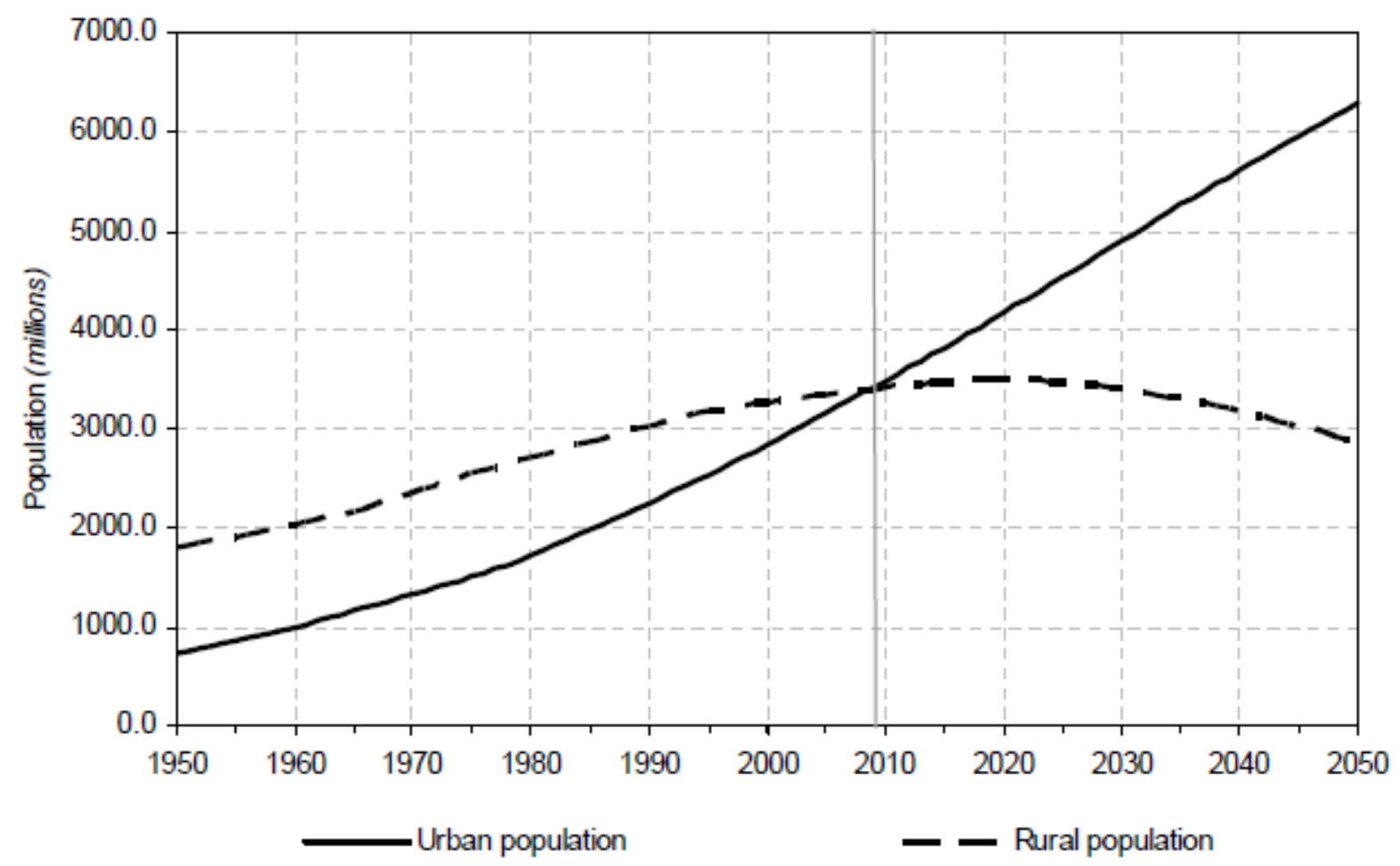

Source: United Nations Department of Economic and Social Affairs, 2010, p. 2

Urbanisation, or the increase in the urban proportions of total populations, 3 is an irresistible, inevitable force (UNFPA, 2007, p. 1). The United Nations Population Fund (UNFPA) claimed in 1996 that the "growth of cities will be the single largest influence on development in the $21^{\text {st }}$ Century" (as cited in ibid, p. 6). It is clear that this statement is becoming increasingly accurate as towns and cities experience major economic, social, demographic and environmental change (ibid).

UNFPA differentiates between two major 'waves' of modern urbanisation. The first wave of transition (1750-1950) occurred in Europe and North America, was tied to industrialisation, was comparatively gradual, and involved only a few hundred million

${ }_{3}^{3}$ More specifically, urbanisation is the rate of transition from a rural to an urban society. The level of urbanisation refers to the proportion of the total population living in urban areas, while the rate of urbanisation refers to the rate at which this proportion grows (UNFPA, 2007, p. 6). 
people (UNFPA, 2007, p. 7). The second major transition has occurred in the last half century and has been vastly different in scale. It has involved much larger and faster urban growth in developing countries tied to rapid increases in population (facilitated by significant decreases in mortality in most regions) and significant economic change (ibid). It is the scale of modern urban change that is unprecedented and this presents huge challenges for managing urban growth and providing adequate infrastructure to all urban residents - including power, clean water, sanitation, roads, and suitable, safe shelter.

In contrast to the conventional interpretation that it is rural to urban migration that primarily accounts for urbanisation, it is actually the combined forces of three factors. That is, in addition to rural to urban migration fuelled by rural push and urban pull factors, natural increase within urban areas, and the transformation of rural areas into urban areas (through small towns growing into small cities and the extension of urban boundaries), also contribute to modern urbanisation (Beall, 2000, p. 428; Beall \& Fox, 2007, p. 4). Of these three forces it is now recognised that natural increase within urban areas is the most powerful contributor (Beall, 2000, p. 428; Hardoy \& Satterthwaite, 1989, p. 229).

Despite a considerable literature on the emergence of 'megacities' (cities with more than 10 million inhabitants) and 'metacities' (huge urban agglomerations with more than 20 million inhabitants), these cities are only home to approximately $4 \%$ of the world's total population (and around $9 \%$ of all urban inhabitants), and have grown at the relatively slow rate of 1.5\% per annum (Lee, 2007, p. 8; UNFPA, 2007, p. 9; UN-Habitat, 2006 , p. 6). In fact, in 2007 more than half (52\%) of the world's urban population continued to live in cities of less than 500,000 people, and these urban areas are expected to account for approximately half of urban population growth from 2005 to 2015 (UNFPA, 2007, p. 9). However, as smaller cities generally face more unaddressed problems and have fewer human, financial and technical resources available (ibid, p. 10), great challenges are faced in managing the expected growth in smaller urban areas.

Urbanisation in the developing world is diverse and often disordered. Increasingly, urban growth is occurring in transitional areas between the countryside and the city proper - or in what is known as the peri-urban interface. This growth, known as peri-urbanisation, is often characterised by a lack of regulations and central authority over land use, as 
growth often falls outside of formal town boundaries. UNFPA writes that peri-urban areas frequently suffer some of the worst consequences of rapid urban growth - including pollution, degradation of natural resources and entrenched poverty (2007, p. 48). The urban periphery also offers cheaper infrastructure, land and labour - which encourages further peri-urbanisation (ibid, p. 49).

Despite frequent attempts by developing country policymakers to prevent urban growth by discouraging rural to urban migration (UNFPA, 2007, p. 3), urbanisation is a positive force and indeed is a rational choice that new urban migrants make to reduce their risk and vulnerability (Tacoli, 2007). As Figure 2.2 shows below, a strong correlation exists between urbanisation and economic development. UNFPA writes that "no country in the industrial age has ever achieved economic growth without urbanisation" (2007, p. 1). Cities have also played decisive roles in positive social, political and economic transformation (Beall \& Fox, 2007, p. 16). Urbanisation has positive effects on productivity and innovation and can encourage the spatial consolidation of production and exchange activities (which can produce positive outcomes) (ibid). However, if these positive effects are to occur, urbanisation must be managed and governed well - often a significant challenge for stretched developing economies. As the United Nations Office for the Coordination of Humanitarian Affairs writes: "[t]he problem is not growth, but unplanned growth" (IRIN, 2007, p. 1).

Figure 2.2. The Positive Correlation Between Urbanisation and Economic Development

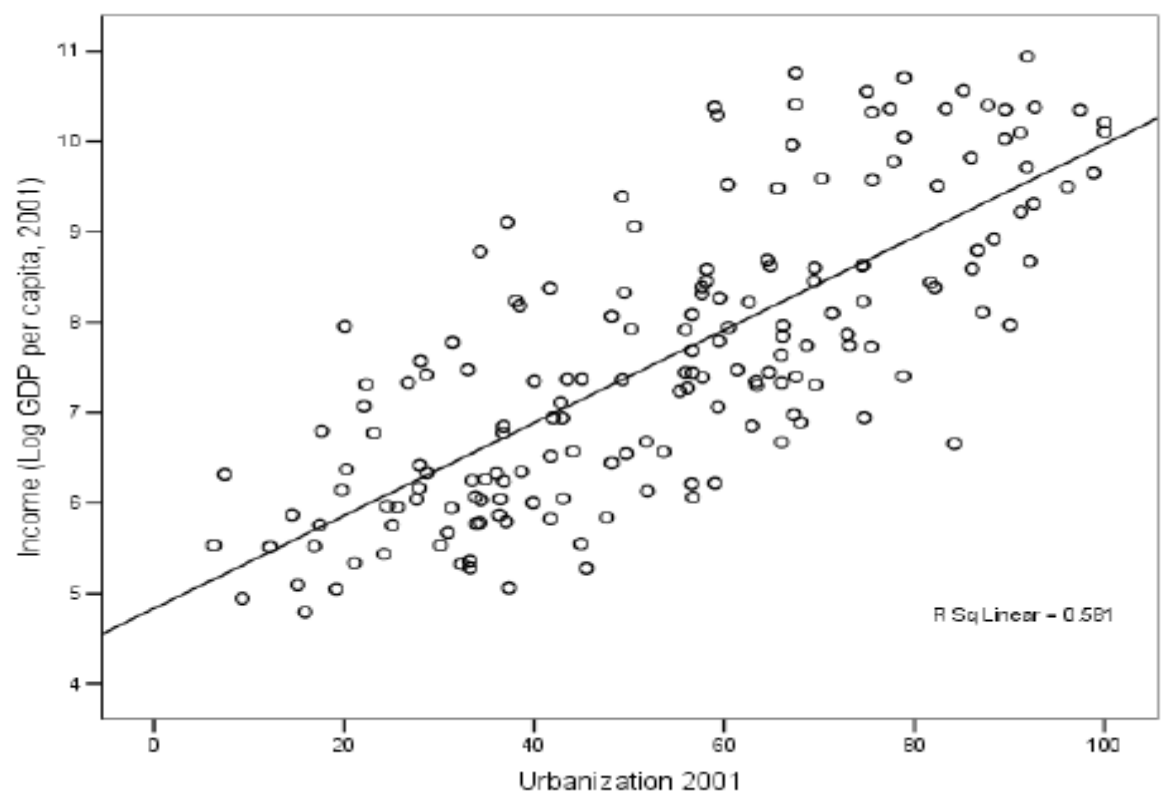

Source: Beall \& Fox, 2007, p. 16 


\subsection{Urban Poverty and the Challenges of Urbanisation}

Beall and Fox write that "it is increasingly clear that ... [cities] ... are becoming centres that also embrace poverty and despair" (2007, p. 6). As continued urbanisation transforms the social fabric of developing countries, massive challenges also need to be overcome. According to UN-Habitat, urban growth in many of the world's regions will become synonymous with slum formation (2007, p. viii); meaning that both inequality and poverty will characterise the majority of cities in the developing world for years to come. In the first major world analysis of disaggregated urban data, UN-Habitat (2006) has shown how urban poverty is becoming as extreme, entrenched and dehumanising as rural poverty. Indeed, perhaps more so, as their report concludes that "living in an overcrowded and unsanitary [urban] slum ... is more life-threatening than living in a poor rural village" (as cited in IRIN, 2007, p. 2). UN-Habitat argues that cities are becoming increasingly unequal as slum populations do not benefit significantly from the advantages and opportunities presented by cities. Hence, they suggest that urban policymakers must no longer treat cities as homogeneous entities. ${ }^{4}$ It is clear that the degree of shelter deprivation is directly correlated with the degree of urban inequality thus the largest, most entrenched, and most poverty-stricken slums are found in the most unequal cities (Biau, 2007, p. 6).

Poverty is a dominant feature of urban life in the developing world, 5 and a number of features are distinctive of urban poverty. Firstly, urban poverty is characterised by dependence on the monetised economy. Beall and Fox (2007) write that the urban poor are often forced to pay more for urban goods and services, 6 are more vulnerable than the rural poor to changes in market conditions, and are more reliant on uncertain wage labour. Amis (1995) furthers this argument writing that urban labour markets and, more specifically, the position of the poor within these markets, are the single most

\footnotetext{
${ }_{4}^{4}$ Traditionally, monitoring of general development progress has focused on two spatial levels: rural and urban (UN-Habitat, 2006, p. ix). However, it is now clear that a third, urban slum, should be added to this analysis. 5 It is, however, problematic to tightly define a concept as complex, contextualised and multi-faceted as poverty. As Rahnema writes, for example, "[t]here may be as many poor and as many perceptions of poverty as there are human beings (1992, p. 158). Wratten (1995, p. 27), however, attempts to categorise different definitions - with particular reference to urban poverty. Wratten distinguishes between: (i) conventional economic definitions where poverty is related to a lack of income (or consumption) defined in absolute or relative terms, and (ii) a more participatory, social development approach where poverty is recognised as multi-faceted and variable (where individual perceptions and experiences of poverty and vulnerability must be understood using more qualitative analysis). Wratten also recognises that causes of poverty are interlinked (including environment, housing, health, education, access to services, and access to income generation possibilities), and, hence, must be understood and addressed in a coordinated fashion (ibid).

6 Water is a salient example - where urban slum dwellers are frequently forced to buy water at high prices from private vendors (Beall \& Fox, 2007, p. 9).
} 
important determinants of urban poverty. Amis argues that the poorest of the urban poor are hence the unemployed, casually employed, and female-headed households.

A second key feature of urban poverty is dependence on the informal economy. In many countries of the developing world, economic growth and job creation have not kept pace with urban population growth. This forces many poor urbanites to rely on the informal sector to earn income - a sector that is as diverse as unregulated selfemployment, casual work, home-based production and illegal activity (Beall, 2000, p. 434; Beall \& Fox, 2007).

Vulnerability to disease and environmental dangers is a third key characteristic of those living in urban poverty. Unclean water and poor sanitation facilities are associated with diarrhoeal diseases, worm infections, and the transmission of mosquito-borne infections. Slum overcrowding also facilitates the transmission of communicable diseases, respiratory infections and tuberculosis. Urban slums are also often located in environmentally hazardous or marginal areas (such as mangroves, steep slopes, or next to industrial sites); locations that present numerous health risks to residents (Beall \& Fox, 2007). A lack of access to basic services (such as water, sanitation, power, and suitable roads) also distinguishes urban poverty - only acting to extenuate the health and safety dangers faced by the very poor in urban areas.

In the 'melting pot' environments of large urban slums, social fragmentation becomes an additional feature of urban poverty. In these environments, individuals and families (in the frequent absence of community and kinship ties) are often forced to compete for income earning opportunities and access to services (Beall \& Fox, 2007). As Amis and Rakodi conclude, urban poverty in such environments can become very individualised and private (1994, p. 632). The increased exposure to violence and crime that also characterises urban poverty (Beall \& Fox, 2007), only adds to the sense of social fragmentation that residents can experience.

Despite most urban poverty having all, or a number of, the characteristics that are described above, it is also important to recognise the heterogeneity of urban areas and the reflection that this has in the great diversity in the extent and depth of urban poverty in the developing world (Wratten, 1995). Wratten also reminds policymakers that, in any analysis of poverty, vulnerability (meaning defencelessness, insecurity and exposure to risks, shocks and stresses) must be separated. Vulnerability is linked to asset 
availability - including access to health and education; infrastructure; productive assets (such as land, housing and equipment); financial assets; government services; and the international donor community (ibid). Because of the great diversity within urban areas, Wratten also stresses the importance of disaggregating within the city in order to analyse and explain urban poverty. Wratten, however, critiques the traditional practice of distinguishing between urban and rural poverty, arguing the need to treat the urban/rural divide as a continuum rather than as a rigid dichotomy.

It is clear that extensive links between rural and urban areas exist in most developing countries and that many individuals cross back and forward between the two areas in the course of their livelihood activities. Examples of such links include rural to urban migration, seasonal labour, flows of remittances, agriculture (including the nature of food markets and the existence of urban/peri-urban farming and horticulture in many developing countries), and extended family networks. Such linkages are often essential to the livelihood strategies of both urban and rural households. Additionally, periurbanisation is increasingly blurring boundaries between urban and rural areas. Overall, Wratten concludes, the "determinants of urban and rural poverty are interlinked and have to be tackled in tandem" (1995, p. 33).

\subsection{The Urban Built Environment for the Poor}

Beall writes that "if anything distinguishes the day-to-day life of poor urban dwellers from their rural counterparts, it is their relationship with the built environment" (2000, p. 19). In general terms, it is clear that the presence of urban slums and urban poverty correlate very closely (Durand-Lasserve, 2006, p. 3). Thus, a final and key characteristic of urban poverty is the presence of inadequate housing. A large proportion of those living in the urban areas of the developing world live in slums - housing that emerges when formal housing markets and government low-income housing programmes fail to keep pace with urban growth (Beall \& Fox, 2007, p. 8). Such housing is usually characterised by the absence of durable structures, adequate service provision, sufficient living space, improved water supplies, and secure tenure. Indeed the absence of one or more of these five factors defines a slum according to UN-Habitat (UN-Habitat, 2006, p. x). The term 'slum' is often used interchangeably with many other words that describe this type of housing or community - generic examples include 'shantytown', 'informal settlements', 'low-income settlements', 'unauthorised settlements', 'uncontrolled settlements', and 'transitional settlements'. More context-specific terms include, for 
example, kampongs (Indonesia), gecekondus (Turkey), favelas (Brazil), colonias populares (Mexico), barricades (Peru), and barong-barongs (Philippines) (Peattie \& Aldrete-Hass, 1981; Davis, 2006; Srinivas, n.d.). ${ }^{7}$ In Fiji, these communities are simply known as 'squatter settlements'.

\subsubsection{The Characteristics of Urban Slums}

Lack of Durable Housing

UN-Habitat estimates that around 133 million people living in the cities of the developing world lack durable housing (2006, p. ix). Such non-permanent housing typically does not meet local building codes and other urban development regulations. Estimates, however, of the extent of non-durable housing globally are constrained by differences around definition, indicator, classification, and approaches to assessing the nature of what constitutes 'durable' housing.

\section{Lack of Sufficient Living Areas}

Overcrowding is a dominant characteristic of the world's urban slums. In 2003, approximately 401 million people (or $20 \%$ of the developing world's urban population) were living in overcrowded conditions (defined as when three or more people have to share one bedroom) (UN-Habitat, 2006, p. x). Particularly pronounced in Asia, overcrowding is positively correlated with a range of illnesses, diseases, overall child mortality and an increase in negative social behaviour (ibid).

Lack of Access to Improved Water

In many cities of the developing world, the quantity, quality and affordability of water in low-income settlements falls significantly short of globally acceptable standards (UNHabitat, 2006, p. xi). It is only two-thirds of the world's urban population that enjoy the luxury of access to tap water (ibid). In addition, extreme differences exist between the

\footnotetext{
7 Such settlements are not isolated to developing countries. Larson (1995-1996 \& 2002), for example, has documented the situation and livelihoods in the approximately 1,500 extra-legal colonias communities in the United States of America (largely in Texas borderlands but also present in New Mexico, Arizona and California) - areas where upwards of 400,000 people live in informal housing settlements. While diverse, these areas are characterised by inadequate housing standards, lack of service provision, quick 'self-help' builds, often precarious tenure situations, and regulatory vacuums - effectively mirroring informal settlements in the developing world.
} 
quantity and quality of water supply available to the wealthy and poor within the cities of the developing world (ibid, p. 74). Limited access to urban water supply is also linked to increased rates of waterborne/water-related diseases in urban areas.

Lack of Access to Improved Sanitation

UN-Habitat (2006) estimates that 560 million people globally (around $25 \%$ of the developing world's urban population) lack adequate sanitation. Inadequate sanitation, in addition to violating the dignity of the urban poor, is clearly linked to adverse health effects especially among women and children.

Lack of Secure Tenure

A key determinant of urban slum communities is the lack of secure tenure. UN-Habitat suggests that globally security of tenure, which they define as the "rights of all individuals and groups to effective protection from the State against forced eviction" (2006, p. 94), is becoming increasingly precarious, particularly in the cities of Africa and Asia where mass evictions of residents are commonplace. Evidence suggests that globally between $30-50 \%$ of urban residents lack security of tenure (ibid, p. xi), although at the city level it is often unknown how many people are living without security of tenure (ibid, p. 95). Overall, it is clear that globally the scale of insecure tenure is increasing and only likely to worsen (UN-Habitat, 2007, p. 113). Security of tenure can be placed on a continuum ranging from home ownership which is typically regarded as the most secure, to the precariousness of living under constant threat of eviction (UN-Habitat, 2006, p. 16), which is quite clearly a state of very insecure tenure. As a key focus of the current research, security of tenure will be explored in much more detail below.

It is clear that poor people will make up a significant part of future urban growth (UNFPA, 2007, p. 3). Many of these new migrants will ultimately locate in urban slum/squatter communities. Urban poverty is becoming one of the most pressing social issues of modern times and a severe and pervasive feature of urban life (Beall, 2000, p. 442; UNHabitat, 2006, p. ix). It is evident that globally the "locus of poverty is moving to cities" (IRIN, 2007, p. 1) - manifested most obviously in the proliferation of slums across the cities of the developing world. However, the situation is not completely dire for if "[c]ities concentrate poverty ... they also represent the best hope of escaping it" (UNFPA, 2007, p. 1). As shelter cuts to the core of urban policy (ibid, p. 38), if dramatic improvements 
are to be made in reducing urban poverty, inclusive and pro-poor housing policies must be implemented. It is to tracing the evolution of urban shelter and slum improvement policy that this chapter turns to next.

\subsection{International Housing Policy}

\subsubsection{Key Theory}

In the seminal article, A Theory of Slums, Stokes (1962) proposed that informal settlements in developing countries have the potential to be gradually incorporated into the more formal built environment through a process of incremental housing improvement, initiated and completed by settlers themselves. Stokes was also the first to propose that informal housing should be appraised as a means to produce positive social change, contrasting 'slums of hope' with 'slums of despair'. Later, Abrams (1966) suggested that urban housing policy could facilitate this gradual improvement of housing by settlers themselves - or what became known as 'self-help' housing improvement. Abrams concluded that a squatter settler could "given a secure foothold and some help ... despite his [sic] impediments, rise to the occasion" (p. 43). In general, Abrams favoured in situ squatter housing improvement programmes and 'instalment construction' over squatter resettlement (ibid, p. 9; Pugh, 2000, p. 326). Overall, Abrams argued that squatter housing will improve over time and with better economic conditions, particularly if settlers are given a "stake in the society and the incentive of ownership" (p. 13). Abrams further argued that effective squatter housing policy requires an extensive and coordinated effort from all levels of government. Mangin (1967) was also influential in this early literature, rebutting common stereotypes of squatters and squatter settlements and arguing that squatter settlements were part of the solution to the lack of cheap housing in Latin America at the time.

Perhaps the best known, and most influential, advocate for self-help housing in squatter settlements has been Turner (1968a, 1968b, 1969 \& 1972). According to Pugh, Turner based his advocacy and social idealism upon humans' sense of self-fulfilment and his belief that housing could contribute to value in peoples' lives (2000, p. 326). Turner wrote about 'freedom to build' and 'housing as a verb' - processes of popular, participatory activity (ibid, p. 327) - and argued that in squatter settlers a "great unused resource exists in the desire, energy, and initiative of families to house themselves" (1972, p. x). Turner's support for self-help housing was based particularly on his field experience in the 
squatter settlements of Peru in the 1950s and 1960s where he noticed that households improved their housing incrementally using earnings and savings (Pugh, 2000, p. 327). Turner argued that such self-improving squatter settlements act as 'bootstraps' through which low and insecure income families could 'pull themselves up' (1969, p. 522) particularly if provided with security of tenure (ibid, p. 528). Turner (1972) also argued that most traditional government housing programmes and rigid building codes (common in many post-colonial states) only distorted the natural ordering of household priorities present in squatter communities. He argued, rather, that households should be free to choose their own housing, to build and direct its own construction, and to use and manage that housing in their own ways (ibid, p. 154).

In responding to what he felt were common misconceptions about the urban settlement process at the time, Turner (1968a) also proposed three basic functions of the urban built environment-location, tenure, and amenity. He argued that for any place to effectively function as a dwelling it must: (i) have an accessible location (particularly in central areas close to work opportunities); (ii) provide opportunities for secure, continued residence for a minimum period of time; and (iii) provide a minimum of shelter standards from hostile climatic and social elements (ibid, p. 356). Overall, Turner suggested that urban settlement patterns were the product of the above needs combined with the means for their satisfaction - that is, the availability of land and capital, and funding to meet construction costs (ibid, p. 358). Turner proposed that squatters, dependent on uncertain labour markets and the need to reduce transport costs and time, must live near the sources of available jobs (ibid, p. 356). This proposition suggested that for squatters the need for a central location dominates over the lesser needs for secure tenure and quality shelter (thus, some trade-offs are present for these two other variables when squatters choose to locate centrally).

\subsubsection{Early Housing Policy}

Prior to the mid-1960s, housing issues were given a relatively low priority in the national development planning process - principally because housing was considered to be an unproductive sector of the economy (Choguill, 1995, p. 404). Despite the low priority during this period, there was a general belief that the state should and could provide housing to growing urban populations, and states did provide some conventional lowcost housing. However, with the emerging proliferation of informal settlements parallel to, and unregulated by, the formal system, it became clear that conventional strategies 
were not coming close to meeting the total demand for low-cost housing (Beall, 2000, p. 436).

By the late 1960s, however, particularly due to the influence of Turner and theories about self-help housing, shelter policy that was directed at the poor began to contribute more to the overall development debate (Choguill, 1995, p. 404). Pugh (2000) summarises the years 1972 to 1982 as the first major phases in international housing policy. Upon recognition that most developing country governments could not come close to addressing their low-cost shelter shortfall (Bamberger, 1982, p. 95), in this phase aid and funding agencies (particularly the World Bank) became involved, accepted and adapted the ideas of Turner and other self-help advocates, and began to finance both 'sites and services' and in situ slum upgrading projects in the effort to reduce costs through the promotion of self-help housing. These projects were based on the three core principles of affordability, cost recovery and reliability (Pugh, 2000, p. 327). In situ slum upgrading involved the improvement of existing communities through the provision of services and the rationalisation of housing and street layout (Bamberger, 1982, p. 96). Sites and services approaches involved the provision of vacant tracts of urban and periurban land, divided into plots and provided with basic, key services (Choguill, 1995, p. 405), and sold or leased to tenants who wished to build upon them. Sites and services approaches proved popular to policymakers initially, and by 1983 the World Bank had funded more than 70 such projects (ibid). Bamberger argues that early upgrading and sites and services projects did prove more accessible to low-income groups than traditional low-cost housing programmes (with squatter upgrading projects usually reaching further down the income scale than sites and services approaches) (1982, p. 98-99). Bamberger argued that if low-income earners perceive improved housing as an investment good, as well as a consumption good, they are more likely to invest in the building or upgrading of their housing - particularly once security of tenure has been obtained and basic key services provided.

Despite early optimism and some positive evaluations of upgrading and sites and services approaches, upon reflection it has become clear that many shortfalls existed in early in situ upgrading and sites and services projects. These problems included that cost recovery was achieved only infrequently (particularly for slum upgrading projects); sites and services projects were often located far from work opportunities and/or on marginal land with only the most basic of services; institutional capability remained weak; and the piecemeal nature of projects did not contribute to city-wide housing reform (Beall, 2000, 
p. 437; Pugh, 2000, p. 327). Further, Angel, Archer, Tanphiphat and Wegelin write that the production of sites and service projects generally remained low and out of reach of most of the poor, and that slum upgrading projects often produced only superficial improvements of no lasting significance (1983a, p. 5-6). Moreover, slum upgrading projects did not often bring improvements in land tenure security - for land tenure reform all too often remained in the 'too hard basket' (Angel et al., 1983b, p. 532).

Self-help housing, however, was not without its critics in this period. Harms, for example, argued that self-help was used as an inexpensive policy option for housing provision without making major structural or resource allocation changes - effectively privatising the challenges to individual households away from collective responsibility and action (1982, p. 23). Similar views have also been expressed more recently. Pinches, in 1994, for example, argued that self-help schemes "served the narrow economic interests of states, elites and international agencies" by suggesting cheap solutions to housing demands (1994, p. 118). Other recent reflective critics have suggested that the self-help mantra became a smokescreen for the World Bank to downsize historic commitments to relieve poverty and homelessness (Davis, 2006, p. 72). Seabrook, for example, writes that "by demonstrating the ability, the courage, and the capacity for self-help of slum people ... the way [was] prepared for a withdrawal of state and local government intervention and support" (1996, p. 196).

Pugh writes that from 1983 the World Bank was ready to re-orientate its housing policies, expanding from an individual project approach to a more general urban policy, programmatic framework (2000, p. 327). The World Bank also began to channel funds through housing finance systems - aiming to extend the availability of credit to lower income earners (ibid, p. 328). During this time, the World Bank gradually reduced its support for sites and services projects, whereas it continued its slum upgrading financing (but under a slightly revised approach). From 1993, the World Bank subtly redirected and extended its programmatic housing policy, particularly aiming to place housing more holistically in the broader context of cross-sector and society-wide transformation and its contribution to overall economic and social development (ibid).

Despite almost half a century of major housing projects and programmes, it is, nevertheless, clear that successive approaches have failed to keep pace with demand for low-income housing in many developing countries (Beall \& Fox, 2007, p. 20). This has resulted in inflated land and housing costs making quality shelter a very expensive item 
for the urban poor (ibid), and has also contributed to rapid increases in the number and scale of informal settlements globally. Effective housing policy and programmes are now more urgent than ever.

\subsubsection{Recent Housing Policy Debate and Practice}

The conventional belief in most housing policymaking is that the best approach to the urban upgrading of low-income settlements is through the provision of legal title - or land tenure 8 legalisation. 9 It is hoped under this approach that titles and thus security of tenure will then encourage residents to upgrade their housing and settlements through their own efforts. Significant debate (which will be introduced below) surrounds the tenure legalisation approach. For example, critics argue that a regularisation approach (which focuses on physical interventions such as infrastructure and service provision), without the provision of legal title, can be enough to encourage residents to upgrade their housing and settlements themselves through increases in perceived or de facto security of tenure. Lastly, redevelopment (involving resettlement on or off site), comprising demolition and subsequent new construction or reconstruction, provides a third (usually more expensive) option open to urban housing policymakers. In practice, urban upgrading approaches can comprise a combination of legalisation, regularisation and redevelopment. However, debate about the merits of each approach, particularly between legalisation and regularisation, remains strong.

\subsubsection{The Importance of Legal Title?}

The security of tenure debate, which has come to dominate discussions around urban upgrading since the year 2000, was kick-started by the influential 'popular economics' writing of Hernando de Soto. In The Mystery of Capital: Why Capitalism Triumphs in the West and Fails Everywhere Else (2000), de Soto advanced a central claim that the poor in developing countries possess huge resources, but hold these resources in defective forms as 'dead capital' that cannot be used to create wealth. de Soto argued that because these possessions (including houses on land with no title, cottage industries, and unincorporated businesses) are not adequately recorded, they cannot be turned

\footnotetext{
8 Land tenure can be defined as "the mode by which land is held or owned, or the set of relationships among people concerning land or its product" (Payne, 2001, p. 416). It usually involves a complex set of rules, or bundle of rights, associated with the use of that land (UN-Habitat, 2004, p. 30). Land tenure needs to be understood separately from property rights which refer to a recognised interest in land or property vested in an individual or group (which can be applied separately to land or development on it) (Payne, 2005, p. 137).

9 In some literature and policy legalisation is also labelled as 'formalisation'.
} 
into capital, cannot be traded outside of narrow local circles, cannot be used as loan collateral, and cannot be used as a share against an investment. In turn, de Soto argued that formal property rights, and the security of tenure that these property rights present, are then essential for mobilising such 'dead capital', encouraging home improvement and upgrading, and obtaining formal credit (ibid, p. 6). In practical terms, de Soto advocates for the legalisation of property ownership by providing legal titles throughout the 'extra-legal' sectors (Mooya \& Cloete, 2007, p. 156) including in the urban informal settlements of the developing world. According to de Soto and many others who support his approach, within these settlements, "dwellers without titles are assumed not to enjoy a high enough level of tenure security to invest significantly in their housing" (as cited in van Gelder, 2007, p. 220).

In general the literature discusses three benefits of property titling - all concerned with market formulation. These include: gains from the trade in land; increased investment incentives; and improved access to credit (Mooya \& Cloete, 2007, p. 156). More specifically, Peter Ward summarises the benefits of legal title as providing security against eviction; bringing people into formal property markets where they can receive full market prices through free sale; increasing property values; stimulating investment in house improvement and consolidation; encouraging access to credit (through using housing as collateral); introducing residents into the formal property-owning democracy and citizenry; and integrating settlements into the formal tax collection and regulatory sector of the city (2003, p. 4).

The perceived general benefits of land titling, and the views of de Soto in particular, have received widespread support by donor agencies and policy makers, finding favour with development agencies from across the political spectrum (Musembi, 2007, p. 1458). This has encouraged attempts by many developing country governments to provide titles, and hence land tenure security, to the poor in major land titling programmes. As Galiani and Schargrodsky summarise, these land titling programmes are generally premised on the belief that formal titles will allow the poor to access credit, thereby transforming their wealth into capital, and, hence, increasing labour productivity and income (and reducing poverty) (2006, p. 29).

Despite the volume, persuasion, and initial general acceptance in policy circles of the arguments of the property legalisation proponents, empirical evidence supporting the benefits of formal property rights is mixed - particularly in its effect on reducing poverty 
(Mooya \& Cloete, 2007, p. 157). In general terms, it is not yet proven that formal or regularised markets are more efficient and productive than informal or unregularised markets. Secondly, it remains unclear whether a more formal land market will actually benefit or harm the urban poor (Doebele, 1994, p. 52).

The criticism of the de Soto thesis has particularly focused on rebutting the link between legal titles (and the security of tenure that these entail) and access to credit (see, for example, The Economist, 2006; Galiani \& Schargrodsky, 2006; Home \& Lim, 2004; Lemanski, 2010). Bromley has also reinforced a crucial point, often missed in arguments favouring legalisation, that any borrower must have a secure income stream before it is possible to leverage credit from a banking system - a necessity that would exclude many informal settlers reliant on uncertain or informal sector income (2008, p. 22). In addition, Gilbert (2002) in a study of (now titled) poor settlements in Bogotá, Colombia, showed how house sales were actually more common when people lacked formal title; how informal credit was often available from the beginnings of settlement; and how little formal finance was available after formal titling. Overall, Gilbert was led to claim that land titling makes very little difference to the lives of the poor, and claimed that now "it is widely recognised that security of tenure does not require the issue of full legal title" ( $p$. 7).

Criticism of the de Soto approach has also extended wider. For example, in a wide United Kingdom Department for International Development commissioned study, Home and Lim (2004) looked to test some of de Soto's ideas through empirical research in periurban areas of Botswana, Trinidad and Tobago and Zambia. Notably, in titled, periurban plots, Home and Lim found little evidence of market activity; with plot holders more likely to pass plots on to family than sell them on the free market. Secondly, they also reported a widespread aversion to the use of land as collateral in all three countries.

Musembi (2007), in a review of land titling experience in Kenya (which has the longest policy experience in sub-Saharan Africa), also provided a general critique of de Soto and the formal titling approach. In addition to dismissing any proven links between titling and access to credit, Musembi raises four other key shortfalls of formal titling which are particularly relevant for Kenya, sub-Saharan Africa, and contexts of customary land tenure. Firstly, Musembi argues that de Soto's rigid dichotomy of formal legality/informal illegality ignores a valid social reality for many societies of informal legality (where broader and dynamic social processes and institutions and informal social norms shape 
property relations). Secondly, de Soto's approach premises private and individual ownership as inevitable for all societies - ignoring other, equally valid, land tenure arrangements (such as customary use). Third, the de Soto approach tends to downplay the fact that markets for land already exist in the absence of formal title. Fourth, legal title can bring security, but also insecurity through distortion effects, land speculation, and pressure to change traditional customary tenure arrangements.

Other reviews of titling experience in sub-Saharan Africa have concluded that efforts were far more complex and difficult than expected and, in general, unsuccessful (Gulyani \& Bassett, 2007) often hindered by unexpected outcomes. Research in customary land areas of Kenya, for example, has shown how project beneficiaries receiving land under titles sell or lose their land use rights - often stimulating further informal settlement growth (Bassett, 2005 \& 2007; Bassett \& Jacobs, 1997).

As Musembi (2007) recognised and criticised, the legality/illegality dichotomy is omnipresent in de Soto's approach. Others too have criticised this aspect of de Soto's thesis. With particular reference to Mexico, for example, Varley (2002) argues that legality and illegality are not always two separate spheres. In Mexico City, Varley writes, informal land transactions are common; the nature of officially 'legal' and 'illegal' communities are not inherently different; and the residents of informal settlements range from the very poor to the very wealthy.

In a wide review of the literature and land titling case studies in Senegal and South Africa, Payne, Durand-Lasserve and Rakodi (2009) also critique legalisation focused approaches. They also argue that titles often fail to improve access to credit, and report a number of cases where titling programmes have ultimately reduced security of tenure (by market driven displacement and forced evictions). They also cite a number of cases where alternative forms of tenure provide adequate security of tenure and scope for infrastructure and service improvements in settlements.

\subsubsection{The Importance of Perceived Security of Tenure}

The key assumption in debates around slum upgrading generally is that security of tenure is associated with improved housing conditions in informal settlements (brought about by self-help housing improvements). Despite this assumption being clear in early literature (Abrams, 1966; Turner, 1972), Varley writes that it was surprising that the link between 
improvements in tenure status and improvements in housing was not substantially empirically tested until the 1980s (1987, p. 463). The 1980s studies (which were largely World Bank funded) did show evidence of a correlation between tenure status and housing improvement (ibid). However, it was clear that these studies focused on the provision of legal title as the principal means of improving tenure status and did not recognise other influencing factors. For according to Varley:

The basic problem with the argument concerning legalization and housing improvements is that security of tenure is not a fixed, objective concept, and that it is affected by a variety of other considerations: not only the legality or illegality of tenure. Changes in residents' assessment of their security of tenure can also, therefore, be produced by other means (1987, p. 464-465).

It is residents' assessments of their own security of tenure that is key - more frequently referred to in the literature as perceived or de facto security of tenure. More recently, the perceived security of tenure approach has come to frame a literature that tends to question the necessity of full legal title in facilitating individual and community self-help housing. As Varley succinctly has written "to argue that 'security leads to improvement' is not to argue that 'legalization is necessary for improvement'" (1987, p. 465, emphasis in original). Authors who support the perceived security of tenure approach argue that perceived security of tenure can be achieved particularly if eviction is thought to be unlikely (de Souza, 2001; Payne, 2001 \& 2004). In such a climate, poor slum dwellers will invest in their dwellings even in the absence of formal title. The idea that perceived or de facto security of tenure can also promote housing improvement is actually not recent; as it was as early as 1983 when this was recognised in critiques of early assessments of the benefits of legalisation programmes (Angel, 1983; Doebele, 1983; Martin, 1983). Doebele, for example, writes that:

While tenure is generally considered a legal category, it is, just as fundamentally, a matter of the state of mind of the persons concerned. Stated operationally, the critical element ... [is] the perception of the occupant of his [sic] security in relation to the investment contemplated (ibid, p. 349-350).

Geoffrey Payne (2001, 2002a, 2002b \& 2004) has been a leading proponent of the benefits of perceived security of tenure. He states that it is "undeniable that perceived security of tenure is widely accepted as a precondition for households to invest in house construction or improvements" (2001, p. 421). Payne (2001 \& 2004) and others (Calderon, 2004; Durand-Lasserve, 2006; Durand-Lasserve \& Royston, 2002; Gilbert, 2002; 
Griffith-Charles, 2004; Gulyani \& Basset, 2007; Porio \& Crisol, 2004; Savant-Mohit, 2004; Taylor, 2004; van Gelder, 2007; Varley, 1987) have proposed a number of key variables that can influence residents' perceived security of tenure and thus influence self-help housing improvement. These include: perceived and real threats of eviction and histories of eviction in similar communities; the duration of settlement occupation; the size of the settlement; the degree and cohesion of community organisation within the settlement; the level of infrastructure and service provision; 'rights' to use the land (such as certificates of use and/or temporary occupation licences); perceptions of past and present government policy; the availability of employment opportunities; the law and order situation; the extent of political patronage; community support from civil society; and project interventions themselves.

Two authors in particular have focused on providing a greater understanding of the nature of perceived security of tenure and its effect on self-help housing improvement (or housing consolidation as it is also labelled). de Souza (2001), for example, in research in Brazilian favelas, concluded that the process of housing consolidation itself increases perceptions of security of tenure. Raising an important distinction between land tenure and house tenure, de Souza argued that "[informal settlers] believe that their houses are secured because they have invested time, labour, building materials, and money when building and improving their houses" (p. 176). de Souza also noted that savings capacity and personal security could influence housing consolidation - indeed in an earlier paper (1999) he had noted that personal security in Brazilian favelas was more significant than tenure security in the housing consolidation process. Overall, de Souza was led to conclude that the relationship between perceived security of tenure and housing consolidation was subtle with significant "gaps in our understanding of what security really means to the individual household, and how security has influenced housing consolidation and improvement" (2001, p. 189).

van Gelder (2007, 2009 \& 2010; Reerink \& van Gelder, 2010) has also led academic research seeking to understand the complexities of perceived security of tenure and the housing consolidation process. From an informal settlement case study in Buenos Aires, van Gelder (2007) distinguishes perceived security of tenure into two separate, but related, variables - (i) perceived probability of eviction; and (ii) fear of eviction - and concluded that fear of eviction was the more influential on housing consolidation. In a later paper van Gelder clarified these variables influencing perceived security of tenure, writing that the "perception of the probability of eviction or losing one's land and/or 
dwelling is something different than ... [the] ... likelihood of that risk" (2010, p. 451, emphasis in original).

Operationalizing perceived security of tenure as 'perceived probability of eviction' van Gelder also sought to understand in greater detail the relationship between perceived security of tenure and housing consolidation. This research has revealed that perceived security of tenure was a significant predictor of housing consolidation in informal settlements of Buenos Aires (van Gelder, 2009) and kampongs of Bandung, Indonesia (Reerink \& van Gelder, 2010). The Indonesian research also assessed a major titling programme - concluding that titling influenced both perceived security of tenure and housing consolidation modestly.

de Soto (2000), and other advocates of legalisation approaches, argue that it is the provision of full, legal title that will facilitate housing improvement in informal settlements. On the other hand, Payne (2001, 2002a, 2002b \& 2004), de Souza (1999 \& 2001), van Gelder (2007, 2009 \& 2010; Reerink \& van Gelder, 2010), and others recognise the influence of perceived security of tenure and suggest that tenure security can be improved through a variety of different means. The broader perceived security of tenure approach also recognises that across the world's cities a wide continuum of land tenure categories exist, usually lying somewhere between the binary extremes of legal/formal and illegal/informal. This approach argues that these distinctions must be understood in order to implement effective habitat policy and practice - policy that should start from building from the existent tenure system (Payne, 2004, p. 167). According to Payne (2001) these intermediate (and often cheaper) options include: increasing the rights of residents to use and/or settle on land (rather than changing formal tenure status); extending existing customary arrangements; and increasing the range of tenure options available (for example, collective leases and temporary occupation licences). Payne argues that these options can all offer improved security, modest increases in tax revenue for government, practical options for financing land development, and increased public sector influence over land development (ibid, p. 427). Payne also argues that increasing security of tenure without providing full title can avoid the major disruptions that legal title can present - such as distorted land markets, rapid increases in land values and the exposure of vulnerable groups to eviction (ibid).

Among other policy approaches, adapting lease arrangements, extending the range of tenure options, and general slum upgrading are all viable options for increasing security 
of tenure. However, perhaps the single most important means to increased perceived security of tenure is to remove residents' fear of eviction (UN-Habitat, 2007, p. 139). After all, it is forced evictions that are the extreme consequence of tenure insecurity (UNHabitat, 2006, p. 92). Announcing a stop to forced evictions and relocations when presently part of government policy is absolutely crucial (Payne, 2004, p. 175).

According to Payne (ibid) often a simple statement by the relevant government minister is enough to reduce uncertainty around eviction and stabilise situations for informal settlers. Political will for improving conditions for informal settlers is hence absolutely essential in implementing a pro-poor urban shelter strategy that will increase perceived security of tenure.

\subsubsection{Effective Housing Policy}

Despite the evolution of international housing policy over the last 40 years, Turner's original theories have remained relevant within the broader housing context (Pugh, 2000, p. 327), and assisted self-help housing still remains an important part of housing policy in developing countries (ibid, p. 333). Indeed, recently upon the realisation of the continuation of the urban housing crisis and self-help housing remaining a vital strategy for millions worldwide (Bredeenord \& van Lindert, 2010a), self-help housing has enjoyed renewed academic and policy attention - particularly in supporting 'aided self-help' (for example, by housing finance and enabling policy frameworks). In fact, recent calls have stressed the ongoing importance of self-help housing and pleaded for reevaluations of its role in effective housing policy (Bredeenord \& van Lindert, 2010b). As Home and Lim write: the "vast scale of housing and land tenure problems has moved both governments and donor agencies from direct provision of mass housing to a neoliberal, facilitative and enabling role for the State ... [and] ... a greater acceptance of all kinds of self-help in housing" (2004, p. 1). Overall, self-help housing improvement is still seen as a useful, intermediary option which is important to facilitate - particularly in climates of rapid urbanisation, proliferation of informal settlements, and resource and funding constraints in the state effectively catering for the shelter needs of all poor urban dwellers. As Turner asserted back in the late 1960s, self-help remains "architecture that works' (Turner, 1968b).

As stated earlier, three (sometimes overlapping) options are open to housing policymakers - legalisation through the provision of full legal titles, regularisation without the provision of title to increase security of tenure, and/or redevelopment (which often 
involves resettlement). It has emerged from the literature that perceived security of tenure is often enough to promote self-help housing improvement. Indeed a shift from a focus on the provision of legal titles to the granting of tenure security through regularisation (by various means) has emerged recently as a global trend (along with temporary and incremental, rather than immediate upgrading of tenure) (DurandLasserve \& Royston, 2002, p. 26).

It is also important to recognise that tenure policy should not be a stand-alone programme. Although "[t]enure ... forms the foundation on which any effort to improve living conditions for the poor has to be built" (Payne, 2002a, p. 3), tenure policy must be part of a package of measures - including increasing access to livelihood opportunities, increasing service provision, and increasing the supply of affordable and appropriate legal housing (Payne, 2004, p. 174). In all, "security of tenure is not in itself sufficient to break the poverty cycle ... [i]t forms only part of a more comprehensive and integrated approach to informal settlement upgrading" (Durand-Lasserve \& Royston, 2002, p. 9).

The role of the poor in tenure policy must also be recognised. Firstly, an integrated policy package must recognise the positive role of the poor in urban and national economies (Payne, 2002b, p. 300). Secondly, housing policy should be driven by the need to offer a range of options that provide various adequate levels of security (co-factored with location, mobility and general livelihood needs) for the urban poor, as perceived and defined by the poor themselves (ibid, p. 306). There is also a need to distinguish between the presence and needs of de jure and de facto security of tenure (and the variables that affect both) (Payne, 2002a, p. 13). Overall, Payne argues that promoting a wider range of tenure options is the best way forward in tenure policy (2002b, p. 307). Given the difficulties and expense of providing full legal titles, perceived security of tenure remains the key. For "[o]nce perceived security of tenure is achieved, the constraint on progress by the poor is not of commitment, but of resources" (Payne, 2002b, p. 301).

Globally, the key agency for shaping shelter policy is UN-Habitat. Recently security of tenure has come to the fore of UN-Habitat's shelter discourse and policy, particularly upon recognition that security of tenure is not reaching the most vulnerable of urban groups (especially the urban poor, tenants and women) (UN-Habitat, 2006, p. 92 \& 2007). As mentioned, UN-Habitat defines security of tenure as the "right of all individuals and groups to effective protection from the State against forced evictions" (UN-Habitat, 
2007, p. 111). It also, however, recognises that security of tenure is context-specific and "complex, multifaceted and difficult to define purely in terms of formality or informality, legality or illegality, or modern or customary law" (ibid, p. 137).

UN-Habitat has now come to recognise that security of tenure is not always equated with titling and ownership of land and housing (a far too common misconception), and they now explicitly state that "ownership is not always the solution" (UN-Habitat, 2006, p. $94 \& 2007$, p. 113). The agency also recognises that security of tenure has as much to do with perception as legal status (UN-Habitat, 2007, p. 118). Upon recognition that legalisation does not often facilitate access to credit or prevent new slum formation (ibid, p. 95), UN-Habitat (without totally discounting titling as part of a broader package of tenure policy) has come to favour a more incremental approach based on facilitating the right to a secure livelihood (ibid). UN-Habitat recognises security of tenure as encompassing a minimum package of rights which can progressively move towards a higher order of rights through a tenure upgrading process moving from de facto to de jure tenure (ibid, p. 94). In targeting tenure insecurity, UN-Habitat regards security of tenure as a prerequisite, or initial strategic entry point, in an incremental tenure regularisation process (UN-Habitat, 2007, p. 159). Thus, they do not favour any policy responses that involve eviction and relocation and thus threaten tenure security. Rather, in situ slum upgrading, through a variety of different incremental, flexible, contextspecific means, is seen as key (UN-Habitat, 2007). Finally, while security of tenure remains a central plank of UN-Habitat's tenure policy, it is also recognised that facilitating access to land for low-income groups remains a twin strategic prerequisite for international housing policy and providing adequate shelter for all (ibid, p. 114).10

These key recognitions of UN-Habitat are reflected in international policy. For example, security of tenure and access to land as key conditions for sustainable development and breaking the cycle of poverty were adopted by the Second United Nations Conference on Human Settlements (Habitat II) in 1996. More recently, UN-Habitat launched the Global Campaign for Secure Tenure in 2000 - stating that secure tenure needs to be part of an integrated, pragmatic, and affordable approach to improving the access of the poor to improved shelter, basic services, political representation, and employment opportunities (UN-Habitat, 2006 \& 2007). Overall, the campaign recognises that security

\footnotetext{
10 In most contexts, facilitating access to land is not inhibited by an absolute shortage of land (Doebele, 1983, p. 353). It is, rather, fundamentally, a question of the structure and operational policies of institutions - as effected by political forces (ibid).
} 
of tenure has a central role in improving the living and working conditions of the urban poor. Particularly important here is the catalytic effect of security of tenure where it invariably leads to other processes vital to sustainable shelter - for example self-help upgrading (UN-Habitat, 2004, p. 17).

\subsection{Land Tenure Type and Security of Tenure}

Land tenure is complex and multifaceted and exists in a wide variety of forms but can usually be categorised along a continuum moving from less to more secure forms of tenure (UN-Habitat, 2007, p. 115). With simplified categories, land tenure can usually by classified six-fold: freehold; leasehold; conditional freehold ('rent to buy'); rent; collective tenure; and communal (ibid). Practically speaking, however, a much wider variation of tenure categories exist globally, varying from state to state, within countries, and within cities and towns. The key is to recognise that, due to the complexity of land tenure arrangements, one-size-fits-all policy prescriptions do not exist (ibid). Rather, a more nuanced and contextualised understanding of tenure needs to be prioritised, along with a flexible and pragmatic approach to policy (ibid, p. 268).

It is clear that even cities are characterised by a wide range of tenure categories varying by both levels of legality and degree of security (UN-Habitat, 2007, p. 137). Figure 2.3 below shows how urban land tenure can typically vary. For the poor within cities of the developing world, a wide range of tenure categories are clear - all largely characterised by illegality and inadequate degrees of tenure security (ibid, p. 115 \& 118). Figure 2.3 identifies that the most vulnerable of these groups include pavement dwellers, squatter tenants, 11 and squatters in non-regularised settlements.

\footnotetext{
11 Amis (1984) was one of the first to recognise that a large, often illegal, rental sector exists within the unauthorised settlements of the developing world (his research was in Nairobi). Amis argued that the provision of low-income shelter was hence very much a commercial activity.
} 
Figure 2.3. Urban Tenure Categories by Tenure Status

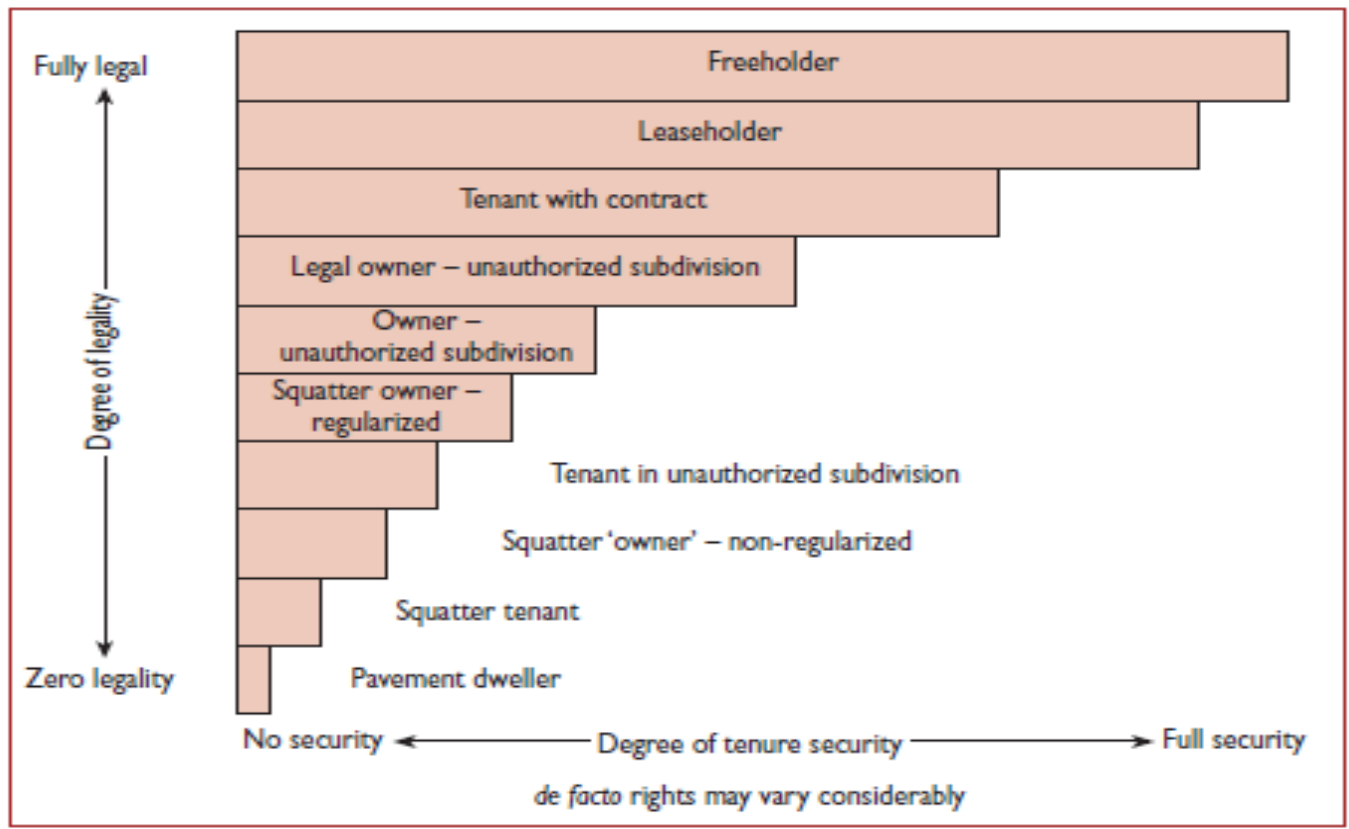

Source: UN-Habitat, 2007, p. 118, originally adapted from Payne, 2001

The presence of customary land in some countries where urbanisation pressure is strong (such as in many nations in sub-Saharan Africa and in South Pacific states such as Papua New Guinea, Fiji, Vanuatu and Solomon Islands) further complicates the urban land tenure situation. While different from context to context, customary land usually can be categorised as offering user rights, control rights, and transfer rights (UN-Habitat, 2007, p. 117). In contexts of customary land, informal (technically illegal) land transactions take place providing land to long-term residents and also newcomers (ibid, p. 116). These transactions may or may not come with broader customary approval, but they do provide occupants with some degree of security of tenure and sometimes even de facto rights of transfer (ibid; Lea, 1983). Durand-Lasserve and Royston $(2002$, p. 6) write (with particular reference to sub-Saharan Africa) that these customary practices can usually guarantee a reasonable level of tenure security - in contexts where recognition by the community and neighbourhood is often considered more important than recognition by government authorities for ensuring tenure. Customary tenure is often more flexible than more formal tenure types, and is constantly changing and evolving to adapt to current realities (UN-Habitat, 2007, p. 117). However, such arrangements can deteriorate when the customary system enters a crisis (such as through a leadership dispute); when multiple allocations through illegal sales of one plot create conflict; and 
when a major conflict erupts between customary owners and public authorities over the use of the land and the legitimacy of the customary claim.

Outside of sub-Saharan Africa little research has focused on the analysis of land tenure security within environments of customary land. One such exception from the Pacific is a study by Chand and Yala (2007) that investigated ways to improve access to land within low-income Port Moresby settlements in Papua New Guinea; a context where squatters settle on state land, or on customary land through the purchase of use-rights from customary owners. The study found that urban settlers in Port Moresby had higher levels of perceived security when settling on customary land as opposed to state land (manifested through reduced fears of eviction) and thus had more stable ownership rights. Chand and Yala summarised that security of tenure on Port Moresby customary land was maintained and improved through: traditional systems of reciprocation and token exchange; clan/tribe group occupation; the attainment of statutory declarations on the right to settle; and the involvement of established intermediary organisations in dialogue between settlers and landowners. On the other hand, they found that (lower) security of tenure on state land was facilitated mainly by political patronage.

\subsection{Summary}

Increased global urbanisation is correlated with a proliferation of urban informal settlements in the developing world. Biau $(2007$, p. 6) writes that these communities are a manifestation of severe social injustice, and a reflection of the social divide which acts to exclude the poor from the benefits of urban life. Poverty and inequality certainly both characterise urban slums. However, as Biau (ibid) notes, such communities are also (i) sites of human resilience and huge pooled human energy, and (ii) economically useful, because they do offer low-cost housing options to the urban poor.

As has been shown, the original idealism of Turner still holds some validity as self-help housing improvement is still seen as a useful, intermediary step for improving conditions in squatter communities - particularly in climates of rapid urbanisation and shortfalls in government low-cost housing initiatives. Legal titles are not always necessary, for it is increasing residents' security of tenure that is key - or more correctly increasing residents' perceived security of tenure. The importance of secure tenure cannot be underestimated - as UN-Habitat (2007, p. 275) summarises, secure tenure is a major contributor to poverty alleviation, advancing sustainable livelihoods, improving choices 
and opportunities, accessing services, and for the general recognition of citizenship rights of the urban poor.

Whilst it is clear that security of tenure is associated with a number of benefits for residents, gaps in the literature do remain. There is still insufficient understanding of what security actually means to individual households. Secondly, the strength and indeed direction of the relationship between security of tenure and housing consolidation and improvement is sometimes unclear. Third, the influence and nature of perceived security of tenure needs more investigation. Finally, little research has focused on a security of tenure analysis for urban informal settlements in contexts of dominant customary land and/or small-island developing states. These gaps, hence, present key avenues for the current research. 


\section{CHAPTER 3: THE REGIONAL CONTEXT - AN INCREASINGLY URBAN PACIFIC}

\subsection{Introduction}

If Papua New Guinea is excluded, around half of the Pacific's population live in urban areas (Australian Agency for International Development (AUSAID), 2008, p. 74). In many Pacific nations, urban population growth rates are far outstripping rural growth rates (ibid). Squatter or informal settlements, particularly in the Melanesian Pacific, are growing rapidly. This chapter builds from the international literature reviewed in Chapter 2 to highlight the nature of an increasingly urban Pacific region. Firstly, internal migration and urbanisation in the region will be traced. Secondly, the challenges of urban management in the Pacific will be introduced. Third, ongoing debates around land tenure in the Pacific, amidst which the current research is situated, will be summarised. Finally, a review of the small, regional literature on security of tenure and housing consolidation is completed.

Figure 3.1. Map of the Pacific

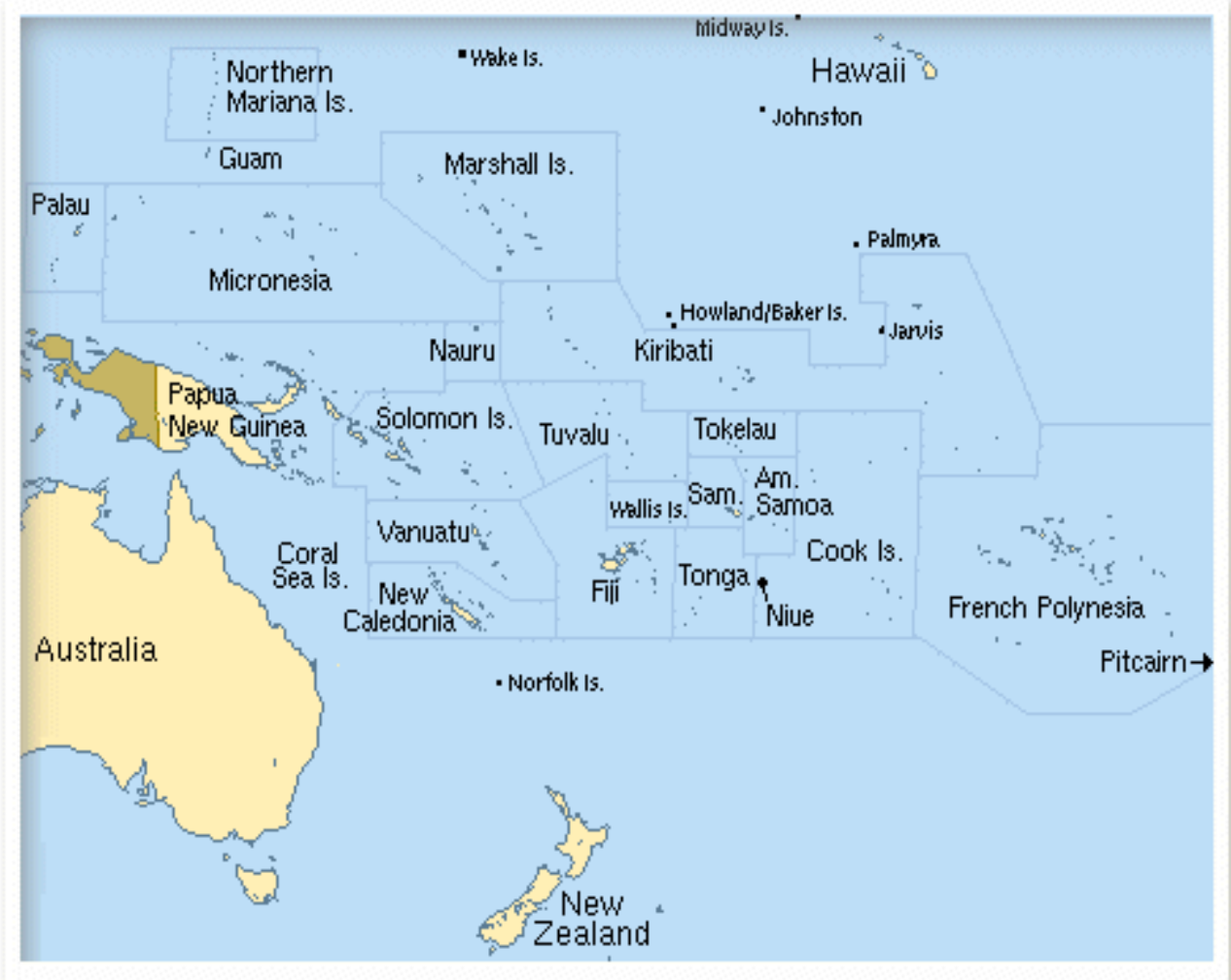

Source: http://www.pip.org.nz/pacific-map.html 


\subsection{Internal Migration and Urbanisation in the Pacific}

The Pacific has long been a region characterised by movements of people - migrations internally within territories and nations, and also emigration to other Pacific states and particularly the more developed nations of the Pacific rim. As will be described in more detail below, migration decisions are traditionally shaped by interacting 'push' and 'pull' factors. Contemporary movements of people in the Pacific region are also particularly influenced by significant, relatively recent, changes in expectations over what may form a satisfactory standard of living, desirable occupation and livelihood, and a suitable mix of accessible services and amenities (Connell, 2003a, p. 36). There is also an overwhelming economic rationale that underpins most migration moves; aimed at improving the income and thus lifestyle of the migrant, and also the living standards of those that remain at home (Connell, 2006, p. 70).

The focus of the current research is internal migration: that is, migration flows within a state or territory. Within the Pacific, this movement has traditionally occurred from smaller, more remote, islands to larger, less remote islands, and from island (and mountainous) interiors to the more accessible coastal areas. Usually, this movement has been from rural areas to urban areas, seeing urban areas in the Pacific grow steadily in recent years.

Early migration research in the Pacific tended to conclude that much of the movement to towns represented what would form the initial stage of a circular process; whereby migrants would eventually return to the village after a period in the towns (Ward; 1998, p. 22). Such circular theory did fit with the early phases of contract labour during colonial times when, for example, as through much of Melanesia, indigenous populations were only permitted in towns under temporary employment contracts (Connell \& Lea, 1994, p. 269). Ward writes that such circular internal migration theory comforted colonial administrators in the 1960s and early 1970s into thinking that migrants, often seen as potential problems, were only in towns temporarily, and thus delayed the introduction of appropriate urban policy (1998, p. 22). However, it has since become increasingly clear that only some migrants eventually returned to the village and that much migration was, rather, one-way, and acting to swell urban populations and increase pressures in urban management, infrastructure and service provision. Connell and Lea summarise that, as opposed to the circular, often seasonal, migration that was usually over short distances, 
more modern urban migration has tended to be characterised by permanent and relatively long-distance family movement (2002, p. 52).

Despite the increasing permanence of Pacific migration, it needs to be recognised that this is not necessarily at the expense of circular movement. As Chapman has concluded: "[t]he perverse result of a vigorous debate among Pacific specialists has been to ossify "circulation" as in diametrical opposition to "migration" and to ignore the obvious fact that each is an integral part of a broader, regional system of mobility" (1991, p. 289). This is a crucial point indicating the contemporary complexity of Pacific movement and the dangers of fixing particular movement metaphors across a diverse region.

\subsubsection{The Colonial Heritage}

Connell and Lea write that few other regions of the world show so little evidence of urbanisation in the pre-colonial era $(2002$, p. 19). Rather, throughout the pre-colonial period, Pacific populations lived in scattered rural villages and hamlets. It was not until the beginning of the nineteenth century that a few dispersed colonial trading centres, mainly in Polynesia and the Fiji Islands, became administrative centres serving the needs of colonialists. These settlements, however, remained tiny and had no significant influence on the surrounding hinterlands. It was only much later in the century that a semblance of urban development began to form the basis of the contemporary urban system in the region (ibid). What was clear was that, as Connell and Lea write, in the Pacific "[u]rban history was colonial history" (ibid, emphasis added).

It was not until the twentieth century, and specifically the inter-war years, that urban centres in the Pacific began to diversify beyond their initial trading and administrative functions (Connell \& Lea, 2002, p. 23). In this period, agricultural processing began in some towns and mining settlements emerged in Fiji and Papua New Guinea (ibid). Urban settlements in this period, however, still remained small: Suva, for example, as the region's biggest town, had a population of 15,500 in 1936, and in Melanesia urban towns remained tiny (ibid, p. 25).

It was only in the years after the Second World War that urbanisation began to become significant in the Pacific. The post-conflict years provided a stimulus to the Pacific's development as the region's colonial administrators began to develop the towns and 
hinterlands of the region (Connell \& Lea, 2002, p. 29). As urbanisation in the region quickened in the immediate pre-independence years, Pacific towns (especially colonial capitals) began to form a particular dualistic shape. This Pacific colonial urban geography took the shape of an expatriate area, typically resembling the forms of urban areas in the metropolitan countries, that coexisted alongside more organic, un-ordered indigenous villages (ibid, p. 34). Ward writes that this dualism was paralleled in the colonial administrative urban policy; whereby towns were administered by expatriates, for expatriates, and through expatriate models - particularly around public health, public order, and the maintenance of appropriate 'standards' (1973, p. 366-367). Ward wrote that this all acted to create an element of insulation from the indigenous population (ibid). In other words, this created European urban enclaves across the region. During the colonial era throughout the Pacific, and particularly in Melanesia, urbanisation was certainly seen as something to avoid - and indeed active policies were typically put in place to discourage the movement of indigenous populations to the colonial towns (Connell \& Lea, 1994 \& 2002, p. 43).

Across the Pacific, the 1970s were a period of significant change - particularly in the emergence of many newly independent nations. The immediate post-independence years were times of increased urbanisation; particularly as enhanced aid flows stimulated urban bureaucracies, and fostered construction and service sector expansion in the towns (Connell \& Lea, 2002, p. 35). The concentration of increasing indigenous power in a single place during these years also stimulated the growth of national capitals. This acted to discourage any decentralisation policies and soon urban primacy, or the dominance of a single urban centre, began to emerge across the region.

Growing urbanisation in the Pacific was also accompanied by increased demand for urban land and subsequent stresses on urban environments. This created enhanced pressure on the need for effective urban management. However, in many emerging Pacific states, pressures were compounded by a rapid weakening of the inherited mechanisms that had previously governed urban development (Connell \& Lea, 1994, p. 287). As will be described in more detail below, squatter or informal settlements, often on marginal land, began to emerge - particularly in Melanesia. In addition to the growth of squatter/informal settlements, the emergence of rapidly growing areas on the urban fringe, usually on customary land, as well as the swallowing of traditional villages into the urban whole, began to form a particular and distinctive form of Pacific Island 
urbanisation (ibid, p. 290). Beginning in the 1970s, the growth of squatter/informal settlements, particularly, showcased the growing socio-economic inequality in Pacific towns and also escalated tension between urban migrants and urban landowners as the demand rose for urban land. Connell and Lea write that conflict between local and migrant populations became common and began to emphasise the social, physical and economic problems of Pacific urban life (2002, p. 41). Land, and particularly access to land, certainly lay at the heart of this tension. Connell and Lea write that urbanisation in the region was fraught with unpleasantness and uncertainty (ibid). Social problems, including growing crime, emerged as significant. In addition, inadequate low-cost housing and service provision exacerbated differences between the urban 'haves' (largely expatriates, indigenous political and economic elites, and urban landowners) and the urban 'have nots' (largely urban migrants and particularly landless settlers). Connell and Lea write that a very distinctive form of urbanisation in the Pacific emerged - "associated with the rights, and the lack of rights, of residents to land in urban areas" (1999, p. 328).

As urbanisation increased in the region, and associated tension and conflict emerged in the independence era, attitudes towards urbanisation hardened further (Connell, 2006, p. 66). Prejudice and opposition towards squatter/informal settlements emerged. This was particularly pronounced in Papua New Guinea but also evident in Fiji (Connell, 2003b). The irony is that, even in the independence era, opposition to urbanisation, or anti-urbanism, has generally remained evident across the region forming a peculiar colonial legacy. Connell writes that this opposition has delayed and discouraged the development and implementation of coordinated urban development plans in the Pacific (2006, p. 66). Uncertainty and insecurity certainly characterise life for many urban migrants. When this is coupled with the ongoing colonial legacy of anti-urbanism, it is clear that significant urban challenges are entrenched across the region.

\subsubsection{The Lure of the City}

Migration decisions are principally a direct response to real and perceived inequalities in social and economic opportunities (Connell, 2003a, p. 47). Despite urban areas in the Pacific frequently displaying high levels of unemployment, migration to the towns continues as the differences between urban and rural average incomes remain substantial (ibid). Clearly, a large economic rationale shapes urban migration decisions as urban migrants are attracted to the economic opportunities offered in the towns, but 
also the education opportunities that, in turn, can increase income earning prospects. The economic rationale for these migrations decisions are also often shaped within a family context (Connell, 2006, p. 70). For, in addition to the enhanced personal income opportunities created through education and employment, individuals who move to towns are often expected to provide financial support to family who remain in rural areas (ibid).

It is not just an economic rationale, however, that shapes urban migration. Social changes and, particularly, growing expectations around the mix of livelihoods and available services and amenities that form an adequate standard of living are shaping urban movement (Connell \& Lea, 2002, p. 53). The lure of the opportunities and amenities of the city is certainly strong. In addition, the attraction of rural livelihoods, and in particular the desirability of agricultural work for young people, has decreased across the Pacific (ibid). Others also move to the city to escape the tight social obligations and controls of highly visible rural village life in the Pacific (ibid), or, further, just to experience life in the city - increasingly a region-wide ritual that is perceived as a modern form of initiation (Lewis, as cited in ibid, p. 54).

Both 'push' and 'pull' factors combine to influence migration decisions in the Pacific. Expectations, particularly for younger generations, are changing, and disparities between rural and urban areas are only widening. Movement to the cities continues, contributing to informal settlement growth and also bringing considerable challenges for effective urban management.

\subsection{Urban Management in the Pacific}

Effectively and strategically managing urban growth is critical in the Pacific. However, as McKinnon, Whitehead, Chung and Taylor write this is constrained by the fact that no Pacific Island nation has yet set in place effective policies, a suitable regulatory environment, and appropriate institutional responses for managing urban growth (2007, p. 6). Across the Pacific, ineffectiveness and confusion tend to prevail in the management of urban growth (Storey, 2005, p. 2) and this is constrained by unclear, conflicting and duplicating demarcations of responsibilities and functions of governance institutions (United Nations Economic and Social Commission for Asia and the Pacific, 2007, p. 68). While some countries in the region have some legal framework in place (such as town planning regulations and policies), effective management and 
enforcement, rather than being pivotal, has remained weak (ibid, p. 67). Overall, many Pacific governments have been slow to acknowledge the inevitability of urban migration and the reality of the growth of informal settlements. A common view persists, for example, that settlements are temporary, and that residents in these areas will one day return to their villages and, if not, they should be sent home (AusAID, 2008, p. 76).

Across the Pacific the growth of urban populations in general, and particularly the growth of informal settlements, is placing increasing pressure on already constrained urban management. In Fiji, for example, towns are increasingly outstripping their boundaries (McKinnon et al., 2007, p. 5) leaving large populations in peri-urban areas without council-supplied services. Debates and arguments are also common around lines of management responsibility for these areas; and, because these areas are often held under customary tenure, it is conflict that is often between formal and customary institutions. Overall, across the Pacific, Storey writes that the expansion of urban populations into customary land and villages beyond town boundaries has created huge political and social conflict and also undermined the capacity of the various responsible authorities to manage current and future urban growth (2003, p. 261). Acute shortages of available and affordable land are common. Conflict over access to land has the potential to be a flashpoint across the Pacific (Storey, 2005 \& 2006). The challenges of effective urban management, and possibilities of conflict, are most pronounced in the burgeoning peri-urban areas (Storey, 2005, p. 3). Storey writes that the peri-urban interface, the growth pole of Pacific cities and towns, is "characterised by a contest for space, changing social structures, and fragmented institutions" (2005, p. 10). In Fiji, for example, the challenges are summarised by McKinnon et al.: "there is no effective system of urban government in place to handle the large and rapidly expanding peri-urban population around Fiji's towns and cities, and no forward development planning to prioritize and provide services to them" (2007, p. iii).

Increasing urban populations also create considerable stresses on local Pacific environments and ecosystems. Inadequate water supply and sewage and solid waste disposal are some of the clearest negative outcomes of urbanisation pressure in the region (Connell \& Lea, 2002, p. 173) - situations that are particularly pronounced in informal settlements. For example, in Fiji, (the nation with traditionally the best urban infrastructure in the region) in the mid-1990s only about $40 \%$ of the urban population had adequate access to water, adequate sanitation facilities, and solid waste collection services (Storey, 2006, p. 25). Due to the proliferation of informal settlements in the last 
decade, it is likely that the poor coverage of services has remained, or, likely, got worse. Inadequate service provision tends to magnify environmental and health pressure in such settlements. Indeed, studies have warned that environmental and health conditions in the informal settlements of Suva were degraded and only worsening with growing populations (Wilkinson, 2002). Overall, it is the poor who suffer disproportionally as they are more likely to live on marginal land, in substandard housing, drink unsafe water, and have less access to efficient sanitation and services (Hardoy \& Satterthwaite, 1989, p. 156).

\subsection{The Pacific Land Tenure Debate}

Broadly, the current research is situated within a protracted and loud debate around whether traditional customary tenure ${ }^{12}$ are still appropriate within the Pacific as a vehicle for development. Land in the Pacific is regarded as equivalent to culture and life (Boydell \& Holzknecht, 2003, p. 203). As such, any discussions of land and potential land reforms are emotive and often political 'hot potatoes' (Levantis \& Yala, 2008, p. 99). Land debate is perhaps strongest in Melanesian where population pressures and push for reform is greatest - particularly Papua New Guinea and Fiji and, more recently, Vanuatu, and to a lesser extent Solomon Islands. Certainly, a distinct feature of the South Pacific is the dominance (between 83-100\% of land area) of customary tenure (Boydell \& Holzknecht, 2003, p. 203). However, ongoing debate and the influence of key regional players and advocates of land reform ${ }^{13}$ do mean that traditional systems of tenure may change.

It is not the intention here to cover in detail the debate about the advantages or disadvantages of customary tenure. But in general terms the ongoing debate is twofold. Hughes, for example, has called for development aid to the Pacific to be tied to the privatisation of customary tenures and even claimed controversially that the "communal ownership of land is the primary reason for deprivation in rural Pacific communities" (2004, p. 4). On the other hand, customary tenures have also been

\footnotetext{
12 Understandings of customary tenure are often conflated with common ownership (Allen, 2008, p. 1). Rather, while recognising that systems of customary tenure are diverse and vary from context to context, customary land tenure can, in simple terms, be understood as a "balance between group and individual obligations, with land ownership being held at group level and land use being at the individual or household level" (Fingleton, 2005a, p. 4).

13 Particularly AuSAID which established the Pacific Land Program in 2006 to support bilateral partners, particularly in Melanesia, to increase the availability of land for economic and social development (AuSAID, 2008). The influence of the World Bank in Papua New Guinea has also been strong, and recently the Asian Development Bank has been supporting the economic use of customary land in Samoa.
} 
defended as an appropriate and viable basis for development (Fingleton, 2005a). Advocates for land reform (generally the privatisation of customary tenures to individual titles) commonly cite a number of arguments. These include that: customary tenure is assumed to encourage small, thus uneconomic, holdings; it provides inadequate tenure security and hence is a disincentive to agricultural investment; it discourages credit extension; it impedes active land markets; and it encourages tribal divisions and disputes (in Boydell \& Holzknecht, 2003, p. 204). Alternatively, defendants of customary tenure systems claim that: successful small-holder cash-cropping does occur on customary land; subsistence food production has improved through intensification, not expansion; and that, particularly, any attempt to introduce large-scale individualisation of land tenure would have extremely harsh social consequences and the possibility of significant increases in socio-economic inequality (given that customary land forms a very important safety net in the Pacific) (Allen, 2008). However, what is often missed in this dualistic debate, often focusing on the replacement of customary tenures or no reform at all, and thus leading to policy stalemate, is that there may be an acceptable middle way - that is, to facilitate the ongoing adaption of customary tenures to modern demands of land use (Fingleton, 2007, p. 116; Levantis \& Yala, 2008, p. 99). This approach recognises the often overlooked fact that tenure systems anywhere, including customary systems, change with time and adapt to new circumstances (Crocombe, 1995; Ward, 1997a). As Fingleton explains, this 'middle way' negotiates a course "between the need to encourage growth and economic development and the fundamental importance of protecting the social, political and cultural values reflected by customary land tenures" $(2008$, p. 1). The approach looks to protect the land rights of groups but ensure individuals have adequate security to invest in land development (Fingleton, 2005b).

Some reforms may well be necessary but must take a cautious and considered approach (lati, 2010, p. 2). Strong forces are shaping a new Pacific including continued urbanisation, population growth, increasingly mobile populations, technological change, new income opportunities, and expanding aspirations (AUSAID, 2008, p. xi; Boydell \& Holzknecht, 2003, p. 204). These acute transformations are challenging the ability of customary tenures to adapt effectively, and certainly undermine the ability of these systems to provide adequate security of tenure to facilitate enhanced agricultural productivity in rural areas and to support enhanced livelihoods and adequate shelter in the cities and towns of the region. Therein is the relevance of this debate to the current research. It needs to be considered as to what level of security of tenure is adequate to 
support a viable and acceptable urban livelihood - which, of course, may not necessarily be freehold (Holzknecht, 2002, p. 10). The status quo presents a situation where informal settlers in urban areas often have little certainty over the continued prospect of being able to reside on the land, and clearly little protection in case of challenge or attempts at forced eviction. In stating the above, however, the research also recognises, indeed embraces, the perspective that customary tenures form vital systems of resilience in the Pacific. Indeed informal settlements on native land form a key avenue increasing the supply of land for low-income housing in the urban areas of the region. With this understanding, as Fingleton explains, appropriate policy responses look to provide mechanisms for the orderly adjustment of customary land rights to better accommodate new urban settlers (2007, p. 119). Indeed as Fingleton writes:

research shows that people operating under the flexibility of their customary tenures are able to adjust to the changing demands they make on their land under modern circumstances, adapting to increased internal migration and new patterns of land settlement, the growing cash economy, new uses of their land and an increasing population (2005a, p. ix).

\subsection{Security of Tenure and Housing Consolidation Research in the Pacific}

The international literature in Chapter 2 revealed that security of tenure is a fundamental requirement for squatter and informal settlers to want to invest in improving their dwellings. Clearly the relationship between security of tenure and housing consolidation is important to understand particularly if self-help home improvement is seen as something beneficial to facilitate in climates of rapid urbanisation, informal settlement growth, and budgetary pressure that can inhibit effective settlement legalisation, regularisation and redevelopment schemes.

Within the Pacific, limited research has focused on security of tenure and home upgrading in settlements. The relationship has been touched on in some studies. For example, in Vanuatu it has been highlighted that informal settlers are reluctant to improve their dwellings because of the uncertainty of their position (Chung \& Hill, 2002, p. 14; Mecartney, 2000, p. 93). There are, however, more detailed security of tenure and home upgrading studies available from the Papua New Guinea context. Bryant, for example, was an early champion of self-help housing in Papua New Guinea arguing that "self help housing is the only way in which Papua New Guineans can be adequately housed" (1979, p. 25, emphasis in original). Bryant argued that settlers in 
Papua New Guinea were more prepared to invest savings into building or buying a house if they felt they could obtain long-term benefit from such improvements (ibid, p. 30). Bryant's research in three Papua New Guinea settlements showed that length of residence was a critical variable influencing feelings of low long migrants expected to remain in town, how often they returned to home villages, and whether or not they improved or built a permanent house. Bryant believed that self-help home upgrading could be promoted especially if the Papua New Guinea government could relax its stringent, complex and restrictive inherited building regulations (ibid, p. 25 \& 32).

More recently in Papua New Guinea, Chand and Yala (2007 \& 2008) identified through a survey of settlements that "[m] ost of the homes in the settlements of Port Moresby ... are under continuous upgrading ... often undertaken with family and clan labour" (2007, p. 5) - household investment that had no distinct differences whether on state owned land, customary land, or land with disputed ownership (2008, p. 95). It is a revealing finding that considerable self-help housing consolidation is occurring in Port Moresby particularly as squatter/informal settlers, on any category of land, by definition do not have any legal security of tenure. Chand and Yala were among the first regional authors to explicitly recognise that security of tenure in settlements was not simply a legal/illegal dichotomy but influenced by perceptions and a security of tenure continuum. Specifically they stated that:

Much of the research thus far has assumed that a property with formal title is secure and those without not. Our work suggests that such demarcation is artificial and settlers and landowners, knowing the value of secure property rights, negotiate some level of security that falls in between the binary extremes used in the literature. Settlers choose the longevity of their investment in houses depending on their perception of the degree of security to the land on which the building takes place. The dynamics of savings, investment, and continual exchange with the owner of the land settled upon and with neighbouring settlers influences the levels of ongoing investment (ibid, p. 7).

Overall, the literature looking at perceived security of tenure and housing consolidation in the wider Pacific region is minimal, and, as Chapter 5 will show, in Fiji is also limited. It is timely that the nature of perceived security of tenure and housing consolidation within informal settlements in a Pacific context is given more attention. Insights from this approach focusing on tenure and security issues in urban areas can complement the rich tradition of geographic research focusing on rural land tenure in the Pacific. 


\subsection{Summary}

Urbanisation is transforming the Pacific. Social change, increased expectations about what constitutes an acceptable standard of living, and economic decision-making (largely directed at the prospect of improving incomes) shape movement towards urban areas. However, as urbanisation continues, tension and conflict around land access also increases, and, further, the challenges of effective management and governance of rapidly expanding urban areas also escalate.

As urbanisation transforms the region, an ongoing debate around the advantages and disadvantages of customary tenure in the Pacific continues. This dualistic debate, however, often focusing on reform or no reform at all, tends to ignore the prospect of an acceptable 'middle way' that would facilitate the ongoing adaption of customary tenures to modern land-use demands; including demand brought on by increased urbanisation and the need to accommodate increased numbers of low-income urban migrants on native land. The current research recognises that the flexibility and resilience of customary land will continue to be important in meeting these new demands.

Little research in the Pacific has explicitly focused on exploring perceived security of tenure and housing consolidation in informal settlements. The exception is the Chand and Yala study (2007 \& 2008) from Papua New Guinea; important for it is the first regional study to explicitly recognise the influence of perceived security of tenure in settlements and how this, too, may influence housing consolidation. It is now timely that further research looks at the nature of perceived security of tenure and housing consolidation in Pacific settlements. This thesis, before reviewing Fijian urbanisation and informal settlements in Chapter 5, now introduces the Fiji context situating the research. 


\section{CHAPTER 4: THE FIJI CONTEXT}

\subsection{Introduction}

The context of the research needs considerable focus. Overall, Fijian society is fractured. The nation's historical legacy, development challenges, systems of land tenure, stuttering economic growth, and turbulent political environment have all coalesced to create a society of divisions between 'haves' and 'have nots', exemplified, as Chapter 5 will reveal, by the proliferation of informal settlements across the nation. This chapter, firstly, provides some geographic and demographic background. The myriad of development challenges affecting Fiji and small island states generally will then be summarised. Third, key historical background will be introduced. Fourth, land tenure, perhaps the most divisive topic in Fijian society, will be detailed. Fifth, the basis of the nation's economy will be highlighted. Sixth, the turbulent political environment, further fracturing society and leaving lasting insecurity, particularly for Indo-Fijians, is detailed. Seventh, the Fijian poverty profile will be discussed. Finally, notions of security and insecurity in Fiji will be broadly summarised. This important context is necessary to detail before Fijian urbanisation and informal settlement experience is detailed in the next chapter.

\subsection{Geography and Demography}

The archipelago of Fiji consists of over 300 islands of which around 100 are inhabited. The two largest islands are Viti Levu, where most of the population resides, and Vanua Levu to the north. The Fiji Islands stretch over some 1.3 million square kilometres of ocean, and total land area is 18,333 square kilometres. Together Viti Levu and Vanua Levu comprise $87 \%$ of total land area (Small Islands Developing States Network, 2010, p. 1). Overall, relative to other Pacific islands, Fiji is well endowed with land and ocean. Both the Viti Levu and Vanua Levu interiors are mountainous and rugged; and overall around onethird of the country is too steep or rocky to be farmed (Donnelly, Quanchi \& Kerr, 1994, p. 136). The country is subject to damaging natural climatic events such as cyclones, flooding and landslips. 
Figure 4.1. Map of Fiji

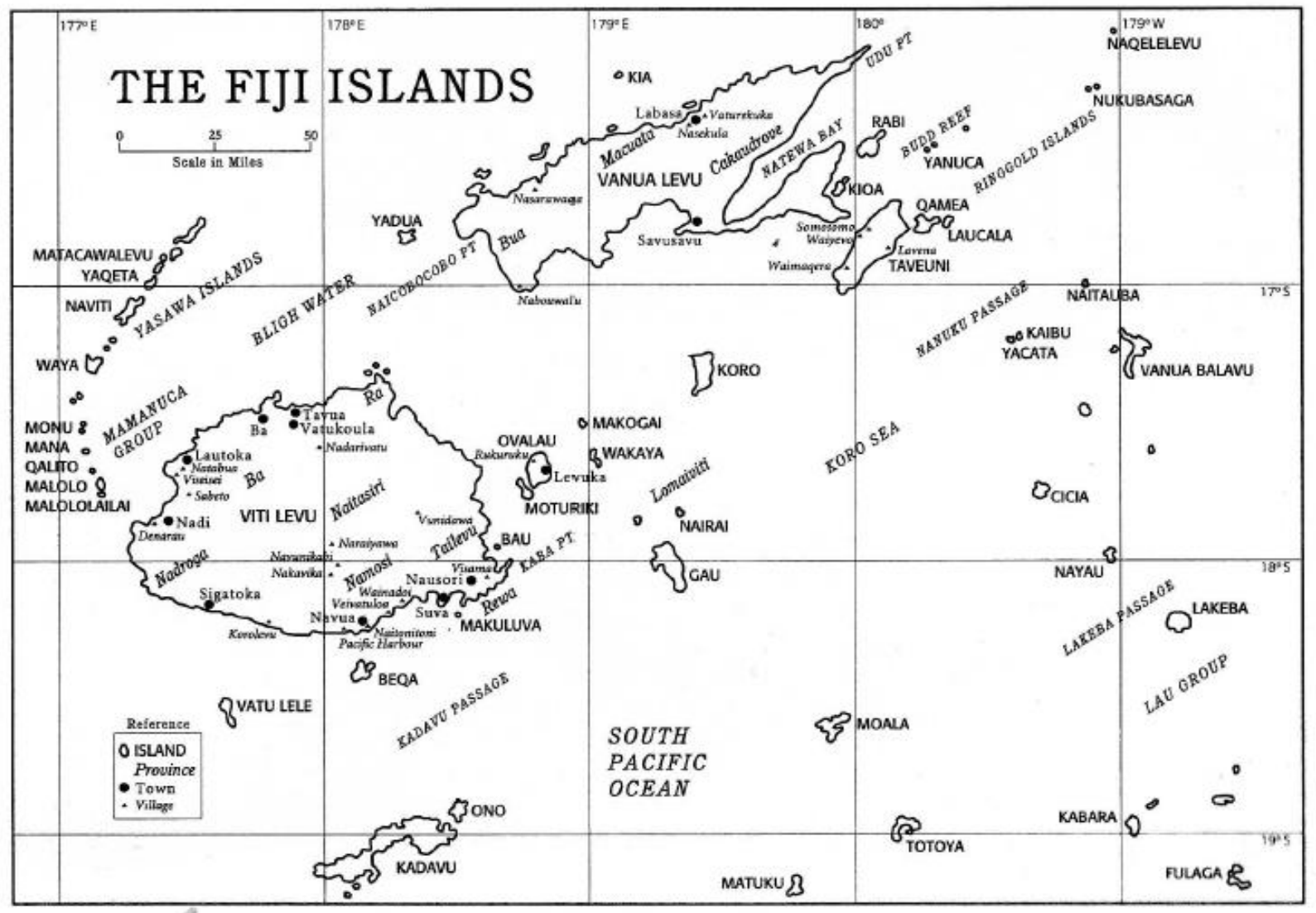

Source: Thomson, 1999, p. 227

The total population of Fiji at the time of the 2007 census was 837,271. Overall population growth from the 1996 census occurred at a rate of $0.7 \%$ per annum (Fiji Islands Bureau of Statistics, 2008). Fiji is an ethnically diverse country. Indigenous Fijians, the original inhabitants, accounted for $56.8 \%$ of the total population in 2007 . Indo-Fijians, who are descendants of Indians brought to Fiji as indentured plantation labour between 1879 and 1916 and a much smaller number of free Indian settlers, accounted for $37.5 \%$ of the population in 2007 (ibid). The remaining $5.7 \%$ of the population is comprised mainly of Europeans, Chinese, Rotumans, ${ }^{14}$ and people of mixed descent. The proportional size of the Indo-Fijian population, accounting for $48.75 \%$ of the total population in 1986 (Chandra, 1996, p. 38) (an absolute majority over indigenous Fijians), has reduced significantly in recent years. Political turmoil (particularly the coups of 1987 and 2000 ) has sparked large emigration, especially of skilled and educated Indo-Fijians, to other Pacific rim nations (notably Australia, New Zealand, and the west coasts of

\footnotetext{
${ }^{14}$ The isolated Polynesian island of Rotuma, part of Fiji, lies around 450 kilometres northwest of Suva. For generations many Rotumans have lived elsewhere in Fiji - particularly in Suva. Rotumans are usually separated from indigenous Fijians in Fijian statistics (often included in the category 'Rotumans/Others').
} 
Canada and the United States of America). High rates of emigration, as well as declining birth rates (particularly in the Indo-Fijian population), have meant that in Fiji overall national population growth has been relatively slow.

While overall population growth may be slow, the rural to urban population structure in Fiji is changing rapidly. As will be discussed more in Chapter 5, the proportional urban population has been increasing over the years, driven by increased rural to urban migration, natural increase in urban areas, and urban boundary changes. In 2007 over half $(50.7 \%)$ of the nation's population lived in urban areas. Indigenous Fijians, who traditionally were dispersed across the archipelago in villages near the ocean and rivers, have been steadily urbanising since the 1950s. The Indo-Fijian population has traditionally remained more concentrated, particularly in the sugarcane belts of western Viti Levu (including the city of Lautoka and the towns of Nadi, Ba, and Sigatoka) and Vanua Levu (including the town of Labasa), as well as in greater Suva (Donnelly et al., 1994, p. 112). The main sugarcane areas of Fiji are shown in Figure 4.2 below.

Figure 4.2. Principal Fijian Sugarcane Growing Areas (shaded)

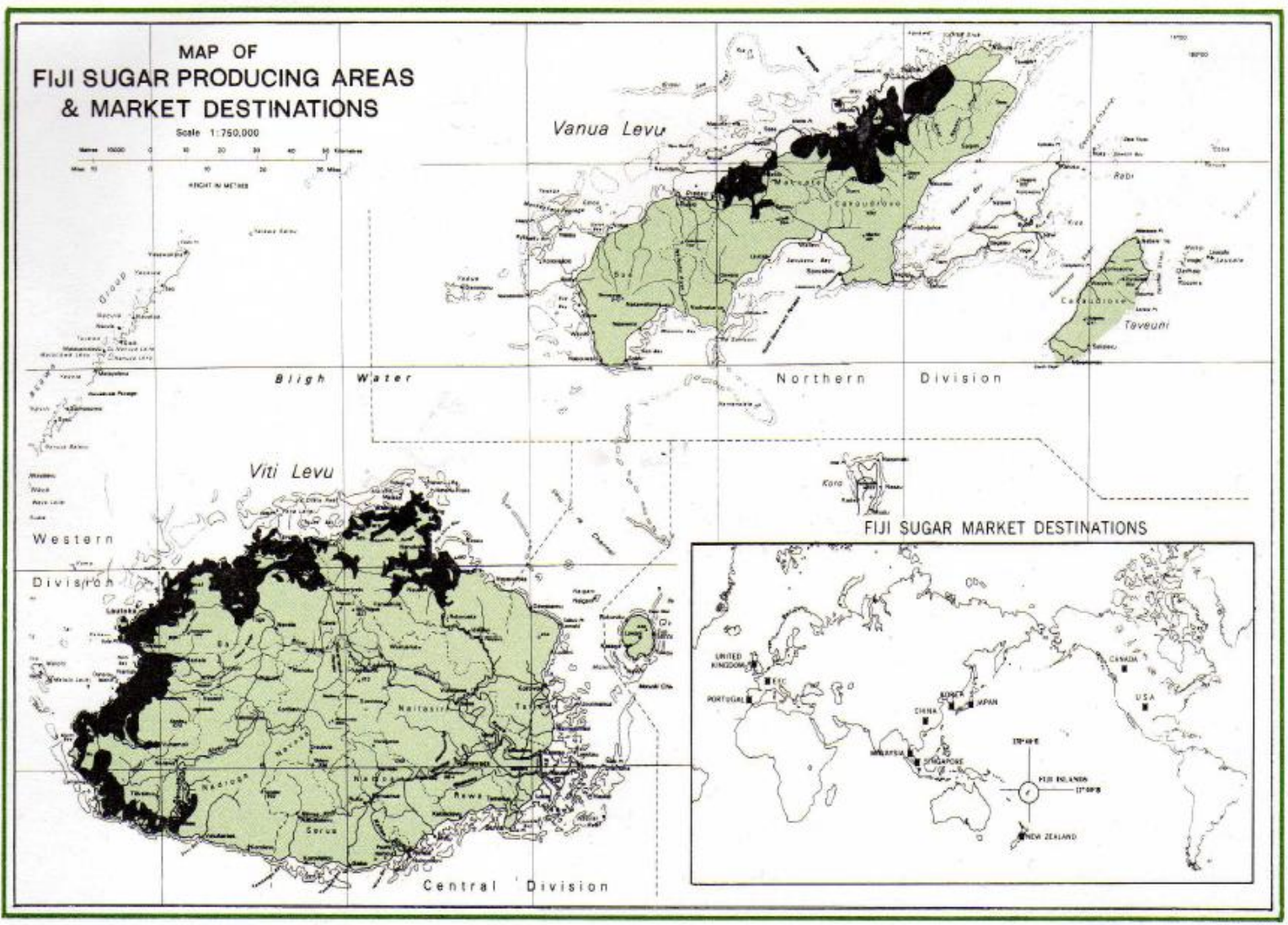

Source: Sugar Commission of Fiji, 2002, p. 37 
Fiji is classified by the World Bank as a middle income developing country (Mahadevan, 2009a, p. 11). Gross Domestic Product (GDP) per capita in 2008 was F $\$ 5,233^{15}$ (Fiji Islands Bureau of Statistics, 2010, p. 23) although the economy is particularly vulnerable to political turmoil and external shocks. GDP, for example, contracted in 2007, 2008 and 2009, and was seriously affected by ongoing political uncertainty after the 2006 coup, natural disasters, and the poor wider economic environment (Asian Development Bank (ADB), 2010, p. 237). Traditionally, however, the economy of Fiji has benefited from a good supply of natural resources and a large pool of well-educated and skilled human resources. Socio-economic indicators are relatively good in the Pacific context; in 2007, for example, life expectancy was 73 years and the literacy rate was 92.9\% (Small Islands Developing States Network, 2010, p. 1). In 2010, Fiji's Human Development Index (HDI) rating was 0.669; ranking the nation $86^{\text {th }}$ out of 169 countries (United Nations Development Programme, 2010) - a ranking, however, that has fallen from $44^{\text {th }}$ in 1996 (Mahadevan, 2009b, p. 2).

\subsection{Development Challenges}

The development challenges confronting Fiji are generally applicable across the developing states of the Pacific. All of these states are vulnerable. As small and noncompetitive producers of raw materials, and often heavily reliant on only one or two commodities, island states are very vulnerable to changes in market prices. Human capital loss through emigration is hugely significant in small nations. Island states are exposed to a wide range of natural hazards - including cyclones, flooding, droughts, tidal surges, earthquakes and tsunamis, volcanic activity, and the potentially catastrophic impact of climate change and sea level rise (Naidu, 2006a, p. 143 \& 146). Fiji is officially classified by the United Nations (along with 50 other countries and territories) as a small island developing state. While a diverse group in many respects, this collection of states is characterised by high vulnerability to natural hazards and other external shocks, low diversification of production, high dependence on international trade, volatile export earnings, high transport and communication costs, expensive infrastructure due to small size, limited opportunities for economies of scale, and, sometimes, poor public administration (McGillivray, Naudé \& Santos-Paulino, 2008, p. 481-482).

\footnotetext{
15 The $F \$$ : NZ $\$$ exchange rate in late 2011 was around $F \$ 1: N Z \$ 0.69$. $F \$ 5,233$ is thus around $N Z \$ 3,624$.
} 
Naidu writes that several 'man made' impediments also combine to intensify challenges for Pacific states: including lack of accountability by political and bureaucratic elites, shortcomings in the rule of law, mismanagement in the use of public funds, sometimes outright corruption, and military intervention in democratic processes (2006a, p. 143). Fiji, certainly, typifies most, if not all, of these constraints. Additionally, social inequality and poverty are growing across the region. The lack of formal sector job opportunities is also a major problem in all Pacific nations. Such joblessness has helped to create large groups of 'idle youth', as they have become known; sections of society that can create conflict in times of political turmoil and other uncertainty (ibid, p. 144). According to the Australian Agency for International Development (AuSAID), unemployment and joblessness, as the most pressing and widespread challenge in the region, are leading to poverty, frustration, and, potentially, growing social instability (2006, p. 2). Cultures of crime and drug-use have become more pronounced. HIV/AIDS is emerging as potentially catastrophic across the region and creates growing health burdens (Naidu, 2006a, p. 144).

\subsection{Fiji's Historical Legacy}

The first settlement in Fiji occurred by voyaging Pacific settlers and traders around 3,500 years ago (Donnelly et al., 1994, p. 8). For the majority of its history, Fiji was made up of people speaking many different languages and influences were diverse from across the Pacific. As Donnelly et al. write: "[n]othing was static in Fiji. It has a history of settlement but also one of mobility" (ibid). As population levels increased and became more permanent, a key form of social organisation began to develop: the mataqali or family group 16 led by a turaga or chief. Land use decisions were made by the mataqali, or, in some areas of Fiji, by a smaller number group within the village called the $i$ tokatoka. Systems of land tenure began to evolve. Mataqali who claimed links to common ancestors began to form yavusa or clans. As population grew with competition for space, resources, power and status, yavusa joined together to form a vanua, or small alliance. Vanua then combined to form a wider political alliance called a matanitu. By around 1800 there were 12 leading powerful and competing matanitu across the archipelago led by great chiefs (ibid, p. 9). These matanitu still remain prominent in the current era (Routledge, 1985).

\footnotetext{
16 Specifically, mataqali refers to an agnatically related (on or descended from the father's or male side) social unit, most often a lineage of the larger clan.
} 
Europeans first came to Fiji in large numbers in the early to middle nineteenth century in search of sandalwood and bêche-de-mer. European contact through whaling activity and 'beachcombers' (mainly shipwrecked and deserting sailors and escaped convicts) also occurred. Considerable numbers of missionaries also arrived to leave a lasting Christian impact on the Islands. European settlers began arriving in substantial numbers in the 1860s and soon developed coconut and cotton plantations. Conflict over land emerged between Europeans and indigenous Fijians, and land ownership became increasingly contested. Two different ideologies around land-use and ownership began to clash, although land sales (some of a dubious nature) continued to the new settlers. After much discussion around governance options, Fiji was formally ceded to the United Kingdom in 1874, in part due to growing concerns in Britain around the abusive plantation labour trade, or 'blackbirding', of the period (Donnelly et al., 1994, p. 17-33).

By 1870, after a major decline in world cotton prices, the colony of Fiji was forced to turn to sugarcane as a major alternative plantation crop (Donnelly et al., 1994, p. 47). The Australia-based Colonial Sugar Refinery (CSR) Company was subsequently invited to the colony; arriving in 1882 and remaining until 1973 (Lal, 2006, p. 370). Because plantation agriculture was very labour intensive the colony faced a labour shortage, particularly as the import of labour from Melanesia had lessened and the first governor of Fiji, Sir Arthur Gordon, was opposed to the use of indigenous Fijian labour (arguing it would undermine traditional village communal life) (Donnelly et al., 1994, p. 48). Hence indentured Indian labour was seen as the solution and subsequently organised. Overall, the indentured labour period, beginning in 1879 and ending in 1916, brought 60,963 Indian men, women and children to Fiji. These migrants came under an agreement - termed the girmit, and, those who came under it, the girmitiyas - of five year terms of plantation labour. After their term, girmitiyas could return to India at their own expense, or at the expense of the government after a second five year term (Lal, 2006, p. 370). Overall, around 24,000 Indians returned to India (ibid); but the rest stayed to form the first generations of IndoFijians. Ultimately, however, the gap between rhetoric and expectation and reality on the ground was substantial for the girmitiyas (ibid). For many, the girmit was a time of back-breaking labour, discrimination, intimidation, humiliation, and frequent corporal punishment and other violence. The voyage from India, and the girmit itself, was also a major social leveller; and consequently the caste system almost disappeared among Indo-Fijians (Donnelly et al., 1994, p. 50). Most of the girmitiyas were Hindu although around $15 \%$ of the migrants were Muslim (Lal, 2006, p. 371). 
After a period of girmit, and after the indentured labour system was abolished in 1916, many Indians remained in Fiji as independent farmers, settling wherever they could obtain land (others joined the largely urban groups of labourers, tradespeople, clerks and businesspeople; ranks that were joined by a trickle of free settling Indians in the 1920s and 1930s (Lal, 2006, p. 375)). The CSR Company divided its land into farms of usually four hectares to be leased to tenant farmers. Scattered homesteads on individually leased farms, rather than clusters of rural villages, began to characterise Indo-Fijian settlement. Among Indo-Fijians emphasis centred on individual enterprise and initiative (Donnelly et al., 1994, p. 51; Lal, 2006, p. 373). The Indo-Fijian community continued to develop largely in social and cultural isolation from other communities, and, significantly, there was very little interaction between Indo-Fijians and indigenous Fijians (Lal, 2006, p. 373). Lal writes that "the two communities lived warily side by side, mutually uncomprehending each other's fears and aspirations in what was fast becoming a plural society" (ibid). As will be highlighted in more detail later, insecurity, particularly of land tenure, dominated life for Indo-Fijians. Rural farmers, for example, could only lease land under limited time frames. For Indo-Fijians "[t]he land problem not ownership but leasing arrangements - remained as intractable as ever" (ibid, p. 379).

Fiji became independent on the 10 th of October 1970. The post-independence period has not always been easy. As will be discussed later in the chapter, four coups since 1987 have created a turbulent political environment and seriously undermined economic growth. Tension, particularly between indigenous Fijians and Indo-Fijians has ebbed and flowed, if not escalated, in what is a fractious society. Conflict over land, and particularly access to land, has intensified. Insecurity of land tenure dominates livelihoods for rural lease-holding farmers and urban informal settlers of both major ethnic groups.

\subsection{Land Tenure in Fiji}

The majority of land in the Pacific is held under what is known as traditional, native or customary tenure. Land is a very important part of Pacific culture and is central to ways of life in the region (Ward \& Kingdon, 1995a, p. 1). In Fiji, the traditional customary system has been modified through alienation and codification in to three forms of primary tenure. Today, native land accounts for $87 \%$ of total land area, state land (before 1987 known as 'crown land') accounts for 6\%, and freehold land accounts for $7 \%$ (Prasad, 2006, p. 178). Freehold land can be bought and sold by anyone. Native land, however, 
cannot be freely traded; but, under certain conditions, can be leased (Boydell \& Reddy, 2000 , p. 4). Land issues in Fiji, particularly around access to land for different ethnic groups, are sensitive topics and are politically charged (Ward, 1995, p. 198).

Kamikamica writes that the "land question is one of the most divisive and potent political issues in Fiji. It underlies and permeates the economic, social and political fabric of Fiji society" (1997, p. 259).

Customary systems of land tenure in the Pacific have traditionally evolved over generations. Communalism and reciprocity were, and have largely remained, key principles in the management and use of customary land (Ward \& Kingdon, 1995b, p. 45). In Fiji, the term used for land, vanua, is a wide, encompassing concept; being so multifaceted that it appears to have no direct parallels in English (Batibasaqa, Overton \& Horsley, 1999, p. 100). Ravuvu writes that:

vanua [land], has physical, social and cultural dimensions which are interrelated. It does not only mean the land area one is identified with, and the vegetation, animal life, and other objects on it, but it also includes ... the people, their traditions and customs, beliefs and values, and the various other institutions established for the sake of achieving harmony, solidarity and prosperity ... It provides a sense of identity and belonging (1983, p. 70).

The term vanua is widely used in Fiji, and its meanings are multiple. As Overton summarises: "it is a term for land and a place, but it also encompasses people in that place who are bound to that land" (1999, p. 180). The bond between people and land is central (Batibasaqa et al., 1999, p. 101). Vanua can be described as the physical and human environment in its totality. However, it can also mean 'people', and also refers to a territorial unit, or combination of yavusa, united under one chief (Overton, 1999, p. 180). Vanua also includes concepts of established customs and protocols that govern how people interact with each other and the land, and the social structure through which this occurs (Batibasaqa et al., 1999, p. 101). It is, perhaps overall, an expression of Fijian values (ibid, p. 102).

Systems of land tenure in Fiji have evolved over hundreds of years. However, it was the contemporary colonial period that produced the most significant change. As France explains: "[t]he land tenure systems which exists in Fiji today evolved from the varied administrative decisions of a colonial government" (1969, p. 174). Prior to the colonial period, land tenure systems held a high degree of flexibility. Mobile populations and 
differences in the supply of land (particularly good, arable land) meant that "ancient boundaries of lands were continually contracting and expanding" (Thomson, as cited in Ward, 1995, p. 206). However, in the colonial period a number of challenges to traditional land tenure systems emerged. Firstly, land began to be alienated; in a rapid and uncontrolled manner prior to cession in 1874, and through a more regulated fashion from 1874 to 1908, when alienation of native land ceased (this alienated land now forms the holdings of state and freehold land in Fiji). Secondly, as will be described in more detail later, the evolution of laws began to regulate the leasing of native land. Third, the mapping and registration of mataqali land in the 1940s by the Native Land Commission, and the accompanying recording of all mataqali members in the national register, the Vola Ni Kawa Bula (VKB), while recognising communal ownership of land, codified a rigid system that removed the flexibility of earlier practices (Overton, 1987, p. 143; Ward, 1995, p. 218). For example, if a mataqali group increased or decreased in size, land holdings could not change. If a mataqali unit died out, their land, rather than reverting to surrounding or new clans, reverted to state tenure as 'Schedule A' land (which became areas able to be leased) (Overton, 1987, p. 143). Individuals recorded on the land register could move away from home areas (for example, to towns and cities), sever links and communal obligations, but have land rights, at least legally, remain intact. Other traditional, flexible arrangements became illegal, such as traditional gifting of land (Ward, 1995, p. 218-219). As Ward explains, underlying the whole mapping process was an assumption that the registered owners of the land would be the users (ibid, p. 219). In practice, however, "ownership and use were often not in accord" (ibid). Considerable inequalities in land holdings have also emerged with population growth (ibid, p. 218). Overton writes that these inequalities, between indigenous Fijians, have increased to the extent that they are becoming an ever important feature of social and economic life in rural Fiji (1992, p. 328). Ward explains that, while it can be argued that at the time of the fixing of mataqali holdings there was some broad relationship between land quality, mataqali numbers and subsistence needs, the changes in total mataqali numbers over time has led to great discrepancies in holdings per capita - even between mataqali in the same village (1997b, p. 254). According to Ward "[t]he general assumption that Native Land guarantees rural security of ethnic Fijians is no longer universally valid" (ibid, p. 255); a situation that is likely a powerful push factor in influencing urban movement.

Traditional concepts of land use began to clash with more Western notions of land as a resource for development in the early to middle twentieth century. The rapid growth of the Indo-Fijian population, and the expansion of agriculture in the 1930s and 1940s, 
brought to the fore issues of land tenure and security (Lal, 2006, p. 376). In the 1930s, Indo-Fijian tenant farmers began to seek greater security of tenure, a cause championed by the client CSR Company (Kamikamica, 1987, p. 228) and also the government of India who expressed concern that the limited leases of the time created much insecurity of tenure for tenant farmers, "leaving the Indian leasee [sic] very much at the mercy of the Fijian landlord' (in Lal, 2006, p. 376). In part due to this support and pressure, and the growing realisation that the agriculture-based economy needed secure tenure (particularly to encourage farm investment and availability of credit), the Native Land Trust Board (NLTB) was established in 1940. The NLTB assumed responsibility for reserving sufficient land to meet the 'use, maintenance and support' needs of indigenous Fijians, and also all legal responsibility for leasing surplus, thus unreserved, land to any ethnic group (ibid; Kamikamica, 1987, p. 230). Over the next 30 years, the NLTB proceeded with reserving native land; a process that when completed accounted for $36.6 \%$ of native land (Ward, 1995, p. 220), or around $30 \%$ of total land area (Kabutaulaka \& Rokolekutu, 2008, p. 65). This native reserve land can be leased, to indigenous Fijians only (as 'Class J' leases), providing there is the agreement of the majority of the landowning mataqali (Kamikamica, 1987, p. 231).

The most important legislation in Fiji affecting agricultural land is the Agricultural Landlord and Tenant Act (ALTA). ALTA was originally enacted in 1966 (as the Agricultural Landlord and Tenant Ordinance (ALTO) legislation), after recommendation to reform landlord/tenant relationships to enable longer term leasing of agricultural land to ensure some security of tenure. Originally 10 year leases were enacted, and after amendment in 1977, the minimum period of leases increased to 30 years (Ushman, 1984, p. 99). ALTA provided leases that as legal titles could be traded and used as collateral to obtain finance from lending institutions (including all commercial banks), and also provided provisions for compensation for improvements to the land (Overton, 1994, p. 119; Prasad, 2006, p. 177). Overall, ALTA played a crucial role in the agricultural development of Fiji and helped to create some stability in the agricultural sector, particularly in the key sugarcane industry where total sugar production increased for many years (Prasad, 2006, p. 177; Singh \& Reddy, 2007, p. 40). However, perhaps the most controversial aspect of ALTA is that there is no automatic right of lease renewal for tenants (Reddy \& Naidu, 2001, p. 33). This lack of long-term security of tenure for farmers hit home from 1997 onwards when many ALTA lease terms began to expire but were not renewed to sitting tenants. 
Under ALTA, rentals for NLTB leases were set at not exceeding more than $6 \%$ of the unimproved value of the land. Of total rent, NLTB first deducts a $20 \%$ fee for administration costs. ${ }^{17}$ Of the remaining $80 \%, 30 \%$ is distributed to the three principal chiefs of the landowning mataqali.18 What is left over goes to the other registered members of the mataqali (which could range from a handful of individuals to hundreds of people; who do not necessarily need to be resident in the community) (Kurer, 2001 a, p. 300). The division of NLTB rents across the mataqali groups has been frequently criticised. For example, in some cases, one individual may hold more than one of the three chiefly positions - so it is possible for some individuals to accumulate considerable wealth. Moreover, where the economy and social activity of the community are no longer based primarily on reciprocity, there can be little redistribution of rents to the wider mataqali from the rent received by the chiefs (Ward, 1995, p. 221). Overall, the division of NLTB rentals means that "the share for those mataqali members left in the village ... is a pittance. In many instances they receive none in practice" (Overton, 1994, p. 121). Further, the divergence between the rents paid for NLTB leases and those set by market forces on freehold land has become significant in recent years (Ward, 1995, p. 221) leading to calls to increase NLTB rents. This culminated in a recent increase in land rentals to landowners of $10 \%$ of the unimproved value of the land of which the difference is paid by the government as a subsidy (for a period of five years - after which the difference will be borne by farmers) (Prasad, 2010, p. 14). Overall, leasing arrangements remain by far the most contentious aspect of the administration and management of native land in Fiji (Kamikamica, 1997, p. 260). Many farmers still believe that 30 year ALTA leases are too short for adequate security of tenure, while many individuals in landowning groups feel aggrieved over low, or unequal, returns for their leased lands. The rise of Fijian nationalism before and after the first coup in 1987 has also complicated the situation (ibid). The non-renewal of many expiring ALTA leases from 1997 onwards has crystallised the scenario and forced many thousands of farmers and their dependents off rural leased land and into urban areas.

In parallel to the formal leasing system of agricultural land, an informal system of vakavanua leasing has persisted for many years. Vakavanua or customary ${ }^{19}$ arrangements are based upon longstanding traditional practices. These 'extra-legal'

\footnotetext{
17 This was reduced from $25 \%$ in 1999.

18 Of the $30 \%$ of NLTB rents allocated to chiefs, $5 \%$ goes to the chief of the vanua, $10 \%$ to the chief of the yavusa and $15 \%$ to the chief of the mataqali (Kurer, 2001a, p. 300).

19 Vakavanua can loosely be translated into English as meaning a 'request after the manner of the land' (Rutz, 1987, p. 547). Vakavanua arrangements will be discussed more in Chapter 5.
} 
arrangements are, in some cases, a continuation of recognised land allocation systems in a village, and, in others, a major alternative to leasing land via the NLTB (Overton, 1987, p. 139). The key feature of vakavanua arrangements is direct negotiation between prospective tenants and particular individuals within the mataqali who hold rights to the land and who represent the true 'controllers' of the land (Overton, 1994, p. 121). Vakavanua practices offer a number of advantages to landowners. First, landowners can retain more control over how land is used. Second, landowners can demand much higher rents. ${ }^{20}$ Third, no rent goes to NLTB; rather rent is divided between certain members of the mataqali only who hold particular usage rights to that land. Fourth, no externally controlled lease conditions apply (Ward, 1995, p. 238). A range of vakavanua practices exist; from small scale arrangements obtained through customary presentation of tabua (whale's tooth), yaqona (kava), and other items in exchange for temporary use of the land (perhaps for a single season), to more long-term and secure arrangements increasingly facilitated by the use of cash (Overton, 1987, p. 148). Despite the disadvantages of vakavanua arrangements, which include insecurity of tenure, the absence of written agreements, and deleterious effects on land and soil quality in shortterm arrangements, they do persist (ibid). Overall, the shortage in availability of good land for leasing through NLTB, and the increasing divergence between NLTB rents and market value, ensures that vakavanua practices continue (Ward, 1995, p. 238; 1997, p. 256). As Overton writes, the practices also free up some land, utilise traditional and respected customs, better equate rents to market values, and present a flexible alternative to official arrangements (1987, p. 148; 1994, p. 129). Vakavanua arrangements are now so common that, despite being strictly illegal, little is done by the NLTB or the state to stop the practice (Overton, 1994, p. 121).

As will be discussed further in Chapter 5, vakavanua arrangements are not limited to rural areas, but are also used to gain access to land in cities and towns particularly in peri-urban areas. Ward writes that squatter settlements on native land held under vakavanua arrangements first appeared on the fringes of Suva in the 1950s (1995, p. 241). Vakavanua practices have also been used for many years to gain access to land for agriculture and market gardening in peri-urban areas (ibid). These practices in urban areas, that can go back generations, are widespread. Today, as pressure for land in increasingly dense urban areas builds, they are essential mechanisms for migrants, both indigenous Fijian and Indo-Fijian, to obtain some urban land on which to build or

20 Eaton (1988), for example, revealed that some landowners through vakavanua arrangements received as much as 10 times above NLTB rentals. 
relocate a dwelling. Within urban and peri-urban areas, vakavanua practices are applied in a context of increasing land shortage, rising land values, and a wage economy (rather than a traditional reciprocal exchange system). Within this context, urban vakavanua arrangements are open for exploitation - both by landowners, who may extract high rents from poor, insecure and vulnerable settlers, and by migrants, who may quickly move in far more extended family members than was originally negotiated for (Ward, 1995, p. 242). As Rutz writes, within urban vakavanua arrangements, "there is genuine confusion about the obligations and duties of Fijians towards each other, about what constitutes proper conduct in general, and, in particular, with regard to land value and the moral order for transactions" (1987, p. 555).

Table 4.1 below shows changes in the distribution of primary land tenure in Fiji - from the early 1970s, to mid-1990s, to 2000s. Changes from the early 1970 s to the mid-1990s reflect mainly small changes in the conversion of state to native land. Changes between the mid-1990s and 2000s reflect the transfer of 'Category A' state land (land which had reverted to the state after the extinction of a mataqali group) and 'Category B' state land (which was land originally unclaimed at the time of the Fijian Lands Commission mapping in the middle twentieth century) to native tenure in 2002 (Prasad, 2006, p. 178). Figure 4.3 and 4.4 below identify the distribution of major types of tenure in the mid-1990s across Viti Levu, and across Vanua Levu and Taveuni. The allocations of state 'Schedule $A$ ' and 'Schedule B' land in these figures can now be read as tracts of native land.

Table 4.1. Primary Land Tenure in Fiji, 1970s, 1990s, and 2000s

\begin{tabular}{|c|c|c|c|c|}
\hline \multirow[t]{2}{*}{ Land category } & \multicolumn{3}{|c|}{ Total land area (\%) } & \\
\hline & 1970s* & $1990 s^{* *}$ & 2000 s*** & \\
\hline Native land & 83 & 82.38 & 87 & \\
\hline State land & 10 & 9.45 & 6 & \\
\hline Freehold land & 7 & 8.17 & 7 & \\
\hline \multicolumn{5}{|c|}{ * As based on Nayacakalou, 1971} \\
\hline \multicolumn{2}{|c|}{ ** As based on Ward, 1995} & & & \\
\hline \multicolumn{5}{|c|}{ *** After conversion of 'Category A' and 'Category B' state land to native tenure in 2002} \\
\hline
\end{tabular}

Source: Adapted from Prasad, 2006, p. 178 
Figure 4.3. Distribution of Land Tenure, Viti Levu, mid-1990s

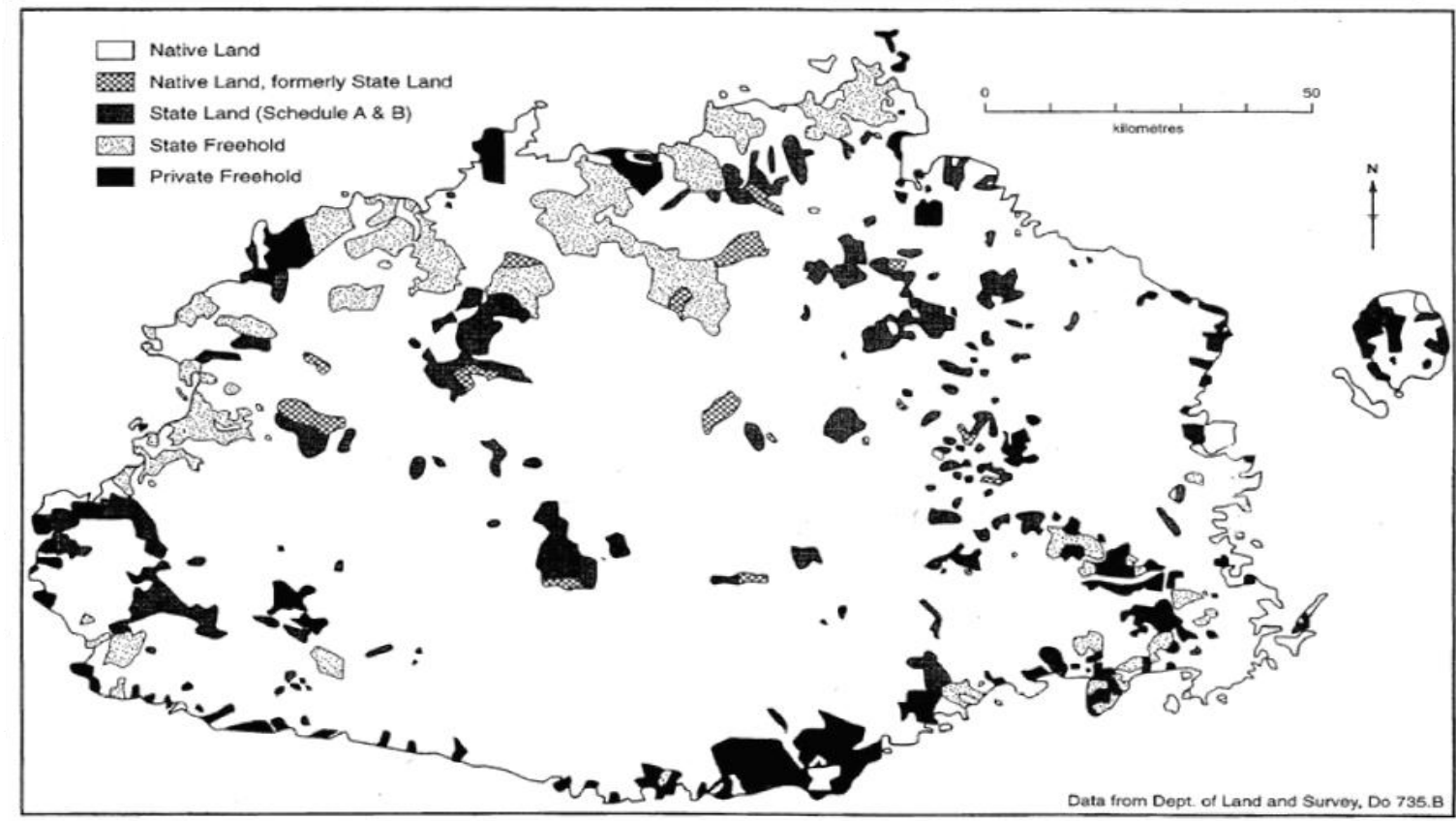

Source: Ward, 1997b, p. 249

Note: Native and state land that is leased is not shown

Figure 4.4. Distribution of Land Tenure, Vanua Levu and Taveuni, mid-1990s

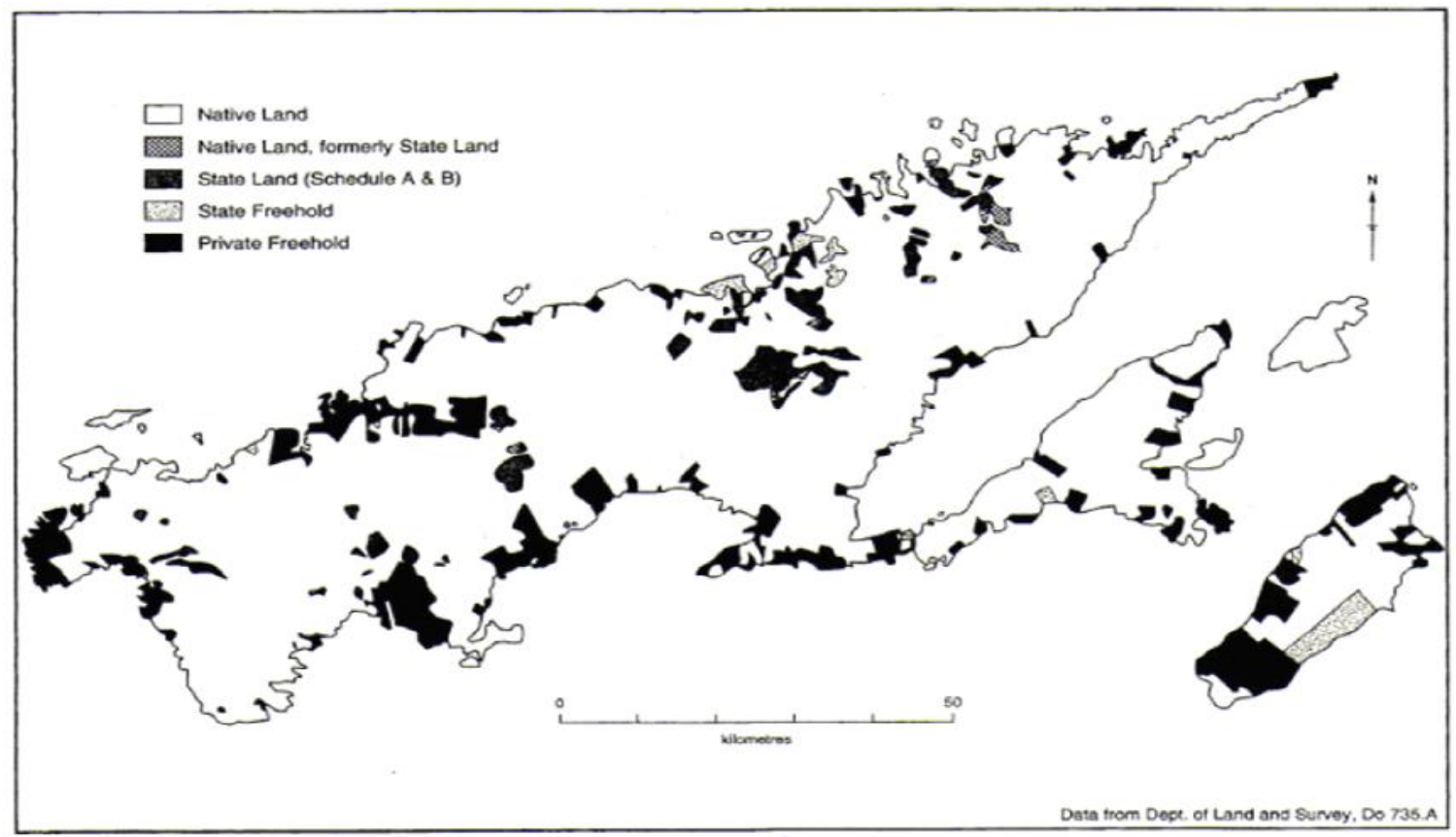

Source: Ward, 1997b, p. 250

Note: Native and state land that is leased is not shown 
Fiji is a nation of 18,333 square kilometres. For a population of less than a million people there is no absolute shortage of land. However, when systems of land tenure, accompanying conditions of access, and land quality and physical geography are analysed, there are major shortages. Firstly, the large, rugged, mountainous interiors of the main islands are too steep to be effectively farmed. Secondly, large proportions of native land are held as native reserve land that can only be leased to indigenous Fijians. Third, as has been identified, large inequalities in land holdings per capita exist between mataqali groups. Fourth, most of the best quality, most arable, land is held in freehold or state tenure - meaning that, if quality is taken into account, the holdings of native land do not seem so dominant (Ward, 1995, p. 200). Further, most of the best quality land in native tenure has been leased already; meaning that the "quality of the overwhelming area of reserved and unreserved Native Land remaining unleased and unused is poor" (Ward, 1997b, p. 251). Overall, it still holds that "it is wrong to assume that unleased native land represents a large store of under-utilised high quality land waiting to be developed if only tenure restriction could be relaxed" (Overton, 1987, p. 139).

In summary, while systems of land tenure traditionally were evolving and flexible in the Fiji Islands, colonisation, alienation, and subsequent codification created a much more rigid structure of land tenure. This system, stressed by population growth and the different needs of Fiji's multi-ethnic population, has, in turn, entrenched various inequalities in access to land particularly - in both rural and urban areas, and for all ethnic groups. In a widely influential and cited speech to the Great Council of Chiefs in 1936, the Fijian statesman Ratu Sir Lala Sukuna, tasked with mobilising support for the leasing of native land, said:

An idle landowner neglects his duty to his state. Should his holding be more than he can utilize, he should lease the surplus to those who can make use of it ... it is our duty to use our influence, our power, to open up waste mataqali lands for agricultural purposes, whether they be taken up by Europeans, Indians or Fijians (as cited in Ushman, 1984, p. 97-98).

In part due to the support gathered by Ratu Sir Lala Sukuna, ultimately the NLTB was established in 1940 with the one prime task to "ensure that land was available for development to meet the needs of both Fijians and non-Fijians in the interests of the country as a whole" (Ward, 1997, p. 252). However, this vision has not been fully realised and difficulties and inequalities in access to land have remained. Vakavanua arrangements have persisted as a way to circumnavigate NLTB control. Significantly, from 1997 onwards, for a variety of reasons, many agricultural leases were not renewed 
to sitting tenants - in particular affecting hundreds, if not thousands, of Indo-Fijian sugarcane growers who contributed significantly to the Fijian economy. Ultimately, the "inalienable control of land has become an icon of ethnic distinctiveness. It is what Fijians have and other ethnic groups do not" (Ward, 1997b, p. 248). Land, and access to land, became a flashpoint and a spark for ethno-political conflict (as will be detailed later). Changes to land tenure legislation are difficult, if not very unlikely. Under the (now abrogated) 1997 Constitution, and a functioning Parliament, for example, changes to ALTA legislation required a two-thirds majority in both Houses, as well as the agreement of at least nine of the 14 Great Council of Chief's representatives in the Senate (Kurer, 2001 a, p. 310).

\subsection{The Fijian Economy}

Fiji is one of the more developed and diversified Pacific economies (Forsyth, 1997, p. 178). Relative to other Pacific nations, Fiji has traditionally enjoyed the availability of a range of natural resources as well as a generally well educated and skilled population. Fiji's economy, however, is very open (a high proportion of national income is generated by exports and spent on imports), and only a small range of commodities can be exported competitively. This makes Fiji highly vulnerable to changes in world commodity prices (ibid). Overall, also influenced by political turmoil, the performance of Fiji's economy has been sluggish and unstable since independence (Mahadevan, 2009b, p. 2).

Key sectors of the Fijian economy include tourism, sugar, textiles and remittances. All of these sectors are, however, vulnerable; sugar and textiles have been hit hard by changes in the international trading environment, tourism is very sensitive to security concerns increased by political turmoil, and remittances are affected by deteriorations in the wider, external economic climate. Other key foreign exchange earners include fish, gold, timber and timber products, and the increasingly important mineral water industry. Table 4.2 below shows changes in the value of exports, by key sector, between 1985 and 2008 . 
Table 4.2. Changes in Fijian Export Values (F\$ million), Key Sectors, 1985-2008

\begin{tabular}{|l|r|r|r|r|r|}
\hline Industry & \multicolumn{5}{|c|}{ Year } \\
\hline & $\mathbf{1 9 8 5}$ & $\mathbf{1 9 9 5}$ & $\mathbf{2 0 0 1}$ & $\mathbf{2 0 0 5}$ & $\mathbf{2 0 0 8}$ \\
\hline & & & & & \\
\hline Tourism & 161.4 & 405 & 496 & 733.2 & 753.7 \\
Sugar & 111.8 & 276.1 & 221.6 & 217.9 & 248.1 \\
Fish & 11.7 & 113 & 91.2 & 82.9 & 134.2 \\
Garments & 2.1 & 185 & 305.2 & 120.4 & 100.1 \\
\hline
\end{tabular}

Source: Mahadevan, 2009b, p. 4

The Fijian economy is hindered by a number of structural and institutional challenges.

Productivity is stymied by a lack of progress in diversifying the industrial base. Agriculture, and the still vital sugar industry, is particularly inhibited by a land tenure system that does not provide long-term security of tenure. A shortage of skills, brought on by high rates of labour migration, also compounds the productivity problem (Forsyth, 1997, p. 182-183). As will be discussed in more detail later, the turbulent political environment has had extremely deleterious effects on overall economic growth.

\subsubsection{The Continuing Importance of Sugar}

Agriculture in Fiji is dominated by the sugar industry which includes the growing of sugarcane and manufacture of sugar for export. From the days of the CSR Company, to nationalisation of the industry in 1973 and the establishment of the Fiji Sugar Corporation (FSC), the sugar industry's role in the economy has remained absolutely central (Chand, 2007b, p. 15) - in fact forming the backbone of the economy for over a century (Lal, LimApplegate \& Reddy, 2001, p. 2). Sugar was by far the largest single industry in Fiji during the 1970s, when it provided for $70 \%$ of total export earnings (Oxfam International, 2005 , p. 9). Sugar production stood at 272,000 tonnes in 1976 , reached 475,000 tonnes in 1980 , and peaked at 517,000 tonnes in 1994 (ibid). Since 1994, production has been declining, with production of 207,000 tonnes in 2008 and only 165,000 tonnes in 2009 (Perry, 2009, p. C2; Prasad, 2010, p. 14).21 The falling sugar production rates are reflected in the diminishing contribution of the agricultural sector to total GDP; figures that fell from $16.3 \%$ in 1995 (when agriculture was still the dominant sector) to 12.4\% in 2004 (Gani, 2007, p. 4).

\footnotetext{
${ }^{21}$ Recent sugar production is now well below the 200,000-250,000 tonnes scheduled to be delivered to market as part of Fiji's quota (Fraenkel, 2010, p. 427). Subsequently FSC has had to import sugar from India to meet local and regional demand (Fraenkel, 2009, p. 344).
} 
In 2005, sugar accounted for 6\% of Fiji's GDP (Chand, 2007b, p. 15). The sector brings in around $\mathrm{F} \$ 200$ million in export revenue - or around 20-22\% of the nation's export earnings (Oxfam International, 2005, p. 9). The importance of the sector is particularly highlighted by the thousands of livelihoods that it supports. Estimates suggest that around 22,500 people are involved directly in cane cultivation, and some 24,000 more in the harvesting, transport and milling branches of the industry (ibid). FSC estimated in 2002 that the sector directly supported $25 \%$ of the country's active labour force. Other estimates suggest that between 200,000 and 250,000 people are directly or indirectly reliant on sugar for their livelihoods (ibid); a very large proportion of the total national population.

The sugar industry in Fiji is based around approximately 17,000 farms holding supply contracts with FSC. The average farm is 4.6 hectares in area and produces around 160 tonnes of sugarcane per annum (Chand, 2005, p. 201). Around $80 \%$ of the harvest, however, is produced by $20 \%$ of the farmers - as the majority of farms are small scale (Mahadevan, 2009b, p. 3). All farms are rain-fed and consequently production between years can vary significantly (Chand, 2005, p. 201). The industry is labour intensive; most farms are run with family labour and animal draught power, and cane is manually harvested by gangs of cane-cutters - much like it was when the industry was first established (ibid, p. 201-202). Cane is transported to the four FSC mills by privately owned trucks and a FSC rail system. Transport is plagued by poor quality farm service roads and dilapidated rail infrastructure. The mills are in drastic need of investment; and mill breakdowns are frequent in crushing season. Overall, relative to other sugar producers, the sector is very inefficient: of the 20 African, Caribbean and Pacific (ACP) sugar producers, Fiji in the early 2000s had the second-lowest cane yield and the lowest sugar yield per harvested hectare (Oxfam International, 2005, p. 10). 


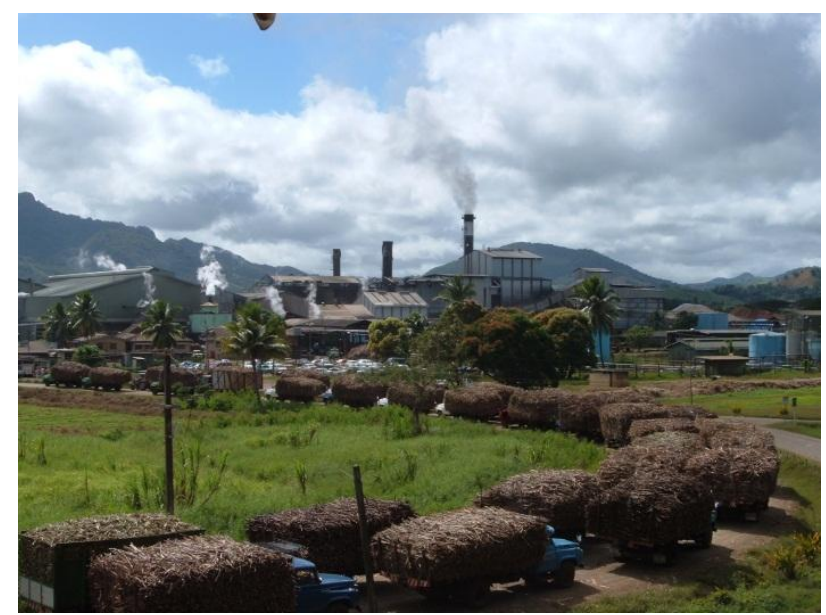

Plate 4.1. Trucks wait to unload sugarcane at Labasa mill, August 2007. Photo: The author.

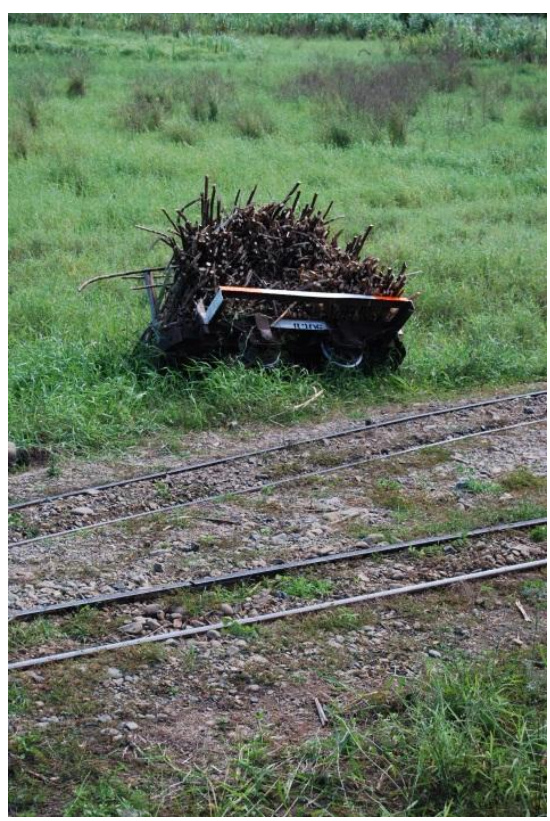

Plate 4.2. A derailed sugarcane rail cart near Nadi, July 2009. Photo: The author.

The sugar industry is dominated by Indo-Fijian growers (despite various incentives from the government over the years to encourage indigenous Fijians to enter the industry) with approximately $74 \%$ of all growers being Indo-Fijian (Chand, 2004, p. 5). Most farms are on leased native or state land. Smaller amounts of farms are held in freehold tenure. Some farmers also use vakavanua arrangements to gain access to farming land or to increase existing farm holdings. Structurally, the Fijian sugar industry is unique in that it is comprised of many producers farming small plots (Oxfam International, 2005, p. 11). Overall, relative to other producers, average production costs per tonne of sugarcane are high (around $\mathrm{F} \$ 40$ per tonne); although this can differ substantially between farms. In most years profit margins for farmers are very slim (ibid, p. 10; Chand, 2005, p. 202). Over time, however, some sugarcane growers have done well (particularly those with large, high yielding farms), and subsequently have invested heavily in the education of their children; many of whom have gone on to service and professional occupations, or emigrated. Other farmers (particularly those with low yielding farms), however, have remained poor - even below the national poverty line (Chand, 2005, p. 202). The cane harvest is heavily reliant on the gangs of some 14,000 cane-cutters (ibid); who traditionally are among some of the poorest groups in Fiji. In 2004, for example, the average non-unionised cane-cutter, during the six month harvest season, earned an average income of US\$62 per week (ibid, p. 206). 
For many years the growth of the Fijian sugar industry was built around the high and stable preferential prices received for raw sugar from the European Union (EU) (Mahadevan, 2009c, p. 82). Under the 1975 Lomé Convention (an agreement between the EU and ACP nations) ACP producers were able to receive well above world market prices for a set export quota to the EU, often three to five times the world market price (Mahadevan, 2009a, p. 126). However, preferential prices under the Lomé Convention (superseded by the Cotonou Agreement in 2002) are being incrementally removed in a transition period as world trade is increasingly opened up under pressure from the World Trade Organization. The final price cut was effective from October 2009 (Fiji Government, 2009a) so now the Fijian sugar industry, typically slow to respond to industry challenges (Prasad, 2007, p. 2), will need to radically reform to survive in a subsidy free environment. Ongoing financial difficulties within FSC - for many years of this decade FSC was technically insolvent and reliant on special assistance from the government to survive (Oxfam International, 2005, p. 10) - complicate reform.

In addition to the end of preferential prices, financial difficulties, and the general inefficiencies of production, the sector is also affected by land tenure issues and particularly lease expiry. Firstly, the majority of farms are leased, and while ALTA guaranteed 30 year terms, investment (particularly if lease expiry is looming) is stymied through non-automatic rights of renewal and the insecurity of tenure that is rife in the sector. Secondly, since 1997 when ALTA leases first began to expire (the majority of which are cane leases), many hundreds, if not thousands, of farmers have been forced off their farms by the non-renewal of expiring leases. (Others have left the industry before a lease expires or because of the uncertainty facing the industry in general.) Despite attempts to encourage new entrants to the industry, many of these previously productive farms are now lying idle (Chand, 2007b, p. 15). The decline of one farm also has a multiplier effect on a number of livelihoods both directly and indirectly supported; as it is estimated that a single cane farming lease supports three to five families (ADB, 2003, p. 139). Many believe that resolving the land tenure issue is absolutely crucial to rehabilitating the faltering industry (see, for example, Lal \& Rita, 2005; Prasad, 2006, 2007 \& 2010; Prasad \& Kumar, 2000; Prasad \& Tisdell, 1996 \& 2006; Mahadevan, 2009a \& 2009c). Indeed, research suggests that uncertainty over land leases overwhelmingly represents farmers' biggest concern (Mahadevan, 2009a). It has been suggested that change does not necessarily mean the privatisation of communally held land, but should at least ensure a system of leasing that increases security of tenure and provides a higher degree of certainty about lease renewal (Lal \& Rita, 2005, p. 37). 
Overall, the sugar sector faces enormous challenges. The sector will struggle with substantially reduced export earnings amidst the need to restructure and resuscitate the industry. The sector, however, is still vital to the national economy and well-being of Fiji (Prasad, 2007, p. 4). Because the sector still supports thousands of, predominantly rural, livelihoods it cannot be left to flounder; doing so will only increase urban movement, swell informal settlements, and increase pressure on strained urban areas and environments. As Lal and Rita write:

Time is running out on the Fiji sugar industry. In the short term, there will be many casualties of trade liberalisation. Many cane farmers will lose their source of livelihood, and many of those who remain financially viable will fall below the poverty line. Their only salvation will be in finding other sources of income. Urban drift will be inevitable, placing additional pressure on already stretched infrastructure (2005, p. 39).

\subsection{The Political Environment: A Legacy of Insecurity}

Following independence in 1970 Fiji enjoyed a period of relative stability and calm until 1987. Since 1987, however, the archipelago has been rocked by an unprecedented level of political and societal turmoil (Chang, 2008, p. 3); in 23 years enduring four coups, over a dozen governments and regimes, four general elections, and three constitutions (Naidu, 2007a, p. 24). At the time of writing, Fiji ploughs on with an unelected interim administration inserted after the most recent coup in December 2006 headed by Commodore 'Frank' Bainimarama, emergency regulations, an abrogated constitution, and an increasingly distant timeline for a return to elections (now pushed back to 2014).

The causes of Fiji's cycle of political upheaval are deeply rooted in the country's historical legacy and its political and social structure (Chang, 2008, p. 19). The issues are tangled and complicated. As Ratuva explains "[t]here is a complex interplay between cultural, religious, political, and socio-economic factors that shape the dynamics and trajectory of conflict in Fiji" (2007, p. 199). The deep divisions within Fijian society can be traced to the colonial period when the separate development of the two major ethnic groups was a cornerstone of colonial policy (Naidu, 2006b, p. 301). In this period, indigenous Fijians were encouraged to remain in the village, and were seen as important in providing land as a crucial resource for development (Naidu, 2007a). Indo-Fijians, on the other hand, were seen as important in providing labour to the colony (ibid, p. 26) 
and were encouraged to live amongst themselves in isolation. In this period too, a hegemony of indigenous Fijian chiefs was established, largely exclusive ethnic institutions began to emerge (such as the Republic of (previously Royal) Fiji Military Forces; almost completely dominated by indigenous Fijians), and a dualistic education system of 'Fijian' and 'Indian' schools developed (ibid, p. 25; Geraghty, 1997).

Overall, divisions have endured between the two major ethnic groups. Broadly speaking, the two groups traditionally occupied distinct geographical niches in Fiji (Geraghty, 1997, p. 7) -indigenous Fijians confined to villages and Indo-Fijians to the cane belt; divisions that have not fully broken down. There remains little voluntary intercommunal activity between the two major ethnic groups, and certainly very little intermarriage. Ethnic divisions within the workplace have remained as certain ethnic groups dominate various industries, and religious affiliations are closely associated with ethnicity (Geraghty, 1997). Geographically, most inter-ethnic mixing has occurred in the cane belt (where indigenous Fijians and Indo-Fijians have lived in close proximity for generations, often co-operating with cane farming), and increasingly in urban areas (ibid). In particular, it is in informal settlements, where roughly equal numbers of indigenous Fijians and Indo-Fijians reside (Ratuva, 2007, p. 208), where perhaps the most inter-ethnic mixing occurs.

In addition to large and lasting inter-ethnic divisions, intra-ethnic differences amidst the larger categories are significant and important to recognise. Indigenous Fijians, for example, can be differentiated physically, linguistically, and culturally, as well as by group political influence. Indo-Fijians can also be differentiated linguistically and culturally, and between the descendents of indentured labourers and free migrants. Religion too is important; indigenous Fijians, mostly Christian, can be differentiated by denomination (the Methodist Church is the dominant denomination and plays a central role in indigenous Fijian society), and most Indo-Fijians are Hindu or Muslim (Naidu, 2007a, p. 25).

While it is inter-ethnic differences that largely shape political discourse in Fiji, particularly in the debate around perceived socio-economic inequalities, it is, in fact, misleading to focus on inter-ethnic inequalities. Both Walsh (2002) and Sriskandarajah (2003), for example, identify that more inequality occurs within than between Fiji's major ethnic communities; an important recognition in correctly understanding Fiji's differentiated society. As Kumar and Prasad conclude in a discussion of the politics of race and 
poverty, debate in Fiji should not be on the distribution of the (shrinking) national cake between the two major ethnic communities but rather on improving conditions for the poor regardless of ethnicity (2004, p. 482). The stumbling block, however, is that, as Sriskandarajah summarises, "[i]n Fiji's case, the strategic deployment of inter-group inequality has served, and continues to serve, the material and discursive interests of some political elites" (2003, p. 305).

As Sriskandarajah (2003) identifies, it is particularly the nature of politics in Fiji that deeply entrench both real and perceived differences between the major ethnic groups. Politics in Fiji is inherently racial (Kotabalavu, 2007, p. 7), and the current ethnically-based electoral system, although guaranteeing representation from all major ethnic groups, has encouraged political parties to form along ethnic lines (Chang, 2008, p. 19). The electoral system in its operation rewards divisive politics that pitch the indigenous and Indo-Fijian communities against one another (Chand, 2007c, p. 31). Overall, the political system is based on race and not on policy differences in key economic and social issues (Kotabalavu, 2007, p. 7); as Lal explains: "in time, virtually every issue of public policy came to be viewed through racial lenses" (2003, p. 336).

One of the most significant divisions in Fijian life, and indeed greatest potential spark for conflict, is around land. It has been mentioned already that two different ideologies around land use, access and ownership clashed between Fijians and European colonialists. However, more relevant today is that ethnic differences in attitudes towards land have emerged between indigenous Fijians and Indo-Fijians - particularly with increased population pressure (Farrell \& Murphy, 1978). Essentially, differences have intensified around claims to land; for indigenous Fijians based on ownership, and for Indo-Fijians based on use (Bennett, 2002, p. 219). The different attitudes towards land are articulated clearly by the politician Sir Vijay R. Singh:

To most non-Fijians, land is an item of economic utility, a basis for income, to be acquired, used and disposed of, if the occasion arises, without much emotional wrench. To most Fijians, on the other hand, and almost every rural Fijian, it is part of his being, his soul; it was his forebears' and shall be his progeny's till time immemorial (as cited in Lal, 2003, p. 343).

Overall, differences towards land have created tensions between the two major ethnic groups, and as Bennett states: "[t]hese tensions have not lessened and have contributed in part at least to the instability that has punctuated Fiji's politics since the first coup in 1987" (2002, p. 219). 
In recent years, in defiance of international criticism, Bainimarama and the current administration inserted after the most recent coup in December 2006 (conducted in the language of 'good governance', multiracialism and anti-corruption) have forged ahead with their own agenda of change. Initially promising to hold elections by 2008 , the timeline has now been pushed back to 2014. A widely criticised process, the Peoples' Charter for Change, Peace and Progress, has been implemented to consult the population, attempt to reach consensus, and introduce change with the overarching goal to "rebuild Fiji into a non-racial, culturally vibrant and united, well-governed, truly democratic nation" (National Council for Building a Better Fiji (NCBBF), 2008a, p. iii). Electoral reform, attempting to end ethnically orientated politics and voting, is a key part of this process. Drastic measures have been taken - including, in response to a decision, on appeal, by the judiciary to declare the interim administration illegal, the abrogation of the constitution in early 2009, the instigation of emergency regulations (which banned public gatherings and placed restrictions on media organisations), and the dismissal of some members of the previously respected and independent judiciary. The potentially explosive issue of land reform has also been recently added to the agenda - although it has been flagged that customary tenure will not be altered (Fiji Government, 2009b).

Overall, the 2006 coup has managed to further fracture the nation. As Lal $(2007$, p. 8) explains indigenous Fijians are confused and divided in their response to the coup some opposing it and some supporting it. The interim government's isolation of the two most important institutions in indigenous Fijian society, the Methodist Church and the Great Council of Chiefs, has hindered reconciliation. Reaction from the Indo-Fijian community was, and still is, divided (ibid, p. 10). The civil society response has also splintered into those resisting any 'barrel of the gun politics' and those who see a chance for positive change (ibid; Naidu, 2007b). Overall, the jury is still out on progress and tensions and flashpoints may surface. Perhaps rather ominously Lal writes: "[t]ime will tell. In the meanwhile, half of the Fiji population, disaffected, disenchanted and disapproving of the unfolding events, watches in sullen silence. Brooding" (2007, p. 17).

\subsection{The Poverty Profile and Coping Strategies}

There is little doubt that Fiji's turbulent political environment has had major deleterious effects on the economy of Fiji and have exacerbated economic decline. Mahadevan (2009b, p. 2), for example, highlights declines of GDP of $1.7 \%$ in 2000 and $6.6 \%$ in 2007 , 
and Chand (2007b) has estimated that the coups of 1987, 2000 and 2006 each wiped off three years of economic progress when measured in terms of national income. The political turmoil has also reduced private investment levels and significantly increased migration (Narayan \& Narayan, 2009, p. 95) - particularly of the most skilled and educated; human resources (and accompanying capital flight) that the small pool of Fiji can barely afford to lose. Important tourism arrivals and receipts (at least in the shortterm) have also been affected by Fiji's coups and heightened security situation.

This political and subsequent economic tumult has had a direct impact on the livelihoods of Fiji's poor. Overall, poverty remains rife in Fiji - pervading across all ethnic groups and entrenched in both rural and urban areas. Data shows that poverty in Fiji has been increasing over recent years; as both the incidence of poverty (the proportion of people living in poverty) and the severity of poverty (the difference between the poverty line and the mean income of the poor) increased between the three last fullyanalysed Household Income and Expenditure Surveys (HIES) in 1977, 1990/91 and 2002/03 (Chand, 2007d, p. 22). Table 4.3 below shows the increasing incidence of poverty in Fiji between these periods - including how it has increased in both urban and rural areas.

Table 4.3. Poverty in Fiji, 1977, 1990/91, 2002/03

\begin{tabular}{|l|l|r|r|r|}
\hline & & 1977 & $1990-91$ & $2002-03$ \\
\hline Poverty incidence & & & & \\
\hline National average & & 15 & 25.5 & 34.4 \\
\hline Urban average & & 12 & 27.6 & 31.8 \\
\hline Rural average & & 20 & 24.3 & 38.1 \\
\hline Poverty line & & $F \$ 1,460$ & $F \$ 4,316$ & $F \$ 9,776$ \\
\hline
\end{tabular}

Source: Mahadevan, 2009b, p. 16

The most recent data forming a full scenario of the contemporary poverty situation in Fiji is from the 2002/03 HIES. Analysis of this data revealed that $34.4 \%$ of Fiji's population were living below the Basic Needs Poverty Line (BNPL) at the time the information was collected (Abbott, 2006, p. 1). The analysis also showed the poverty incidence amongst indigenous Fijians was 33.8\% (up from $27.7 \%$ in 1990/01) and $34.9 \%$ amongst Indo-Fijians (up from $31 \%$ in 1990/91). In urban areas the incidence of poverty was estimated at $31.8 \%$ (up from $27.6 \%$ in 1990/91), while in rural areas it was estimated at $38.1 \%$ (up substantially from $24.3 \%$ in $1990 / 91$ ) (ibid). These figures reveal that there was no significant statistical difference in the levels of poverty between the two major ethnic 
groups; but rather highlight that rural-urban differentiation was the more significant. Key poverty data from the 2002/03 HIES is displayed in Table 4.4 below.

Table 4.4. Incidence of Poverty in Fiji (percentage of population with weekly per capita income less than the poverty line), 2002/03

\begin{tabular}{|l|r|r|r|}
\hline & \multicolumn{2}{|l|}{ Food Poverty Line } & \multicolumn{2}{l|}{ lasic Needs Poverty } \\
\hline National average & & & \\
\hline Indigenous Fijian & 11.3 & 34.4 \\
\hline Indo-Fijian & 12.6 & 33.8 \\
\hline & 8.7 & 34.9 \\
\hline Urban average & & & 31.8 \\
\hline Indigenous Fijian & 6.4 & 29.9 \\
\hline Indo-Fijian & 7.5 & 33.9 \\
\hline High/Middle class housing & 5 & 31.1 \\
\hline Settlement/Housing Authority & 4.8 & & 34.7 \\
\hline Squatter area/Urban village & 6.7 & 36.4 \\
\hline & 13.8 & 38.1 \\
\hline Rural average & & 15.2 & 37.3 \\
\hline Indigenous Fijian & 15.1 & 39.2 \\
\hline Indo-Fijian & 13.3 & \\
\hline
\end{tabular}

Source: Abbott, 2006, p. 3

Table 4.4 also shows that within urban areas the highest rates of poverty were recorded by households living in (i) settlement and Housing Authority areas (34.7\% of the resident population below the BNPL and 6.7\% below the Food Poverty Line (FPL)) and (ii) squatter and urban village areas (36.4\% below the BNPL and $13.8 \%$ below the FPL). This indicated that the very poorest households, those below the FPL, were disproportionally concentrated in squatter and urban village areas (Abbott, 2006, p. 25); areas where access to land for subsistence purposes is most limited (Chand, 2007d, p. 27).

The 2002/03 HIES data revealed that increases in poverty were seen most clearly in rural areas; where poverty affected more than one-third of total households. Abbott proposes that rural poverty has increased due to a relative decline in rural incomes compared with urban incomes, and argues that the increasing need for cash in rural areas to meet non-food needs has also been significant (2006, p. 2-3). Table 4.4 also shows that the sub-group with the most severe basic needs poverty (39.2\%) was rural Indo-Fijians - something that Narsey puts down to the decline of the sugar industry and the expiry of rural land leases (2008, p. 77). Overall, Abbott was led to summarise from his 
analysis of the 2002/03 HIES data that: poverty at the national level has increased measurably; pockets of serious poverty were present in urban areas; but that poverty appears to be more widespread in rural areas (where cash incomes tend to be lower) (2006, p. 3).

While rural poverty is more widespread in Fiji, urban poverty, however, tends to be more severe and acute (Chung \& ECREA, 2007, p. 4). In urban areas poverty manifests in social stigma, high levels of unemployment, crime, poor health status, and low educational achievement (National Council for Building a Better Fiji (NCBBF), n.d., p. 27). This excludes certain urban groups from mainstream social, economic and political life and concentrates urban poverty, particularly in squatter and informal settlements (ibid; Chung \& ECREA, 2007, p. 4). Chand writes that the concentration of poverty in the burgeoning informal settlements runs the risk of keeping asset poor households in urban areas in poverty permanently (2007b, p. 7).

The role of subsistence activities, particularly fishing and gardening, remains critical in Fiji. In urban areas home gardening is increasing as a vital coping strategy, clearly visible across urban Fiji, for many households (Abbott, 2009, p. 1). The 2002/03 HIES information, for example, shown in Table 4.5 below, shows the importance of home gardening (in terms of proportional contribution to home consumption) across rural and urban Fiji. This information reveals that, nationally, rural households provided on average $44.2 \%$ and urban households $9.5 \%$ of their food needs in 2002/03. Amongst the poorest urban households (those forming the lowest three deciles) food production averaged $10.2 \%$ of consumption (while in rural areas this figure was a high 48.4\%). Table 4.5 also shows that indigenous Fijian households are much less reliant on purchased food than Indo-Fijian households; the lowest three deciles of urban indigenous Fijian households, for example, produced on average $16.8 \%$ of their total consumption compared with $5.0 \%$ for IndoFijian households. (The difference between the poorest rural indigenous Fijian and IndoFijian households was even more severe.) Overall, Abbott was led to conclude that these key ethnic differences meant that the risk of falling into poverty amongst IndoFijian households was likely to be exacerbated by the fact that they provide far less of their own food than indigenous Fijian households (2006, p. 34). In short, for low-income indigenous Fijians particularly, the subsistence production of food at home, especially in rural areas, but increasingly evident in urban areas, forms an increasingly critical safety net. 
Table 4.5. Proportion of Own Production in Household Food Consumption, Fiji, 2002/03

\begin{tabular}{|l|r|r|r|r|r|r|}
\hline & \multicolumn{2}{|c|}{ All Households } & \multicolumn{2}{c|}{ Indigenous Fijian } & \multicolumn{2}{c|}{ Indo-Fijian } \\
\hline & Urban & \multicolumn{1}{c|}{ Rural } & \multicolumn{1}{l}{ Urban } & \multicolumn{1}{l|}{ Rural } & Urban & \multicolumn{1}{c|}{ Rural } \\
\hline Average all households & 9.5 & 44.2 & 12.3 & 55.8 & 7 & 16.1 \\
\hline Lowest quintile & 11.1 & 45.7 & 18 & 63.6 & 5.4 & 19.2 \\
\hline Lowest three deciles & 10.2 & 48.4 & 16.8 & 63.1 & 5 & 17.5 \\
\hline
\end{tabular}

Source: Abbott, 2006, p. 22

\subsection{Notions of Security and Insecurity in Fiji}

Notions of security in Fiji are especially influenced, as has been shown, by the divisive nature of society, the nature of land tenure, and the turbulent political environment - all a part product of Fiji's particular historical legacy. In general, as Kotabalavu (2007, p. 7) explains, indigenous Fijians consider their security from their perspective as the $i$ taukei, landowners, and also as Christians. Indo-Fijians, on the other hand, regard themselves as the tenant community and also as victims of the 1987 and 2000 coups and of subsequent affirmative action programmes favouring indigenous Fijians that deprived Indo-Fijians of fair access to state opportunities and resources. Indo-Fijian concerns for security, Kotabalavu explains, have been heightened particularly by the expiry of agricultural leases and their declining proportional contribution to the national population (which under the current system affects political representation). Finally, for other minorities in Fiji, according to Kotabalavu, their insecurity is based on feelings of not being sure of their place in Fiji (ibid).

For Indo-Fijians, issues of security, or more correctly insecurity, are a constant part of everyday life. As Pangerl explains from a period of fieldwork among Indo-Fijian communities: "the language of insecurity was omnipresent in describing socio-political and everyday realities in Fiji" (2007, p. 251). Clearly the historical legacy of Indo-Fijian experience has contributed to perceptions of marginalisation and deprivation (ibid). Land issues for a largely tenant community are central to notions of insecurity among Indo-Fijians and also the crux of much tension between them and indigenous Fijians (Bennett, 2002, p. 205). Uncertain and insecure rural land tenure has pushed many IndoFijian farming families into a perhaps even more insecure urban future in the burgeoning informal settlement areas. Ongoing political turmoil only compounds the level of insecurity for Indo-Fijians. Poor economic conditions, and growing poverty, are also additional elements to insecure and uncertain futures - in this case applicable to all 
ethnic groups. Migration has certainly formed a typical Indo-Fijian response to insecurity - featuring both internal movement (particularly urbanisation) and emigration. Ultimately increased emigration might come to shape Indo-Fijian futures - as Lal concludes in his account of the experience of the Indo-Fijian diaspora: " "From Immigration to Emigration'; that may in time come to be the epitaph of Fiji's Indo-Fijian community" (2006, p. 82). However, the emigration response to insecurity may not be open to all, particularly the poorest Indo-Fijian individuals and families, largely living in the informal settlements of greater Suva and the cane belt towns of Lautoka, Ba and Labasa, who do not possess the financial capital or in-demand skills that make emigration possible. For these groups ongoing uncertain and insecure urban futures are most likely - unless effective policy and intervention can improve security of urban land tenure, enhance access to urban land (especially for low-income groups), and generally improve urban livelihoods.

\subsection{Summary}

Fiji as a Pacific small island developing state faces a lot of the natural disadvantages faced by other nations in the region. However, it is the more context-specific factors, influenced by the nation's colonial experience, that have created the lasting legacy that has become entwined with ongoing conflict in the nation. Fiji remains a divisive society particularly between its two major ethnic groups. Systems of land tenure, in simple terms, reinforce these divides and entrench indigenous Fijians as owners of the land and Indo-Fijians as tenants, although there are also inequities among ethnic groups around the use of, and access to, land. Broadly, land remains the most sensitive and politically charged issue in Fijian society. Additionally, for both rural tenant farmers, and urban informal settlers, insecurity of tenure is rife.

The Fijian economy is still heavily reliant on a few key sectors. The sugar industry, currently facing a highly uncertain future, remains vital - not just for the export earnings that it generates but also for the thousands of rural livelihoods that it supports. It is a sector, however, that has been seriously undermined by insecurity of tenure - and the non-renewal of expiring leases in particular. It is also the families of former cane farmers and farm workers who form a high proportion of those moving to urban areas. These groups often have little choice but to locate in the growing informal settlements. 
Having become independent in 1970 Fiji is only a young nation. In 40 years of nationhood Fiji has been rocked by a turbulent political environment. This tumult has further fractured and divided the nation, and has also severely undermined growth in the Fijian economy. In part due to this political turmoil, notions of insecurity are omnipresent for Indo-Fijians particularly, and manifest in high rates of emigration and a general belief among many Indo-Fijian families that the future for their children lies elsewhere.

Poverty is entrenched in Fiji - for both major ethnic groups. Coping strategies such as urban gardening are vital for many. Informal settlements are burgeoning and remain the only viable housing options for the majority of new low-income urban residents despite the insecurity of land tenure, poor service provision, and unhealthy environments in these areas. The usual ethnic lens is not always helpful in understanding the fractured nature of Fijian society. What is more appropriate to understand is the cleavages between the 'haves and the have nots' of Fijian society regardless of ethnicity - for example, those reliant on regular, formal sector employment, and those not; those who reside on land with secure tenure, and those who do not; those who enjoy the use of land for whatever purpose they choose, and those who cannot; and those who have the safety valve of migration open, whether that be internal movement to rural or urban areas or emigration overseas, and those who do not. 


\section{CHAPTER 5: URBANISATION AND INFORMAL SETTLEMENTS IN FIJI}

\subsection{Introduction}

As Chapter 3 revealed, urbanisation is transforming the Pacific. This chapter details urbanisation experience and informal settlement growth and research in Fiji - the site of the current study. Firstly, the chapter traces urbanisation in Fiji, including recent changes identifiable from the 2007 census. Secondly, and centrally, the chapter introduces the nature of Fijian informal settlements, reviews early literature, traces the growth of informal settlements, highlights the nature of informal, vakavanua arrangements that are increasingly used to gain access to native land in urban areas, and reviews more recent relevant research.

\subsection{Urbanisation in Fiji}

For many years Fiji has been urbanising. Results from the 2007 census show that $51 \%$ of the total population (or approximately 421,000 people) now live in urban areas (Fiji Islands Bureau of Statistics, 2008). Greater Suva in the Central Division certainly holds a high degree of urban primacy. However, a number of secondary towns are also important urban growth poles - notably Lautoka, Nadi, and Ba in the Western Division and Labasa in the Northern Division.

As elsewhere in the Pacific, 'push' and 'pull' factors combine to shape urbanisation in Fiji. Traditionally, pull factors have been strong (Walsh, 1977, p. 3), particularly the lure of enhanced services and greater educational and employment opportunities in urban areas. However, recent studies (such as Gounder, 2005, and Reddy, 2006) have highlighted how expiring rural land leases particularly have pushed people out of rural areas and into towns in search of alternative livelihoods. The increasingly significant push factor of land lease expiry is shaping contemporary Fijian urbanisation and will be expanded upon later in the chapter. The huge impact of expiring land leases means that 1997 (the year that farming leases first began to expire) has become a watershed year dividing two broad phases of urbanisation. Thus, pre- and post-1997 presents a convenient structure for the following account of Fiji urbanisation. 
Figure 5.1. Map of Fiji with Main Urban Centres

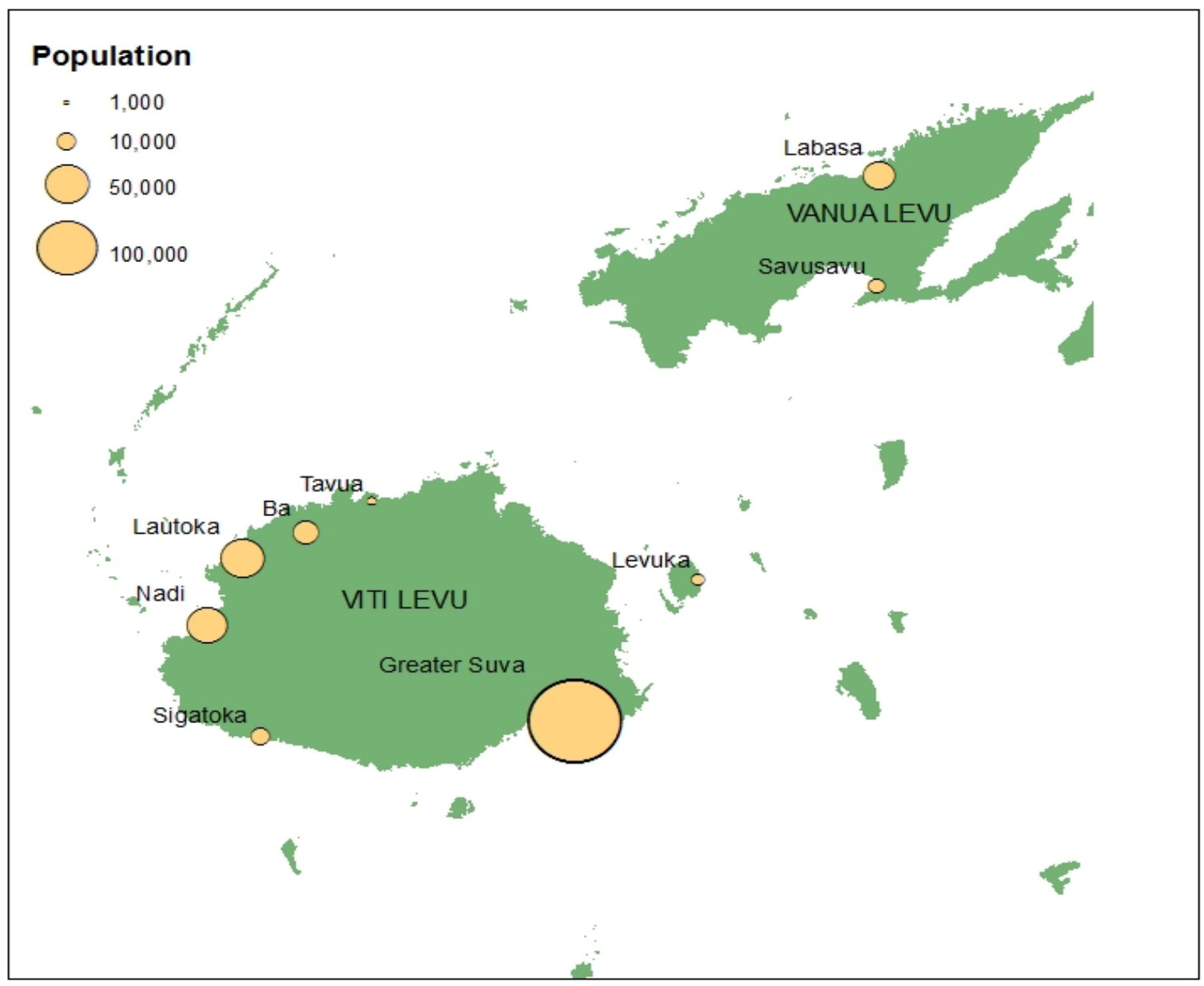

Source: Drawn in ArcGIS. (Urban centre size based on 2007 census data.)

\subsubsection{Pre-1997 Fijian Urbanisation}

The first significant town in Fiji was Levuka which flourished from 1840 as a colonial settlement (Connell \& Lea, 2002, p. 20). However, the dominance of Levuka did not last long for as soon as the national capital was transferred to Suva in 1882, the town's influence began to fade. Suva from this time, particularly due to its new capital status, excellent harbour, large peninsula, and fertile hinterland, began to grow more quickly than any other Pacific town of the era (ibid, p. 21) - but total population still remained very small.

It was not until the inter-war years of the twentieth century that a wider Fijian urban system began to emerge. During this time, towns such as Lautoka, Ba and Labasa grew 
as agricultural processing centres (particularly for sugarcane) and market centres. Additionally, Nadi, Sigatoka and Nausori emerged as market towns, and Vatakoula grew as a mining settlement (Connell \& Lea, 2002, p. 24; Walsh, 1977, p. 2). Despite this growth, however, no more than 13,000 people lived in Fijian secondary towns in the mid1930s. Suva, on the other hand, was now emerging as a relatively substantial colonial capital.

In the years immediately after World War Two, urban growth became more rapid in Fiji. From 1946 to 1956, for example, the urban population increased from less than 30,000 to more than 60,000 (Connell \& Lea, 2002, p. 31). This urban growth can be attributed to urban boundary extensions, the growing maturity of the Fijian urban economy, and the increasing permanence of urban populations (ibid). By the mid-1970s, the primacy of Suva, and particularly the greater Lami-Suva-Nausori corridor, began to strongly emerge. Suva, pre- and post-independence in 1970, was the centre of colonial then indigenous power, as well as the nation's political and economic hub. By the 1970s Suva's primacy meant that the city's population was four times greater than the next largest town, Lautoka, and was growing much faster (ibid, p. 36). Census results from this period show that the percentage of Fiji's population in urban areas, or, in other words, level of urbanisation, was $37.2 \%$ in 1976 (Chandra, 1996, p. 24).

By the time of Fiji's next census in 1986, the level of urbanisation in Fiji was $38.7 \%$ (Chandra, 1996, p. 24) - representing a relatively modest increase from 1976. Chandra argues that unfavourable international economic conditions affected Fiji significantly in the 1980s - increasing urban unemployment which, in turn, decreased rural to urban movement (ibid, p. 24 \& 27). In addition, during this period, the development of a tourist industry centred in western Viti Levu around Nadi and Lautoka and on outlying islands meant that many Fijians could have paid employment in this industry while continuing to reside in their villages (ibid, p. 28). Despite the urbanisation slow-down during this period, Suva's primacy was becoming even more pronounced. Chandra highlights, for example, that Suva contained $51 \%$ of the national urban population in 1986 (ibid, p. 34). However, when combined with its satellite centres of Lami and Nausori to form the greater Lami-Suva-Nausori corridor, this percentage increased to over two-thirds of the total urban population. Certainly, peri-urban Suva increased its share of the national urban population significantly during this period (ibid, p. 31). 
Between the next inter-censual period, 1986-1996, urbanisation increased sharply in Fiji. By 1986 the urbanisation rate had increased to $46.4 \%$ (Walsh, 2006, p. 76) although particularly influenced by urban boundary changes (ibid). As will be shown below, this growing urbanisation trend continued from 1996 to 2007 - a process that, as indicated, is linked to the expiry and non-renewal of rural farming leases among other things.

\subsubsection{Post-1997 Fijian Urbanisation: The Legacy of Land Lease Expiry}

In 1977, in an effort to expand total land under sugarcane cultivation, the Agricultural Landlords and Tenant Act (ALTA) was introduced (amending the original Agricultural Landlord and Tenant Ordinance (ALTO) legislation enacted in 1966). This legislation enabled mainly Indo-Fijian farmers to formally lease native land, administered through the Native Land Trust Board (NLTB), for sugarcane cultivation. The majority of these leases were for small 10 acre blocks spread over lease terms of 30 years. These leases eventually began to expire - beginning in the watershed year of 1997. Table 5.1 below shows the breakdown of all expiring ALTA leases22 from 1997 to 2010.

Table 5.1. Expiry and Renewal of ALTA Leases, 1997-2010

\begin{tabular}{|r|r|r|}
\hline \multicolumn{1}{|l|}{ Year } & Leases Expirying & Leases Renewed (and \%) \\
\hline 1997 & 100 & $50(50)$ \\
\hline 1998 & 213 & $107(50.2)$ \\
\hline 1999 & 1529 & $721(47.2)$ \\
\hline 2000 & 1949 & $1068(54.8)$ \\
\hline 2001 & 467 & $164(35.1)$ \\
\hline 2002 & 673 & $280(41.6)$ \\
\hline 2003 & 428 & $196(45.8)$ \\
\hline 2004 & 351 & $100(28.5)$ \\
\hline 2005 & 375 & $131(34.9)$ \\
\hline 2006 & 477 & $143(30.0)$ \\
\hline 2007 & 666 & $183(27.5)$ \\
\hline 2008 & 384 & $106(27.6)$ \\
\hline 2009 & 370 & $183(49.5)$ \\
\hline 2010 & 461 & $223(48.4)$ \\
\hline & & $3655(43.3)$ \\
\hline Total & 8443 & \\
\hline
\end{tabular}

Source: Ministry of National Planning, 2010, p. 11

From 1997, when rural farming leases first began to expire, many were not renewed to the mainly Indo-Fijian sitting tenants. These leases were not renewed for a variety of

22 Table 5.1 includes all ALTA leases of which by far the majority are sugarcane leases. 
reasons - including concerns that landowners were not receiving adequate returns and also a growing influence of nationalistic indigenous Fijian politics (Prasad, 2006). Table 5.1 shows, for example, that between 1997 and 2010 only $43.3 \%$ of expired cane leases were renewed - likely forcing the majority of those families who did not have leases renewed to urbanise in search of alternative livelihoods (if other options were not available in rural areas). The significance of expiring leases is clear. For example, Table 5.1 reveals that between 1997 and 2010, 4,788 farming leases were not renewed (directly affecting around 22,743 people at an average Indo-Fijian family size of 4.75 persons). Further, it is estimated that a single ALTA cane lease may support around three to five families (Asian Development Bank (ADB), 2003, p. 139) (such as those families supported by cane cutters, for example), further indicating the degree of social upheaval, and subsequent urbanisation pressure, that lease expiry can cause. Data also shows that from 2011 to 2016 a further 2,538 ALTA leases will expire (McKinnon, Whitehead, Chung and Taylor, 2007, p. 13). It is likely that these expiring leases will create further urbanisation pressure through possible non-renewal (despite recent rhetoric emerging from the interim government on the importance of lease renewal) and also the simple uncertainty created by an upcoming lease expiry and the structural problems of the sugar industry generally.

In summary, it is clear that lease expiry, and the uncertainty surrounding ALTA leases generally, are now major push factors influencing contemporary urbanisation in Fiji. As Reddy concludes from a study on the causes of internal migration in Fiji: "the key reason for migrating to urban areas is not a purely economic reason but rather ... a social problem. The expiring land leases have pushed people out" (2006, p. 12). The tenure insecurity surrounding the expiry of leases lies at the heart of any discussion of urbanisation and land more generally in Fiji. Lease expiry is also a direct factor behind the recent rapid growth of squatter/informal settlements in Fiji as ex-cane farming families and their dependents urbanise - for as Chung and the Ecumenical Centre for Research, Education and Advocacy (ECREA) write: these people "have little other choice than to live in the burgeoning, poorly-serviced informal settlements" (2007, p. 14). It is clear that, in a small island country, lease expiry "constitutes a social upheaval of major proportions" (Kurer, 2001b, p. 94). 


\subsubsection{An Emerging Urban Future: Evidence from the 2007 Census}

Results from the 2007 Fiji census show that of the nation's total population of 837,271 people, 424,846 were classified as living in urban areas. That is, for the first time in Fiji's history, mirroring the global trend noted in Chapter 2, more than one in two $(50.7 \%)$ Fijians were urban (Fiji Islands Bureau of Statistics, 2008, p. 1). According to the Fiji Islands Bureau of Statistics the increase in the urban population can be attributed to natural increase, rural to urban migration, and also the incorporation of formerly rural areas into the urban sector23 (ibid, p. 4). Table 5.2 below highlights urbanisation in Fiji by showing the changes in the rural/urban composition of Fiji from the 1966, 1976, 1986, 1996 and 2007 censuses, as well as by showing projected figures for 2010, 2020 and 2030.

Table 5.2. Past and Projected Levels of Fiji Urbanisation, 1966-2030

\begin{tabular}{|c|c|c|c|c|c|}
\hline Year & Total & Rural Popt & ulation & Urban Pop & ulation \\
\hline & thousands & thousands & $\%$ & thousands & $\%$ \\
\hline 1966 (Census) & 476,727 & 317,468 & 66.6 & 159,259 & 33.4 \\
\hline 1976 (Census) & 588,068 & 369,573 & 62.8 & 218,495 & 37.2 \\
\hline 1986 (Census) & 715,375 & 438,350 & 61.3 & 277,025 & 38.7 \\
\hline 1996 (Census) & 775,077 & 415,582 & 53.6 & 359,495 & 46.4 \\
\hline 2007 (Census) & 837,271 & 412,425 & 49.3 & 424,846 & 50.7 \\
\hline 2010 (Projected) & 857,000 & 411,000 & 48 & 446,000 & 52.0 \\
\hline 2020 (Projected) & 936,000 & 409,000 & 43.7 & 527,000 & 56.3 \\
\hline 2030 (Projected) & $1,034,000$ & 405,000 & 39.2 & 629,000 & 60.8 \\
\hline
\end{tabular}

Source: Fiji Islands Bureau of Statistics, 2008, p. 29

Figure 5.2. Map of Fiji Administrative Divisions

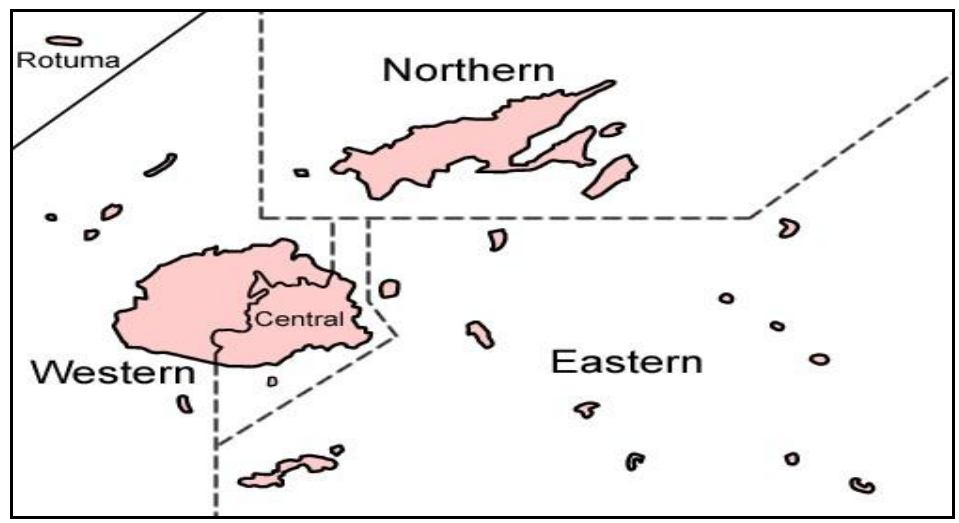

Source: http://www.juggle.com/fiji

23 Boundary changes are often an important contributor to urbanisation. For example, prior to the 2007 census the urban boundaries of Lautoka and Nadi were extended. Most significantly in this period, Nasinu Town was incorporated - creating an entirely new urban zone from part of Suva's peri-urban area (Fiji Islands Bureau of Statistics, 2008, p. 31). 
Table 5.3 below shows changes in divisional population distributions, by major ethnicity, between 1996 and 2007. Highlights from the table are clear. Firstly, it is evident that recent national population growth is centred in both the Western and (particularly) Central Divisions. Secondly, the table shows that both the Northern and Eastern Divisions have lost population during the intercensal period - the Northern Division, for example, decreased $2.5 \%$ from a population of 139,516 in 1996 to 135,961 in 2007. Table 5.3 also reveals that the total Indo-Fijian population of the Northern and Western Divisions has changed substantially: the Indo-Fijian population of the Northern Division reduced $20.5 \%$ from 66,488 in 1996 to 52,844 in 2007, and in the Western Division reduced $9.1 \%$ from 172,975 in 1996 to 157,170 in 2007. The Fiji Islands Bureau of Statistics summarises that these changes in the Northern Division are particularly a result of an exodus of IndoFijians from Macuata Province $(2008$, p. 3) which is the cane belt area of Vanua Levu. In the Western Division, the Fiji Islands Bureau of Statistics summarises that these changes are particularly due to very high levels of out-migration of rural Indo-Fijians from Ba Province (ibid) - the cane belt area of Viti Levu. This evidence does suggest that lease expiry is significant in influencing out-migration 24 from the cane belt areas - although this may also be influenced by the structural problems in the sugar industry more generally that may reduce the desirability of a rural cane farming livelihood. Overall, it is evident that population decreases in the Northern Division have been particularly influenced by Indo-Fijian out-migration. It is also clear that population falls in the Eastern Division are tied to ongoing indigenous Fijian out-migration (given that the indigenous Fijian population, making up a big majority, fell during the intercensal period - the only division of Fiji where this occurred).

\footnotetext{
${ }^{24}$ Of course out-migration can comprise rural to urban movement and also emigration. Emigration is very significant in Fiji and is reflected in the broader population figures that show that from 1996 to 2007 the IndoFijian population of the nation reduced from 338,818 ( $43.7 \%$ of the total population) to 313,798 (37.4\% of the total population). This is a trend that is based on the growing emigration of Indo-Fijians (particularly to Pacific rim nations such as Australia, New Zealand, Canada and the United States of America) escaping both political turmoil and land tenure insecurity particularly. A second major contributor to the declining Indo-Fijian population of Fiji has been a falling fertility rate for Indo-Fijians - which is now below replacement rate (Fiji Islands Bureau of Statistics, 2008).
} 
Table 5.3. Divisional Population Distribution, Fiji, by Ethnicity, 1996 and 2007

\begin{tabular}{|c|c|c|c|c|c|}
\hline \multirow[t]{2}{*}{\begin{tabular}{|l|} 
Division \\
\end{tabular}} & \multicolumn{2}{|c|}{ Ethnic Group } & \multicolumn{3}{|c|}{ Census Population } \\
\hline & & & 1996 & 2007 & $\%$ Change \\
\hline \multirow{4}{*}{ Central } & Total & & 297,607 & 342,386 & 15.0 \\
\hline & Indigenous & Fijian & 175,878 & 212,580 & 20.9 \\
\hline & Indo-Fijian & & 98,660 & 103,133 & 4.5 \\
\hline & Other & & 23,069 & 26,673 & 15.6 \\
\hline \multirow[t]{4}{*}{ Eastern } & Total & & 40,770 & 39,313 & -3.6 \\
\hline & Indigenous & Fijian & 36,302 & 35,615 & -1.9 \\
\hline & Indo-Fijian & & 695 & 651 & -6.3 \\
\hline & Other & & 3,773 & 3,047 & -19.2 \\
\hline \multirow[t]{4}{*}{ Northern } & Total & & 139,516 & 135,961 & -2.5 \\
\hline & Indigenous & Fijian & 64,940 & 75,358 & 16.0 \\
\hline & Indo-Fijian & & 66,488 & 52,844 & -20.5 \\
\hline & Other & & 8,088 & 7,759 & -4.1 \\
\hline \multirow[t]{4}{*}{ Western } & Total & & 297,184 & 319,611 & 7.5 \\
\hline & Indigenous & Fijian & 116,455 & 152,186 & 30.7 \\
\hline & Indo-Fijian & & 172,975 & 157,170 & -9.1 \\
\hline & Other & & 7,754 & 10,255 & 32.3 \\
\hline
\end{tabular}

Source: Fiji Islands Bureau of Statistics, 2008, p. 20-26

Table 5.3 also shows that the Central Division grew 15.0\% from a population of 297,607 in 1996 to 342,386 in 2007 . The Fiji Islands Bureau of Statistics has summarised that $76 \%$ of the Central Division's population growth in this period has occurred in Naitasiri Province (one of the division's five provinces), accounting for $55 \%$ of total national growth in the period (2008, p. 21). Furthermore, results show that growth in Naitasiri Province is almost entirely (more than 95\%) due to growth in just one of its tikana ${ }^{25}$ - Naitasiri Tikina. The Fiji Islands Bureau of Statistics also analyses further and summarises to state that $50 \%$ of the intercensal growth of the entire country was due to the growth of the urban sector of Naitasiri Tikina, specifically the urban areas of Nasinu and Nausori (ibid, p. 21 \& 24). These urban areas are also one of the few areas of Fiji that are experiencing a very high growth rate of the Indo-Fijian population (ibid, p. 21) suggesting that the urban areas of Nasinu and Nausori are a likely destination for many Indo-Fijian migrants from the cane belt areas.

It is clear from the 2007 census results that there have been fundamental changes in the structure of Fiji's population between 1996 and 2007. Firstly, a rural exodus is occurring

${ }^{25}$ A Fijian administrative unit equivalent to district. 
particularly of Indo-Fijians ${ }^{26}$ (likely tied to land lease expiry; although there is no direct evidence for this). Secondly, urban growth (and indeed national growth) is centred around the urban areas of Naitasiri Tikina, specifically Nausori and particularly Nasinu.27 Indeed, the Fiji Islands Bureau of Statistics summarises that many of the possible future problems associated with rapid urbanisation will be centred in these areas $(2008$, p. 3).

In summary, Fiji is certainly facing a predominantly urban future. It is also increasingly clear that the movement to cities is permanent (Reddy, 2006). In fact, Fijian urbanisation trends are generally representative of wider international patterns - and it is clear that an increasingly urban Fiji is inevitable. What this does create, however, is huge pressures on urban environments and on urban management - as will be seen further below highlighted strongly by the emerging squatter/informal settlements of Fiji.

\subsection{The Emergence of Fijian Squatter/Informal Settlements}

Squatter or informal settlements have been present in Fiji for many years. Continued urbanisation has enhanced pressure on existing urban areas particularly in providing adequate housing and infrastructure for all residents. Consequently, for many years, new migrants have resorted to obtaining or building shelter in squatter settlements. This section will highlight some early research on squatter settlements in Fiji; detail the growth of settlements across the nation; provide a snapshot of the contemporary situation; and review some more recent research on Fijian settlements.

To set the scene, it has recently been estimated that upwards of 140,000 people (or upwards of $15 \%$ of Fiji's population) are living in around 190 squatter settlements across the nation - predominantly in the Lami-Suva-Nausori and Nadi-Lautoka-Ba corridors and in Labasa (McKinnon et al., 2007, p. i-ii). As will be highlighted later in the chapter, the recent growth of settlements has been fast. Within the greater Suva area, where growth has been concentrated, it has recently been estimated that around $16.5 \%$ of the total population are squatters (Barr, 2007; McKinnon et al., 2007). Squatter settlements in Fiji are present on all three categories of primary land tenure: state, native and freehold. Typically (and particularly true for Suva), settlements on state land tend to be within town

\footnotetext{
26 Wider census figures, for example, show that the total Indo-Fijian population in the national rural sector decreased from 170,783 in 1996 to 135,918 in 2007 (Fiji Islands Bureau of Statistics, 2008, p. 1).

27 Nasinu is certainly the urban growth pole of Fiji. In fact in 2007 there was the rather odd situation of Nasinu Town $(76,064)$ having a larger population than both Suva City $(74,481)$ and Lautoka City $(43,473)$ (Fiji Islands Bureau of Statistics, 2008, p. 5).
} 
boundaries, were among the first to be established, 28 and tend to be very congested. Settlements on native land are also within urban areas, but are now growing particularly fast in periphery areas (McKinnon et al., 2007, p. ii), and typically are less congested than communities on state land. The communities on freehold land are fewer in number, and typically face considerable eviction pressure and hence insecurity of tenure. Large amounts of people from both major ethnic groups in Fiji, indigenous Fijian and Indo-Fijian, live in squatter settlements. Some settlements are dominated by one ethnic group, but in many communities relatively equal populations of indigenous Fijian and Indo-Fijians live side-by-side. There are also a number of settlements that are predominantly Melanesian - people who are descendants of Solomon and Ni-Vanuatu 'blackbirder' migrants originally brought to Fiji for plantation work (Callinan, 2007, p. 30). The size of Fijian settlements also varies considerably; some communities are very large, perhaps numbering a few hundred households, whereas some are very small, even numbering less than 20 households. In many settlements considerable fragmentation of housing plots has occurred; particularly as new dwellings are constructed for family adjacent to existing structures (Lingam, 2007, p. 2; Wilkinson, 2002, p. 16).

It is difficult to generalise in describing the characteristics of squatter settlements in Fij; for, in fact, they are by nature quite heterogeneous. However, in most, although the quality of dwellings does vary within and across settlements, houses tend to be constructed of wood and more often corrugated iron (often using recycled materials; sometimes dismantled, transported to the settlement, and reassembled). The majority of dwellings could be described as temporary; that is, non-durable and certainly not complying with building regulations. Many settlements are located on marginal land, for example steep hill slopes, mangrove edges and other swampy ground, or next to industrial zones. Settlements are poorly serviced: power and water supplies are frequently shared by many households, feeder roads are of a very poor quality, and sewage connections are absent. Poverty is concentrated in settlements and legal security of tenure is completely absent.

It is necessary at this stage to provide some important clarification around definitions. The former chief government official for squatter settlements in Fiji has defined a squatter as "a person who is in occupation of State, Freehold or Native land illegally or without

28 State land was typically targeted first by squatters (Lingam, 2007, p. 2; McKinnon et al., 2007, p. 18) as settlers thought that government, for political and social reasons, would be unlikely to remove them (Hassan, 2005, p. 15). 
any form of security of tenure or without any consent from the landowner" (Lingam, 2005 , p. 2). However, what complicates this definition is the fact that many Fijian squatters on native land are living with landowner consent under informal arrangements - either under conditions requiring rent payment or alternative forms of exchange. These arrangements are known in Fiji as 'vakavanua' agreements - and are often only verbal. However, typically in Fiji, 'squatter' is the commonly used term for those living on state, native or freehold land without secure tenure. More specifically, as Bryant explains, the term squatter is loosely used to include all spontaneous or informal settlements, not necessarily occupying land illegally, which have substandard and unauthorised structures and tend to lack basic services (1993, p. 52). Overall, in the Fiji context, 'informal settler' is a more appropriate umbrella term as it better encompasses those vakavanua settlers on native land who are living with landowner consent - and in later chapters this term will normally be used. In this review chapter, however, 'squatter settlers/settlement' and 'informal settlers/settlement' will be used interchangeably.

\subsubsection{Early Research on Fijian Squatter/Informal Settlements}

Much of the early research on Fijian squatter communities sought to present the social and economic characteristics and conditions of particular case-study settlements. For example, Samy (1973) focused on Vitogo-Drasa in Lautoka, a community of over 1,000 households on ex-Colonial Sugar Refinery (CSR) land that was due for Housing Authority redevelopment, to highlight some of the extreme difficulties that households faced in this settlement. Samy identified that typically residents of Vitogo-Drasa (a community including both indigenous Fijians and Indo-Fijians) were earning low wages in manual occupations - wages that were often supplemented by urban gardening by many households. The survey also showed that the average household had been in the community for 14 years - initially arriving as illegal occupiers of the land, and later paying rent to CSR. Samy also summarised that most homes in the community were of very substandard and temporary quality. Overall, Samy concluded that "[o]ne thing that stands out is the people's feeling of hopelessness" (1973, p. 70).

A second early study on squatters in Fiji was Reddy's (1976) quantitative and qualitative research on three case-study communities in greater Suva: Walu Settlement in central Suva; Newtown Nasinu; and Bangladesh located between Nasinu and Nausori. Reddy summarised that although squatters were far from homogenous across her survey, each settlement was generally characterised by low-cost housing and a lack of amenities 
such as electricity, adequate sanitation and quality roads. Reddy's research also revealed that only a third of squatters interviewed were rural migrants (the majority of which were indigenous Fijian). The majority of Indo-Fijian squatters interviewed were locally displaced people who had moved from surrounding areas and from other areas of the city to squatter areas. Her study, although based on a very small sample, helped her to summarise that squatters in Fiji had very little choice in their movement and migration decisions, and to conclude that squatters in Fiji faced both a fight for survival and a fight for land - struggles that are still ongoing today.

The most comprehensive and revealing early research on squatters in Fiji was Crosbie Walsh's 1978 PhD study: The Urban Squatter Question: Squatting, Housing and Urbanization in Suva, Fiji. Walsh's study looked to provide a socio-economic profile of squatters in Suva using a survey of 12 settlements and analysis of 1976 census data, and also looked to test a number of hypotheses and assumptions derived from the literature. Of particular relevance to the current research, Walsh looked to engage with, and test, Turner's theory that squatters can be encouraged to undertake 'self-help' activities to improve the conditions of their dwellings - particularly if provided with security of tenure. In response to this hypothesis, Walsh summarised that, overall, squatters in Suva were shown to participate in self-help activities that led to greater adequacy of housing. Specifically, from his survey, $68 \%$ of squatters had built their own house, and $64 \%$ had made some improvements since construction or occupancy (cited in Walsh, 1984, p. 193). However, despite the evidence of self-help activities, Walsh argued that these improvements were generally not sufficient and involved too few households to accept Turner's hypothesis without reservation; highlighting that only $7 \%$ of the housing being improved in his survey could be considered adequate in structure, size, water supply and sanitation (as cited in Bryant, 1990, p. 182). Walsh agreed with Turner in confirming the relationship between security of tenure and house improvement by revealing that in Fiji home improvements in squatter communities did occur among owner occupiers and other households with some degree of security of tenure. However, Walsh argued that income was the critical variable affecting housing quality and that the majority of squatter households in Fiji seemed unlikely to improve their dwellings to minimal adequate standards (even if they had some security of tenure) because they lacked the sufficient income to do so. He also argued in a later paper that self-help improvements were inhibited by rigid building codes in Fiji (1984, p. 185). Overall, as he also argued later, Walsh was led to conclude that "without major changes in the economic position 
of the poor ... little change can be expected in the overall squatter condition" (ibid, p. 193).

Walsh's study reveals that, for people living on land that they did not own, some squatters did communicate feelings of security of tenure. Specifically, Walsh in his survey of 333 urban squatter households, showed that $45.5 \%$ of respondents felt secure (as opposed to $20.9 \%$ of respondents feeling insecure, and $32.8 \%$ uncertain) (1978, p. 250). Results were also interesting when presented along ethnic lines; generally indicating that Indo-Fijian squatters felt much less secure that their indigenous Fijian counterparts. For example, Walsh's survey revealed that $79.4 \%$ of the surveyed indigenous Fijian urban squatters felt secure as opposed to only $18.5 \%$ of Indo-Fijian urban squatters, and that only $5.8 \%$ of urban indigenous Fijian squatters felt insecure as compared to $34.3 \%$ of urban Indo-Fijian squatters (ibid).

Walsh (1978) also observed and concluded that indigenous Fijian and Indo-Fijian squatters tended to use different strategies to improve their livelihoods and also their dwellings. For example, he argued that indigenous Fijians placed considerable importance on kinship, community and mutual self-help, and on urban gardening to supplement income, to improve livelihoods in the city. In contrast, Walsh argued that the Indo-Fijian urban poor placed increased emphasis on the nuclear household and individual effort to improve urban livelihoods particularly through enhancing privacy, improving sanitation, increasing the exchange value of houses, and extending dwellings to provide additional rent income. Specifically, Walsh argued that indigenous Fijian home improvement was the result of the urban transfer of traditional group behaviour, and Indo-Fijian improvement was the eventual result of individual effort. Overall, Walsh argued that the flexibility of squatter housing (as opposed to the formal housing sector) offered residents the environment in which they could better utilise informal sector activities and kinship networks for a viable urban livelihood on a low income. Walsh warned, however, of the danger in placing too much emphasis on the self-help capacity of squatters in Fiji - particularly due to the constraints of low income. He also cautioned that the self-help hypothesis often fails to recognise the often grossly inequitable systems of land tenure around the world; part of the very system that in many environments has produced squatting in the first place. These comments around access to land seem to still hold much relevance to the Fiji context, even more than 30 years on from Walsh's pioneering research in 1978. 
In a later paper Walsh (1979a) focused on further articulating the key differences between the livelihood strategies of indigenous Fijian and Indo-Fijian squatters. Around access to settlements, Walsh argued that indigenous Fijians tended to gain entry through kinship ties and traditional practices. He wrote that many settlements comprised clusters of indigenous Fijians from the same region, many of whom were relatives. Walsh recognised that many indigenous Fijians looked to gain easier and more secure access to tracts of urban and peri-urban native land by presenting tabua (whale's tooth) and other gifts to the local mataqali landowners - practices known as vakavanua arrangements (discussed further later in the chapter). For Indo-Fijian arrivals, on the other hand, Walsh argued that many squatters gained access to a settlement through the purchase of a house or the ongoing payment of rent - meaning kinship and region of origin clusters for Indo-Fijian squatters were less common. Walsh emphasised again that Indo-Fijian squatters tended to feel less secure than their indigenous Fijian counterparts, and argued that this created Indo-Fijian settlement that was less cohesive than indigenous Fijian settlement. He argued that this lack of cohesion meant that in IndoFijian areas of settlements resistance to eviction was rare, and also led to an underutilisation of the residential area for income-supplementing actives such as urban gardening. Walsh also went on to argue that housing priorities were influenced by ethnicity. He stated, for example, that the typical indigenous Fijian squatter household, with its obligation to accommodate visiting relatives and provide for social occasions, experienced a need to provide open areas within the house and to increase dwelling size. On the other hand, Walsh argued, the typical, usually nuclear, Indo-Fijian squatter household placed a higher priority on increasing the number of rooms in the household improving privacy within the household and also providing options to rent out rooms for extra income. Overall, despite the strategies used by indigenous Fijians and Indo-Fijians to improve urban livelihoods, Walsh recognised that the constraints on squatters were considerable; concluding that "the urban poor have been largely excluded from the benefits of development and their opportunities for self-improvement and social mobility are limited" (1979a, p. 6).

Other early scholarship from this period emerged largely as case-study accounts of usually single squatter communities, typically in Suva, and typically based on small surveys. The volume In Search of a Home (Mason \& Hereniko, 1987) included a number of chapters that provided accounts of squatter communities and insight into the conditions and difficulties faced by settlers. In this collection, for example, Laqere (1987) provided a revealing account of Malekula settlement - a small community of mainly 
indigenous Fijian settlers on freehold land in central Suva that was facing eviction pressure, and thus ongoing uncertainty and insecurity, in the mid-1980s. ${ }^{29}$ Laqere's survey showed that most settlers arriving as rural migrants in Malekula had come principally to improve their children's education opportunities and to attempt to obtain regular wage employment. Urban gardening was again identified as important with the majority of households interviewed maintaining crop gardens within the settlement and in surrounding areas, and the majority of those frequently selling any surplus at market. Dwellings in the settlement were largely typical of other squatter settlements in Fiji; constructed of wood and corrugated iron and, in Laqere's words, not intended for permanent occupation. However, almost all households interviewed affirmed that they would build structurally sounder houses if given a degree of security of tenure on the land. Despite the poor quality housing in the settlement, Laqere was led to conclude that residents at Malekula were "squatters only because they are on land which legally does not belong to them" (1987, p. 63); arguing, rather, that characteristics in Malekula such as income levels and sanitation were relatively similar to other poor, non-squatter sections of urban society. This claim is also endorsed by Walsh's earlier analysis of 1976 census data in his PhD work which showed that in most squatter settlements demographic, social, and economic characteristics were not significantly different from other sections of Fiji's urban poor (Walsh, 1979b, p. 3). Laqere (1987) was also led to conclude that, particularly due to the level of community cohesion and the sharing of service infrastructure at the settlement, the indigenous Fijian squatters of Malekula were, consciously or unconsciously, beginning to transform the settlement into a replica of the Fijian village system. This last claim is important, and is reflective of other volumes and scholarship of the period (such as the 1986 collection Fijians in Towns by Griffin and Monsell-Davis) that began to challenge, particularly relevant for indigenous Fijians, the conception of 'rural' and 'urban' as bounded social entities. For example, Young summarises that Fijians in Towns helped highlight that the distinction between rural and urban in Fiji was becoming increasingly blurred in the more populated parts of Fiji, such as Suva - given the diverse range of urban settlement, and forms of mobility no longer synonymous with rural village and town (2000, p. 63-64).

It is clear that, as in and across squatter settlements internationally, a variety of tenure categories are present in the settlements of Fiji. Sugata (1987) in the volume In Search of a Home was one of the first authors to suggest a typology of squatters in Fiji. Sugata

29 The Malekula settlement no longer exists. Settlers were long ago evicted to make way for private housing and a park (Walsh, 2006, p. 84). 
divided Fijian squatters into: (i) squatter/tenants - those neither building or owing a dwelling, but renting; (ii) squatter/holder - former squatter/tenants who no longer pay rent because the landlord refuses to accept it as the land is marked for development; (iii) sitting tenants - who, without the present approval of the owner still live on the land they formally occupied legally; and (iv) settlers (or illegal tenants) - who live on sites specifically allocated to them by landowners, but occupation is still technically illegal as the settlement has not been approved by government.

Bryant (1990) also understood that there were a number of key different tenure categories within Fijian squatter settlements and focused her research on letting and subletting in settlements; the category of 'squatter tenants' mentioned in Sugata's typology above.30 Bryant argued that in the 1980s the level of subletting particularly had been increasing in Fijian settlements; and argued that the subletting of rooms in squatter households was the inevitable attempts of survival by landlords and tenants alike in the face of growing inequalities in the period. She also believed that the publicity given to squatters in Fiji tended to focus on the possibility that some certain groups of squatters were exploiting even poorer groups to pay off housing and land assets elsewhere; acting, as often portrayed by media and government, as 'speculators' using squatting as some type of business venture. Bryant recognised, in her words, the importance of examining whether a wealthier landlord class existed in settlements. Bryant's research focused on a survey of the Muslim League settlement; at the time, a settlement of around 180 households on freehold land in central Suva (where residents did have the permission of the freehold landowners to live there). ${ }^{31}$ Her fieldwork in 86 households, across 35 dwellings, identified that $70 \%$ of households were involved in letting or subletting (with 25 of the 35 dwellings surveyed having one, or sometimes more, tenant households). Bryant also looked at the level of self-help home upgrading in the settlement and identified that considerable extensions and improvements were happening. Bryant's research helped to show that a number of households in the settlement were supplementing their income by letting and subletting rooms. Despite her interviewees claiming rent money was being solely used for day-to-day survival, Bryant did believe that a movement towards capitalist landlordism in the settlement was beginning to emerge; particularly pronounced for Indo-Fijians who made up almost all

\footnotetext{
30 Amis (1984) was one of the first researchers to focus on rental markets in squatter settlements. His research in the large squatter settlement of Kiberia in Nairobi, Kenya, showed the presence of a large private rental sector. Overall, he argued the provision of low-income shelter was now a commercial activity - so much that "[w]ithin Nairobi the squatter is now a tenant" (p. 95).

31 The Muslim League settlement still exists today. However, in the years after Bryant's research, parts of the settlement were cleared, with residents evicted, to make way for private housing (Walsh, 2006, p. 84).
} 
landlords. Bryant justified this claim on: the level of upgrading that was occurring in the settlement; the substantial proportions that rentals were contributing to weekly incomes; and the fact that a number of settlers did own one or a number of homes elsewhere. This led Bryant to argue in a later paper that subletting was important in enabling landlords to marginally improve their living conditions in the long-term (Bryant, 1992, p. 96).

To summarise, a number of key points emerge from the early literature on settlements in Fiji. Firstly, the research shows that self-help home upgrading was occurring across settlements - particularly if households had some degree of security of tenure. However, as Walsh (1978) identified, self-help home upgrading may be constrained by low income levels and may not occur at a level and quantity to improve the quality of the housing stock as a whole; the 'self-improving suburbs' contention of Turner and others from earlier international literature. Secondly, it is revealing that the early research does indicate that many squatters did experience some degree of security of tenure without, of course, owing the land that they reside on. This may be influenced by the fact that many settlers in Fiji do live with landowner consent on native and sometimes freehold land. What the early research seems to ignore, however, is that security of tenure often comes down to a perception influenced by a number of variables; a recognition central to the body of literature around perceived security of tenure that emerged later. Third, the early research identified that settlers in Fiji utilise a number of different strategies (for example, wage employment, urban gardening and other informal sector activity, and subletting) to improve their chances of a successful, and permanent, urban livelihood. The early research also identified that there are important differences between the livelihood strategies of indigenous Fijians and Indo-Fijians; indicating that, despite the problems of generalisations across ethnicity, inter-ethnicity analysis is important in any research on Fijian squatter settlements. Fourth, it is clear that squatters can be divided into a number of key different tenure categories; owner-occupiers and tenants being perhaps the simplest categorisations for the current research's focus on perceptions of security and housing consolidation.

\subsubsection{The Growth of Fijian Squatter/Informal Settlements}

Fijian settlements have been growing steadily for many years. Vuetibau writes that the earliest squatter settlements appeared to have been established around Suva City by 
Solomon Islanders 32 and Indo-Fijians in the 1940s and 1950s (1987, p. 148-149). These settlements (some of which do no exist today, or appear more as urban villages) included the Solomon settlements of Wailoku, Kalekana, and Kaunikuila at Flagstaff (which moved to Newtown Nasinu after a hurricane in 1952). Other early settlements emerged at Villa Star in Nasinu, Malekula and Tamavua-i-wai (ibid). Vuetibau writes that the first Indo-Fijian settlements were located at Vatuwaqa and Samabula (ibid). Until the Second World War most indigenous Fijians in towns were temporary visitors, particularly as what were known as galala regulations made it expensive through a colonial commutation tax for indigenous Fijians to be away from villages and thus exempt from communal obligations (Overton, 1988). However, the settlement of Valenimanumanu in Suva appears to be the oldest indigenous Fijian settlement; originally settled in 1910, but only occupied in substantial numbers after the war. This settlement, established by Ra migrants, expanded into nearby Nauluvatu in 1941 and Walu Bay in 1952; which also appear to be some of the earliest indigenous Fijian settlements (Vuetibau, 1987, p. 149).

Walsh writes that the early growth and distinctive features of squatting in Fiji arose from the country's colonial heritage (2000, p. 437-438). Fijian towns, for example, were originally European spheres of activity and urban tenure was typically state or freehold. Walsh writes that early squatter settlements within town boundaries tended to be established by Melanesians on church land (often paying contributions to church rates) and by Indo-Fijians on other freehold land. Indigenous Fijians locating in settlements, on the other hand, typically established themselves on state or native land - normally accessed by ceremonial request and presentation to city councils and land-owning mataqali, and maintained by irregular but ongoing payments, and meeting customary obligations (ibid).

Quantifying the growth of squatter settlements in Fiji can be problematic. Firstly, an official count can be constrained by definitions and the loose terminology that is often employed (Bryant, 1993, p. 61). For example, vakavanua settlers who are living with landowner consent may be omitted from official counts, underestimating total figures, or informal dwellings in urban villages can be included or excluded. Secondly, data may simply be missing, erroneous, contradictory, misleading, or based on incorrect assumptions. Despite the data problems, however, published figures from various

\footnotetext{
32 Descendants of Solomon and Ni-Vanuatu 'blackbirders' originally brought to Fiji for plantation work, today known as 'Melanesians', remain some of the poorest groups in Fiji (Halapua, 2001; Nomae, Manepora'a, Kumar \& Prasad, 2004). Many settlements remain across Suva and Lautoka that are known locally as 'Melanesian' although due to intermarriage with indigenous Fijians are essentially Fijian in character.
} 
sources are available, and show that, without question, total numbers of squatters in the country have been increasing over the years, to what some commentators have called a crisis situation today (McKinnon et al., 2007; Pareti, 2007; Storey, 2006).

By 1964, it was estimated that one-fifth of Fiji's total urban population lived in squatter communities (World Bank, 1995, p. 5). More detailed figures from 1976 (as cited in Bryant, 1990, p. 179) estimated that 2,256 squatter households existed across Fiji - with the most being in Suva $(1,728)$ and Lautoka $(375)$ respectively, and a much smaller amount in Labasa, Levuka and Ba. Walsh suggests higher 1976 numbers for Suva, and quotes an estimate of 23,000 total squatters, or around $20 \%$ of Suva's total population (1984, p. 186). By 1986, the official census report identified that nationwide there were 3,412 squatter households in urban areas (including 2,766 in greater Suva and much smaller numbers of 240 in Labasa, 137 in Ba, 118 in Nadi and 97 in Lautoka) accounting for approximately 17,060 people (Lingam, 2007, p. 5; World Bank, 1995, p. 37). In Suva, around this time, surveys showed that 9,330 people were squatting in 26 settlements within the town boundary - or approximately one-eighth of Suva's urban population. Of these 9,330 people, the survey showed that 57\% were Indo-Fijian, $40 \%$ indigenous Fijian, and 3\% other ethnicities (Bryant-Tokalau, 1995, p. 125; 2008, p. 3).

Figure 5.3. Distribution of Squatter Settlements in Central Suva, mid-1980s

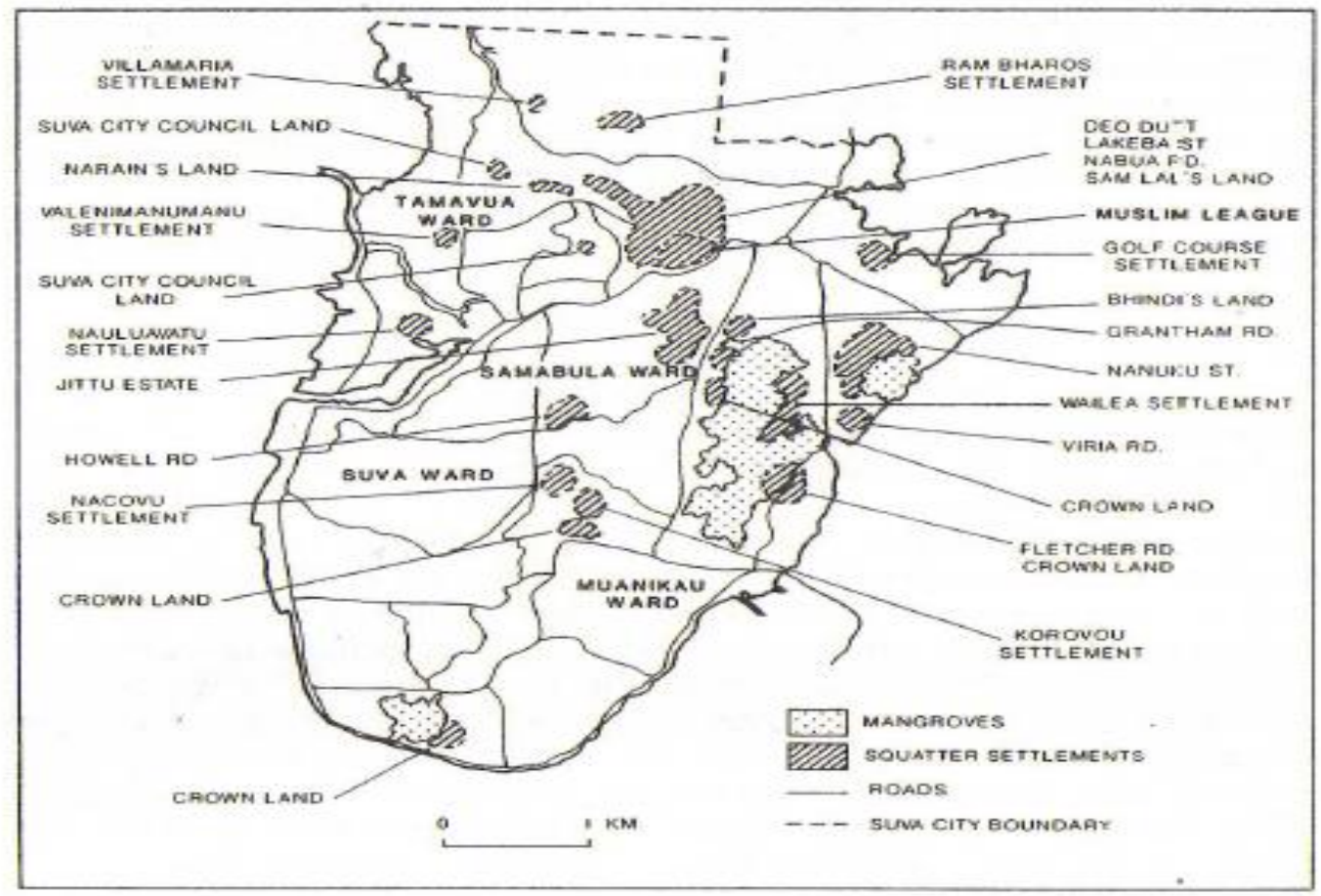

Source: Bryant, 1990, p. 177 
By 1996, more comprehensive analysis and figures were available for total squatter numbers. A survey by Walsh based on aerial photographs claimed that, across Fiji, approximately 70,000 people, or around $20 \%$ of Fiji's total urban population, were living in 14,000 informal dwellings, including approximately 35,000 people in the Suva urban area (Walsh, 1996; Walsh, 2000, p. 438). Walsh's figures (which also included urban villages) showed that $18.8 \%$ of Suva's population lived in informal dwellings. The corresponding figures for other major urban centres included Lautoka (21.8\%), Nadi (24.3\%), Labasa (14.5\%), Nausori (12.2\%) and Ba (17.6\%) (Walsh, 2000, p. 437). The more conservative official census count from the period suggested that there were 9,209 informal dwellings across the country - accounting for approximately 46,045 people ( $12.8 \%$ of Fiji's urban population) (National Council for Building a Better Fiji (NCBBF), 2008b, p. 6).

Since the late 1990s, official figures from the Fiji Government's Housing and Squatter Resettlement Unit (HSRU) have been available on squatter numbers. Despite concerns with the reliability of these figures33 (Barr, 2007, p. 6; Chung \& ECREA, 2007, p. 39) the data is frequently cited. Original surveys in 1999 by the HSRU enumerated 9,231 squatter dwellings across the nation. Out of this figure, Suva had 5,333 squatter households. Other major squatter areas included Lautoka (1,300), Ba (520), Labasa (500) and Nadi (500) (Lingam, 2007, p. 4). Tables 5.4 and 5.5 below show HSRU estimates of total squatter household numbers, by Division and ethnicity, for 2003 and 2007.

Table 5.4. Squatter Households by Division and Ethnicity, 2003, HSRU Data

\begin{tabular}{|l|l|l|l|l|l|}
\hline Division & Indigenous Fijian & Indo-Fijian & Others & Total & \\
\hline & & & & & \\
\hline Northern & 177 & 655 & 38 & 870 \\
\hline Western & 837 & 3,316 & 15 & 4,168 \\
\hline Central/Eastern & 5,295 & 3,377 & 15 & 8,687 & \\
\hline Grand Total & 6,309 & 7,348 & 68 & 13,725 & \\
\hline
\end{tabular}

33 For example, Chung and ECREA claim that the HSRU figures are significantly lower than the 1996 estimates by Walsh suggest they should be. They also express concerns with the general robustness of figures - including rounding (2007, p. 39). 
Table 5.5. Squatter Households by Division and Ethnicity, 2007, HSRU Data

\begin{tabular}{|l|l|l|l|l|l|}
\hline Division & Indigenous Fijian & Indo-Fijian & Others & Total & \\
\hline & & & & & \\
\hline Northern & 212 & 786 & 46 & 1044 & \\
\hline Western & 1,004 & 3,979 & 18 & 5,001 & \\
\hline Central/Eastern & 7,413 & 4,728 & 21 & 12,162 & \\
\hline Grand Total & 8,629 & 9,493 & 85 & 18,207 & \\
\hline
\end{tabular}

Sources: Lingam, 2007, p. 5; NCBBF, 2008b, p. 7

The HSRU estimates that, originally in 1999, 46,155 people were living in 106 squatter settlements across Fiji (Barr, 2007, p. 6; Lingam, 2007, p. 4). In 2003 and 2007 they revised these totals to 82,350 in 182 settlements and 100,000 in 200 settlements respectively (Lingam, 2007, p. 5; NCBBF, 2008b, p. 7). However, the total population estimates have been calculated using an average housing size of five persons - probably too low for squatter settlements that typically have households of far greater size (Barr, 2007, p. 7).

The 2007 census data ${ }^{34}$ presents another set of figures on total squatter numbers. This information (which may in time come to supersede the HSRU data as a common reference), displayed in Table 5.6 below, reveals that there were 15,445 enumerated squatter dwellings of 77,794 people at the time of the census. Of total squatter numbers, 70\% were concentrated in the Central Division and $25.9 \%$ in the Western Division. Of the major ethnic groups, the data reveals that $57.5 \%$ of total squatters were indigenous Fijian and $36.8 \%$ were Indo-Fijian. The official census figures, however, are an underrepresentation of total squatter numbers in Fiji - although are useful as indicating absolute minimum numbers of squatters. It appears, for example, that many recognised squatter communities were not enumerated - reflecting the common disputes around definitions and what actually constitutes a squatter community that were discussed earlier. ${ }^{35}$ Whatever the exact figures, all evidence suggests that there have been recent substantial increases in Fiji squatter populations (Chung \& ECREA, 2007, p. 39). Given problems with the HSRU data and exclusions for the 2007 census enumeration, perhaps around 140,000 is a more likely figure reflecting total squatter numbers (ibid). Certainly

\footnotetext{
${ }^{34}$ Made available directly by the Fiji Islands Bureau of Statistics.

35 It appears, for example, that some recognised squatter communities may have been classified as 'urban villages' - most likely settlements on native land accessed by vakavanua arrangements. As one such example, the community of Vunato, on native land in Lautoka, one of the case studies for this research, was not classified as a squatter area during the census - although the community is commonly referred to as a squatter settlement.
} 
the largest numbers of squatters (over 10,500 households) are found concentrated in greater Suva - particularly in the Lami-Suva-Nausori corridor (Barr, 2007, p. 7).

Table 5.6. Squatter Population and Households by Division and Ethnicity, 2007 Census Data

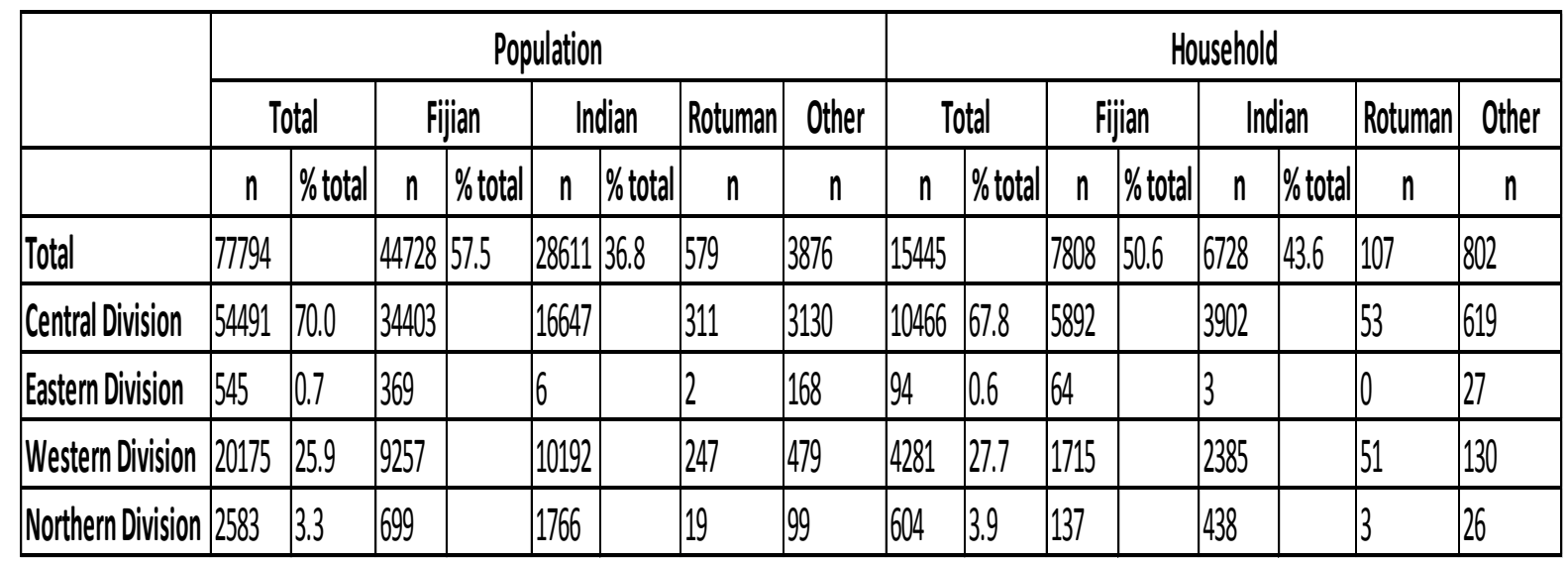

Source: Fiji Islands Bureau of Statistics

Within towns the recent growth of squatter settlements has been dramatic. Gibson, for example, found that in Ba squatter populations grew ten-fold between 1986 and the mid-1990s (as cited in NCBBF, 2008b, p. 6). More recent analysis by Chung and ECREA (2007) compared the aerial photograph surveys by Walsh in 1996 to more recent satellite images. This analysis (which unfortunately could not provide comparative detail for the Lami-Suva-Nausori corridor due to the absence of recent imagery) showed a rapid growth of informal settlements in and around Ba (250\% growth over 16 years), Nadi (72\% growth over approximately 10 years), and Lautoka (30\% growth over 10 years) (Chung \& ECREA, 2007, p. 50).

Within the Lami-Suva-Nausori corridor, much squatter growth is concentrated in and around Nasinu (Lingam, 2007, p. 5). A survey by Nasinu Town Council in 2007, for example, enumerated 1,847 squatter dwellings within the Nasinu town boundary housing a population of 9,669 people (Nasinu Town Council, 2007). The recent growth of Nasinu reflects the trend that squatters are increasingly locating on Suva's periphery. It is in these areas, both within and outside the town boundaries of Nasinu and Nausori, where most available land exits - usually native land accessed via informal, vakavanua arrangements. 
Statistics have often shown that there have been more Indo-Fijians than indigenous Fijians living in squatter settlements (Barr, 2007, p. 7). A government survey showed, for example, that in $2005,53 \%$ of squatters nationwide were Indo-Fijian and $46 \%$ indigenous Fijian. In the Central Division indigenous Fijians (61\%) outweighed Indo-Fijians (39\%), and the reverse being true in the Western and Northern Divisions (Mohanty, 2006, p. 65). However, as Barr explains, if informal housing in urban villages is included, indigenous Fijians would be over-represented in statistics (2007, p. 8). Despite the fact that over $90 \%$ of Fiji is held under native Fijian tenure, many indigenous Fijians are land-poor (for various reasons without official mataqali land holdings36) (McKinnon et al., 2007, p. 13; Naidu, 2009 , p. 4). There is little doubt that many of these land-poor indigenous Fijians reside in squatter settlements or with relatives in urban villages (Barr, 2007, p. 8).

A number of processes combine to influence the growth of squatter areas in Fiji. Walsh contends that the root causes of informal housing in Fiji are similar to that of the world over: gross rural/urban and income disparities; tracts of unused urban land; the continuation of inappropriate and unaffordable official building standards; and the high cost of state and private land and housing priced beyond the reach of poor and migrant families (2000, p. 439). Walsh argues that, contrary to public perception, most squatting in Fiji was not a product of ongoing rural to urban migration - arguing, rather, that many squatters were in fact born into their communities; indicating that natural increase within established settlements may traditionally have contributed significantly to total squatter growth (ibid).

As will be highlighted in the next chapter, a low-income housing shortage is certainly clearly linked to the growth of squatter settlements. It is largely government that provides low-income housing in Fiji - through rental accommodation provided at subsidised rates through the Public Rental Board (PRB), and through the construction of homes and serviced plots meant for lower income earners by the Housing Authority. However, supply for many years has been insufficient - the amount of PRB units, for example, do not come close to matching demand (Stabile, 2000, p. 139). In addition, Housing Authority dwellings and plots have remained unaffordable for the majority of low-income earners (ibid; Brochu, 2004, p. 79; McKinnon et al., 2007, p. 21). Overall, the

\footnotetext{
${ }^{36}$ Originally fixed mataqali land holdings were determined three to four generations ago. Holdings, originally considerably varied in size, however, are now divided amongst growing mataqali groups. In addition, inequalities are growing in Fijian villages; particularly as some individuals gain access to the best quality land (McKinnon et al., 2007, p. 13).
} 
problem is about under-supply but also limited affordability (Barr, 2009a; Bryant, 1990, p. 177; Hassan, 2005, p. 2).

More recent analysis of the growth of squatter settlements has tended to recognise that there are a myriad of factors that all combine to influence the growth of these areas. Barr (2007), for example, recognises the importance of the inadequate supply of lowincome housing since 1955 (including the difficulty of obtaining land through formal channels), but also recognises that affordability is limited by poverty, lack of employment opportunities, low (and declining real) wages, and rising rents and real estate prices. Barr also recognises that a traditional negative and insensitive attitude from government towards settlers (where squatting has often been seen as something to discourage) influences a general lack of political will for improving conditions for lowincome urban residents. Finally, and contrary to Walsh's earlier claim, rural to urban migration is certainly influencing the contemporary growth of squatter communities. As earlier sections of this chapter have shown, this is shaped by combining push and pull factors that influence urbanisation, and particularly the huge, seismic, impact of expiring land leases from 1997.

It is clear that Fiji is facing an emerging housing crisis. For example, McKinnon et al. (2007, p. ii) in a recent study estimate that 730 households are being added to informal settlements each year - a figure likely to increase to almost 1,300 a year over the next 15 years. They estimate that on the basis of current supply a shelter shortfall of over 30,000 dwellings over 15 years will be created (ibid). Storey too recognises the significance of the shelter shortfall and states in quite alarming fashion that "Fiji may only be at the edge of a significant and potentially chaotic urban demographic explosion for which it is barely prepared" (2006, p. 16).

\subsubsection{Vakavanua Settlers}

Little research in Fiji has focused on revealing the nature of the informal or vakavanua arrangements that are increasingly used by settlers to gain access to areas of urban and peri-urban native land for housing. Walsh (1979a) recognised, as has been mentioned, that Fijians often used traditional practices, such as the presentation of tabua and yaqona to the leader of the settlement or the local mataqali in the urban area, to gain access to a settlement. However, Walsh did not focus on highlighting the variety of vakavanua arrangements; perhaps because they were less significant in the 1970s and 
1980s when there was continuing availability of vacant areas of urban state land. McKinnon et al. (2007, p. 18-19) do summarise the nature of vakavanua arrangements. They write that to gain access to native land, settlers are required to get permission and make payment to traditional landowners. Payments may include customary gifts such as tabua, yaqona or drums of kerosene, and increasingly cash. Ongoing ad hoc contributions to landowner events (particularly for weddings and funerals) or fundraising (particularly for the church) are also often expected. Vakavanua arrangements have occurred for generations in Fiji; and indeed an agreement between landowner and land-using family may extend back for generations. Vakavanua arrangements are formally recognised in Fiji under the Native Land Act; where landowners can give out land in response to a traditional request. However, these recognised vakavanua agreements are usually used to gain access to rural land for farming (Eaton, 1988) (although commercial vakavanua arrangements that are strictly illegal are also used in rural areas). In urban areas, however, a vakavanua arrangement is almost always strictly commercial in nature - rather than between two parties who have a traditional relationship. In NLTB's view these urban, commercial arrangements do not fall under the influence of the Native Land Act and are thus strictly illegal. However, rather than taking legal action, the NLTB typically ignores ongoing urban commercial vakavanua arrangements (ibid) - perhaps avoiding a potential can of worms.

McKinnon et al. summarise that under vakavanua arrangements settlers typically pay around $\mathrm{F} \$ 1,000-\mathrm{F} \$ 3,000$ for a house site, and then build on or relocate their homes at their own cost (2007, p. 19). Further payments are also usually required-ranging from regular monthly payments, occasional payments on demand, customary gifts, or all three. All vakavanua arrangements have no legal standing. Security of tenure under vakavanua arrangements depends on the nature of the landowner, and also on the nature of settlers' relationships with landowners. For example, where landowners are generous and tolerant, some settlements have been stable and long-standing. However, in other settlements, residents, regardless of ethnicity, complain of harassment, extortion and threats of eviction. Rutz, for example, provides evidence from Nadouumai Settlement in Suva; claiming that in this community youth from the landowning mataqali frequently extort money from others in the settlement for drinking and gambling, and that landowners request money for school and hospital fees (1987, p. 548-549). Rutz argued that, in such settlements, landowners "have taken advantage of the scarcity of land to obtain unearned income from their landless kinsmen" (ibid, p. 549). Some Fijian 
landowners, Rutz heard summarised across the community, now 'go only for the money' (ibid).

McKinnon et al. summarise that under vakavanua arrangements security of tenure ranges "from traditional and fairly secure, to quite at the will of the landowner and very insecure" (2007, p. 19). Vakavanua arrangements are very open to exploitation. Involuntary evictions and extra-judicial seizures of dwellings have occurred (particularly in the Western Division) (ibid). Some house sites have also been resold many times by landowners as settlers voluntarily depart or are forced out through eviction and payment default. Settlers have no legal recourse to any form of official protection and support (ibid). However, because of the shortage of legal, low-cost housing across urban Fiji, more and more settlers are driven to, often vulnerable, vakavanua arrangements. This type of settlement by its very nature presents limited security of tenure.

There are limited available accounts of the nature of urban vakavanua arrangements. Wilkinson (2002), however, in his assessment of squatter settlements for the Nasinu Town Council, did identify the typical nature of vakavanua arrangements around this area. In his survey of 108 Nasinu squatter households across eight settlements, $21 \%$ of households were found to be squatting on native land. Most of these settlers did make some form of payment to the traditional landowners - but the amount and frequency of the payments varied considerably, was often irregular, and was often made to assist the landowners to meet customary commitments and obligations. Across his interviews, Wilkinson found no formal or written evidence of understandings regarding land rentals, and also found a considerable degree of uncertainty from settlers around who the rightful landowners actually were.

\subsubsection{Location Preferences, Stereotypes, the Importance of the Informal Sector, and}

\section{More Recent Research}

In Chapter 2 it was highlighted how Turner (1968a) proposed three basic functions of the urban built environment - location, tenure and amenity; arguing that an effective dwelling must have: (i) an accessible location (particularly close to work opportunities); (ii) opportunities for secure, continued residence; and (iii) minimum shelter standards. Turner proposed that, for squatters dependent on uncertain labour markets and the need to reduce transport costs and time, the need to live centrally was paramount dominating the lesser needs for secure tenure and quality shelter. In Fiji, Walsh has 
summarised (across his studies) that in Suva squatters indicate a strong preference for proximity to town, followed by secure tenure as the next priority (Walsh, 2006, p. 84). This claim, however, needs to be looked at again - particularly in a current environment where inner city settlements are increasingly congested and where the majority of new settlers are thus locating on tracts of native land on the urban periphery.

As in Papua New Guinea and Vanuatu, certain perceptions and stereotypes abound around squatters in Fiji. As has been discussed already, Bryant (1990) identified the perception, commonly portrayed in government and media discourse, that many squatters could afford to live elsewhere and are involved in squatting as some sort of entrepreneurial, business activity. Barr (2007), in a paper calling for a need for attitudinal change towards squatters, tries to correct this perception and argues that, contrary to common belief, probably only $5 \%$ of squatters could afford to live elsewhere. Barr summarises some of the common negative stereotypes of squatters and argues, using clear case examples, that many politicians especially have portrayed squatters in a negative fashion - as 'eyesores', as like 'thieves' living on other people's land, as 'social ills', as a 'bane' in any society, and as 'lazy, hopeless, uneducated and worthless'. Barr writes that such attitudes have tended to constrain realistic, appropriate policymaking in favour of top-down authoritarian responses such as evictions (ibid, p. 19). Barr argues that what is needed is radical attitudinal change and policy that actively involves squatters in a positive light as partners and "part of the solution, not part of the problem" (ibid).

Mohanty (2006) focused on highlighting the critical importance of the informal sector as a survival strategy for squatters. ${ }^{37}$ Mohanty surveyed 290 squatter households across seven Suva settlements. His survey revealed that across the sample, $48 \%$ of household heads relied on casual labour for their principal income (other main categories included salary earners (25\%) and the self-employed (16\%)). Overall, $37 \%$ of the squatters surveyed were involved in a wide range of informal sector activity - including as casual carpenters, plumbers and electricians, backyard mechanics, and in unregulated taxi driving, hair dressing, tailoring, and the selling of various goods (including vegetables, seafood, yaqona, food and barbeque). He argued that the informal sector plays a critical dual role for squatters - a supplementary role in providing employment and generating income, and also a complementary role in providing goods and services.

37 A point that had earlier been recognised by Walsh (1978) and also in Bryant's earlier research on urban poverty in the Pacific and the role of the informal sector for the urban poor (1992 \& 1993). 
Overall, Mohanty's research helped to reinforce the important contribution that squatters make to urban economies in Fiji - in both the formal and informal sectors. What Mohanty did not focus on, however, was the importance of urban gardening for squatters and the urban poor more generally - something that was recognised as a crucial livelihood activity of squatters by Walsh in his early research (1978).

In 2005/2006 Chung and ECREA (2007) completed a large survey of 680 squatter households across 18 settlements in eight Fijian urban areas. Results were particularly revealing around movement and location choice rationale. They found, for example, that among older indigenous Fijian squatter households who had moved to their residence in the 1970s and 1980s, pull factors were particularly important - especially the lure of better employment opportunities and education opportunities for children, as well as marriage and joining extended family. With more recent indigenous Fijian arrivals, on the other hand, push factors were more significant - particularly unaffordable rents, village and family conflicts, marriage break-ups, and overcrowded living conditions. For Indo-Fijians, the survey showed that push factors were the most significant - particularly land lease expiry. For example, in all of the Indo-Fijian households who reported moving to a settlement after 2000 (half of those interviewed), $45 \%$ of respondents explained that their move was due to land lease expiry or a similar problem. In fact, the survey showed that expiring land leases were not a new event with some Indo-Fijian survey respondents reporting that this was what initiated their move to a settlement in the 1980 s.

The Chung and ECREA survey also revealed that for informal settlers in Fiji "insecurity of tenure is a common concern" (2007, p. 61). For example, from their survey: $48 \%$ of respondents reported that they occupied land with no special agreement with any landowner; $16 \%$ did not know who owned the land; and 16\% were living with vakavanua arrangements with Fijian landowners. Ten per cent of the informal settlers interviewed also reported threats of eviction largely coming from government and municipal councils due to land development projects. Considerable anxiety was reported when dealing with landowners particularly when requiring landowner signatures for utility connection, when negotiating neighbourhood disputes, when coping with harassment when payments were due, and when landowner boundary or ownership disputes rebounded on settlers (ibid). The Chung and ECREA survey also revealed that such insecurity meant that a high $74 \%$ of respondents reported that they made no improvements to their house. Frequently respondents reported that there was no guarantee that the house could remain on the site, and that dwellings should remain 
possible to dismantle should a move be necessary. In addition, when landowners receive rent, they could refuse permission for any apparently more permanent dwelling such as for the use of concrete or even utility connection (ibid).

Clery (2006) in a case study of the very small, seven-household Korova squatter settlement has problematised the term 'squatter', and also highlighted some of the uncertainties that pervade around land tenure for settlers. Korova, for example, a community situated on a small strip of mangrove-lined land at Suva Point, is officially state land (as is all land on the foreshore that is subject to the low and high water marks (Naidu, 2009, p. 13)). However, the settlers are living in the community through a vakavanua arrangement with the Tui Suva - for them the 'true' owner of the land. ${ }^{38}$ Clery argues that settlers at Korova are thus forced to navigate between two dualistic conceptualisations of land ownership and attendant land rights; a situation that brings considerable insecurity of tenure particularly because at the time of the research the government was pressuring the community to move to a major squatter relocation area in Nausori. Clery also argues that because people at Korova were living with the consent of the Tui Suva (despite the lack of legality) they are better termed 'settlers' as opposed to 'squatters'. This small case study does identify the uncertainties and difficulties settlers can face - particularly when land ownership is unclear or contested.

It is clear that squatter settlements are growing quickly in Fiji. A number of forces combine to influence this growth although it seems that, particularly, the impact of expiring rural land leases has been huge. Increasingly new settlers are locating on the fringes of traditional urban areas. In greater Suva, for example, most of the new growth is centred around Nasinu and Nausori. These emerging squatter areas are often on native land and accessed via various vakavanua arrangements. However, as Chapter 6 will highlight, these growing urban fringe settlements, often outside of municipal town boundaries, create increasing pressure for effective urban management.

\subsection{Summary}

Urbanisation continues to transform the social fabric of Fiji. As elsewhere in the Pacific, the growth of informal settlements is a clear manifestation of continued urbanisation. In

38 The Tui Suva, who lives very near the squatter settlement of Muanivatu at Suva Point, is a descendant of landowners originally living on the Suva Peninsula before Suva began to grow as a colonial city. The Tui Suva continues to assert his claim to the land on which Suva developed ("Chief warns", 2008). 
Fiji this growth has been occurring for many years, but has been particularly pronounced since rural farming leases began to expire in large numbers from 1997. Informal settlement growth is also influenced by a number of other factors - inequities in land availability and limits in housing availability and affordability being perhaps the most significant. New settlers are increasingly driven to locate on peri-urban native landaccessed via informal, vakavanua arrangements. Conflict over access to land, particularly at the peri-urban interface, looks likely to increase. Insecurity, particularly pronounced for Indo-Fijians, prevails. All informal settlers in Fiji lack legal security of tenure. While some settlers may experience a degree of perceived security of tenure, this - particularly all its influencing variables - is not well understood. Research and understanding around various tenure categories within informal settlements, and particularly around vakavanua arrangements, is also lacking.

In Fiji, thus far in the literature, an analysis of squatter/informal settlement security of tenure and housing consolidation has not been undertaken using the framework and lens of perceived security of tenure. As mentioned earlier, Walsh (1978) found evidence of housing consolidation across his case studies in his early research on Suva settlers. In addition, Bryant (1990) and Wilkinson (2002, p. 18) have revealed evidence of housing consolidation in Fijian informal settlements in the absence of legal security of tenure. However, none of these studies were undertaken with the explicit recognition that security of tenure can be fluid and that it often comes down to perceptions influenced by a number of key variables. This recognition is integral to the thrust of the current research - that asks as its central research question 'What is the nature of perceived security of tenure and housing consolidation in the urban informal settlements of Fiji?'

In a climate of increased urbanisation, and rapid informal settlement growth, an urban crisis looms. As will be discussed further in the next chapter, effective intervention and management in the sector is constrained by huge funding shortfalls and a stunted regulatory environment. Self-help housing consolidation by informal settlers themselves may be something worth aiming to facilitate in such a climate - particularly if some evidence linking perceived security of tenure and ongoing upgrading in Fijian settlements can be found. However, perceived security of tenure and housing consolidation both need to be understood in more detail first - particularly in a small island context where most land is held under customary tenure. 


\section{CHAPTER 6: INTERVENTION ACTIVITIES WITHIN THE FIJIAN LOW- INCOME HOUSING AND INFORMAL SETTLEMENT SECTOR ${ }^{39}$}

\subsection{Introduction}

A wide variety of stakeholders in Fiji are engaged in the low-income housing sector and activities in informal settlements including government agencies, various NGOs, and donor and international organisations. As Chapter 5 highlighted, recent estimates suggest that around 140,000 people are living in approximately 190 informal settlements across Fiji (McKinnon, Whitehead, Chung \& Taylor, 2007). Intervention looking to provide adequate shelter to Fiji's low-income earners and informal settlers is more urgent than ever. However, as will be discussed, the challenges are vast. Low-income housing availability and affordability remains limited and funding shortfalls and a stunted regulatory environment also inhibit urban management and intervention. This chapter will introduce and discuss the various actors, activities and challenges in the Fijian lowincome housing and informal settlement sector - forming further important background and context for the fieldwork and research. Indeed, some of the intervention activities to be discussed have, or are likely to have, direct effects on residents of the research case studies.

\subsection{State Intervention}

Three principal state agencies are involved in Fijian informal settlements and low-income housing: the Housing Authority and the Public Rental Board which are both engaged in the provision of housing aimed at lower income earners; and the Fiji Government's Housing and Squatter Resettlement Unit which is involved directly in activities that target current informal settlements.

The Housing Authority (HA) was established under the Housing Act of 1955 to provide low-income housing across Fiji - initially as a non-profit institution providing subsidies and rebates to facilitate the leasing or purchasing of homes and, later, serviced sites (Chung

\footnotetext{
${ }^{39}$ A version of this chapter entitled 'Intervention in the Fijian Low-Income Housing Sector: Challenges, Partners and Prospects' was presented to the 2010 Oceania Development Network Conference 'Regionalism and Service Delivery: Meeting the Needs of Pacific Island People' in April 2010 at the Coral Coast, Fiji.
} 
\& ECREA, 2007, p. 32; Walsh, 1984). Over the years, however, the function of the HA changed from its original welfare orientation to a more commercial institution that built homes for sale at market rates (Chung \& ECREA, 2007, p. 32). Indeed, today the HA is enacted as a commercial statutory authority seeking to make profit by providing 'commercial housing' for those on incomes between $\mathrm{F} \$ 6,500$ and $\$ F 16,500$ (or effectively those on lower middle incomes) who can service loans of $F \$ 20,000$ or more (Barr, 2009a, p. 3). The HA does retain a 'social housing' obligation; fulfilled when it assists the Housing and Squatter Resettlement Unit by providing low-cost lots for evicted informal settlers (ibid).

Even in its early days the HA could not supply enough housing at rates low-income earners could afford. Indeed, in 1964 a rental programme was instigated upon recognition that temporary accommodation was needed for workers unable to purchase homes (Sharma \& Lawrence, 2005, p. 146). Despite the new rental programme, however, the gap between supply and demand widened (Chung \& ECREA, 2007, p. 32); with the waiting list for a HA site or home in late 2008 being over 4,000 (M. Tupua, personal communication, November 13, 200840). By the late 1980s the HA was close to financial collapse, and, in 1989, upon the advice of the World Bank, its rental function was transferred to a newly created agency, the Public Rental Board (PRB) (along with close to $\mathrm{F} \$ 20$ million of debt${ }^{41}$ ) (Chung \& ECREA, 2007, p. 32; Sharma \& Lawrence, 2005, p. 147). In late 2008, the PRB, also now enacted as a commercial statutory authority, was managing 1,334 rental units across Fiji42 (M. Senibulu, personal communication, November 13, 2008). The building of new units, however, has been constrained by the inherited debt (only 70 units have been built since 2005) and in 2009 over 3,600 people were on the PRB waiting list (Barr, 2009a, p. 3). While older units have affordable rents to those on low incomes, newer and renovated units, renting for upwards of $\mathrm{F} \$ 90$ per week, remain unaffordable for many (although rents are subsidised by the Department of Social Welfare for those on the Family Assistance Scheme) (ibid).

\footnotetext{
40 See Appendix 1 for the list of key informants.

${ }^{41}$ The level of inherited debt also prompted the PRB to immediately raise rents in the late 1980s; a move also replicated by the private sector (at the time providing around $90 \%$ of Fiji's low-income housing). These changes caused an abrupt $16 \%$ rise in the housing index at this time (Chung \& ECREA, 2007, p. 32).

42 PRB housing stock used to include multi-level flats at Raiwaqa and Raiwai in central Suva housing thousands of residents in often overcrowded conditions. Over the years these flats received much criticism and were frequently finger-pointed as hot beds of crime and other social problems. The design and residential environment, however, played a role in some of these problems. New tenants often had little in common with neighbours, old supporting socio-economic networks were broken when new tenants moved in, and design (such as the lack of communal space) inhibited cultural income-support systems such as urban gardening or room for informal sector activity. Compartmentalised units also had very little room for extended family (Walsh, 1984, p. 189). In 2008, the old Raiwaqa and Raiwai flats were demolished to make way for new PRB developments. Little is known about the fate of tenants however - certainly many were forced to relocate to other low-income housing areas of Suva (including informal settlements).
} 

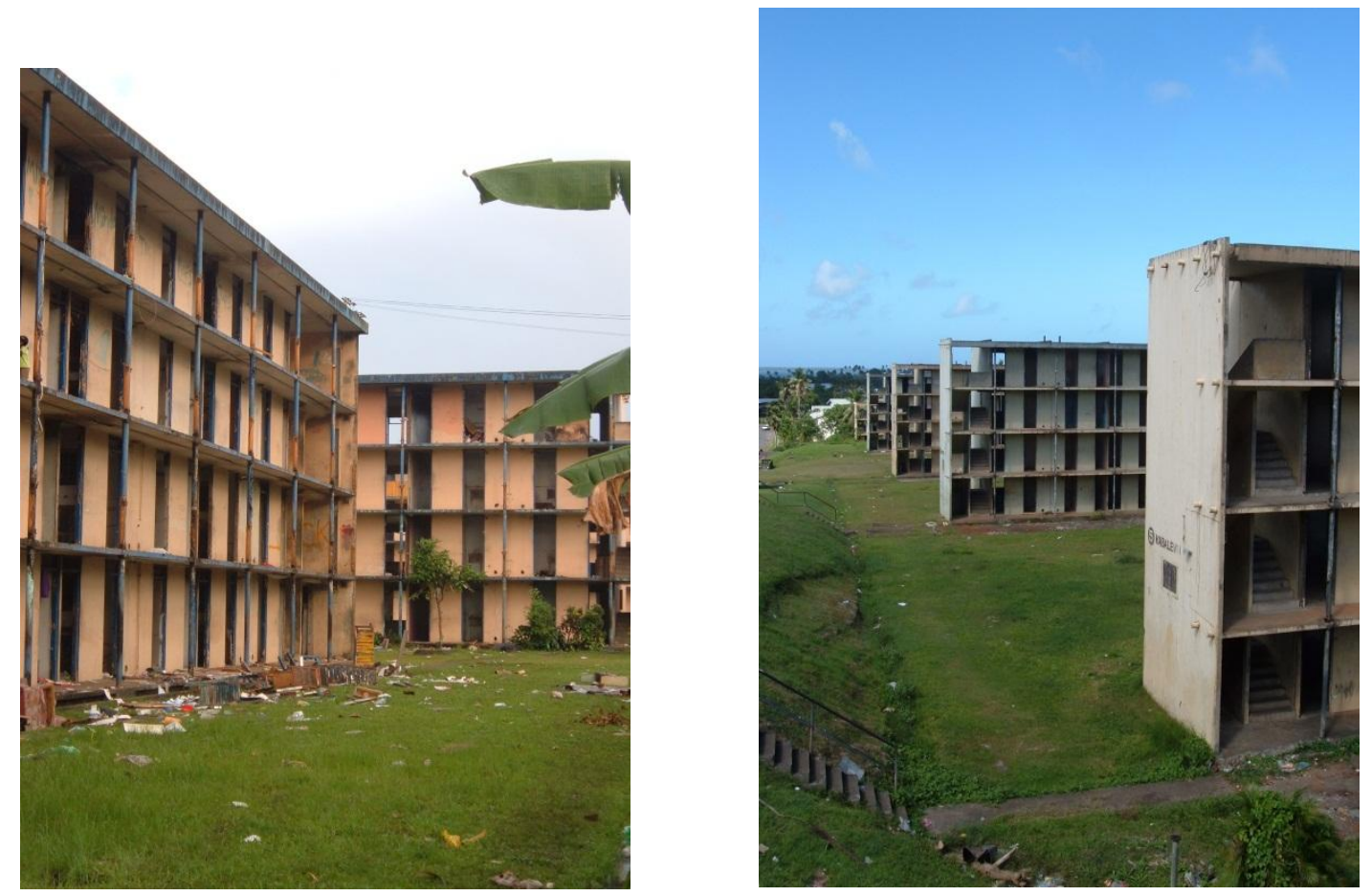

Plates 6.1-6.2. Recently emptied PRB flats at Raiwaqa and Raiwai, central Suva, July and August 2008. Both sets of flats were demolished in late 2008. Photos: The author.

Overall, both the HA and PRB, also constrained by capacity and funding shortfalls, have been unable to make a critical difference. In particular, the ability of low-income earners to afford suitable housing has progressively become worse (Chung \& ECREA, 2007, p. 33; McKinnon et al., 2007, p. ii). The twin constraints of limited availability and limited affordability continue to inhibit progress (Barr, 2009a, p. 4). Overall, housing costs have continued to increase more rapidly than average incomes (Chung \& ECREA, 2007, p. 34). Indeed, while it was originally envisaged that people would move up the housing ladder, for example from an informal settlement to a PRB unit to purchasing their own land and homes through HA, this rarely occurs (Barr, 2009a, p. 1; National Council for Building a Better Fiji (NCBBF), 2008b, p. 12). House ownership has moved beyond the reach of many urban dwellers and $\mathrm{HA}$ areas have typically become areas of long-term, middle-income renters (Chung \& ECREA, p. 33). The supply of public sector housing, now commercial in nature, inhibits intervention that targets those most in need of good quality, affordable shelter. 
The principal government agency intervening directly in informal settlements is the Housing and Squatter Resettlement Unit (HSRU). ${ }^{43}$ Key functions of the HSRU include resettlement to new subdivisions (this focus is reflected in the unit's name), limited upgrading schemes for existing settlements, socio-economic surveying, and ongoing efforts to discourage new settlement growth (Chung \& ECREA, 2007, p. 34; Lingam, 2007, p. 12). The HSRU aims to coordinate closely with the HA, PRB, Native Land Trust Board (NLTB), municipal councils and other NGO housing providers. The focus of HSRU's activities over the last few years has been resettlement; particularly to the Waila 3B subdivision (of around 460 serviced lots) between Nasinu and Nausori. Overall, however, Waila 3B has not been very successful (Thornton, 2009, p. 890). The subdivision is far from central Suva, public transport servicing the settlement is limited, and the accessibility of schools and other amenities have not been well considered (NCBBF, 2008b, p. 14 \& 18). Indeed in 2008 many plots remained empty. Recently, the HSRU has also been resettling some families to around 115 basic (not fully serviced) plots in Sasawira in greater Suva. This, however, is only seen as a temporary 'holding' option (M. Tupua, personal communication, November 13, 2008) and is even further from Suva than Waila 3B. ${ }^{44}$ Overall, it is fair to state that resettlement has not worked well in Fiji. Chung and ECREA conclude, for example, when summarising a resettlement scheme in Lautoka that: "the only real change may be that they are moved further away from job opportunities" (2007, p. 35).
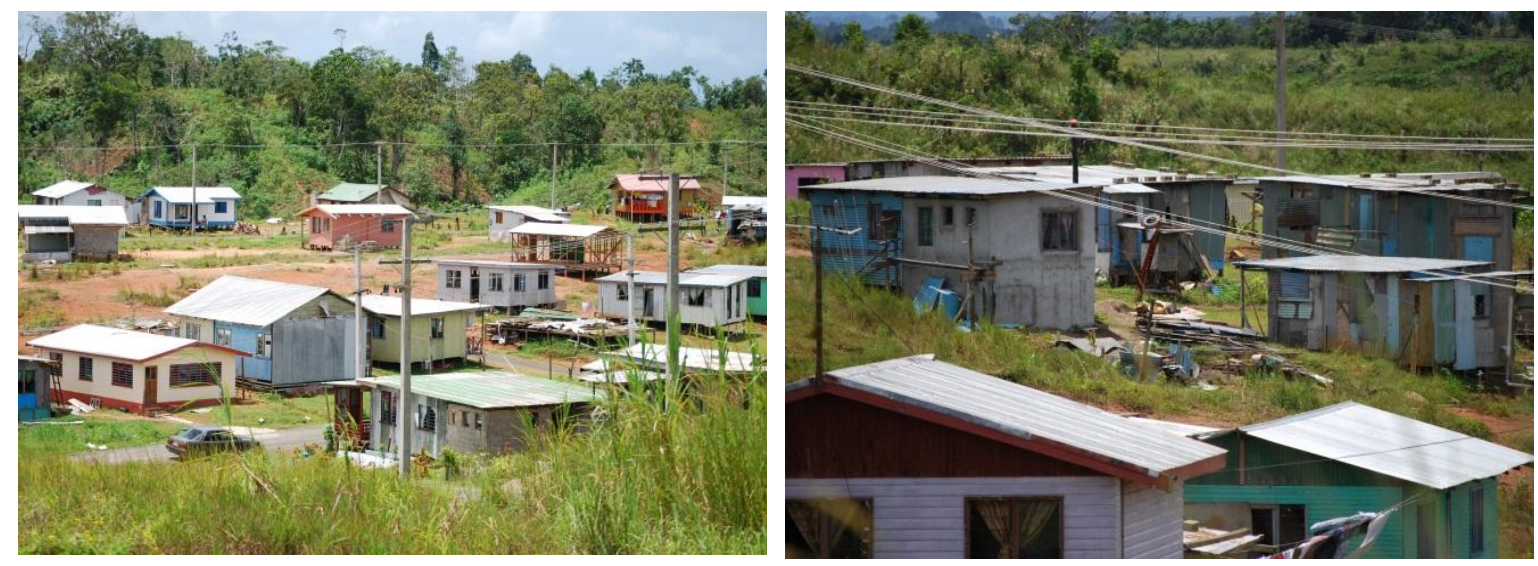

Plates 6.3-6.4. Relocated households at Waila 3B, February 2008. Photos: The author.

\footnotetext{
43 In 2011 , the HSRU was located in the Ministry of Labour, Industrial Relations, Employment, Local Government, Urban Development, Housing and Environment.

44 In the Western Division some resettlement of informal settlers is also occurring to the HA's Field 40 subdivision in Lautoka ("City plans", 2009).
} 
While the HSRU's focus has clearly been on resettlement, some notable upgrading schemes have been, or will be, trialled. These upgrading projects involve the formal subdivision of land, installation of infrastructure, and the selling of lots to previous residents or new applicants. In 2006, for example, the HSRU began a partnership with the Ba Town Council to upgrade an existing informal settlement on state land at Badrau. This was one of Fiji's first significant settlement upgrading schemes 45 that aimed to develop 80 serviced lots and to construct a significant feeder road (Caucau, 2006). The development, however, has been problematic and as of late 2008 the project was still affected by major contracting delays (T. Ram, personal communication, September 11 , 2008). More recently, the HSRU has also been working with the Ecumenical Centre for Research, Education and Advocacy (ECREA) to upgrade the community of Lagilagi in Jittu Estate in central Suva (which will be discussed later in the chapter). In general, however, past informal settlement upgrading schemes in Fiji have proved difficult. Chung and ECREA summarise that residents have often resisted the temporary relocations necessary (particularly as residents must bear the moving costs) (2007, p. 35). Applicants for new housing lots must also meet a number of criteria such as having a clean police record, normally being married, and being able to afford annual land rentals, dwelling construction costs, and utility connection fees. The government also has power to evict in the event of misconduct, disputes, overcrowding and noncompliance with regulations (ibid). Overall Chung and ECREA summarise that "[m] any households that move away to allow the upgrading to proceed are therefore unable to return" (ibid).

The HSRU also works with NLTB to develop tracts of native land as resettlement areas. The most significant NLTB partnership development in recent years aimed to develop a very large area of native land at Veikoba in Kalabu in greater Suva; targeting the creation of over 800 serviced lots (Caucau, 2006). However, the Veikoba initiative has been very unsuccessful. As of late 2008 the site was empty, access was difficult and needed the construction of a significant (and expensive) bridge, rumours of financial irregularities surfaced, frustrations with NLTB were emerging, the project had been dumped in the 'too hard basket', and development was halted (B. Lal, personal communication, November 7, 2008; NCBBF, 2008b, p. 20). Overall, HSRU's partnerships with NLTB have been hindered by the same problems as similar HA/NLTB initiatives. That

\footnotetext{
45 Other upgrading schemes that are recently completed, ongoing, or planned are in Wailea in central Suva Bangladesh and Vatoa in Nasinu, Lakena Hill One and Lakena Hill Two in Nausori, Clopcott Street in Ba, and Cuvu in Sigatoka (B. Lal, personal communication, November 7, 2008; Fiji Government Online, 2010; Lingam, 2007; Rina, 2010).
} 
is, as Walsh pointed out back in the 1980s: "NLTB has preferred to lease its land to wealthier clients who can pay high rentals. In turn the shortage of suitable land obliges the [Housing] Authority to develop difficult land at an ever increasing distance from the city and places of work." (1984, p. 199).

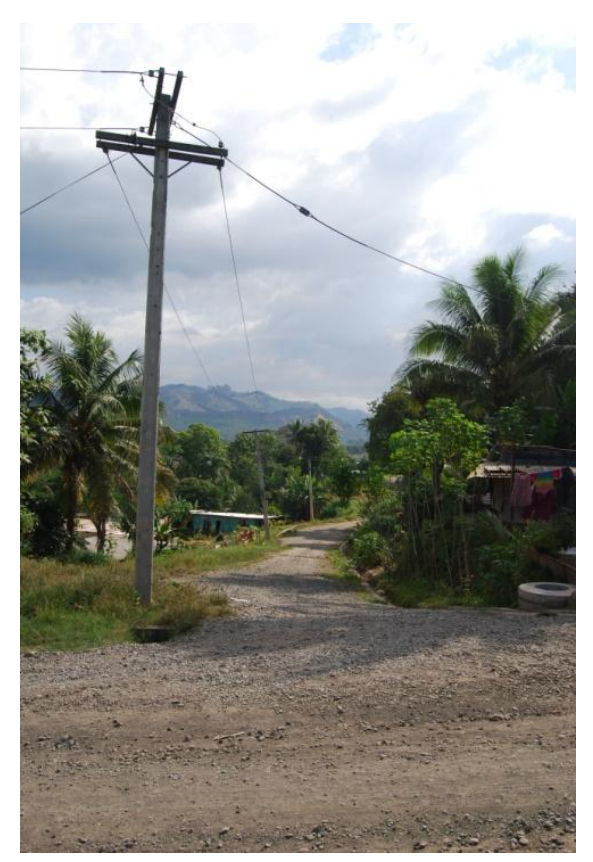

Plate 6.5. Partially finished upgrading at Badrau, Ba, September, 2008. Photo: The author.

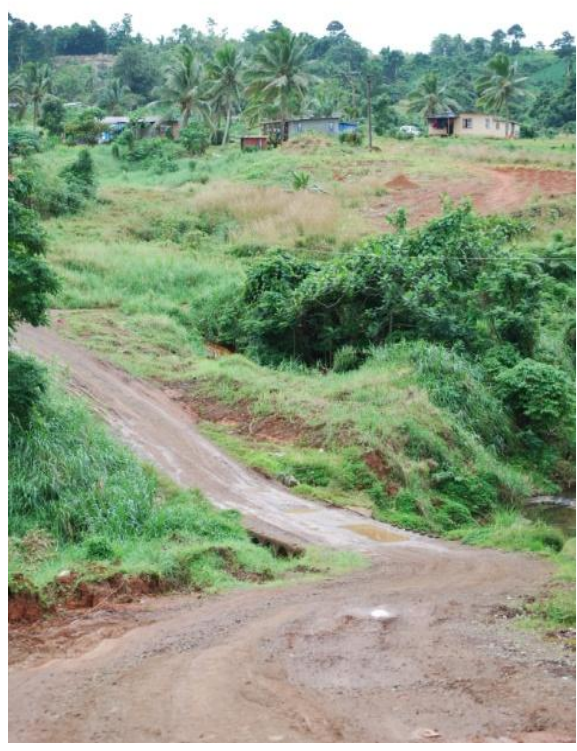

Plate 6.6. Access to the proposed Veikoba housing site, greater Suva, July 2008. Photo: The author.

The HSRU itself reports that its resettlement and upgrading function is limited by a shortage of suitable and affordable land, complexities in land tenure, and construction difficulties (cited in Chung \& ECREA, 2007, p. 34). In addition, frequent major funding shortfalls constrain the ability of the agency to perform its functions. For example, this annual funding varied from $F \$ 1$ million in 2007, to $F \$ 5$ million in 2008, to $F \$ 2$ million in 2009 (Callinan, 2007, p. 29; Fiji Government, 2007, p. 49 \& 2008, p. 87). The 2007 and 2009 figures compare to estimates by HSRU itself that funding of at least $F \$ 5$ million per year is necessary to better accommodate existing informal settlers and provide for new resettlement subdivisions (Chung \& ECREA, 2007, p. 35). Overall, it is still clear (2008 perhaps excluded) that "funding is totally inadequate vis-à-vis need" (Storey, 2006, p. 16). The HSRU is also caught between its policy directive to discourage new settlement growth, which it recognises conflicts with various international protocols and agreements that Fiji has signed, and the realisation that there are few alternatives for new lowincome urban migrants (ibid; Lingam, 2007, p. 13). 
The lack of adequate funding for the HSRU is reflective of the traditional government perspective on squatting and settlements in general. In 2007, a New Zealand Aid Programme (NZAP) study noted that the government did not appear to be aware of the scale of the shelter problem facing Fiji and argued that government commitment did not even come close to keeping pace with the growth of settlements. This report also argued that political will to improve livelihoods of informal settlements in Fiji was absent (McKinnon et al., 2007, p. ii \& 17). Barr (2007) elaborates on the traditional lack of political will to improve conditions for informal settlements in Fiji; arguing that there is a crucial need for broad attitudinal change. Barr writes that negative and insensitive attitudes have dominated discussions about informal settlements for too long (ibid, p. 21). Such attitudes are still reflected in the functions of the HSRU particularly in its policy directive to attempt to discourage new settlement growth (Lingam, 2007).

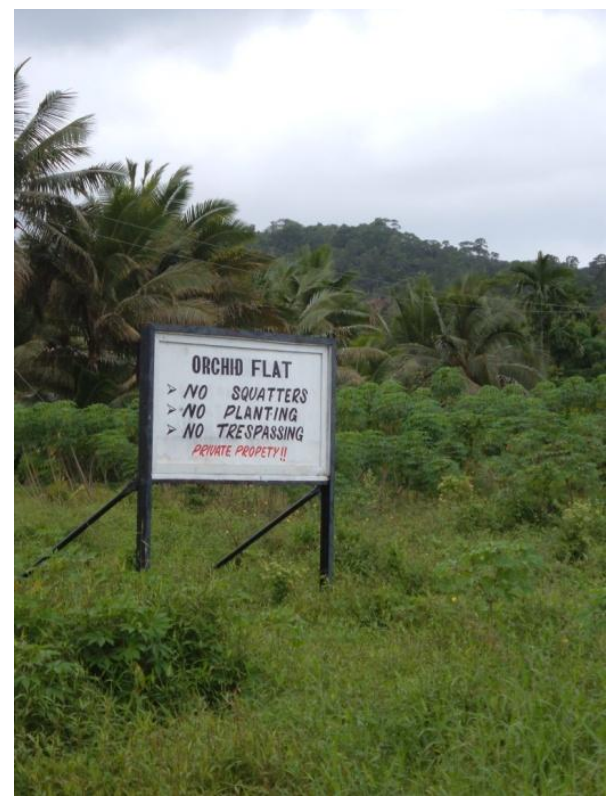

Plate 6.7. Sign deterring squatters at Orchid Flat, between Suva and Navua, Viti Levu, August 2007. Photo: The author.

Some recent developments in the low-income housing sector are, however, positive. The governing boards of the HA and PRB have merged in an attempt to improve coordination within the sector; although it is too early to see if this has improved overall strategic planning and the supply and accessibility of government-provided low-income housing. HA and PRB also plan major new developments over the next few years: HA to provide homes to over 5,000 extra families through the development of fully serviced lots and new home construction (Fiji Government Online, 2009); and PRB to build many more units. The HA and PRB plans are expected to be part-financed through a F $\$ 70$ million 
low-interest loan from the Chinese Exim Bank. Of this money, $\mathrm{F} \$ 50$ million is allocated towards HA construction at Tacirua in Nasinu (near the site of the stalled HSRU developments at Veikoba). This is expected to provide 1,500 serviced lots and 350 homes for sale to customers ("Authority outlines", 2009). F\$20 million is also allocated to PRB to build 500 multi-unit flats at Raiwaqa and Raiwai in central Suva replacing the units demolished in 2008. It is likely that the new Raiwaqa and Raiwai developments will include some commercial units (where monies generated can subsidise the residential rents) (M. Senibulu, personal communication, November 13, 2008). Despite the HA and PRB plans, 46 however, it is clear that these initiatives will still not come close to meeting the demand for low-income housing. Additionally, new HA developments and PRB units may remain unaffordable for those on low incomes. Finally, because these new housing developments will be funded through the Chinese loan, it is possible that strict conditions (such as around the use of Chinese labour and materials) may constrain local benefit, appropriateness, and innovation. ${ }^{47}$

The HA and PRB plans suggest that the Fiji government may be beginning to take the growing low-income housing crisis more seriously. Over the last few years awareness has slowly increased as to the challenges in the sector and need for coordinated action (Barr, 2008; NCBBF, 2008b). Despite this, however, evictions and strong eviction pressure continue for those living in informal settlements. Over the years 2008 to 2010, for example, many informal settlements have been forcibly relocated or have experienced pronounced and continuing eviction pressure from various sources.48 Indeed, in 2010 renewed eviction threats directed at settlers on state land from senior figures in the interim administration were widely reported in national media. These eviction threats

\footnotetext{
46 In early 2011 the Fiji government also began consultations to finalise a national housing policy. Major pipeline initiatives that have been flagged include: the 'Waila City' project, a joint project between the HA and a Malaysian construction company to build 5,000 housing units in Nausori; and price control mechanisms to reduce new hardware prices (and thus house construction costs) (Elbourne, 2011; Fiji Government Online, 201 1; "Government plans", 2011; "Housing unveils", 2011).

47 Recently, the China Railway First Group Company Ltd. was contracted for the construction of the new Raiwaqa and Raiwai flats under an agreement in which they will utilise more than $50 \%$ of local labour (Vula, 2010).

48 In the period 2008-2010 reported forced relocations occurred from: Kilikali Settlement in Nepali, Nasinu, to Sasawira (to make way for land development); Masimasi in Sabeto, Nadi (to make way for a planned school); Namara in Tacirua, Nasinu (due to planned HA developments funded by the Chinese loan); and freehold land at Naivitavaya, Laucala Beach, Nasinu. Strong eviction pressure in this period, as reported in the media, has also continued for families at: Muanivatu in central Suva (the Suva City Council, holding a lease for the land, wishes to use the land for a recreational park); Wailea in central Suva (the freehold owner, the Arya Pratinidhi Sabha, desires to use the land for an educational institution); Villa Maria in Suva (the Catholic Church of Fiji and Rotuma wants to use the land for a school); Vitoga and Drasa in Lautoka (issued with eviction notices by the HA); Nuvutu in Lautoka (Lautoka City Council wants to develop the land for an industrial estate); and Tavakuba in Lautoka (issued with eviction notices by HA) (Chand, 2010; "Church faces", 2009; "City raises", 2009; "City to", 2010; "Court rejects", 2010; Delaivoni, 2008; Elbourne, 2008; "Houses come", 2010; "Housing Authority", 2009; "No payout", 2009; "Relocated squatters", 2008).
} 
were also specifically directed at those settlers: involved in any illegal activity; earning above poverty levels; and involved in subletting activity within their settlements ("Jittu 'tenants'", 2010; "Squatters put", 2010; "Squatter squeeze", 2010; "Warning to", 2010).

\subsection{NGO Activities}

A number of NGOs also provide interventions targeted at informal settlers and the Fijian low-income housing sector generally including the Housing and Relief Trust (HART), Rotahomes, Habitat for Humanity Fiji, and ECREA. HART was established in 1970 by the Fiji Council of Churches and operates 748 apartments across Fiji for very destitute families with funding largely from government. HART tenants tend to be single parent families, elderly couples and others on very low incomes although residents are bound by strict codes of behaviour and must not have criminal records (Chung \& ECREA, 2007, p. 35). HART rents are very low, ranging between F $\$ 0.50-1.00$ per week for older units and F\$5 per week for newer units, and have not increased since the mid-1990s (HART, 2007, p. 3).

Rotahomes, a project of the Rotary Club of Lautoka beginning in 1985, has built close to 800 houses for low-income and destitute families in the Western Division of Fiji (Chung \& ECREA, 2007, p. 35). This organisation, with most funding from NZAP, is now building fully engineered community subdivisions. The first of these communities is Koroipita; 49 a village close to Lautoka on 15 acres of native land leased from NLTB (as a residential, 99-year lease). Koroipita consists of around 80 simple cyclone-resistant one-bedroom homes, community facilities (including a kindergarten, shop, office and playground), and income generation activities (including chicken coops and orchid growing). Access to the community is tightly controlled (new arrivals are assessed by Rotarians on a case-bycase basis) and must meet various guidelines such as having small families and clean police records. Rotahomes now plans a second stage of construction at Koroipita consisting of another 160 homes over a further 265 acres known as 'K2'.

\footnotetext{
${ }^{49}$ Koroipita translates as 'village of Peter' (Peter Drysdale is a leading Lautoka Rotarian driving the initiative).
} 


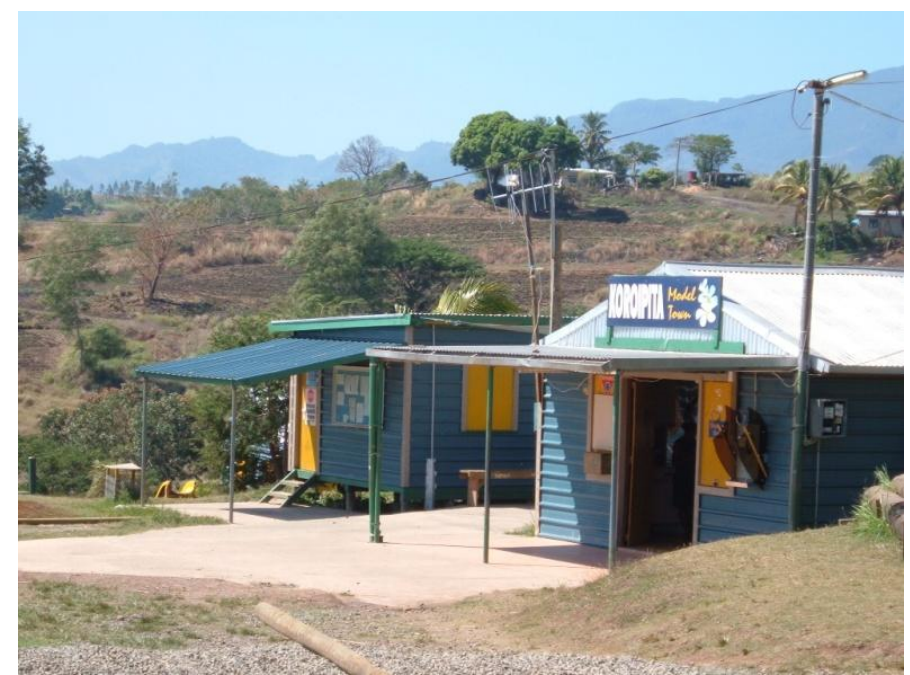

Plate 6.8. Community shop and administration building at Koroipita, August 2007. Photo: The author

Habitat for Humanity Fiji (HFHF) has operated since 1993, renovating and building simple homes in both urban and rural areas for lower and middle income families (who must be able to afford an upfront contribution and repayment plan). Housing costs (at approximately US\$10,000 for a two-bedroom dwelling) are reduced by grants, collaboration with financers, revolving community credit programmes, and 'sweat equity' aiding in construction (HFHF, 2010; R. Counts, personal communication, June 27, 2008). However, currently scale is very low, averaging around 20 new homes built each year (R. Counts, personal communication, June 27, 2008). As such, HFHF hopes to scale up its engagement in the sector, potentially collaborating with other actors such as HA, or even developing community subdivisions on native land leased via NLTB (ibid). From 2008 to 2009 HFHF also probed the feasibility of developing, with potential NZAP funding, two new villages on bequeathed rural land in the Western Division (each about 12 kilometres from Nadi) resettling and providing secure tenure for current informal settlers. The proposed project, however, was eventually discarded due to concerns about the appropriateness of the two sites (particularly due to their distance from most nearby employment opportunities, requiring relatively expensive public transport for those on low incomes) (HFHF, 2009).

ECREA is the most active NGO working in Fijian informal settlements. ECREA has programme activities in around ten informal settlements in the Lami-Suva-Nausori corridor focussing on empowering residents and improving dialogue with government and other stakeholders as part of its Economic Justice Programme. This programme of ECREA also facilitates a squatter network, called the Peoples' Community Network 
(PCN), of which 45 communities in the greater Suva area had joined by late 2009 ("Families have", 2009). The PCN aims to empower settlers by facilitating savings schemes and running various community programmes across its members (Koi, 2010; "Squatter groups", 2007). This work is important for raising the collective voice of informal settlers across Fiji, and potentially marks the beginning of a process that may challenge the negative attitudes and stereotypes that have traditionally pervaded government perceptions of informal settlers.

ECREA with the PCN is also beginning an innovative pilot project in Lagilagi in central Suva with the active participation of community residents. This project will look to upgrade the community and eventually provide over 100 new homes to participating residents (after a period of temporary resettlement in the wider Jittu Estate). Funding for this will be split between community contributions (many in the community have been saving collectively since 2003), the Fiji Government (which has allocated F\$1.4 million), and Misereor in Germany (which has provided around F\$1 million). Each new home at Lagilagi is expected to cost around $\mathrm{F} \$ 20,000-\mathrm{F} \$ 24,000$ to build and families will be expected to repay half of this amount (at around $\mathrm{F} \$ 18$ a week over 12 years). The repaid money is expected to form a 'revolving fund' that can be used, in time, to build more homes. A further feature of the Lagilagi pilot project is that the state has granted ECREA and the PCN a 99-year community lease.50 This means that individual families will not be able to speculate and profit from selling on individual leases. Rather, families moving out of the community will be expected to resell the house back to the community ("Ball rolls", 2010; Barr, 2009b; "Facelift for", 2010; "Families have", 2009; "House saving", 2009). As a new model of informal settlement upgrading in Fiji, the Lagilagi pilot is important - for if it is successful other PCN communities may be in line for similar housing schemes ("Ball rolls", 2010).

50 The 2.8 hectares of state land will be leased at a nominal rate of US $\$ 235$ per year (Asia Coalition for Housing Rights, 2009, p. 90). 

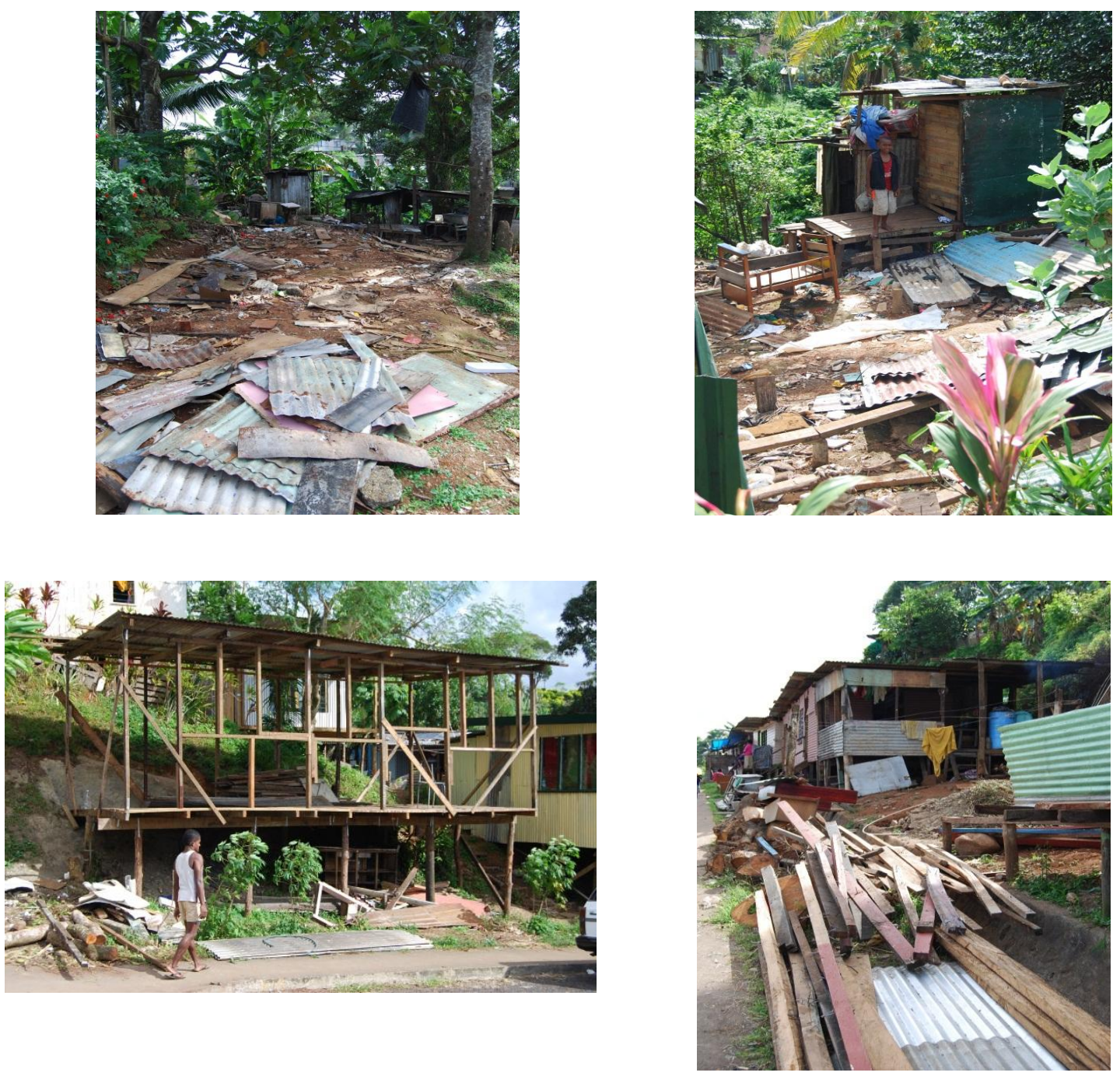

Plates 6.9-6.12. Temporary relocation of dwellings from Lagilagi to elsewhere in the wider Jittu Estate to allow for community upgrading, July 2009. Photos: The author.

\subsection{Donor and International Organisations}

A number of donor and international organisations have been, are, or will be active within the Fijian low-income housing sector and informal settlements including multilateral development banks, bi-lateral aid donors, and United Nations agencies. From 1990 to 1996 the Asian Development Bank (ADB) led a multi-donor approach (packaged to work closely with the World Bank, United Nations Development Programme (UNDP) and Government of Japan) focusing on the low-income housing sector. The ADB's Low-Income Housing Development Project looked to promote an incremental approach to housing development building from self-help activities of residents through the project's key aim of reducing housing standards and thus 
development and building costs for low-income housing subdivisions. However, despite developing the reduced standards and the implementation of some of these standards during the project, the new standards were not supported by an effective regulatory environment, policy development, key senior government figures, or adequate promotion, and subsequently fell out of use. Overall, official evaluation of the project rated it as unsuccessful. Indeed, over the course of the project the number of informally housed families grew rapidly and the ability of low-income earners to afford suitable housing was not improved (in fact became worse) (ADB, 1999). 51

Other international organisations that are likely to be active in Fijian informal settlements in the future include the New Zealand Aid Programme (NZAP) and the United Nations Human Settlement Programme (UN-Habitat). NZAP (as NZAID at the time) completed an informal settlements scoping study in 2007 looking to plan engagement in the sector. This study ultimately advocated: a pilot approach that emphasised regulatory change (including reduced building standards and reduced plot sizes for new subdivisions); participatory and community involvement in decision-making; capacity building; intervention emphasis at the local government level; and the potential design of a major loan programme that would build from the pilot projects (McKinnon et al., 2007). In 2010, NZAP, constrained by the turbulent political environment in Fiji and frosty relationships between the two countries, was still deliberating on plans for major intervention in the sector, although in situ upgrading and significant infrastructure projects have been flagged (R. Dirks, personal communication, August 19, 2010). As such, engagement in the last few years has focused on funding support to Rotahomes, HFHF and other NGOs active in informal settlements, 52 flood recovery efforts that have improved infrastructure in some informal settlements, and support to a Fiji Land Information System project that looks to map informal settlements (ibid).

UN-Habitat is also looking to begin a number of pro-poor settlement upgrading projects in greater Suva, Lautoka and Nadi (C. Radford, personal communication, July 25, 2007). As of mid-2010, however, these projects had not yet begun while UN-Habitat supported

\footnotetext{
51 In 2005, upon the recognition of adverse effects of sugar industry restructuring and land lease expiry, the ADB also approved the design of another major initiative in Fiji called the Alternative Livelihoods Development Project. This project looked to increase sustainable on-farm and off-farm livelihoods in Fijian rural sectors and aimed to reduce rural poverty and migration to urban informal settlements. However, the project never proceeded to its implementation phase as it was cancelled on the Government of Fiji's request in 2007 due to concerns with overlaps with other planned initiatives (such as the European Union's planned, but subsequently cancelled, sugar industry restructuring) and concerns with project design (ADB, 2009).

52 Such as Save the Children Fiji which runs early childhood education programmes in informal settlements and the Foundation for Rural Integrated Enterprises ' $N$ ' Development which runs a number of income generation programmes across Fiji - including in some informal settlements.
} 
ongoing efforts by the Ministry of Labour, Industrial Relations, Employment, Local Government, Urban Development and Housing to complete an urban profiling exercise and formulate a national social housing policy (S. Mecartney, personal communication, July 29,2010$)$.

\subsection{Challenges to Intervention}

Fundamentally, it is the scale of the emerging low-income shelter crisis in Fiji that poses the greatest challenges to effective intervention in the sector. The NZAP scoping study in 2007, for example, estimated that between 730 and 1,300 new households would be added each year to informal settlements over a fifteen year period, creating a shelter shortfall of over 30,000 dwellings in that time (McKinnon et al., 2007, p. ii). Current plans to create new HA plots and dwellings and PRB units, still commercially-orientated, will not come close to meeting projected demand. Additionally, as preceding sections of this chapter have identified, limited affordability further constrains access to adequate quality shelter - and many low-income residents cannot still afford a PRB unit or HA plot or dwelling. Despite repeated calls for reducing building standards (and thus development costs) for low-income housing subdivisions, this has not occurred53 (Storey, 2006, p. 16) and Fij's cities and towns remain starkly divided between formal and informal housing areas. The Fiji Government's HSRU is also limited in what it can achieve; inhibited by inadequate funding and, despite a few localised community upgrading projects, a focus on resettling informal settlers to less central areas.

As Chapter 3 identified, no Pacific Island nation has put in place effective guiding policy, a suitable regulatory environment, and appropriate institutional responses for managing continued urban growth (McKinnon et al., 2007, p. 6). Fiji is no different and urban growth continues apace without a guiding policy master plan. A national Urban Policy Action Plan and an Urban Growth Management Plan for greater Suva ${ }^{54}$ have been prepared and approved by various governments. However, these policy frameworks are still not actively in place. As such, a lack of coordination prevails with a wide variety of agencies responsible for managing urban growth active alongside a variety of

\footnotetext{
53 The Department of Town and Country Planning, responsible for approval of subdivision, development and building applications, has particularly resisted calls for reduced building costs or staged development (M. Tupua, personal communication, November 13, 2008).

54 These two strategic plans aim to achieve an efficient, effective and sustainable urban sector. Key objectives are: (i) expanding capacity of central and local government; (ii) improving urban infrastructure and services and affordable land supply; and (iii) emphasising responsive institutional, regulatory and policy frameworks for management of urban development (Ministry of Local Government, Urban Development and Public Utilities, 2007, p. 2).
} 
organisations providing piecemeal intervention in the sector. Responsibility for managing the urban growth of central Suva, for example, is shared by a plethora of organisations; including the local government authorities of Lami, Suva, Nasinu and Nausori, and also rural local authorities under the jurisdiction of the Ministry of Health responsible for the expanding peri-urban areas. Further, within the boundaries of each municipal area, urban management also involves the Department of Town and Country Planning, local planning boards, NLTB, HA, and individual landowners (World Bank, 2000, p. 18). Government at the local level also remains financially weak (McKinnon et al., 2007, p. 25), constrained particularly by nationwide difficulties in collecting rates (meaning local government has very little incentive to increase the size of town boundaries to encompass the burgeoning peri-urban informal settlement areas).

A turbulent political environment, including a current situation where decisions are made by decree (often without consulting concerned civil servants), also constrains intervention options. Local government, for example, is seen by NZAP, particularly in a climate of ongoing tensions between the New Zealand Government and the Fiji interim administration, as an appropriate level for engagement, relationship building and possible pilot projects (McKinnon et al., 2007). These plans were hindered, however, by a decision in early 2009 by the interim administration to remove elected mayors and councillors from local municipalities and replace them with appointed administrators (Fraenkel, 2010, p. 417), effectively eliminating the autonomy of local government. This change also prompted the postponement of a major initiative, coordinated by the Fiji Local Government Association, for municipal councils to jointly plan for major new lowincome housing developments and regularisation of some existing settlements (Fiji Government Online, 2008; "Projects on", 2009).

The location of much new informal settlement growth, on tracts of peri-urban native land (including land in native reserve tenure), is also one of the major barriers to intervention in the sector (Ward, 1995, p. 241). As mentioned, local councils have little incentive to intervene in areas outside their municipal boundaries and little incentive to increase these boundaries (which would only increase servicing obligations). It is also difficult for government to install services such as water, sewage and electricity on native land (AusAID, 2010, p. 14). Central state agencies, such as the HSRU, are also unlikely to intervene in settlements on native land, limiting their involvement to more central, older settlements on state land (particularly in central Suva). Suggestions have recently been made that informal settlements on native land could be formalised (Barr, 2009a, p. 7; 
NCBBF, 2008b, p. 24). However, this would be inhibited by the fact that landowners can obtain greater rents and control over the land with existing vakavanua arrangements than if the land was formally leased via NLTB. Further, some informal settlements are located on 'Class J' native reserve land (Ward, 1995, p. 241) (land that can only be formally leased if it were to be de-reserved with majority mataqali support); acting as an additional impediment to the prospect of formalising settlements on native land. As Chapter 3 also identified, the challenges of urban management, and possibilities of conflict (particularly between formal and customary systems of land use and institutions), are acutely pronounced in burgeoning peri-urban areas (Storey, 2003). Overall, the challenges facing the sector are vast. Indeed the recent Second Fiji Millennium Development Goal Report (covering the period 1999-2009) stated that it is unlikely that significant improvements in the lives of urban slum dwellers will be achieved by 2015 (Ministry of National Planning, 2010, p. 7).

\subsection{Summary}

It is increasingly obvious that a growing number of people in Fiji are now living as informal settlers in poorly serviced, inadequate housing with no legal security of tenure; areas that remain, for various reasons, the only viable option for many low-income urban migrants. It is also evident that major changes in approach and policy are needed to avoid a huge shelter shortfall in Fiji over the coming years. Massive shortfalls still exist in funding and commitment to low-income housing provision in Fiji. Despite the HA and PRB plans, government is clearly not doing enough at present, and attitudes towards squatters/informal settlers also need to change. Perhaps most importantly, strong political will to improve conditions in settlements needs to be present. The activities of NGOs and possibly donor and international organisations may reduce the gap between supply and demand for low-income housing and also improve general conditions for squatters/informal settlers. However, affordability constraints are likely to continue. Intervention in the sector is currently diverse but unfortunately not guided by overarching policy frameworks and is thus piecemeal in nature. Intervention activities in the sector, however, are important to document, particularly as they affect many informal settlers directly and indirectly and may influence perceptions of security of tenure.

In Fiji appropriate policy and adequate resources must be put in place to begin the huge, essential process of providing suitable shelter for all of the country's population. Understanding the processes influencing informal settlement growth and the nature of 
security of tenure and housing consolidation in Fiji in settlement areas can aid this process. The methodology underpinning the research is now detailed. 


\section{CHAPTER 7: RESEARCH METHODS}

\subsection{Introduction}

It is clear that Fiji is facing an emerging housing crisis as demand for low-income housing far exceeds supply, existing and new informal settlements in turn condense and grow on state, native and freehold land, and authorities, donors and civil society scramble to cope and intervene to improve conditions for the thousands of low-income urban families affected. It is timely that research documents the contemporary growth of Fijian informal settlements, assesses intervention activities in the sector, and, shaping the central research question and key objectives of the thesis, focuses on investigating the nature and nuances of security of tenure and housing consolidation within Fiji's informal settlements.

The research is positioned amidst a broader literature addressing the underlying processes behind informal settlement growth, informal settler behaviour, and international housing policy and practice. As Chapter 2 revealed, this literature tends to be divided into two principal debates: (i) property rights approaches to tenure security that largely extol the benefits of legalisation (or titling) as the prime means of intervening in the tide of growing informality; and (ii) 'perceived security of tenure approaches' or simply 'tenure security approaches' that accept that tenure security is more complex than the formality/informality and legal/illegal dichotomies prevalent in property rights approaches suggest. The current research aligns most closely with the second perspective. This body of literature saliently argues that: (i) a more contextualised understanding of all variables that may influence a feeling or personal experience of security or insecurity of tenure is needed; (ii) a range of tenure categories typically exist as a continuum in any context; and (iii) households may engage in processes thought vital to addressing growing informality (such as 'self-help' housing consolidation) in the absence of any legal security of tenure. These key considerations have guided the objectives and methodology of the current research.

To date, most of the research looking to investigate the dynamics of informal settlements and suggest policy through a perceived security of tenure framework has been through settlement case studies in Latin America, Asia, and sub-Saharan Africa. The framework has not been applied to a small island developing state context of dominant customary 
land. The Fijian and Pacific location of the research also places discussions within a historical but ongoing debate in the region, summarised in Chapter 3 , that tends to either: (i) argue that customary tenure in the Pacific acts as a barrier to 'development' and that rather individual, largely freehold tenures and subsequent land reforms should be pursued; or that (ii) traditional customary foundations of land tenures remain appropriate and indeed still vital in the region. Perceived security of tenure approaches align more closely with the second regional perspective; specifically recognising the difficulties and unintended consequences of legalisation interventions and building on existing tenure systems such as the customary foundations of land in the Pacific.

This chapter will firstly focus on explaining the key methodology, and underlying epistemology, behind the choice of research approach. Key methods informing the primary and secondary research objectives will then be explored before the fieldwork itself will be detailed and subsequent shape of data analysis introduced. The chapter will finally explore the limitations and biases of the methodology and methods employed.

\subsection{Methodology and Epistemology}

As the methods section below will reveal, mixed-methods research was conducted in the course of long-term field immersion in Fiji. Investigations across seven case-study communities utilised in-depth semi-structured interviewing with households in informal settlements and my own observations. A number of informal interviews were also held with key informants from government, civil society, donor and international organisations, and academia. Census data, and other information from various secondary sources, were additionally used to aid presentations, explanations and interpretations. The use of mixed methods allows a fuller picture to emerge than would the use of a single method alone.

At the very core of this research lies a pragmatic orientation to enter and engage in the ongoing debate and process of suggesting options and possible policy for improving security of tenure in informal settlements and addressing an ongoing and intensifying low-income housing crisis in Fiji. Overall, the research has a focus on producing changes in policy and positive social change. The research draws from the epistemological perspective of critical realism. Realism accepts that there is an external reality (independent of knowledge and descriptions of it) worthy of attention and attempts to 
investigate the underlying mechanisms and structures of social relations - or the 'building blocks' of reality (Bryman, 2004, p. 12; Kitchin \& Tate, 2000, p. 15). Critical realism, a specific form of realism, attempts to recognise the reality of the natural order and the events and discourses of the social world. Critical realism holds that to understand, and change, the social world, identification of the structures at work (or mechanisms of policy and practice; or 'generative mechanisms') that generate these events and discourses is necessary through the practical and theoretical efforts of social science (Bryman, 2004, p. 12). Critical realists believe that there are many unobservable features of social life (the 'generative mechanisms' described above) that can be revealed in order to aid in explanations of the existence, reproduction and transformation of social phenomena (Frauley \& Pearce, 2007, p. 4). Overall, critical realist approaches do not accept that an investigator's conceptualisation of reality directly reflects that reality (as positivists do, for example), but argue that such conceptualisations are only one way of knowing that reality. It is the focus on change, however, that really sets critical realism apart. As Bryman writes: "[w]hat makes critical realism critical is that the identification of generative mechanisms offers the prospect of introducing changes that can influence the status quo" (ibid, emphasis in original). And as Bassett and Gregory elaborate: the critical aspect of critical realism "lies in the belief that bringing underlying structures and their unconscious reproduction to the level of consciousness opens the way for emancipatory critique and social change" (2009, p. 622).

This research adopts a critical realist epistemology for a number of key reasons. As I have mentioned above, the research aims to influence policy and practice; and as such looks to help generate positive change. In order to produce change the research aims to recognise the underlying mechanisms, structures, events and discourses that affect social relations, practice, general livelihoods, and indeed security of tenure and housing consolidation within informal settlements. As a Western, educated, privileged, monolingual visitor to Fiji, I believe it is impossible for my conceptualisation to fully reflect the reality of the daily struggle, and often grinding poverty, of life in informal settlements. A research epistemology informed by critical realism, however, does enable descriptions, interpretations and possible explanations to be made in the interests of introducing change. Critical realism, while not prescribing the use of a particular methodology, also supports the use of qualitative research and mixed-methods (Bassett \& Gregory, 2009, p. 622). The reality of the daily struggle of thousands of informal settler households in Fiji is hard to ignore. Further insight is needed into the generative mechanisms influencing the natural and social order within informal settlements. Positive 
change, and policy to help direct this, is also necessary to begin to ameliorate a growing shelter crisis in urban Fiji.

\subsection{Methods}

The completion of in-depth semi-structured interviews with informal settler households in the seven case-study communities formed the principal research method utilised. These interviews, along with my own observations, were used to explore the central research question and primary research objectives; which aimed to investigate the nature of security of tenure and housing consolidation in the case-study communities. Two of the three secondary research objectives also required additional research methods. Firstly, the research looked to document the contemporary growth of informal settlements. A number of key secondary sources were utilised here; including early data releases from the 2007 Fiji census (which the Fiji Islands Bureau of Statistics made available directly). Secondly, the research looked to explore the extent of intervention within informal settlements and the low-income housing sector more broadly (the focus of the previous chapter). Here, a number of informal interviews were held throughout the fieldwork with key informants from various stakeholders within government, civil society, donor and international organisations, and academia. A summary list of these key informants is included at Appendix 1. These interviews were unstructured and focused on: (i) exploring the extent of current and planned intervention in the sector; (ii) identifying previous research and data of relevance; and (iii) broadly aiding the ongoing refinement of the research approach. I also gathered articles from the mainstream media to help explore the extent of intervention in informal settlements.

\subsubsection{The Field Study}

The main period of fieldwork occurred over five and a half months between June and November 2008. This was preceded by two earlier one-week scoping visits to Fiji in August 2007 and February 2008. These early visits were used to familiarise myself with the local context, obtain secondary data, meet stakeholders, build relationships with key contacts, identify possible case studies, and refine research options. The principal period of fieldwork was also followed by a one-week visit to Fiji during July 2009 which was used to follow up and obtain additional key secondary data, briefly revisit Viti Levu case-study communities, and obtain an update on sector intervention activities. 
Five and a half months were allocated for the main period of fieldwork as I felt that a number of months in the field would be necessary to enable contacts to be established, trust and rapport to be established with key informants, and simply manage the logistics of interviewing in seven case-study communities across Fiji. The initial six weeks of fieldwork were used to interview stakeholders, build relationships with key contacts, and select case studies. In this period I liaised closely with the NGO the Ecumenical Centre for Research, Education and Advocacy (ECREA). ECREA was engaged in establishing the Peoples' Community Network (PCN); a network of informal settlements across the Lami-Suva-Nausori corridor that aimed to raise the collective voice of informal settlers, encourage community saving, and ultimately initiate community upgrading projects. Through ECREA I was introduced to key PCN contacts in communities in the Lami-SuvaNausori corridor, and they were also able to pass on key initial contacts in communities in Lautoka, Ba and Labasa. Other key institutional contacts during the period of fieldwork included the University of the South Pacific (I was attached to the Development Studies Program for the duration of my fieldwork) and the New Zealand Aid Programme (NZAP) (NZAP were looking to refocus their bi-lateral aid programme in Fiji towards informal settlement interventions - and provided some funding to support the fieldwork).

\subsubsection{Case Study Selection and Access to Participants}

Seven case-study communities were selected (three in greater Suva (Central Division), two in Lautoka and one in Ba (Western Division) and one in Labasa (Northern Division)). I felt that a range of case studies would be necessary to reflect the true diversity of informal settlements in Fiji. The communities selected covered the nation's three principal administrative divisions ${ }^{55}$ and represented a spread of primary land tenure, community size, ethnicity break-down, urban and peri-urban location, and government and civil society intervention level. ECREA aided in the selection of case studies within greater Suva and facilitated introductions with individuals who became my key contacts and community gate-keepers in these settlements. These individuals were all PCN representatives in their respective communities and formed key initial informants. As already mentioned, ECREA also provided key initial contacts in the towns of Lautoka, Ba and Labasa who were then able to direct me to other individuals within individual informal settlements in these areas. Short early visits were then made to the Western

55 Much of the previous case-study research in informal settlements has occurred only in settlements in greater Suva. 
Division and Labasa to meet with these individuals, select case-study communities, and prepare for longer visits later in the fieldwork. Two later visits to the Western Division and one visit to Labasa were then undertaken to complete interviewing in these areas.

Prior to interviewing, introductory sessions were held with my key contacts in each community (in one case approval from a landowner was needed prior to any interviewing). In these sessions I explained my background, purpose and affiliations. These sessions were also used to gather key basic community history and data, and were usually followed by a 'guided tour' of the settlement. After these initial sessions, individual interviews were arranged with each key community contact. These key informants then provided introductions to other households who could then be interviewed. Overall, because of the need to establish contacts and build trust and rapport within communities, there was a necessary slow start to the fieldwork. As such, it was not until the forty-second day of the fieldwork that the first household interview was conducted. Soon after the first interviews were made, however, the process began to 'snowball'. In six of the seven case-study communities, participants were a mixture of key informants (my initial contacts), introduced contacts, and more random informants (who I personally met during my visits to communities). Sampling was purposeful in these six larger case-study settlements; guided by time and participant availability. In the seventh case study (the very small community of Bouma in Labasa) sampling was almost representative as I was able to interview 15 of the 16 households in the settlement.

\subsubsection{Interviewing}

The research required a depth of insight about informal settler experience, perception, behaviour, and motives that was best facilitated by interviewing aimed as extracting rich, detailed qualitative information. Interviews also focused on gathering basic quantitative demographic and socio-economic data from each participating household; information necessary to help form a profile of each community. In-depth semi-structured interviews with household heads (both men and women) were the most appropriate method to obtain the necessary data. Each interview included a number of structured specific questions that were asked in all interviews to obtain the demographic and socio-economic data needed to form community profiles. In addition, each interview was guided by a number of unstructured questions and themes to explore participant experience, perceptions, behaviour and motives. The unstructured part of each interview enabled flexibility and sessions could be varied in 
approach according to the individual experience, interests, and views of participants. The guiding template used for each household interview can be seen at Appendix 2.

Interviews, after introductions, proceeded in informal environments; sometimes around the tanoa (kava bowl) and almost always accompanied with sweet cordial or tea and snacks (I always offered a small contribution such as a packet of biscuits). All interviews occurred within, or just outside, participants' homes. Only in unusual circumstances were interviews one-on-one; in most cases family members, neighbours and/or friends were also present and many of these people also participated. Overall, the level of informality helped break down barriers between researcher and participants and promoted conversation. The interview approach enabled participants to freely express their experience and views in their own words. I was able to encourage wide ranging discussions, explore unforeseen avenues, clarify uncertainties, and explore certain issues more thoroughly. The interviews provided scope for richer, detailed testimonies, and more sensitive and people-centred discussion environments promoting participants to be free and frank. In effect, interviews proceeded more as discussions and the level of informality seemed appropriate for the Pacific context. Overall, with the interview approach, I did not attempt to represent without fail the worlds of participants, but rather to facilitate an interpretation of the experience, perception, behaviour and motives of participants.

Interviews only proceeded after ethical approval, involving the participant reading (or being guided through) an information sheet, having the opportunity to ask questions, and then signing or verbalising their informed consent. The information sheets and consent forms used for the ethical approval process can be seen at Appendix 3. I emphasised the confidential and anonymous nature of interviews to participants carefully. Having taken the decision not to employ interpreters, 56 all interviews were undertaken in English (in a few small cases in each interview with indigenous Fijian participants Fijian was used to articulate some cultural concepts). In some cases a family member, neighbour or visitor acted as an interpreter if the prime interviewee was not fluent in English. Interviews often lasted between 45 minutes and two hours. Many interviews were conducted during evenings and weekends, although the majority occurred during working hours (which had the advantage of enabling many women to participate as prime household interviewees). A tape recorder was not used, but notes

56 This was mainly for practical reasons as the cost of hiring interpreters for all interviews (and across the dispersed case studies) would have been prohibitive. 
were taken. Overall, I completed twenty household interviews in each of the six larger case-study communities and 15 interviews in the small settlement of Bouma in Labasa (135 key informal settler household interviews were completed in total). A gender profile of prime interviewees can be seen at Appendix 4. This shows that $57 \%$ of prime interviewees were women and $33.33 \%$ were men (in $9.66 \%$ of cases members of both sexes were jointly participating as interviewees).

A key component of each interview centred on investigating the nature of participants' perceived security of tenure. I explored this in a variety of different ways. For example, when investigating eviction threats I would normally ask questions such as: 'Do you feel threatened by eviction?', 'Has anybody tried to make you move?' and 'Have you had any problems with the owner of the house or land?' I would also ask a number of questions around the concept of 'security' such as: 'What does security mean to you?', 'Do you feel secure or insecure?' and 'What does security of tenure mean to you?' In all interviews I also asked participants to indicate their level of security of tenure on a tenpoint scale. In many cases I would need to explain the concept of security of tenure; thus would usually explain it as 'protection from eviction' and/or meaning that 'you can stay on this land for as long as you want'. For indigenous Fijian participants I often explained security of tenure through the concept of vakadeitaki; loosely translated in English as having some assurance that it is possible to stay on the land as long as a household may want. In all interviews I finished by asking participants to suggest options for improving security of tenure.

A second central part of each household interview explored the nature of housing consolidation. Here I would explore: (i) all dwelling improvements that had been made after arrival in the settlement (and their dates, costs and financing); (ii) the motivation behind any improvements (or reasons why no improvements had been made); and (iii) participants' planned and desired improvements. My own observations on the nature of the dwelling were also used at this point.

\subsubsection{Reflection and Analysis}

Throughout the period of fieldwork I maintained a daily journal. I used the journal to record my thoughts and reflections and note issues, points and themes as they arose during the course of interviewing and fieldwork in general. The journal was also used to 
help fine-tune my research approach and record relevant happenings as they were reported in the mainstream media.

At the end of each day in the field I would carefully go through my notes from each interview - tidying, organising, and noting from memory supporting information that was not originally documented. An important part of this process was making an initial call on the interviewee's perceived security of tenure - in particular whether this was positive, negative, not positive or negative, or uncertain (this was, of course, a very subjective call on my behalf). If I noted perceived security of tenure as uncertain it was normally when a number of contradictory statements had been made during discussions, and/or when, in a very small number of cases, I was unable to convey the meaning of security of tenure effectively. Finally, at the end of each day in the field I would also go through notes from each interview and consolidate key information - including summarising each household's current tenure status, length of community residence, previous location and tenure, reason for move, average monthly income, quality of dwelling, and history of housing improvement. I would also note any payments that households made to access the land and/or dwelling. This summary information aided what was essentially a process of ongoing analysis that began during the fieldwork period.

Upon return from the field I continued analysis by working through interview notes slowly and systematically; noting ideas, issues and common themes as they emerged. I also slowly extracted and organised verbatim quotations from my research notes. I additionally extracted the basic household demographic and socio-economic data from each household interview, consolidated this to form a community profile of each case study, and in turn consolidated this data across all seven case studies. Fundamentally, analysis was ongoing and involved a continued re-reading of research notes in the search for particularly pertinent information, commonalities and themes.

\subsection{Limitations and Potential Biases}

All research aimed at extracting qualitative information, perhaps particularly true for cross-cultural developing country contexts, inherently presents limitations and potential biases. The positionality of the researcher, individually and in relation to participants, can produce potential bias. As Winchester has written: geographers "represent others through their words, but mediated by our own words, knowledge, experience and power" (1996, p. 129). It becomes essential to recognise that a researcher's identity and 
positionality shapes representations of the views and worlds of others and interpretations of findings (Baxter \& Eyles, 1997, p. 505). A researcher's position of relative power will also shape interactions with participants (Valentine, 1997, p. 113); particularly important to recognise in developing country contexts.

A reflexive consideration of how knowledge is produced in interview situations is important in qualitative research (Baxter \& Eyles, 1997, p. 510). Qualitative research can be highly susceptible to subjective biases from the researcher and is always explicitly and implicitly informed by a researcher's individual experiences, aims and values (Debus, 1995, p. 3). Katz writes that the "research relationship is a peculiar relationship unequally initiated, situationally lop-sided, temporarily polluted, extrinsic in purpose - it oozes with power (as cited in Valentine, 1997, p. 114). Inherent dangers also exist in qualitative research of investigators making assumptions, value judgements and misinterpretations (Valentine, 1997, p. 113). These potential biases form important recognitions in research extracting qualitative information and when attempting to facilitate an interpretation of the experience, perception, behaviour and motives of participants.

Limitations and potential biases characterised the field study. Firstly, the case-study research approach constrains the potential for generalising beyond the targeted communities. However, this is mitigated to some extent by the selection of seven, diverse case-study settlements. 57 Secondly, in the larger case-study communities I only interviewed 20 households in each settlement; a fraction 58 of each community. This also limits the potential of generalising across, and beyond, the case-study settlements. However, the use of mixed methods and, as Baxter and Eyles note, information on participant selection and the use of verbatim quotations are important means of ensuring rigor in research relying on small samples and qualitative information (1997, p. 506). Demographic and socio-economic information have also been provided for each case study from the sample and whole-community census information for five of the six larger case-study settlements has also been provided.

\footnotetext{
57 Although I did not work in a community on freehold land or a majority Melanesian settlement; both of which would have been useful in an ideal research scenario.

58 The percentage of community households interviewed (when compared to 2007 census information on household numbers) was 3.5\% in Tomuka, $10.5 \%$ in Lakena Hill Two, $12.5 \%$ in Tauvegavega, $13.5 \%$ in Caubati Topline and $20.5 \%$ in Lagilagi. Around $40 \%$ of households were interviewed in Vunato (no census data is available for this community) and 15 of 16 households, $94 \%$, were interviewed in Bouma.
} 
Sampling in the six larger case studies was not random, but largely purposeful with many interviews set up via introductions. This may have meant that introduced participants were perceived by those making the introductions as willing to be interviewed, possessing good English, and 'interesting' to the researcher. As in much development and cross-cultural research, my position as a foreign, English-speaking, white, male, privileged student also shaped power and interview relationships (Scheyvens, Nowack \& Scheyvens, 2003; Scheyvens \& Storey, 2003) and may have inhibited the transfer of some information (along with the sensitive nature of some discussions; such as when exploring all household income streams, access to land and housing, and payments to land and housing owners). Having mentioned this, however, almost all participants seemed very open about describing their experience, perception, behaviour and motives. This was aided by the research strategy of ensuring informal interviews and interview environments and the effort that I made to ensure that I was welcomed in communities (through introductions to gatekeepers). In short, I aimed to approach interviews and all research environments with a very sensitive and respectful manner.

All interviews were conducted in English. This normally worked fine (English is widely spoken across Fiji - particularly in urban areas) although, as mentioned earlier, sometimes a family member, neighbour or visitor acted as an interpreter if the prime participant was less than proficient in English. As was also mentioned earlier, 'security of tenure' was often quite a difficult concept to convey (particularly in a cross-cultural environment); and I had to communicate its meaning in a variety of different ways (in a small number of cases unsuccessfully).

One of the reasons why security of tenure was a difficult concept to convey was due to the complexity and varied meanings of the term 'security'. 'Security', for example, can relate to land tenure, but also to personal safety and the law and order situation (personal security), and it also can have financial and spiritual connotations. In some cases, for example, it became evident that participants were discussing personal security rather than land tenure security (as later sections of this thesis will elaborate on, personal security may indeed influence housing consolidation and security of tenure in general). Additionally, in the Fijian context, perhaps particularly for Indo-Fijians, 'security' is a very loaded concept; and many Indo-Fijians I met used expressions of insecurity to describe their general position within Fijian society. Pangerl, for example, has previously noted that in his ethnographic research in Suva and Sydney (on Indo-Fijian emigration) "the language of insecurity was omnipresent in describing socio-political and every day 
realities in Fiji" (2007, p. 251) and argues that "[i]nsecurity and uncertainty were ... symptomatic of the Indo-Fijian experience from its inception" (p. 253). The encompassing spread of notions of insecurity for Indo-Fijian participants certainly influenced discussions and clouds analysis.

Finally, the methods chosen only begin to look at the nature of housing consolidation in Fijian informal settlements (discussions focussed on exploring the history, motivations and financing of improvements rather than systematically indexing and comparing the size and quality of dwellings for example). This means the research will only begin to investigate the fourth key objective of this research: the nature of the relationship between perceived security of tenure and housing consolidation. As Chapter 11 will discuss, for example, a number of other variables ideally would be isolated in investigating this relationship (such as income levels, length of residence in the community and natural hazard risk).

\subsection{Summary}

The current research, positioned within an international debate on the merits of property rights when intervening amidst escalating informality and a regional debate around customary land in the Pacific, investigates the nature, dynamics and nuances of perceived security of tenure and housing consolidation within Fiji's informal settlements. A case-study approach extracting a mixture of quantitative and qualitative information from in-depth semi-structured interviews with informal settlers was the most appropriate primary research method; providing basic demographic and socio-economic data for seven communities and richer, detailed testimonies on the experience, perception, behaviour and motives of informal settlers. Observations, informal interviews with stakeholders intervening in settlements, and the use of key secondary data (such as census information) accompanied household interviewing - and enables a fuller picture to emerge.

While the research does have inherent limitations and biases; it is hoped that findings can help produce change and specifically suggest policy options for improving security of tenure in informal settlements and for beginning to address the low-income housing crisis in Fiji. The research epistemology, methodology and methods chosen allow descriptions, interpretations and possible explanations to be made when investigating the central research question and primary and secondary objectives of this study. 
Grinding poverty and an ongoing struggle are symptomatic of life for many in Fiji's informal settlements. If a growing shelter crisis is to be ameliorated, data-rich information and detailed personal testimonies are needed to gain better insight into livelihoods, security of tenure and housing consolidation in informal settlements. It is hoped that the current research can aid this. 


\section{CHAPTER 8: THE CASE STUDIES}

\subsection{Introduction}

Seven urban informal settlements from across Fiji were chosen as research case studies. In the Central Division of Fiji, and specifically the greater Suva area, the case studies selected were the communities of Lagilagi in central Suva, Caubati Topline in Nasinu, and Lakena Hill Two in Nausori. In the Western Division the settlements of Vunato and Tomuka in Lautoka, and Tauvegavega in Ba, were selected. Finally in the Northern Division the small community of Bouma in Labasa was chosen. As was mentioned in Chapter 7, a range of case studies were selected to reflect the diversity of informal settlements in Fiji. The location of the research case studies can be seen in Figures 8.1 and 8.2 below.

Figure 8.1. National Location of Case Studies

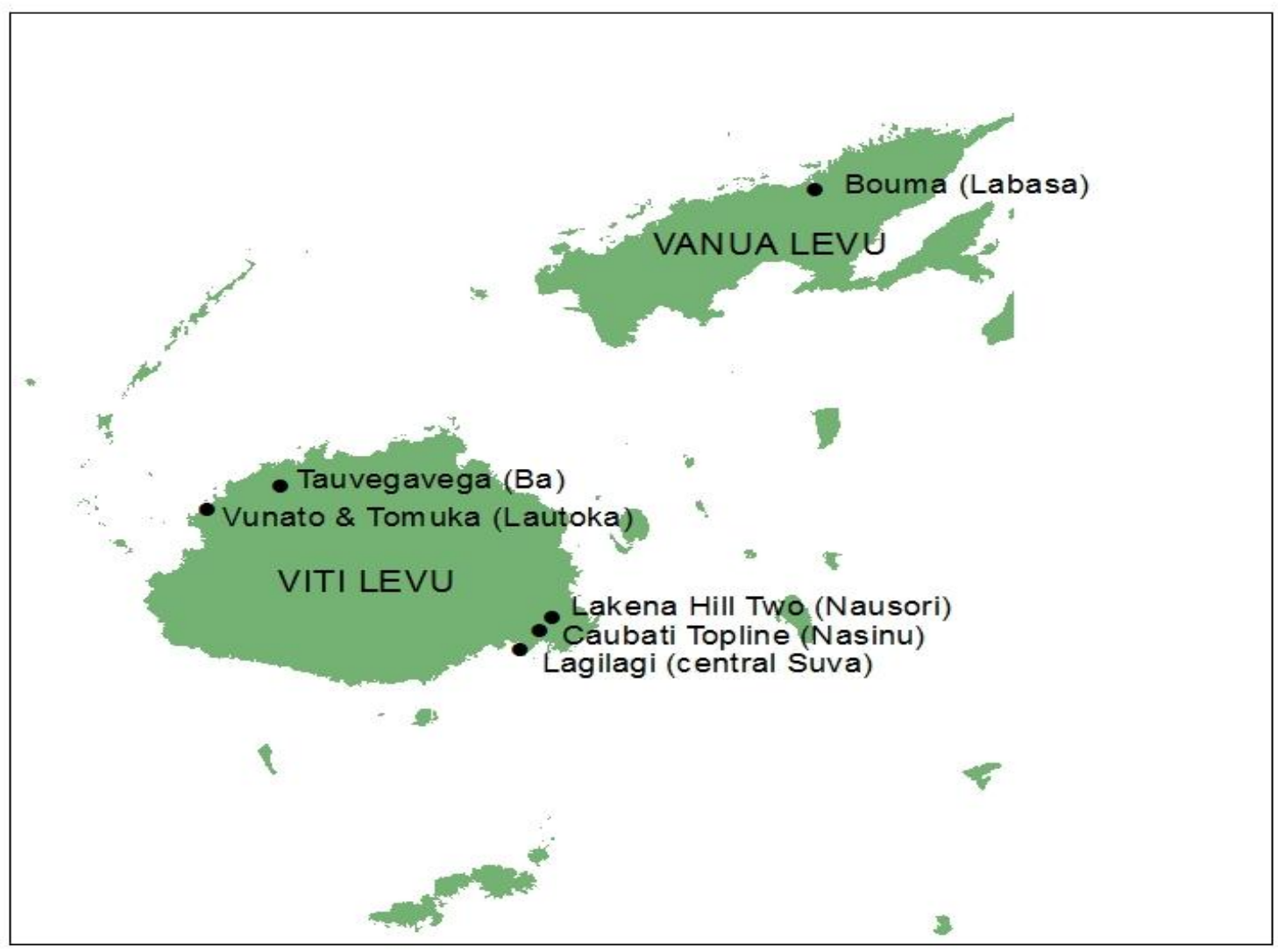

Source: Drawn in ArcGIS 
Figure 8.2. Location of the Greater Suva Case Studies

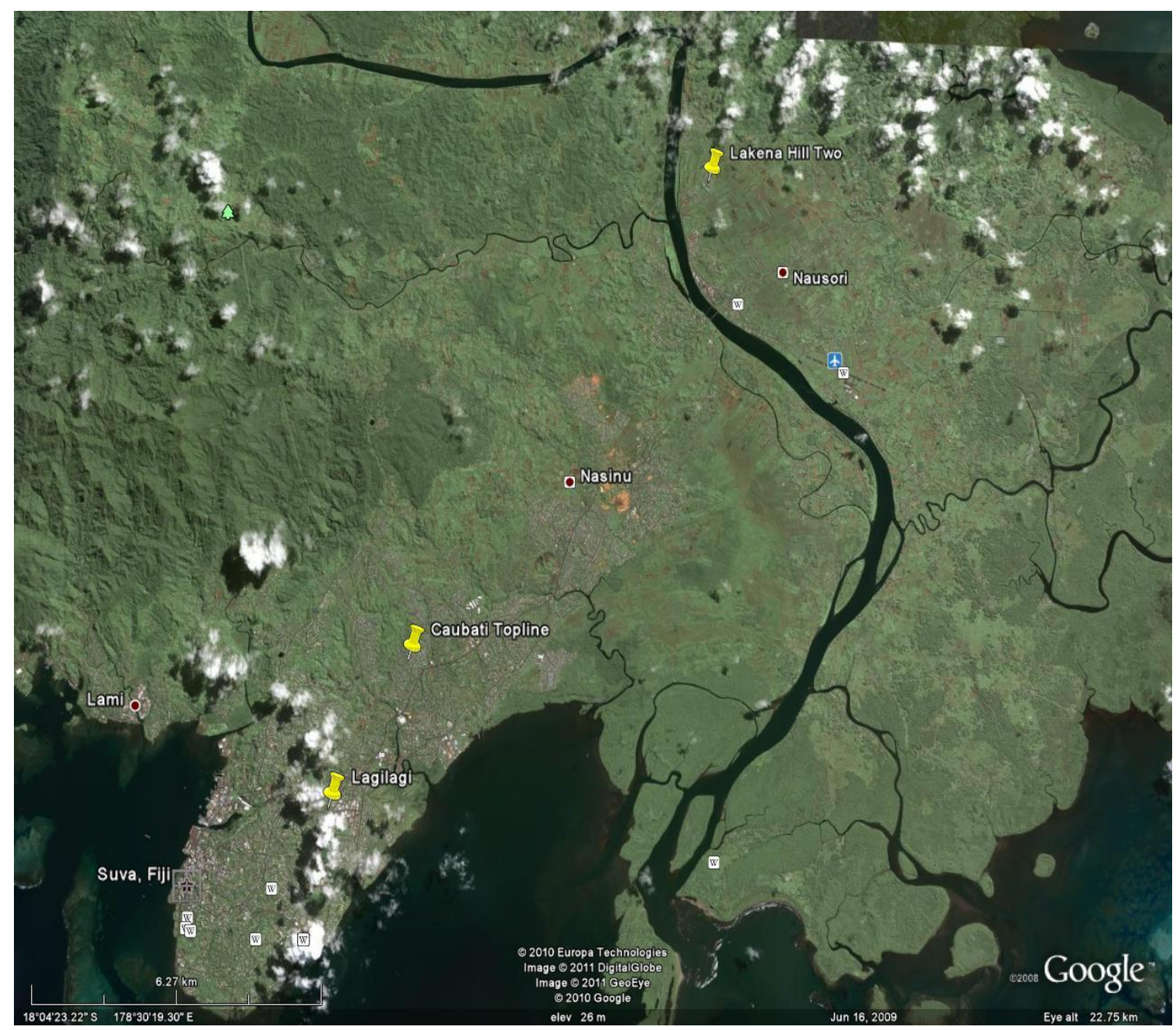

Source: Google Earth

Four of the research case studies are located on state land (Lagilagi, Caubati Topline, Lakena Hill Two in greater Suva and Bouma in Labasa). Vunato, Tomuka (both in Lautoka) and Tauvegavega (in Ba) are located on native land; and the first two of these settlements are accessed via informal, vakavanua arrangements with landowners. All communities, with the exception of Vunato (which is $100 \%$ indigenous Fijian), are ethnically diverse; with indigenous Fijian and Indo-Fijian residents. In factors such as community size, length of occupation, and government and civil society intervention level the case studies were, in general, differentiated and diverse.

This chapter aims to detail the nature and characteristics of the selected case studies. Firstly, basic settlement demographic information will be tabulated. Secondly, the distinctive features of each community will be introduced and satellite and 
photographic images will be displayed. Secondly, the chapter will thematically discuss key features of the case studies; linked to single settlements, and also common across a set of communities. Overall, this chapter aims to provide essential context before detailing the key results from the research. Some of the case-study features and themes introduced in this chapter will be discussed further in later chapters. 
Table 8.1. Key Summary Basic Data: All Communities

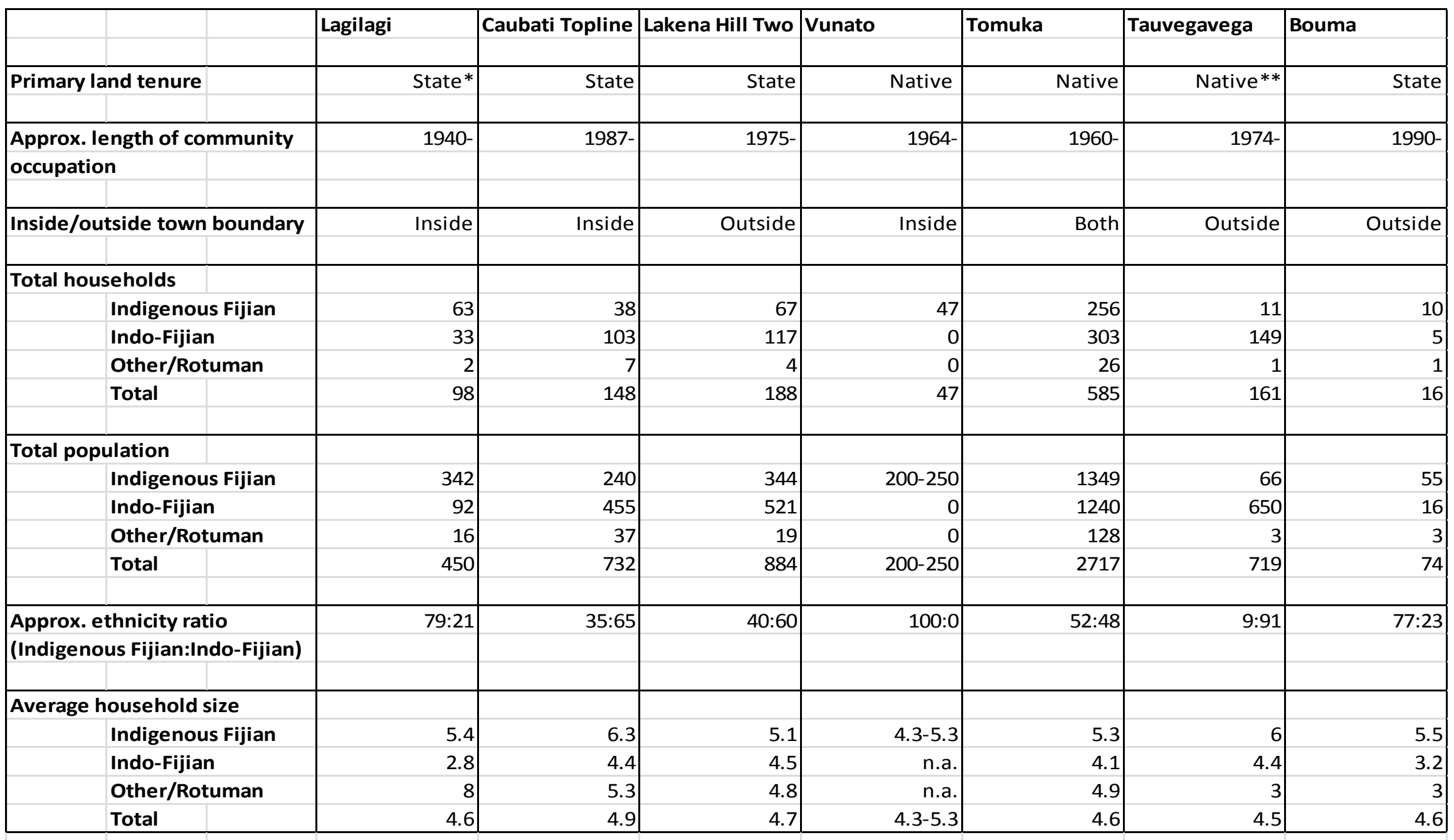

* Transferred from freehold tenure in 2000

** Transferred from state tenure in 2002 


\subsection{Lagilagi}

The community of Lagilagi is part of the larger Jittu Estate, all on state land, in central Suva. Jittu Estate is one of Fiji's oldest informal settlements; probably first established in the 1940s when the land was held in freehold tenure. In 2000, however, the ownership of the land transferred to the state (when the government covered outstanding payments due by the then freehold owner, the Methodist Church). Census data reveals that the wider Jittu Estate consisted of 639 households and had a population of 3,110 in 2007. Lagilagi itself, according to the census count, had a total population of 450 across 98 households. Census information shows that approximately three-quarters of the population of Lagilagi are indigenous Fijian. Housing is congested and much is of very poor quality. Many large sprawling dwellings have seen considerable extensions over the years. A distinctive feature of Lagilagi is the presence of a number of very large buildings, known locally as 'barracks', divided into rental units (there is an extensive rental and subletting market in the community).

Lagilagi is the site of an innovative and nationally-significant pilot project, detailed in the previous chapter. This project is one of the first examples of a major in situ informal settlement upgrading project in Fiji. The pilot project, coordinated by the Peoples' Community Network (PCN) and the Ecumenical Centre for Research, Education and Advocacy (ECREA), looks to upgrade the community through temporarily relocating households to other areas of Jittu Estate, rationalisation and demarcation of layout and houseblock sites, and subsequent rebuilding. At the time of the field research other salient features of Lagilagi included: vibrant informal sector activity (such as the presence of small household-based retail canteens, barbeque vending, and car washing businesses); and considerable sharing of electricity and water meters across a number of households.

Access to Lagilagi is regulated by a small number of long-term residents and usually involves new arrivals purchasing an established dwelling or plot area on which to build (unless renting). However, at the time of the field research, there were few new arrivals and little new building; mainly because the PCN/ECREA upgrading project was imminent. A satellite image of the community is shown in Figure 8.3 and photographs of the area are shown in Plates 8.1 to 8.6. 


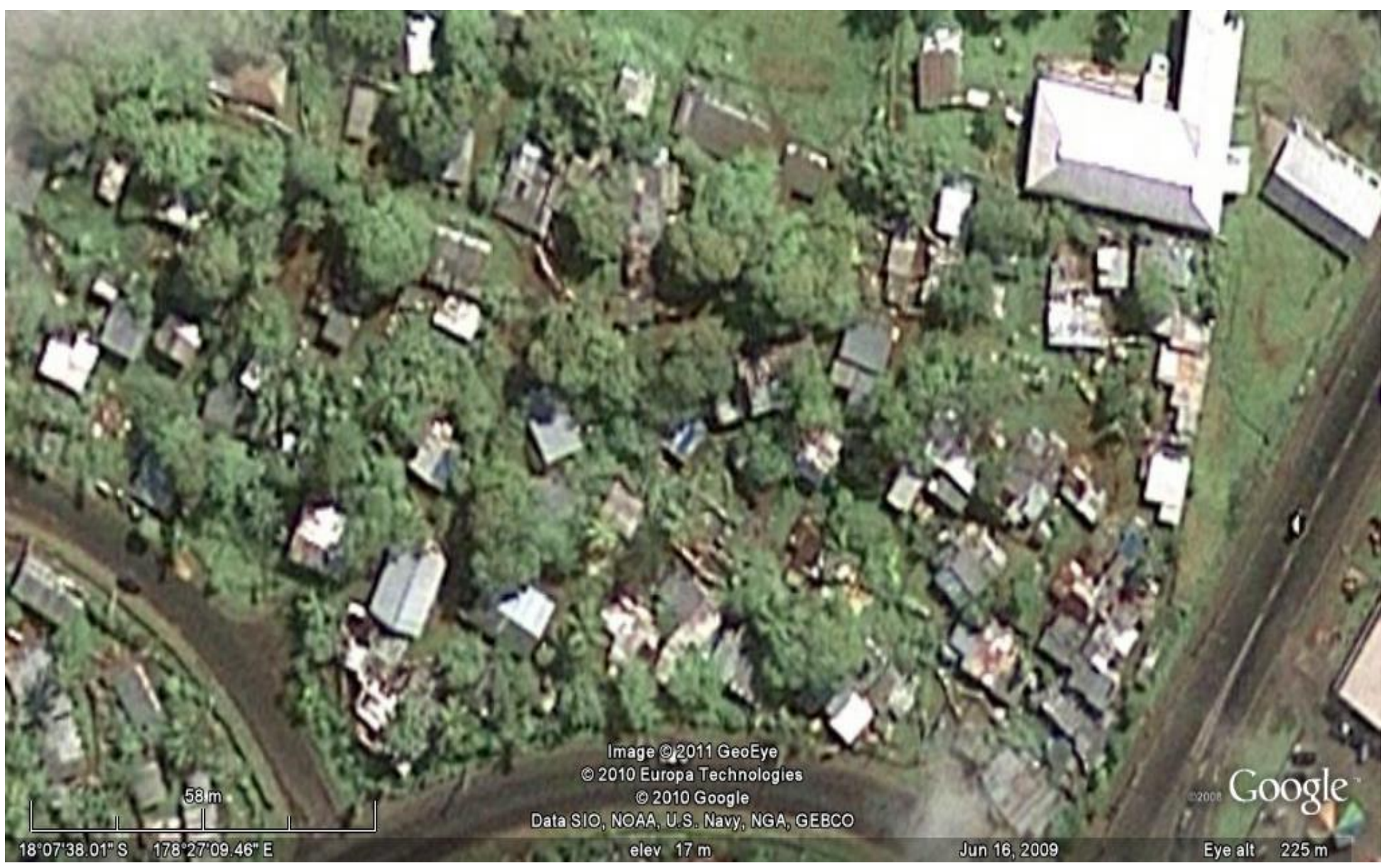

Most of Lagilagi can be seen in this image. The dwellings below the roads at the bottom left of the image are part of the wider Jittu Estate. 
Plates 8.1-8.6. Photographic Images of Lagilagi (all photos in this chapter taken by the author)

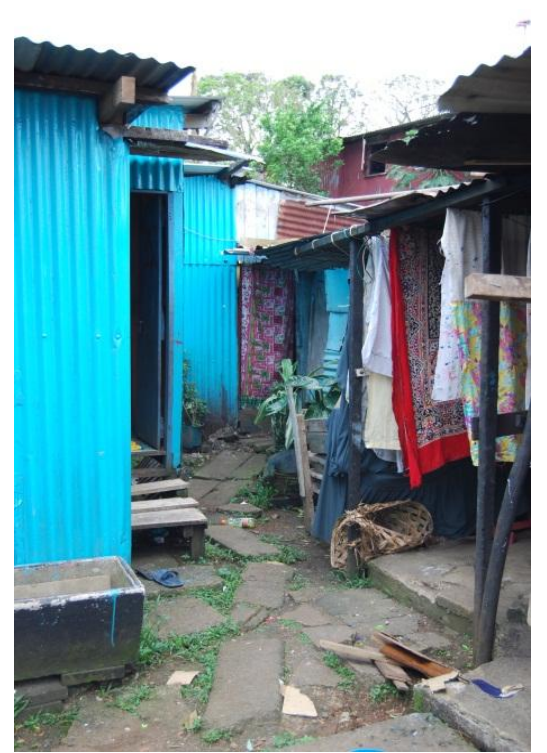

Plate 8.1. Multiple dwelling access in Lagilagi, August 2008.

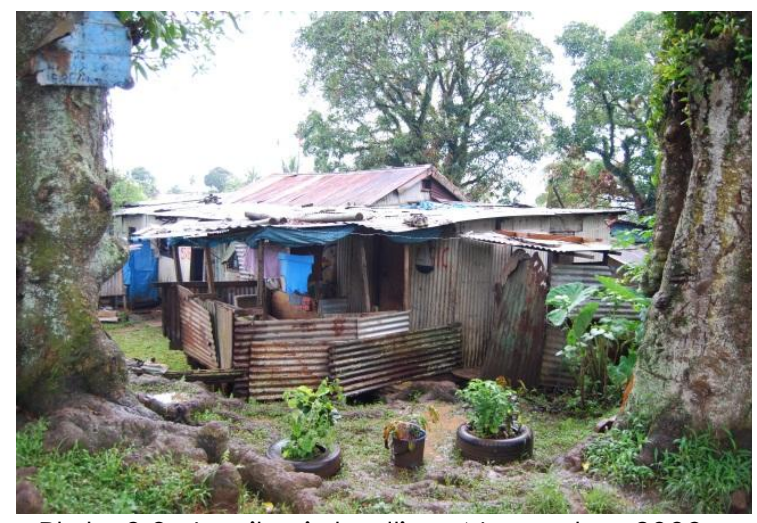

Plate 8.3. Lagilagi dwelling, November 2008. The large trees throughout the community are visible.

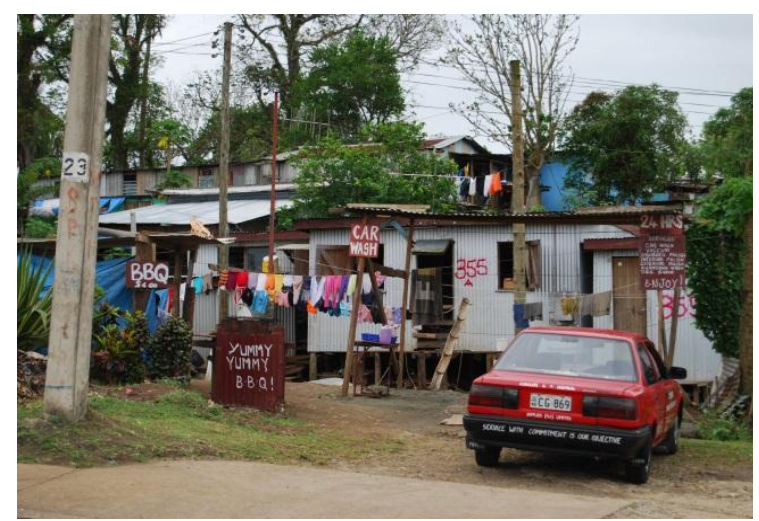

Plate 8.5. Dwellings and informal sector activity at Lagilagi, September 2008.

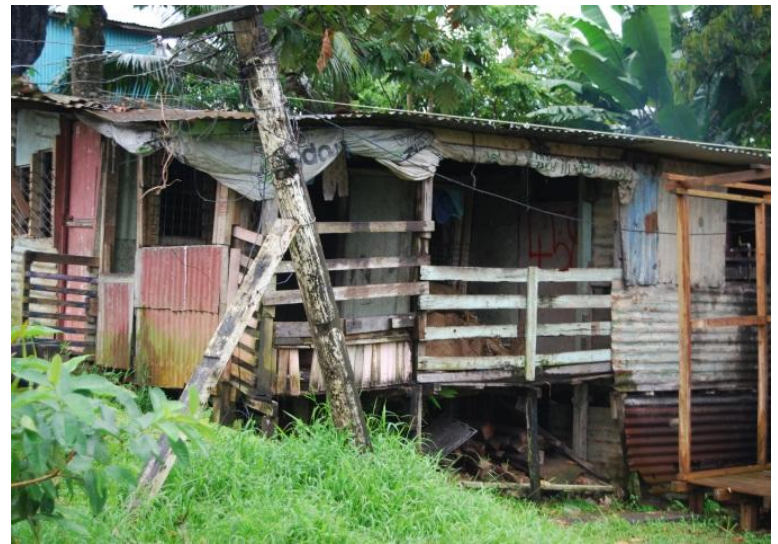

Plate 8.2. Lagilagi dwelling, November 2008.

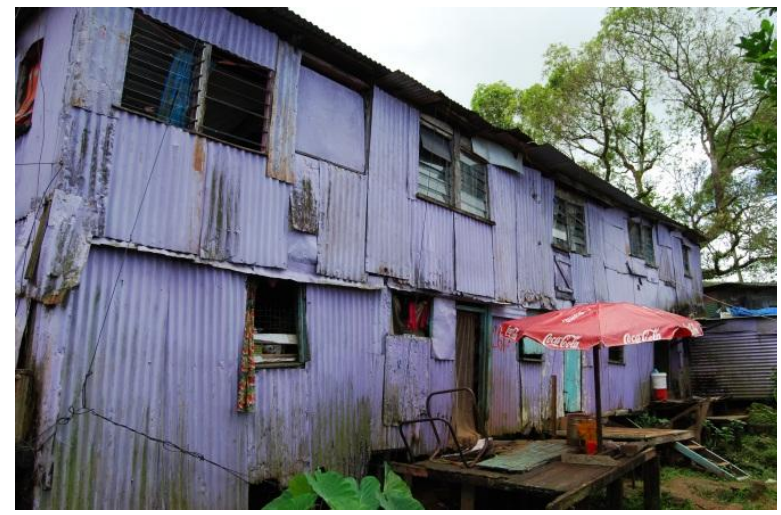

Plate 8.4. Large Lagilagi dwelling, September 2008. This structure houses the home of the occupying owner and a number of rental units. These types of structures are known locally as 'barracks'.

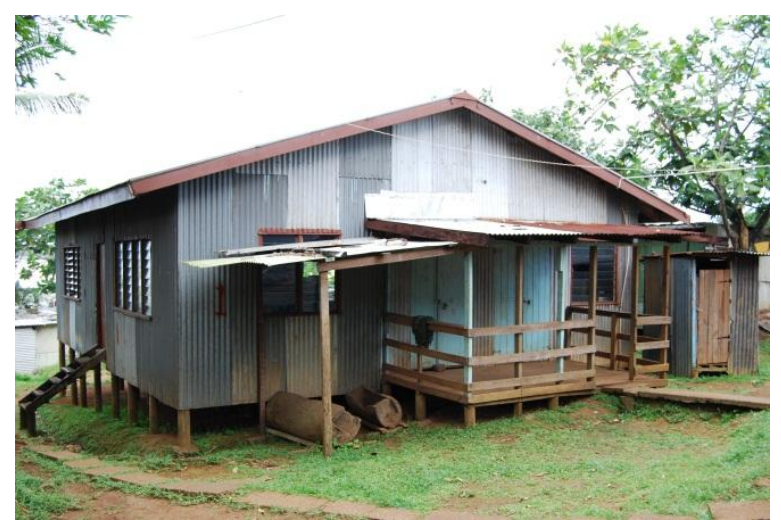

Plate 8.6. Lagilagi community church/hall, September 2008. 


\subsection{Caubati Topline}

Caubati Topline (a division of the larger Caubati informal settlement) in Nasinu in the greater Suva area is a relatively new, and rapidly growing, informal settlement on state land. According to the 2007 census, the settlement consisted of 148 households and had a total population of 732 . Census figures reveal that $90 \%$ of the settlement's population are Indo-Fijian. The community has been growing rapidly from the late 1990s and even more rapidly from the early 2000s. A large proportion of new arrivals are exfarming families from Vanua Levu; largely migrating to Suva because of lease uncertainty and expiry. ${ }^{59}$ Housing is very condensed, of varying quality, and often on relatively steep terrain. Considerable family grouping is evident with a number of extended family living in adjacent, but separate, dwellings. The condition of access roads is poor.

Access to the community is regulated by a small number of long-term residents. New arrivals utilise various methods for access; almost all requiring payment of some form. For example, some new settlers purchase an established dwelling, some (despite the community being officially on state land) pay local mataqali or current community residents a negotiated amount for a plot of land on which to build (often as compensation for losing the use of land once used for food gardens), and a smaller amount of new arrivals rent rooms or parts of dwellings from established residents.

59 Local police post survey records, for example, reveal that 39 out of 91 (43\%) surveyed Caubati Topline households had migrated from the cane belt areas of Vanua Levu. 
Figure 8.4. Satellite Image of Caubati Topline

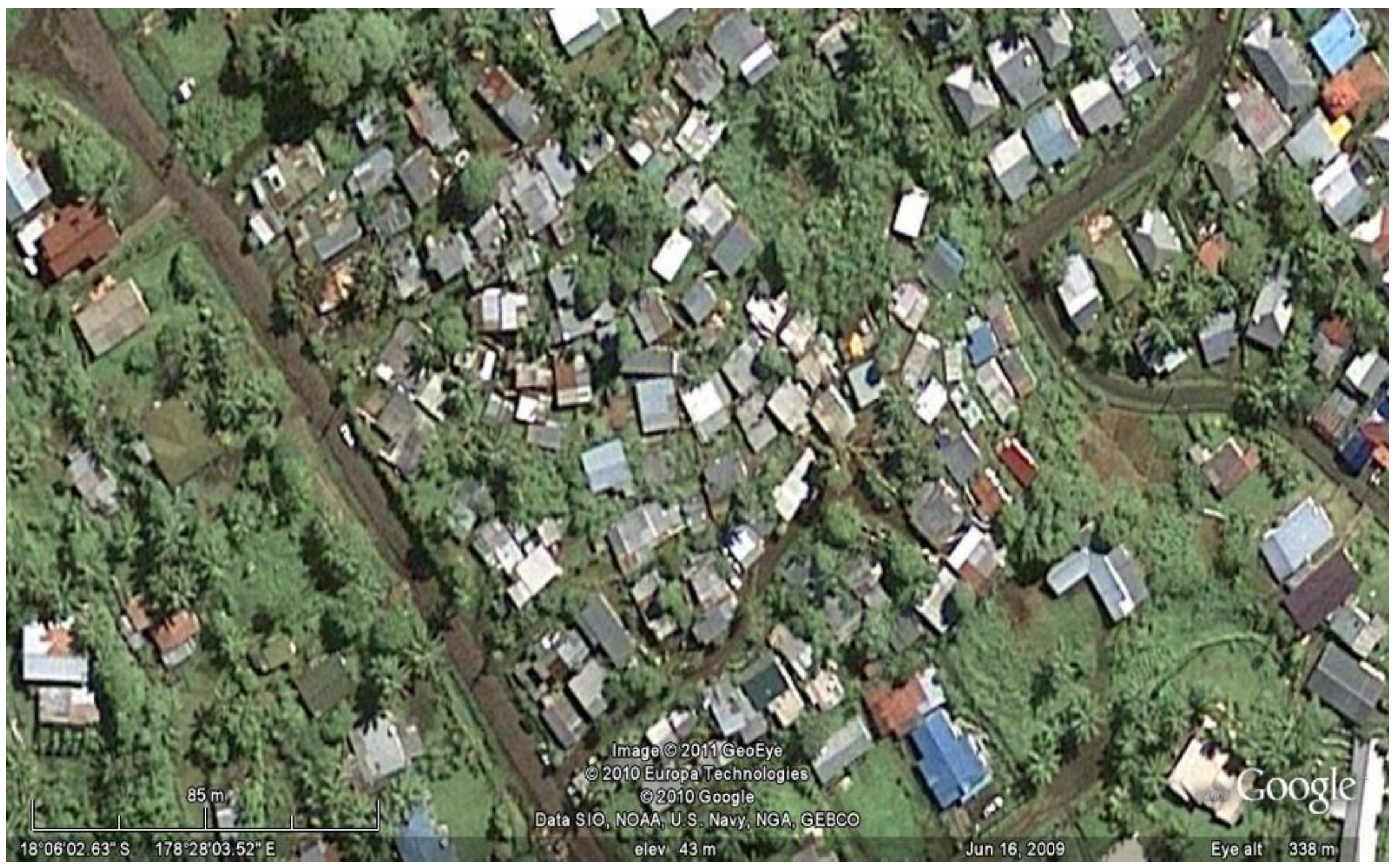

Caubati Topline is the discrete housing area in the centre of this image (the dwellings in the top right of the image are not part of the community). The community's principal small access road can be seen coming off the larger road.

Source: Google Earth 
Plates 8.7-8.12. Photographic Images of Caubati Topline

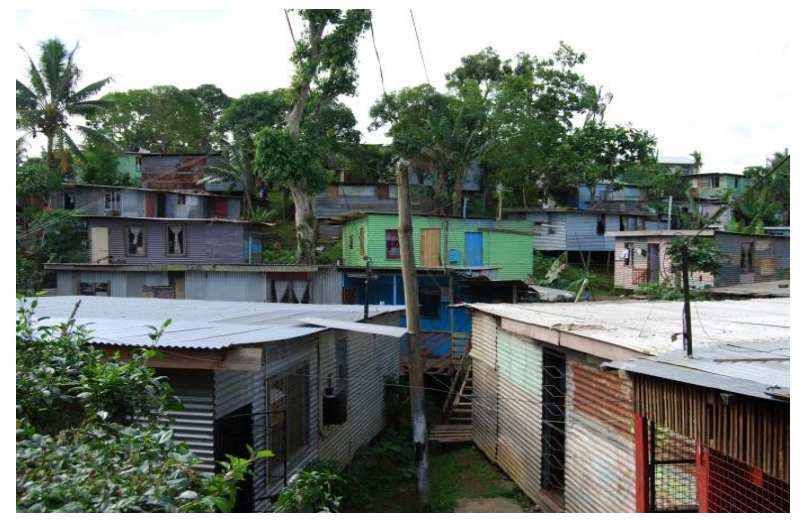

Plate 8.7. Congested hillside housing at Caubati Topline, September 2008.

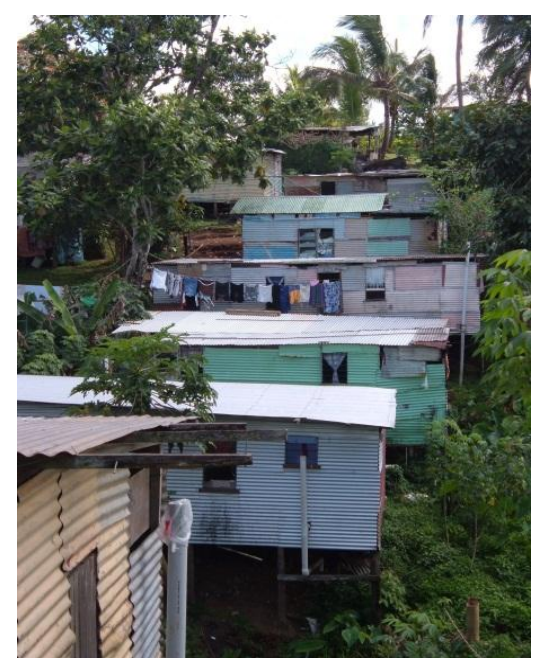

Plate 8.9. Caubati Topline dwellings, August 2008.

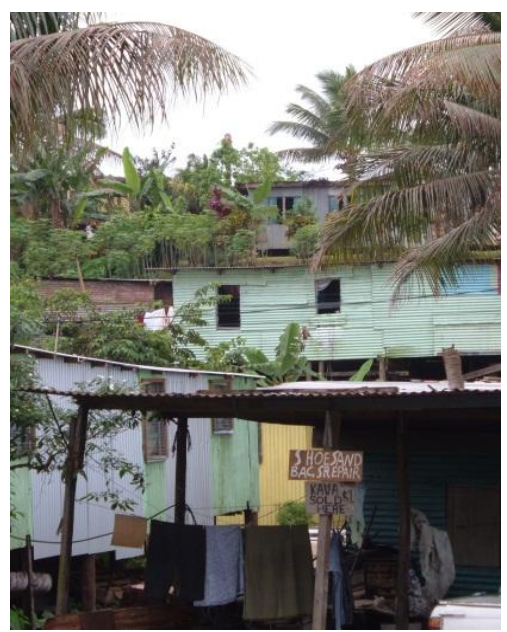

Plate 8.11. Caubati Topline dwelling and informal sector activity (the signs advertise shoe and bag repairs and yaqona sales), August 2008.

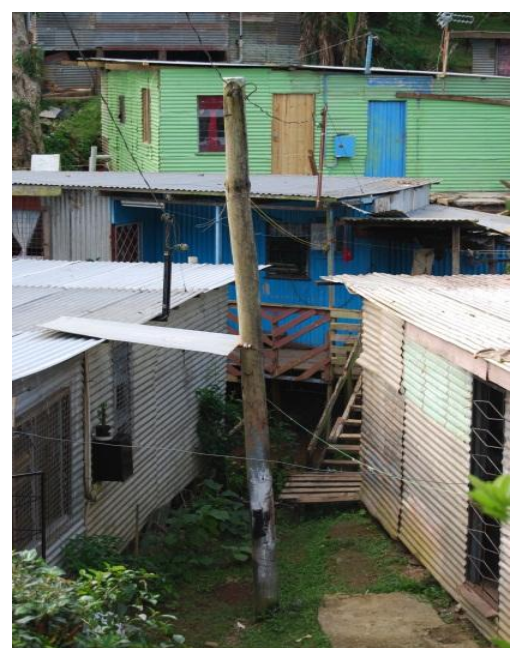

Plate 8.8. Caubati Topline dwellings, September 2008.

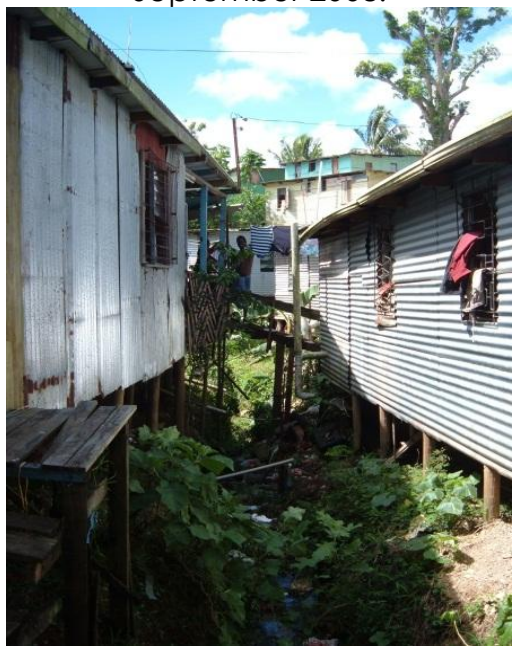

Plate 8.10. Dwellings and drainage ditch, Caubati Topline, August 2008.

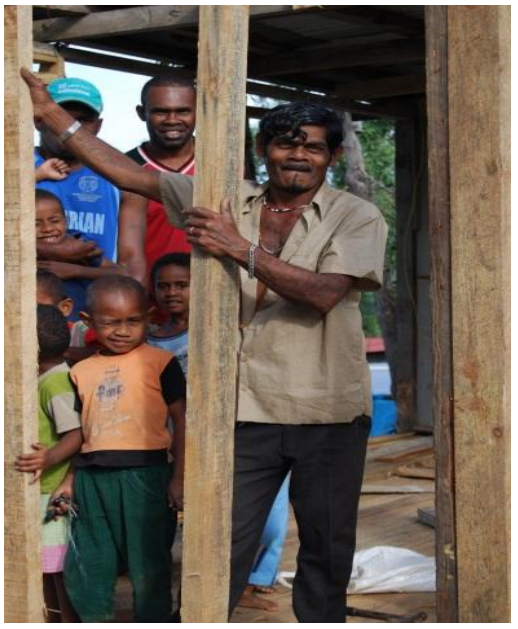

Plate 8.12. Workers and children pause for a photo during home extensions at Caubati Topline, September 2008. 


\subsection{Lakena Hill Two}

Lakena Hill Two is an established informal settlement situated on peri-urban state land in the outskirts of Nausori. Settlement began around the mid-1970s and little new building now occurs as all land has been allocated by the central government as individual plots to residents. 2007 census data reveals that the community had a population of 884 across 188 households. Fifty-nine per cent of the community are Indo-Fijian. Much extended family grouping occurs.

Compared to many other informal settlements on state land, housing in Lakena Hill Two is relatively dispersed. Plots are clearly demarcated and usually very spacious. Many households have some room for small gardens in their own plots or nearby. Most housing is of relatively high quality although a number of very poor quality dwellings using extremely makeshift materials are evident. Electricity infrastructure is permanent (with most households having individual meters), and footpaths and some road areas have been sealed. For many years the settlement has been targeted by central government for intervention and upgrading; as such, many residents are optimistic of eventually obtaining a lease or title of some form for their houseblock site. Access to the community is now primarily via the sale and purchase of dwellings. 
Figure 8.5. Satellite Image of Lakena Hill Two

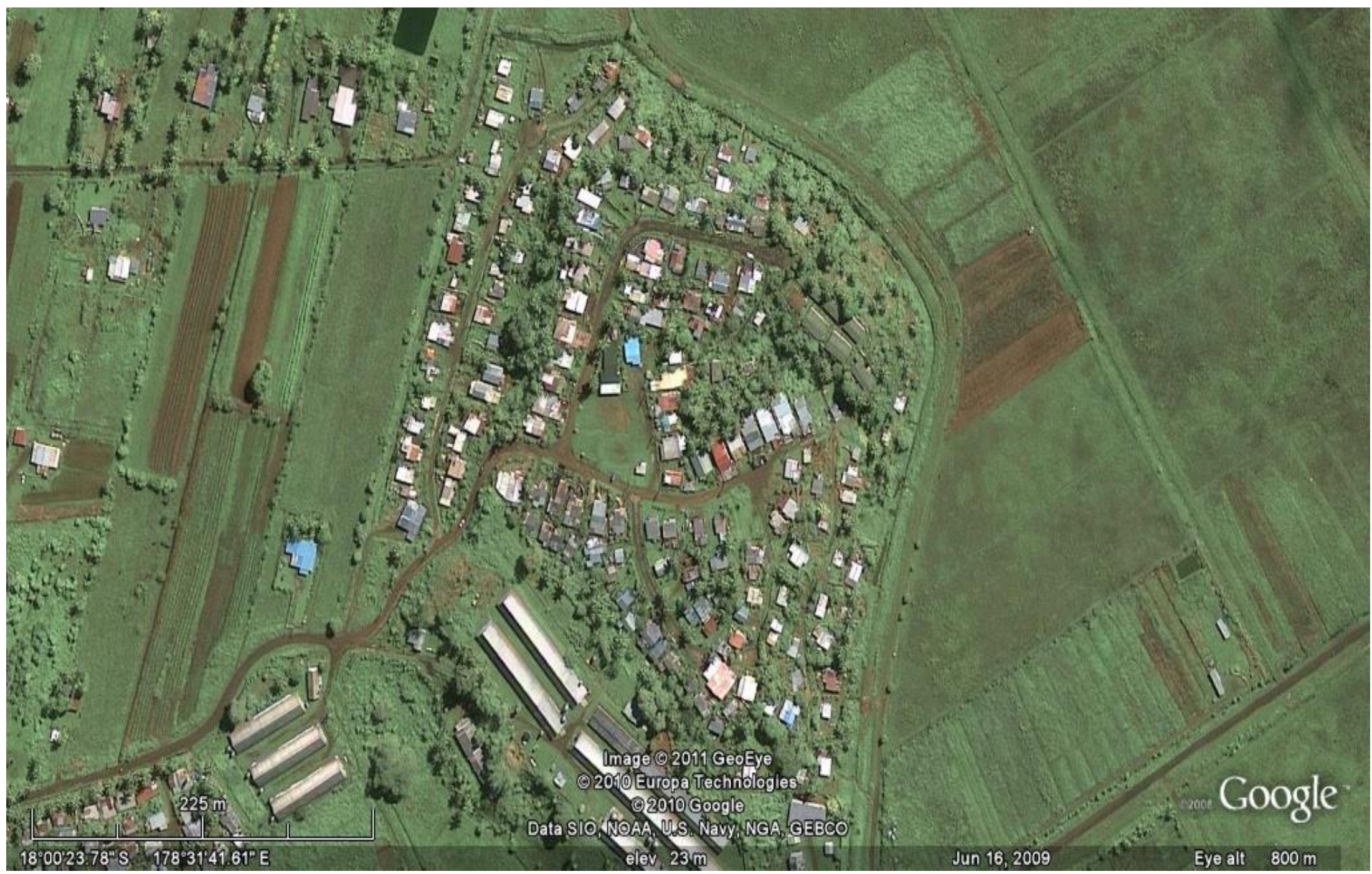

The peri-urban character of Lakena Hill Two is clearly evident from this image.

Source: Google Earth 
Plates 8.13-8.18. Photographic Images of Lakena Hill Two

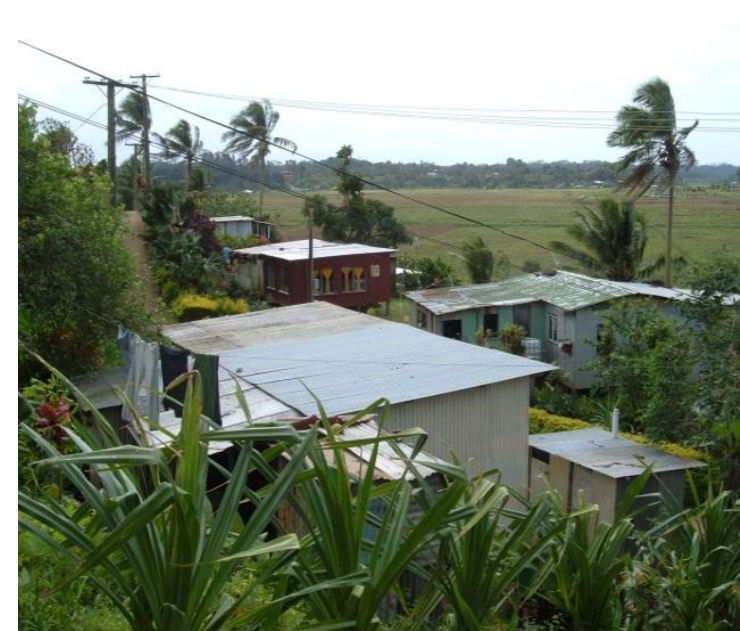

Plate 8.13. Lakena Hill Two dwellings, July 2008. Footpaths and power infrastructure are visible.

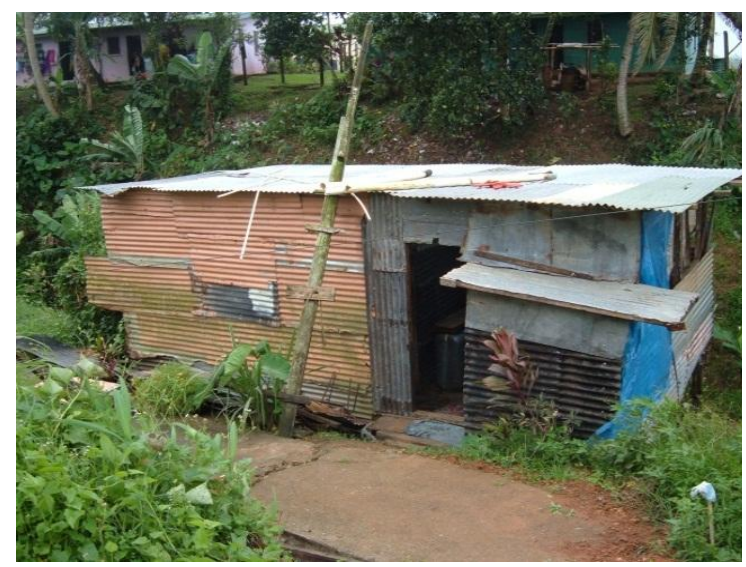

Plate 8.15. Lower quality Lakena Hill Two dwelling, August 2008.

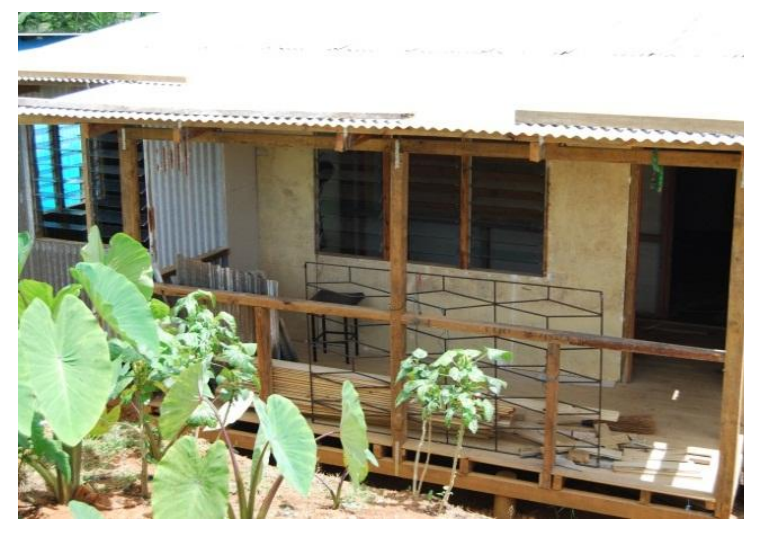

Plates 8.17-8.18. Ongoing dwelling renovations at Lakena Hill Two, September 2008 (left). Finished renovations, July 2009 (right). This dwelling also operates as a small retail canteen (the advertising is for cell-phone top-ups).

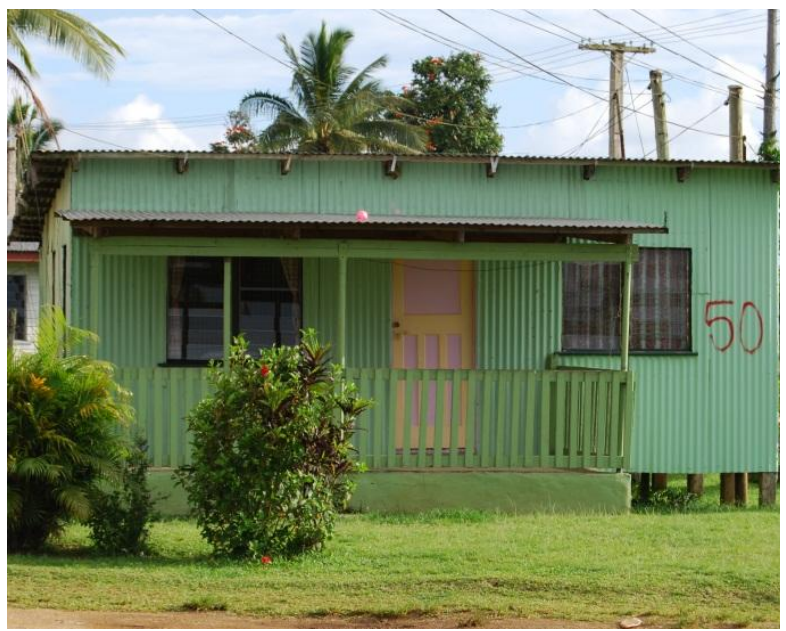

Plate 8.14. Relatively typical Lakena Hill Two dwelling, November 2008.

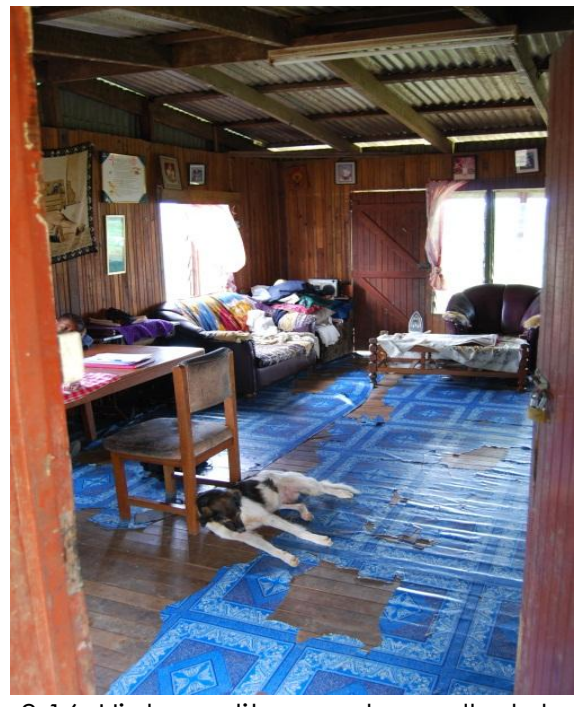

Plate 8.16. High quality wood panelled dwelling interior, Lakena Hill Two, September 2008.

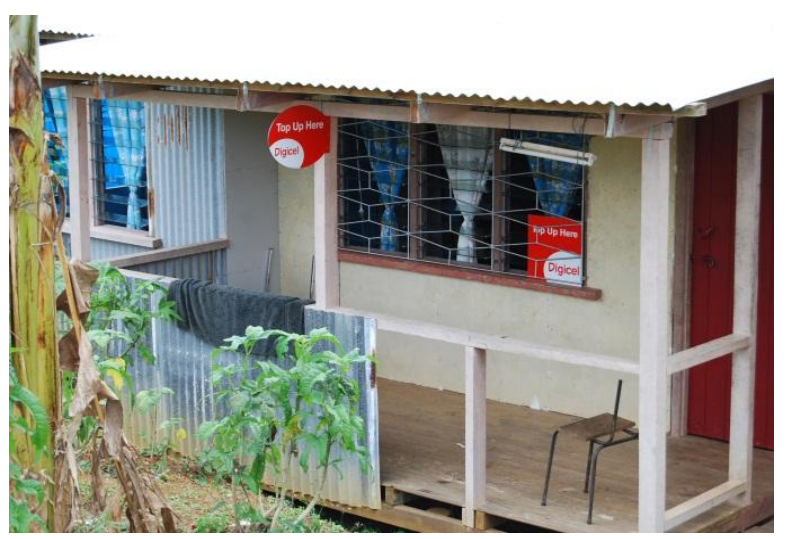

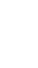




\subsection{Vunato}

Vunato, a small community of around 47 households, is located on native land very near the Lautoka rubbish dump. All of the approximately 200-250 residents are indigenous Fijian. Settlement first occurred in the 1960s. All residents obtain access to the community and often garden plots via informal, vakavanua arrangements with the controlling landowner individual (who personally lives in the settlement). These arrangements are usually facilitated by formal sevusevu (traditional request) and the accompanying customary exchange of yaqona, mats, kerosene and/or cash.

Most residents of Vunato come from outer islands (particularly the Lau Group and the Yasawa Islands) or the Viti Levu interior; and most already have extended family living in the settlement. The community is very centrally located; only a few minutes of walking to the centre of Lautoka town. Most residents move to Lautoka to be closer to employment opportunities and particularly secondary schools. Dwellings are a mixture of large, sprawling structures that have seen considerable extensions over the years and a lesser number of small, single room structures. The condition of the dwellings is poor; in part due to the frequent floods affecting the community at the height of the annual wet season. Most cooking is completed on open fires. Over the years there have been considerable discussions amongst community members about trying to formalise lease arrangements. This would be very difficult, however, as formally the land is held under native reserve tenure (land that cannot be easily leased) and some council zoning restrictions may apply. 
Figure 8.6. Satellite Image of Vunato

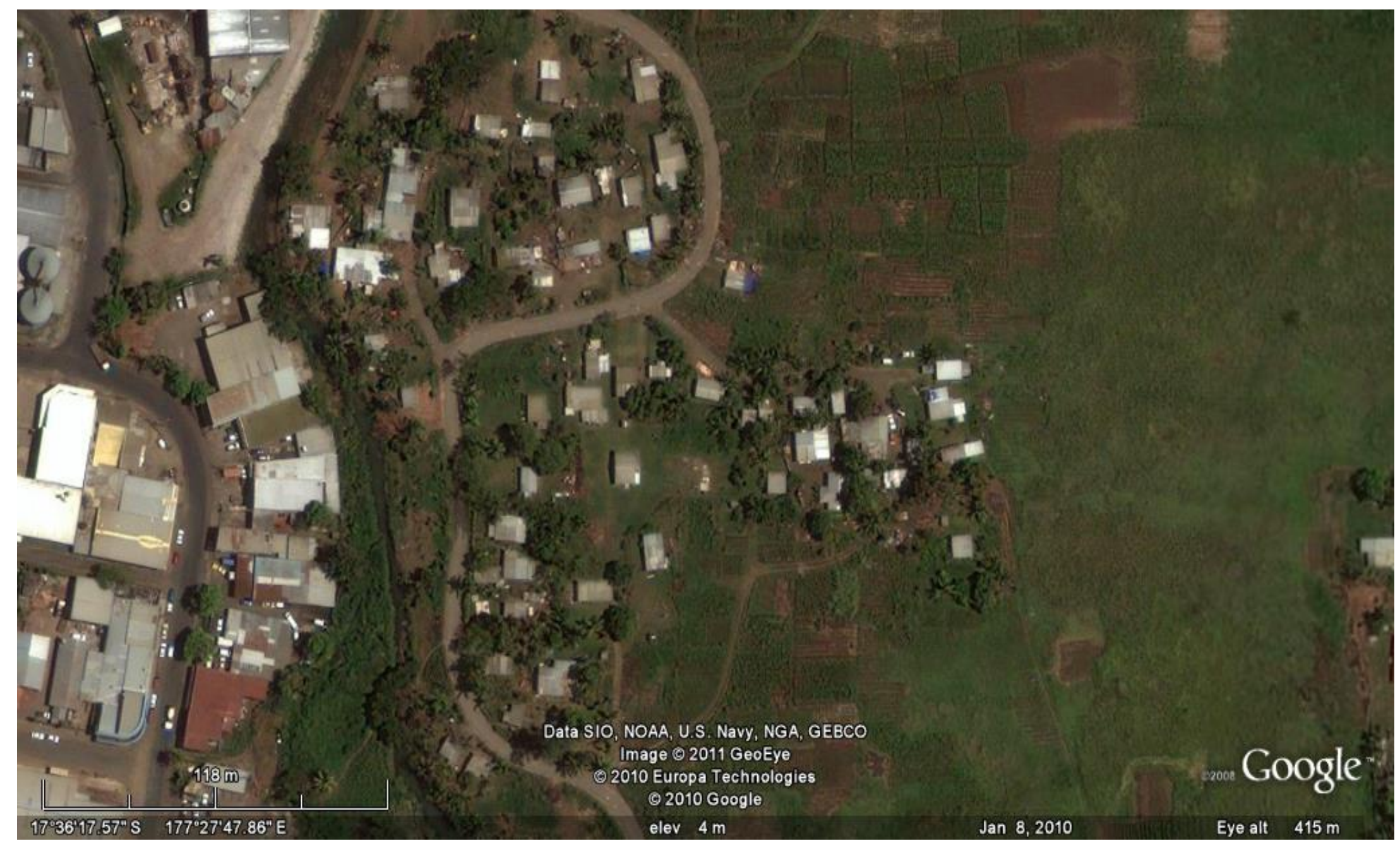

All of Vunato is visible in this image. The close proximity to commercial areas of Lautoka (left) is clear. The road accessing Vunato also leads to the Lautoka dump.

Source: Google Earth 
Plates 8.19-8.24. Photographic Images of Vunato

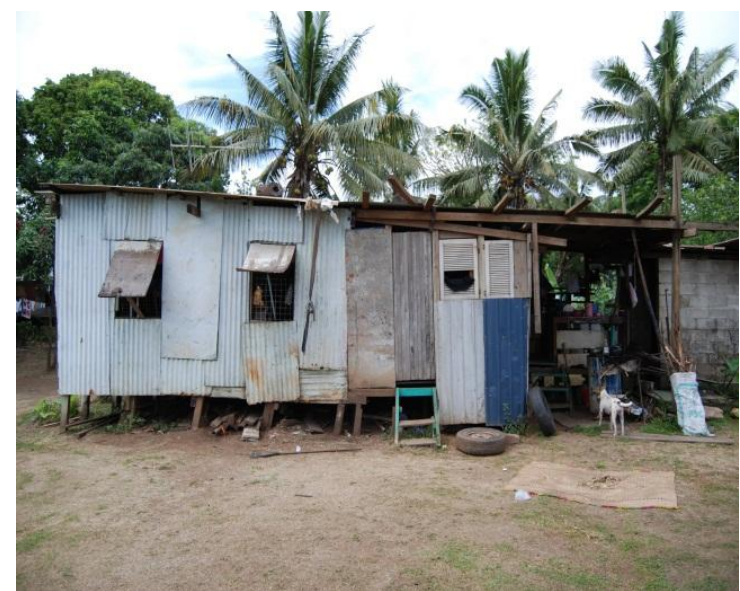

Plate 8.19. Vunato dwelling, October 2008.

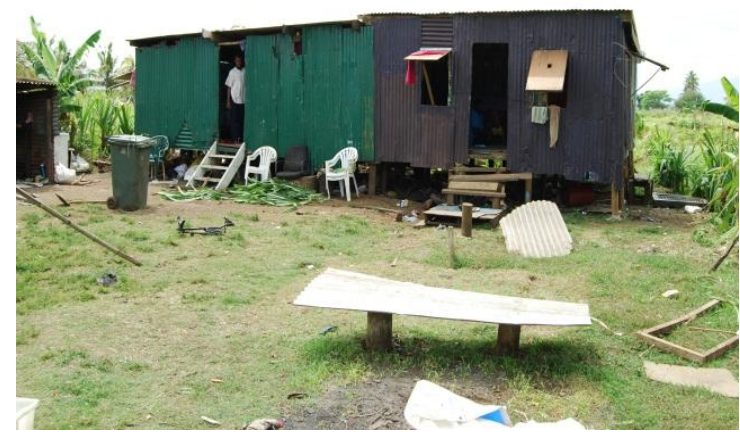

Plate 8.21. Vunato dwelling, September 2008. This household had moved their dwelling within Vunato a number of times in the preceding few years - seeking relief from floods and a more isolated place in the community to worship as Pentecostal Christians.

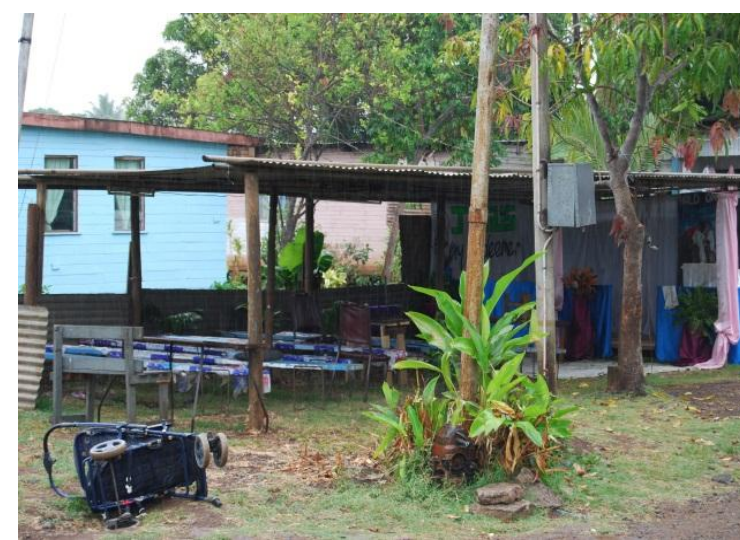

Plate 8.23. Vunato Seventh Day Adventist Church, September 2008.

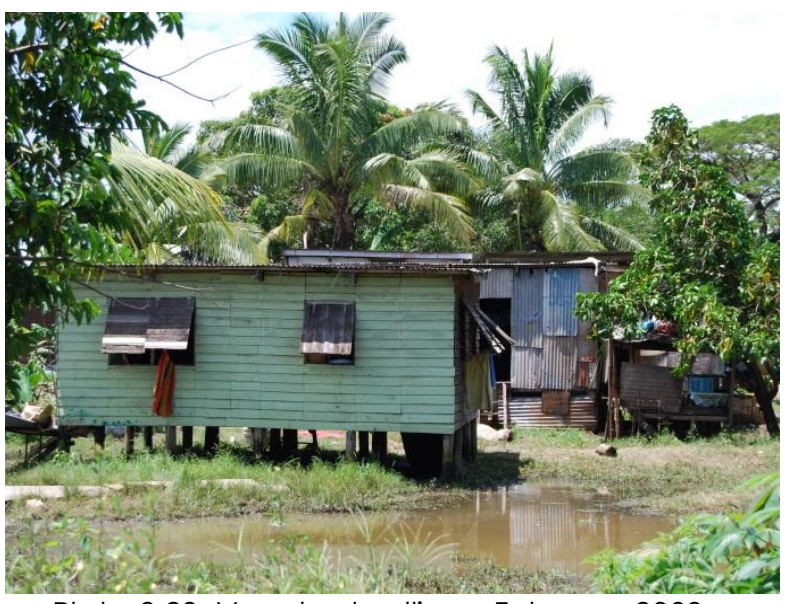

Plate 8.20. Vunato dwellings, February 2008.

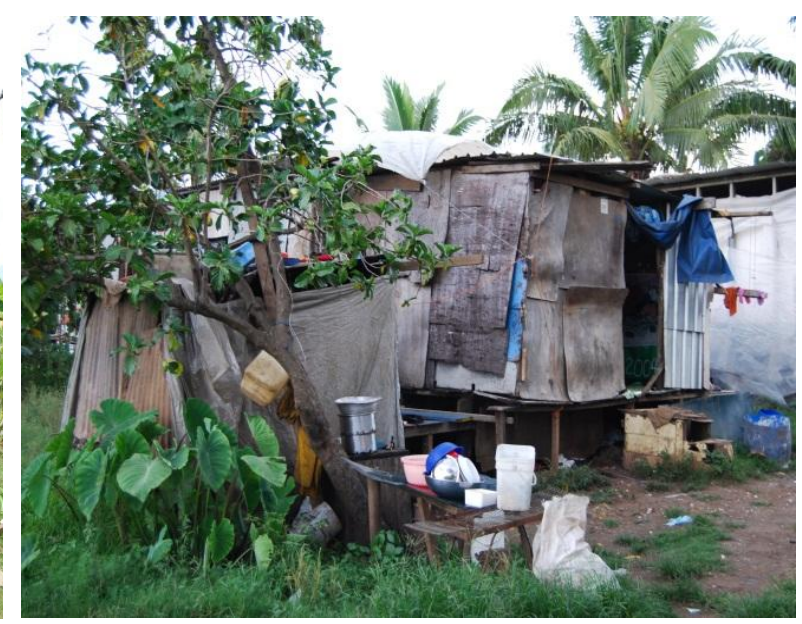

Plate 8.22. Rear of a Vunato dwelling showing cooking areas, October 2008.

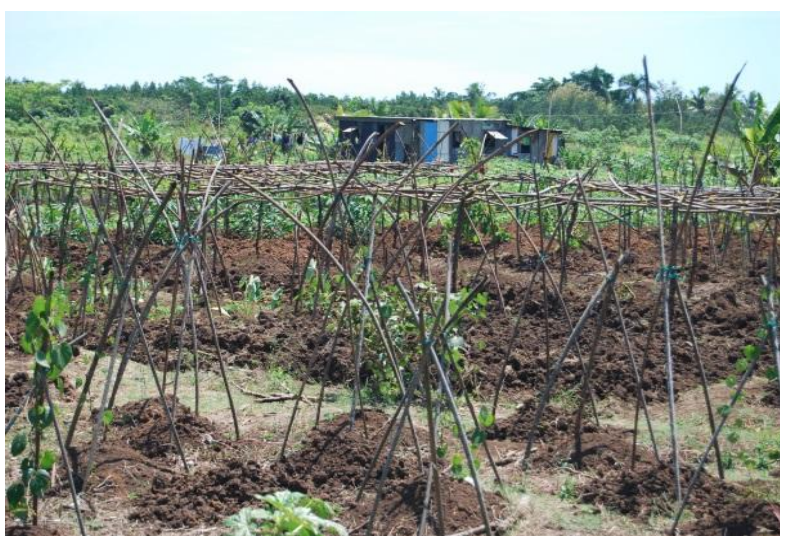

Plate 8.24. Gardens, Vunato, September 2008. 


\subsection{Tomuka}

Tomuka is a very large informal settlement on native land in the Lautoka hills. 2007 census data shows that the community had a population of 2,717 across 585 households (with a relatively even split of indigenous Fijian and Indo-Fijian residents). Settlement goes back to the 1960s with considerable growth from the 1970s. Settlers looking to build new dwellings gain access to Tomuka and a plot of vacant land via negotiation and agreement with the members of the local mataqali landowning family. These arrangements are not legal, but include detail down to the 'lease' term, amount of annual land rent, and initial houseblock purchase price (and terms if this needs to be paid off). These arrangements are all usually written down on 'lease' documents (that most settlers recognise as not having any legal standing). There is also a vibrant market for dwellings within Tomuka; and many new entrants gain access by buying an established dwelling (sellers must give a proportion of the purchase price, specified in their 'lease' documents, to the landowners).

Dwellings in Tomuka are of relatively high quality (compared with the other case-study informal settlements) and plot sizes are clearly demarcated and relatively large. The settlement is serviced by public transport and most dwellings have individual water and power connections (as in other Fijian informal settlements pit and flush to tank toilet facilities are the norm). The community, however, has a history of eviction; with many families being evicted over the years for causing community disturbances or falling behind in payments due to the landowners. In such cases plots are simply resold by the landowners, or, in cases when evicted families have not been able to dismantle and relocate their dwellings, structures become rental units controlled by the landowners. The community has a reputation for crime; some taxi drivers, for example, refuse fares to Tomuka at night, and many homes are protected by high security fencing and security grills. 
Figure 8.7. Satellite Image of Tomuka

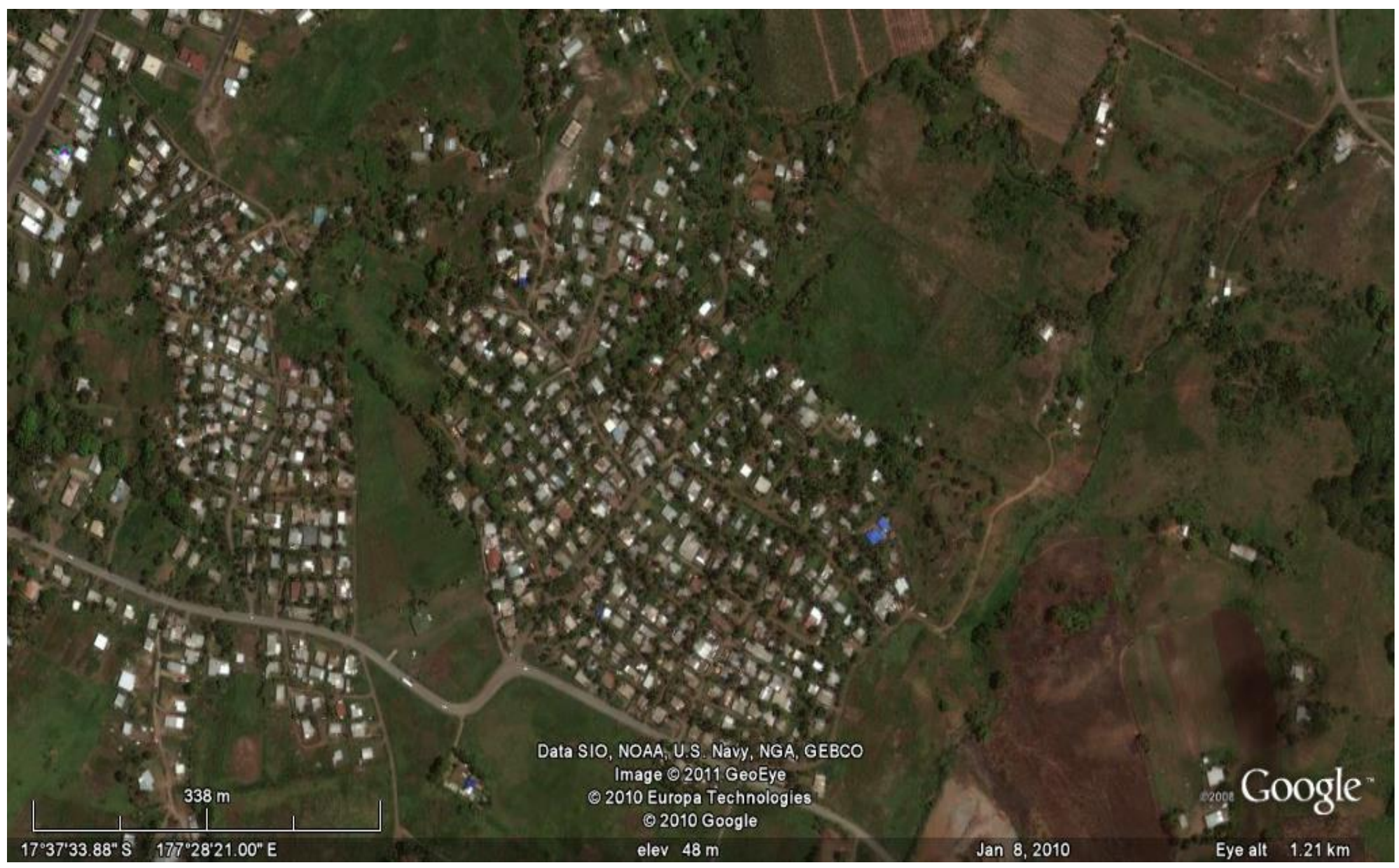

The large community of Tomuka is in the centre of this image.

Source: Google Earth 
Plates 8.25-8.32. Photographic Images of Tomuka

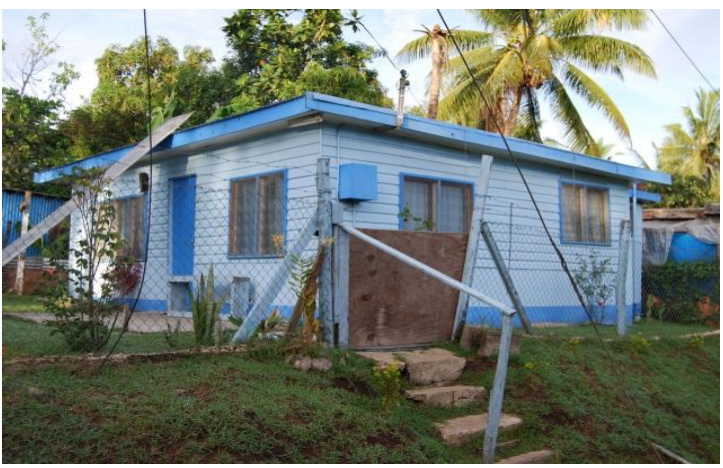

Plate 8.25. High quality Tomuka dwelling, October 2008.

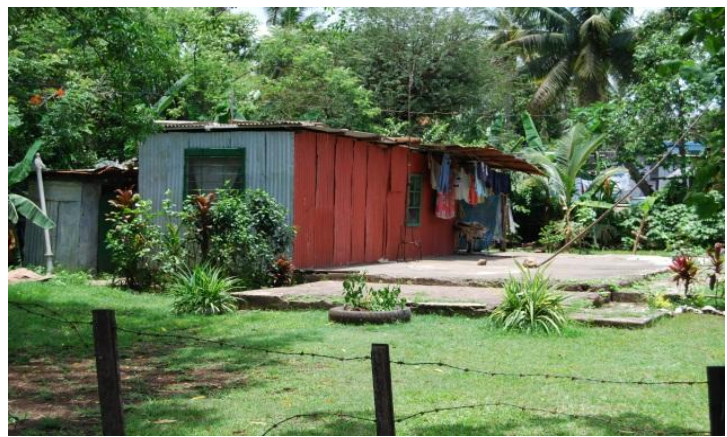

Plate 8.27. Tomuka dwelling, October 2008. The large concrete foundations indicated the past presence of a (now relocated) larger dwelling.

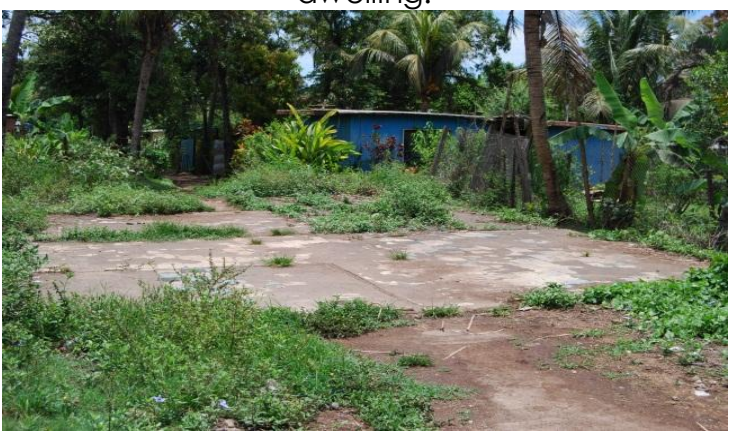

Plate 8.29. Vacant houseblock site, Tomuka, October 2008.

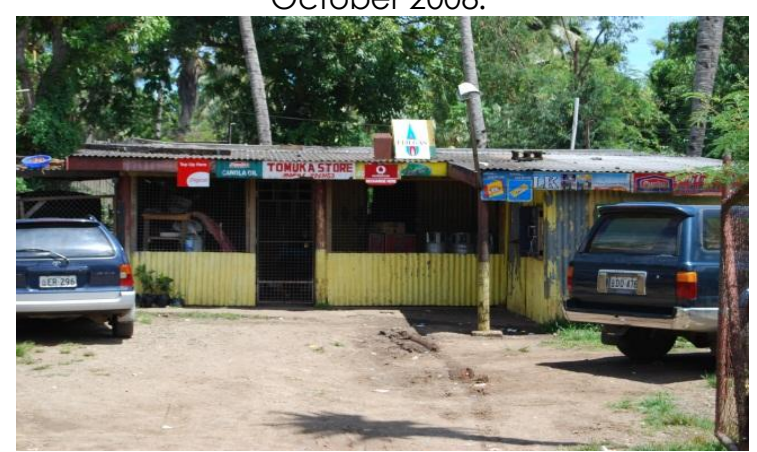

Plate 8.31. Tomuka store, October 2008.

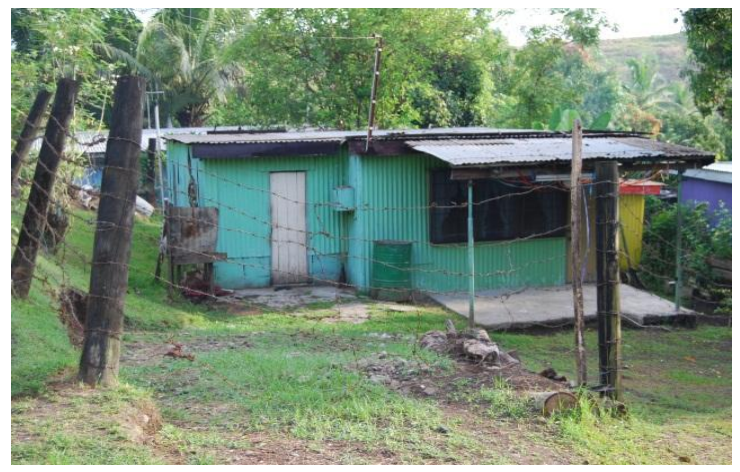

Plate 8.26. Tomuka dwelling, October 2010.

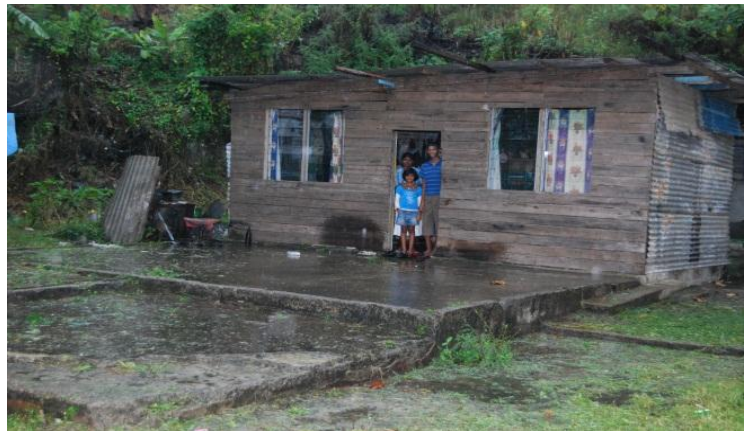

Plate 8.28. A very new dwelling at Tomukaagain on much larger foundations, October 2008.

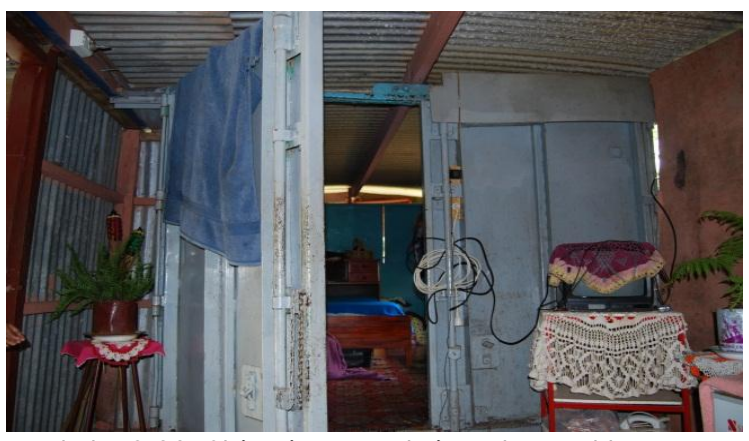

Plate 8.30. Shipping container-based home, Tomuka, October 2008.

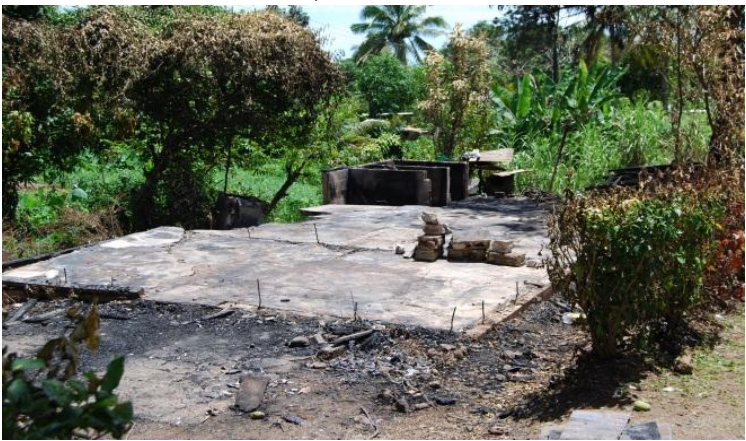

Plate 8.32. Recent fire remains, Tomuka,

October 2008. (Fire - often starting from cheap imported kerosene stoves - is a large hazard in informal settlements.) 


\subsection{Tauvegavega}

The settlement of Tauvegavega in Ba accommodates a population of 719 people across 161 households (according to 2007 census figures). Around 90\% of the population is Indo-Fijian. Tauvegavega is reportedly Fiji's largest informal settlement by area. Housing is dispersed across the hilly terrain of the settlement. The community was first settled as state land, but transferred into native tenure in 2002 when all Category A and Category B state land reverted to customary ownership. Land tenure is confused (not all residents are aware of the new legal status of the land) and contested (several mataqali groups are legally disputing what landowning group holds claims to the land).

The community is heterogeneous; with some relatively high income earners and some extremely poor families. Subsequently the condition of housing varies substantially. The settlement is serviced by public transport and permanent electricity infrastructure. Many arrivals from 2000 onwards were compelled and forced to move (from rural Ba particularly) due to lease uncertainty and expiry. A few households have food gardens; although the soil is poor on the hilly terrain. 
Figure 8.8. Satellite Image of Tauvegavega

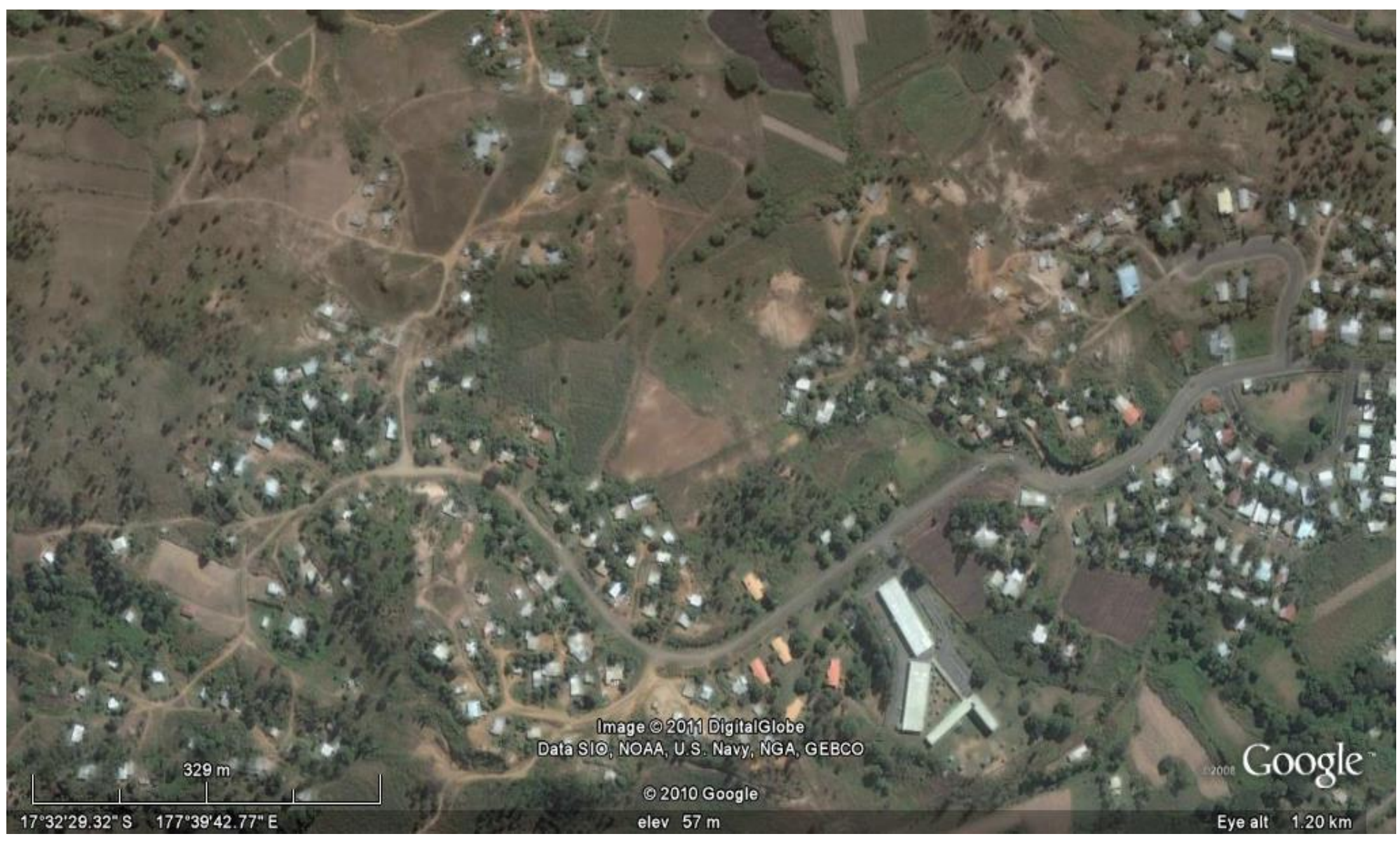

Most of the houses in this image make up the large, dispersed community of Tauvegavega (with the exception of the dwellings south of the road in the right of the image). The large buildings in the centre of the image make up the Ba campus of the Fiji Institute of Technology (now Fiji National University). 
Plates 8.33-8.38. Photographic Images of Tauvegavega

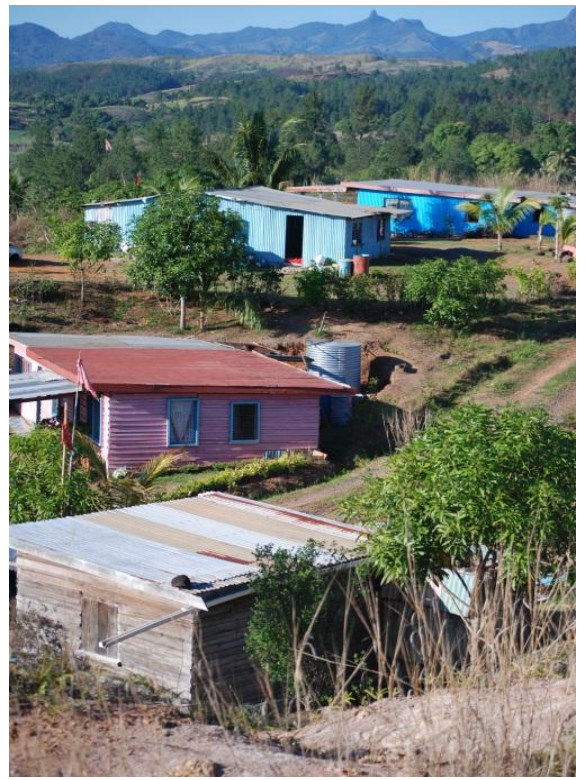

Plate 8.33. Tauvegavega dwellings, October 2008.

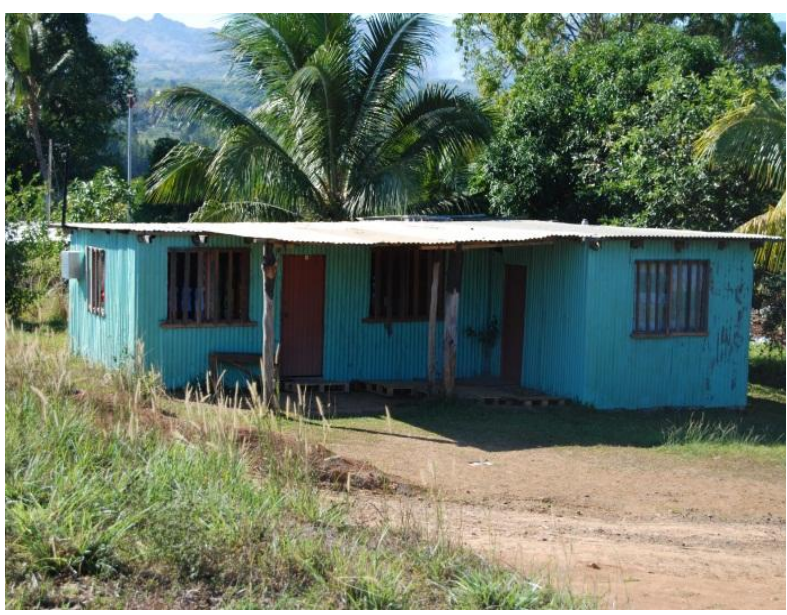

Plate 8.34. Relatively typical Tauvegavega dwelling, October 2008.

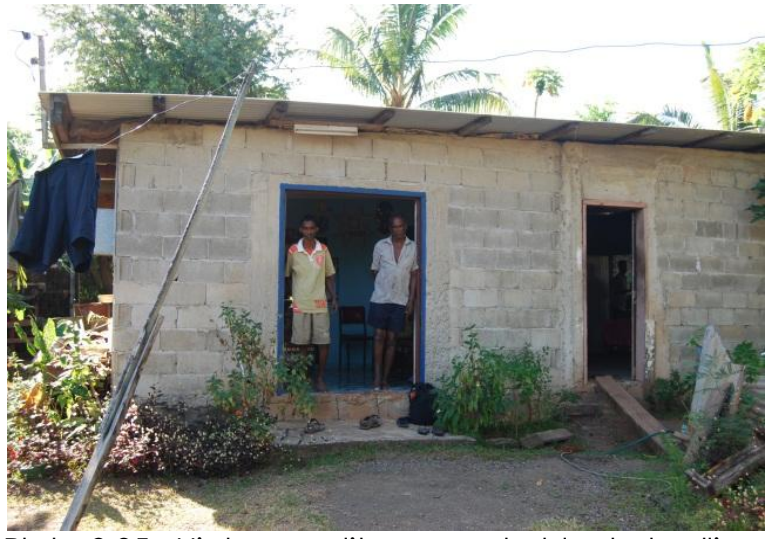

Plate 8.35. Higher quality concrete block dwelling, Tauvegavega, September 2008.

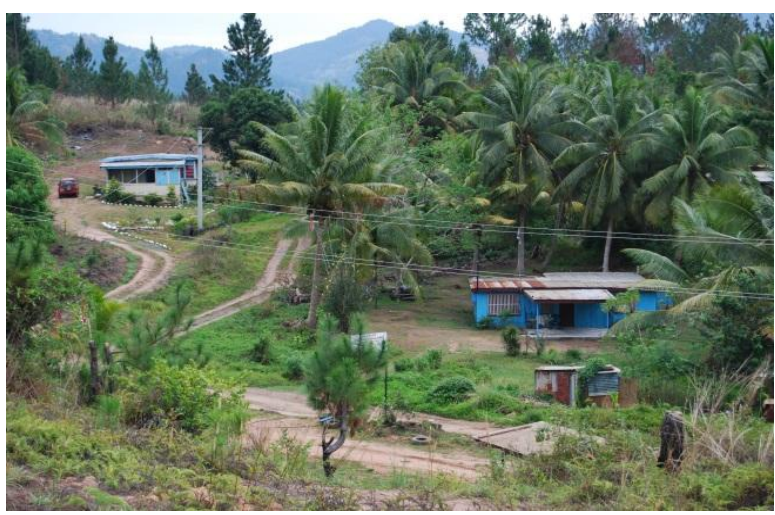

Plate 8.37. Tauvegavega dwellings, roads and power infrastructure, October 2008.

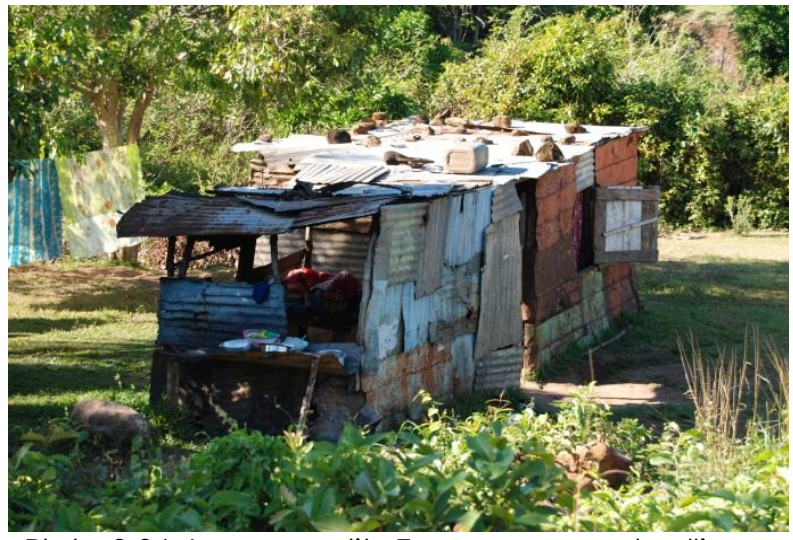

Plate 8.36. Lower quality Tauvegavega dwelling, October 2008.

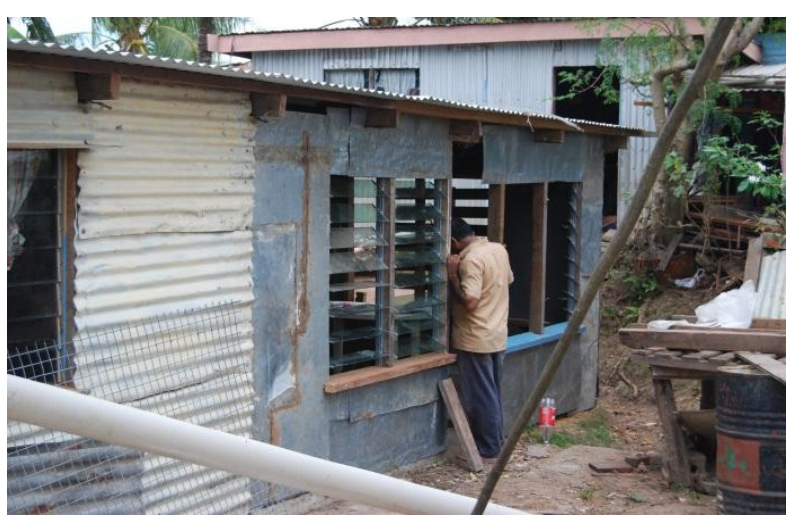

Plate 8.38. Ongoing renovations, Tauvegavega, September 2008. 


\subsection{Bouma}

Bouma is a very small, majority indigenous Fijian community of 16 households (total population 74) on the banks of the Labasa River opposite Labasa Town in Vanua Levu. The tiri (or mangrove) location means that legally the community is sited on state land (although some residents believe that the area is owned by local mataqali). Most residents are from elsewhere in Vanua Levu; coming to Labasa principally for employment opportunities and to be near to secondary schools.

The community is subject to frequent, often devastating floods (some families have rebuilt a number of times). The small, poor-quality dwellings are all raised on stilts as some flood protection. Water connections are shared from two meters - creating great pressure on supply. No households have electricity connection (although some households have small generators that are mainly used for lighting in the evenings). The riverbank is often used for waste disposal. New building still occurs to accommodate new arrivals. 


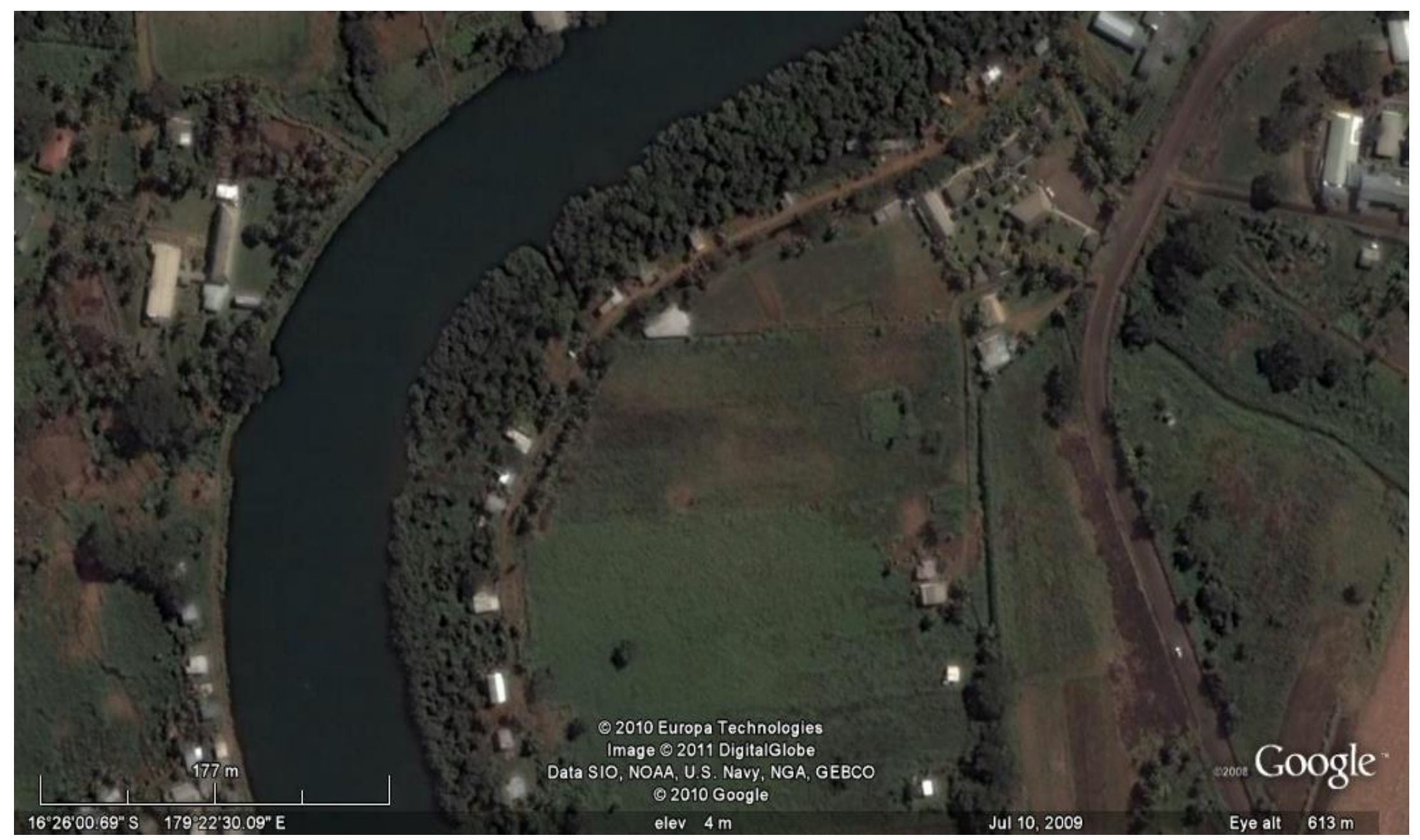

The dwellings making up the community of Bouma can be seen along the riverside access path/road in the centre of the image. Proximity to Labasa river (and the associated flood risk) is clear.

Source: Google Earth 
Plates 8.39-8.44. Photographic Images of Bouma

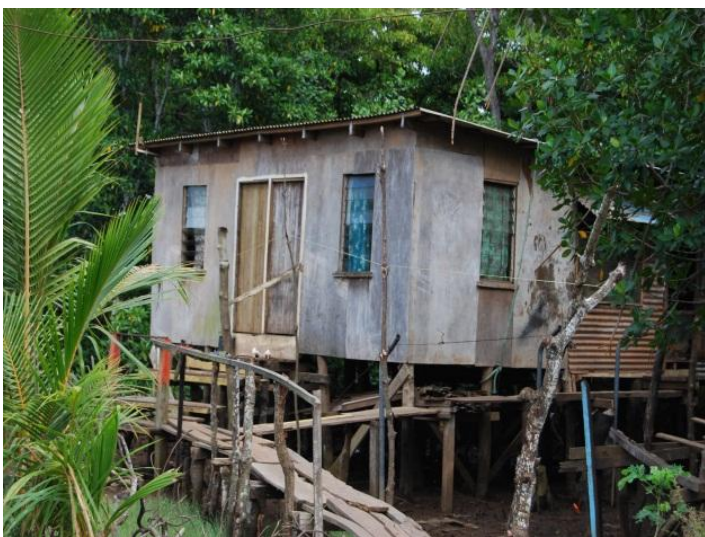

Plate 8.39. Bouma dwelling, October 2008.

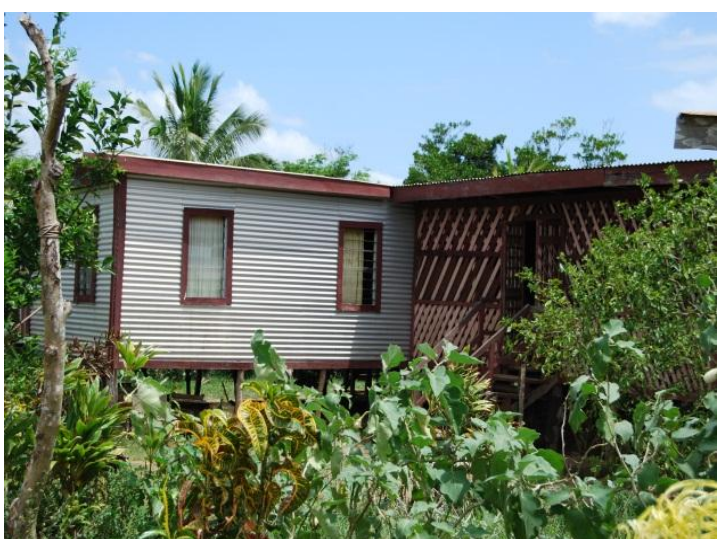

Plate 8.40. Higher quality Bouma dwelling, October 2008

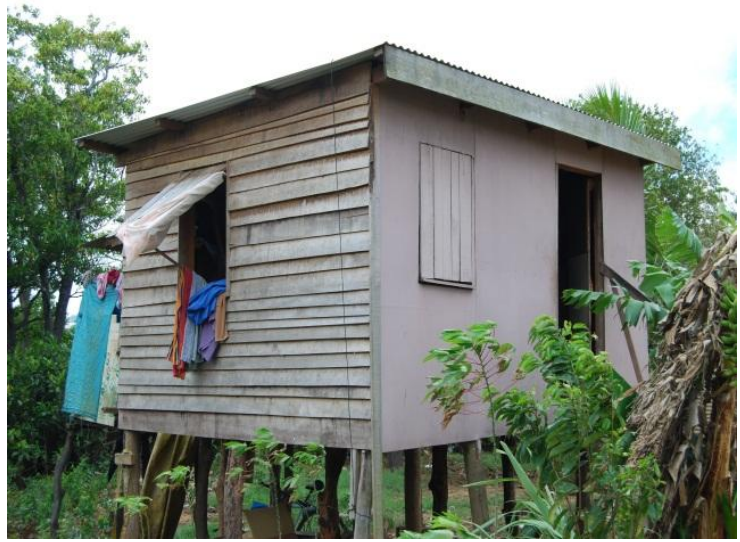

Plate 8.41. Small Bouma dwelling, October 2008.

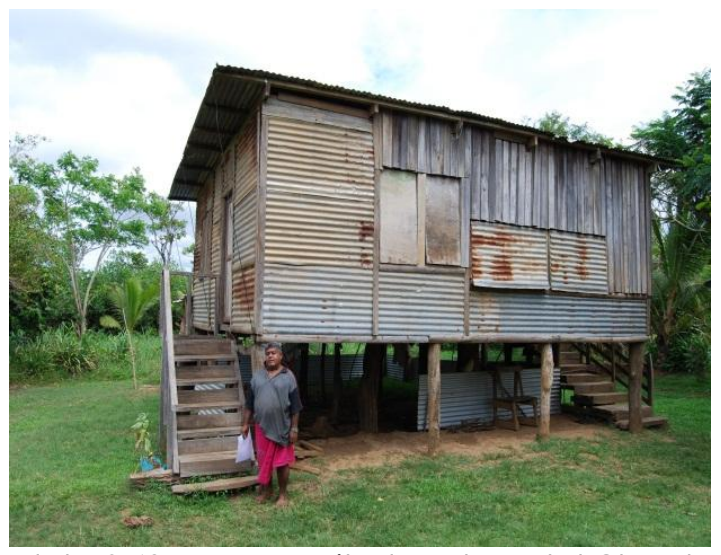

Plate 8.42. Bouma United Pentecostal Church (and pastor), October 2008.

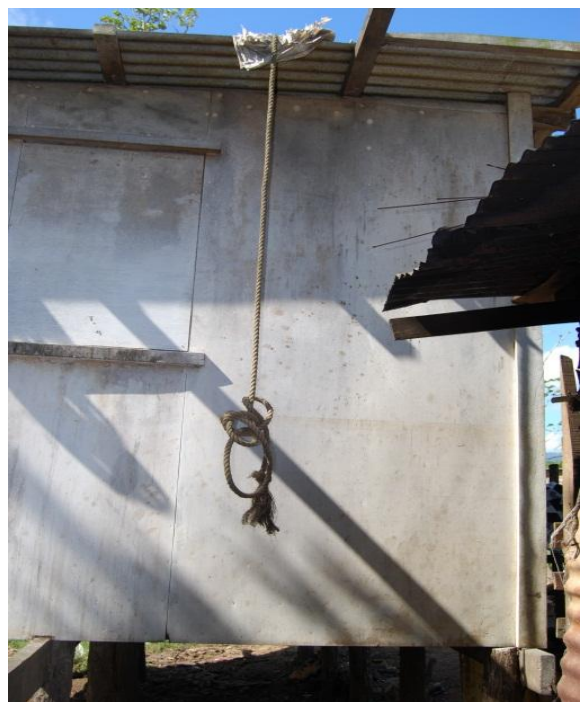

Plate 8.44. A recent flood level is clearly evident on the side of this Bouma dwelling October 2008. 


\subsection{Key Features of the Case Studies}

\subsubsection{Tenure}

Fijian informal settlements are located on all three primary categories of land tenure: state, native and freehold land. In the current research a mixture of communities were selected - with the Suva and Labasa settlements situated on state land and the Lautoka and Ba settlements on native land. Primary land tenure is one of the most significant variables influencing the nature of informal settlements. Across settlements in Fiji, for example, communities on state land tend to be more central, older, and more congested; whereas communities on native land tend to be on the urban periphery, newer, and more dispersed. Within the research sample, Lagilagi in central Suva and Tauvegavega in Ba certainly meet this general profile. Lagilagi, for example, part of one of Fiji's oldest informal settlements (Jittu Estate), has been targeted by settlers due to its very close proximity to employment opportunities, educational facilities and other urban services - and, as such, is very congested. Tauvegavega, on the other hand, is situated on large tracts of native land outside the official Ba town boundary, was settled more recently, and is, by area, a very large and dispersed community.

The category of land tenure also influences how settlers gain access to a community. Settlements on state and freehold land, for example, are typically settled without new arrivals requesting permission from the legal owners of the land. On the other hand, settlements on native land are typically accessed through new arrivals directly negotiating specific informal agreements with landowners; what are known locally as vakavanua arrangements. However, as will be explained in more detail below, changes and confusions around legal land ownership mean that in many communities access is organised in a variety of different ways - often with a variety of different agents who have some real or perceived claim of ownership to the land.

All squatters/informal settlers in Fiji, by definition, do not own the land that they reside on; that is, they have no legal security of land tenure. However, by house tenure they can be differentiated in simple terms three-fold. Most settlers, having built or relocated a dwelling onto a site, or having purchased an established dwelling, can be conceptualised as occupying owners - that is, they are occupying land with very little security of tenure but hold much more significant tenure and ownership rights to their individual dwellings. As will be seen in the next chapter, across the seven case studies, 
around $89.5 \%$ of all households interviewed fell into this category. A second smaller group of residents are renting accommodation in settlements. These residents lease dwellings from resident and absentee landlords or sublet a room or part of a dwelling. Across the sample $6 \%$ of all households interviewed were renting. A third group of settlers can be conceptualised simply as occupiers. Those in this category hold almost no tenure/ownership rights to the dwellings that they reside in as they are 'looking after' dwellings for absentee owners (usually extended family) - although over the years, particularly when the owners of the dwelling have migrated, tenure/ownership rights for occupiers do often increase. Across the case studies $4.5 \%$ of households interviewed were occupying dwellings.

\subsubsection{Settler Origins and the Nature of Movement}

As was revealed in Chapter 5, migration to informal settlements in Fiji tends to be from the rural periphery to the urban core - particularly movement emanating from the outer islands and the interiors of Viti Levu and Vanua Levu. From the sample of case studies, this general trend was reflected particularly in movement towards Vunato in Lautoka and Bouma in Labasa. In Vunato, for example, most residents interviewed had arrived from outer islands (the Lau Group and the Yasawa Islands especially) or the Viti Levu interior; and, in Bouma, most new arrivals had come from across rural Vanua Levu. The nature of movement to informal settlements across the sample was not, however, always so clear cut. In Lagilagi, Caubati Topline and Lakena Hill Two in the Suva area, for example, many migrants had come from neighbouring rural areas (with home villages often being only a drive of 0.5-2 hours away). These residents also often returned to their villages on holidays and weekends and for farming activities. In Tauvegavega in Ba movement also tended to be localised; with many residents arriving in the settlement from neighbouring, not distant, farming hinterlands (prompted, in part, by agricultural lease expiry and uncertainty). Finally, across the case studies, an informal settlement often did not constitute the first urban location following a move from a rural area. In many cases, for example, families had first rented in low-cost (but still often unaffordable in the longer-term) formal sector housing in urban areas, or stayed with extended family in other sectors of the city, before eventually moving to an informal settlement. As will be discussed in the next chapter, in a relatively small number of cases families had moved from another informal settlement. 
Overall, across the seven case studies, the type of movement to informal settlements was diverse in nature. This movement often constituted rural to urban migration but also sometimes made up urban to urban flows. Movement to informal settlements, as will be discussed further below, was sometimes permanent. However, at other times, movement was more fluid with frequent returns to rural home areas and/or temporary in nature with eventual returns to rural villages planned.

Across the research sample 'push' and 'pull' factors clearly influenced migration decisions and movement. Rural lease expiry and uncertainty was often the clearest push factor pinpointed - with this influencing movement for many research participants to Caubati Topline in greater Suva and Tauvegavega in Ba particularly. The clearest pull factors, discussed in more detail in the next chapter, influencing movement to settlements, unsurprisingly, were the enhanced educational and employment opportunities of urban locations (coupled with the low-cost nature of housing in informal settlements). In Lagilagi in central Suva, for example, the settlement's extremely close proximity to concentrated employment opportunities was a major pull factor. Additionally, in Caubati Topline, many new arrivals, experiencing or facing the loss of farming leases in Vanua Levu, moved to pursue alternative livelihood opportunities in the greater Suva area. In Lakena Hill Two in Nausori, Vunato in Lautoka and Bouma in Labasa, the proximity of schools, and particularly secondary schools, was seen as a significant advantage of the settlement location. Overall, however, the various push and pull factors influencing movement decisions were very diverse.

\subsubsection{Access and Payments}

Across the seven case studies, access to settlements normally occurs in three different principal ways for new arrivals: (i) purchasing an established dwelling; (ii) organising rental accommodation; or (iii) obtaining a site, usually called a houseblock, and building or relocating a dwelling. In the third case, for communities on native land, approval is almost always needed from landowners. Access to settlements, in the majority of cases, is also facilitated by the presence of immediate and extended family, kinsfolk, and friends already living in the community. Additionally, in some cases (such as in Bouma and Vunato) church organisations have facilitated community access for members of their congregations. 
Overall, however, access to settlements occurs in a number of quite context-specific ways; usually facilitated by various types of payment. For some of the communities on state land (Lagilagi and Lakena Hill Two in the Suva area and Bouma in Labasa being the principal examples) original settlement was often a case of 'land invasion' where no permission from the state as legal owner of the land was sought. In Lagilagi, for example, where little new building now occurs, the only payments that have been made to gain access to the community are dwelling purchases (of up to a few hundred dollars) and rental payments. In Lakena Hill Two new arrivals are limited to purchasing established dwellings (sale prices reach up to a few thousand dollars) as no space exists for new building. In Lakena Hill Two the only other money paid by residents were 'fines' of around $\mathrm{F} \$ 30$ made by early arrivals to the Department of Land and Surveys (that have had the benefit of registering some claim to the land). In Caubati Topline in greater Suva access occurs through more varied channels; with some of the first residents arriving after being evicted from nearby Housing Authority land, some purchasing existing dwellings, some purchasing vacant houseblock sites, and some renting. At Caubati Topline some new residents looking for a houseblock site, despite the land being officially in state tenure, have purchased sites from existing residents already using that land (for gardens mainly). Further, at Caubati Topline, some new arrivals, incorrectly believing that the land is owned by local mataqali groups, have purchased sites from certain individuals from neighbouring urban villages.

In all the state land case studies, new building (if it still occurs) is often regulated by a small number of long-term residents; individuals who often have the most knowledge about the legal ownership of the land and procedures needed to facilitate access. This probably contributes to the considerable clustering of family groups (where a number of extended family dwellings are grouped together) in Lagilagi, Caubati Topline and Lakena Hill Two particularly.

For the settlements on native land, access to vacant area on which to build or relocate a dwelling, 60 as already mentioned, is facilitated by vakavanua arrangements - specific to communities and negotiated with specific landowners. In Vunato in Lautoka, which is $100 \%$ indigenous Fijian, vakavanua arrangements are traditional in nature: customary, organised directly with the landowner, and usually facilitated by an original traditional request and presentation (sevusevu) of yaqona, mats, kerosene, and, increasingly, cash.

60 Small rental markets existed in the native land case-study settlements; where access is facilitated by agreements with home, not land, owners. 
Beyond this initial exchange, households at Vunato meet ongoing payments due to the landowner of \$10-20 per month and must also meet customary, irregular requests for extra payments and goods (largely Fijian mats) around the time of local landowning mataqali events (such as weddings and funerals).

At Tomuka in Lautoka, vakavanua arrangements are very different in nature to those at Vunato - overall, less customary and more commercial in nature. Tomuka is a majority Indo-Fijian settlement and most new arrivals negotiate specific arrangements with the landowners ${ }^{61}$ - down to the original houseblock purchase price (of up to a few thousand dollars); terms (if this payment, sometimes called a 'goodwill' payment, needs to be paid off over a number of years); annual land rental (of up to two hundred dollars); and other terms and conditions of the 'lease' (which is usually across a term of 25 years). These lease terms and conditions are usually recorded in paper documents - often also stipulating conditions of on-sale (percentages of proceeds, usually around 10-20\%, must be paid to the landowners) and conditions and extra rents required if running businesses in the community. This type of transaction and subsequent 'lease' document is the norm for Indo-Fijian settlers at Tomuka. However, for indigenous Fijian residents in the community arrangements are more varied; sometimes involving similar arrangements but more often facilitated by more customary practices (such as sevusevu). For some indigenous Fijian families, particularly for households with tribal and church connections to the landowners, ongoing rentals are absent or dropped after a period of time. Finally, for all residents at Tomuka, irregular, customary requests for cash and goods at the time of mataqali events, in the normal Fijian customary manner, are also expected to be met.

In Tauvegavega in Ba, access and payments are again different in nature. Despite being native land, vakavanua arrangements have not been used to facilitate access largely because most residents arrived before the community transferred to native tenure in 2002. In Tauvegavega most arrivals looking for land simply build homes without seeking the approval of the state, local mataqali, or any other parties (some new arrivals also purchase existing dwellings or rent). Around half of the households interviewed in Tauvegavega had made payments of some form - either early Department of Land and Surveys 'fines' for at the time residing on state land (such as in Lakena Hill Two), or, after the transfer to native tenure, monies demanded by the Native Land Trust Board (NLTB) for what are known as 'tenancies at will' permitting a stay on the land. In the latter case,

${ }_{61}^{61}$ The local mataqali have split the community into different zones controlled by different members of the immediate landowning family. 
many households paid up to $F \$ 500$ to the NLTB (up to $F \$ 1,500$ in total was originally demanded from each household) - although considerable uncertainty, and a stalled court case, surrounds the legality of these NLTB demands (no records of payments made seem to exist at NLTB).

In summary, across the seven case studies, access to communities occurs in a number of different ways; often requiring various forms of facilitating payment. For settlements on state land, longer established residents have tended to avoid major payments; whereas newer arrivals have tended to make payments of some, usually significant, form. In state land communities, such as Lagilagi and Lakena Hill Two in the Suva area where space restrictions mean that little new building occurs, new arrivals are usually limited to purchasing existing dwellings or renting. In the native land settlements of Vunato and Tomuka in Lautoka vakavanua arrangements are quite different in nature; tending to be customary for indigenous Fijians in Vunato and Tomuka and commercial for Indo-Fijians in Tomuka. Adding complexity, however, is the fact that, in many communities, land tenure is often confused and sometimes contested. This means that new arrivals often negotiate with all sorts of agents claiming ownership or control of land; leaving settlers vulnerable to extra monetary demands. Access arrangements will be discussed more in the next chapter.

\subsubsection{Markets for Land and Dwellings}

As was discussed in the previous section, active markets, involving the buying and selling of dwellings, exist in all case-study communities and form a key avenue through which new entrants gain access to a settlement. Across the case studies, prices for dwellings ranged from a few hundred dollars for poorer quality, less permanent dwellings (such as in Lagilagi in central Suva) to a few thousand dollars for higher quality, more permanent dwellings, in established settlements such as Lakena Hill Two in Nausori and Tomuka in Lautoka. In addition to a market for dwellings, an active market for land sales is also present in some of the case-study settlements; despite the fact that no informal settlers in Fiji have any legal security of tenure. Land sales occur particularly in Tomuka where houseblock sites are clearly demarcated, and to a lesser degree the state land settlements of Lagilagi, Caubati Topline, and Lakena Hill Two in the Suva area. It is in Tomuka, however, where considerable amounts of vacant land are still available, that the most vibrant land market for land sales exists. In this community, vacated or still 
vacant62 houseblock sites sell for upwards of a few thousand dollars; forming a significant revenue earner for the local landowners.

\subsubsection{Ethnicity and Household Composition}

Chapter 5 revealed that there are relatively equal numbers of indigenous Fijian and Indo-Fijians, as the nation's two principal ethnic groups, living in Fiji's informal settlements. Across the seven research case studies, all communities, with the exception of Vunato in Lautoka, had sizable populations of both major ethnic groups living side-by-side in considerable daily interaction. Vunato by nature is quite different to the other six research case studies; accessed via customary channels and appearing more as an urban indigenous Fijian village.

As has been already discussed, ethnicity is an important variable particularly when obtaining access to a settlement on native land. Indigenous Fijians, for example, can more readily facilitate access through customary practices and obviously can have tribal connections with landowning groups. Indo-Fijians, on the other hand, must usually resort to vakavanua arrangements that are more commercial in nature; such as those at Tomuka in Lautoka for example.

Across the informal settlement case studies, as will be discussed further in the next chapter, average household sizes tended to be higher than the Fijian norm. For indigenous Fijian households in the sample the average household size was 5.8 (compared with 5.25 as the national norm for all indigenous Fijian households (Fiji Islands Bureau of Statistics, 2008)). For Indo-Fijian households interviewed the average household size was 4.6 (compared with 4.17 as the national norm for all Indo-Fijian households (ibid)). Indigenous Fijian households in the seven case studies often included members of extended family; with considerable comings and goings related to work availability, village-based farming activities and communal responsibilities, and school or tertiary institution terms. Indo-Fijian households, on the other hand, were more nuclear in structure; although often were accommodating visiting family from overseas for short and medium terms.

${ }^{62}$ Many moving or evicted families from Tomuka choose to dismantle and relocate their dwelling. 


\subsubsection{Livelihoods}

As will be discussed in more detail in the next chapter, across the seven case studies, average household incomes tended to be low. Livelihoods were often based on variable casual work, low-paid service sector employment, security work, uncertain and irregular informal sector income, government social welfare payments, support from family, or child support payments for single mothers. Women were important income earners across the case studies; typically engaged in work in the low-paid service sector, garment factories, 63 and in informal sector. Across the case studies, among the poorest households were single-parent families; typically widows or separated or divorced mothers raising children alone. Those families with sick and disabled former breadwinners were also among the most destitute.

Diverse informal sector activity was significant across all seven case studies. Those households solely reliant on the informal sector largely depended on casual labouring to support their livelihoods - grass-cutting and carpentry were frequent examples. Most often, however, informal sector activity complemented other sources of income; examples included backyard tailoring, home car mechanics, small-scale retail via household-based canteens (selling consumer products such as cigarettes, biscuits and tinned fish and meat), and yaqona sales.

Many households interviewed did not rely on a single income earner. In many cases, two, three, or more individuals (of immediate and extended family) from an individual household were earning incomes from various sources and contributing to household expenses. In some cases (depending on total household size and the number of dependents being supported) these households were relatively better off compared to their neighbours relying on fewer income streams.

Backyard and local gardening, across all case studies, was vital in supporting livelihoods; through reducing food spending and raising cash by selling surplus. Almost all households interviewed were producing fresh produce of some form. Some gardens were very small; for example, just a few tomatoes, chilli and cabbages might be grown in houseblock sites for immediate family consumption. Some families in their houseblock sites were able to grow more significant amounts of key food staples - such as dalo

${ }^{63}$ A surprisingly large number of women interviewed had once worked in garment factories - but had lost jobs through the industry changes discussed in Chapter 4. 
(taro) and cassava for consumption and sale - and some families also farmed significant amounts of staples on land around the community. Overall, across the case studies, urban gardening was more significant in the peri-urban and less congested settlements of Lakena Hill Two in Nausori and Vunato and Tomuka in Lautoka. In the central communities of Lagilagi and Caubati Topline space restrictions and congestion meant that urban gardening was less significant - although some indigenous Fijian individuals from these communities were growing crops in vacant areas of urban land nearby. At Tauvegavega in Ba and Bouma in Labasa, poor quality soils, and regular flooding, respectively reduced the viability of urban gardening on larger scales.

Ethnicity was a very important variable influencing the significance of urban gardening. Indo-Fijian families, for example, typically grew just a small amount of food in their houseblocks for immediate family consumption. Many indigenous Fijian families, on the other hand, grew food on a much larger scale. At Vunato and Tomuka in Lautoka, for example, many indigenous Fijian families, through their various vakavanua arrangements with the landowners, were provided with additional land outside their immediate houseblock site on which to plant food; seen by many of these families as absolutely crucial to supporting their livelihoods. Finally, many indigenous Fijians, predominately residing in settlements, grew crops (often on a much larger scale) on their own mataqali land in home villages (if in neighbouring areas) - and returned home often to tend these plantations and bring food to urban markets.

Across the case studies, remittances from abroad were often an important, but irregular, income stream. Many indigenous Fijian families interviewed, for example, had family members serving overseas in armed forces (particularly for Great Britain) or as private security contractors in the Middle East - who often sent remittance payments home. Many Indo-Fijian families interviewed also irregularly received money from family abroad; windfall payments that would often be used for major purchases and housing extensions and improvements.

\subsubsection{Marginal Locations and the Nature of Dwellings}

Chapter 5 revealed that the majority of informal settlements in Fiji are situated on environmentally marginal areas; for example, lowland, flood prone locations or steep hill slopes. The research case studies were often no different. Caubati Topline in greater Suva and Tauvegavega in Ba, for example, are located on hilly terrain. In these areas, 
feeder roads are of poor quality and wet season access is difficult. In addition, in some parts of Tauvegavega, major levelling earthworks were required before new building and to create road access; adding expense for new settlers. In addition, Lakena Hill Two in Nausori, situated on the crest of a small hill, is exposed to hurricanes; a number of which over the years have significantly damaged dwellings. Finally, Bouma, located on the banks of the Labasa River, and Vunato, situated in a lowland coastal area of Lautoka, are highly vulnerable to flooding. At Bouma, for example, frequent annual floods at the height of the wet season rise into dwellings and a number of devastating floods have forced total rebuilds for some households over the years. At Vunato annual floods in December and January also rise into dwellings and more damaging floods strike irregularly. Both Bouma and Vunato were heavily hit by the catastrophic flooding across Fiji in December 2008.

The fact that settlements are usually in marginal locations affects the nature, and overall quality, of dwellings in informal settlements. Along with Lagilagi in central Suva, for example, both flood prone Bouma and Vunato generally had the poorest quality dwellings across the case studies. Dwellings at Vunato and Bouma are also raised on stilts to minimise flood impact. Across the seven case studies most dwellings tended to be constructed of make-shift and temporary materials; usually wood and corrugated iron. The lower cost of these materials was clearly important (indeed many dwellings, in part or in full, were constructed of materials obtained freely or donated from others). Insecurity of legal land tenure means that the portability of dwellings is another key consideration and many settlers are prepared to move (and relocate their dwelling) if necessary. Indeed, across the case studies, (and in Caubati Topline, Vunato and Tauvegavega particularly) many dwellings had been dismantled and relocated to the settlement area (in Caubati Topline some dwelling materials had come from as far as Vanua Levu).

Although the majority of dwellings across the sample were of relatively poor quality, a number of higher quality dwellings were identifiable. For example, in Lakena Hill Two in Nausori, Tomuka in Lautoka, and Tauvegavega in Ba, particularly, a number of high quality, concrete, and hence very permanent, dwellings existed. The considerable investment expended into these dwellings, by settlers without any legal security of tenure, may suggest that in some settlements at least some households may feel secure enough to improve their homes to relatively high standards. 
Across the case studies, ethnicity was an important variable influencing the nature of dwellings. Generally, for example, Indo-Fijian households tended to prefer more compartmentalised dwellings with a discrete living room, kitchen and bedrooms. Typical Indo-Fijian households also tended to be more concerned with personal security issues. For example, in Tomuka in Lautoka and Tauvegavega in Ba particularly, many Indo-Fijian households had invested in high fencing (at Tomuka) and burglar bars and security grills (in both communities). Typical indigenous Fijian households, on the other hand, tended to prefer more open dwellings; often with just one large communal living, cooking and sleeping space (in some cases divided by curtains for privacy).

\subsubsection{Services and Infrastructure}

Across the case studies, $98.5 \%$ of households interviewed enjoyed a piped water supply. ${ }^{64}$ There was, however, considerable sharing of water meters; particularly in more congested communities and in settlements where individual houseblock sites were not clearly demarcated. In some communities the high number of users sharing a single meter (for example, at Bouma in Labasa) and hilly terrain (for example, at Tauvegavega in $\mathrm{Ba}$ ) mean that the water supply is variable and sometimes nonexistent (at Tauvegavega, in past dry seasons, for example, water supply for many higher households was zero; forcing families to collect water elsewhere).

The majority (77.5\%) of households across the sample enjoyed a mains electricity supply. In Lakena Hill Two in Nausori, Tomuka in Lautoka, and Tauvegavega in Ba most households with electricity had their own meter. In Lagilagi and Caubati Topline in the Suva area and Vunato in Lautoka considerable sharing of electricity meters occurred 65 with some households being limited, through agreements with households with meters, to electricity in evening hours only. In Bouma no households had mains electricity (although some used generators).

In Fiji a landowner signature is needed as part of the paperwork for new power and water connections. For many households across the case studies this led to considerable difficulty. For those settlements on state land, for example, settlers desiring a new utility connection need to obtain the necessary signature from the state as legal owner of the

\footnotetext{
${ }^{64}$ The $1.5 \%$ of households across the sample without a piped water supply usually collected water from family and friends in other parts of the settlement.

65 The considerable extent of utility sharing across communities means that disputes are common when dividing bill payments between various households.
} 
land (usually from a civil servant at the Department of Land and Surveys or the Housing and Squatter Resettlement Unit). For communities where legal land tenure for many residents was confused (for example Caubati Topline: officially state land, but thought by many residents to be in native tenure) and contested (for example Tauvegavega: claimed by a number of local mataqali) the process was very difficult - leaving settlers vulnerable to exploitation and extra monetary demands. In many cases across the sample, for example, settlers were forced to pay (perhaps around fifty to a hundred dollars) to legitimate landowners and pretenders for utility connection signatures.

Informal settlers in Fiji, many living in communities within official town boundaries (such as in Lagilagi and Caubati Topline in the Suva area and Vunato and parts of Tomuka in Lautoka) do not pay council rates. As such, town councils are not encouraged to provide any services or expand infrastructure into settlement areas. Further, for communities outside of official town boundaries (such as Lakena Hill Two in Nausori, Tauvegavega in Ba, and Bouma in Labasa) there is no compulsion at all for councils to provide services and build infrastructure. Thus, none of the case-study settlements enjoyed sewage connections. Toilet facilities were rather usually of latrine (pit), waterseal66 (to tank), and flush (to tank) style; in some cases leading to sanitation concerns (such as when pit toilets overflow or in the wet season). Across the case studies, permanent electricity infrastructure seldom reached deep into communities (apart from in Lakena Hill Two and Tauvegavega). In most cases electricity connections were jury-rigged from permanent infrastructure in adjacent areas. Access roads into communities were also often poorly maintained and thus of low quality; affecting the viability of public transport connections for peri-urban communities. Organised waste collection was also very minimal across all case studies (the one example was a single skip bin, infrequently collected, at Caubati Topline). Thus, across all case-study communities, household waste was burnt or buried on site or dumped in designated spots in the settlements or in adjacent areas (including on the banks of the Labasa River in the case of Bouma). Service and infrastructure coverage will be discussed further in the next chapter.

\subsubsection{Community Organisation and Advocacy}

In all case-study settlements the church and religious bodies play important roles in community life and organisation. Active congregations were present in five of the seven

${ }^{66}$ A waterseal toilet is manually flushed using a bucket of water. 
case studies; typically comprising one or a few Christian denominations and, in the case of Lagilagi and Lakena Hill Two, Hindu and Muslim places of worship. ${ }^{67}$ Across the casestudy settlements, churches also organised various groups, such as youth and women's collectives, that helped to pull members of the community together. Some communities (such as Lagilagi, Caubati Topline and Lakena Hill Two in the Suva area) were relatively well organised with many residents active in various community committees (examples included crime prevention committees and neighbourhood watch groups, health committees, a multi-racial mothers' club, a community clean-up group, and a group for the elderly and disadvantaged).

The case-study settlements that were clearly the most organised were those located in the greater Suva area. Lagilagi and Lakena Hill Two were highly organised, and Caubati Topline, at the time of research, was beginning to be so. Lagilagi and Lakena Hill Two were, of course, among the more established of the case-study settlements; but the activities of the PCN were also very important in facilitating community organisation in the three greater Suva communities. In Lagilagi, for example, the PCN was organising community savings groups in preparation for the PCN/ECREA flagship community upgrading pilot project, and facilitated a number of other community committees. A number of individuals from Lagilagi were also key members of wider groups active across the PCN. In both Caubati Topline and Lakena Hill Two the PCN had also organised community savings groups and PCN committee structures.

The PCN was also very important in advocating for the needs, rights and aspirations of settlers in Lagilagi, Caubati Topline and Lakena Hill Two; and, in overall terms, raising the collective voice of its members (at the time of research 45 communities in the greater Suva area were part of the PCN). The case-study settlements in Lautoka, Ba and Labasa, however, enjoyed very little support and advocacy from NGOs and other external organisations. These settlements continued to struggle on the margins of society to have their needs prioritised by municipal councils and national government.

\footnotetext{
${ }^{67}$ Churches and religious organisations present in the case-study communities included: Lagilagi (Methodist and Pentecostal denominations and Hindu temples); Lakena Hill Two (three Christian denominations and Hindu and Muslim temples); Vunato (Methodist and Seventh Day Adventist denominations); Tomuka (Methodist denominations); and Bouma (the United Pentecostal Church). Churches or religious organisations were not present in Caubati Topline or Tauvegavega (although numerous churches and places of worship were nearby).
} 


\subsubsection{Evictions}

At the time of research, no current significant eviction pressures were present at Lagilagi, Caubati Topline and Lakena Hill Two in the Suva area, Tauvegavega in Ba, and Bouma in Labasa. In the past, however, eviction threats had been real, or more significant, for most of these communities. For example, in the late 1980s, residents at Lagilagi were very close to being forced off the land. 68 Additionally, at Lakena Hill Two, over the years residents had endured various eviction threats from the state and local mataqali groups unlawfully claiming the land. At Tauvegavega, after transfer into native tenure in 2002, residents had been warned by the NLTB that failure to pay the $\mathrm{F} \$ 1,500$ demanded for 'tenancies at will' would lead to eviction. At the native land settlement of Tomuka in Lautoka, eviction threats are omnipresent for many residents - if they fall behind in payments to the landowners or cause trouble within the community. At Tomuka, despite most residents possessing 'lease' documents, most settlers clearly realised the tenuousness of their situation and the fact that their 'leases' had no basis of legal enforcement.

At the time of research, and as was discussed in Chapter 6, eviction threats were very significant for a number of other state land communities in central Suva. Many whole community evictions, particularly from state and freehold land areas across Fiji, had also occurred in previous years. These ongoing eviction threats and past events tend to be highly publicised in national media. News and rumours of evictions tend to spread fast through other informal settlement areas. Overall, past and current eviction threats for individual settlements affect all informal settlements across the nation - as will be discussed in much more detail later, forming one of the key variables influencing perceptions of security of tenure.

\subsection{Summary}

Certain features characterise the seven research case studies. The selected informal settlements tend to be in marginal locations. Dwellings tend to be of poor quality. Settlements are poorly serviced, and utility connections are haphazard and often unreliable. Residents of the case-study settlements also tend to be low-income earners; often dependent on the informal sector and home gardens to complement incomes.

\footnotetext{
68 This pressure came from a powerful political figure upset after a local murder.
} 
The key defining feature of all informal settlements across Fiji, however, is insecurity of legal land tenure.

The case studies also reveal the diverse nature of informal settlements. The wide variety of access arrangements, often facilitated by various types of payments to different agents (some with legitimate, and some with illegitimate, legal claims to the land), is one principal example. Key differences also exist between settlements on state and native land; particularly important in shaping the nature of access arrangements. The Vunato and Tomuka cases in Lautoka, for example, reveal that vakavanua arrangements are often very different in nature. The case studies also highlight that land tenure changes and confusions also increase the vulnerability of informal settlers; often leading to additional monetary demands.

Movement to informal settlements is diverse in nature; both permanent and temporary (and not necessarily an initial case of rural to urban migration). The peri-urban nature of many settlements, and the fact that many residents appear to frequently return temporarily to home rural areas (at weekends and holidays and for farming, for example), also tends to blur the rural/urban divides that often frame analysis of urban (and rural) issues.

All of the research case studies are different, but essential examples helping to understand the nature and diversity of informal settlements in Fiji (and processes leading to their growth). Vunato and Tomuka reveal the diversity (and vulnerability) of vakavanua arrangements for communities on native land. Tauvegavega in Ba and Caubati Topline in greater Suva, as the destination of many migrants affected by rural lease expiry and uncertainty, focus attention on this important group; and also reveal the difficulties for migrants when land tenure is confused or contested. Lakena Hill Two in Nausori focuses attention on a peri-urban community where the prospect of legal security of tenure has tantalised settlers for many years. The flagship pilot upgrading project at Lagilagi in central Suva also makes this settlement worthy of special attention. Finally, Bouma in Labasa showcases the Vanua Levu experience and the environmental vulnerability (in this case the high risk of flooding) of many informal settlements.

Security or insecurity of tenure needs to be understood in ways that extend beyond a legal/illegal dichotomy. All informal settlements in Fiji have no legal security of tenure. However, the international perceived security of tenure literature discussed in Chapter 2, 
the diverse nature of settlements in Fiji, and the variation in home quality evident (particularly in Lakena Hill Two, Tomuka and Tauvegavega) suggest that perceptions of security of tenure are also important to reveal. All sorts of different variables may influence the nature of perceived security of tenure within informal settlements. Perceived security of tenure is also a key variable influencing the nature of housing consolidation, and thus home quality, in settlement areas. These avenues of investigation will be detailed in the next two chapters that reveal key results from the research and focus attention on the guiding central research question and key objectives shaping the study. 


\section{CHAPTER 9: KEY RESULTS - SOCIO-ECONOMIC CHARACTERISTICS, MOVEMENT, ACCESS, LIVELIHOODS, AND SERVICES AND AMENITIES69}

\subsection{Introduction}

This chapter, the first of two key results chapters, presents information from the field research exploring a number of themes applicable to settlement areas including: basic socio-economic characteristics (including tenure status and length of residence); the nature of movement to and from informal settlements; access arrangements; livelihoods; and the nature of services and amenities. A number of data sources are utilised to explore these themes, including: basic quantitative and qualitative information derived from research interviews; official 2007 census releases and national and case-study level census information made available directly by the Fiji Islands Bureau of Statistics; 70 and, to a lesser degree, 2002/2003 Household Income and Expenditure Survey (HIES) data.71 The information presented all provides important context highlighting the nature, commonalities and differences of the selected case studies, before the nature of perceived security of tenure and housing consolidation in the case studies, the central focus of this research, is presented in the next chapter.

\subsection{Basic Socio-Economic Characteristics: Household Size and Average Incomes}

Table 9.1 below shows information on average respondent household size across the case-study communities. These figures from the sample can be compared with those in Table 9.2; obtained and calculated from the 2007 census information. Table 9.1 shows that the average household size across the research sample was 5.2 - higher than the national figures from 2007 census data for all Fijian squatter settlements (5.0) and all

\footnotetext{
69 Key sections of this chapter and Chapter 10 - effectively the central statistical results from the research have been published in the article: Kiddle, G.L. (2010) 'Perceived security of tenure and housing consolidation in informal settlements: Case studies from urban Fiji', Pacific Economic Bulletin, 25(3), pp. 193-214.

70 At the time of writing, analysis of the 2007 national census data was still continuing and no official information had been released on housing characteristics or squatter settlements by the Fiji Islands Bureau of Statistics (summary census information and official releases on national population growth and structure and labour market characteristics were available). The case-study level census data provided directly by the Fiji Islands Bureau of Statistics can only be presented for Lagilagi, Caubati Topline, Lakena Hill Two, Tauvegavega and, partly, Tomuka. Unfortunately census data is not available for Bouma (this very small community is part of a much larger census enumeration area). Data gaps and inconsistencies and the make-up of census enumeration areas also mean that information for Vunato and some data for Tomuka is unavailable and/or unreliable.

71 2002/2003 is the most recent available full HIES data.
} 
households (4.75) seen in Table 9.2. Table 9.1 also reveals that across most of the research sample the average size of indigenous Fijian households was larger than for Indo-Fijian households (with Lakena Hill Two as the exception). Across all case-study communities the average indigenous Fijian household size was 5.8 and Indo-Fijian household size was 4.6. The census information from Table 9.2 also reveals that squatter households tend to be larger in size than the average for all Fijian households.

Table 9.1. Average Household Size, All Case Studies, Research Sample

\begin{tabular}{|l|r|r|r|c|}
\hline Community & Indigenous Fijian & Indo-Fijian & Other & All Ethnic Groups \\
\hline & & & & \\
\hline Lagilagi & 4.7 & 3.5 & n.a. & 4.6 \\
\hline Caubati Topline & 5.5 & 4.3 & n.a. & 4.7 \\
\hline Lakena Hill Two & 4.8 & 5.4 & 5 & 5.1 \\
\hline Vunato & 7.2 & n.a. & n.a. & 7.2 \\
\hline Tomuka & 6.5 & 5.1 & n.a. & 5.5 \\
\hline Tauvegavega & 8 & 4.3 & n.a. & 4.7 \\
\hline Bouma & 5.2 & 4 & 3 & 4.8 \\
\hline & & & & \\
\hline All Communities & 5.8 & 4.6 & 4 & 5.2 \\
\hline
\end{tabular}

Source: Fieldwork data

Table 9.2. Average Household Size, Lagilagi, Caubati Topline, Lakena Hill Two, Tomuka, Tauvegavega and all Fiji, 2007 Census Information

\begin{tabular}{|l|r|r|r|r|}
\hline Community & Indigenous Fijian & Indo-Fijian & Other & All Ethnic Groups \\
\hline & & & & \\
\hline Lagilagi & 5.4 & 2.8 & 8 & 4.6 \\
\hline Caubati Topline & 6.3 & 4.4 & 5.3 & 4.9 \\
\hline Lakena Hill Two & 5.1 & 4.5 & 4.8 & 4.7 \\
\hline Tomuka & 5.3 & 4.1 & 4.9 & 4.6 \\
\hline Tauvegavega & 6 & 4.4 & 3 & 4.5 \\
\hline & & & & \\
\hline All Fiji (squatter settlements) & 5.7 & 4.3 & 4.9 & 5 \\
\hline All Fiji (all households) & 5.25 & 4.17 & 4.49 & 4.75 \\
\hline
\end{tabular}

Source: Fiji 2007 census data; Fiji Islands Bureau of Statistics, 2008

Tables 9.3 and 9.4 below reveal average income details for the case-study samples. Table 9.3 shows that the average household monthly income across the sample was 
F\$592. Across all case-study communities the average monthly income for indigenous Fijian households was $\mathrm{F} \$ 652$ and for Indo-Fijian households $\mathrm{F} \$ 566$. However, because indigenous Fijian households tend to be larger than Indo-Fijian households, the more pertinent figures are revealed in Table 9.4; showing that the average household income per person per day across the sample for indigenous Fijian respondents was $F \$ 2.56$ and for Indo-Fijian respondents a much higher $\mathrm{F} \$ 4.08$. Table 9.4 also reveals the quite significant variation in household income per person per day across the case-study communities; ranging from $F \$ 2.70$ in Bouma to $F \$ 4.77$ in Caubati Topline.

Table 9.3. Average Household Monthly Income, Fijian Dollars, All Case Studies, Research Sample

\begin{tabular}{|l|c|c|c|c|}
\hline Community & Indigenous Fijian & Indo-Fijian & Other & All Ethnic Groups \\
\hline & & & & \\
\hline Lagilagi & 570 & 365 & n.a. & 547 \\
\hline Caubati Topline & 479 & 638 & n.a. & 596 \\
\hline Lakena Hill Two & 434 & 496 & 200 & 448 \\
\hline Vunato & 965 & n.a. & n.a. & 965 \\
\hline Tomuka & 751 & 714 & n.a. & 725 \\
\hline Tauvegavega & 310 & 502 & n.a. & 483 \\
\hline Bouma & 434 & 291 & 280 & 380 \\
\hline & & & & \\
\hline All Communities & 652 & 566 & 240 & 592 \\
\hline
\end{tabular}

Source: Fieldwork data

Table 9.4. Average Household Income Per Person Per Day, Fijian Dollars, All Case Studies, Research Sample

\begin{tabular}{|l|r|r|r|c|}
\hline Community & Indigenous Fijian & Indo-Fijian & Other & All Ethnic Groups \\
\hline & & & & \\
\hline Lagilagi & 4.5 & 2.89 & n.a. & 4.32 \\
\hline Caubati Topline & 3.88 & 5.08 & n.a. & 4.77 \\
\hline Lakena Hill Two & 3 & 3.47 & 1.33 & 3.11 \\
\hline Vunato & 4.65 & n.a. & n.a. & 4.65 \\
\hline Tomuka & 4.27 & 4.36 & n.a. & 4.33 \\
\hline Tauvegavega & 1.29 & 3.83 & n.a. & 3.58 \\
\hline Bouma & 2.95 & 2.23 & 3.11 & 2.7 \\
\hline & & & & \\
\hline All Communities & 2.56 & 4.08 & 2.22 & 3.92 \\
\hline
\end{tabular}


The average monthly income figures from the research sample can be compared to the 2002/2003 HIES data displayed in Table 9.5 below. This table reveals that the average monthly incomes of the households in the research sample are significantly lower than the 'all Fiji' and urban categories from the 2002/2003 HIES data. The 2002/2003 HIES data also categorised average household income by residential status. The data reveals that the average monthly income for households in 'Squatter and Urban Village' areas was F\$21.87 (compared to F \$1,478.19 in 'High and Middle Class' housing areas and F\$1,027.74 in 'Settlement and Housing Authority' areas) (calculated from Abbott, 2006, p. 12) - figures that are significantly higher than those in the research sample. ${ }^{72}$

Table 9.5. Average Monthly Household Incomes, Fijian Dollars, 2002/2003 HIES Data

\begin{tabular}{|c|c|c|c|}
\hline Category & Indigenous Fijian & Indo-Fijian & All Fiji \\
\hline Rural & 923.5 & 804.42 & 879.92 \\
\hline Urban & 1378.25 & 1132.75 & 1272.25 \\
\hline All & 1081 & 991.83 & 1062.75 \\
\hline
\end{tabular}

Source: Calculated from Narsey, 2006, p. 3

\subsection{Tenure Status and Length of Residence in Informal Settlements}

Research data (see Table A.1 in Appendix 5) reveals that by far the majority of households (89.5\%) across the research sample can be classified by tenure status as 'land occupying, dwelling owners'. As squatters/informal settlers these households clearly have no legal ownership rights to the land that they reside on, but they do hold much stronger rights to the dwellings that they live in. This majority group will henceforth be labelled 'occupying owners'. Across the sample the dominance of occupying owners can be compared with renters (6\%) and 'others' (4.5\%). The group 'others' mainly encompasses occupiers who are looking after dwellings for owners (usually family) who are absent (and usually offshore).

\footnotetext{
72 These residential status categories in the 2002/2003 HIES are a little confusing and problematic. Officially 'Settlement and Housing Authority' areas are those areas which have been designated for housing, and 'Squatter and Urban Village' areas are informal. However, pockets of squatter areas are also located in high and middle class housing areas as well as settlement and Housing Authority areas (D. Abbott, personal communication, September 2, 2009). The category 'Squatter and Urban Village', however, is best used for comparisons with the field research sample (despite this category including urban villages - which may explain why the average monthly incomes for households in squatter and urban village areas from the HIES data are significantly higher than average monthly incomes from the research sample).
} 
Table 9.6 below reveals the history of settlement in each case-study community; for example, showing how settlement at Caubati Top Line, Tauvegavega and Bouma is much more recent than at Lagilagi, Vunato, Lakena Hill Two and Tomuka. At Lagilagi and Vunato initial settlement extends back to the 1960s or earlier. Specifically, the table shows the average length of participant residence across the case studies (of household length of residence or partner length of residence, if longer); revealing that the average length of residence across all case studies was long at 15.6 years. The table also shows that average length of community residence was longest at Lagilagi (29.5 years), Lakena Hill Two (17.8 years), Vunato (17.8 years) and Tomuka (17.5 years) and shortest at Bouma ( 6.5 years) and Caubati Topline (6.7 years).

Table 9.6. Average Length of Community Residence (Primary Interviewee or Partner), All Case Studies, Research Sample

\begin{tabular}{|l|r|}
\hline Community & Average Years \\
\hline & 29.5 \\
\hline Lagilagi & 6.7 \\
\hline Caubati Topline & 17.8 \\
\hline Lakena Hill Two & 17.8 \\
\hline Vunato & 17.5 \\
\hline Tomuka & 11.5 \\
\hline Tauvegavega & 6.5 \\
\hline Bouma & 15.6 \\
\hline All communities &
\end{tabular}

Source: Fieldwork data

\subsection{The Nature of Movement}

As this section will reveal, the nature of movement to and from informal settlements is diverse. This section explores the nature of movement by tabulating interview basic data; by investigating 2007 census data on locality at birth and locality in 2002 for casestudy residents (where data is available); and by extracting interview citations to showcase motivations for movement and plans for future movement. Research data on location of prime fieldwork interviewee immediately prior to moving to their current community (see Appendix 5; Table A.2) has been used to create Figures 9.1 and 9.2 below. Figure 9.1 reveals that the largest category (44.5\%) of all research respondents had previously resided in other urban areas of their current province. This category was followed by rural areas in the Central Division (14\%), Western Division (13.5\%), Northern 
Division (10.5\%) and Eastern Division (6.5\%) respectively. The data also reveals that 52\% of respondents had previously resided in an urban area (either in their current province or elsewhere in Fiji). This figure compares with $44.5 \%$ of respondents previously residing in a rural area. This is charted in Figure 9.2 below. In short, this data challenges a common view that movement to informal settlements primarily constitutes rural to urban flows. 
Figure 9.1. Location of Previous Residence, Urban Area within Province and Rural Area by Division, All Case Studies, Research Sample

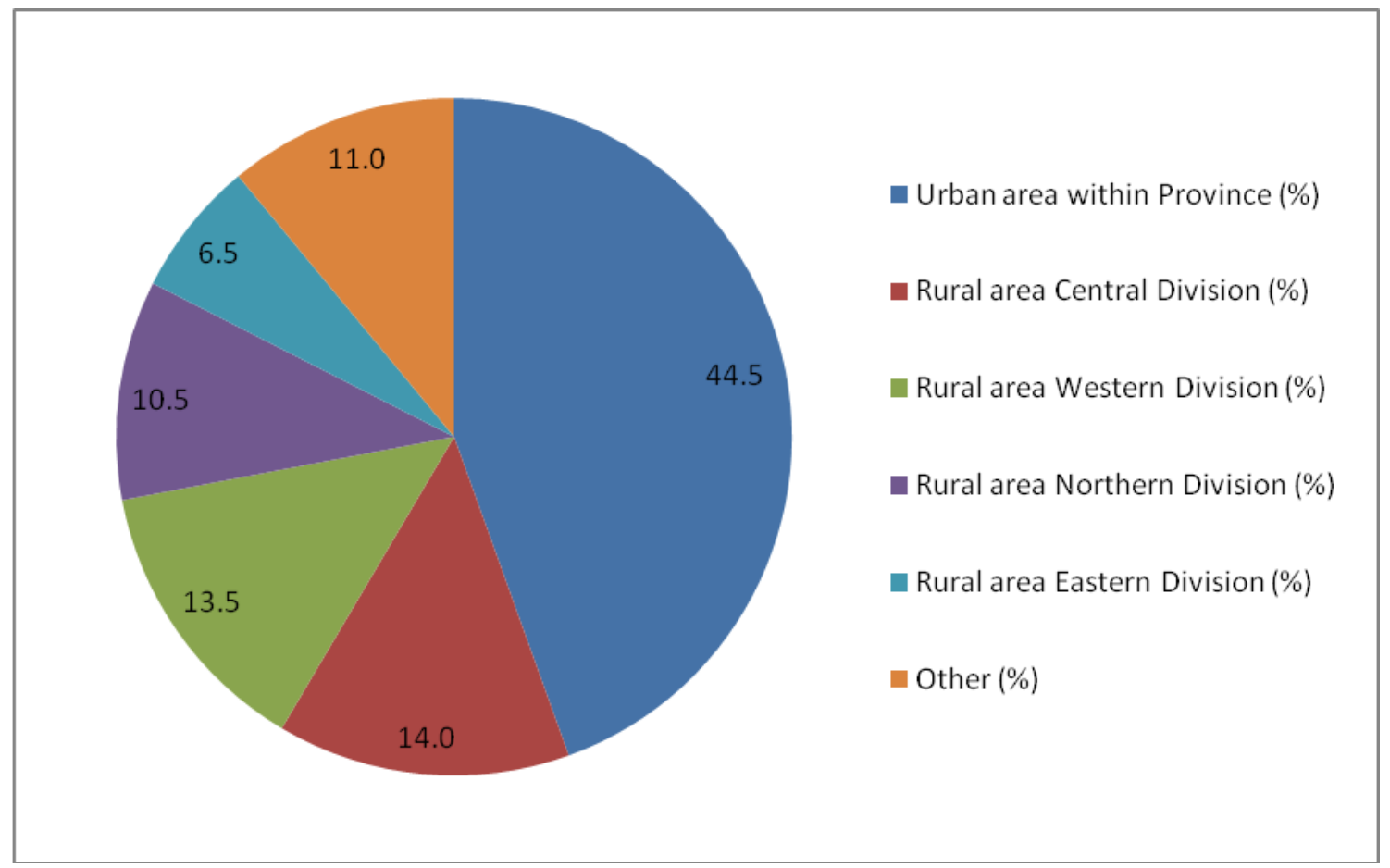

Source: Fieldwork data

Figure 9.2. Location of Previous Residence, All Urban Areas and All Rural Areas, All Case Studies, Research Sample

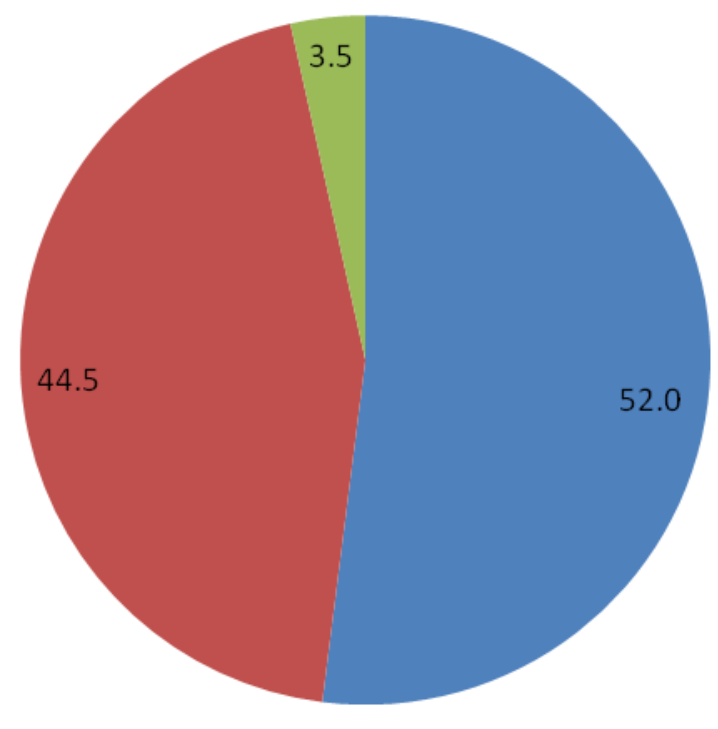

All urban areas (\%)

- All rural areas (\%)

other / NA (\%)

Source: Fieldwork data 
It is illustrative to compare the information presented in Figures 9.1 and 9.2 with that in Table 9.7 below, revealing the previous tenure status of respondents. Table 9.7 shows that across all communities the largest previous tenure categories were 'renting' (30.5\%) and 'village' (26\%). The data also shows that only $6 \%$ of respondents had immediately previously lived within another informal settlement.

Table 9.7. Previous Tenure Status, All Case Studies, Research Sample

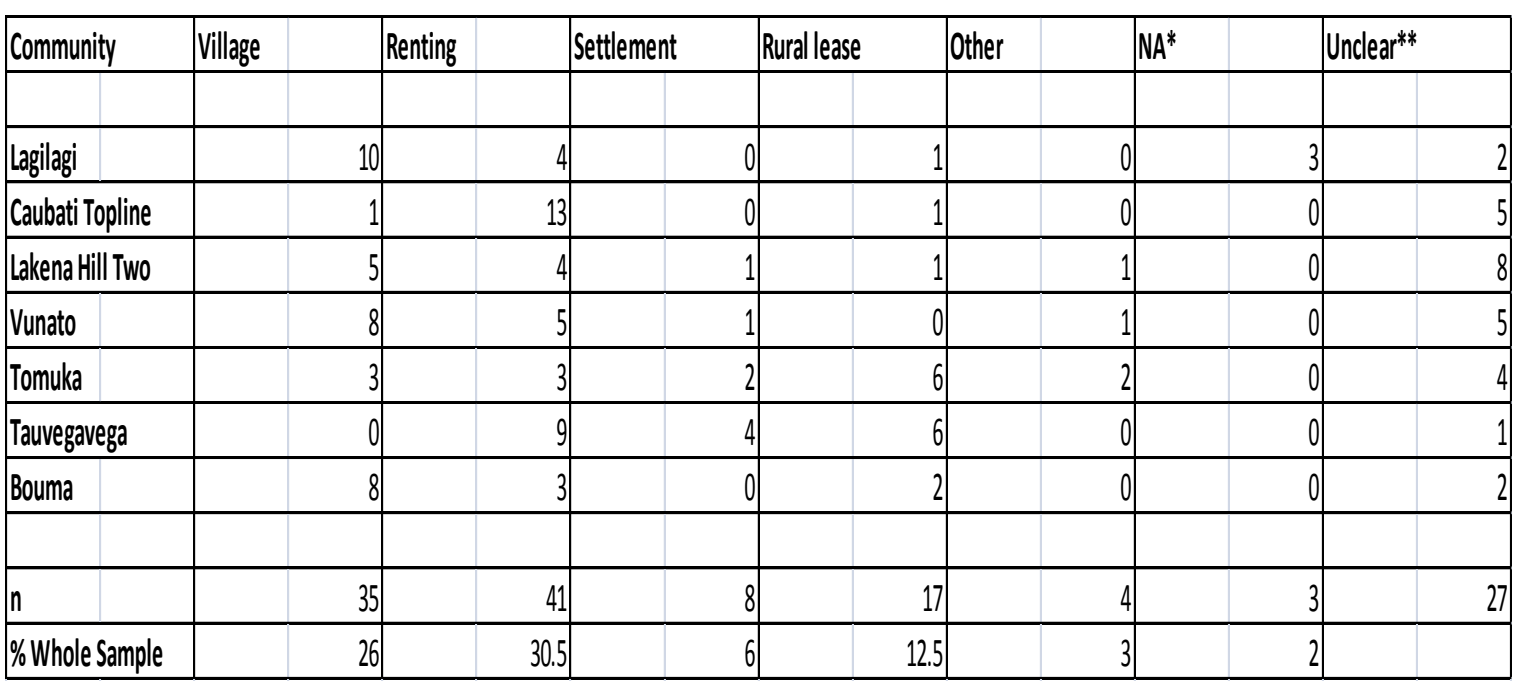

* Prime interviewee born in community

** Includes respondentswho were previously living with family in various, sometimes uncertain, tenure situations

Source: Fieldwork data

Figure 9.3 below reveals information on the principal reason that respondents chose to locate in their current site of residence. ${ }^{73}$ This information shows that the single most important category selected was 'proximity to education and other services' $132.8 \%$ of respondents) followed by 'opportunity for continued residence' (30.9\%) (essentially the security of tenure variable). The categories 'proximity to employment opportunities' (18\%) and 'availability of adequate shelter' (13.9\%) were of secondary importance.

73 When respondents were asked to name, what of the four categories, was the single most important factor in influencing their location decision. 
Figure 9.3. Principal Reason for Location Decision, All Case Studies, Research Sample

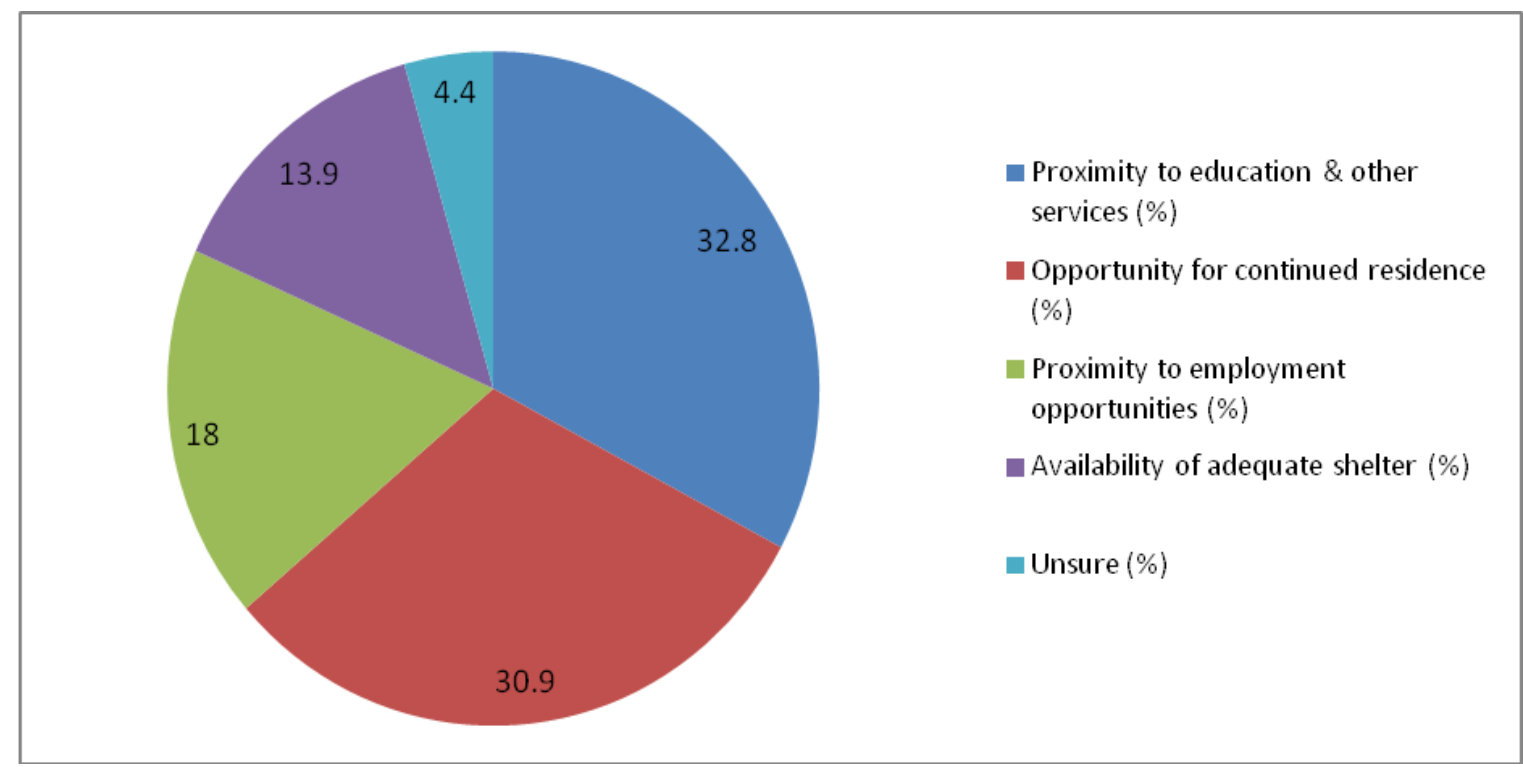

Source: Fieldwork data

Table 9.8 below unpicks the above primary categories motivating location decisions a little further. ${ }^{74}$ This table reveals that the largest categories across all communities included: (i) 'forced from previous location' (20\% of respondents) (usually associated with rural lease uncertainty and/or expiry and forced moves from rental properties); (ii) 'the chance or need to get one's own place' (19.5\%);75 and (iii) 'rent saving' (15\%). Table 9.8 also reveals information for individual communities around principal reason for location. Significant categories include: (i) those seeking rent savings at Caubati Topline (60\% of all respondents in this community); (ii) 'forced from previous location' appearing significant at Tauvegavega (45\%), Tomuka (35\%) and Caubati Topline (30\%); and (iii) education opportunities prompting movement to Bouma (40\%).

\footnotetext{
74 These narrower categories were made after questioning respondents' motivations for their move from previous locations and reasons for choosing their current location.

75 There are some overlaps with the category 'marriage/relationship' here; as in some cases marriage creates a need to obtain a new dwelling for the new couple.
} 
Table 9.8. Principal Reason for Location, All Case Studies, Research Sample

\begin{tabular}{|c|c|c|c|c|c|c|c|c|c|c|c|c|c|}
\hline Community & Chance/need for & Marriage/ & Employment & Eduction & & General proximity & Rentsaving & & Forcedfrom & Other & & Unclear & \\
\hline & own place & relationship & & & & to town & & & previous location & & & & \\
\hline Lagilagi & & 4 & 7 & 5 & 2 & 0 & 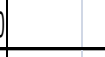 & 1 & & 0 & 0 & & 1 \\
\hline Caubatit Topline & & 1 & 0 & 1 & 0 & 0 & 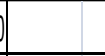 & 12 & & 6 & 0 & & 0 \\
\hline Lakena Hill Two & & 4 & 9 & 0 & 1 & 0 & 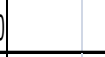 & 1 & & 3 & 2 & & 0 \\
\hline Vunato & & 7 & 1 & 3 & 4 & 2 & 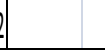 & 2 & & 0 & 1 & & 0 \\
\hline Tomuka & & 5 & 2 & 3 & 0 & 0 & 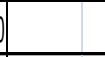 & 1 & & 7 & 1 & & 1 \\
\hline Tauvegavega & & 5 & 0 & 1 & 0 & 1 & 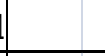 & 3 & & 9 & 1 & & 0 \\
\hline Bouma & & 0 & 0 & 0 & 6 & 3 & 3 & 0 & & 2 & 4 & & 0 \\
\hline & & & & & & & & & & & & & \\
\hline n & & 26 & 19 & 13 & 13 & 6 & 6 & 20 & & 27 & 9 & & 2 \\
\hline$\%$ Whole Sample & 19 & 9.5 & 14 & 9.5 & 9.5 & 4.5 & & 15 & & 20 & 6.5 & & 1.5 \\
\hline
\end{tabular}

Source: Fieldwork data

The fieldwork data presented above on movement to communities can be complemented by 2007 census information. Tables 9.9 and 9.10 below, adapted from census data supplied directly by the Fiji Islands Bureau of Statistics, show the locality at birth and locality in 2002 for all residents of Lagilagi, Caubati Topline, Lakena Hill Two and Tauvegavega. While the data supplied unfortunately does not break down the category 'rural area', it does, however, group by urban areas (which can then by categorised by administrative division).

Table 9.9 shows data that can be used to compare the urban and rural origins of residents at Lagilagi, Caubati Topline, Lakena Hill Two and Tauvegavega. When comparing the four communities, the table reveals that the settlement with the highest proportion of residents born in rural areas was Lagilagi (61\%); followed by Tauvegavega (59.5\%), Caubati Topline (51\%) and Lakena Hill Two (39.5\%) The data in the table also allows more extensive analysis of urban origins; for example, revealing the significant proportions of each community were born in their current urban area. This ranged from $44 \%$ in Lakena Hill Two, $33.5 \%$ in Tauvegavega, $30.5 \%$ in Lagilagi, to $26 \%$ in Caubati Topline.

Table 9.10, displaying information on locality five years prior to the census data collection (2002), is particularly useful for showcasing the origins of recent community growth. For example, the table shows that significant proportions of each community were residing in rural areas in 2002 - ranging from 32\% in Caubati Topline, 31\% in Tauvegavega, 23\% in 
Lagilagi, to $19 \%$ in Lakena Hill Two. These figures suggest that, in Caubati Topline and Tauvegavega particularly, significant recent settlement growth can be linked to rural to urban movement.

Table 9.9. Population by Locality of Birth, Lagilagi, Caubati Topline, Lakena Hill Two and Tauvegavega, 2007 Census Information

\begin{tabular}{|c|c|c|c|c|}
\hline Area & Lagilagi & Caubati Topline & Lakena Hill Two & Tauvegavega \\
\hline Total & 450 & 731 & 881 & 718 \\
\hline \multicolumn{5}{|l|}{ Urban Area Central Division } \\
\hline Suva & 137 & 84 & 28 & 5 \\
\hline Lami & 1 & 7 & 4 & 2 \\
\hline Nausori & 3 & 6 & 387 & 1 \\
\hline Navua & 0 & 2 & 1 & 2 \\
\hline Korovou & 0 & 1 & 3 & 0 \\
\hline Deuba & 0 & 0 & 2 & 0 \\
\hline Nasinu & 22 & 189 & 41 & 5 \\
\hline Total all Urban Areas Central Division & 163 & 289 & 466 & 15 \\
\hline \multicolumn{5}{|l|}{ Urban Area Western Division } \\
\hline Lautoka & 3 & 17 & 26 & 16 \\
\hline Nadi & 0 & 5 & 0 & 7 \\
\hline $\mathrm{Ba}$ & 0 & 3 & 1 & 241 \\
\hline Sigatoka & 1 & 1 & 6 & 0 \\
\hline Tavua & 3 & 0 & 0 & 3 \\
\hline Rakiraki & 0 & 4 & 5 & 1 \\
\hline Vatakoula & 0 & 1 & 8 & 6 \\
\hline Total all Urban Areas Western Division & 7 & 31 & 46 & 274 \\
\hline \multicolumn{5}{|l|}{ Urban Area Northern Division } \\
\hline Labasa & 4 & 21 & 20 & 2 \\
\hline Savusavu & 0 & 4 & 1 & 0 \\
\hline Nabouwalu & 0 & 1 & 0 & 0 \\
\hline Seaqaqa & 2 & 8 & 0 & 0 \\
\hline Total all Urban Areas Northen Division & 6 & 34 & 21 & 2 \\
\hline \multicolumn{5}{|l|}{ Urban Area Eastern Division } \\
\hline Levuka & 0 & 4 & 0 & 0 \\
\hline Total all Urban Areas Eastern Division & 0 & 4 & 0 & 0 \\
\hline Total All Urban Areas & 176 & 358 & 533 & 291 \\
\hline \% Community from Current Urban Area & 30.5 & 26 & 44 & 33.5 \\
\hline$\%$ Community from Current Divisonal Urban Area & 36 & 39.5 & 53 & 38 \\
\hline$\%$ Community from All Urban Areas & 39 & 49 & 60.5 & 40.5 \\
\hline All Rural Areas & 274 & 373 & 348 & 427 \\
\hline \% Community from All Rural Areas & 61 & 51 & 39.5 & 59.5 \\
\hline
\end{tabular}

Source: Adapted from Fiji 2007 census data 
Table 9.10. Population by Locality in 2002, Lagilagi, Caubati Topline, Lakena Hill Two and Tauvegavega, 2007 Census Information

\begin{tabular}{|c|c|c|c|c|}
\hline Area & Lagilagi & Caubati Topline & Lakena Hill Two & Tauvegavega \\
\hline Total & 450 & 725 & 881 & 714 \\
\hline \multicolumn{5}{|l|}{ Urban Area Central Division } \\
\hline Suva & 327 & 54 & 6 & 0 \\
\hline Lami & 3 & 2 & 5 & 0 \\
\hline Nausori & 0 & 5 & 660 & 0 \\
\hline Navua & 0 & 0 & 0 & 0 \\
\hline Korovou & 0 & 0 & 0 & 0 \\
\hline Deuba & 0 & 0 & 0 & 0 \\
\hline Nasinu & 7 & 404 & 24 & 0 \\
\hline Total all Urban Areas Central Division & 337 & 465 & 695 & 0 \\
\hline \multicolumn{5}{|l|}{ Urban Area Western Division } \\
\hline Lautoka & 6 & 9 & 3 & 2 \\
\hline Nadi & 0 & 2 & 0 & 0 \\
\hline $\mathrm{Ba}$ & 0 & 1 & 0 & 490 \\
\hline Sigatoka & 0 & 0 & 2 & 0 \\
\hline Tavua & 0 & 0 & 0 & 0 \\
\hline Rakiraki & 0 & 0 & 0 & 0 \\
\hline Vatakoula & 1 & 0 & 1 & 0 \\
\hline Total all Urban Areas Western Division & 7 & 12 & 6 & 492 \\
\hline \multicolumn{5}{|l|}{ Urban Area Northern Division } \\
\hline Labasa & 2 & 6 & 11 & 0 \\
\hline Savusavu & 0 & 4 & 0 & 0 \\
\hline Nabouwalu & 0 & 0 & 0 & 0 \\
\hline Seaqaqa & 1 & 6 & 0 & 0 \\
\hline Total all Urban Areas Northen Division & 3 & 16 & 11 & 0 \\
\hline \multicolumn{5}{|l|}{ Urban Area Eastern Division } \\
\hline Levuka & 0 & 1 & 0 & 0 \\
\hline Total all Urban Areas Eastern Division & 0 & 1 & 0 & 0 \\
\hline Total All Urban Areas & 347 & 494 & 712 & 492 \\
\hline$\%$ Community from Current Urban Area & 72.6 & 55.5 & 75 & 68.5 \\
\hline$\%$ Community from Current Divisonal Urban Area & 75 & 64 & 79 & 69 \\
\hline$\%$ Community from All Urban Areas & 77 & 68 & 81 & 69 \\
\hline All Rural Areas & 103 & 231 & 169 & 222 \\
\hline$\%$ Community from All Rural Areas & 23 & 32 & 19 & 31 \\
\hline
\end{tabular}

Source: Adapted from Fiji 2007 census data 
A number of themes emerge from the interviews when exploring motivations for movement to settlement areas. In many cases participants inherently compared the benefits (and disadvantages) of living in urban and central settlements to that of rural life. In other cases, participants simply expressed the principal benefits of living in informal settlements or what their primary reason was for their original move to their settlement. Most strongly, throughout all the case studies, participants were attracted to informal settlements because of the proximity of one or all of: education opportunities and facilities; employment opportunities; and the enhanced amenities of urban locations. Education opportunities were seen as particularly important. For example: "I struggle for education, not everything else. It's very good for me to stay in a poor house, but education comes first in my life. If I stay in the village, they [my children] will never pick up. Education is very important" (LL476); "I'm still living here to support my school children ... We are only here for education, [which is] now onto my grandchildren" (V19); "Here in settlement in Tomuka plenty people come to further education" (To 1); "We stay in one big house in the village but we want to come here for school aye ... but schooling in the village and schooling in town are different. In town Fijian, Indian, Rotuman. In village only the Fijian, so too late to speak in English" (B3). Other participants communicated the additional lure of employment and urban amenities: "From that time there was a big strike in Vatakoula and [my] husband can't look for work ... so we shift to Lautoka" (V1); "[We came] just for the studies and the working. Because in the village we don't have anywhere to work, so we shift over here" (V3); "That's why we come and build here - [to be] close to school and healthcare" (T4).

Other participants communicated the location benefits of informal settlements when responding to the question 'what is good about this community?' Respondents particularly focused on the advantages of being close to town amenities, education and employment. For example: "It's good in Lagilagi as it's close to everywhere ... This is the centre of Fiji, of Suva" (LL4); "[It's] near to hospital, near to town, near to work, near to school ... We can save a little bit, we can get better education for the kids" (LL3); "[It's] near to the city, access to supermarkets, medical is near, and entertainment aye. Suva town is not very far away from here" (LL20); "It's just near to town. Don't have to buy bus fare to town, can just walk down, and [near] to schools. That's why we want to

\footnotetext{
76 A coding system is used henceforth when labelling interview citations ( $L L=$ Lagilagi; $T L=$ Caubati Topline; $L=$ Lakena Hill Two; $V$ = Vunato; To = Tomuka; $T$ = Tauvegavega; and B = Bouma). For example, 'LL4' is a citation from Lagilagi interview four. More information on the particulars of each interview (including date, ethnicity of prime interviewee, length of residence in community, average monthly income, house tenure, analysis of perceived security of tenure, evidence of housing consolidation, and access to formal credit) is provided at Appendix 6.
} 
live here. That's why [we] never mind floods, that's why we stay here" (V3). In other cases the advantages of living in urban informal settlements emerged when discussing the relative benefits of living in current communities vis-à-vis village or previous areas. For example: "[We came] because of employment problem [in Vanua Levu] ... [and] here we can send our children to FIT [Fiji Institute of Technology]" (TL19); "Like here, good place for the children aye, our work is near aye, transportation aye, good job opportunities for the children, people here are good, aye, in the settlement" (TL16); "But in Taveuni we never buy anything from the market, we just plant the food. But education was very difficult ... we have to travel by bus at five in the morning, we reach that place [the secondary school] at eight-thirty ... and my eldest daughter had to wake up early in the morning, cook the food, but it's still dark and we were far from the main road" (V16).

Cost advantages were often the prime motivator for a move to an informal settlement. These benefits included savings on housing and transport costs, and, for indigenous Fijian settlers particularly, the benefits accrued from being able to have urban gardens. Just a few examples of many include: "[We] wanted our own place. Can't be renting. If you own your own place you don't have to look for the money at the end of the month. We looked for the savings aye" (To 17); "Everything is near. The health centre is near, the market, the education. It's easy to live in Lagilagi, you can plant, we have plantation" (LL7): "We won't be paying any house rents, city rates, and [there is] a low cost of living" (LL 16); "This place here, to me, is one of the best places to stay. If you get no money you still can survive. That's why I like this place" (L7); "It's free from the city life, very quiet. As I've said before even if I don't work, I don't earn money, I go get the dalo there, the rourou.77 Something good in Lakena [is] we don't rely on money, we can survive" (L7); "First of all it's cheap. You don't need to pay anything at the moment. It's near the town, near to school, and this area we have plenty vegetables" (L11); "Because we [are] close to everywhere we want to go - town, school and what we need, firewood. We don't spend too much money for travelling" (V1); "Firstly we came from the village so far away. We didn't pay our house, but luckily we are given the house and the land. Only we pay the school fees. Secondly, my husband is only doing the casual work, and we can live from the land" (Tol); "To me as I'm not renting and, source of income, what my son just three weeks ago started working. I've got a place to plant some cassava and dalo. And it's near to the bush where I can get firewood" (To3).

\footnotetext{
77 Dalo leaves.
} 
Other interviewees communicated the necessity of a forced move to a settlement area (particularly through problems and affordability constraints at previous residences and rural lease uncertainty and expiry). Others simply expressed that they had no other options available. Examples of these push factors included: "Lease expired then we come here" (TL17); "Fijian people chase us away, we have no place to go. This was the only vacant place we can go" (L14); "There was no other place to live, that is why they came here" (L19); "I was staying in Bua Bua, we have 46 acre cane farm, so my father sold that land so he gave some small amount [of money] to me, I tried going to Housing [Authority] area but can't afford. I came here, as can't get better than this, that's the reason" (To 17); "Because the land there [at the previous residence], one Punjabi, she bought the land there and did court order for us to go" (T12); "Expiry of the lease was very near, and at that time the reserve of the land was in full force. So I didn't have any fund to buy a piece of land, and when I came to look for land I heard from the people that if I build a house here I can live here for a long time" (T18); "After twenty-two years my wife's brother stopped me planting. That's why I am sitting here in Labasa ... Only this small house I buy" (B7). One Indo-Fijian woman expanded on her problems with native landowners at a previous informal settlement (first and second citations) before arriving in Tomuka (third citation): (i) "I gave the owner fifteen hundred dollars, but the owner really betrayed me ... I gave the owner one thousand dollars, then another two hundred and another three hundred ... but I could not build the house ... I didn't make the house there. He [the landowner] said 'Pay the money'. I paid the money but he betrayed me and gave me only one small land"; (ii) "That owner [at the previous settlement] is very bad. Night time he comes to the door [and says] 'Give me the money' ... [lt is a] very small land, no room to build the house. Even if I build the house, the land will be finished ... on top of the fifteen hundred dollars I gave that owner one kilogram grog, 78 thirty dollars grog I gave that owner there. I take the grog, sevusevu ... very bad owner there"; (iii) "Because I'm divorced from my husband and I've got four kids. We had to shift from there. I was looking for land, that's why I came to the neighbours. They told me there is one landowner there selling the land. I was in a very rush and I went to the owner to ask 'What is the cost?'" (To8).

Other participants indicated that the original free availability of the land was the principal reason and pull factor for locating in their settlement. For example: "As we have said already, the land was vacant aye. That's why we built this house" (LL9); "They shifted because they were renting there, and came here to build their own house ... at

78 Kava. 
that time everyone was building their house over here" (L19); "It was all crown land here. That's why we come and build here, because you can't build on native land" (T11). Finally, other, less frequent, reasons communicated by interviewees for their choice of location in settlement areas included: (i) the need for one's own place after marriage or simply the desire to have one's own place; (ii) the prospect or hope of eventually receiving title for a piece of land; (iii) good relationships with native landowners; and (iv) church affiliations facilitating access.

Interviews with participants also focused on exploring motivations for future movement. In response to the question 'Would you like to move out of this community?', and when discussing the future plans of interviewees generally, mixed responses were generally received. Some participants communicated that they did not want to move from their current settlement. For example: "We just live here. After we just go straight to heaven. Go back to the island? No" (LL1 1); "No. This place is near to everywhere ... We are working hard to develop this place for everyone ... to secure this place" (LL6); "[No] because I like the place here, and all my family is here" (TL12); "[No it's] near for my children's school, near to the hospital, it's near to the town" (L12). Other participants expressed a desire to stay in their current community, but only if their security of tenure could be improved. For example: "I like to stay here forever. It's a good place to me. The quarters coming now... they build for us. I like it [the prospect of the pilot project] cause I don't want to stay like this all the time" (LL14); "We'll see aye how the things work. We are fighting for this land. If we get the land here it's very good or else we move aye" (TL16).

Other respondents expressed that it would be very difficult to move. Many of these reasons focused on the convenience of current settlements and particularly the lack of alternative housing options (especially due to financial constraints). For example: "For me, for me ... it's very hard to move out ... because there is no other place like Lagilagi. We are close to everywhere" (LL4); "It's like we don't have any future. We are just planning to stay as long as we can. We don't have any other place to go" (TL19); "We can move. But we already build a house here. [To] pull the house very hard, the children schooling here" (TL15); "Well my concern is we will be probably be staying like this ... But we can't afford, as he doesn't work, I don't work ... He can move to his village, but me? Where am I going to stay?" (L9); "Because, that time, my children all schooling and there was no funds... That time was very hard time... At the moment we only have the piece of land to live on, and we are not in the situation of being able to afford 
another piece of land ... it's quite expensive" (L15); "No, no. I am satisfied. If you buy the Housing [Authority] land lowest price is ten thousand dollars. That is the block price, how can you build the house? If I got the money then I can shift, buy the house block. Otherwise, no way" (To7); "Nobody wants to stay here for a long time. Because of their needs they can't move from here. We have to stay here like this" (To8); "[No] because where we going to go? Because the land is too dear to buy. With four dollars twenty nine [per hour wages] I cannot afford to buy the land" (T1 1); "Every moment I have been wanting to move out. But this poverty is holding me back" (B13).

Some interviewees expressed a desire to move elsewhere within the urban area; often to somewhere with enhanced degrees of security of tenure. For example: "I feel like shooting to the other place. We [are] just looking forward to getting a big house [elsewhere]" (V3): "[Yes] I want to stay in my own place, and stay in a place that is better than this aye" (V5); "We want to look for another land, another house. As nowadays it's very hard for renting" (V12); "I'm still working for buying one land at the Housing Authority ... I have to move there, secure" (To2); "Actually we're planning to go somewhere better ... in anywhere like Kashmir [Housing Authority] area" (To 11). Other interviewees communicated the general desire to move elsewhere; or, in the case of Indo-Fijian participants particularly, expressed a wish to eventually migrate overseas. For example: "[Yes] sometimes I think of that [moving]. I don't want my children to grow up here" (LL1); "Actually we know that we have to move away from here, because this place [Fiji] does not belong to us. Maybe in ten years, maybe in twenty years, maybe in thirty years" (TL 1 1); "Well I stay here nearly twenty-seven years. But now my kids overseas. My three kids are in New Zealand. I am trying to move [there too]" (To7); "If I got a chance tomorrow I would just pack and go. It's no use here ... Thinking about the long run, my children's future, there is nothing here" (T3). Finally, some respondents (in all cases indigenous Fijian) expressed plans to eventually return to rural, village areas (particularly once children finish education). For example: "When they finish school we can go back to the village" (V1); "We make the thing for we just staying here [kerekere ${ }^{79} /$ sevusevu to the landowners]... One day we leave here and go back to the village" (V19): "[No but] when we leave this place we will go to the koro, village. Only to provide education for the kids [are we here]" (To l); "I think we will go back to the island [after education is over] and the son will go to the town every day to work" (B2); "My aim is the education of the children. When they finish I think [of] going back to my village in Savusavu" (B7).

\footnotetext{
79 To request.
} 
Overall, across the case studies, the nature of movement towards informal settlements is mixed. Movements comes from both rural and other urban areas, appears more fluid than temporary or permanent, and is influenced by coalescing push factors (particularly being forced out of previous locations in various ways) and the well documented pull factors of urban areas and the costs savings that informal settlements can generate.

\subsection{Access to Informal Settlements and Payments}

Original access to the case-study communities for the research respondents occurred in a number of often quite context-specific ways. As Table 9.11 below reveals, the majority (65\%) of all respondents had existing connections prior to moving into a community; particularly family links but also friendship and church and religious organisation connections. Indeed, in many of the case-study settlements, considerable clustering of extended family occurs with a number of extended family dwellings grouped in a part of settlement.

Table 9.1 1. Previous Connections to the Community, All Case Studies, Research Sample

\begin{tabular}{|l|r|r|l|r|}
\hline Community & Yes & No & NA* & Unsure \\
\hline Lagilagi & 14 & 4 & 2 & \\
\hline Caubati Topline & 13 & 7 & & \\
\hline Lakena Hill Two & 16 & 3 & & 1 \\
\hline Vunato & 16 & 4 & & \\
\hline Tomuka & 10 & 10 & & \\
\hline Tauvegavega & 6 & 14 & & \\
\hline Bouma & 13 & 2 & & \\
\hline & & & & \\
\hline $\mathbf{n}$ & 88 & 44 & 2 & 1 \\
\hline \% Whole Sample & 65 & 32.5 & 1.5 & 1 \\
\hline
\end{tabular}

* Prime interviewee born in community

Source: Fieldwork data 
Table 9.12. House Built or Obtained, All Case Studies, Research Sample

\begin{tabular}{|l|r|r|}
\hline Community & Built & Obtained \\
\hline Lagilagi & 10 & 10 \\
\hline Caubati Topline & 13 & 7 \\
\hline Lakena Hill Two & 12 & 8 \\
\hline Vunato & 17 & 3 \\
\hline Tomuka & 14 & 6 \\
\hline Tauvegavega & 16 & 4 \\
\hline Bouma & 9 & 6 \\
\hline & & \\
\hline n & 91 & 44 \\
\hline \% Whole Sample & 67.5 & 32.5 \\
\hline
\end{tabular}

Source: Fieldwork data

New entrants to a community first either build an initial dwelling or obtain a dwelling. Table 9.12 above shows that, across the sample, $67.5 \%$ of respondents initially built on arrival and $32.5 \%$ obtained a dwelling. The nature of initial building tends to vary. For example, in some cases new arrivals start from scratch, seek and purchase initial materials, and construct a dwelling that may be improved and extended in future. In other cases, new arrivals bring from their previous residences materials from a dismantled dwelling that are then reassembled. The smaller group of respondents who obtained a dwelling on arrival also do so in a number of different ways. These include: (i) purchasing a dwelling from departing residents (as Table A.3 in Appendix 5 shows, house purchase prices averaged $\mathrm{F} \$ 2,250$ across all communities and ranged from an average purchase price of a few hundred dollars in Bouma and Lagilagi to over $\mathrm{F} \$ 7,000$ in Caubati Topline); (ii) renting; (iii) or inheriting a dwelling from a family member or looking after a home while owners are absent.

Tables 9.13 and 9.14 below reveal greater information on how access to communities occurred across the sample and whether payments of some sort were necessary to facilitate this. Table 9.13 shows that for most respondents access to communities was either freely available, facilitated through family linkages, obtained via vakavanua approaches (where land use rights have been purchased and/or customary presentations have been made to facilitate access), or through dwelling purchases. Table 9.14 reveals that in $36.5 \%$ of cases respondents had made no payments at all to any parties for the duration of their settlement in their community. In other cases applicable across more than two communities, payments were made: (i) to purchase 
dwellings (12.5\% of total respondents); (ii) for original customary presentations and irregular customary contributions to legal and claimant landowners when asked $19.5 \%$ of respondents); and (iii) for rentals 80 ( $6 \%$ of respondents).

80 The average monthly rental across individual communities in the sample ranged from $\mathrm{F} \$ 50$ to $\mathrm{F} \$ 250$ and averaged $\mathrm{F} \$ 95$ across all communities. 
Table 9.13. Principal Means of Community Access, All Case Studies, Research Sample

\begin{tabular}{|c|c|c|c|c|c|c|c|c|c|c|c|c|c|c|c|c|}
\hline \multirow[t]{3}{*}{ Community } & \multirow{3}{*}{\multicolumn{2}{|c|}{$\begin{array}{l}\text { Freely available } \\
\text { at time* }\end{array}$}} & \multirow{2}{*}{$\begin{array}{l}\text { Via family } \\
\text { (no payments)* }\end{array}$} & Dwelling bought & \multirow{2}{*}{$\begin{array}{l}\text { Land use rights } \\
\text { bought** }\end{array}$} & \multirow{2}{*}{\begin{tabular}{|l|} 
Sevusevu to \\
native landowners
\end{tabular}} & \multirow{3}{*}{\begin{tabular}{|l|} 
Permission from \\
community figure \\
(no payments) \\
\end{tabular}} & \multirow{3}{*}{ Renting } & \multirow{2}{*}{\multicolumn{2}{|c|}{$\begin{array}{l}\text { Inheritance / took } \\
\text { on dwelling }\end{array}$}} & \multirow[t]{2}{*}{ Via Church } & \multirow[t]{3}{*}{ Other } & \multirow[t]{3}{*}{ NA } & \multicolumn{3}{|c|}{ Unclear } \\
\hline & & & & & & & & & & & & & & & & \\
\hline & & & & & & *** & & & & & & & & & & \\
\hline Lagilagi & & 4 & 2 & 7 & 0 & & $0 \quad 0$ & 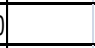 & 1 & 1 & 1 & & 0 & 2 & & 2 \\
\hline Caubati Topline & & 1 & 4 & 3 & 6 & & 1 & 1 & 2 & 2 & 0 & & 0 & 0 & & 0 \\
\hline Lakena Hill Two & & 7 & 5 & 4 & 0 & & 1 & 1 & 0 & 2 & 1 & & 0 & 0 & & 0 \\
\hline \begin{tabular}{|l|l|} 
Vunato \\
\end{tabular} & & 0 & 0 & 0 & 0 & 16 & 1 & 1 & 2 & 0 & 0 & & 1 & 0 & & 0 \\
\hline Tomuka & & 0 & 0 & 0 & 14 & 1 & 1 & 1 & 2 & 0 & 0 & & 1 & 0 & & 1 \\
\hline Tauvegavega & & 14 & 0 & 3 & 0 & 1 & 1 & 1 & 1 & 0 & 0 & & 0 & 0 & & 0 \\
\hline Bouma & & 1 & 5 & 2 & 0 & 1 & 1 & 1 & 0 & 3 & 2 & & 0 & 0 & & 0 \\
\hline & & & & & & & & & & & & & & & & \\
\hline$n$ & & 27 & 16 & 19 & 20 & 20 & 6 & 6 & 8 & 8 & 4 & & 2 & 2 & & 3 \\
\hline$\%$ Whole Sample & & 20 & 11.5 & 14 & 15 & 15 & 4.5 & & 6 & 6 & 3 & & 1.5 & 1.5 & & 2 \\
\hline
\end{tabular}

* There is considerable overlap in these first two categories

** From legal landowners or other claimants

*** Real or claimant native landowners

Source: Fieldwork data

Table 9.14. Principal Method of Payment to Facilitate Community Access (if any), All Case Studies, Research Sample

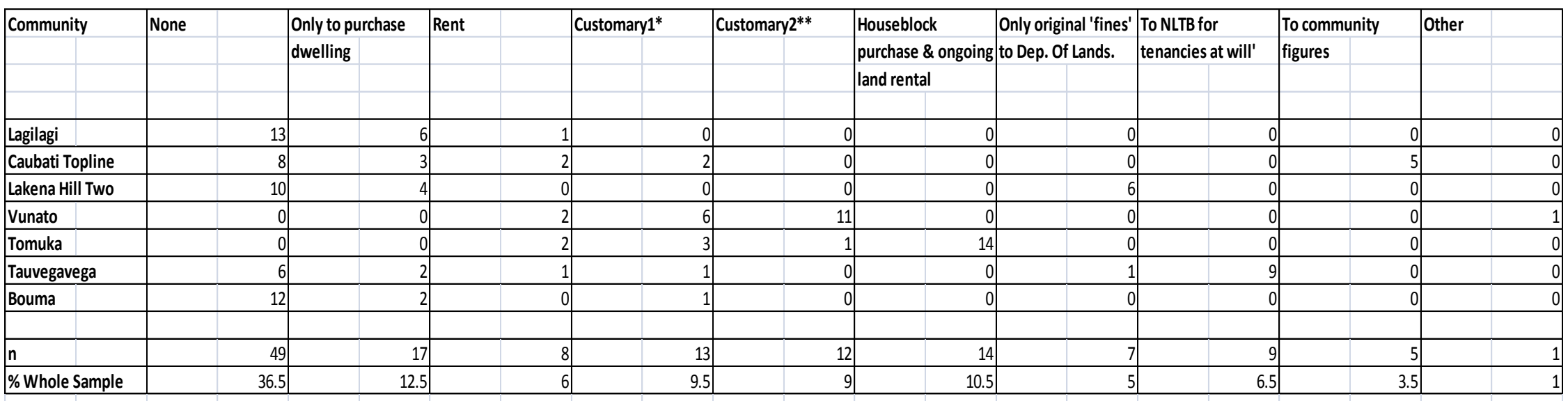

* Original sevusevu and irrgeular customary payments and contributions when asked

** Original sevusevu and ongoing fixed monthly payments to landowners

Source: Fieldwork data 
From Tables 9.13 and 9.14 what particularly stands out is the context specific nature of how access to communities is obtained and whether payments were made. For example, in Tauvegavega, $70 \%$ of respondents reported that the land was freely available at the time of their arrival (although, as Table 9.14 shows, $45 \%$ of respondents later made payments 81 to the Native Land Trust Board (NLTB) for temporary 'tenancies at will'). Further, Table 9.13 shows that, at the native land settlement of Vunato, $80 \%$ of respondents initially facilitated access to the community by making a traditional customary sevusevu presentation to the landowners (of all, or a combination of, cash, yaqona, kerosene, Fijian mats, and tabua). Table 9.14 also shows that, at Vunato, 55\% of residents (in addition to the initial customary request) make ongoing monthly payments 82 to the landowner. Tables 9.13 and 9.14 also reveal that, at the native land settlement of Tomuka, $70 \%$ of respondents gained access to the community through negotiating and purchasing land use rights. These informal vakavanua arrangements all involve the purchase of a houseblock site 83 and the payment of ongoing land rentals. ${ }^{84}$ Finally, Table 9.14 shows that at the state land settlements of Bouma, Lagilagi and Lakena Hill Two high proportions of respondents $(80 \%, 65 \%$ and $50 \%$ respectively) indicated that no payments at all had been made for occupying the land. 85

As is indicated by Tables 9.13 and 9.14 and some of the earlier citations highlighting motivations for movement, access to settlements 86 can occur in a number of ways and is often facilitated by initial and sometimes ongoing payments of some form. Overall, access to communities can normally be differentiated by category of primary land tenure; as accessing a state land area may not necessarily require permission, but accessing a native land area, where the landowners are clear, always requires permission. For the case-study communities on state land, in some cases, the land is perceived as freely available but access might need to be approved by a government agency. Example citations from the interviews include: "Free land aye, because not enough income ... This land was free. We just apply from Lands [Department], and then we build" (TL15); "Looking for a place to build, we were shown this block ... This old man

\footnotetext{
81 These payments averaged $\mathrm{F} \$ 433$ and ranged to a maximum of $\mathrm{F} \$ 500$.

82 These payments range from $\mathrm{F} \$ 10-20$ per month.

83 At Tomuka these prices ranged from $\mathrm{F} \$ 200-3,000$ and averaged $\mathrm{F} \$ 1,538$.

84 Of F $\$ 100$ due every six months.

85 At Lakena Hill Two a further $30 \%$ of respondents had only once made payments of around $\mathrm{F} \$ 30$ to the Department of Lands and Surveys as 'fines' for living as squatters (which had the benefit of providing some record of occupancy).

86 This section applies mainly to new settlers who acquire land in a community and then build a dwelling (as compared with new residents who access a settlement by purchasing an established dwelling - as in this case, in all case-study communities, the arrangement is usually negotiated between the house selling and buying parties only).
} 
went to the Lands [Department]. He went and stamped the thing and came back" (L9); "Because at that time all the empty space, people just come [and build]. Nobody stopped anybody" (L15). For communities on both state and native land, existing networks (particularly family, friends and church and religious organisation affiliations) often facilitate access to communities. For example: "One Fijian fella he was staying here before and we church together and ... he tell us to come and build a house here ... He just tell us 'pull the cassava' for building the house, then we shift" (TL5); "Yes, plenty family here ... [we] tell family 'cheap and easy', that's how people move in here" (L11); "When we left Drasa ... my father and the owner of this land knew each other. That's how we come to know this land" (V20); "One of my uncles married a landowner's daughter. That's why they gave us this land" (V7). For those settlements on state land, in many cases, some sort of payment is also necessary to facilitate community access perhaps to obtain authorisation from a government agency, to provide compensation to an individual previously using the land for some purpose, or when new settlers incorrectly believe the land is held in native tenure. For example: "Everyone staying in the squatters, they have to pay thirty-three dollars [to the Department of Lands and Surveys]" (TL7); "Some of the houses that come here went to him [who was thought to be the landowner] and paid some money" (TL7); "I took one pile of grog there, and sevusevu. [But now] we know this is [state] lands, so we stop going there" (TL6); "It's like the friends told us to come and build ... One Fijian fella was planting cassava here, so we have to give him some goodwill [payment], like three hundred and fifty dollars" (TL19).

For the native land settlements of Vunato and Tomuka, where the landowning groups and individuals are clear, access arrangements are context specific and usually facilitated by payments of various forms. For example, at Vunato original access is usually facilitated by sevusevu: "We give a sevusevu, our Fijian custom to stay on the land" (V3); "When I came here I met the landowner, we take one big bundle of yaqona, do the sevusevu and we present to the landowner. Then I stay here and they give me the land. Tabua, Fijian custom aye" (V11); "When we came here there was no house so my in-laws came to buy the land from the landowners. They give tabua like that for us to stay" (V16); "Once we approached him [the landowner said] 'Do anything you like'... I take some cash money and two whale's tooths, approach him in that way" (V19); "We prepare the whale's tooth and the grog and the money too, five hundred dollars" (V1). At Vunato the payments made to the landowner to facilitate access and allow ongoing stay are diverse - but usually involve regular monthly payments of ten or twenty dollars and also customary contributions for mataqali events when asked. For example: "[At 
the] end of the month we should give twenty dollars to the landowners" (V8); "Every month we collect all the money, [from] all the village, to bring to the landowner. More than four hundred dollars" (V11); "Us, when somebody passed away like that we have to give some money ... [and] when one month finished we have to give ten dollars, then one month [again]" (V13); "When they ask for something, when they need something, in the koro, we give money, or mat, or tabua. Recently we always give money" (V1); "That [regular, monthly payment] is excluding what the mataqali wants from the village. Like one death, or one soli87 in the village, or church thing ... [and] when somebody passes away in the village, then we take mats, kerosene, something like that" (V20).

At Tomuka, original access to the community is sometimes, for indigenous Fijian settlers, directly organised by the native landowners. For example: "[The landowner] came right to us [and said] 'One house is empty, we want you to come'. To give contribution to Namoli Village and the church [was the only agreement]" (To 1); "[The landowner] and the small brother, they give this house to us ... The deal is like this: here when we come here we were renting. They saw us, we go to church, we help them. They feel sorry for us so they give us this house. That's why we stay here for free" (To 1); "Some they come to borrow a piece of land, but [the landowner] came to me" (To3). More frequently at Tomuka, however, particularly for Indo-Fijian settlers, access payments are more commercial in nature - involving a house or houseblock purchase and ongoing annual land rentals. Arrangements are specific and usually recorded on paper documents provided to new settlers.88 For example: "This land, when my father started working here at Coca Cola, this land was also an agricultural land and the landlord was doing the cane farming and he started giving the blocks to the poor people... He was selling the land at a very low price, two hundred dollars, and we build the house and started living ... Likewise some more people came and bought the pieces of land and started [the] settlement ... but this [area is] also known as squatter settlement ... Then later on, after some time, they also generated another ... they said that they renewed the lease to give for another thirty years" (To5); "Nearly all the pieces of land they have house, and they sell the piece of land for eight hundred dollars, one thousand dollars ... The area is full. When somebody goes away from here he sells to another poor person ... When the

\footnotetext{
$87 \mathrm{Gift} /$ collection.

88 The paper lease documents provided to most new settlers are detailed and specific. They note the original cost of the land, the length of the lease, and the amount of annual land rental. Lease documents also specify the additional land rentals should a household operate a business from the site (such as a retail shop or home garage) or lease a dwelling. For example, in one lease document seen the fee for change of ownership was $\$ 300$ and annual land rental was specified at: $\$ 200$ per house; $\$ 700$ for a shop; $\$ 500$ for a house on rent; and $\$ 1,000$ for running a garage.
} 
house-owner sells the house, whatever the selling price the landlord charging twenty per cent of that" (To5); "When [the landowner's son] die we paying the rent to the wife ... every year pay the two hundred dollars ... we buy the land then we build the house" (To6); "When we buy the land they give us a thirty year lease ... When lease finishes we have to pay money again. We don't know how much, two thousand dollars, three thousand, like that" (To6); "We collect some money and we bought this area here ... we've got thirty years lease of this block ... two hundred dollars per year we paying now rent of this block" (To10): "Now this time when these people are selling they give fifty year lease. They are written by themselves, no lawyer anything. They write the letter, give [to] us. When we pay these people they gave us receipt" (To 10). Lease documents at Tomuka also specify that, if dwellings are sold, proportions of proceeds (of often up to $20 \%$ of the purchase price) must be paid to landowners. For example: "In this area, if you sell the house, you can get four thousand dollars ... [and] maybe if you sell for three thousand dollars, they [the landowners] will ask for five hundred dollars, like that" (To6); "[The worth of the house is] more than forty-five [thousand]. But because of the land [you cannot get that much]. When you sell you have to give twenty per cent to the landowner" (To16).

At Tomuka for indigenous Fijian settlers and, in some cases, Indo-Fijian residents, payments of cash or goods are also requested (but accepted as customary) for mataqali events. For example: "That's the only deal. But not so many, sometimes we heard and go to them. You have to give to the church, the wedding ceremony, just Fijian custom" (To1); "All his community events and church sick. If he asked us to contribute. It's not forcing, but what we can give... Sometimes he asked if we can contribute money or mats" (To3); "Like somebody get married we have to go there. If somebody die, go there and take mats" (To20); "If their family die, not forced, they kerekere, the public can donate. No demand, not forced" (To7); "Just because their child is going to school, or if somebody dies, or wedding, they ask for extra money ... twenty dollars, thirty dollars, fifty dollars, like that" (To 15). At Tomuka some respondents also indicated that extra payments to landowners were necessary on request, indicated their difficulty in meeting ongoing monetary demands, or expressed the possible trouble and repercussions if payment amounts and deadlines were not met. For example: "One day they [the landowners] they will come and ask for the grog and the cigarette, 'Give five dollars for the grog, two dollars fifty for the smoke'" (To4); "He comes every month, take the money [\$50] and go ... If we don't pay the money, the problem. If you pay, then he just go" (To8); "On time we give them money, no problem. If you don't give 
them money [on time] they can make problem" (To10); "He come all the time. He want money, money, money... All the time he want money, money, money. How can we give money?" (To12); "But only the land rent is too high. It's too much. Because sometimes you can't make the land rent in the shop, because plenty shops around ... In this area if you give the house as rent, that's another two hundred and fifty dollars to the landowner ... It's too much. In the Housing [Authority] area you only pay the city rate. But can't do much aye" (To16); "If they don't have money they come kerekere ten dollars, twenty dollars. December coming they will come for the money. If we don't pay they will kick us out" (Tol7).

At Tauvegavega arrangements for community access are different again - largely due to land tenure changes (the area converted from state to native tenure in 2002) and confusions (different mataqali are contesting claims to the land) complicating the situation for settlers. In many cases (particularly for those settlers arriving prior to 2002) the land was freely available (but sometimes requiring approval from a government agency). For example: "My sister bought that house ... This was the Lands Department place. It was not squatters at that time. I applied for the place. I went to Lands Department in Lautoka. I asked them for the consent for the land, so they gave me the consent" (T8); "I looked for the rent[al] for one month, but they want the couple ... I applied for HART [Housing and Relief Trust] home, but they said 'You are earning', so I couldn't go there ... Boss helped me to give some material in my account - twenty five dollars they deduct every week ... I just [have]one room here, one passage ... I stayed here for one year with no electricity ... No one was here. This area was empty. Now since 2000 so many people come" (T8); "I bulldozed this place, so now I just use" (T1 1); "See one lady was staying here and what happened, the old lady asked from the Land Department 'Give me a piece of land'. So Native Lands Trust Board give them a place here" (T1 1); "I heard a rumour in Ba market when I was talking about the land. I heard that there is some land vacant in Tauvegavega and you can settle with your family" (T19): "At that time [of arrival] it was crown land, so there was no mataqali. I was hassled by the Lands Department, but after that the [2000] coup came" (T19). Upon Tauvegavega's conversion into native tenure in 2002, however, many residents were asked to pay money to NLTB for temporary 'tenancies at will' - of which details and official record seem to be very unclear. For example: "After we built this house, Native Land [NLTB] came ... they told me it won't be in black and white but we have to pay [fifteen hundred dollars]" (T9); "One time Native Land [NLTB] they came and ask for money, fifteen hundred dollars. So we paid them five hundred dollars and they give us a 
receipt. After that there was two landowners claim [ing] for this land. So I don't know who win this case. After then, nobody came and ask for the money... We went to see native land [NLTB]. They said 'Whatever the money we pay is not in the computer'. So we don't do anything. We keep the receipt here" (T11); "This thing is like when they [NLTB] ask for the money, three to four month they come in every house. After then they did not come... We thought they could pull the house down, so we just pay [the] five hundred dollars ... They said they gonna give the temporary lease, but, till now, nothing" (T1 1): "[We had] to pay five hundred dollars or they pull the house. Within seven days we have eighty-nine dollars there, how can I pay? But lucky Native Lands [NLTB] manager was good, whole day I was sitting there ... That day was big coup in Tauvegavega" (T14); "NLTB when they came here and made meeting and offered us tenancy at will on temporary basis, they offered us tenancy at will for fifteen hundred dollars and we asked them to come down a bit... They told us this will go, twenty to twenty-five years" (T16).

At Tauvegavega, post 2002, the existence and activities of various groups claiming ownership of the land, and the past involvement of NLTB, make for confusion and possible exploitation when arranging community access and utility connection. ${ }^{89}$ For example: "About five, ten years back some guys came wanting money. So we kerekere them. But we met some other guy from Nailaga and they told us not to give" (T4); "We heard that this area [was a] squatter area. We just have to go and ask Nailaga Village and they will allow us to build our house over here, and when it's divided we going to get it" (T9); "Before, when they [NLTB] offered a tenancy at will lease, according to them people have to go to NLTB. But now people come and don't ask anybody, [they] just find a place and build... They just come and see the vacant land. They probably ask the neighbours, see the vacant land and build. [But] when they find the rightful mataqali we may face trouble. They may come and ask for money, then we don't know what to do. Life is very fearful" (T16); "So there is no [recorded] mataqali, so different people from different tribes, groups, come here and demand that they are the rightful mataqali. [Sometimes] they ask for money" (T16); "If you have to do one water collection we have to [get signatures from the mataqali]... Sometimes PWD [Public Works Department] accepts [signatures] from Maruru Village, but sometimes they say go to Nailaga Village" (T16).

\footnotetext{
89 In Fiji, signatures from landowners are required by the Fiji Electricity Authority and Public Works Department (for water) on paperwork when informal settlers attempt to get utility connections. For communities on state land, settlers usually go to the Squatter Housing and Resettlement Unit (if in greater Suva) or the Department of Lands and Surveys. For communities on native land, settlers must go to native landowners (who sometimes charge a fee for their signature). In practice, however, settlers are often unclear about legal tenure of land creating difficulty and possible financial exploitation when attempting to get utilities connected.
} 
In summary, access arrangements to informal settlements are mixed. In some cases (particularly for communities on state land) land is perceived as freely available and permission may not necessarily be required. In other cases (particularly for communities on native land), access is controlled, requires permission, and initial and sometimes ongoing payments are necessary.

\subsection{Livelihoods in Informal Settlements}

Table 9.3 showed that mean household incomes across the research sample averaged \$F592 per month (F\$136 per week; approximately F\$19.50 per day) to provide for an average household size from the sample of 5.2. Table 9.15 below reveals the principal income source across the respondent households; and shows that regular wages (from both the formal and informal sector) were dominant (in $62.5 \%$ of cases). Other principal income sources forming greater than $5 \%$ of the sample included casual/irregular labour (8\%) and taxi driving (7\%). 
Table 9.15. Main Household Income Source, All Case Studies, Research Sample

\begin{tabular}{|c|c|c|c|c|c|c|c|c|c|c|c|c|c|c|c|}
\hline Community & Reglalar weres & Taxiding & Cassal| bour & Inthomal setrota & if Socidwelta & Chillosiport & $\mid$ |amily| & Small bisines & & Framing||fishing & If Marketrend & ing Garecutitin & Other & None & \\
\hline & & & & retilling & & & Ienititnes & & & & & & & & \\
\hline & & & & & & & & & & & & & & & \\
\hline |agl|xid & & 14 & 1 & ? & 0 & 1 & 0 & 1 & 0 & & 1 & 0 & 0 & 0 & 0 \\
\hline Callatitopline & & 14 & 2 & 4 & 0 & 0 & 0 & 0 & 0 & & 0 & 0 & 0 & 0 & 0 \\
\hline blenathll Tivo & & 12. & 2 & 0 & 1. & 2. & 2 & 0 & 1 & & 0 & 0 & 0 & 0 & 0 \\
\hline Vunto & & 16 & 2 & 0 & 1 & 0 & 0 & 0 & 1 & & 0 & 0 & 0 & 0 & 0 \\
\hline Tomla & & 12 & 1 & 2 & 1 & 0 & 1. & 0 & 1 & & 0 & 1 & 0 & 0 & 1 \\
\hline Taverageraga & & 10 & 1 & 2 & 2 & 2 & 0 & 1. & 0 & & 1. & 0 & 1 & 0 & 0 \\
\hline bouna & & 6 & 0 & 1 & 0 & 1 & 0 & 0 & 0 & & 3 & 2 & 1 & 1 & 0 \\
\hline & & & & & & & & & & & & 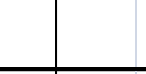 & t & & \\
\hline I & & 84 & 9 & 11. & 5 & 6 & 3 & ? & 3 & & 5 & 3 & 2 & 1 & \\
\hline WWWho Sarmple & & 0.5 & 1 & 8 & 3.5 & 4.5 & 2 & 1.5 & ? & . & 3.5 & 2 & 1.5 & 1 & \\
\hline
\end{tabular}

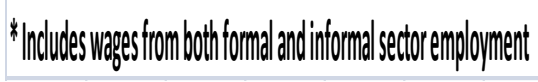


Many of the respondent households did not rely on a single income stream (and additionally often had more than one individual in the household earning regular wages). Research data (see Table A.4 in Appendix 5), for example, shows that $29.5 \%$ of the households interviewed reported significant supplementary income of some form in addition to their principal income stream. Research data (Appendix 5; Table A.5) shows that these forms of supplementary income were varied. However, major categories included: informal sector retail90 $22.5 \%$ of the 40 households reporting major supplementary income streams); income from farming ${ }^{91}$ and home gardens (20\%); support from family and remittances from abroad (17.5\%); casual labour (10\%); and income from government pensions (10\%).92 The field research also revealed that only $12 \%$ of households across the sample had a household member receiving social welfare payments93 from the government.

Tables 9.16 and 9.17 below highlight information on household food spending. Table 9.16 shows that the average weekly food spend across the sample was $F \$ 63.70$; ranging from $\mathrm{F} \$ 46.40$ in Bouma to $\mathrm{F} \$ 82.20$ in Vunato. Table 9.16 also reveals that in all case-study communities (with the exception of Bouma) Indo-Fijian households tended to spend more on food than indigenous Fijian households (despite Indo-Fijian households tending to be smaller in size). The more pertinent figures, however, are presented in Table 9.17; showing the percentage of average household income that is spent on food. This information shows that, across the sample, on average a high figure of $51.6 \%$ of total household income was spent on food. By community, this ranged from a low of $34.7 \%$ of household income in Vunato, to $36.4 \%$ in Lagilagi, $41.6 \%$ in Tomuka, $45.6 \%$ in Caubati Top Line, $57.6 \%$ in Lakena Hill Two, $69 \%$ in Tauvegavega, and $76.4 \%$ in Bouma. These figures compare with national data from 2005 that show that across Fiji the average household spent $40.3 \%$ of their income on food (Fiji Islands Bureau of Statistics, 2008, p. 28). Table 9.17 also shows that, on average, Indo-Fijian households across the sample spent a higher percentage of their household income on food $153.9 \%$ compared with $44.6 \%$ for indigenous Fijian households).

\footnotetext{
90 Saliently including household-based retail 'canteens' and yaqona sales.

91 Usually in home villages.

92 As distinctive from supplementary income, many households also had two or more regular wage earners. 93 These social welfare payments, as the Family Assistance Allowance, typically range from F $\$ 60-120$ per month.
} 
Table 9.16. Average Household Food Spend Per Week, Fijian Dollars, All Case Studies,

Research Sample

\begin{tabular}{|c|c|c|c|c|c|c|}
\hline Community & Indigenous Fijian & Indo-Fijian & Other & & Total & \\
\hline Lagilagi & 58.6 & 60 & & n.a. & & 58.7 \\
\hline Caubati Topline & 60 & 63.5 & & n.a. & & 62.4 \\
\hline Lakena Hill Two & 48 & 72.5 & & 50 & & 57.5 \\
\hline Vunato & 82.2 & n.a. & & n.a. & & 82.2 \\
\hline Tomuka & 54 & 63 & & n.a. & & 61 \\
\hline Tauvegavega & 65 & 79.5 & & n.a. & & 77.7 \\
\hline Bouma & 67.8 & 56 & & 35 & & 46.4 \\
\hline Whole sample & 64.9 & 68.4 & & 42.5 & & 63.7 \\
\hline
\end{tabular}

Source: Fieldwork data

Table 9.17. Percentage of Average Household Income Spent on Food, All Case Studies, Research Sample

\begin{tabular}{|c|c|c|c|c|c|c|}
\hline & Indigenous Fijian & Indo-Fijian & Other & & Total & \\
\hline Lagilagi & 36.4 & 37 & & n.a. & & 36.4 \\
\hline Caubati Topline & 55.3 & 42.6 & & n.a. & & 45.6 \\
\hline Lakena Hill Two & 53.5 & 56 & & 100 & & 57.6 \\
\hline \begin{tabular}{|l|l} 
Vunato \\
\end{tabular} & 34.7 & n.a. & & n.a. & & 34.7 \\
\hline Tomuka & 28.8 & 47.5 & & n.a. & & 41.6 \\
\hline \begin{tabular}{|l|} 
Tauvegavega \\
\end{tabular} & 83.4 & 66.8 & & n.a. & & 69 \\
\hline \begin{tabular}{|l|} 
Bouma \\
\end{tabular} & 69.3 & 76.4 & & 50 & & 76.4 \\
\hline Whole sample & 44.6 & 53.9 & & 75 & & 51.6 \\
\hline
\end{tabular}

Source: Fieldwork data

The figures presented above suggest that food costs are very significant for households across the sample. A principal means of reducing dependence on purchased food items, however, is to grow in home gardens a proportion of a household's food needs. Table 9.18 below shows that across the sample $73 \%$ of households did have their own gardens (in areas immediately surrounding a dwelling, or, for mainly indigenous Fijian gardeners, in other areas of the settlement). There were, however, important differences between the major ethnic groups around the nature of gardens. For example, the home gardens of Indo-Fijian households tended to be quite small - perhaps consisting of just a few small tomato, chilli and cabbage plants and maybe some fruit; whereas the 
gardens of indigenous Fijian households tended to be larger and more focused on producing significant quantities of root crop staples such as dalo and cassava - items that go further when feeding a family. A closer look at the figures also reveal that only $17.5 \%$ of all indigenous Fijian households interviewed were not growing any food; a figure compared with $38 \%$ of all Indo-Fijian households interviewed.

Table 9.18. Presence of Household Food Gardens, All Case Studies, Research Sample

\begin{tabular}{|l|r|r|}
\hline Community & Yes & No \\
\hline Lagilagi & 14 & 6 \\
\hline Caubati Topline & 9 & 11 \\
\hline Lakena Hill Two & 18 & 2 \\
\hline Vunato & 18 & 2 \\
\hline Tomuka & 16 & 4 \\
\hline Tauvegavega & 14 & 6 \\
\hline Bouma & 10 & 5 \\
\hline & & \\
\hline $\mathbf{n}$ & 99 & 36 \\
\hline$\%$ Whole Sample & 73 & 27 \\
\hline
\end{tabular}

Source: Fieldwork data

The sections of this chapter highlighting motivations for movement suggest that the cost savings of living in informal settlements (partly due to their often central location) is a prime advantage of living in these areas. However, in interviews many participants across the case studies communicated that making ends meet, and in particular meeting ongoing and increasing cash demands in times of rising prices, was still often an ongoing struggle. For example: "Now we don't buy a lot from the market, supermarket ... sometimes we just have biscuit" (LL1 1); "Before ten kilos of flour eight dollars, now eighteen dollars, and wages the same" (LL20); "We can't buy the timber, get the electricity. Money for just eat every day" (TL5); "[My income is $\$ 60$ per month] that's nothing, peanuts. I buy ten kilo rice, ten kilo sharps [flour], and some other. The money is gone, sixty dollars is nothing" (T8); "We haven't got any single cent in the bank, we are only alive" (T7); "My water bill is one hundred dollars, I can't pay. I don't know when they will come and cut [the service] ... But still I am here as I don't have any other opportunity" (T8); "My pay is three hundred and thirty dollars. For the FEA [Fiji Electricity Authority], food and bus fare I spend all that money, nothing left" (T1 1); "But this time we can't pay. Very hard time, oil price going up" (T17); "I have to cut off my budget every 
day. One day I have to bring two kgs flour, another day rice ... only the house is good" (T20).

Many participants (particularly when responding to the question "what is bad about this community?') expressed the disadvantages of living in settlement areas. Many of these responses focused on coping with poor roads, other infrastructure, and services. For example: "Only the road [is a problem and] that should be upgraded too aye, where we put our rubbish" (L7); "Here water problem aye. Sometimes come, sometimes not" (L14); "Sometimes when the winds come [from the] other side [it] smells bad. And the road too, it's gravel, all the dust comes into the house, not good for the children" (V3); "Road, drainage [are problems]. There's people still dumping rubbish anyhow, anywhere" (To 19). Other participants from across the case studies communicated the problems of crime and other community disturbances. For example: "From the community, yes, sometimes crime arises from there" (LL1 1); "Living here it's okay, but sometimes people they drink and fight here" (TL7); "I just came here one year ago. I don't know many people ... that boy got murdered there, there is no security here" (To8); "Sometimes there are break-ins ... plenty times the carrier drivers are robbed, taxi drivers are robbed. Plenty times you are in town and the drivers don't want to come to Tomuka. Plenty drunkards aye" (To 16). Also raised as disadvantages of settlement areas, for some communities only, were: (i) vulnerability and flood risk in the wet season; (ii) living in crowded conditions; and (iii) (for peri-urban communities such as Lakena Hill Two) living without good public transport connections.

As was introduced in previous sections of the chapter, having the room for urban home gardens was seen by many, particularly indigenous Fijian respondents, as a critical advantage of informal settlements. For example: "I just have to manage, going into the water getting the clams from there, going out into the bush getting some vegetables from there" (L9); "[We spend $\$ 60$ per week on food] but mostly we depend on land. Sometimes when there is no rice we eat cassava, rourou. That's why the most important thing to me [is that] [the landowner] gave us the land [to use]" (Tol); "[We spend \$40 per week on food] cause most of our foods we get it from the garden" (To 19); "I think this settlement is different from all over Fiji as we plant" (To2); "He gave us this land for planting free. Planting cassava, dalo, yams ... that shows the good relationship between us and [the landowner]" (To2). In short, home gardening enabled many participants to reduce their reliance on cash income. 


\subsection{Services and Amenities in Informal Settlements}

Data in Appendix 5 (Tables A.6-A.14) displays fieldwork information on service provision, toilet facilities, rubbish disposal and cooking methods across the case studies of the research sample (cross-referenced with census data where available). The data (Table A.6) first shows that $98.5 \%$ of the total research sample enjoyed a piped water supply; either with individual meters $(69.5 \%)$ or shared meters $(29 \%)$. Those households sharing meters, however, were often doing so with a number of households. For example, at Bouma all 16 households in the community shared water from two meters; generating great pressure on supply and often creating shortages for those households farthest from the meters. 2007 census data (Table A.7) shows that all households in Lagilagi and Caubati Topline had access to metered water supply; and $96 \%$ and $94 \%$ respectively in Lakena Hill Two and Tauvegavega. ${ }^{94}$

Research data (Table A.8) shows that mains electricity coverage across the research sample was $77.5 \%$. Of the remaining $22.5 \%$ with no mains connections (including all households at Bouma), a small fraction (4\%) did have generators (largely used in the evening only, if at all) while the remaining $18.5 \%$ had to cope without any power supply at all. A considerable amount of the sample (25\%) shared electricity meters; with often a number of households sharing a single meter. For example, at Lagilagi, where all households who were interviewed shared electricity meters, a jury-rigged network of power cables crossed the community; creating safety concerns and also some disputes when power bills arrive. Census data (Table A.9) reveals that metered electricity coverage was universal in Lagilagi and Caubati Topline, and covered $81.5 \%$ of households in Lakena Hill Two and $92.5 \%$ of households in Tauvegavega at the time of the 2007 census. ${ }^{95}$

Fieldwork data (Table A.10) shows that only $2 \%$ of respondents who were interviewed did not have access to a landline or mobile telephone within the household. Indeed, the table shows that $33 \%$ of the households who were interviewed had access to both a mobile and a landline telephone. Data (Table A.1 1) also reveals that, while none of the

\footnotetext{
94 What this census data does not reveal, however, is the extent of water meter sharing across these communities.

95 Again these census figures do not reveal the extent of electricity meter sharing across these communities. The census information also suggests that metered electricity coverage was universal in Lagilagi and Caubati Topline; whereas during fieldwork I visited two households in each of these communities without metered electricity supply - a small discrepancy that may be explained by the different dates of census (2007) and fieldwork (2008) data collection.
} 
case-study communities enjoyed sewage connections, $66 \%$ of the sample had flush (to septic tank) toilets; $9 \%$ had waterseal96 (to tank) facilities; and $23 \%$ had pit/latrine toilets (although considerable sharing of toilets by a number of households occurred). 2007 census information (Table A.12) shows information on toilet facilities in Lagilagi, Caubati Topline, Lakena Hill Two and Tauvegavega; revealing the extent of flush, waterseal and latrine (pit) toilets in these four communities in 2007. In brief, this highlights the dominance of flush toilet facilities, but also the continued presence of poor quality and more unsanitary pit/latrine toilets in Tauvegavega, Lagilagi and Lakena Hill Two.

Research data (Table A.13) also highlights the nature of rubbish disposal across the casestudy settlements of the sample; revealing that organised collection (through roadside collection or skip bins) was the most dominant (37\%), followed by burning (34.5\%) and burying (12.5\%) refuse as other significant categories. Finally, research data (Table A.14) shows principal cooking methods across the research sample; revealing that the use of fire was dominant (63\%), followed by kerosene stove (29\%) and gas (6.5\%). In short, field research and census data reinforces that services and amenities in informal settlements are less than adequate.

\subsection{Summary}

This chapter focused on highlighting the nature of informal settler movement, the various arrangements that are used to gain access to settlements, the livelihood strategies used in informal settlements, and the nature of service and infrastructure provision in settlement areas. The chapter revealed that the nature of informal settler movement is mixed; coming from both rural and other urban areas and being voluntary and involuntary. Movement to informal settlement often looks to benefit from the advantages of informal settlements (particularly the housing cost savings that they offer). Perhaps, however, all reasons for movement to settlements areas are encapsulated in the words of one indigenous Fijian interviewee from Lagilagi: "[The] hope for a better life aye. That's all we are searching for" (LL 3). The chapter also showed that access arrangements to informal settlements are context specific - influenced particularly by primary category of land tenure. Overall, it is clear that the informal settlements of the research sample are diverse in nature - making it difficult to generalise the character of Fijian informal settlements.

\footnotetext{
96 Usually flushed by using a bucket of water.
} 
Despite the cost advantages of informal settlements, for many households in these areas making ends meet (and particularly meeting cash demands) is difficult with low average incomes the norm. Notwithstanding of the difficulties of generalising across all settlements, informal settlers also often cope with less than adequate infrastructure and service provision, environmentally marginal locations and associated natural hazard risk, and, of course, insecurity of legal land tenure (which all may indeed influence the quality of dwellings in settlement areas). To focus on security of tenure, it is clear, however, that a more complex and nuanced understanding extending beyond the simple legal/illegal dichotomy is necessary. It has earlier been suggested that security of tenure can be perceived or de facto in nature; and this recognition leads to the core focus of this research - understanding the nature of perceived security of tenure and, in turn, housing consolidation in settlement areas - which is turned to in the next chapter. 


\section{CHAPTER 10: KEY RESULTS - PERCEIVED SECURITY OF TENURE AND HOUSING CONSOLIDATION}

\subsection{Introduction}

This chapter presents key results from the research pertaining to perceived security of tenure and housing consolidation in the case-study areas. In particular, the chapter aims to address the first and third key objectives guiding this research: firstly, to explore the extent of perceived security of tenure in the informal settlements of urban Fiji, and, then, to explore the extent of incremental 'self-help' home improvements, or housing consolidation, in these areas. In doing this, the chapter presents summary data from the research sample, displays citations from the interviews, and showcases 2007 census information.

\subsection{Perceived Security of Tenure}

As was discussed in the research methods chapter, perceived security of tenure was investigated in a number of ways - essentially by soliciting responses to direct questions, 97 by asking participants to indicate their level of security of tenure on a ten-point scale, and finally by making my own analysis of participants' security of tenure when analysing interview responses and my research notes.

\subsubsection{Eviction Threats and Pressure to Leave}

When beginning to explore perceived security of tenure I normally began by asking participants the question: 'do you feel threatened by eviction?' Table 10.1 below displays the summary responses to this question; revealing that only $6.5 \%$ of total respondents did feel some form of current eviction threat and $63 \%$ of respondents did not $(30.5 \%$ of respondents were unsure).

\footnotetext{
97 These questions included: (i) 'Do you feel threatened by eviction?'; (ii) 'Has anyone tried to make you move?'; (iii) 'Have you had any problems with the owner of the house or land?' (iv) 'Do you feel your position in this community is threatened in any way?'; ( $v$ ) 'What does security mean to you?'; ( $v i)$ 'Do you feel secure or insecure?'; (vii) 'What does security of tenure mean to you?'; and (viii) 'What could be done to improve your security of tenure?'.
} 
Table 10.1. Responses to the Question 'Do You Feel Threatened By Eviction?', Research Sample

\begin{tabular}{|c|c|c|c|c|c|c|c|c|c|c|c|c|}
\hline \multirow[b]{2}{*}{ Community } & \multicolumn{3}{|c|}{ Indigenous-Fijian } & \multicolumn{3}{|c|}{ Indo-Fijian } & \multicolumn{3}{|c|}{ Other } & \multicolumn{3}{|c|}{ All Ethnic Groups } \\
\hline & Yes & No & Unsure & Yes & \begin{tabular}{l|l} 
No & l
\end{tabular} & Unsure & Yes & No & Unsure & Yes & \begin{tabular}{l|l} 
No & U
\end{tabular} & Unsure \\
\hline Lagilagi & & 11 & 5 & 2 & 0 & 0 & 0 & 0 & 0 & 0 & 11 & 5 \\
\hline Caubati Topline & & 2 & 3 & 0 & 11 & 3 & 0 & 0 & 0 & 0 & 13 & 6 \\
\hline Lakena Hill Two & & 7 & 3 & 0 & 8 & 0 & 0 & 1 & 0 & 0 & 16 & 3 \\
\hline Vunato & & 15 & 5 & 0 & 0 & 0 & 0 & 0 & 0 & 0 & 15 & 5 \\
\hline Tomuka & & 1 & 4 & 0 & 5 & 9 & 0 & 0 & 0 & 0 & 6 & 13 \\
\hline Tauvegavega & & 2 & 0 & 1 & 11 & 6 & 0 & 0 & 0 & 0 & 13 & 6 \\
\hline Bouma & & 9 & 1 & 1 & 2 & 1 & 0 & 0 & 1 & 1 & 11 & 3 \\
\hline & & & & & & & & & & & & \\
\hline Total & & 47 & 21 & 4 & 37 & 19 & 0 & 1 & 1 & 1 & 85 & 41 \\
\hline \% Sampled Ethnic Group & & 64.5 & 28.5 & 6.66 & 61.66 & 31.66 & 0 & 50 & 50 & & & \\
\hline \% Whole Sample & & & & & & & & & & 6.5 & 63 & 30.5 \\
\hline
\end{tabular}

Source: Fieldwork data

A number of participants elaborated on the lack of eviction threats. For example: "No not really. In here we are happy because it's under state land" (LL3 F98); "No I [don't] think it's going to happen, but that all depends on God" (LL4 F); "We haven't heard anything about that here" (TL5 F); "No, no, no. I don't worry much about this. I don't think that the government can do something like that" (L7 F); "[No] we don't have that often. If you go with the landowners it's okay" (V5 F). Responses indicating the existence of current eviction threats included pressure from others in the community, landowners and institutions. For example: "[Yes] they say, go to India, don't stay here" (LL20 I); "[Yes] I've been moving around, moving around. Nowhere to get steady ... I have been going around listening to fancy tales" (L9 F); "Yeah one time it was like that. Native Land [NLTB] was forcing us to move, [saying] 'If you don't pay you have to move'" (TL8I); "[Yes] by this landowner and by this neighbours [sic]. The drunkard type neighbours" (B13 I). A significant proportion (30.5\%) of respondents indicated that they were unsure if they felt vulnerable to eviction. This position is summed up by a response by an indigenous Fijian resident at Lagilagi indicating the precariousness of living in squatter settlements: "Maybe, because we don't know, don't know what will happen. Because it's squatters" (LL11 F).

98 In the field research it quickly became evident that the primary ethnicity of the interviewee was a key determinant influencing perceived security of tenure. Thus, labels of citations in this chapter note primary ethnicity ( $\mathrm{F}=$ indigenous Fijian; $\mathrm{I}=$ Indo-Fijian; and $\mathrm{O}=\mathrm{Other}$ ). For example, 'LL3 $\mathrm{F}$ ' is a citation from Lagilagi interview three with an indigenous Fijian participant. Appendix 6 provides more information on key interview particulars. 
Past and current eviction threats were also explored by the question asked to all participants: 'Has anyone tried to make you move?' Table 10.2 displays responses to this question; showing that across the sample a high $86.5 \%$ of respondents had never experienced someone trying to make them move. Table 10.2 does reveal, however, that $20 \%$ of Indo-Fijian participants had experienced someone trying to make them move; compared with a lower figure of $5.5 \%$ for all indigenous Fijian respondents. Table 10.2 also shows that, by case-study community, pressure to move has been felt to be more pronounced by respondents at Tauvegavega, Lagilagi and Bouma.

Table 10.2. Responses to the Question 'Has Anyone Tried To Make You Move?', Research Sample

\begin{tabular}{|c|c|c|c|c|c|c|c|c|c|c|c|c|}
\hline \multirow[b]{2}{*}{ Community } & \multicolumn{3}{|c|}{ Indigenous-Fijian } & \multicolumn{3}{|c|}{ Indo-Fijian } & \multicolumn{3}{|c|}{ Other } & \multicolumn{3}{|c|}{ All Ethnic Groups } \\
\hline & Yes & No & Unsure & Yes & No & Unsure & Yes & No & Unsure & Yes & No & Unsure \\
\hline Lagilagi & 2 & 16 & 0 & 2 & 0 & 0 & 0 & 0 & 0 & 4 & 16 & 0 \\
\hline Caubati Topline & 0 & 6 & 0 & 0 & 14 & 0 & 0 & 0 & 0 & 0 & 20 & 0 \\
\hline Lakena Hill Two & 0 & 9 & 2 & 1 & 7 & 0 & 0 & 1 & 0 & 1 & 17 & 2 \\
\hline Vunato & 1 & 19 & 0 & 0 & 0 & 0 & 0 & 0 & 0 & 1 & 19 & 0 \\
\hline Tomuka & 1 & 5 & 0 & 1 & 13 & 0 & 0 & 0 & 0 & 2 & 18 & 0 \\
\hline Tauvegavega & 1 & 1 & 0 & 5 & 13 & 0 & 0 & 0 & 0 & 6 & 14 & 0 \\
\hline Bouma & 0 & 10 & 0 & 3 & 1 & 0 & 0 & 1 & 0 & 3 & 12 & 0 \\
\hline Total & 4 & 67 & 2 & 12 & 48 & 0 & 0 & 2 & 0 & 16 & 117 & 2 \\
\hline$\%$ Sampled Ethnic Group & 5.5 & 92 & 2.5 & 20 & 80 & 0 & 0 & 100 & 0 & & & \\
\hline$\%$ Whole Sample & & & & & & & & & & 12 & 86.5 & 1.5 \\
\hline
\end{tabular}

Source: Fieldwork data

A variety of responses were received that expanded on the initial responses shown in Table 10.2 above. Responses elaborating on the absence of anyone trying to force movement included: "[No] everyone in my PCN [Peoples' Community Network] group are happy that I can stay here, that I can stay on my own" (L17 I); "[No] this is my block now" (L18 I); "[No] I respect him [the landowner], and he respect me in the Fijian way" (T2 F); "[NO] if you pay your land rent on time there is no problem" (T13I). However, other negative responses to the question noted potential uncertainty in future. For example, as communicated by an Indo-Fijian resident of Lakena Hill Two: "Not till now, but we don't know about the future" (L15 I). 
Responses that elaborated on the existence of various pressures to leave are specific to the case-study community. At Lagilagi responses focused on historic, or more recent and ongoing, pressure. For example: "Around the time of the first coup owners [of the land] were trying to get the land vacated ... us all moved out, and the church intervened ... [as] originally this was free land, then the church bought this land" (L4 F); "Government gave us a notice to [vacate], but where can we go? They come with a bulldozer and a truck" (L20 I); "Only the government. But all the people here now only listen to what the ECREA [Ecumenical Centre for Research, Education and Advocacy] say" (L15 F). At Caubati Topline, positive responses to the question indicated the existence of real, but unfulfilled, threats or more latent pressure. For example, as was communicated by one Indo-Fijian resident of the community: "Every year someone comes and tells us we have to move the house from here ... [but] nothing have happened, I got three kids [in that time]"; "No people don't come here. [Rather] message come through" (TL7 I). At Tomuka, an Indo-Fijian woman reported her experience of losing her previous dwelling during a vulnerable time when her husband was overseas (she was subsequently residing in a dwelling initially based from a shipping container in a houseblock nearby): "[Yes] it was by force. They put our things outside. They close our door and blocked the entrance. They told me if you're gonna report they [would] block me from here also ... They demanded me to give two thousand dollars, then they will give me new lease. But the lease was not over. They gave me seven days time, but I had no money, my husband was in America. They did kick me out of the house ... I want my house. If they don't give me the house, I want my materials. As I could use those materials" (To17I).

At Tauvegavega, the positive responses around pressure to leave indicated the diversity of claims on the land. For example: "People just like me, who don't own this land, try and shake things up. Trying to con aye" (TI F); "They came before, it was after 2000 I think. They came, but they were different, they were not the mataqali people. Afterwards we got the letter from the police saying they were not the mataqali people ... They were saying that this land was theirs. [But] the owner of [this] land is a nice person, he was saying that "It is good you people staying here, cultivating it'" (T6 I); "Yeah some of the Fijian people. Those people were asking for the money aye [saying] 'You people have built the house and never paid us.' But we paid the Native Land [NLTB]" (T20 I). Other responses from Tauvegavega solely or additionally raised the eviction threat from NLTB in the early 2000s unless payments were made for 'tenancies at will'. For example: "Yeah the mataqali people came, the Native Lands [NLTB] came. 
They said 'You have to pay fifteen hundred dollars'... I attended court so many times" (T8 I); "One time they are making that one, trouble. They [NLTB] said 'You have one week to get off, otherwise you pay five hundred dollars'... When we pay five hundred dollars we ask for the Nailaga people. The Fijian man said 'Don't pay'" (T10 I); "Before after the second coup the native land [NLTB] said 'If you don't pay the money we will come and pull your house down"' (T1 1 I); "Yeah first when I settled here in 2000 I received an eviction notice from Crown Land Department. And after the reserve take place I received the eviction notice from NLTB, or to pay their demands. So I paid part of their demands" (T19l). The responses from Bouma also indicate the contesting claims on the land (even though the land is officially held in state tenure). For example: "[Yes but we] went to Native Land [Trust Board] and they said 'This isn't anybody's land'. [It's] Drainage Board [land] aye" (B12 I); "[Yes], before one Fijian man, I don't know from where, they ask us to move from here. As before only two or three houses here. But now plenty houses here and he not come back. He was saying this land is all ours ... because we don't have any place to live. That's why we didn't listen to him" (B14 I); "Yeah [also] one Muslim man. Before, one old lady was staying, she sell that house to one Muslim man, and he came and said 'That all my land'. Then after that, when he go, these people [neighbours came and said] 'These people are good' ... He [the Muslim] planted bele 99 here and we just pull it" (B14 I).

In some interviews the additional question 'Has anyone been made to leave this community?' was also asked. Positive responses to this question were most evident at the native land settlement of Tomuka. In this community, forms of social control are evident as failure to meet payments due to the landowner or simply causing conflict in the area can result in pressures to leave. For example, as was told by one Indo-Fijian long-term resident (who acts on behalf of the landowner in dealings with Indo-Fijian residents of the community): "We do have some strictness on people who rent. If there are any nuisances we do ask them to leave. I have sent two of them away from here"; "Those people who are living in this area, the people have improved a lot in their attitude, behaviour, conduct. But there are some elements around who become rowdy, especially when they are drunk ... Before what [the] landlord used to do [if there was a problem in the community] he told the person just to pack and go" (To5 I). Other responses indicated the ongoing cycle of movement out of Tomuka (including evictions): "Yeah plenty people have been made to move out. Some of them have got their Housing [Authority] land. Some of them have been forced to move out. Some of

99 An edible shrub. 
them might have some problem [with the landowner], we don't know" (To13 I); "Yeah plenty people they move from here. When people they move from here they pull out their houses and the landowners sell the block again ... [and] when the people, they make the problems, then the owners tell them to leave from here" (To6 I); "[Yes] if you fight here, spoil the neighbours, they will take the actions, pull your house" (To7 I); "Yeah plenty move from here ... I don't know if they chase" (To12 I).

To further explore possible eviction threats and general pressures to leave communities, the question was also posed to participants: "Have you ever had any problems with the owner of the house or land?' The absolute numbers of positive responses to this question are displayed in Table 10.3 below; revealing that $12.5 \%$ of the total sample answered 'yes' to this question. Table 10.3 also reveals that, within the sample, problems with landowners or house owners are most pronounced at Lagilagi (where five of the seven noted cases were problems with landlords in current or previous renting situations), and to a lesser degree Tomuka and Tauvegavega.

Table 10.3. Positive Responses to the Question 'Have You Ever Had Any Problems With The Owner Of The House Or Land?', Research Sample

\begin{tabular}{|l|l|l|r|r|}
\hline Community & $\begin{array}{l}\text { Indigenous } \\
\text { Fijian }\end{array}$ & Indo-Fijian & Other & \multicolumn{1}{l|}{ Total } \\
& & & & \\
\hline Lagilagi & 5 & 2 & 0 & 7 \\
\hline Caubati Topline & 0 & 1 & 0 & 1 \\
\hline Lakena Hill Two & 1 & 0 & 0 & 1 \\
\hline Vunato & 1 & 0 & 0 & 1 \\
\hline Tomuka & 1 & 2 & 0 & 3 \\
\hline Tauvegavega & 0 & 3 & 0 & 3 \\
\hline Bouma & 1 & 0 & 0 & 1 \\
\hline & & & & 17 \\
\hline Total & 9 & 8 & 0 & 17 \\
\hline \% Sampled Ethnic Group & $\mathbf{1 2 . 5}$ & $\mathbf{1 3 . 5}$ & $\mathbf{0}$ & \\
\hline \% Whole Sample & & & & $\mathbf{1 2 . 5}$ \\
\hline
\end{tabular}

Source: Fieldwork data

Responses from participants renting and experiencing problems with landlords included: "Yeah a few times. When we complain about the condition of the house he [the landlord] says 'if you're not happy, you find a new place'" (LL10 F); "Sometimes we are late in paying the rent. That's when she [the landlord] gets wild" (LL9 F). Responses 
indicating problems with landowners included: "Yeah some problems ... He [the landowner] just came here and want to collect some money, but I never give the money. That's why he come to angry" (V18 F); "He's [the landowner] the one that took that house ... my husband went to America, they put our things outside and told us to move" (To 17 I); "Yeah there were some people going around saying they were the mataqali. But we didn't give them any money" (TL19 I). At Tomuka, the responses to the question 'Have you ever had any problems with the owner of the house or land?' further indicated the potential implications of causing problems in the community and the continuing element of social control emanating from the landowners. For example: "[No] you should pay the land rent at the time and there's no problem ... If we stay here properly and do not fight anyone and do not cause a problem, there is no problem" (To6 I); "No, no ... I don't think so. If you stay here nicely, no problem. If your ways are no good, then you come into problem" (To7 I); "In my twenty-seven years here, not any problem. But with the other fellas happen like that they [the landowners] hold the house and chase" (To7 I).

In some interviews the additional question 'Do you feel your position in the community is threatened in any way?' was posed to respondents. Across all interviews only 13 positive responses were received to this question - some focusing on threats from real or claimant landowners but more focusing on neighbourhood disputes or local crime. For example: "This land is for the village of Verata. Sometimes they threaten us and say they want the land back" (L10 F); "[Yes] my older sister in law was late in paying rent and they came inside threatening us, our house too ... You know, they are a very dangerous people around here ... They got plenty brothers, we just know that ... We just pay the rent, enough" (To9 I); "Sometimes they always complain. Neighbours complain. Kids they throwing stones to the neighbours' house. They go into other compounds" (To20 F); "Yeah too much fighting and stealing, murders ... yeah especially the murders. I hate these things. Scared" (To15 I); "Before plenty breaking and stealing going on. That was when we feel afraid" (To16I).

\subsubsection{Perceptions of Security and Security of Tenure}

'Security' and 'security of tenure', and particularly participants' perceptions of these quite multifaceted concepts, were explored in interviews through a series of questions. Before introducing and discussing security of tenure, I first asked all respondents to explain what 'security' meant to them. Responses varied: some were general and/or 
focused on the family, some centred around personal safety/security and crime, and some discussed land and land tenure. Some participants also recognised that security is a concept that can mean a number of different things. Just a few general responses and those focusing on the family included: "Somebody have to look for Us" (LL17 F); "As long as your family members are safe aye ... Secure means you have secured the family" (LL20 I); "In my mind it's we are safe aye" (TL7 I); "It means somebody to guide me, to keep me safe" (L7 F); "Just to make yourself look after you and your family" (V15 F); "You are safe in your relations with others - personally, boundary, livelihood, without enemy" (T1 F). Responses linking security to personal safety/crime included: "Free from any criminals" (LLO F); "It's a very big topic this one security. This [general] area is targeted by thieves, housebreaking, larceny. But actually this [immediate area] is a safe area" (TL4 F): "Only the neighbours. Here anything happen people run ... [But] nobody do anything bad in this area" (TL6 F); "Like sometimes some other places if your stay thieves come, and here I think it's better" (TL15 I). Participants linking the general concept of security to land and land tenure focused on the need for long-term residence. For example: "That means to own the place aye" (LL5 F); "The way I thought ... to security me, to secure our leaving, something like that" (L9 F); "We are under the government. Security is like somebody is guiding us, protecting us. The government is giving us permission to live in this land, as we are not paying rent" (L10 F); "To be not moved from here" (L15 I); "It's good about being secured, no one is doing anything to make them move. Everyone is very friendly" (L19 I); "We want proper paperwork and the government should be involved. And longer lease - thirty years just come and go" (Tol7 1). A number of participants recognised that security is a multifaceted concept meaning many different things. For example: "If we have developed land we can fence our area and put the burglar bar. The way we stay here anyone can be a mataqali and threaten [us] to leave this place. As far as we are concerned if we have proper title we are secured" (TL18 I); "It's like to protect the land, and to look after the land, people in the land" (V12 F); "It comes to me. Ten years we staying here and we never get in trouble with anybody. And secondly [the landowner] is always watching us for the security of the land. If one person is making trouble they have to go [home] to the village, that is [the landowner's] law. That's why we are secured here" (Tol F).

After introducing and discussing security broadly, the question 'What does security of tenure mean to you?' was asked to all participants. Responses to this question were again diverse in nature. Some respondents linked security of tenure to land and holding increased rights to use that land. For example: "To own. What I need is to own. Not 
own the house, [but] own the land. If I own the land I can build the [better] house" (LL2 F); "If I save up more money I can get land tenure, can get better housing ... I can get better education for my kids" (LL3 F); "Like a lease or [to] buy" (LL6 F); "Like if you pay up this land, like you know if you own something, the property is totally under your name. Or if people give you the title of this land" (L1 1 F). Other respondents linked security of tenure to the possibility of living permanently on the land. For example: "We are relying on ECREA now to help us [get] a permanent place to live. That is our hope aye, to get our land secured" (LL10 F); "Something to keep me on the land. I don't think there is any security because it's up to the government. There would be no security if the government asked us to vacate the land, all we have to do is pack and go" (L7 F); "We want to stay here for long time aye" (To 12 I). Other respondents (particularly those living on native land or in areas where mataqali groups assert some claim to the land) indicated that security of tenure was inherently linked to relationships with native landowners. For example: "Since we are staying here, we don't know the landowner, we haven't seen him. So here we haven't spent any money on this land" (L17 I); "Sometimes he [the landowner] has to come and we have to share grog bowls with him. And if he needs grog we have to provide him, or smoke. Just to keep him happy" (To3 F); "I've been staying here [with] no security. I've never been in touch with the owner of the land" (B7 F). Other respondents simply associated security of tenure with what they did not currently have. For example: "People they know very well that we don't have any security. Any time we can be forced by the NLTB or the landowners out of here" (T16 I); "If they ask us to move out there is no security. They made an agreement for thirty years but not secured. There is nothing from the government. There is not a legal agreement" (To13 I); "Here we are under the squatter settlement, we don't have much security at present" (TL16 I); "Over here, Vunato, this place ... there is no lease, so we just live like [this]" (V3 F).

As was mentioned in the methods chapter, in discussing security of tenure with indigenous Fijian participants, I often used the Fijian expression vakadeitaki - loosely translated in English as having some assurance that it is possible to stay on the land for as long as an individual or household may want. I usually asked participants two questions: (i) 'What does vakadeitaki mean to you?'; and (ii) 'Do you have vakadeitaki now?' In response to the first question, participants explained vakadeitaki in a variety of associated ways. For example: "Assurance ... we are hoping that ECREA will help us stay here" (LL9 F); "Vei vakadeitaki means to keep us secure in one place" (LL1 1 F); "To stay here forever" (LL15 F); "Like an anchor, an anchor of a ship. We are settled" (LL18 F); 
"That means, like if you build your place here you won't pull it down again. Because I'm renting I can't say [if I have vakadeitaki]" (TL2 F); "Means you are living permanently in a place" (TL3 F); "Like when you stay in one place, you gonna to stay there for all of your life ... yeah [we have vakadeitaki] because we give the tabua everything like that" (VI F); "Just to stay here forever and ever. You don't have to go to another place. You stay here until you die" (V3 F); "To me it's asking me if I'm affirmed. If the land is mine for the rest of my life, for the amount of time that I want to" (V10 F); "You will settle in a place. An agreement will be made that you will stay there forever [or] until you want to leave" (Tol F); "That one is from the landowner. He can only say that one for us to come and stay. You are allowed to stay on this land for forever, or fifteen years" (To2 F).

In response to the second question, 'Do you have vakadeitaki now?', a number of responses were received indicating that vakadeitaki is linked to improving relationships with landowners or having legal security of tenure (such as a lease for the land). For example: "No because this land is their land. We can just make the sevusevu to stay here. We can [be made to] go anytime. If we have the lease we have vakadeitaki" (V3 F); "[Vakadeitaki would be] different if we sit with whole clan, mataqali - as we only sit with one landowner" (V9 F); "Vakadeitaki, we have to present a tabua. Ten years we stay here [with] vakadeitaki" (Tol F); "[Yes but] he [the landowner] told me when we came up that the land is with the house for me and my family... [but] because after he passed away who knows about the children? Will they stick to that promise?" (To3 F); "[No] because I just buy this house. In our culture you have to bring one whale's tooth and you have to go to the owner of the land and have to apologise to the owner for not knowing you" (B7 F); "Without papers there is no assurance really ... the landowner might get cranky and say 'You people must leave', it can happen" (V10 F); "[No] anytime if he [the landowner] just come [and say] 'You give me ten dollars for the grog' [or] just pack and go ... Only vakadeitaki if this land is lease" (To2 F).

After discussing security broadly and introducing and discussing security of tenure, the question was asked to all participants 'Do you feel secure or insecure?' At this point, in cases where it was evident that participants were still unclear about the meaning of security of tenure, I often would reinforce security of tenure as meaning: protection from eviction; being able to stay on the land for as long as an individual or household may want; and/or, for indigenous Fijian participants, as vakadeitaki. Table 10.4 below displays the responses to this question (in this table the category '+/-' reflects responses where participants communicated their situation as 'not secure and not insecure'). The 
table shows that, across the whole sample, $52 \%$ of respondents felt secure, $34 \%$ felt insecure, $7.5 \%$ did not feel secure or insecure, and 6.5\% were unsure. Table 10.4 also reveals that, in general, indigenous Fijian respondents felt more secure than Indo-Fijian participants ( $63 \%$ of all indigenous Fijian respondents felt secure compared to $40 \%$ of Indo-Fijian respondents). Table 10.4 also shows that, by case-study community, security appears to be highest at the $100 \%$ indigenous Fijian settlement of Vunato $185 \%$ of respondents indicated they felt secure) and at Caubati Topline (65\% secure). The table also shows that insecurity appears most pronounced at Tomuka $150 \%$ of respondents felt insecure) and Tauvegavega ( $45 \%$ insecure).

Table 10.4. Responses to the Question 'Do You Feel Secure or Insecure?', Research Sample

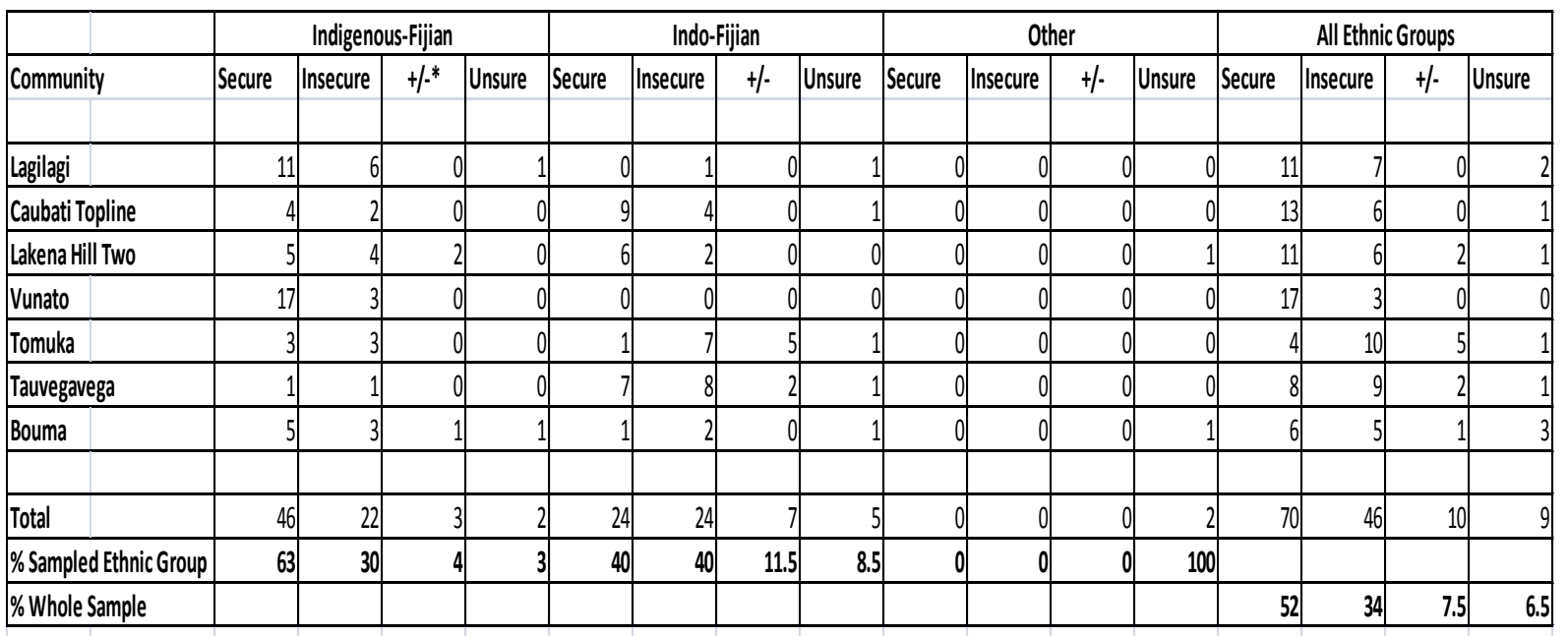

* Not secure and not insecure

\section{Source: Fieldwork data}

A number of participants elaborated on their feelings and answer of secure or insecure; responses that are beginning to indicate important variables that influence security of tenure. For example, it was clear that the projects, community savings schemes and advocacy facilitated by and from the NGO ECREA were important for influencing feelings of security in the greater Suva communities where this organisation was active. For example: "Oh yes I feel secure ... I feel secure as my husband's getting a good job now. I trust that whatever we are fighting for, the pilot project, will be happening soon" (LL3 F); "Now I feel secure. I feel secure because of the savings with ECREA" (LL4 F); "I don't have to worry, the only concern is being forced to move from here. [But] the information we have received from ECREA we are confident that we will not be forced to move from here" (TL4 F). Other participants suggested that their long-term presence in 
settlements, often without any pressure to leave, or simply the absence of any eviction threats, was important in influencing their secure position. For example: "[Secure] because down there, down on that side, they have concrete buildings and still the land is not marked, and the childrens [sic] are still living there" (T6 I); "We feel secure because right now I have built the house" (T7 I); "Secure, no one here to give the warning to vacate the place" (L12 I). At Lakena Hill Two, it was also mentioned that the prospect on the horizon of residents receiving legal security of tenure was important in influencing feelings of security: "[Secure] because we have got the file already there [at the Department of Lands and Surveys], our name is there. Very soon we have to get the land" (L18 I); "[Secure] just because they were told they will have this piece of land ... Actually there has been some improvements in Lakena, they have been making the footpath" (L19 I).

Participants living on native land suggested that positive relationships with the landowners were integral in maintaining their sense of security in their community. For example: "Taking into account the attitude of the landowner I think they are quite secured" (V10 F); "The security of this place is so good, it's secure. The way we are relating [with the landowners] because we are attending the same church" (Tol F); "[Secure] because no one comes and makes any problems ... Before the Fijian people used to come and say we need to pay them this much, but now everything is okay" (T9 I): "[Secure] because the land's fathers, owners, tell us that they will never say us to go from here. Only we have to pay the payment aye" (T121); "[Secure] because the owner doesn't interfere with this neighbourhood. He just leaves people in peace" (T15I). Residents at the native land settlement of Vunato also suggested that the close-knit nature of the community was important in facilitating a sense of security: "[Secure] cause we live with relatives, close family, aye. She [the grandmother] will stay here as long as she lives" (V7 F); "[Secure] because we like each other, we know each other ... sometimes we look after each other" (V12 F).

Some respondents who felt currently secure, however, were aware that the situation could alter in the future with changes in government, the deaths of native landowners, and possible intervention from state agencies. For example: "At the moment we are feeling secure. At the moment we can't say much about that - if the other government comes..." (TLI 1 I); "[Yes I can stay as long as I want] but on the other hand I am not taking advantage of it as we don't know. Times may change with the landowners. We don't know what they are going to do" (To19 F); "It's indefinite. It all depends ... If the 
landlord is no more there, and his children come up and what they decide we never know ... The story is like this. I don't think people are very much aware. This land belongs to all the brothers [and] they have divided all this area. If [the landowner dies his children will take on his area" (To5 I); "We feel secure if sixty or seventy years we can stay here. It's good for us as we can't rebuilt [sic] the house ... If God helps us we can stay, if Native Land [NLTB], sudden, we don't know" (T7 I).

The majority of respondents who felt insecure in their settlements seemed to recognise the reality of their situation. Some participants indicated that they did not have any legal security of tenure. For example: "We are not secured for this land, we don't know, unless we get the title for this land we are [then] secured" (L16 I); "[Insecure] because this land is Native Land and not lease under the NLTB Act. The power of ownership is under the owner. Anytime he can just come and [say] 'Get out of this area'" (To2 F). Most participants who felt insecure, however, communicated that they felt vulnerable because one day they might be asked or forced to leave. For example: "[Insecure] right now because we're living in squatters. I've been thinking too that one day we might be made to move" (LL10 F); "[Insecure] because if the government saying you go, go" (LL18 F); "[Insecure] because we can leave this land at any time, because it's not ours and we are not paying anything ... For Fijian people when you tell them to move from where they're staying, it's very hard. On top of that they know it's government land" (L1 1 F); "[Insecure as] we don't know when the landowner will take back his land" (V2 F); "[The] land is not ours ... when the landowner says to go, just go" (V5 F); "[Insecure] because over here anytime the landlord can [force us] to pack our bag and go. If we don't pay our rent they can force us to go" (To10 I): "[Insecure] because the agreement we got it, it can't work. You can't fight it. Anytime the owner going to come and say 'You pull the house' we have to. Because this is a settlement" (To16 I); "[Insecure] because if they tell us to move, we have to move from here. I feel if this land is secure it is good for the future of my wife and children. Because five hundred dollars [paid to NLTB] is nothing. When we go and check there is nothing in the computer. Any time they can ask us to leave" ( $\left.\begin{array}{lllll} & 1 & l\end{array}\right)$. Other participants feeling insecure raised that evictions were happening from other informal settlements (for example: "At times when we look at what's happening in other squatter settlements we feel insecure as anything can happen to us anytime" (LI F)), and that they could not stop others from building in the area (for example: "It's not secure. If any fella comes and builds a place here. We can't stop him" (B 14 I)). Other participants suggested that their insecurity was linked to land tenure arrangements or uncertainty over the legal holders of the land. For example: "[Insecure] 
cause we are not sure about this land. Whether one day the government might be making leases for this crown land. Or they be taking back this land" (B9 F); "[Insecure] because plenty people come bossing around this place. Mataqalis, landowners although we understand that the government owns this land. So it's better to move out than getting into disputes" (B13 I); "[Insecure because] we don't know who's land is this" (TL17 I); "[Insecure as] if the landowners change then we can't tell if it is secure or unsecure [sic]" (To9 I).

Some respondents communicated that they did not feel secure or insecure. Comments elaborating on this choice indicated the differences between legal security of tenure (understood as absent) and perceived security of tenure. For example: "Sometimes I feel insecure, sometimes I feel secure ... I have to take it, as where else am I going to go?" (L9 F); "[Secure because] we not having any problem, but it's not definite security. Only definite security we will have is when we buy the land from Housing Authority" (To5 I): "If the landowners want to chase us away we can't do anything, we have to go. Otherwise if they demand for the extra money, we can pay and stay" (To6 I); "So the regulation here is this, if you stay kindly, no problem. If you create problem ... there is no security. You can't take the case to the court ... If you make the mistake they hold your house and chase you from here, no lawyer or magistrate will help you ... because this is not a real legal place" (To7 I).

Some participants still seemed to be referring to other dimensions of security in their responses (particularly as related to personal security) - situations that may, however, remain influential in affecting perceived security of tenure. For example: "I feel secure. Like there is no one, no one is troubling me, no one is saying anything bad about me during my stay in Lakena here, everything is okay" (L9 F); "[Secure] because in this area amongst all the Indians I am the youngest Indian, everyone is very caring ... At night too we are not disturbed by anyone" (L17 I); "[Insecure as] sometimes good, but sometimes drunken people cause the problem. And the thiefs [sic], three times they broke my house and steal the things" (To6 I); "Like here they smoke drugs, abuse, stealing. Especially in this area. Boys around here smoke drugs. We got daughters we worry about. They abuse people, hustle them. Very insecure ... I feel that one day we're going to leave" (To20 F).

Participants were also asked to indicate their level of security of tenure on a ten-point scale: with 'ten' being the most secure, 'one' being the most insecure, and 'five' being 
not secure and not insecure. Table 10.5 below displays the mean results from this activity; showing that the average score for all ethnic groups across all communities was 6.0. The table also shows that, using this method, security of tenure for all indigenous Fijian participants (an average score of 6.2) was higher than for Indo-Fijian participants (an average score of 5.6). Table 10.5 also reveals differences in security of tenure, using this method of investigation, between case-study communities; suggesting that security of tenure was highest at Bouma (average score of 6.8) and Vunato (6.5) and lowest at Tomuka (5.1) and Tauvegavega (5.6) (Lakena Hill Two averaged 6.4 and Lagilagi 6.3).

Table 10.5. Security of Tenure on a Ten-Point Scale(Weighted Score Average), Research Sample

\begin{tabular}{|l|r|r|r|r|}
\hline Community & Indigenous Fijian & Indo-Fijian & Other & All Ethnic Groups \\
\hline Lagilagi & 6.6 & 3.5 & n.a. & 6.3 \\
\hline Caubati Topline & 6.9 & 5.6 & n.a. & 6 \\
\hline Lakena Hill Two & 5.4 & 8 & 4.5 & 6.4 \\
\hline Vunato & 6.5 & n.a. & n.a. & 6.5 \\
\hline Tomuka & 5.7 & 4.8 & n.a. & 5.1 \\
\hline Tauvegavega & 6 & 5.5 & n.a. & 5.6 \\
\hline Bouma & 7 & 5.6 & 10 & 6.8 \\
\hline & & & & 6 \\
\hline All Communities & 6.2 & 5.6 & 7.25 & \\
\hline
\end{tabular}

Source: Fieldwork data

A number of participants elaborated on the score that they indicated. Those scoring less than five on the scale mentioned: "[4] because it's not that secure that we can stay here for long" (TL18 I); "[4] because I'm not a citizen, and someone might just walk up and take it [the land] out of my [hands]" (L20 O); "[1] because we don't know. See our landowner has brothers and sisters and he's the eldest, and we only listen to him. If he's gonna die, he [the younger brother] might tell us to uproot and leave" (V9 F); "[1] because any time they gonna push you out" (To17I). Comments from participants who scored greater than five - the majority linking security of tenure to long stays on the land - included: "[7] because long time we live here" (LL17 F); "[6 or 7 as] we're staying here seven years" (V18 F); "[10] because this place, you never pay anything. You stay for free life. Firewood is free. House is yours. Only pay the water" (B7 F); "[10 because] people have been staying here so long" (B8 F); "[10] cause my parents said they will be here until the government tells them to go and they will declare a special land for them to 
lease" (B15 I). The comments from the many respondents who indicated a security of tenure score of five 100 indicated that they seemed to be conscious of the reality and possible vulnerability of their situation. For example: "[5] I hope that I will be here my whole life. But if something happen I don't know [person 1]" ... "So it's in between aye [person 2]" (LL14 F); "[5] when we hear the news we feel insecure. When nothing happen we feel relaxed" (L1 F); "[5] when the landowners they started asking us to give [monthly] money ... so we are not sure about whether they will take back the land ... there is no guarantee" (V2 F); "[5] because I'm not really sure what will happen if [the landowner] dies [person 1]... [Maybe] pack and go [person 2]" (V17 F); "[5] because if they [the landowners] are not angry we'll stay. If they're angry, we'll go" (To4 F); "[5] because it will be insecured [sic]. One day they going to inform us to leave" (To20 F); "[5] because I'm still renting" (T2 F).

It was necessary to explore security of tenure in a number of ways: as the results displayed have shown, by exploring possible eviction threats and pressures to leave, by discussing security broadly, by discussing possible meanings of security of tenure (and explaining the concept clearly if needed), by asking participants if they felt secure or insecure, and by using a ten-point scale. Through evaluating all these responses, I was able to make my own analysis of all research participants' perceived security of tenure results that are displayed in Table 10.6 below. The results in this table are different than those in Table 10.4 as the results only showcase perceived security of tenure (rather than other dimensions of security, such as personal security, that cloud the results to some extent in Table 10.4). In Table 10.6, it was necessary, however, to include the category 'uncertain' - applicable when: (i) there were contradictory responses to different questions around security and security of tenure; and/or (ii) respondents focused on alternative dimensions of security. In these cases it was difficult to make a call on perceived security of tenure.

100 Close to $37 \%$ of the sample. 
Table 10.6. Perceived Security of Tenure, Author's Analysis, Research Sample

\begin{tabular}{|c|c|c|c|c|c|c|c|c|c|c|c|c|c|c|c|c|c|}
\hline & \multicolumn{5}{|c|}{ Indigenous Fijijan } & \multicolumn{4}{|c|}{ Indo-Fijian } & \multicolumn{4}{|c|}{ Other } & \multicolumn{4}{|c|}{ All Ethnic Groups } \\
\hline Community & Positive & Negative & +1 & & Uncertain & Positive & Negative &.+ & Uncertain & Positive & Negative & +1. & Uncertain & Positive & Negative & $+\mid-$ & Uncertain \\
\hline & & & & & & & & & & & & & & & & & \\
\hline Lagilagi & 8 & 8 & & 4 & 6 & & 1 & 1 & & & & & & 8 & 1 & 5 & 6 \\
\hline Caubati Topline & 3 & 3 & & 2 & 1 & 7 & 3 & 2 & 2 & & & & & 10 & 3 & 4 & 3 \\
\hline Lakena Hill Two & 4 & 4 & 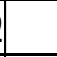 & 2 & 3 & 6 & & 1 & 1 & & & & 1 & 10 & 2 & 3 & 5 \\
\hline Vunato & 10 & 0 & 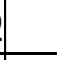 & 6 & 2 & & & & & & & & & 10 & 2 & 6 & 2 \\
\hline Tomuka & 2 & 2 & 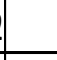 & 1 & 1 & 2 & 4 & 7 & 1 & & & & & 4 & 6 & 8 & 2 \\
\hline Tauvegavega & & & & 1 & 1 & 9 & 6 & 2 & 1 & & & & & 9 & 6 & 3 & 2 \\
\hline Bouma & 5 & 5 & & 4 & 1 & 2 & 2 & & & 1 & 1 & & & 8 & 2 & 4 & 1 \\
\hline & & & & & & & & & & & & & & & & & \\
\hline Total & 32 & 2 & 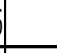 & 20 & 15 & 26 & 16 & 13 & 5 & 1 & & & 1 & 59 & 22 & 33 & 21 \\
\hline \% Sampled Ethnic Group & 4 & 4 & 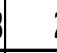 & 7.5 & 20.5 & 43.5 & 26.5 & 21.5 & 8.5 & 50 & & & 50 & & & & \\
\hline \% Whole Sample & & & & & & & & & & & & & & 43.5 & 16.5 & 24.5 & 15.5 \\
\hline
\end{tabular}

* Not secure and not insecure

Source: Fieldwork data

Table 10.6 presents the key statistical research data on perceived security of tenure across the research sample. It reveals that $43.5 \%$ of all research respondents indicated positive perceived security of tenure; $24.5 \%$ showed their perceived security of tenure as not secure and not insecure; $16.5 \%$ indicated negative security of tenure; and in $15.5 \%$ of cases responses were uncertain. When comparing the perceived security of tenure of the two major ethnic groups, Table 10.6 shows that, while similar percentages of respondents indicated positive security of tenure ( $44 \%$ for indigenous Fijians compared with $43.5 \%$ for Indo-Fijians), much higher percentages of Indo-Fijian participants indicated negative security of tenure than indigenous Fijian participants $26.5 \%$ compared with $8 \%)$. Table 10.6 also highlights differences between case-study communities. For example it reveals that: (i) positive perceived security of tenure is strongest at Bouma (56.5\% of all respondents indicated positive security of tenure) and Caubati Topline, Lakena Hill Two and Vunato (all 50\%); (ii) negative security of tenure is strongest at Tomuka and Tauvegavega (at both communities $30 \%$ of all respondents indicated negative security of tenure); and (iii) the category 'not secure and not insecure' is significant at Tomuka ( $40 \%$ of all respondents).

Table 10.7 below highlights the influence of primary land tenure on perceived security of tenure across all ethnic groups in the sample. It shows that positive security of tenure is 
higher in the state land case-study settlements ( $48 \%$ of the state land sample showing evidence of positive security of tenure) than in native land areas (38.33\% of the sample). Correspondingly, the table shows that negative security of tenure is higher in the native land settlements (23.33\% of the sample) compared to the state land areas $10.5 \%$ of the sample).

Table 10.7. Perceived Security of Tenure by Primary Land Tenure, All Ethnic Groups, Research Sample

\begin{tabular}{|l|r|r|r|r|}
\hline & Positive & Negative & \multicolumn{1}{|c|}{+ - } & Uncertain \\
\hline \% All State Land Sample* & 48 & 10.5 & 21.5 & 20 \\
\hline \% All Native Land Sample** & 38.33 & 23.33 & 28.33 & 10 \\
\hline \% Whole Sample & 43.5 & 16.5 & 24.5 & 15.5 \\
\hline \multicolumn{4}{|l|}{} & \\
* Lagilagi, Caubati Topline, Lakena Hill Two \& Bouma (n=75) \\
** Vunato, Tomuka \& Tauvegavega (n=60)
\end{tabular}

Source: Fieldwork data

Table 10.8 below shows perceived security of tenure by major ethnic group and primary land tenure. The table reveals that for the indigenous Fijian sample: (i) positive security of tenure is relatively equal in the state land sample (44.5\%) to the native land sample (43\%); and (ii) negative security of tenure is higher in the native land sample (14.25\%) than the state land sample (only 4.5\%). For Indo-Fijian participants, Table 10.8 shows negative security of tenure is higher in the native land sample (31.25\%) than the state land sample (21.5\%). The table also shows that over half $(53.5 \%)$ of the Indo-Fijian state land sample showed evidence of positive security of tenure.

Table 10.8. Perceived Security of Tenure by Primary Land Tenure, Indigenous Fijian and Indo-Fijian Participants, Research Sample

\begin{tabular}{|l|r|r|r|r|r|r|r|r|}
\hline & \multicolumn{4}{|c|}{ Indigenous Fijian } & \multicolumn{3}{c|}{ Indo-Fijian } \\
\hline Community & Positive & Negative & +/- & Uncertain & Positive & Negative & +/- & Uncertain \\
\hline \% State Land Sample* & 44.5 & 4.5 & 26.5 & 24.5 & 53.5 & 21.5 & 14.5 & 10.5 \\
\hline \% Native Land Sample** & 43 & 14.25 & 28.5 & 14.25 & 34.5 & 31.25 & 28 & 6.25 \\
\hline
\end{tabular}

Source: Fieldwork data 
Despite lack of legal security of tenure, informal settlers in Fiji, particularly those living on native land through vakavanua arrangements, may hold rights to use land. The literature suggests that possessing documentation (indicating rights to use land or as evidence to help prove length of occupation) is useful for informal settlers (and indeed influences perceived security of tenure). When documentation to show land use rights or help show length of occupation existed in the research sample, it tended to be particular to each case-study community. Specifically, at Lakena Hill Two, 30\% of participant households held letters and receipts for early 'fines' paid to the Department of Lands and Surveys (for example: "Only we have letter from the Lands Department just to confirm that we are living in the squatter settlement" (LI F)). These households had their names and details recorded in a register at this agency; a clear benefit for the household if titles or leases are ever provided to Lakena Hill Two residents (as promised by central government for many years). At Vunato, $40 \%$ of participant households possessed a letter from the landowner confirming the vakavanua agreement allowing the family to stay in the community. At Tomuka, $70 \%$ of the participant households held paperwork from the landowners detailing the length and terms of their informal 'lease' agreement (often mimicking official NLTB documents). And, at Tauvegavega, $60 \%$ of participant households held letters and receipts from the Department of Lands and Surveys registering their occupation of the land, or NLTB offers of tenancies at will. However, in Lagilagi, Caubati Topline and Bouma, official documentation was absent. 101 As was explained by participants, this lack of documentation influenced their vulnerability: "No, no guarantee here. Anytime they can chase us from here ... no security of the land here" (LL2O I); "No black and white. These people can move us anytime aye" (TL15 I). At Lagilagi, Caubati Topline and Lakena Hill Two, however, where the Peoples' Community Network was active, significant proportions of households interviewed (85\% at Lagilagi; $60 \%$ at Caubati Topline; and $40 \%$ at Lakena Hill Two) were participating in collective community savings schemes - and receiving receipts for payments. These receipts were noted by some participants as providing some documentation of their community occupation.

\footnotetext{
101 While any official documentation was absent at Lagilagi, Caubati Topline and Bouma, participants did note some single, discrete cases of paperwork that could help prove their length of occupation. These included: paperwork necessary for electricity connection (one case at Lagilagi); possession of a lot number from the local council (one case at Caubati Topline); receipts for rent payments to the house owner (one case at Caubati Topline); bank records showing payments (one case at Caubati Topline); possession of a letter from a previous house owner (one case at Caubati Topline); a letter from the previous user of the land (one case at Caubati Topline); and an ancient payment book of cash paid to freehold landowners (one case at Lagilagi). At Bouma, all 15 households interviewed had no documentation at all. (Two households at Bouma once held paperwork from the local church detailing their occupation - documents, however, that had been lost in subsequent floods. These two examples indicate the challenges and precariousness of informal settlements in natural hazard prone areas.)
} 
In addition to documentation, the literature also suggests that, if informal settlers and settlements can obtain some political patronage, perceived security of tenure can be improved. However, in general across the case studies, real political support or community projects instigated by central government were absent or minimal. For example: "From the time I move in I haven't met any politicians around here" (TL4 F); "Nothing. Nobody comes to Tomuka" (To17 I); "They will not come to us, they will not reach us" (T8 I); "From our point of view, no. Except the 2000 post government. That's the only government that made some improvements in this community. They made the road. Before then there was no road here ... At this moment, the interim government, no nothing" (LL1 1 F). Some initiatives in informal settlements planned by governments had been stymied by political change. For example: "Yeah, a couple of years back for the past few governments have been telling [US] that development is going to happen. But when government changes nothing happens" (LL10 F); "Yeah this is what they promise, they give electricity, they upgrade the road. But they stop there because of the coup" (L7 F); "Yeah, yeah. When Labour win the election. [A politician] came here and said he would help us. He told us that he would help us get electricity, and for the job. Then after sometimes the Labour Government was thrown away aye" (T12 I). Normally, however, when promises had been made by political parties and individuals (usually before elections), they were largely unfulfilled - and were thus met with great dissatisfaction and subsequent scepticism. Just a few examples of many from across the sample included: "They promise us that they are going to secure this place for us, but they go [and] in [the] end they forget us" (LL6 F); "Oh yes so many times. They have promised us to develop this place. But all these problems are lies. When elections comes they start running [here]. Why? Because we have the majority of voters living in the squatters" (LL7 F); "When election comes near the ministers will come around [and] promise us they will do something about the land. That's the only time" (L1 1 F); "Plenty [political promises], they said they going to make this, make the road good, put lights on the road. None of them turned out good" (L17 I); "SDL102 said they would build new homes for us, but we are still waiting" (V6 F); "Plenty when they come for campaign. Come around, electricity, telephone, roads. But they forgot about Tomuka" (To2 F); "Yeah sometimes when the election comes, then they come and say 'You will have a block here, drain here'. But nothing has been done" (T8 I); "Just recently the

102 Soqosoqo Duavata Lewe Ni Vanua Party - the party led by Laisenia Qarase that was deposed in the December 2006 coup. 
Commissioner Northern was meant to come to talk about the water, electricity thing. They waited at the church there, but he never appeared" (B13I).

In finishing discussions around security of tenure I always asked participants the open question of 'What could be done to improve your security of tenure?' Responses were varied - many suggesting key variables that influence perceived security of tenure. Many participants communicated that it was largely only by receiving titles or leases that their security of tenure could be improved - usually requiring government intervention and the approval of native landowners if necessary. Respondents often mentioned that government action would be essential for improving their security of tenure. For example: "Well the government could come up and, although the land is state, they can come and mark pegs around. They can start charging rates, so that people can start upgrading, making the place more beautiful than at the moment ... [But] they don't want to face those problems, they want the easy way out" (TL9 I); "Well we normally rely on the government. If they can give us some aid, or subdivide the block, sort of a loan scheme, they can do the payment on the forms" (TL19 I); "If government marked the area in one block, and give us some time. Every month I can pay, we can make our block here that will be ours" (T8I). Many respondents communicated the necessity of receiving titles or leases if their security of tenure was to be improved. Just a few examples of many included: "This one if we get the title. If we get the title to this land you are a recognised citizen. We are in the squatters here and we are not recognised citizens" (TL16 I); "If the government can give us the title from this land ... People are sitting in their own block. They already made it. They are just waiting for title" (L1 1 F); "If it is possible I think NLTB should allow landowners to de-register the reserve land, and give it out on lease to the people. Since that the relationship between the mataqali and the people is good. It will also bring in some income to the landowner aye" (V10 F); "One thing can be, most important thing, we have to get the lease. The land should be subdivided. We don't know how long we should be staying. Only God knows. And in time a new generation [of landowners] will come, so we don't know [what will happen]. So we need the lease" (Tol F); "Only the thing is to give us a full legal ways leases. We can build our good house and live our happy lives, that's all. If you want a loan you can go to the bank and show your lease, the legal ways. That's why I want the government to do these things" (Tol3 I). Some participants, however, indicated that any change to their security of tenure would require relocation. For example: "If the government happens to relocate this land, yeah maybe they will move us somewhere else and divide this into blocks" (TL3 F); "They give the place and move 
from here" (TL10 F). A number of respondents also mentioned that possessing documentation recognising their residence on the land was important. For example: "The paper. They do the paperwork, it's not legal. If they want to chase us away, they can do it ... When the people buy the land here they should make the papers through the legal way" (To6 I); "Only the document for this land. Then we have the security" (To 11 I); "I think that to get some approval from Lands Department is good security aye. In written" (T12 I).

For communities on native land, residents recognised that receiving greater security of tenure would require the cooperation of mataqali landowners. For example: "The NLTB should talk to mataqali and develop the land. Housing Authority or NLTB. Main problem [though] is houses are really close [together]" (To 17 I); "If mataqali can give us the land, [for] ninety years, only the house land, maybe the quarter acre" (T7 I). In communities on native land some participants indicated that they needed to improve their relationship with the landowners, often by meeting necessary and requested payments, in order to increase their security of tenure. For example: "We'll need a guarantee from the landowner, [so that] at least we can stay here for so and so years. Rather than [the landowner] changing his mind" (V2 F); "Cause the landowner, he demands twenty dollars per month. If we pay that every month he will give us the vei vakadeitaki in this area" (V7 F); "Just make some more grog, one hundred dollars give to the landowner, one drum kerosene, and one mat" (V18 F); "We'll have to do one vakavinavinaka103 ... prepare food, yaqona, tabua to present to the landowner to thank him for what he has provided for us, this house, in accepting that it will be clear for us to extend ... That is what he has already said 'This is for me and my family.' But I have to do something [like a sevusevu and] I'll have to provide some capital for extending" (To3 F). Other respondents suggested that improving relationships with landowners is important even in communities not held in native tenure. For example: "Only the security is to try and make a good friendship with the landowner" (TL1 F); "To make sure that everything is all good and ... good friendship with owner, landowners" (L2 F); "I have to go to the owner of the land with a tabua. If they approve it I'll go to the Lands [Department]. I'll ask 'Can I lease this place'"' (B7 F).

At Lagilagi many residents linked the community savings schemes and upcoming pilot project facilitated by the NGO ECREA and the Peoples' Community Network to improved security of tenure. For example: "To continue the soli from the ECREA, the

103 Vakavinavinaka is an expression of appreciation for being accorded a favour or is used to say thank you. 
saving" (LL16 F); "If only the ECREA [Can] do what they are trying to do. I think that will be better for security here, housing improvement and everything" (LL 11 F); "We have to save some money for the ECREA, so they can buy the land and build the house. They

will see that we are saving some money and agree to pay for the land and house" (LL12 F); "The people [ECREA and the Peoples' Community Network] who are trying to run this squatter settlement. They're ones who can make it work ... But the only thing we can do, the people here, is support [ECREA and the Peoples' Community Network]" (LL14 F).

Other participants across the case studies suggested that security of tenure could be improved through community harmony and cooperation. For example: "We have to work together that's all. Put hand in hand together" (LL3 F); "You know what I was thinking, you only stay properly with your neighbour it will be okay" (TL6 F); "Well the only thing to do is if you live well in the community ... even if the landowner interferes and you do what they say they won't force you out of this community" (T15I). Finally, remaining responses indicated that security of tenure could be improved, firstly, through general community improvements and improving infrastructure. For example: "Improving our health condition aye ... cleaning the compound, something like this" (LL5 F); "Make the village beautiful, clean and tidy. To clean up first then we can come and stay" (V12 F); "I think the road facilities and the proper drainage" (To9 I); "We want to improve the water and the electricity" (B3 F); "They said that from last year there is plenty people saying there is money coming from the government. They want to make the road, giving the electricity, the water to those staying in this land" (B15I). Remaining responses secondly suggested that security of tenure could be improved through developing higher quality dwellings. For example: "Building concrete aye. [A] permanent house like that" (LL5 F); "Get one nice house, like in Wellington, like in Naenae" (L6 F). Remaining responses thirdly suggested that security of tenure could be improved through enhancing personal security. For example: "Want to put lights around the house" (L13 I); "First of all the fencing for the houses ... because every second day the thiefs [sic] [come] here or over there. And we also have small areas, we don't have much space" (To10 I); "One police post should be here to stop people doing the murdering and stealing. And the road. The road is not good aye" (To15 I).

\subsection{Housing Consolidation}

Housing consolidation, or in other words the nature of self-help incremental housing investment, in the research sample was investigated in interviews by exploring: (i) the 
dates, character and financing of housing improvements and extensions; (ii) the motivations behind any improvements (or reasons why no improvements had been made); and (iii) plans and wishes for future investment. Before detailing the results of these investigations, however, 2007 census data can be used to explore the nature of squatter dwelling construction nationally and at Lagilagi, Caubati Topline, Lakena Hill Two, Tomuka and Tauvegavega. ${ }^{104}$

\subsubsection{Squatter Dwelling Construction and Quality: Evidence from the 2007 Census}

The 2007 Fiji census included a section on households and housing - collecting information on, among other things, principal wall construction materials and wall quality. Firstly, Table 10.9 below shows wall construction data across all households in Fiji officially recognised as squatter settlements at the time of the census. ${ }^{105}$ The table shows that $59.2 \%$ of the 15,455 officially counted squatter households nationally had walls principally constructed of tin or iron; followed by wood (21.6\%), and concrete (18.5\%). Very insignificant numbers of squatter dwellings nationally had walls constructed of makeshift materials $(0.4 \%)$, bure 106 materials $(0.2 \%)$ and 'other materials' $(0.1 \%)$.

Table 10.9. Construction of Dwelling Walls, All National Squatter Households, Total Numbers, 2007 Census Information

\begin{tabular}{|l|c|c|c|c|c|c|c|}
\hline & \multicolumn{6}{|c|}{ Principal Wall Construction Material } & \\
\hline Division & Concrete & Wood & Tin or ron & Bure Materials & Makeshift & Other Materials & Total \\
\hline Central & 1572 & 2301 & 6522 & 15 & 48 & 8 & 10466 \\
\hline Western & 1205 & 692 & 2350 & 14 & 20 & 0 & 4281 \\
\hline Northern & 70 & 337 & 196 & 0 & 0 & 1 & 604 \\
\hline Eastern & 9 & 5 & 80 & 0 & 0 & 0 & 94 \\
\hline & & & & & & & \\
\hline Total all Fiji & 2856 & 3335 & 9148 & 29 & 68 & 9 & 15455 \\
\hline$\%$ & 18.5 & 21.6 & 59.2 & 0.2 & 0.4 & 0.1 & 100 \\
\hline
\end{tabular}

Source: Fiji 2007 census data made available directly

104 The Fiji Islands Bureau of Statistics provided this census data directly. As mentioned earlier, community-level census information could not be provided for Vunato and Bouma.

105 The official 2007 census count of squatter households nationally of 15,455, as was explained in Chapter 6, is likely to be an underestimation of total squatter households in Fiji.

106 A bure is a traditional Fijian thatched hut. 
The national figures on wall construction can be compared with community data for Lagilagi, Caubati Topline, Lakena Hill Two, Tomuka and Tauvegavega; information displayed in Table 10.10 below. The table shows that at Caubati Topline, Lakena Hill Two, Tomuka and Tauvegavega the majority of dwelling walls are constructed of tin or iron (ranging between $59.5 \%$ at Caubati Topline and $72.5 \%$ at Tauvegavega); followed by concrete (ranging between 19\% at Tauvegavega and 32\% at Caubati Topline) and wood (ranging between $8 \%$ at Caubati Topline and Tauvegavega and $15 \%$ at Tomuka). Table 10.10 also highlights Lagilagi as distinctive; where $88 \%$ of all dwellings have walls principally constructed of wood (compared with, for example, a figure of $21.6 \%$ nationally). ${ }^{107}$

Table 10.10. Construction of Dwelling Walls, Lagilagi, Caubati Topline, Lakena Hill Two, Tomuka and Tauvegavega, Total Numbers and Percentage of all Households in Community, 2007 Census Information

\begin{tabular}{|c|c|c|c|c|c|c|c|c|c|c|c|c|c|}
\hline \multirow{3}{*}{ Community } & \multicolumn{12}{|c|}{ Principal Wall Construction Material } & \multirow[b]{2}{*}{ Total } \\
\hline & Concrete & & Wood & & norlion & & Bure Mater & & Makeshif & & Other Mate & & \\
\hline & $n$ & $\%$ & $n$ & $\%$ & $\mathrm{n}$ & $\%$ & $n$ & $\%$ & $n$ & $\%$ & $n$ & $\%$ & $n$ \\
\hline Lagilagi & 4 & 4 & 86 & 88 & 8 & 8 & 0 & ( & 0 & 0 & 0 & ( & 98 \\
\hline Caubati Topline & 47 & 32 & 12 & 8 & 88 & 59.5 & 0 & 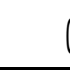 & 0 & 0.5 & 0 & ( & 148 \\
\hline Lakena Hill Two & 43 & 23 & 22 & 11.5 & 122 & 65 & 0 & 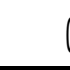 & 0 & 0.5 & 0 & ( & 188 \\
\hline Tomuka & 145 & 24.75 & 87 & 15 & 352 & 60 & 0 & 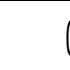 & 0 & 0.25 & 0 & l & 585 \\
\hline Tauvegavega & 30 & 19 & 13 & 8 & 117 & 72.5 & 0 & 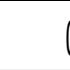 & 0 & 0.5 & 0 & l & 161 \\
\hline All5Communities & 260 & 23 & 220 & 18.5 & 687 & 58 & 0 & 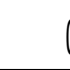 & 0 & 0.5 & 0 & l & 1180 \\
\hline
\end{tabular}

Source: Fiji 2007 census data made available directly

Table 10.11 below shows information on wall quality in Lagilagi, Caubati Topline, Lakena Hill Two and Tauvegavega as recorded in the 2007 census. While the comparability between communities of this data may be a little unreliable, 108 the information does suggest that wall construction was of the highest quality at Lagilagi; followed by Caubati Topline, Tauvegavega and Lakena Hill Two.

107 Census data on principal wall construction material is not available for Vunato and Bouma. However, fieldwork data reveals that, of the research sample in these communities, at Vunato $70 \%$ of participant households had walls principally constructed of tin/iron and $30 \%$ of wood. At Bouma $66.6 \%$ of participant households had walls principally constructed of wood and $33.3 \%$ of tin/iron.

108 A call on wall construction quality by different census enumerators, working in different areas of Fiji, no matter how well trained, is likely to be partly subjective. 
Table 10.11. Wall Quality, Lagilagi, Caubati Topline, Lakena Hill Two and Tauvegavega, 2007 Census Information

\begin{tabular}{|l|r|r|r|r|r|r|r|}
\hline & \multicolumn{9}{|l|}{ Condition of Walls } \\
\cline { 2 - 8 } & \multicolumn{1}{c|}{ Total } & \multicolumn{2}{|c|}{ Good } & \multicolumn{2}{|c|}{ Average } & \multicolumn{2}{c|}{ Poor } \\
\hline & \multicolumn{1}{c|}{$\mathrm{n}$} & \multicolumn{1}{c|}{$\mathrm{n}$} & \multicolumn{1}{c|}{$\%$} & $\mathrm{n}$ & \multicolumn{1}{c|}{$\%$} & $\mathrm{n}$ & \multicolumn{1}{c|}{$\%$} \\
\hline Lagilagi & 98 & 85 & 86.5 & 13 & 13.5 & 0 & 0 \\
\hline Caubati Topline & 148 & 76 & 51.5 & 67 & 45 & 5 & 3.5 \\
\hline Lakena Hill Two & 188 & 35 & 18.5 & 91 & 48.5 & 62 & 33 \\
\hline Tauvegavega & 161 & 61 & 38 & 76 & 47 & 24 & 15 \\
\hline
\end{tabular}

Source: Fiji 2007 census data made available directly

It is perhaps surprising that census results show that $18.5 \%$ of squatter dwellings nationally had walls constructed principally of concrete - what is a very permanent building material (compared to tin/iron or wood, dwellings constructed of concrete are more difficult to dismantle and relocate; a necessary contingency option for some informal settlers with precarious tenure situations). The relatively high percentage of concrete squatter dwellings nationally suggests that a significant proportion of informal settlers feel secure enough to invest in building materials that make their dwelling largely permanent. It also may suggest that housing consolidation is occurring nationally (assuming that most squatter dwellings are first built with more temporary building materials such as tin/iron and/or wood).

Table 10.10 also showed the use of concrete as principal wall construction material across the sample: specifically $4 \%$ of dwellings at Lagilagi, $19 \%$ at Tauvegavega, $23 \%$ at Lakena Hill Two, 24.75\% at Tomuka, and 32\% at Caubati Topline. Again this relatively significant use of a very permanent building material suggests that housing consolidation is occurring in these areas generally. Fieldwork results are now displayed to investigate housing consolidation in the research case studies in greater detail.

\subsubsection{Housing Consolidation: Evidence from the Fieldwork}

In the research interviews housing consolidation was explored in a number of ways. Table 10.12 below, firstly, displays the households across the sample revealing any evidence of housing investment, or specifically dwelling extensions and significant 
dwelling improvements, 109 in the five years preceding interviews (2003-2008) (for the purposes of this analysis 'housing consolidation' is defined as 'housing investment in the last five years'). This table reveals that: (i) across the whole sample $55.5 \%$ of households showed evidence of housing consolidation; (ii) by ethnicity, $52 \%$ of indigenous Fijian households and a higher $58.5 \%$ of Indo-Fijian households showed evidence of housing consolidation; and (iii) by case study, housing consolidation ranged from a high of $70 \%$ of households in Lagilagi and Tauvegavega to lows of $35 \%$ at Tomuka and $45 \%$ at Vunato.

Table 10.12. Housing Investment in Last Five Years (2003-2008), Research Sample

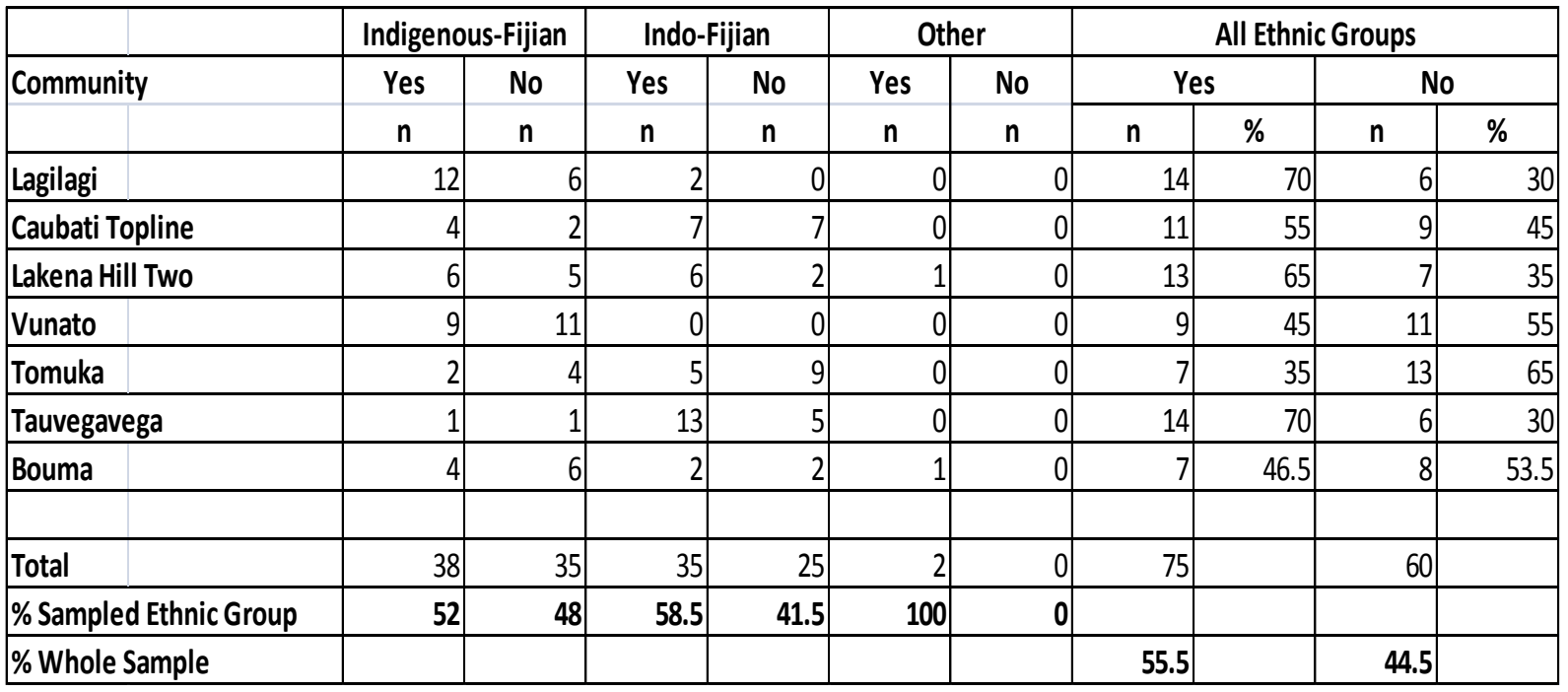

Source: Fieldwork data

Table 10.13 below shows data looking at housing consolidation by primary land tenure. The table shows that housing consolidation for all ethnic groups is more apparent in state land areas than native land areas (60\% of the state land sample showed evidence of housing consolidation compared with $50 \%$ of the native land sample). This trend across all ethnic groups is reflected when analysing individually the major ethnic groups. As the table shows: (i) $58 \%$ of the sampled indigenous Fijian households on state land showed evidence of housing consolidation compared with $43 \%$ of the sample on native land;

\footnotetext{
109 In this analysis the following investments were classified as housing consolidation: room extensions; new immediately adjacent building for immediate or extended family use; total dwelling rebuilds; small dwelling relocations (often accompanied by improvements); improvements to exterior walls (such as 'double walling' usually adding wooden interiors to tin/iron exteriors); adding interior walls; improvements to toilets/bathrooms (such as installing flush toilets and/or bringing toilets/bathrooms inside dwellings); permanent power connection and wiring; and other significant dwelling improvements beyond small cosmetic improvements and materials replacement.
} 
and (ii) $60.5 \%$ of the sampled Indo-Fijian households showed evidence of housing consolidation compared with $56 \%$ of the sample on native land.

Table 10.13. Housing Investment in Last Five Years (2003-2008), by Primary Land Tenure, Indigenous Fijian and Indo-Fijian Participants and all Ethnic Groups

\begin{tabular}{|l|r|r|r|r|r|r|}
\hline & \multicolumn{2}{|c|}{ Indigenous Fijian } & \multicolumn{2}{c|}{ Indo-Fijian } & \multicolumn{2}{c|}{ All Ethnic Groups } \\
\hline & \multicolumn{1}{|c|}{ Yes } & \multicolumn{1}{c|}{ No } & \multicolumn{1}{c|}{ Yes } & \multicolumn{1}{c|}{ No } & \multicolumn{1}{c|}{ Yes } & \multicolumn{1}{c|}{ No } \\
\hline \% All State Land Sample* & 58 & 42 & 60.5 & 39.5 & 60 & 40 \\
\hline \% All Native Land Sample** & 43 & 57 & 56 & 44 & 50 & 50 \\
\hline All Communities & 52 & 48 & 58.5 & 41.5 & 55.5 & 44.5 \\
\hline
\end{tabular}

Source: Fieldwork data

Tables 10.12 and 10.13 revealed that evidence of housing consolidation, or specifically housing extensions and improvements over the period 2003-2008, was considerable across the sample. Housing consolidation, if it occurs, begins after an initial structure is built or after an existing dwelling is purchased. In some cases dwelling materials (such as sheets of corrugated iron) are brought from previous locations to construct a new dwelling, extend an existing structure, or perhaps to build temporary accommodation while a better quality dwelling is constructed. For example, as was described by an indigenous Fijian resident at Caubati Topline: "I just take my roof tin, twelve roof tin from my island. One boat, I just bring to my home. The wood we just collect ... We never buy any wood, only the tin. [The wood] they give it to us" (TL5 F). As a further example, an Indo-Fijian participant from Tauvegavega communicated his experience after farming lease expiry necessitated a move from a rural area of Ba Province. In what were tumultuous times (in the area many farming leases expired at once - forcing the moves of many farming families who could not pay the large 'goodwill' payments'10 to the landowning mataqali necessary to renew leases), his family, unable to obtain suitable transport in time, were only able to relocate a small fraction of family dwelling materials. The family's experience is indicated by the following citations: "But that time was very struggle for me. I have three house there. One house mataqali took it ... I can't took ... house and built ... again [sic]"; "Because all the people go everywhere, I can't find the loading. [Come] New Year the mataqali took it"; "Half-house I bring there and put it

110 'Goodwill' payments are extralegal transfers often made to landowner groups to facilitate lease renewal. 
temporarily so they can sleep there. Two, three months I dig here"; "Then some families helped from overseas. Sometimes they give me one tin, and I built this one" (T7 I).

After initial building or dwelling purchases, housing consolidation, when it occurs, tends to be incremental in nature - usually completed in small steps as finances and savings make improvements and extensions possible. For example: "I just extend, extend and make it three bedrooms now" (L7 F); "My mother in law was working. They buy things little by little" (L1 1 F); "[l] buy little by little to complete ... All second hand timbers" (LL4 F); "We never built it in one go. One week we put aside twenty dollars ... week by week, little by little" (LL7 F); "We extend this house, and after then we extend again ... We don't have enough money to build one big house ... we just buy [materials] slowly" (V3 F); "My husband built our small shed for only our family. From there my in-laws were working and my husband buy the timber like that" (V16 F). In many cases households rely on the use of second-hand materials to reduce building costs, and/or family help and donated materials. For example: "Somebody give the tin. We got no money to buy the tin, the timber. We are a very poor family" (TL5 F); "It was a second hand material. My sister helped me, one house was broken up. It's second-hand tin and woods" (To8 I); "The block was empty. Our family help us for timber everything. So we build this house ... before when we come here we only build two rooms. Then slowly, slowly we make [extensions]" (To10 I); "So when we were forced to this house, slowly, slowly, I started collecting the tin material to extend the house. Second-hand tin, everything. I asked my friends to help" (To17I).

It is clear that a key feature of housing consolidation is household extensions - often for extra bedrooms or living space. Table 11.14 below shows data on the average number of rooms ${ }^{111}$ across the sample. While room sizes can of course vary, the data is useful as a part measure of housing consolidation - particularly useful for comparing between the major ethnic groups and gauging differences between case studies. The table shows that the average number of dwelling rooms across the whole sample was 3.8 - ranging from highs of 4.3 at Tauvegavega and 4.1 at Tomuka to lows of 3.0 at Bouma and Vunato. The table also reveals that across all communities the average number of rooms for indigenous Fijian dwellings was 3.4 compared to 4.2 for Indo-Fijian households. These figures perhaps suggest different preferences between the major ethnic groups as in general indigenous Fijian dwellings are more open with greater communal living

111 Including discrete bedrooms, living areas, and kitchens, as well as separate exterior bedrooms. Bathrooms/toilets were not counted. 
space (a number of indigenous Fijian dwellings in the sample consisted of only one open room, for example) than Indo-Fijian dwellings that tend to be more compartmentalised. The table also shows that Indo-Fijian dwellings tended to have more discrete rooms than indigenous Fijian dwellings at Lagilagi, Caubati Topline, Lakena Hill Two and Tomuka.

Table 10.14. Average Number of Dwelling Rooms, Research Sample

\begin{tabular}{|l|r|r|r|}
\hline Community & Indigenous Fijian & Indo-Fijian & All Ethnic Groups \\
\hline Lagilagi & 3.9 & 4 & 4 \\
\hline Caubati Topline & 3.3 & 4.2 & 4 \\
\hline Lakena Hill Two & 3.7 & 4.6 & 4 \\
\hline Vunato & 3 & n.a. & 3 \\
\hline Tomuka & 3.3 & 4.4 & 4.1 \\
\hline Tauvegavega & 5 & 4.2 & 4.3 \\
\hline Bouma & 2.9 & 2.8 & 3 \\
\hline & & & 3.8 \\
\hline Average all & 3.4 & 4.2 & \\
\hline
\end{tabular}

Source: Fieldwork data

The process of housing consolidation does not just involve extending dwellings. Often investment is undertaken or desired to improve the amenities of a household - such as improving toilets (by installing flush toilets to replace pit latrines or by bringing toilets/bathrooms inside dwellings). For example: "We want to make our toilet and bathroom [inside]" (L1 F); "The problem now is the toilet. That's what I need most in my house, my toilet is not very good" (L7 F); "The next renovation we will make our own toilet inside" (TL3 F); "We want to build the toilet, bathroom properly" (TL19 I).

Interviews reveal that housing consolidation is motivated by various reasons. Firstly, improvements may be necessary or desired simply to improve dwelling quality and liveability. For example: "I was willing to make the thing [improvements] as leaking in plenty places. We were trying to double wall the thing" (TL7 F); "Because the house was very bad to live in" (L14 I). Or, as was communicated by a recent Indo-Fijian arrival at Caubati Topline who had invested over $\mathrm{F} \$ 8,000$ on immediate extensions and improvements to the family dwelling: "I didn't want to be a lazy dad. Whatever you have in your house, that's what you have in your mind. The more you beautify your house, that's it in the mind ... Even though we live in the squatter, the house has to be nice" (TL9 I). The need for more space (particularly to accommodate growing and extra children, visitors and extended family) was often cited as a key motivator for housing extensions. For example: "Actually childrens [sic] growing you know. They need more 
space" (TL1 1 I); "[We are planning extensions] cause sometimes we do some family function here, and nearly every week we have visitors aye" (V7 F); "I'd like to extend this house because I've got children aye" (V8 F); "I'm planning to extend ... Big room, as my son is getting bigger" (To3 F). In some cases the act of children getting married created a need for housing extensions (separate housing areas under the one roof for extended family were reasonably common across the sample ${ }^{12}$ ) or new building in immediately adjacent sites. For example: "I would like [to extend] if my son gets married" (T8 I); "Yeah I got three sons and when they get married I have to extend one or two rooms for them" (T19 I). Some participants, particularly Indo-Fijian, were also motivated by the need to improve personal security. For example: "I just want to paint the roof. The roof is leaking [so] I want to replace the roof, [and] put the burglar bar" (T1 1 I); "First we want to complete the house. Grills, strengthen doors" (LI4 I).

At Bouma, located in a very flood prone area on the banks of the Labasa River, housing investment (including small dwelling relocations and/or raising houses higher on their stilts) was regarded by many participants as necessary to reduce flood risk. For example: "Plan to move this house this side. Because down here it's wet" (B3 F); "We want to shift the house up the back" (B9 F); "Only want to make it higher. Cause the flood" (B1 1 F). (At Bouma devastating floods over the years had also meant that many households had totally rebuilt ruined dwellings - often more than once.)

The extent of housing consolidation across the sample could be viewed as surprising particularly as legal security of tenure for informal settlers is absent. However, as has been suggested elsewhere, the various motivations influencing housing investment may be better understood, in part, by moving beyond a legal/illegal dichotomy of security of tenure and viewing security of tenure as also influenced by perception. For example, one indigenous Fijian participant from Lakena Hill Two had the following to say in explaining the motivations for past housing consolidation creating her current large, relatively good-quality dwelling: "Cause what I was thinking is the house would be mine forever. I hope that I will get the title one day. I hope that when I finished my son will get the house" (L7 F) - a citation, in its context, that indicates the strong influence of perceived security of tenure.

112 These separate housing areas under the same roof sometimes created difficulty in determining the size and particulars of the participant household. In some cases, especially for Indo-Fijians, a nuclear family living in a discrete part of a dwelling, but under the same roof as extended family, was considered by participants to be a separate household. As a rule of thumb, I treated these cases as a separate household if the nuclear family normally ate separately from extended family. 
Housing consolidation, however, was not always evident across the sample; as Table 10.12 indicated, $44.5 \%$ of all respondents did not show any evidence of housing investment in the period 2003-2008. In some cases the only investments that had been made were the replacement of deteriorating materials (insignificant investments that were not analysed as housing consolidation). For example: "We just change the roofing tin, nothing more" (LL8 F).

In the cases where housing consolidation was absent, a variety of reasons were cited by participants. Some participants indicated that the reality of their situation as informal settlers living without legal security of tenure was the principal reason why no housing consolidation had been made. For example: "There's not much time to extend. We don't know what's going to come. We might just lose it again" (LL 11 F); "[No] I'm just waiting. If they give the block, I can do something, but I don't want to waste the money. So I don't want to make any improvements at this time, unless we get the title" (L15 I); "[None but] if we have proper title we can make a proper house, concrete house. Rather than staying in this tin house, wooden house" (TL18 I); "Unless the land and everything is properly secured, then we will improve the house or build another" (To13 F).

In other cases a lack of financial resources or competing cash priorities (particularly the education of children) was cited as inhibiting housing consolidation. For example: "We cannot extend ourselves now, remain as we are. Just to eat, that is it" (L5 F); "Because there is no one to build, because my father passed away there is no more money to build the house. Whatever they are earning, they are spending" (L19 I); "[None, the] problem is the money aye, the main thing is the money" (TL13 I); "Yeah we want now [to extend]. [But] right now we are looking after six children schooling, so it's a bit hard for us now ... [we are] just temporarily living like this" (V9 F); "Yeah [we want to extend] but I need plenty things. But in Fiji very hard to get the money now. I need plenty things, but only one thing: the [lack of] money" (V14 F); "I'm not going to spend the money on the home. The main thing is to get the children educated" (T4 I).

House tenure was also an important variable in influencing housing consolidation - with those participants making major investments almost always being occupying owners. Renters and those occupying dwellings for absentee owners were far less likely to be engaged in housing consolidation. Renters, for example, were not likely to invest in extending or improving a dwelling that they did not own: "No [none] as this house does 
not belong to me" (V5 F); "Because this house not for me, plus the land" (To2 F); "Cause I'm renting, it's not mine" (T2 F). Some occupiers also cited similar reasons for a lack of housing investment. For example: "I can't make any improvements to this house, cause this house isn't under my name" (L10 F); "I call her [the owner of the house and she said] 'You continue renovating the house, we won't take the house'. [But] it's no use we spend money renovating the house, then they [might] come and take the house" (LI7 I).

In other cases where housing consolidation was not present: (i) dwellings were regarded as sufficient in quality and size (particularly if children had already moved away from home); (ii) cramped neighbourhoods inhibited extension possibilities; and (iii) temporary stays in informal settlements provided insufficient motivation. For example: "We don't think about making it bigger. This will be alright for us" (L9 F); "My family grow big and small again" (To7 I); "Because I've got a big house now" (To16 I); "No as not enough area, not enough land" (LL12 F); "Because we haven't got any area left, no space aye" (To10 I); "[None as] we're not going to live here all our lifetime, as we have our land and home [in Kadavu]" (V19 F).

A closer look at the $44.5 \%$ of sample cases showing no evidence of housing consolidation reveals further possible explanations. Table 10.15 below classifies and displays the principal explanatory factor in each of the 60 cases where housing consolidation was not evident. The table shows that lack of finances/competing cash demands was the most commonly cited reason for lack of housing consolidation $25 \%$ of the 60 households not involved in housing consolidation cited this explanatory factor). This was followed by cases where dwellings were regarded as adequate in size/quality (20\% of the sample of 60 households). Often, in this case, particularly in the Tomuka case study and for long-established residents, dwellings had been completed to an acceptable standard originally or incrementally many years previously. The third most commonly cited category (excluding 'uncertain') encompassed tenure situations where renters and occupiers did not have strong incentives to invest in extending or improving dwellings that they did not own (15\% of the sample of 60 households). Other categories, excluding 'other', included: 'house just built/acquired (in last two years)' (8.5\%) (often situations where new households had not yet got around to making additional housing improvements) and 'insecure tenure' (5\%). 
Table 10.15. Principal Reason for No Housing Consolidation, Research Sample

\begin{tabular}{|c|c|c|c|c|c|c|c|}
\hline Community & Insecure tenure & Lack of finances / & Dwelling adequate & Not occupying & House just built/ & Other & Uncertain \\
\hline & & competing cash & in quality/size & owner & acquired (in last & & \\
\hline & & demands & & & 2 years) & & \\
\hline Lagilagi & & 1 & 1 & 1 & & $4^{*}$ & \\
\hline Caubati Topline & 1 & 1 & 2 & 2 & 1 & 1 & 2 \\
\hline Lakena Hill Two & & 2 & 1 & 1 & 1 & $1 * *$ & 1 \\
\hline Vunato & & 5 & 2 & 1 & 1 & 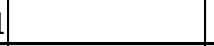 & 2 \\
\hline Tomuka & 1 & 2 & 6 & 2 & 1 & 1 & 1 \\
\hline Tauvegavega & 1 & 1 & 1 & 1 & 1 & & 2 \\
\hline Bouma & & 3 & & 1 & 1 & $1^{* * *}$ & 2 \\
\hline n & 3 & 15 & 12 & 9 & 5 & 6 & 10 \\
\hline$\%$ Sample & 5 & 25 & 20 & 15 & 8.5 & 10 & 16.5 \\
\hline \multicolumn{8}{|c|}{ * Waiting to see outcome of ECREA/PCN pilot project (x2); Lack of space (x2) } \\
\hline \multicolumn{8}{|c|}{ ** Planning and saving for total rebuild } \\
\hline *** Flood risk & & & & & & & \\
\hline
\end{tabular}

Source: Fieldwork data

\subsubsection{Community-level Improvements}

In addition to discrete household-level investment, various initiatives to improve whole communities, instigated with varying degrees of success, were also evident across the research sample - important to investigate as they may influence perceived security of tenure (and, in turn, perhaps individual household investments themselves). At Lagilagi, for example, prior to the ongoing ECREA/Peoples' Community Network pilot project, experience with community-wide initiatives was largely negative with the collector of community funds absconding overseas. For example: "Before, way back, they were talking about a soli to make a co-op, a shop [person 1]" ... " but they lost the money [person 2]" (LL1 1 F); "When he disappeared with the money we lose hope with the saving until ECREA [came in]... Some of us gave a thousand dollars, some hundreds. My dad gave about one hundred and sixty dollars, we gave about twenty dollars ... All we know is he went overseas" (LL10 F). Similar negative experiences were communicated during fieldwork at Vunato - this time concerned with collections to fund a community hall. For example: "Once we collected for the project, we wanted to build for the community hall. But the tins went missing, the wood went missing. Nothing happened [and] no other project have been done" (V9 F); "[Yes, money was collected for a community hall] but we couldn't complete it. We elected a headman. But he left and 
lost that money" (V19 F). More positively, at Tauvegavega, community collections have been undertaken more successfully to improve access roads, help with police post funding and prepare for a water project. For example: "Only the road we have got two thousand two hundred dollars. This road is handmade. Then we use the grader and gravel" (T7 I); "They collect money for the police post. All three zones are collecting money for water project as in dry season we don't get water over here" (T6 I). Similar community initiatives had also been instigated at Tomuka. For example: "There was only once, last year. We have to give twenty dollars for the road [gravelling] ... that's what we are looking forward to. If we could have a community soli for upgrading all of these things" (To19 F). Other ongoing community initiatives, such as fundraising for permanent power connections at Tauvegavega and Bouma, were struggling to make progress: "We supposed to do that, but there is not any cooperation ... [eg] the electricity project" (T1 F); "Last year I think they talk about the electricity. They ask us to save one hundred and seventy-five dollars for the electricity. But till now [nothing else]" (B14 I).

Earlier sections of this chapter revealed that, where active, the advocacy and community savings schemes supported by the NGO ECREA and the Peoples' Community Network were important in increasing perceived security of tenure particularly in Lagilagi where programmes were farthest progressed and the pilot upgrading project was underway. The experience of the Lagilagi pilot project is worthy of attention - due to its significance in the community and also the prospect of the model, if successful, eventually being replicated in other members of the Peoples' Community Network (such as Caubati Topline and Lakena Hill Two). Overall, the Lagilagi pilot project was mostly viewed by participants positively. For example: "ECREA told us not to move. Everything they say we must believe. We are looking forward for them to help us aye" (LL12 F); "Because this is what we are waiting for. We can give the money bit by bit" (LL13 F); "That's what we are all waiting for ... good house, facilities" (LL14 F). Some Lagilagi residents, however, particularly those who had negative experiences with community savings schemes in the past, were sceptical of the pilot project: "Same issues, develop this place, develop this place. Same issues aye, mostly nothing has been done" (LL20 I); "Our concerns [are] if nothing is going to happen, this [pilot project] development aye, where will we go?" (LL9 F).

At the time of fieldwork, the Lagilagi pilot project was having a pronounced effect on housing consolidation across the community, effectively removing the incentive to 
improve or extend dwellings earmarked for relocation.113 For example: "No we just leave it like this as we are waiting for the pilot now" (LL6 F); "We were planning to build a [new] house last year. But ECREA told us not to build a house as the development is about to happen" (LL10 F); "We can't extend ... If we go to the Lands Department they say that ECREA is about to give out this land. Everything is on hold" (LL1 1 F); "[l am planning] no more extension, because I look forward to pay [for the] new house ... [through] the pilot project" (LL3 F).

\section{$\underline{\text { 10.3.4 Access to Credit }}$}

As was mentioned in Chapter 2, the international literature is divided when discussing access to credit in informal settlements. de Soto (2000), for example, argues that legal titles are necessary to obtain access to formal credit and encourage home improvement and upgrading. Others, however, suggest that the link between property rights and access to credit is flawed (The Economist, 2006; Gailani \& Schargrodsky, 2006; Home and Lim, 2004; Lemanski, 2010) and argue that informal credit is often available from the beginnings of settlement and that, further, even after titling, access to formal finance does not necessarily improve (Gilbert, 2002).

Table 10.16. Access to Formal Credit, Research Sample

\begin{tabular}{|l|r|r|l|}
\hline Community & Yes & No & Unsure \\
\hline Lagilagi & 3 & 17 & \\
\hline Caubati Topline & 4 & 16 & \\
\hline Lakena Hill Two & 2 & 18 & \\
\hline Vunato & 6 & 14 & \\
\hline Tomuka & 4 & 16 & \\
\hline Tauvegavega & 3 & 15 & 2 \\
\hline Bouma & 2 & 13 & \\
\hline & & & \\
\hline Total & 24 & 109 & 2 \\
\hline \% Whole Sample & 18 & 80.5 & 1.5 \\
\hline
\end{tabular}

Source: Fieldwork data

113 As Chapter 6 discussed, the Lagilagi pilot project involves the relocation of dwellings into other parts of the wider Jittu Estate while the area is demarcated and the new housing units built. 
Table 10.16 above shows results from investigations around access to formal credit across the research sample. ${ }^{114}$ The table shows that $18 \%$ of participant households had signed for current or past loans (used for various purposes including housing, education, farming, and vehicle costs) from banks. Participants who had been able to obtain formal finance were normally in steady employment or could find others to act as guarantors. For example: "Yeah my sons will get it because they are working" (L15 I); "Before when I work, I loan aye. ANZ Bank. The amount only five hundred dollars, used for my daughter's wedding" (L20 O): "When we buy the land my husband took a loan from the bank ... one of his uncles signed for the security" (To6I).

A high $80.5 \%$ of participant households had never had a bank loan. Many participants expressed that their lack of work or adequate income was the major inhibitory factor. For example: "No, we don't come in that range, our wages don't come up to that standard" (LL2O I); "We can't get loan because we don't have secure job, no?" (TL1 1 I); "No I can't get a loan as I'm not working" (L10 F); "Have tried, one time, for a loan from the bank, but they said 'Your income is very low'" (L12 I). Other participants expressed that their lack of collateral inhibited the possibility of formal finance. For example: "It depends on what security we have to give bank. In place like this they won't give ... our job too is not security ... because nowadays the loan officers ask for a mortgage, we don't have anything to mortgage" (TL19 I); "It's hard to get a loan from the bank. The land is not ours" (L19 I); "My husband tried one time but they want him to have one security" (V1 F); "It's very hard to get. Because in this land you can't secure any land or the house" (To13I).

It was evident from interviews, however, that credit and finance could often be obtained from other channels discrete from banks - including from individuals; hire purchase/credit arrangements from retail stores (including from hardware stores for building materials); and microfinance schemes.115 For example: "Not from the bank, but I have to take loan from individual people to fulfil the major needs and when I get the job I pay them back ... The bank only gives loan on security. So I don't have any" (T19 I); "Only MH [Morris Hedstrom"16] give the permit for tin, timber. MH price high, but easy to

\footnotetext{
114 When responding to all or some of the questions: 'have you any current loans?'; 'have you ever had a loan?'; and 'have you ever tried to get a loan?'

115 In responding to questions around access to credit a number of participants reported that they had withdrawn from their Fiji National Provident Fund savings to pay for costs associated with dwelling purchases, builds and extensions. While not representing access to credit per se, Fiji National Provident Fund withdrawals are nevertheless important sources of capital for housing.

116 A major retailer in Fiji; including of hardware.
} 
get the permit" (L14 I); "I only loan from my microfinance, and I only loan from there for my education, only their school fees that's all" (V9 F). Overall, despite the lack of legal title to act as security for a bank loan, credit from various sources seems possible to obtain (including from banks if formal income is sufficient) - finance that can and could be used to fund housing consolidation. However, in general, it seems that low incomes are deterring or inhibiting access to credit for the majority of households in the sample.

\subsection{Summary}

The chapter looked to explore the extent of perceived security of tenure and housing consolidation in the case-study informal settlements. Table 10.6, presenting the key perceived security of tenure findings, showed that $43.5 \%$ of the research sample indicated evidence of positive perceived security of tenure; $24.5 \%$ indicated that they were not secure or insecure; and $16.5 \%$ showed evidence of negative perceived security of tenure ( $15.5 \%$ of responses were uncertain). Differences in perceived security of tenure were also evident between the case studies. Positive perceived security of tenure was greater than the whole sample average at Bouma, Caubati Topline, Lakena Hill Two and Vunato, while negative perceived security of tenure was pronounced at Tomuka and Tauvegavega. It is also clear that primary land tenure is a key variable affecting perceived security of tenure. Table 10.7, for example, revealed that positive perceived security of tenure was higher in state land communities than native land areas and, correspondingly, negative perceived security of tenure was greater in native land areas. Ethnicity was also an important variable to investigate. Tables 10.6 and 10.8, for example, revealed that much higher percentages of Indo-Fijian participants (particularly in native land areas) showed evidence of negative perceived security of tenure than indigenous Fijian respondents. Overall, perceived security of tenure seems to be influenced by a number of often quite context-specific variables (to be discussed more in the next chapter). What is surprising, perhaps, is the $43.5 \%$ of the whole sample indicating positive perceived security of tenure; a substantial percentage suggesting, for informal settlers living on land that they do not own, that perceived security of tenure is influential and thus worthy of attention.

2007 census results, particularly the surprising $18.5 \%$ of squatter dwellings nationally with walls constructed principally of concrete, a very permanent building material, suggested that housing consolidation was occurring in the informal settlements of Fiji. Fieldwork results (displayed in Table 10.12) subsequently showed that $55.5 \%$ of the households that 
were surveyed showed evidence of housing consolidation - or specifically housing extensions and significant improvements in the five years preceding interviews.

Differences between the major ethnic groups were also evident with slightly higher percentages of Indo-Fijian households showing evidence of housing consolidation than indigenous Fijian households. Differences between the case studies were also clear with housing consolidation more pronounced at Lagilagi and Tauvegavega (and in general in state land areas), and least at Tomuka and Vunato (and in general in native land areas). Housing consolidation was constrained by a number of factors. Table 10.15, for example, showed that lack of finances, not being the house owner, and the dwelling already being perceived as adequate in quality/size, were important factors that participants often cited as influencing a decision not to extend or improve a dwelling. Table 10.15 also showed that lack of secure tenure did not seem to be a significant inhibitor of housing consolidation. This suggests that perceived security of tenure may hold an important relationship to housing consolidation - something that will be discussed further in the next chapter. 


\section{CHAPTER 11: DISCUSSION - THEMES, THE DYNAMICS OF PERCEIVED SECURITY OF TENURE AND HOUSING CONSOLIDATION, RESEARCH NEEDS, AND POSSIBLE POLICY RESPONSES}

\subsection{Introduction}

The previous chapter presented key results from the research, particularly focussing on addressing the first and third key objectives of the study exploring the extent of perceived security of tenure and housing consolidation in Fijian informal settlements. This chapter will discuss these results along with the information presented in Chapter 9 , highlighting the nature of Fijian informal settlements. The chapter will focus particularly on addressing the second and fourth key objectives of the study: exploring the key variables influencing perceived security of tenure in Fijian informal settlements; and beginning to explore the relationship between perceived security of tenure and housing consolidation.

The chapter, firstly, reiterates and discusses a number of themes applicable to Fijian informal settlements. These themes are clustered around the broad nature of settlements, tenure and markets for land and dwellings, movement, access, and livelihoods. Perceived security of tenure and housing consolidation results are then discussed before the possible relationship between perceived security of tenure and housing consolidation is explored. The chapter then discusses some limitations of the current study and future research needs, before, finally, presenting some policy responses that the results (and perceived security of tenure literature more broadly) suggest as potential avenues for addressing Fiji's growing shelter crisis.

\subsection{Key Themes from the Case Studies}

\subsubsection{The Broad Nature of Fijian Informal Settlements}

It has been noted in earlier sections of this thesis, and throughout the wider literature, that the key characteristics of informal settlements in Fiji are insecurity of land tenure, inadequate service provision and infrastructure coverage, and their frequent location in environmentally marginal areas. Chapters 8 and 9, however, revealed the great 
diversity between, and indeed within, informal settlements in Fiji; making it difficult to generalise beyond the case-study settlements and indeed even between the seven case-study settlements. This diversity suggests that it is important to re-evaluate these frequently noted key characteristics of Fijian informal settlements. In spite of the generalisation difficulties, some claims are possible across the case studies and Fijian informal settlements as a whole. Certainly legal security of tenure is completely absent in informal settlements on all categories of primary land tenure (state, native and freehold land). Secondly, service provision and infrastructure coverage is inadequate; with sewage connections completely absent and considerable sharing of electricity and water connections. In terms of environmentally marginal locations, certainly many informal settlements are located on steep slopes and in low-lying areas. The informal settlements in low-lying areas are extremely vulnerable to, often catastrophic, flooding; events that occur regularly (indeed often annually at the height of the wet season). All informal settlements, dominated by non-durable housing structures, are also particularly vulnerable to tropical cyclone events.

Chapter 2 noted that the United Nations Human Settlements Programme (UN-Habitat) has five key determinants of urban slums. These are lack of: (i) durable housing; (ii) sufficient living areas; (iii) access to improved water; (iv) access to improved sanitation; and (v) secure tenure. These factors generally hold true for Fijian informal settlements; where housing quality is lower than in formal housing areas; where average household sizes are greater than the Fijian norm; and where sewage connections are absent meaning latrine toilets are common. However, there are important caveats. Firstly, piped water supply is close to universal in Fijian informal settlements (although considerable sharing of meters occurs). Secondly, as has been repeatedly stressed throughout this thesis, security of tenure needs to be understood beyond a legal/illegal dichotomy. Thus while legal security of tenure is, of course, absent in Fijian informal settlements, perceived or de facto security of tenure needs further investigation. In summary, while there are considerable overlaps between features of Fijian informal settlements and UN-Habitat's key determinants of urban slums, informal settlements in Fiji are unique; reflective of local context. Overall, UN-Habitat's term 'urban slum' is not appropriate for the Fijian context and indeed this recently resuscitated term, frequently used amidst international development goals and global shelter policy and discourse, has many negative associations and attached negative stereotypes (often directed at residents of these areas) that suggest it should not be used anywhere (Gilbert, 2007). In addition, to continue on the importance of language, the commonly used terms of 
'squatter settlement' and 'squatter settler' in Fiji ideally would be replaced by the less derogatory terms of 'informal settlement' and 'informal settler' - indeed these more technically correct terms better encapsulate the nature of these areas.

\subsubsection{Tenure and Markets for Land and Dwellings}

The primary category of land tenure, as will be emphasised throughout this chapter, is one of the key variables influencing the nature of informal settlements, access arrangements to communities, and perceived security of tenure and housing consolidation in these areas. It is clear that all informal settlers in Fiji lack legal security of tenure to the land that they reside on. However, because informal settlers hold greater rights to the dwellings that they reside in, it becomes important to investigate house tenure; indeed discussions of tenure in Fijian informal settlements need to distinguish between land and house tenure. Results have shown that a simple, three-fold typology of house tenure is initially clear in Fijian informal settlements: (i) occupying owners (by far the majority of informal settlers); (ii) occupiers; and (iii) renters (the latter two categories are applicable to much smaller numbers of informal settlers). However, given the importance of the land tenure variable, it becomes essential to divide occupying owners into those on state land and those on native land (the latter usually with informal, vakavanua arrangements with native landowners). Thus, a simple typology of (house) tenure status for Fijian informal settlers becomes four-fold: (i) occupying owners (state land 177); (ii) occupying owners (vakavanua); (iii) occupiers; and (iv) renters. As will be discussed later, this typology influences a continuum of effective security of tenure.

Vibrant markets for dwellings existed in all case-study settlements and indeed the purchase of an existing dwelling formed a key avenue through which new entrants gained access to a community (and occupying owner status). Given that informal settlers have much stronger ownership rights to their dwellings (compared with the land on which they reside) this active dwelling market is perhaps no surprise. It was more unexpected, however, that vibrant markets for land existed in some communities. At Tomuka, for example, houseblocks were commonly bought and sold for upwards of a few thousand dollars (of which the native landowners take a fixed percentage); reflecting the informal transactions of land noted in Chapter 2 as characteristic of

117 The research did not include a case study on freehold land. However, in very general terms, the tenure status of an occupying owner on freehold land might be similar to that of an occupying owner on state land although further research is needed to investigate this claim and perceived security of tenure in informal settlements on freehold land in general. 
customary land contexts. However, land markets were also present (to a lesser extent) at the state land case studies; particularly when current settlers sell off surplus areas of land adjacent to their own dwellings or when new settlers purchase usage rights from individuals attached to local mataqali groups claiming the area as their own (despite the land legally being held in state tenure). This finding was surprising and perhaps reflects the lack of clarity (particularly for new settlers) around the exact legal tenure status of some informal settlements.

\section{$\underline{11.2 .3 \text { Movement }}$}

As Chapters 8 and 9 revealed, it is difficult to generalise about the nature of movement to informal settlements in Fiji. Overall, movement is mixed; originating from both rural and other urban areas and also being voluntary and involuntary (involuntary movement, applicable to $20 \%$ of the sample (Table 9.8), is primarily caused by lease non-renewal and uncertainty generally or other problems with land and house owners). In many cases, an informal settlement was not the first originally settled urban location. In $30.5 \%$ of all cases, for example, respondents had previously been renting (almost exclusively in other urban areas) (Table 9.7). Upon arrival in an informal settlement, however, results suggest that many settlers stay a long time; with the average length of community residence for all research respondents being 15.6 years (and ranging from 6.5 years at Bouma to a very high 29.5 years in the old, established community of Lagilagi in central Suva) (Table 9.6). This finding lends some support to the view that informal settlers are not climbing up the housing ladder to more formal forms of tenure (such as Public Rental Board or Housing Authority dwellings).

As was discussed in Chapter 2, Turner (1968a) in his seminal early research proposed three basic functions of the urban built environment essential to an effective dwelling: (i) an accessible location (particularly in central areas close to employment opportunities); (ii) opportunities for secure, continued residence; and (iii) minimum shelter standards. Turner argued that squatter settlers prioritised the need for a central location over the lesser needs for secure tenure and quality shelter (ibid). In Fiji, it has also been argued that informal settlers prioritise the need to be close to employment opportunities over the need for secure tenure (Walsh, 2006, p. 84). The current research suggests a slightly different scenario. Specifically, Figure 9.3 revealed that 'proximity to education and other services' was the most significant location motivator (in $32.8 \%$ of cases). This was followed by 'opportunity for continued residence' (essentially the security of tenure 
variable) (30.9\%), 'proximity to employment opportunities' (18\%), and 'availability of adequate shelter' (13.9\%). These results suggest that in Fiji the need for an accessible, central location does dominate (but is particularly tied to proximity to education and other services, not necessarily employment opportunities). Availability of adequate shelter is clearly a lesser need in Fiji (and is, of course, reflected in the quality of informal settlement housing stock compared with more formal housing areas). However, what is particularly interesting from the current research is the level $(30.9 \%)$ of respondents who indicated that 'opportunity for continued residence' was their principal location motivator. This suggests that, despite ongoing, and highly publicised, evictions from state land and the ultimate uncertainty of some vakavanua arrangements on native land, many informal settlers feel sufficiently secure to stay for as long as they wish (which indeed suggests that it is important to investigate perceived security of tenure).

Overall, movement to informal settlements primarily seeks to benefit from the advantages that they offer. These advantages are effectively three-fold. Firstly, informal settlements present significant cost savings (compared with more formal urban housing). Secondly, informal settlements typically have a number of location benefits (given that many settlements, especially those on state land, are in very central areas), including proximity to education services (particularly secondary schools), other services (such as healthcare), and most work opportunities. Third, some informal settlements, at least, provide opportunities for continued residence (and hence some level of perceived security of tenure).

Past debates on the movement of Pacific Island people, both between and within nations, have often focused on whether movement tends to be circular or one-way. Chapter 3 noted, however, that this typically dualistic debate tends to ignore the overall complexity and fluidity of broader systems of regional mobility (Chapman, 1991). Results from the current research support the claim that internal mobility within Fiji at least should not be defined as circular or one-way. Certainly more and more people are moving to urban informal settlements in Fiji. However, this may not necessarily be permanent. Many indigenous Fijian research respondents, for example, indicated that they planned to eventually return to their rural village (particularly when the education of their children was finished). It was also evident from fieldwork that much continued movement persisted between rural areas and urban informal settlements. Many respondents predominantly residing in informal settlements, for example, returned to nearby village areas at weekends (often for farming; the results of which were sold in urban markets). 
Many children and young adults studying at secondary and tertiary institutions also stayed in informal settlements during term, but returned to rural areas in holidays and weekends. Further, some peri-urban settlements, outside municipal boundaries, are very different in character to more central settlements - certainly more dispersed and with larger garden areas and in general more similar to rural villages. Overall, both movement to and from informal settlements and the character of settlements themselves suggest there is considerable blurring of rural/urban divides in Fiji, and indeed indicate the perils of analysis that tends to separate the urban from the rural (dangers that are perhaps particularly pronounced in small island states).

\subsubsection{Access}

It is clear that access to informal settlements normally occurs in three primary ways, with new arrivals: (i) purchasing an existing dwelling; (ii) finding rental accommodation; or (iii) obtaining a site and building or relocating a dwelling. The primary category of land tenure is the critical variable influencing access arrangements. For example, state land areas were often freely available; with no permission originally needed from the state as the legal owner of the land (although in some cases arrangements are made with existing members of that community who may be using areas of land for particular purposes). On the other hand, accessing native land areas almost always requires permission from native landowners; often facilitated by traditional sevusevu (particularly for indigenous Fijian settlers) and ongoing payments of some form. In many cases, for all types of informal settlements, access is often facilitated by existing personal links; particularly immediate and extended family, friends, and church and religious organisation affiliations. This can lead to considerable clustering in informal settlements particularly extended family living in a number of adjacent dwellings.

It is, however, still difficult to generalise about the nature of access arrangements (beyond the typical differences between informal settlements on state and native land). Chapters 8 and 9, for example, revealed the wide variety of access arrangements across and between the seven research case studies. The research has also been able to reveal the diversity of vakavanua arrangements used to gain access to native land areas. At Vunato, for example, vakavanua arrangements are traditional in nature; almost always facilitated by request and sevusevu (usually accompanied by presentation of tabua, yaqona, other items, and cash), and made by indigenous Fijians only. At Tomuka, in contrast, vakavanua arrangements have adapted and are more 
commercial in nature, indeed often mimicking official Native Land Trust Board (NLTB) leases, detailed in their terms and conditions, and recorded on paper. At Tomuka these types of vakavanua arrangements are used by the landowners particularly for Indo-Fijian settlers; and, in contrast to the situation at Vunato (and to arrangements for indigenous Fijian settlers at Tomuka), essentially represent a functional landlord/tenant relationship. The Tomuka case study also presents a clear example of the need for nuanced and context specific understandings of Fijian informal settlements. Tomuka, for example, is a very large settlement by area and population and, as such, zones of control have been demarcated between the principal landowner and his children. Thus, new and existing settlers must make arrangements and manage relationships with different landowning individuals - some, in this case, more reasonable than others.

It is incorrect to suggest that all informal settlements on native land are accessed via the traditional or more commercial vakavanua arrangements seen at Vunato and Tomuka. Tauvegavega in Ba, for example, originally held in state tenure but transferring to native tenure in 2002, presents an interesting case. At Tauvegavega many residents arrived prior to 2002 while the area was held in state tenure. A number of local mataqali groups also continue to contest legal ownership of the area; and the continuing confusion around ownership means that no settlers have detailed vakavanua arrangements with any one landowner (although permission from one mataqali group or another was often sought before new building).

It was also evident from Chapters 8 and 9 that a wide variety of payments are used to facilitate access and enable continued stays in informal settlements. In general, payments differ by the primary category of land tenure. In state land areas, for example, many settlers have made no payments at all (or perhaps one initial payment to enable access or to register occupancy). On native land, however, regular payments and customary contributions were often necessary to enable continued stays and an ongoing amicable relationship with landowners.

\subsubsection{Livelihoods}

Results reinforced that Fijian informal settlers are typically reliant on low incomes. Results also revealed that principal income sources were diverse across the sample (Table 9.15). Overall, $62.5 \%$ of households from the sample relied on regular wages as their principal 
income source (from both the formal and informal sectors ${ }^{118}$ ). Additionally, a broad range of activities or income streams (such as informal sector retail and other services, farming/home gardening, support from family, casual labour, and pensions) were important as supplementary income streams; indeed results showed that $29.5 \%$ of households across the sample earned additional income to their main income stream (Table A.4 in Appendix 5).

Weekly household food spending across the sample was significant; averaging $51.6 \%$ of household income across the sample and ranging from a low of $34.7 \%$ at Vunato to a high of $76.4 \%$ at Bouma (Table 9.17). Results also revealed that home gardening, a principal means of reducing reliance on purchased food, was important across the sample; with $73 \%$ of all households interviewed producing some food (Table 9.18). In general, however, home gardening was much more significant for indigenous Fijian settlers than for Indo-Fijians. Many indigenous Fijians focused on planting root crop staples and indeed, in native land areas such as Vunato and Tomuka, were provided with garden space by landowners (often as specific parts of vakavanua arrangements). This garden space was seen as a critical advantage by many indigenous Fijians who were interviewed in these areas. Indo-Fijians, on the other hand, in native land settlements and state land areas, simply did not have room to plant significant gardens (or have access to gardens in adjacent areas). The importance and viability of home gardening (or more correctly 'urban gardening' given that some gardens are located in nearby areas) also varied by case study. It comes as no surprise that the highest percentages of average incomes were spent on food at Bouma (76.4\%) and Tauvegavega (69\%); areas with gardens affected by salinity and regular floods (Bouma) and poor quality soils (Tauvegavega). Additionally, it also comes at no surprise that the lowest percentage of income (34.7\%) was spent on food at Vunato; where most residents have significant garden space. Overall, the importance of urban gardens for many indigenous Fijian informal settlers is critical; and an essential means of reducing reliance on purchased food and thus stretching limited income.

It is a common stereotype in Fiji that many residents of informal settlements could afford to live elsewhere in urban areas (in rental accommodation, for example). Results have shown, however, that this is largely a fallacy (although at Tomuka and Tauvegavega particularly there were a number of medium-income households with breadwinners employed in the civil service). Given the low average incomes across the sample, and

118 Unfortunately, during interviews it often proved difficult to distinguish between formal or informal income. 
the proportion of household income that is required to be spent on food, most of the informal settler households interviewed would find it extremely difficult to move up the (effectively theoretical) Fijian urban housing ladder.

It is not clear from the research as to what proportions of participants were living in poverty as per officially defined levels. Overall, however, it is abundantly clear that typical livelihoods in informal settlements remain a continuing struggle. Chapter 2 revealed that urban poverty typically has a number of features including dependence on the monetised economy, dependence on the informal sector, and greater exposure to disease and environmental dangers. In general, these are applicable to Fijian informal settlements, where cash demands are continual (but reduced by urban gardening); where informal sector activity is vibrant; and where inadequate sanitation and environmentally marginal locations expose residents to disease 119 and natural hazards. Certainly informal settlers in Fiji are vulnerable, with enhanced exposure to risks, shocks and stresses and reduced asset availability. Saliently, as was revealed in Chapter 10, insecurity, across many dimensions, is constant for many informal settlers.

\subsection{Perceived Security of Tenure}

It has been stressed throughout this thesis that no informal settlers in Fiji enjoy legal security of tenure. In recognising this, however, the research sought to investigate the extent of perceived security of tenure - or, in other words, feelings of security of tenure across the research case studies. The research also aimed to investigate the key variables that influence perceived security of tenure in Fijian informal settlements. Ultimately, it was hoped that meeting these objectives would inform a more nuanced and contextualised understanding of security of tenure in Fijian informal settlements. Indeed recognition of all variables influencing security of tenure, and key differences here between settlements on state and native land, may inform and enable a broader range of policy responses to increase (perceived) security of tenure in these areas.

Chapter 10 revealed that it was necessary to explore perceived security of tenure in a number of ways: by investigating eviction threats and other pressures; by discussing 'security' broadly; by discussing possible meanings of security of tenure; and by asking

119 For example, an outbreak of typhoid struck parts of Fiji in early 2010. Much of this outbreak was centred in informal settlements - including Jittu Estate (of which Lagilagi is part of) and Wailea in central Suva ("Residents fail", 2010; "Water ill", 2010). 
participants if they felt secure or insecure. After evaluating all of these responses it was possible to make an analysis of all research participants' perceived security of tenure key results that were displayed in Table 10.6 in the previous chapter. To reiterate, these results revealed that $43.5 \%$ of the research sample indicated evidence of positive perceived security of tenure; $24.5 \%$ indicated that they were not secure or insecure; and $16.5 \%$ showed evidence of negative perceived security of tenure $15.5 \%$ of responses were uncertain). Given that evictions continue from state land areas in Fiji, and the reported precariousness of some vakavanua arrangements on native land, these results were perhaps surprising. Specifically, positive perceived security of tenure was higher than what might have been expected (and negative perceived security of tenure was lower than what might have been anticipated). Differences in perceived security of tenure were also evident between the case studies. Positive perceived security of tenure was greater than the whole sample average at Bouma, Caubati Topline, Lakena Hill Two and Vunato; while negative perceived security of tenure was pronounced at Tomuka and Tauvegavega. It also became very clear that primary land tenure is a crucial variable influencing perceived security of tenure. Table 10.7, for example, revealed that positive perceived security of tenure was higher in state land communities than native land areas; and correspondingly negative perceived security of tenure was greater in native land areas. Ethnicity was also an important variable. Tables 10.6 and 10.8, for example, revealed that higher proportions of Indo-Fijian participants (particularly in settlements on native land) showed evidence of negative perceived security of tenure than indigenous Fijian respondents.

There is very little other research on perceived security of tenure in Fijian informal settlements; thus little previous data to compare the current results to. One exception is from Walsh's (1978) early PhD research (reported in Chapter 5); a small component of which investigated perceived security of tenure through the question 'How secure do squatters feel?' from a survey sample of 333 squatter households in greater Suva. Walsh's key perceived security of tenure results are compared with results from the current research in Table 11.1 below. 
Table 11.1. Perceived Security of Tenure, Fiji Informal Settlers, Current Research and Walsh, 1978

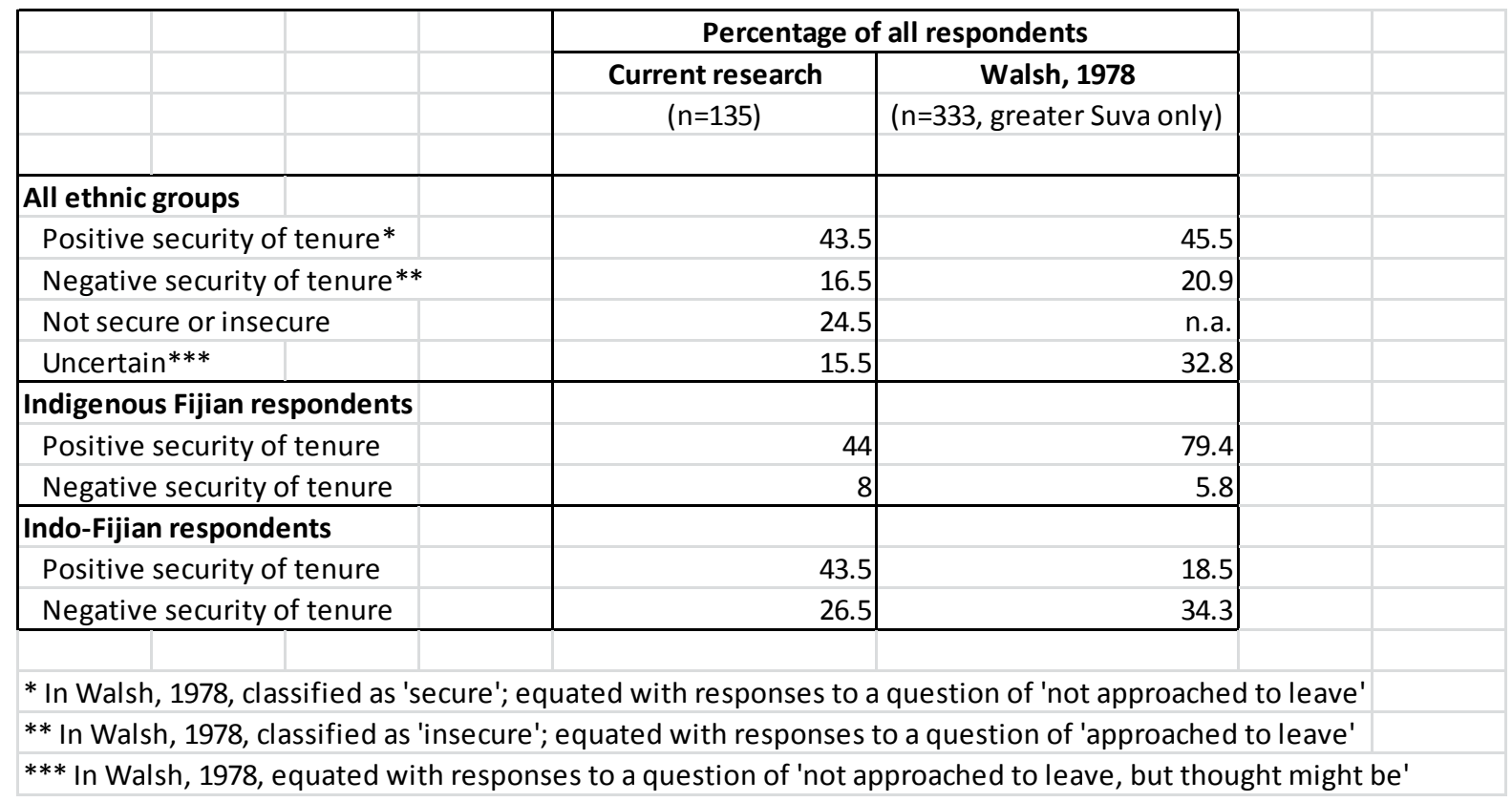

Source: Fieldwork data and Walsh, 1978, p. 250

A number of highlights from Table 11.1 are clear. Firstly, positive perceived security of tenure across the whole sample was similar in the current research (43.5\%) to Walsh's 1978 research (45.5\%) (although Walsh did not include a category 'not secure or insecure'). Secondly, low percentages of indigenous Fijian respondents displayed negative perceived security of tenure in both samples (8\% from the current research and $5.8 \%$ from Walsh). Third, compared to indigenous Fijian participants, much higher percentages of Indo-Fijian participants revealed evidence of negative perceived security of tenure in both samples (26.5\% in the current research and $34.3 \%$ from Walsh). Overall, comparing the results from the current study to similar questioning from Walsh's pioneering work in the late 1970s helps make one claim abundantly clear: that is, IndoFijian informal settlers continue to feel much less secure than their indigenous Fijian counterparts. Given that many dimensions of insecurity continue to shape socio-political and everyday realities in contemporary Fiji, particularly for Indo-Fijians, this claim indeed comes as little surprise.

International literature suggests that myriad key variables interplay to influence perceived security of tenure in squatter/informal settlements. These variables can include: perceived and real eviction pressures; histories of eviction in other, similar settlements; duration of settlement occupation; settlement size; degree and cohesion of 
community organisation; level of infrastructure and service provision; 'rights' to use the land (often recorded in documentation of various forms); perceptions of past and present government policy; availability of employment opportunities; the law and order situation; extent of political patronage; support from civil society; and specific project interventions themselves. In general, from the current research, it is evident that many of these variables also influence perceived security of tenure within Fijian informal settlements. The presentation of results in Chapter 10, exploring 'security' more generally, then security of tenure specifically, began to indicate some of the important variables influencing perceived security of tenure in Fijian informal settlements. The following discussion aims to elaborate on these key variables in more detail.

The significant differences between settlements on state and native land make it clear that a discussion of the variables influencing perceived security of tenure in Fijian informal settlements must be separated by primary category of land tenure. Overall, it seems that some variables are particularly relevant for state land settlements only, some for native land settlements only, and some for all informal settlements. For those communities on state land, perceived security of tenure seems influenced by a number of key factors. Firstly, the fact that evictions continue to occur from communities on state land across Fiji is important. These evictions are tumultuous events for the many dozens of families affected; who are usually relocated to resettlement areas on urban outskirts. These evictions are also widely reported in local media. Thus news spreads quickly to residents of all informal settlements. In addition, acute eviction pressure continues for many other settlements on state land (particularly in central Suva); situations that also receive high-profile media coverage. Overall, continuing evictions and eviction pressures in some communities influence perceived security of tenure in all other informal settlements, particularly for those on state land. Alarmingly, as Chapter 6 reported, in mid-2010 rhetoric from senior figures in Fiji's government indeed escalated eviction pressure for informal settlers on state land, particularly for those earning above poverty levels (civil servants have been specifically targeted for relocation), those involved in subletting activity, and those involved in unspecified 'illegal activity' ("Jittu 'tenants'", 2010; "Squatters put", 2010; "Warning to", 2010). Overall, it is likely that these widely reported threats will increase precariousness and insecurity for many informal settlers on state land across Fiji.

In some state land settlements the prospect of eventual legal security of tenure influences current levels of perceived security of tenure. The state land settlement of 
Lakena Hill Two, for example, has long been earmarked by central government for upgrading. In this community the prospect of titles or leases, and hence legal security of tenure, has tantalised residents for many years. Given that Lakena Hill Two was scheduled for upgrading, the community was also quite different in a number of key aspects from some of the other case-study settlements. Many residents, for example, had paid early 'fines' to the Department of Lands and Surveys; which at least provided some record of their occupancy on the land. In addition, most houseblock sites at Lakena Hill Two were clearly demarcated; indeed had been 'pegged' by the Department of Lands and Surveys as part of the early upgrading process. Last, as will be discussed further below, infrastructure was of better quality at Lakena Hill Two than some of the other case-study communities; likely associated with the scheduled upgrading intervention. Overall, it was clear that the prospect of legal title on the horizon influenced current perceived security of tenure at Lakena Hill Two - although some residents were sceptical that they would eventually receive legal security of tenure given that they had waited so long already.

The state land settlement of Lagilagi was also scheduled for intervention; in this case by the Ecumenical Centre for Research, Education and Advocacy (ECREA)/Peoples' Community Network (PCN) pilot project that was looking to upgrade the community and provide legal security of tenure through a long-term community lease. As Chapter 10 revealed, this project certainly was a key factor influencing perceived security of tenure in Lagilagi - and it was clear that, for many in the community, their ongoing security of tenure was completely entwined with the work of ECREA, the PCN, and the pilot project intervention itself. At Lagilagi (and to a lesser extent at Caubati Topline and Lakena Hill Two) PCN membership, and specifically the community organisation facilitated by the PCN, was a vital factor influencing perceived security of tenure. The support and advocacy from ECREA was also clearly important in helping to facilitate the work of the PCN and commonly cited in these areas as influencing levels of security. ${ }^{20}$

For settlements on native land - where clear vakavanua arrangements exist - perceived security of tenure seems to be influenced by quite different factors to settlements on

\footnotetext{
120 These claims are particularly significant for Lagilagi as it was a pioneering and very active member of the PCN and the site of the pilot project. To a lesser degree, PCN membership and ECREA facilitation and advocacy were also important variables influencing perceived security of tenure for some research participants at Caubati Topline and Lakena Hill Two. However, in Caubati Topline, at the time of research, the PCN was just beginning to organise the community. Additionally, at Lakena Hill Two, at the time of research, the PCN was losing some traction - particularly as the settlement's distance from central Suva made it difficult for ECREA staff to visit the community and, conversely, difficult (and expensive) for Lakena Hill Two PCN representatives to attend meetings in central Suva.
} 
state land areas. Specifically, at both Vunato and Tomuka, two variables seem especially important: (i) the nature of the landowner(s); and (ii) the nature of the settler/landowner relationship. At the $100 \%$ indigenous community of Vunato, for example, where perceived security of tenure was greater than the whole sample average, all research participants enjoyed a positive relationship with the landowner (who lived in the heart of the community). Indeed, many residents of Vunato had family connections to the landowner. Almost all research participants had also facilitated their initial access to the community by traditional sevusevu involving the presentation of tabua, yaqona, kerosene, Fijian mats, other items, and/or cash. Residents of Vunato also made customary contributions when necessary for landowning mataqali events (in the normal Fijian way) and continued to pay small monthly land rentals. All of these activities essentially enabled residents to maintain, and improve, their relationship with the landowner. Although as the following citations indicate there was some uncertainty about what might happen when the elderly land owner died: "Maybe they just waiting for the big brother to die, then they'll tell us to move" (V9); "Maybe the brothers will take over the land. But we don't know exactly what will happen. We just pray that the landowners will let us stay for as long as we want" (V17); "The only problem we thinking of is if the old man die [sic]. We only hope that whoever comes after him [will let us stay]" (V19). It was also evident that the death of the landowner at Vunato potentially presented a situation that might require a renegotiation of vakavanua agreements. For example: "He's got another brother. We just ask him if we're gonna stay. We demand on him again. That's our Fijian way" (V3). Overall, Vunato was quite different in nature to the other research case studies; appearing and functioning more as an urban village (indeed the community had appointed a headman or turaga ni koro).

The situation at the native land settlement of Tomuka was different to that at Vunato. For indigenous Fijian residents at Tomuka, firstly, the situation was not dissimilar to Vunato. Residents, for example, often facilitated access via traditional sevusevu, met expected customary obligations, and, overall, could improve and personalise their relationship with the landowner (and hence could improve their security of tenure). However, for the majority Indo-Fijian residents it was clear that there was little prospect of personalising relationships with the landowner. Rather, a functional landowner/tenant relationship prevailed and perceived security of tenure effectively hinged on continuing to meet annual land rent payments (and the repayments on houseblock purchase prices if negotiated) and avoiding trouble or disturbing the community. Certainly, at Tomuka, as was indicated in Chapter 10, failure to do either of the above could lead to eviction. 
In state land settlements such as Lagilagi and Lakena Hill Two it was clear that project interventions could improve residents' security of tenure (by eventually providing legal security of tenure and improving perceived security of tenure while interventions were planned). However, at the native land areas of Vunato and Tomuka very little intervention prospects existed. For example, as the following citations indicate, at Vunato, council zoning restrictions and the area's native reserve tenure status effectively eliminated any realistic chance of formalisation: "We're trying to lease this place. But the owner wasn't allowed to lease. He said this place is for the Lautoka City Council" (V3); "Well because this land, they can't subdivide, they can't give it for lease as it is where the landowner grows his plantation" (V9); "The reason why they turned it into a village, as it would be easier to get the land, because the land is reserved land ... [but] native land [NLTB] says they cannot lease it as this small portion was left out of the original map so the landowners could use it for their own purposes" (V10). Additionally, at Tomuka, previous discussions between the landowners and the Housing Authority about the potential for developing a formal Housing Authority subdivision had been discontinued due to landowner concerns and frustration with the process. ${ }^{121}$ Essentially, in these communities, residents had to accept the status quo (that upgrading and/or formalisation was unlikely), continue to meet terms of vakavanua agreements and customary expectations, and attempt to improve relationships with landowners.

Other variables influencing perceived security of tenure in the research case studies emerged as significant in both state and native land areas. Firstly, as Chapter 10 reported, many research participants indicated that they had lived in their community for many years without significant eviction pressure; and thus felt secure. This makes it clear that length of residence in a community - particularly without any pressure to leave - is a key variable influencing perceived security of tenure. Secondly, the presence of infrastructure, utility and service coverage also appears important in influencing perceived security of tenure in state land areas. At Lakena Hill Two, for example, where perceived security of tenure was greater than the whole sample average, infrastructure was of better quality than the other case studies. Firstly, power infrastructure was permanent. Secondly, central government had constructed sealed footpaths across the community. Third, access roads to the heart of the community

121 This stalled Housing Authority development at Tomuka also apparently resulted in the mass eviction of 20 to 25 households a number of years ago - households who were not willing to make advance payments to the landowner to facilitate the development plans. 
were of reasonable quality (and had once enabled scheduled public transport to service the area; although at the time of research these services had ceased). ${ }^{122}$

In summary, a number of variables seem crucial in influencing perceived security of tenure within the case-study settlements. Most acutely, for those settlers from state land areas of the sample, well-reported evictions and eviction pressure from and in other state land areas contribute to feelings of vulnerability and specifically influence negative perceived security of tenure, or levels of insecurity in general. On the other hand, positive perceived security of tenure within settlements on state land appears particularly influenced by: the prospect of legal security of tenure in the form of titles or leases being on the horizon; and community organisation, support and advocacy from civil society, and project interventions themselves. In contrast, in native land areas specifically where customary or commercial vakavanua arrangements exist - perceived security of tenure particularly rests on the nature of residents' relationships with landowners. In addition, further variables seem important for both state and native land areas; particularly continued residence in communities (especially without any pressure to leave) and the presence of infrastructure, utilities, and services. Overall, however, it is difficult to isolate or prioritise all of these variables. Indeed, some of these variables seem particularly relevant for some case studies only. In summary, perceived security of tenure in Fijian informal settlements remains context-specific and complex; influenced by a number of coalescing factors.

The preceding discussion is most relevant when the legal land tenure status is clear to residents of informal settlements. This was certainly the case in the native land settlements of Vunato and Tomuka where all residents were acutely aware that these areas were held in native tenure. However, adding complexity, and indeed heightened vulnerability for settlers, was that land tenure was often confused and/or contested in many of the research case studies. For example, many research participants from Lagilagi, Caubati Topline, Lakena Hill Two, Tauvegavega and Bouma when asked the question 'Who owns this land?' often admitted uncertainty or were technically incorrect. For example: "Right now no one owns this land. But the quarters [PCN housing units] are

\footnotetext{
122 Infrastructure, utility and service coverage also appeared an important variable affecting perceived security of tenure at Tauvegavega (where a relatively recent transfer from state tenure and ongoing disputes among neighbouring mataqali groups meant that the type of customary or commercial vakavanua arrangements seen at Vunato and Tomuka were absent). At Tauvegavega, for example, access roads were of reasonable quality and the Fiji Electricity Authority had installed permanent power infrastructure across the community - perhaps because the area had been earmarked by the NLTB for eventual intervention/upgrading.
} 
coming. I don't know who owns this land" (LL14); "To my knowledge it is under an Indian man ... it is state land, but part of it is owned by that Indian man in America" (LL7); "This is crown land, owned by the people in Kalabo" (TL1); "Three times some Fijian people come here. Some from Nine Mile, some from Nausori, some from Newtown. We are confused [about] who owns this place" (TL7); "[The] land is not ours aye, as we did not pay ... I don't know [who owns the land], sometimes people says it's for Housing [Authority] aye, but we're not sure" (TL15); "We are not sure if it is under Housing [Authority], or if it is under crown land" (L16); "Before there was a queen in [the] koro. Different koros have different queens [but] I'm not really sure who is taking care of her post because she died ... To my knowledge it's always been a squatter area. I'm not really sure [if] it's native land or crown land. If we get the lease we might know aye" (T9); "The owner of this land, she stays at Nasekola" (B2). In addition, mataqali groups were also often contesting ownership of some areas - most specifically at the native land settlement of Tauvegavega and the state land settlement of Lakena Hill Two. For example: "Cases are in court now regarding this land. The village in front there [Verata] is claiming this land, they waiting for the court decision" (L7); "This case is going on between the mataqali and the Lands Department. They might demand a lot of money to stay here" (L15); "Yeah some problem is going on between the Wailaga people and the Nailaga people, but we know the Nailaga people" (T9). Overall, land tenure confusion and contestation simply add another level of insecurity for many settlers, and also often leads to situations where some settlers, attempting to gain access to settlements or to connect utilities (where signatures from landowners are necessary), are taken advantage of.

When comparing the variables influencing perceived security of tenure from the international literature to those evident from the research case studies, there are a few notable differences. Firstly, size of the settlement and availability of employment opportunities did not emerge as significant from interviews. Secondly, documented rights were only notable for their absence (for those on state land) or for being legally unenforceable (commercial vakavanua arrangements at Tomuka). Most significantly, perhaps, was the absence of political patronage as a key variable influencing perceived security of tenure. Indeed, as Chapter 10 recorded, many informal settlers expressed that previous political promises had only been made in the course of electioneering and remained unfulfilled; creating general dissatisfaction and great scepticism of further political promises among residents. 
It has also become clear that the international perceived security of tenure literature has tended to ignore the crucial influence of land tenure, perhaps because other research has tended to focus on case studies on one category of land tenure only. This research in the small island, customary land context of Fiji, however, where informal settlers reside on state, native and indeed freehold land, reveals that category of land tenure forms an essential, distinguishing, variable influencing perceived security of tenure within informal settlements.

An understanding of perceived security of tenure in Fijian informal settlements needs to be contextualised. The diversity across all Fijian informal settlements and, particularly, the critical differences between settlements on state and native land suggest that holistic understandings are needed. Certainly perceived security of tenure, influenced by multiple variables, is complex. Overall, perceived security of tenure can be positive, negative, or fitting into the category 'not secure or insecure' (the latter where residents essentially recognise the reality of their situation - particularly the potential vulnerability to one day being forced to vacate the land). An important question also remains to be addressed: 'What is security of tenure for Fijian informal settlers?' The answer to this question is clearly not legal rights to the land on which informal settlers reside (for no informal settlers on all primary categories of land tenure hold such rights). UN-Habitat defines security of tenure as the "rights of all individuals and groups to effective protection from the State against forced evictions" (2006, p. 94). This definition, however, holds little utility in the Fijian context. Firstly, the Fijian state indeed instigates and perpetuates evictions from state land areas and also does little to halt evictions from freehold land. Secondly, the Fijian state has little jurisdiction (let alone will) to be able to stop evictions from native land areas. The research suggests, alternatively, that a more appropriate conceptualisation of security of tenure in the Fijian informal settlement context corresponds with the prospect of being able to stay on the land for as long as a household may want. Indeed, it became clear during interviews with indigenous Fijian respondents that the Fijian concept, vakadeitaki, loosely translated as having assurance that a household may stay on the land as long as is desired, was the most effective way of conveying the meaning of the complex and often confusing concept of 'security of tenure'. This all suggests that (positive) perceived security of tenure in Fijian informal settlements could be achieved if eviction is thought to be unlikely (which is tied to both real and perceived eviction pressures). Effectively, as is also recognised in the emerging wider international literature (van Gelder, 2007, 2009 \& 2010; Reerink \& van Gelder, 2010), 
perceived security of tenure in Fijian informal settlements equates with perceived probability of eviction.

The perceived security of tenure literature suggests that across the world's urban areas a continuum of tenure categories exist; often falling between the binary extremes of legal/formal and illegal/informal and presenting varying degrees of tenure security. Fieldwork results have also helped to make it clear that, in the Fiji context, ethnicity is a key variable that must be considered in such a continuum; particularly in differentiating vakavanua agreements on native land. Figure 11.1 below attempts to schematically map tenure categories within the case-study informal settlements by escalating degree of tenure security; and has been developed after considering perceived security of tenure results from the survey sample and the reality of the current situation in Fiji.

Figure 11.1. Tenure Categories Within the Case-Study Settlements

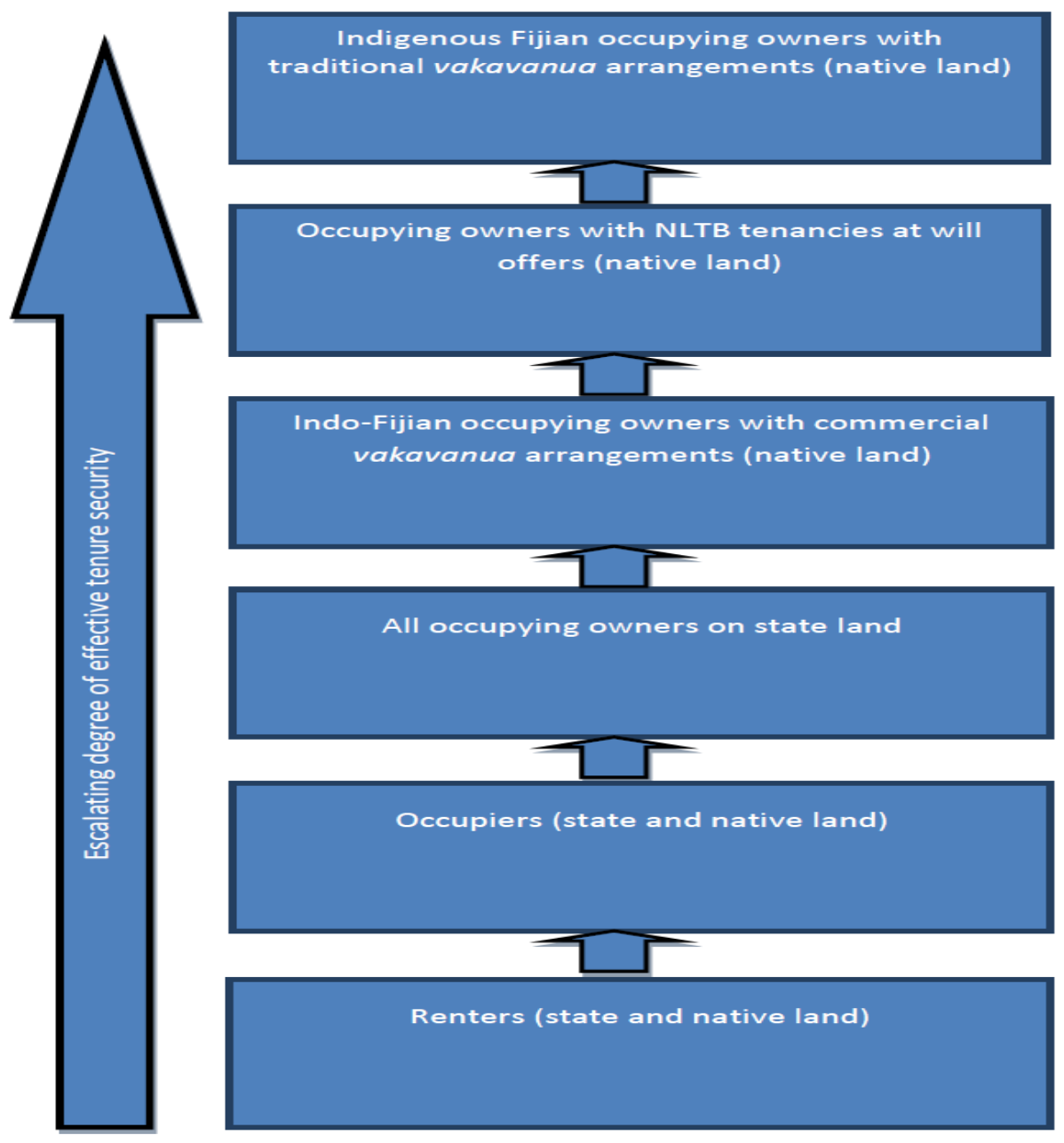


Figure 11.1 differentiates between major category of house tenure and shows that occupying owners typically have greater tenure security than renters or occupiers. The figure also shows that indigenous Fijians with customary vakavanua arrangements with native landowners (such as those at Vunato) typically have the greatest effective tenure security and certainly greater tenure security than Indo-Fijians with more commercial, vakavanua, tenant/landlord arrangements (such as those common at Tomuka). It is also clear that: (i) evictions continue from state land areas in Fiji (indeed recent threats from the state have escalated); (ii) commercial vakavanua arrangements for Indo-Fijians, like those seen at Tomuka, do offer at least the prospect of being able to stay for the duration of the 'lease' term (as long as residents meet payment terms and avoid community disturbances); and (iii) Native Land Trust Board (NLTB) tenancies at will, like those seen at Tauvegavega, do at least provide crucial documentation and record of occupancy. These crucial recognitions have aided in the sequencing of the categories in Figure 11.1.

\subsection{Housing Consolidation}

"Everything I got I invest in this house. I am penniless" (T14). The preceding citation is from an interview with an Indo-Fijian resident of Tauvegavega who had moved to the community in 2001 and built a new home. The dwelling was high quality, constructed of concrete blocks and hence very permanent. In fact, the interviewee estimated that close to $F \$ 30,000$ had been invested in building and improving the dwelling in the first year of residency. ${ }^{123}$ The experience of this household and particularly the considerable level of investment made helps to reveal the significance of housing consolidation - or in other words self-help housing investment - in Fijian informal settlements; even in the absence of legal security of tenure.

The household and housing census results displayed in Chapter 10, particularly the $18.5 \%$ of national squatter/informal settler dwellings with walls constructed principally of concrete (see Table 10.9), a very permanent building material, suggested that nationally housing consolidation was occurring in Fijian informal settlements. Census data for casestudy settlements also revealed that concrete was a significant primary wall construction material at Caubati Topline (32\% of dwellings), Tomuka (24.75\%), Lakena Hill Two (23\%),

\footnotetext{
123 Interestingly, this household halted all dwelling improvements after Tauvegavega's conversion from state to native tenure in 2002: "That day was big coup in Tauvegavega" (T14) was the interviewee's summary of the effect of the land tenure changes that necessitated payments to NLTB for tenancies at will on the newly legislated native land.
} 
and Tauvegavega (19\%) (see Table 10.10); suggesting that a significant number of dwellings in these areas were of relatively high quality and very permanent.

Fieldwork results subsequently revealed that $55.5 \%$ of all households surveyed showed evidence of housing consolidation ${ }^{124}$ - or, as defined, significant housing investments in the years 2003-2008. Differences between the major ethnic groups were also evident; with slightly higher percentages of Indo-Fijian households (58.5\%) showing evidence of housing consolidation than indigenous Fijian households (52\%). Primary land tenure was also an important variable influencing housing consolidation. Table 10.13, for example, showed that housing consolidation for all ethnic groups was greater in state land areas (60\%) than native land areas (50\%); a trend also reflected when analysing individual ethnic groups. Across the case studies housing consolidation was most evident at Tauvegavega and Lagilagi (70\% of surveyed households), Lakena Hill Two (65\%) and Caubati Topline (55\%), and least evident at Tomuka (35\%), Vunato (45\%) and Bouma (46.5\%). It also became clear that housing consolidation was motivated by a variety of reasons, particularly including the need for: extra bedrooms and living space (to accommodate growing families or to create separate, adjacent extended family households); improved amenities (such as toilets and bathrooms); reduced natural hazard risk (such as by raising dwellings on stilts); and improved personal security (for example, by installing fences and security doors/bars; something that was particularly important for many Indo-Fijian participants).

Fieldwork also made it clear that housing consolidation was particularly stymied by a number of factors including not being the house owner (renters and occupiers were not surprisingly far less likely than occupying owners to be engaged in housing consolidation) and lack of necessary finances. In $8.9 \%$ of all cases (and $20 \%$ of cases for those not involved in housing consolidation; see Table 10.15) dwellings were also perceived as already adequate in quality/size. In these cases (particularly in Tomuka and for longestablished residents in other areas) recent housing consolidation was not evident primarily because dwellings had been completed to an acceptable standard originally

\footnotetext{
124 As with perceived security of tenure, very little previous research is available to compare the current research results around housing consolidation to. Chapter 6 did reveal that significant levels of housing investment had been noted in earlier informal settlement case studies (Bryant, 1990). Providing more detail, Walsh (1978) showed that, from his survey of 333 squatter households across greater Suva, 68\% had built their own house (closely comparing to $67.5 \%$ from the current research; see Table 9.12 ) and $64 \%$ had made improvements since construction or occupancy (significant levels of housing consolidation that roughly compare to the current research) (cited in Walsh, 1984, p. 193). In contrast to these findings (and that of the current research) a survey by Chung and ECREA across 680 households in 18 settlements found that only $26 \%$ of respondents had made improvements to their dwellings (2007, p. 61).
} 
or incrementally many years earlier. Overall, in general, fieldwork results showed that housing consolidation was a process undertaken primarily by: occupying-owners; more recent arrivals in settlements; and those with the available necessary finances.

Across and between case studies a wide variety of housing quality was evident. Census results (see Table 10.9) have shown how principal wall construction materials tend to be tin/iron, wood or concrete in all Fijian informal settlements. Overall, concrete dwellings tend to be the highest quality and the most permanent. Wood or, particularly, tin/iron dwellings tend to be lower quality - but do have the considerable advantage of being transportable if necessary. Between the case studies, the poorest quality dwellings were observable at Bouma and Vunato (where regular flood risk was greatest) and at Lagilagi (where the community was very congested and, as was discussed in Chapter 10, the looming ECREA/PCN pilot project was removing incentives for housing improvements). In general, higher quality dwellings were observable at Caubati Topline, Lakena Hill Two and Tomuka. At Tauvegavega, a variety of dwellings, including very low and very high quality, were observable - reflecting the diversity in the settlement.

Differences in housing preferences were also observable between the major ethnic groups. Many indigenous Fijian dwellings, for example, were more open with large communal living spaces; reflecting cultural preferences and the need to accommodate extended family and visitors. Indo-Fijian dwellings, on the other hand, were often more compartmentalised (averaging more rooms than indigenous Fijian dwellings; see Table 10.14) and often reflected preferences for personal security needs such as security doors and grills and high fences (the latter most observable at Tomuka).

It is clear that significant levels of housing consolidation were occurring in Fijian informal settlements. Indeed this may suggest that housing consolidation may be so important (perhaps to accommodate the large household sizes common to informal settlements) that it can occur whatever the circumstances - even in the absence of legal security of tenure. An important question that needs to be considered is "What is an adequate informal settlement dwelling in Fiji?' Certainly an adequate dwelling must provide a particular standard of shelter; including protection from non-extreme climatic conditions. An adequate dwelling also should provide suitable space; including communal areas for indigenous Fijian households and enough rooms for Indo-Fijian preferences (including privacy within the family). For Indo-Fijians, particularly, adequate informal settlement 
dwellings should also provide a level of personal security; ideally protected by security doors and grills and fences in some areas.

The pioneering research by Walsh (1978) showed that significant levels of self-help housing investment were evident in Fiji's informal settlements. Walsh argued, however, that, despite such ongoing housing investment, few dwellings in his sample could be considered adequate in terms of structure, size, water supply and sanitation (as cited in Bryant, 1990, p. 182); pointing out that the incremental creation of adequate quality dwellings was inhibited by the low incomes of settlers particularly and rigid building codes (ibid; 1984, p. 185). As Walsh contends, (low) income may well still be the critical variable inhibiting the overall improvement of whole informal settlement neighbourhoods. However, the current research makes it clear that an adequate informal settlement dwelling also, in many cases, needs to be transportable (for example, in the event of eviction); something that inhibits the use of permanent building materials and the overall creation of high-quality housing stock in some informal settlements. The current research has additionally revealed that the location of many informal settlements - in low-lying areas that flood regularly - clearly removes the incentive for the development of high-quality dwellings. In Bouma and Vunato, for example, annual wet season floods and more severe events in some years, and, additionally, the fact that many residents in these extremely environmentally marginal areas view stays as temporary, meant that overall housing quality was very low. In summary, despite evidence of significant housing improvements and extensions, the development of high quality housing stock in Fijian informal settlements is inhibited by a number of factors including: lack of legal security of tenure; low incomes (that, as discussed in Chapter 10, also limit access to formal credit); natural hazard risk; and the fact that dwellings may need to be transportable. Overall, housing consolidation occurs in Fijian informal settlements; but to a level that often falls short of creating neighbourhoods that meet acceptable levels of housing quality. Walsh claimed in the mid-1980s that "without major changes in the economic position of the poor ... little change can be expected in the overall squatter condition" (1984, p. 193). Given the extremely low wages and incomes earned by the majority of informal settlement households in Fiji today, this claim still holds much validity. 


\subsection{The Relationship between Perceived Security of Tenure and Housing Consolidation}

International literature clearly links legal security of tenure to processes of housing consolidation in informal settlements. More recently, perceived security of tenure literature and associated emerging international housing policy has also emphasised that informal settlers will invest in improving their dwellings even in the absence of formal title - particularly if eviction is thought to be unlikely. A key objective of the current study was to begin to explore the relationship between perceived security of tenure and housing consolidation in a new research setting: a small island state of dominant customary land. Table 11.2 below explores associations between perceived security of tenure and housing consolidation from the research sample. Some highlights are clear. Firstly, the largest category of respondents from the whole sample (23\%) displayed evidence of both positive perceived security of tenure and housing consolidation; suggesting that there may be some relationship between the two variables. However, the data also reveals that $20.7 \%$ of the whole sample displayed evidence of positive perceived security of tenure but no evidence of housing consolidation (indeed $47.5 \%$ of those displaying evidence of positive perceived security of tenure were not engaged in housing consolidation as defined). ${ }^{125}$ Further, if there was a strong correlation between positive perceived security of tenure and housing consolidation it might be expected that the inverse was true; that those displaying evidence of negative perceived security of tenure were more likely not to be involved in housing consolidation. However, in this case, the data shows that those displaying evidence of negative perceived security of tenure were in fact more likely to be engaged in housing consolidation. Indeed, close to $10 \%$ of the whole research sample showed evidence of negative perceived security of tenure but evidence of housing consolidation. This last finding indicates that housing consolidation is a process likely to be influenced by additional variables; factors that could be isolated in further research looking at perceived security of tenure and housing consolidation in Fijian informal settlements.

125 It is likely that some of this group displaying evidence of positive perceived security of tenure but no housing consolidation would have dwellings regarded as adequate in quality/size; where housing improvements and extensions had finished many years previously. 
Table 11.2. Perceived Security of Tenure and Housing Consolidation, Research Sample

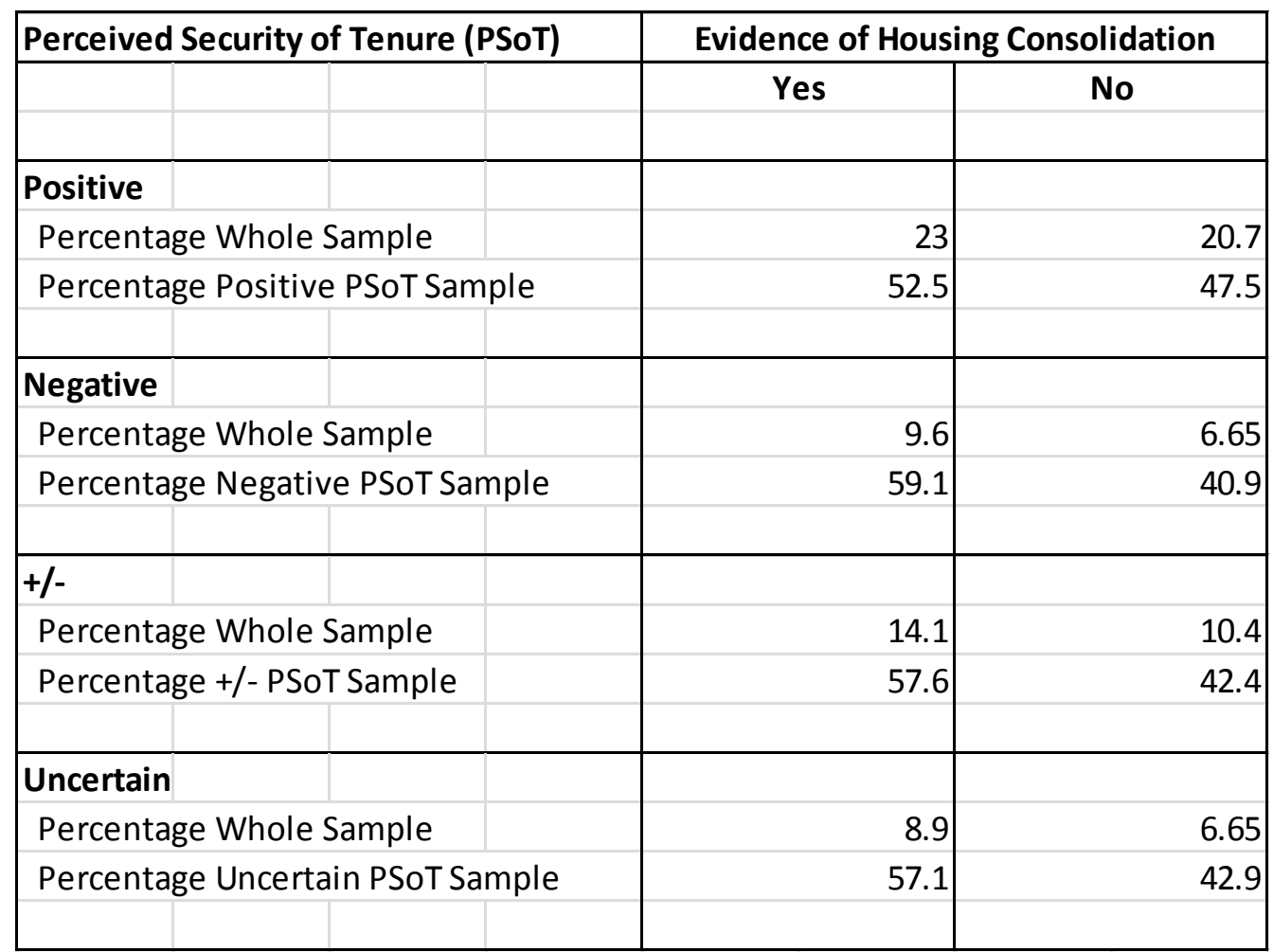

Source: Fieldwork data

The fieldwork results displayed in Table 11.2 do not allow strong assertions to be made about the relationship between perceived security of tenure and housing consolidation. Overall, the relationship is likely to be complex. As is recognised in the wider literature, a number of additional variables are also likely to influence the level of housing consolidation in any context - including income, length of residence in informal settlements, and access to formal credit (Bryant, 1979; Reerink \& van Gelder, 2010; van Gelder, 2009; Walsh, 1978). Table 11.3 below highlights summary data investigating the effects of these variables on housing consolidation from the current research sample. The table firstly shows that average length of residence is not a significant predictor of housing consolidation; with those groups displaying evidence of housing consolidation and those who did not having very equal average lengths of residence. ${ }^{26}$ Secondly, and more significantly, the data shows that average income appears an important predictor of housing consolidation with the average monthly incomes of those displaying evidence of housing consolidation (\$F619.1) being 6.6\% greater than those displaying no evidence of housing consolidation (\$F580.8). This result provides support for the principal

126 Again, some of the households displaying no evidence housing consolidation may well have had dwellings already regarded as adequate in quality/size; completed many years previously. 
housing consolidation contention of Walsh from his 1978 research who argued that income was the critical variable affecting overall housing quality in Fijian squatter settlements. Finally, Table 11.3 shows data looking at the relationship between evidence of housing consolidation and access to credit (although the proportion of the whole sample with access to formal credit was a relatively low 18\%). Here it might be expected that informal settlers with access to formal credit would be more likely to be involved in housing consolidation. The data from the current research, however, does not support this claim; in fact, revealing some evidence for the opposite.

Table 11.3. Average Length of Residence, Monthly Income, and Access to Credit by Evidence of Housing Consolidation, Research Sample

\begin{tabular}{|l|r|r|}
\hline Variable & \multicolumn{2}{|c|}{ Evidence of Housing Consolidation } \\
\hline & Yes & No \\
\hline Mean Length of Residence (years) & 15.5 & 15.7 \\
\hline Mean Monthly Income (F\$) & 619.1 & 580.8 \\
\hline Percentage of respondents with & & 54.2 \\
\hline access to formal credit & 45.8 & \\
\hline
\end{tabular}

Source: Fieldwork data

If a strong relationship between perceived security of tenure and housing consolidation exists, it might be expected that evidence of housing consolidation would increase alongside the escalating tenure categories evident within the case-study settlements displayed in Figure 11.1. Housing consolidation levels within these categories are tabulated and charted in Table 11.4 and Figure 11.2 below, showing that evidence of housing consolidation was lowest for renters (12.5\%) and occupiers (20\%) (although the sample sizes of these groups were small) and highest (excluding the category 'other') for occupying owners with NLTB tenancies at will on native land (66.6\%) (all cases at Tauvegavega) and occupying owners on state land. Perhaps surprisingly only $42.1 \%$ of indigenous Fijians with customary vakavanua agreements (the tenure category assessed as giving the highest degree of effective tenure security) showed evidence of housing consolidation; although a possible explanation for this is the very high annual flood risk at Vunato where $89.5 \%$ of the participant proportion of this tenure category resided.

Overall, it is again difficult to make strong assertions from the data displayed in Table 11.4 
and Figure 11.2; indicating the complex relationship between perceived security of tenure and housing consolidation and the likely effect of other variables.

Table 11.4. Evidence of Housing Consolidation by Category of Tenure Security,

Research Sample

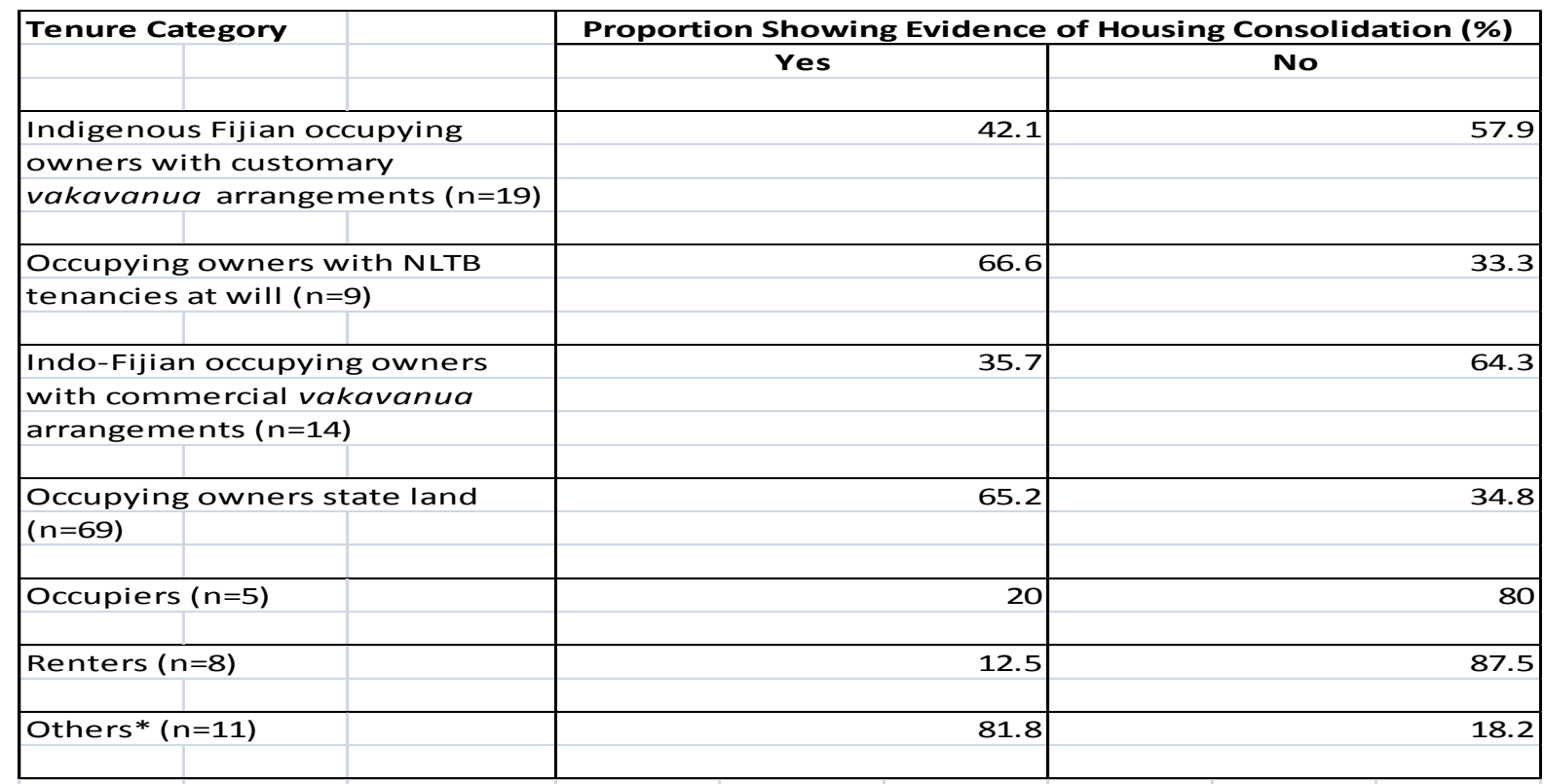

* Largely those at Tauvegavega (arriving post-2002) without NLTB tenancies at will

Source: Fieldwork data

Figure 11.2. Evidence of Housing Consolidation by Category of Tenure Security,

Research Sample

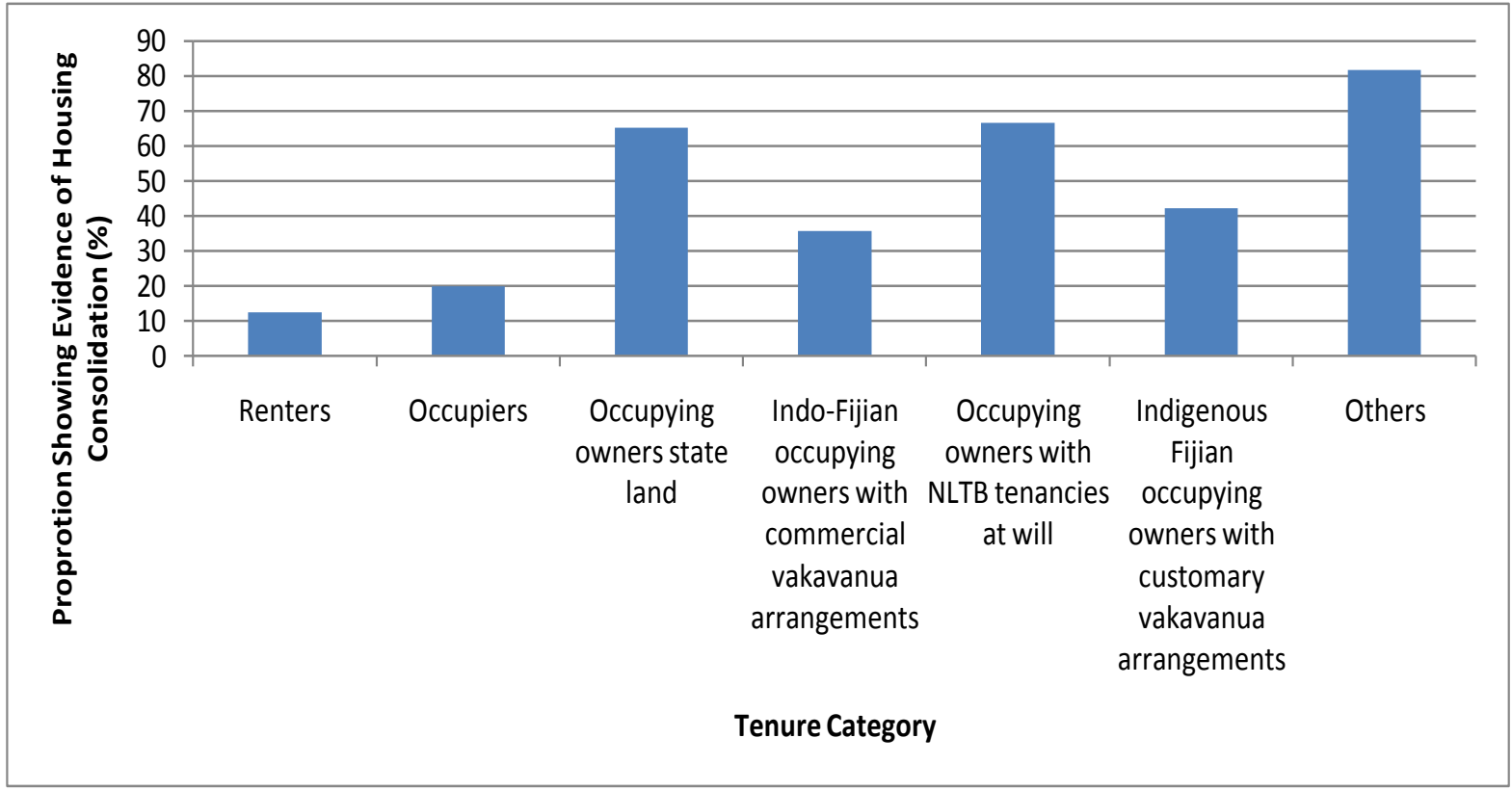

Source: Fieldwork data 
de Souza (2001) argues that within informal housing environments the relationship between perceived security of tenure and housing consolidation is subtle and complex. Evidence from the current research supports this claim. Overall, in addition to perceived security of tenure, many coalescing variables influence levels of housing consolidation. The current research suggests that income is likely to be an important additional variable influencing housing consolidation in Fijian informal settlements (while not supporting length of residence and access to formal credit as important predictors of housing consolidation). Wider international literature additionally suggests that saving capacity (as discrete from average incomes), building skills, and personal safety (or, in other words, personal security) are also likely to influence levels of housing consolidation in many informal environments (de Souza, 1999 \& 2001). These latter variables were difficult to isolate given the current research's methodology. However, future research looking at housing consolidation in Fijian informal settlements could investigate the effect of these variables on housing consolidation; along with the relationship between natural hazard risk and housing consolidation.

The relationship between perceived security of tenure and housing consolidation in many informal settlement environments is also likely to be two-way (de Souza, 2001). That is, in addition to increases in tenure security promoting housing consolidation, the process of housing consolidation itself, in some cases, could improve levels of tenure security (ibid). In these cases the process of improving dwellings - effectively making houses more permanent - improves household perceptions of their security; or, in other words, improves their perception of their chances of avoiding eviction and remaining on the land. As Gulyani and Bassett summarise from a review of informal settlement upgrading projects in sub-Saharan Africa: "[i]nvestment in housing, in fact, is a strategy for obtaining security ... [often] ... reflecting an implicit understanding that a completed house would not be demolished by the local administration" (2007, p. 11). Future research could also further investigate the relevance of this claim within Fijian informal settlements.

\subsection{Limitations of the Current Study and Additional Future Research Needs}

The methodology of the current study enabled a thorough investigation of the first three key research objectives; essentially exploring the extent and nature of perceived security of tenure (including its key influencing variables) and housing consolidation within Fijian 
informal settlements. The selection of a variety of informal settlement case studies from across Fiji allowed both a holistic and contextualised investigation of processes within settlements. The research methodology utilised, however, only allowed limited investigation, and tentative assertions, around the fourth key research objective aiming to begin to explore the relationship between perceived security of tenure and housing consolidation in Fijian informal settlements. As wider international literature has concluded (for example de Souza, 2001), it appears that the relationship between perceived security of tenure and housing consolidation is complex and subtle. Clearly further research exploring perceived security of tenure and housing consolidation in Fijian informal settlements needs to investigate, and isolate, other important variables (including income and savings capacity and natural hazard risk especially) that also may influence housing consolidation. A more structured approach, perhaps utilising indices of perceived security of tenure and housing consolidation and quantitative methods of analysis, would also enable stronger assertions about the relationship between perceived security of tenure and housing consolidation to be made.

The current study employed a rather narrow definition of housing consolidation, specifically extensions and major improvements in dwellings in the five years preceding interviews (2003-2008). This approach differed from earlier studies and surveys (such as Walsh, 1978, and Chung \& ECREA, 2007) (investigating housing consolidation amid broader investigations of informal settlements) that essentially defined households engaged in housing consolidation as those completing any extensions or improvements since occupancy or original build. The advantage of the current study's definition of housing consolidation was that it only captured those households engaged in recent investment. However, the disadvantage was that it excluded a number of long-term resident households that had made very significant housing investments over the years; but had finished such work prior to 2003. Again, further work exploring housing consolidation in Fijian informal settlements could use indices (perhaps of principal wall construction material, dwelling size, number of dwelling rooms, overall dwelling quality, etc) to enable more structured investigations.

As the methods chapter flagged, interviews encountered a number of challenges. Firstly, all interviews were conducted in English. Although English is widely spoken across Fiji (including in informal settlements) in a few small cases this meant that broad ranging discussions allowing rich, qualitative testimonies were limited. Secondly, despite carefully structured interviews and explanations if needed, it was sometimes difficult to convey 
the meaning of 'security of tenure'. This contributed to the relatively high percentage of cases (15.5\%) where a participant household's perceived security of tenure was ultimately defined as uncertain. Additionally, the term 'security' has many different meanings in any context which can confuse discussions of security of tenure. In Fiji, particularly for Indo-Fijians, security is also is a very loaded concept; and is, as Pangerl writes, omnipresent in describing socio-political and everyday realities (2007, p. 251). Thus, in a small percentage of examples (part of the $15.5 \%$ of cases where perceived security of tenure was uncertain) some respondents continued to discuss issues of personal security (as related to the local law and order situation and personal safety) despite efforts to focus on security of tenure. This unanticipated eventuality, however, is important in itself. For, as was noted in Chapter 2, personal security can be an important variable influencing perceived security of tenure. Further, wider literature (in this case from contested settlements in Brazil) has also shown how personal security can be more significant than tenure security in influencing housing consolidation processes (de Souza, 1999). Overall, the nature of personal security clouded results in the current research to some extent. Further research in Fijian informal settlements could thus carefully isolate personal security from security of tenure.

Much discussion around informal settlements in Fiji anecdotally links the recent growth of these areas to the expiry of rural farming leases from the mid-1990s onwards. An early (but unfulfilled) intention of the current research was to focus on revealing experience and detailed testimonies of individuals and families affected by expiring leases and given little option but to locate to informal settlements. While a number of participants in the current study did fall into these categories, overall total numbers (at around $6 \%$ of respondents - all in Caubati Topline and Tauvegavega) were less than expected. Further research looking at Fijian informal settlements could focus on revealing the often tumultuous experience of these groups directly and indirectly ${ }^{127}$ affected by lease expiry. This could be enabled by the use of qualitative methods extracting rich, detailed testimonies, careful selection of participants, and the inclusion of case studies where significant numbers of those affected reside. As Chapter 5 discussed, fundamental changes have been occurring in the structure of Fijian society including continued urbanisation fuelled partially by a rural exodus of Indo-Fijians from the cane belt areas of Viti Levu and Vanua Levu. As many commentators claim, certainly expiring rural leases have contributed to this process (although evidence for this remains anecdotal); as is

127 Those indirectly affected include those with previous livelihoods dependent on the sugar sector - such as cane-cutters, mill workers, and lorry drivers. 
the general downturn of the sugar industry. However, further research is still needed to validate claims that expiring leases continue to influence the growth of informal settlements in Fiji.

\subsection{Possible Policy Responses}

From the onset this thesis has had an overarching practical orientation: to inform a more nuanced understanding of the dynamics of Fijian informal settlements and to suggest potential policy options for intervening in the tide of escalating housing informality. Specifically, the research attempted to suggest possible policy options for increasing perceived security of tenure in Fijian informal settlements, promoting housing consolidation, and improving access to land and housing for low-income urban residents and new migrants.

The level of housing consolidation occurring in the case-study informal settlements suggests that many settlers, despite not owning the land that they reside on, feel sufficiently secure to invest significantly in improving their dwellings - as Chapter 2 discussed, a process recognised in international literature and shelter policy as the crucial first step in improving informal settler livelihoods and communities. Some evidence from this study and international literature also suggests that improving perceived security of tenure may also be a way to facilitate increased housing consolidation in Fijian informal settlements. Perceived security of tenure approaches may thus present a useful theoretical framework informing policy for the Fiji context. The dominance of customary land in Fiji (and the fact that much new informal settlement growth is concentrated on peri-urban tracts of native land) also means that the provision of full legal title (often the ultimate objective of many land tenure programmes) is not feasible. Rather, perceived security of tenure approaches can suggest a wider variety of initiatives all aimed first and foremost at improving perceived security of tenure (Payne, 2001).

Perceived security of tenure approaches, in general terms, look to recognise and build from existing land tenure categories present in any context (which can often be conceptualised as existing as a wide continuum of escalating tenure security). Perceived security of tenure approaches thus look to: increase the rights of residents to use/settle on land (rather than changing formal tenure status); extend existing customary approaches; and increase the range of tenure options available (such as promoting 
collective leases and temporary occupation licenses and other documented rights). Broadly, perceived security of tenure approaches look to facilitate incremental initiatives to improve effective tenure security (essentially any step along the continuum is seen as a step in the right direction) (Payne, 2001 \& 2004).

In general terms, perceived security of tenure approaches suggest a number of broad potential policy avenues for Fiji. Firstly, it may be possible to build from the wide variety of existing vakavanua arrangements that are currently used to gain access to areas of native land - perhaps by giving more official recognition to these practices. Secondly, amid upgrading schemes on state land, collective leases could be issued to whole communities (indeed this approach is currently being trialled in the ECREA/PCN Lagilagi pilot) particularly in an attempt to avoid speculation and target beneficiaries moving out of communities. Third, more effort could be made to ensure that settlers have some form of documentation to help show negotiated rights to use land (for example, vakavanua arrangements) or at least show a period of occupancy on state land (by encouraging settlers to collect receipts for building materials, utility connection, etc). Concerned civil society groups could certainly facilitate such activities.

Ultimately, it is political will that is essential in effective perceived security of tenure approaches. ${ }^{128}$ Perhaps the single most important means to increase perceived security of tenure, for example, is to remove residents' fear of eviction (UN-Habitat, 2007, p. 139); and announcing a halt to forced evictions when presently part of government policy is the prime, and most crucial, means of doing so (Payne, 2004, p. 175). Overall, in any context, political will for improving conditions for informal settlers is essential for implementing a pro-poor urban shelter strategy aimed at increasing perceived security of tenure. At the time of writing however - evident in the eviction pressure directed at all informal settlers on state land - it seems that political will and pro-poor strategies to improve conditions for informal settlers is absent in Fiji.

Alongside reducing fear of eviction, this research has made it clear that increasing perceived security of tenure in informal settlements can be facilitated by a number of additional means. It became clear that the work of the PCN (and the accompanying facilitation and support of ECREA) was crucial in increasing perceived security of tenure in the case-study communities that were part of the network. Being a member of the

128 Civil society and donor and international organisations can promote perceived security of tenure approaches; but any progress will require a supporting and enabling state apparatus. 
PCN enabled communities to increase their voice, in time to benefit from communal savings, and active individuals to benefit and grow from the collective and participatory principals and methods espoused. News in 2010 that the PCN was expanding out of greater Suva into the Western Division ("Help on", 2010) was positive; as ultimately more informal settlements and settlers across Fiji will benefit from PCN membership. As already noted, scope may also exist for other civil society groups to find niche areas aimed at supporting informal settlers; initiatives and advocacy that could also increase perceived security of tenure in settlements.

The research has also made it clear that any effort to improve services, utilities and infrastructure in informal settlements can increase perceived security of tenure. Enabling environments can thus be facilitated and encouragement directed at the Fiji Electricity Authority, Fiji Public Works Department, local council service delivery (such as waste collection) and public transport operators to provide or improve coverage in informal settlement areas. It was also clear that ongoing project interventions (particularly community upgrading schemes) increase tenure security for targeted residents, and that even the prospect of eventual project interventions acted to increase current perceived security of tenure for settlers. Thus, government agencies such as the Housing and Squatter Resettlement Unit (HSRU) could widely publicise planned upgrading initiatives. Finally, if free and fair elections are to be held in Fiji (elections are currently scheduled for 2014), given the wide electorate base that informal settlers form, political parties could actively champion and support the needs, priorities, aspirations and rights of informal settlers. Although for this to be successful in increasing the tenure security of settlers, political promises would need to be followed through with committed support and action (which is in contrast to past experience in Fiji).

All the above approaches aimed at increasing tenure security need to be accompanied by essential political will to improve conditions for informal settlers. They also need to be accompanied by a crucial recognition, applicable to settlements on state land particularly, that informal settlements will eventually be (if not already) vibrant town and city suburbs supporting urban growth and development. For informal settlements on state land this important recognition (that is currently largely absent in Fiji) will also promote a focus on in situ community upgrading rather than on the disruptive, often tumultuous, relocation schemes that have characterised informal settlement intervention efforts thus far in Fiji. 
An important question remaining to be addressed in the current research is 'What is adequate security of tenure in Fijian informal settlements?' In the volume 'Land, Rights \& Innovation: Improving Tenure Security for the Urban Poor' Sims specifies five criteria for addressing this question in any urban context. Namely, the extent to which a tenure situation: (i) protects against arbitrary eviction; (ii) allows for provision of infrastructure and public services; (iii) permits market values to apply to property; (iv) allows residents to leverage equity for credit; and ( $v$ ) encourages investment and house improvement (2002, p. 79). Within a Fijian informal settlement context these criteria need some adjustment. Certainly, most crucially, security of tenure requires protection from eviction. Categories three and four in Sim's typology, however, are not relevant for a Fiji informal settlement context. Firstly, full market values will not apply to dwellings in informal settlements. Secondly, informal settlers in Fiji cannot use housing capital as equity in accessing credit (fieldwork suggests however that informal settlers in Fiji can often already access informal credit and indeed formal sector finance (the latter if income is sufficient)). Thus, to summarise, adequate security of tenure in Fijian informal settlements: (i) protects against eviction; (ii) encourages (as distinct from 'allows') the provision of infrastructure and public services; and (iii) encourages housing investment.

Given a positive relationship between perceived security of tenure and housing consolidation, any initiatives aimed at improving perceived security of tenure in Fijian informal settlements should encourage residents to invest in improving dwellings and communities. Upon recognition of the continuing global housing crisis, recent international literature and shelter policy has refocused attention on self-help housing and specifically the mechanisms via which it can be supported. Thus 'aided self-help housing' or 'assisted self-help housing' suggest "pro-poor housing policies ... that both promote and support self-build initiatives institutionally, financially, technically and politically" (Bredenoord \& van Lindert, 2010b, p. 286). Aided self-help approaches suggest a wide range of policy options that could be employed in Fiji to promote housing investment. Amid a comprehensive habitat approach these options could include the promotion and facilitation of: (i) communal savings groups; (ii) housing microfinance schemes; (iii) building advisory bureaus; (iv) self-help technical assistance; (v) affordable housing products; and (vi) varied housing packages (for example, differentiated by plot and dwelling size and thus costs) that better reflect the diversity of target groups (Bredenoord \& van Lindert, 2010a \& 2010b). 
While the promotion of self-help housing holds some benefit within Fijian shelter policy, it should not be seen as a panacea that can improve conditions for all current informal settlers. As will be discussed further below, tenure policy and enabling self-help housing need to be part of a more comprehensive, city-wide and integrated, shelter strategy aimed also at increasing the supply and affordability of alternative housing options, increasing service provision, and increasing access to livelihoods opportunities (DurandLasserve \& Royston, 2002; Payne, 2002a). The current research also emphasises that: (i) despite the level of housing consolidation occurring across the sample, much informal housing in Fiji still falls short of acceptable standards of quality; (ii) housing consolidation is also likely to be facilitated by increased incomes (thus enhanced by overall economic growth and improving economic opportunities for settlers); and (iii) promoting extensive self-help housing investment may not be advisable in informal settlements located in areas of high natural hazard risk.

Leading global shelter policy emanating from UN-Habitat discourages responses (such as resettlement) that involve eviction and relocation of informal settlers. Rather in situ upgrading, through a variety of incremental, flexible, context-specific means is favoured (UN-Habitat, 2007). Given that this research has reinforced that Fijian informal settlements continue to prioritise central locations close to work opportunities and most urban services and amenities, and the fact that resettlement schemes in Fiji continue to prove unpopular, certainly the Fiji government should end the current focus on relocation as the prime intervention response targeted at informal settlers. Rather, in situ upgrading projects (such as that piloted at Lagilagi), perhaps in partnership with donor and international organisations and/or civil society, should be prioritised. Such initiatives, beginning in communities on state land, if designed well and in partnership with recipient communities, will not be as disruptive as relocation programmes and would increase tenure security for existing informal settlers.

The potential policy responses discussed above apply particularly to informal settlements on state land. Intervention targeted at informal settlements on native land, in contrast, pose a distinct set of significant challenges, particularly as much new growth of informal settlements is concentrated in these areas. As Chapter 6 discussed, given the peri-urban location of many native land informal settlements, local councils have little incentive to intervene in these areas that are typically located outside of their boundaries. Local government also has very little incentive to increase the size of municipal boundaries (which would increase servicing obligations to a reluctantly-paying rate base). Central 
government agencies are also unlikely to intervene in settlements on native land; limiting intervention to more central, state land informal settlements. Suggestions have recently been made that informal settlements on native land could be formalised (Barr, 2009a, p. 7; National Council for Building a Better Fiji, 2008b, p. 24) although details on how this would occur in practice are lacking. In addition, as Chapter 6 noted, formalisation would be hindered by the fact that many informal settlements on native land are located on areas of native reserve land that cannot easily be formally leased. In addition, and perhaps most significantly, landowners can obtain greater rents and control over their own land with existing vakavanua arrangements than if the land was leased through NLTB. Essentially, there are very few incentives for change. Overall, security of tenure for informal settlers on native land continues to rest on the whims of landowners. This suggests that awareness raising - particularly focused on highlighting the situation of informal settlers, the lack of alternative housing options available, the positive contribution that settlers make, and rebutting common negative stereotypes holds some benefit. Such awareness raising could be targeted at particular groups including directly at landowners.

As is recognised by the New Zealand Aid Programme (NZAP), perhaps the most appropriate level of engagement, particularly targeting the burgeoning peri-urban native land settlements, is with local government. Compared to many other Pacific nations, the capacity of local government in Fiji is relatively high (although recent changes by the interim administration have reduced the autonomy of local government). There thus may be scope for international and donor organisations to initiate strategic partnerships with councils aimed particularly at encouraging the expansion of servicing into informal settlements.

While the expanding informal settlements of native land pose some of the greatest challenges to intervention in Fiji, it must be recognised that they also perform an important function in enabling many informal settlers to live centrally. Indeed, as the examples of Vunato and Tomuka revealed, vakavanua arrangements can allow relatively secure long-term residence in communities (providing ongoing payments are made and perhaps particularly true for indigenous Fijian settlers who can utilise traditional practices such as sevusevu to improve relationships with landowners). Ultimately, vakavanua arrangements in Fiji are a flexible adaption to current realities - in the case of Tomuka even presenting de facto rights of land transfer (although a percentage of houseblock sale price must be paid to the landowner). Overall, informal 
settlements on native land present the opportunity for new residents to live in, or near to, urban areas at relatively affordable rates. Vakavanua arrangements, however, do also present potential scope for conflict. As Chapter 2 noted, informal customary tenures can deteriorate in times of crisis (such as leadership transfers and disputes), in cases of multiple sales of one plot, and when customary systems clash with formal systems of land use and institutions. This potential conflict must be recognised within policy and intervention efforts; and an active strategy put in place to manage its occurrence.

Interviews revealed that considerable confusion often prevailed for informal settlers around the exact legal tenure status of the land that they resided on. In addition, for communities such as Lakena Hill Two and Tauvegavega, ongoing disputes between different mataqali groups or between the state and native landowners further complicated the picture and added to the sense of insecurity that some informal settlers in these areas faced. Interviews also revealed many examples where settlers had paid individuals and groups claiming ownership of certain areas (when the community was actually held in state tenure) funds to facilitate access and utility connection. This suggests that what is needed in Fiji is enhanced transparency and accessibility of land tenure information; so that settlers can easily obtain information on the exact legal status of the area that they live in or are planning to move to. This will reduce the possibility of exploitation of informal settlers by unscrupulous individuals and possibly increase perceived security of tenure; and is perhaps the most empowering knowledge that concerned informal settlers could have.

Chapter 6 revealed the significant challenges in ameliorating Fiji's emerging housing crisis. Perhaps the most significant of these challenges are the scale of continued informal settlement growth and affordability and availability constraints that reduce access to alternative housing options for low-income residents. International literature also reminds policymakers that initiatives to increase tenure security should not occur in isolation. Payne (2005), for example, recommends a 'twin-track approach' aimed at: (i) improving living conditions for current informal settlers through incremental, innovative approaches to increase perceived security of tenure; and (ii) reducing the need for future informal settlement growth through revising regulatory frameworks and improving access to legal land and shelter. Certainly in Fiji consideration must be given to policies that improve access to alternative housing choices - particularly to increasing supply and affordability of Housing Authority plots and dwellings and Public Rental Board units. Consideration should be given, for example, to the often-recommended (but resisted) 
approach of reducing building and development standards that continue to constrain affordability. Ensuring that low-income groups participate in housing planning decisions will also ensure that their particular needs - especially the priority to live centrally - are at the forefront of policy decisions. Consideration should also be given to promoting the role of (affordable) rental accommodation; often a typically neglected, but essential, tenure option (Gilbert, 2008).

As earlier sections of this thesis have discussed, shelter policy in Fiji, characteristic of other Pacific nations, is piecemeal and uncoordinated. Guiding strategic master plans have been prepared (but are not yet actively in place) and a plethora of organisations are involved in managing urban growth. Overall, as the NZAP informal settlement scoping study summarised in 2007, there are urgent needs for integrated urban policy, a suitable regulatory environment, and appropriate institutional responses for managing urban growth (McKinnon, Whitehead, Chung \& Taylor, 2007). In contrast to the current situation, strategic planning must be located within one well-resourced government agency. Information and previous research on informal settlements and the shelter sector generally - reflecting the uncoordinated approach thus far - is also scattered in Fiji. Centralising these resources would aid future shelter sector research and policymaking. Finally, coordinating shelter sector engagement by international and donor organisations - perhaps within a harmonised strategy and through civil society partnerships - would support a more coordinated approach from all actors.

The challenges within the shelter sector in Fiji are vast. A complex land tenure environment - where informal settlement is situated on state, native and freehold land also complicates intervention options. In Fiji shelter issues, priorities and needs are most acute in urban areas. It is important, however, that coordinated policy responses do not exclude the needs of rural areas. Continued extensive urban/rural links, and higher density land-use in peri-urban areas, or at the urban/rural interface, also remind policymakers that urban and rural issues are often entwined. Improving security of tenure for rural leasing farmers (perhaps by lengthening Agricultural Landlord and Tenant Act terms or introducing automatic rights of lease renewal), as just one example, will increase the viability and attractiveness of farming and will likely reduce some urbanisation pressure. Ultimately, however, urbanisation is inevitable (UNFPA, 2007). Fortunately, if urbanisation is managed well, slum formation is not inevitable (UN-Habitat, 2006, p. xii). Certainly, increased awareness of the benefits of urbanisation and political will to improve conditions and security of tenure for informal settlers are needed in Fiji. 
An end to ongoing evictions is also of crucial importance. Sadly, as is clear from the recent, escalating threats towards informal settlers on state land, these crucial needs are currently lacking in Fiji.

\subsection{Summary}

Informal settlements in Fiji are diverse and often unique - making broad generalisations of the nature of settlements problematic. This research has shown that there are also important distinctions between settlements on state land and native land. Overall, the primary category of land tenure is the key variable that influences the nature of informal settlements and, particularly, access arrangements to communities.

Given that no informal settlers in Fiji enjoy legal security of tenure, it is perhaps surprising that the research results showed considerable evidence of positive perceived security of tenure and housing consolidation across the sample. It is also clear that investigation of perceived security of tenure and housing consolidation in Fijian informal settlements needs to separate analysis by the crucial variables of ethnicity and primary land tenure. The research suggests, for example, that the variables that affect perceived security of tenure are particularly distinguished by the primary category of land tenure. Perceived security of tenure in informal settlements on native land accessed via vakavanua arrangements, for example, hinges particularly on the nature of the settlers' relationship with the landowner. In contrast, in state land areas, perceived security of tenure is influenced by a wider range of crucial variables including length of residence; the presence of infrastructure, utilities, and services; ongoing and potential project interventions; community organisation, advocacy and external support; and the fact that evictions and eviction pressure continue from and in other state land informal settlements across Fiji. Overall, a continuum of tenure security is evident within Fijian informal settlements, ranging between the extremes of those renting (the lowest tenure security) and indigenous Fijian occupying owners with traditional vakavanua arrangements on native land (the highest tenure security).

It has been difficult to make strong assertions about the nature of the relationship between perceived security of tenure and housing consolidation. Overall, the relationship appears complex, affected by a number of additional variables that could not be isolated within the study's methodology. Further research could carefully isolate these variables where possible, income and natural hazard risk being perhaps the most 
important, within a more structured approach that could use indices of perceived security of tenure and housing consolidation.

Potential policy responses that could be employed in Fiji to address the emerging housing crisis are again distinguishable by the primary category of land tenure. For informal settlements on state land, consensus needs to build that in situ upgrading (rather than relocation) is the best route forward. For informal settlements on native land, however, the challenges are different and significant because the current incentive structure for vakavanua arrangements remains. More research is needed to help suggest options for intervening in native land areas. This research, however, needs to be guided by the important recognitions that such areas perform an important function in enabling many low-income groups to live centrally and are a flexible adaption to a land tenure system that restricts legal access to land for many groups within Fijian society. Overall, awareness building around the positive contribution that informal settlers make is important. This can help rebut some of the negative stereotyping attached to these large groups of Fijian society. As was mentioned earlier, it is also important to begin to replace the common terms 'squatter settlement' and 'squatter settler' with the more technically correct, and less derogatory, terms of 'informal settlement' and 'informal settler'. Finally, a moratorium on evictions from state land areas should be announced. International literature and shelter policy clearly suggests that this, solely, is the most effective means of increasing perceived security of tenure for current informal settlers living on state land. 


\section{CHAPTER 12: CONCLUSION}

This thesis aimed to investigate the nature of perceived security of tenure and housing consolidation in Fijian informal settlements. Four primary research objectives aided this investigation and explored: (i) the extent of perceived security of tenure; (ii) key variables that influence perceived security of tenure; (iii) the extent of housing consolidation; and (iv) the possible relationship between perceived security of tenure and housing consolidation in Fijian informal settlements. Addressing gaps in the literature, the thesis also had a number of secondary objectives including: (i) to document the recent growth of informal settlements in Fiji (detailed in Chapter 5); (ii) to review past, current and planned intervention activities within the informal settlement/low-income housing sector (covered in Chapter 6); and (iii) to explore the full variety of access arrangements that are used to gain access to informal settlements including vakavanua arrangements used to access native land areas (introduced in Chapter 8 and covered in detail in Chapter 9). The research also had an overarching practical orientation aiming to inform a more nuanced understanding of informal settlements in Fiji and to suggest potential policy options for intervening in the tide of escalating housing informality. The research was positioned within a broader theoretical context. Firstly, the research engaged with an international debate around whether property rights approaches (largely extolling the benefits of legalisation and formalisation) or perceived security of tenure approaches are the best means of addressing escalating housing informality. In addition, the research was situated within a regional debate about whether customary tenure is an appropriate and viable basis for development in the Pacific.

The first key primary research objective was addressed in Chapter 10. After careful questioning around many aspects of both 'security' and 'security of tenure' it was possible to make an analysis of a participant household's perceived security of tenure, categorising perceived security of tenure as positive, negative, not secure or insecure, or uncertain. Overall, across the whole sample, these results showed that: $43.5 \%$ of respondents showed evidence of positive perceived security of tenure; $16.5 \%$ revealed evidence of negative perceived security of tenure; $24.5 \%$ were not secure or insecure; and $15.5 \%$ were uncertain. Important differences in perceived security of tenure were also evident between the case studies with positive perceived security of tenure greater than the whole sample average at Bouma, Caubati Topline, Lakena Hill Two and 
Vunato, while negative perceived security of tenure was pronounced at Tomuka and Tauvegavega. Primary category of land tenure and ethnicity were also important variables influencing perceived security of tenure. Results indicated, for example, that positive perceived security of tenure was higher in state land areas and, correspondingly, negative perceived security of tenure was pronounced in native land areas. Higher proportions of Indo-Fijian participants, particularly in native land areas, also showed evidence of negative perceived security of tenure when compared to indigenous Fijian respondents. Overall, the research methodology that was employed allows some confidence in these results. Although, as has been discussed, difficulties in conveying the meaning of 'security of tenure' and the fact that some participants continued to discuss personal security rather than tenure security contributed to the $15.5 \%$ of cases where perceived security of tenure was ultimately assessed as uncertain.

The second key research objective, exploring the variables influencing perceived security of tenure, was primarily discussed in the preceding Chapter 11. Important differences between settlements on state and native land were revealed. Perceived security of tenure in informal settlements on native land accessed via vakavanua arrangements, for example, essentially hinged on the nature of the settlers' relationships with the landowner. Ethnicity was an important variable here. Indigenous Fijians, for example, could improve and personalise their relationship with the landowner by making a traditional sevusevu presentation, meeting ongoing customary obligations, and meeting any ongoing regular payments due; effectively acting to increase their perceived security of tenure. Indo-Fijians, on the other hand, with vakavanua arrangements with landowners, essentially negotiated and remained within a landlord/tenant relationship; and tenure security effectively hinged on meeting ongoing payments due and avoiding community disturbances (although most residents were aware that they could still be made to leave at any time). Perceived security of tenure in state land areas, in contrast, was influenced by a broader range of key variables including: length of residence; the presence of infrastructure, utilities, and services; ongoing and potential project interventions; community organisation, advocacy and external support; and the fact that evictions and eviction pressure continue from and in other state land informal settlements across Fiji. Overall, the research methodology employed facilitated open and rich qualitative discussions around perceived security of tenure; so some confidence can be held in these results. The Fijian research setting also revealed and emphasised that primary category of land tenure is a crucial lens of analysis in diverse tenure environments. International literature (thus far not investigating 
perceived security of tenure in small-island, customary-land contexts and tending to focus on single type of tenure case study approaches) had not made this important distinction clear.

Results addressing the third key objective exploring the extent of housing consolidation in Fijian informal settlements were presented in Chapter 10 and discussed in Chapter 11. Census results, particularly the surprising number of informal settlement dwellings nationally and in Caubati Topline, Tomuka, Lakena Hill Two and Tauvegavega with walls constructed primarily of concrete, suggested that housing consolidation was occurring. Fieldwork results subsequently showed that $55.5 \%$ of all participant households were engaged in housing consolidation (which was defined as household improvements or extensions in the five years preceding interviews). Differences between the case studies were also revealed; with housing consolidation most evident at Tauvegavega and Lagilagi and least evident at Tomuka, Vunato and Bouma. The primary category of land tenure and ethnicity were again important variables through which to frame investigation of housing consolidation. Slightly higher proportions of Indo-Fijian households (58.5\%) across the whole sample, for example, showed evidence of housing consolidation than indigenous Fijian households (52\%). Housing consolidation, additionally, for all ethnic groups, was greater in state land areas (60\%) than native land areas (50\%); a trend that was also reflected when analysing single ethnic groups. Overall, some confidence can be held around the housing consolidation results. Although, as has been previously discussed, the narrow definition of housing consolidation employed could not capture those households who had engaged in significant household investment prior to 2003. Further, more comprehensive investigation of housing consolidation within Fijian informal settlements could also employ carefully structured indices of housing consolidation. Such indices (perhaps of overall quality, dwelling size, number of dwelling rooms, bathroom/toilet quality, etc) would promote a more nuanced understanding of housing consolidation dynamics and priorities. Using indices would also enable researchers to explore the overall quality of individual dwellings and whole settlement housing stock that housing consolidation processes were contributing to; an important investigation given that the current study suggested that housing consolidation was occurring in Fijian informal settlements but to a level that fell short of creating neighbourhoods that meet acceptable levels of housing quality. 
The fourth key research objective, beginning to explore the relationship between perceived security of tenure and housing consolidation, was discussed in the previous chapter. The research methodology employed, however, did not allow strong assertions about this relationship to be made for the Fiji context (although international literature clearly links increases in legal and perceived tenure security to housing consolidation processes in many other contexts). Saliently, it was not possible within the research methodology to isolate the effect of other variables on housing consolidation. Results suggested, for example, that income levels and natural hazard risk, particularly, may influence housing consolidation within Fijian informal settlements. Further research investigating the clearly subtle and complex relationship between perceived security of tenure and housing consolidation (which, as was discussed, may also be two-way) should thus isolate such other variables.

This research was among the first to apply a perceived security of tenure framework of analysis to a small island, customary land context. The research was also certainly among the first in the Pacific region to investigate informal settlement dynamics, and suggest policy options, through a particular focus on perceived security of tenure and housing consolidation. Within Fiji, the study also looked to extend the typical scope of informal settlement research beyond case studies in greater Suva to the Western Division and Northern Division. It was hoped that this regional spread, and the inclusion of case studies on both state and native land, would better reflect the true diversity of informal settlements in Fiji.

The research has revealed the extent of perceived security of tenure and housing consolidation across Fijian informal settlements. The research has helped to reveal the crucial influence of the land tenure variable in the Fiji context - particularly in access arrangements to informal settlements, perceived security of tenure, and housing consolidation. The research has also reinforced the importance of the ethnicity variable in the Fijian context, for there were key differences in both perceived security of tenure and housing consolidation for indigenous Fijian and Indo-Fijian participants. As Chapter 4 discussed, Fiji remains a divided society. Any social science research - perhaps particularly that investigating land tenure, land issues generally, and broad, complex and often loaded concepts like 'security' and 'security of tenure' - needs to understand these significant cleavages in society. Overall, the diversity of informal settlements in Fiji, and particularly the effect of key variables like land tenure and ethnicity, suggests that nuanced understandings of informal settlement dynamics are needed in any context. 
It has been mentioned throughout this thesis that much recent informal settlement growth in Fiji is concentrated within communities on native land. While these areas do present great challenges for intervention, they also perform an important function; essentially enabling many low-income households to live affordably in relatively central areas close to most employment opportunities and urban amenities. It is also clear, for indigenous Fijian settlers particularly, that vakavanua access arrangements and meeting ongoing customary obligations, do often permit households to reside in these areas for as long as they may want; or effectively with sufficient tenure security. Overall, informal settlements on native land are not part of the problem but part of the solution. Customary land in the Pacific has long been a source of resilience. The flexibility of customary tenure has also meant that land use has been able to adapt to contemporary demands. Vakavanua settlement in Fiji is simply another example of such continuing adaption. Certainly, in Fiji and in other Pacific nations, privatising tenure to individual titles is not the solution to suitably housing all urban residents with security of tenure, for this will likely push more and more low-income urban residents and potential migrants further to the margins. At the same time, however, strong forces in Fiji and the wider region - particularly continued population growth, urbanisation, enhanced mobility, technological innovation, and expanding horizons - are challenging the ability of customary tenure to adapt effectively to changing demands. Encouraging and enabling continued adaption, perhaps through cautious and considered reform, may thus be necessary.

The work of geographers on land tenure in the Pacific region has tended to focus on rural areas and agricultural productivity. Very little geographic research has focused on issues of urban tenure and security in the region. More specifically, it is clear that human geography has not engaged extensively with perceived security of tenure theory despite security of tenure being inherently geographical and grounded in relationships between people, livelihoods, and land. Overall, this research has extended knowledge about the nuances of perceived security of tenure and housing consolidation in Fiji specifically and the Pacific and contexts of customary land/complex land tenure environments more generally. It is hoped that the research has succeeded in aiding geographers' understanding of the dynamics and influence of perceived security of tenure in contexts of informal housing. More broadly, enhanced understandings of urban tenure and security will also inform the ongoing work of geographers in the Pacific interested in land tenure. The research has shown, for example, that perceived security 
of tenure is important in influencing the decisions informal settlers make. In addition, understanding forms of informal tenure such as vakavanua arrangements - that in some cases present adequate security - inform enhanced insights into the flexibility of customary tenure in the Pacific - and indeed could be extended outside of the urban and housing spheres as potential durable tenure models.

Upwards of around 140,000 people are now living in all types of informal settlements in Fiji; a number only likely to increase. If managed well, the resilience and adaptability of native land is likely to be part of the solution. For the proportion of informal settlers living in state land areas, however, the scenario is different. Indeed many thousands of settlers in often very central state land areas are living with ongoing, and recently escalating, threat of eviction. A broad package of options are available to policymakers intervening amid increasing housing informality; including the quite contrasting approaches of relocation and in situ upgrading. Certainly, within a coordinated, holistic, pro-poor shelter strategy, upgrading and, essentially, an end to most evictions should be prioritised in Fiji; for ultimately this is the most powerful means of increasing perceived security of tenure for current settlers and promoting processes such as housing consolidation.

Urbanisation - effectively the largest migration in human history - is transforming the social fabric of the globe. Human future, including in Fiji and the Pacific, is predominantly an urban future. The inevitability of urbanisation as a positive force, vital to ongoing national and global development, must be embraced. Of course, the likelihood of continued housing informality and escalating tenure insecurity is a great challenge. Fortunately, however, if urbanisation is managed well, continued slum growth is not inevitable. Policy that understands and reflects the diversity of informal settlement dynamics (including the nuances of perceived security of tenure) and the needs and aspirations of informal settlers will aid positive urbanisation experience. 


\section{REFERENCES}

Abbott, D. F. (2006). Fiji: Analysis of the 2002/03 Household Income and Expenditure Surveys - Estimation of basic needs poverty lines and incidence of poverty in Fiji. Suva: United Nations Development Programme, Pacific Sub Regional Centre.

Abbott, D.F. (2009). An estimation of the possible impact of GEFC and general economic slowdown on poverty incidence in Fiji. Unpublished mimeo.

Abrams, C. (1966). Squatter settlements: The problem and the opportunity. Washington D.C.: Division of International Affairs, Department of Housing and Urban Development.

Allen, M. (2008). Land reform in Melanesia. State, Society and Governance in Melanesia Briefing Note Number 6. Retrieved from http://rspas.anu.edu.au/melanesia/BriefingNotes/BriefingNote_LandReformlnMelanesia. pdf

Amis, P. (1984). Squatters or tenants: The commercialization of unauthorized housing in Nairobi. World Development, 12(1), 87-96.

Amis, P. (1995). Making sense of urban poverty. Environment \& Urbanization, 7(1), 145157.

Amis, P., \& Rakodi, C. (1994). Urban poverty: Issues for research and poverty. Journal of International Development, 6(5), 627-634.

Angel, S. (1983). Land tenure for the urban poor. In S. Angel, R. W. Archer, S. Tanphiphat \& E. A. Wegelin (Eds.), Land for housing the poor (pp. 110-142). Singapore: Select Books.

Angel, S., Archer, R.W., Tanphiphat, S. \& Wegelin, E. A. (1983a). Introduction and summary. In S. Angel, R. W. Archer, S. Tanphiphat \& E. A. Wegelin (Eds.), Land for housing the poor (pp. 2-31). Singapore: Select Books. 
Angel, S., Archer, R.W., Tanphiphat, S. \& Wegelin, E. A. (1983b). Conclusions and recommendations. In S. Angel, R. W. Archer, S. Tanphiphat \& E. A. Wegelin (Eds.), Land for housing the poor (pp. 528-556). Singapore: Select Books.

Asian Coalition for Housing Rights. (2009). Yearly report. Retrieved from http://www.achr.net/ACCA/ACCA\%20Downloads/AACA\%20Country\%20Downloads\%20 Year\%201/Fiji\%20First\%20Year\%20Report\%20Dec\%202009\%20PART\%203.pdf

Asian Development Bank (ADB). (1999). Project performance audit report on the LowIncome Housing Development Project in the Republic of the Fiji Islands. Manila: Asian Development Bank.

Asian Development Bank. (2003). Republic of the Fiji Islands: Alternative Livelihoods Project - Technical assistance consultant's report. Manila: Asian Development Bank.

Asian Development Bank. (2009). Fiji Islands: Alternative Livelihoods Development Project - ADB completion report. Manila: Asian Development Bank. Retrieved from http://www.adb.org/Documents/PCRs/FIJ/32541-FIJ-PCR.pdf

Asian Development Bank. (2010). Asian Development Outlook 2010: Macroeconomic management beyond the crisis. Manila: Asian Development Bank. Retrieved from http://www.adb.org/Documents/Books/ADO/2010/ado2010.pdf

Australian Agency for International Development (AusAID). (2006). Pacific 2020:

Challenges and opportunities for growth. Canberra: Australian Agency for International Development. Retrieved from http://www.ausaid.gov.au/publications/pdf/pacific2020.pdf

Australian Agency for International Development. (2008). Making land work: Volume 1 Reconciling customary land and development in the Pacific. Canberra: Australian Agency for International Development.

Australian Agency for International Development. (2010). Social protection in the Pacific - A review of its adequacy and role in addressing poverty. Canberra: Australian Agency for International Development. Retrieved from http://vanuatu2010.un.org.fj/resources/uploads/attachments/documents/Social\%20Prot 
ection\%20in\%20the\%20Pacific\%20\%E2\%80\%93\%20A\%20Review\%20of\%20its\%20Adequacy \%20and\%20Role\%20in\%20Addressing\%20Poverty\%20\%282\%29.pdf

Authority outlines plans for 10,000 new homes. (2009, September 9). Fiji Sun. Retrieved from http://www.fijisun.com.fj

Ball rolls on squatter project. (2010, March 4). Fiji Times. Retrieved from http://www.fijitimes.com

Bamberger, M. (1982). The role of self-help housing in low-cost shelter programmes for the Third World. Built Environment, 8(2), 95-107.

Barr, K. J. (2007). Squatters in Fiji: The need for attitudinal change (CCF Housing and Social Exclusion Policy Paper No. 1). Suva: Citizens' Constitutional Forum.

Barr, K. J. (2008). Memo: The way forward for squatter housing in Fiji: Submission to Interim Prime Minister Cdr Frank Bainimarama. Unpublished mimeo.

Barr, K. (2009a, July). Housing affordability. Paper presented at the Australian National University Fiji Update, University of the South Pacific, Suva.

Barr, K. (2009b, March 27). Land plan on offer. Fiji Times. Retrieved from http://www.fijitimes.com

Bassett, E. M. (2005). Tinkering with tenure: The community land trust experiment in Voi, Kenya. Habitat International, 29(3), 375-398.

Bassett, E. M. (2007). The persistence of the commons: Economic theory and community decision-making on land tenure in Voi, Kenya. African Studies Quarterly, 9(3). Retrieved from http://www.africa.ufl.edu/asq/v9/v9i3al.pdf

Bassett, K. \& Gregory, D. (2009). Realism. In D. Gregory, R. Johnston, G. Pratt, M. J. Watts, \& S. Whatmore, S. (Eds.), The dictionary of human geography (pp. 621-623). Chichester: Wiley-Blackwell. 
Bassett, E. M., \& Jacobs, H. M. (1997). Community-based tenure reform in urban Africa: The community land trust experiment in Voi, Kenya. Land Use Policy, 14 (3), 215-229.

Batibasaqa, K., Overton, J., \& Horsley, P. (1999). Vanua: Land, people and culture in Fiji. In J. Overton \& R. Scheyvens (Eds.), Strategies for sustainable development: Experiences from the Pacific (pp. 100-106). London: Zed Books.

Baxter, J., \& Eyles, J. (1997). Evaluating qualitative research in social geography:

Establishing 'rigour' in interview analysis. Transactions of the Institute of British Geographers, 22(4), 505-525.

Beall, J. (2000). Life in the cities. In T. Allen \& A. Thomas (Eds.), Poverty and development into the 21 st Century (pp. 425 - 442). Oxford: Oxford University Press.

Beall, J., \& Fox, S. (2007). Urban poverty and development in the 21 st Century: Towards an inclusive and sustainable world (Oxfam Research Report). Oxford: Oxfam. Retrieved from http://www.oxfam.org.uk/resources/policy/trade/downloads/research_urban_poverty.p df Bennett, J. A. (2002). Wartime emergency and the displacement of Indians in Fiji. The Journal of Pacific History, 37(2), 205-219.

Biau, D. (2007, March). Three things that we should know about slums. Habitat Debate, $13(1), 6$.

Boydell, S., \& Holzknecht, H. (2003). Land-caught in the conflict between custom and commercialism. Land Use Policy, 20(3), 203-207.

Boydell, S., \& Reddy, W. (2000, January). Contemporary land tenure issues in the Republic of Fiji. Paper presented at the 6th Pacific Rim Real Estate Society Conference, Sydney. Retrieved from www.prres.net/proceedings/proceedings2000/P7C 1.doc

Bredenoord, J., \& van Lindert, P. (2010a). Equal access to shelter: Coping with the urban crisis by supporting self-help housing. Habitat International, 34 (3), 274-277. 
Bredenoord, J., \& van Lindert, P. (2010b). Pro-poor housing policies: Rethinking the potential of assisted self-help housing. Habitat International, 34 (3), 278-287.

Brochu, M. (2004). Preliminary paper to assist participants at the National Consultation on Eviction, Squatter Settlements and Housing Rights Workshop. In National Consultation on Eviction, Squatter Settlements and Housing Rights Workshop: Saturday 28th September 2002 (pp. 74-89). Suva: Citizens' Constitutional Forum.

Bromley, D. W. (2008). Formalising property relations in the developing world: The wrong prescription for the wrong malady. Land Use Policy, 26(1), 20-27.

Bryant, J. J. (1979). Why self help housing is necessary - but difficult. Yagi-Ambu: Papua New Guinea Journal of the Social Sciences and Humanities, 6(3/4), 25-34.

Bryant, J. J. (1990). The acceptable face of self-help housing: Subletting in Fiji squatter settlements - exploitation or survival strategy? In D. Drakakis-Smith (Ed.), Economic growth and urbanization in developing areas (pp. 171-195) London: Routledge.

Bryant, J. J. (1992). Poverty in Fiji: Who are the urban poor? Singapore Journal of Tropical Geography 13(2), 90-102.

Bryant, J. J. (1993). Urban poverty and the environment in the South Pacific. Armidale, New South Wales: Department of Geography and Planning, University of New England.

Bryant-Tokalau, J. J. (1995). The myth exploded: Urban poverty in the Pacific. Environment and Urbanization, 7(2), 109-129.

Bryman, A. (2004). Social research methods. Oxford: Oxford University Press.

Calderon, J. (2004). The formalization of property in Peru 2001-2002: The case of Lima. Habitat International, 28(2), 289-300.

Callinan, R. (2007, April 9). Wrong side of paradise. Time, 26-31. 
Caucau, A. (2006). Resumption of debate on the 2007 Appropriation Bill, 2006. Retrieved from

http://www.parliament.gov.fj/hansard/viewhansard.aspx?hansardID=563\&viewtype=full

Chand, Satish. (2004). Sweet land or sweat land: Two proposals for facilitating access to land and adjustment to eroding sugar preferences in Fiji (Australian National University Crawford School of Economics and Government Working Papers: International and Development Economics). Canberra: Australian National University. Retrieved from http://www.crawford.anu.edu.au/degrees/idec/working_papers/IDEC04-6.pdf

Chand, Satish. (2005). Preference erosion: The case of Fiji sugar. In S. Chand (Ed.), Pacific Islands regional integration and governance (pp. 195-213). Canberra: Asia Pacific Press.

Chand, Satish. (2007a, March). Squatters: A ticking time bomb? Island Business, 32-33.

Chand, Satish. (2007b). Swim or sink: The predicament of the Fiji economy. Pacific Economic Bulletin, 22(2), 1-21.

Chand, Satish. (2007c, December). A year on after the last coup. Islands Business, p3132.

Chand, Satish. (2007d). 50/50 by 2020: Poverty and redistributive politics in postindependence Fiji. Pacific Economic Bulletin, 22 (2), 22-35.

Chand, Shalveen (2010, May 25). Judge stops eviction. Fiji Times. Retrieved from http://www.fijitimes.com

Chand, Satish \& Yala, C. (2007). Improving access to land within settlements of Port Moresby (Australian National University Crawford School of Economics and Government Working Papers: International and Development Economics). Canberra: Australian National University. Retrieved from http://www.crawford.anu.edu.au/degrees/idec/working_papers/IDEC07-04.pdf

Chand, Satish, \& Yala, C. (2008). Informal land systems within urban settlements in Honiara and Port Moresby. In Making Land Work: Volume 2 - Case studies on customary 
land and development in the Pacific (pp. 85-105). Canberra: Australian Agency for International Development.

Chandra, R. (1996). Urbanisation in Fiji, 1976-1986: A preliminary analysis. Journal of Pacific Studies, 19, 23-45.

Chang, K. (2008). After the storm of 2000: Fiji's troubled path toward justice and reconciliation. Sydney: Centre for Peace and Conflict Studies, University of Sydney.

Chapman, M. (1991). Pacific island movement and socioeconomic change: Metaphors of misunderstanding. Population and Development Review, 17(2), 263-292.

Chief warns SCC on land. (2008, December 12). Fiji Sun. Retrieved from http://www.fijisun.com.fj

Choguill, C. L. (1995). The future of planned urban development in the Third World: New direction. In B. C. Aldrich \& R. S. Sandhu (Eds.), Housing the urban poor: Policy and practice in developing Countries (pp. 403-413). London: Zed Books.

Chung, M., \& ECREA (2007). Fiji poverty report 2006: No fit state, housing the urban poor in Fiji. Unpublished report.

Chung, M., \& Hill, D. (2002). Urban informal settlements in Vanuatu: Challenge for sustainable development. Suva: Pacific Islands Forum Secretariat/United Nations Economic and Social Commission for Asia and the Pacific, Pacific Operation Centre. Retrieved from http://www.forumsec.org.fj/resources/uploads/attachments/documents/Vanuatu\%20Sq vatter\%20Settlement\%20Study\%202002.pdf

Church faces lawsuit. (2009, April 8). Fiji Sun. Retrieved from http://www.fijisun.com.fj

City plans extra housing lots. (2009, October 31). Fiji Times. Retrieved from http://www.fijitimes.com

City raises alarm over squatters. (2009, September 7). Fiji Times. Retrieved from http://www.fijitimes.com 
City to relocate squatters. (2010, June 18). Fiji Times. Retrieved from http://www.fijitimes.com

Clery, T. (2006). Place, cultural identity and the consequences of change for the Korova 'squatter' settlement, Suva. In R. Robertson (Ed.), Livelihoods \& identity in Fiji (pp. 57-84). Suva: Development Studies Program, Pacific Institute for Advanced Studies in Development \& Governance, University of the South Pacific.

Connell, J. (2003a). Migration in Pacific island countries and territories. In Asian Population Studies Series No. 160: Migration patterns and policies in the Asian and Pacific Region (pp. 35-65). New York: United Nations Economic and Social Commission for Asia and the Pacific. Retrieved from http://www.unescap.org/esid/psis/population/popseries/apss160/apss160chap2.pdf

Connell, J. (2003b). Regulation of space in the contemporary postcolonial Pacific city: Port Moresby and Suva. Asia Pacific Viewpoint, 44 (3), 243-257.

Connell, J. (2006). Migration, dependency and inequality in the Pacific: Old wine in bigger bottles. In S. Firth (Ed.), Globalisation and governance in the Pacific Islands. (pp. 59-80 \& 81-106). Canberra: The Australian National University E Press. Retrieved from: http://epress.anu.edu.au/ssgm/global_gov/pdf/ch04.pdf \& http://epress.anu.edu.au/ssgm/global_gov/pdf/ch05.pdf

Connell, J., \& Lea, J. (1994). Cities of parts, cities apart? Changing places in modern Melanesia. The Contemporary Pacific, 6(2), 267-309.

Connell, J., \& Lea, J. P. (1999). Urban dilemmas. In M. Rapaport (Ed.), The Pacific Islands: Environment \& society (pp. 326-335). Honolulu: The Bess Press, Inc.

Connell, J., \& Lea, J. P. (2002). Urbanisation in the island Pacific: Towards sustainable development. London: Routledge.

Court rejects Authority's application to remove squatter settlers. (2010, May 25). Fiji Sun. Retrieved from http://www.fijisun.com.fj 
Crocombe, R. (1995). Overview. In R. Crocombe (Ed.), Customary land tenure and sustainable development: Complementarity or conflict? (pp. 5-21). Noumea/Suva: South Pacific Commission/Institute of Pacific Studies, University of the South Pacific.

Davis, M. (2006). Planet of slums. London: Verso.

Debus, M. (1995). Methodological review: A handbook for excellence in focus group research. Washington D.C: Academy for Educational Development.

Delaivoni, C. (2008, November 2). Squatters face bleak future. Island Life (Fiji Times lift out), pp. 3.

de Soto, H. (2000). The mystery of capital: Why capitalism triumphs in the West and fails everywhere else. New York: Basic Books.

de Souza, F. A. M. (1999). Land tenure security and housing improvements in Recife, Brazil. Habitat International, 23(1), 19-33.

de Souza, F. A. M. (2001). Perceived security of land tenure in Recife, Brazil. Habitat International, 25(2), 175-190.

Doebele, W. A. (1983). The provision of land for the urban poor: Concepts, instruments and prospects. In S. Angel, R. W. Archer, S. Tanphiphat \& E. A. Wegelin (Eds.), Land for housing the poor (pp. 348-374). Singapore: Select Books.

Doebele, W. A. (1994). Urban land and macro-economic development. In G. Jones \& P. M. Ward (Eds.), Methodology for land and housing market analysis (pp. 44-54). Cambridge, MA: Lincoln Institute of Land Policy.

Donnelly, T. A., Quanchi, M., \& Kerr, G. J. A. (1994). A history and geography of Fiji: Fiji in the Pacific (4th ed.). Milton, Queensland: John Wiley \& Sons Australia, Ltd.

Durand-Lasserve, A. (2006). Informal settlements and the Millennium Development Goals: Global policy debates on property ownership and security of tenure. Global Urban Development Magazine, 2, 1-15. Retrieved from http://www.globalurban.org/GUDMag06Vol2Iss 1/Durand-Lasserve.htm 
Durand-Lasserve, A., \& Royston, L. (2002). International trends and country contexts from tenure regularization to tenure security. In A. Durand-Lasserve \& L. Royston (Eds.), Holding their ground: Secure land tenure for the urban poor in developing countries (pp. 1-34). London: Earthscan.

Eaton, C. (1988). Vakavanua land tenure and tobacco farming. In J. Overton (Ed.), Rural Fiji (pp. 19-30). Suva: Institute of Pacific Studies, University of the South Pacific.

The Economist. (2006, August 26). The mystery of capital deepens: Giving land titles to the poor is no silver bullet, 62.

Elbourne, F. (2008, June 19). No joy for evicted squatter. Fiji Times, pp. 1.

Elbourne, F. (2011, January 9). Housing bungle. Fiji Times. Retrieved from http://www.fijitimes.com

Facelift for Jittu. (2010, June 24). Fiji Times. Retrieved from http://www.fijitimes.com

Families have 99-year leases. (2009, December 11). Fiji Times. Retrieved from http://www.fijitimes.com

Farrell, B. H., \& Murphy, P. E. (1978). Ethnic attitudes toward land in Fiji. Santa Cruz: Center for South Pacific Studies, University of California.

Fiji Government. (2007). 2008 budget address. Retrieved from http://www.fijilive.com/archive/showpdf.php?pdf=2007/1 1/budget_speech_2008.pdf

Fiji Government. (2008). Economic and fiscal update: Supplement to the 2009 budget address - "raising economic growth and alleviating poverty" Retrieved from http://www.mfnp.gov.fj/Documents/2009_Budget_Supplement.pdf

Fiji Government. (2009a). PM Bainimarama - Statement on Fiji's sugar funds under accompanying measures support programme. Retrieved from http://www.fiji.gov.fj/publish/page_15087.shtml 
Fiji Government. (2009b). PM Bainimarama - A strategic framework for change.

Retrieved from http://www.fiji.gov.fj/publish/page_15376.shtml

Fiji Government Online. (2008). Press releases: Ray of hope for squatter settlements.

Retrieved from http://www.fiji.gov.fj/publish/page_13597.shtml

Fiji Government Online. (2009). Press releases: Housing Authority development projects.

Retrieved from http://www.fiji.gov.fj/publish/page_14028.shtml

Fiji Government Online. (2010). Ministry of Labour, Industrial Relations, Employment, Local Government, Urban Development and Housing. Retrieved from http://www.fiji.gov.fj/index.php? option=com_content\&view=article\&id=134:ministry-oflabour-industrial-relations-employment-local-government-urban-development-andhousing \& catid=76:department\&ltemid $=171$

Fiji Government Online. (2011). Affordable housing. Retrieved from

http://www.fiji.gov.fj/index.php?option=com_content\&view=article\&id=3193:affordablehousing\&catid=71:press-releases\&ltemid $=155$

Fiji Islands Bureau of Statistics. (2008). Statistical news: Census 2007 results: Population size, growth, structure and distribution. Suva: Fiji Islands Bureau of Statistics.

Fiji Islands Bureau of Statistics. (2010). Key Statistics: June. Retrieved from http://www.statsfiji.gov.fj/Key\%20Stats/National\%20Income/3.1_GDP\%20Summary.pdf

Fingleton, J. (2005a). Privatising land in the Pacific: A defence of customary tenures (Discussion Paper No. 80). Canberra: The Australia Institute. Retrieved from https://www.tai.org.au/documents/downloads/DP80.pdf

Fingleton, J. (2005b). Pacific 2020 background paper: Land. Canberra: Australian Agency for International Development. Retrieved from http://www.ausaid.gov.au/publications/pdf/background_land.pdf

Fingleton, J. (2007). Rethinking the need for land reform in Papua New Guinea. Pacific Economic Bulletin, 22(1), 115-121. 
Fingleton, J. (2008) Pacific land tenures: New ideas for reform (FAO Legal Papers Online \#73). Rome: Food and Agriculture Organization of the United Nations. Retrieved from http://www.fao.org/legal/prs-ol//po73.pdf

Forsyth, D. (1997). The economy of Fiji. In B. V. Lal and T. R. Vakatora (Eds.), Fiji in transition (pp. 178-185). Suva: School of Social and Economic Development, University of the South Pacific.

Fraenkel, J. (2009). Fiji. The Contemporary Pacific, 21 (2), 337-352.

Fraenkel, J. (2010). Fiji. The Contemporary Pacific, 22 (2), 416-433.

France, P. (1969). The charter of the land: Custom and colonization in Fiji. Melbourne: Oxford University Press.

Frauley, J., \& Pearce, F. (2007). Critical realism and the social sciences: Methodological and epistemological preliminaries. In J. Frauley \& F. Pearce (Eds.), Critical realism and the social sciences: Heterodox elaborations (pp. 3-29). Toronto: University of Toronto Press.

Galiani, S., \& Schargrodsky, E. (2006). Property rights for the poor: Effects of land titling. Retrieved from http://www.econ.yale.edu/seminars/develop/tdw06/schargrodsky060327.pdf

Gani, A. (2007). The Fiji macroeconomy: An introduction. New York: Nova Science Publishers, Inc.

Geraghty, P. (1997). The ethnic base of society in Fiji. In B. V. Lal \& T. R. Vakatora (Eds.), Fiji in transition (pp. 1-23). Suva: School of Social and Economic Development, University of the South Pacific.

Gilbert, A. (2002). On the mystery of capital and the myths of Hernando de Soto. International Development Planning Review, 24 (1), 1-19.

Gilbert, A. (2007). The return of the slum: Does language matter? International Journal of Urban and Regional Research, 31 (4), 697-713. 
Gilbert, A. (2008). Slums, tenants and home-ownership: On blindness to the obvious. International Development Planning Review, 30 (2), i-x.

Gounder, N. (2005). Rural urban migration in Fiji: Causes and consequences (School of Economics Working Paper 2005/12). Suva: School of Economics, University of the South Pacific. Retrieved from

http://www.usp.ac.fj/fileadmin/files/schools/ssed/economics/working_papers/2005/wp2 005_12.pdf

Government plans national housing policy. (2011, January 9). Fiji Sun. Retrieved from http://www.fijisun.com.fj/

Griffen, C., \& Monsell-Davis, M. (Eds.). (1986). Fijians in towns. Suva: Institute of Pacific Studies, University of the South Pacific.

Griffith-Charles, C. (2004). Trinidad: 'We are not squatters, we are settlers'. In R. Home \& H. Lim (Eds.), Demystifying the mystery of capital: Land tenure and poverty in Africa and the Caribbean (pp. 99-119). London: Cavendish Publishing Limited.

Gulyani, S., \& Bassett, E. M. (2007). Retrieving the baby with the bathwater: Slum upgrading in Sub-Saharan Africa. Environment and Planning C, 25(4), 486-515.

Haberkorn, G. (2006). Preliminary stocktake of urbanization policies in the Pacific Island region. Noumea: Secretariat of the Pacific Community.

Habitat for Humanity Fiji (HFHF). (2009). Nadi Housing Resettlement Project Phase 1: Final report \& recommendations. Suva: Habitat for Humanity Fiji.

Habitat for Humanity Fiji. (2010). Fiji at a glance. Retrieved from http://www.habitat.org/intl/pdf/fiji_pdf.pdf

Halapua, W. (2001). Living on the fringe: Melanesians in Fiji. Suva: Institute of Pacific Studies, University of the South Pacific. 
Hardoy, J. E., \& Satterthwaite, D. (1989). Squatter citizen: Life in the urban Third World. London: Earthscan.

Harms, H. (1982). Historical perspectives on the practice and purpose of self-help housing. In P. Ward (Ed.), Self-help housing: A critique (pp. 17-53). London: Mansell Publishing Limited.

Hassan, A. (2005, January). A preliminary study on the supply of low cost housing in Fiji. Paper presented at the 11 th Annual Conference of the Pacific-Rim Real Estate Society, University of Melbourne. Retrieved from http://www.prres.net/papers/Hassan_A_Preliminary_Study_On_The_Supply.Pdf

Help on the way for West squatters. (2010, August 22). Fiji Sun. Retrieved from http://www.fijisun.com.fj

Holzknecht, H. A. (2002). Land, people and governance: Conflicts and resolutions in the South Pacific. Development Bulletin, 60, 8-12.

Home, R. \& Lim, H. (2004). Introduction: Demystifying 'the mystery of capital'. In R. Home \& H. Lim (Eds.), Demystifying the mystery of capital: Land tenure and poverty in Africa and the Caribbean (pp. 1-10). London: Cavendish Publishing Limited.

House saving scheme to benefit families. (2009, March 19). Fiji Sun. Retrieved from http://www.fijisun.com.fj

Houses comes down. (2010, February 18). Fiji Times. Retrieved from http://www.fijitimes.com

Housing Authority orders squatters to vacate land. (2009, June 7). Fiji Sun. Retrieved from http://www.fijisun.com.fj

Housing and Relief Trust (HART). (2007). Annual report 2007. Suva: Housing and Relief Trust.

Housing unveils billion dollar plan with Malaysian company. (2011, January 5). Fiji Sun. Retrieved from http://www.fijisun.com.fj 
Hughes, H. (2004). The Pacific is viable! (Issue Analysis No. 53). Canberra: The Centre for Independent Studies. Retrieved from http://www.cis.org.au/images/stories/issueanalysis/ia53.pdf

Iati, I. (2010). Reconsidering land reform in the Pacific: Research for the Council for International Development. Wellington: Council for International Development.

IRIN (2007). Tomorrow's crises today: The humanitarian impact for urbanisation. Retrieved from http://www.irinews.org/InDepthMain.aspx? InDepthID=63\&Reportld=73996

Jittu 'tenants' face the boot. (2010, June 11). Fiji Sun. Retrieved from http://www.fijisun.com.fj

Kabutaulaka, T. T., \& Rokolekutu, P. (2008). Review of the role and dynamics of landrelated politics and political parties in conflict and conflict escalation in the Pacific Islands (Land Management and Conflict Minimisation Sub-Project 2.5). Suva: Pacific Islands Forum Secretariat. Retrieved from http://www.forumsec.org.fj/resources/uploads/attachments/documents/LMCM\%202_5\% 20COMPLETE.pdf

Kamikamica, J. N. (1987). Fiji: Making land more productive. In R. Crocombe (Ed.), Land tenure in the Pacific (pp. 226-239). Suva: University of the South Pacific.

Kamikamica, J. N. (1997). Fiji native land: Issues and challenges. In B. V. Lal \& T. R. Vakatora (Eds.), Fiji in transition (pp. 259-290). Suva: School of Social and Economic Development, University of the South Pacific.

Kitchin, R., \& Tate, N. J. (2000). Conducting research in human geography: Theory, methodology and practice. Harlow: Pearson Education.

Koi, H. (2010, January 14). 35 attend forum. Fiji Times. Retrieved from http://www.fijitimes.com

Kotobalavu, J. (2007, June). Resolving the current crisis in Fiji - a personal perspective. Paper presented at the State, Society and Governance in Melanesia and The Pacific Centre Workshop: The Fiji Coup - Six Months On, Australian National University. Retrieved 
from

http://rspas.anu.edu.au/papers/melanesia/conference_papers/0706_FijiCoup_Kotobala vu.pdf

Kumar, S., \& Prasad, B. (2004). Politics of race and poverty in Fiji. International Journal of Social Economics, 31 (5/6), 469-486.

Kurer, O. (2001 a). Land and politics in Fiji: Of failed land reforms and coups. The Journal of Pacific History, 36(3), 299-315.

Kurer, O. (2001b). Land tenure and sugar production in Fiji: Property rights and economic performance. Pacific Economic Bulletin, 16(2), 94-105.

Lal, B. V. (2003). Heartbreak islands: Reflections on Fiji in transition. Asia Pacific Viewpoint, $44(3), 335-350$.

Lal, B. V. (2006). Fiji. In B. V. Lal (Ed.), The encyclopedia of the Indian diaspora (pp. 370382). Singapore: Editions Didier Millet/National University of Singapore.

Lal, B. V. (2007). 'The process of political readjustment': Aftermath of the 2006 Fiji coup (State, Society and Governance in Melanesia, Discussion Paper 2007/2). Canberra: Research School of Pacific and Asian Studies, Australian National University. Retrieved from http://rspas.anu.edu.au/papers/melanesia/discussion_papers/07_02_dp_lal.pdf

Lal, P., Lim-Applegate, H., \& Reddy, M. (2001). ALTA or NLTA: What's in the Name? Land Tenure Dilemma and the Fiji Sugar Industry (University of Wisconsin-Madison Land Tenure Center Working Paper No. 46). Madison: Land Tenure Center, University of WisconsinMadison. Retrieved from http://minds.wisconsin.edu/handle/1793/21953

Lal, P., \& Rita, R. (2005). Potential impacts of EU sugar reform of the Fiji sugar industry. Pacific Economic Bulletin, 20(3), 18-42.

Laqere, W. (1987). The Malekula settlement, Suva. In L. Mason and P. Hereniko (Eds.), In search of a home (pp. 56-64). Suva: Institute of Pacific Studies, University of the South Pacific. 
Larson, J. E. (1995-1996). Free markets deep in the heart of Texas. The Georgetown Law Journal, 84, 179-260.

Larson, J. E. (2002). Informality, Illegality, and Inequality. Yale Law \& Policy Review, 20, 137-182.

Lea, J. P. (1983). Customary tenure and urban housing land: Partnership and participation in developing societies. In S. Angel, R. W. Archer, S. Tanphiphat \& E. A. Wegelin (Eds.), Land for housing the poor (pp. 54-72). Singapore: Select Books.

Lee, K. N. (2007). An urbanizing world. In L. Starke (Ed.), 2007 state of the world: Our urban future (pp. 3-21). London: Earthscan.

Lemanski, C. (2010). Moving up the ladder or stuck on the bottom rung? Homeownership as a solution to poverty in urban South Africa. International Journal of Urban and Regional Research, 35(1), 57-77.

Levantis, T., \& Yala, C. (2008). Breaking away from the land policy stalemate. Pacific Economic Bulletin, 23(1), 99-110.

Lingam, D. (2005). Squatter upgrading/Resettlement proposal (Fiji Islands). Suva: Ministry of Local Government, Housing, Squatter Settlement and Environment.

Lingam, D. (2007). The shanty towns of Fiji. Suva: Fiji School of Medicine. Unpublished paper.

Mahadevan, R. (2009a). The less than sweet solution to Fiji's sugar industry problems. Journal of International Development, 21 (1), 126-136.

Mahadevan, R. (2009b). The rough global time and political storm in Fiji call for swimming hard and fast but with a different stroke. Pacific Economic Bulletin, 24(2), 1-23.

Mahadevan, R. (2009c). The withdrawal of EU sugar preferences and the bittersweet reform pill for Fiji. Pacific Economic Bulletin, 24 (2), 82-94. 
Mangin, W. (1967). Latin American squatter settlements: A problem and a solution. Latin American Research Review, 2(3), 65-98.

Martin, R. J. (1983). Upgrading. In R. J. Skinner \& M. J. Rodell (Eds.), People, poverty and shelter: Problems of self-help housing in the Third World (pp. 53-79). London: Methuen.

Mason, L., \& Hereniko, P. (Eds.). (1987). In search of a home. Suva: Institute of Pacific Studies, University of the South Pacific.

McGillivray, M., Naudé, W., \& Santos-Paulino, A. (2008). Small island states development challenges: Introduction. Journal of International Development, 20 (4), 481-485.

McKinnon, J., Whitehead, S., Chung, M., \& Taylor, L. (2007). Report of the Informal Settlements Scoping Mission. Wellington: New Zealand Agency for International Development.

Mecartney, S. A. N. (2000). Blacksands Settlement: A case for urban permanence in Vanuatu (Unpublished master's thesis). University of Sydney, Sydney, Australia.

Ministry of Local Government, Urban Development and Public Utilities. (2007). Terms of reference: The establishment of a framework for the implementation of the Government of Fiji - Urban Policy Action Plan and Urban Growth Management Plan. Suva: Ministry of Local Government, Urban Development and Public Utilities.

Ministry of National Planning. (2010). Millennium Development Goals: 2nd report, 19902009. Suva: Ministry of National Planning.

Mohanty, M. (2006). Urban squatters, the informal sector and livelihood strategies of the poor in Fiji Islands. Development Bulletin, 70, 65-68.

Mooya, M. M., \& Cloete, C. E. (2007). Informal urban property markets and poverty alleviation: A conceptual framework. Urban Studies, 44(1), 147-165.

Musembi, C. N. (2007). De Soto and land relations in rural Africa: Breathing life into dead theories about property rights. Third World Quarterly, 28(8), 1457-1478. 
Naidu, V. (2006a). Development assistance challenges. In M. Powels (Ed.), Pacific futures (pp. 142-163). Canberra: Pandanus Books.

Naidu, V. (2006b). The state of the state in Fiji: Some failings in the periphery. In S. Firth (Ed.), Globalisation and governance in the Pacific Islands (pp. 297-315). Canberra: The Australian National University E Press. Retrieved from http://epress.anu.edu.au/ssgm/global_gov/pdf/ch16.pdf

Naidu, V. (2007a, February). Coups in Fiji: Seesawing democratic multiracialism and ethno-nationalist extremism. CID Development Forum, 26, 24-33.

Naidu, V. (2007b). Human rights and social justice: Moving beyond the divide. The Annual Rev. Paula Niukula Lecture, 18 th April, University of the South Pacific. Retrieved from http://www.ecrea.org.fj/publications_files/Papers/niukula.pdf

Naidu, V. (2009). Draft report: Fiji Islands country profile on excluded groups. Suva: United Nations Economic and Social Commission for Asia and the Pacific.

Narayan, P. K., \& Narayan, S. (2009). Understanding Fiji's declining foreign reserves position. Pacific Economic Bulletin, 24(2), 95-112.

Narsey, W. (2006). Report on the 2002-03 Household Income and Expenditure Survey. Suva: Fiji Islands Bureau of Statistics. Retrieved from http://www.fijichris.gov.fj/docs/95.pdf

Narsey, W. (2008). The incidence of poverty and the poverty gap in Fij: Unpalatable facts for ethno-centric political parties. Pacific Economic Bulletin, 23(2), 70-81.

Nasinu Town Council. (2007). Squatter area: Report and proposal. Suva: Nasinu Town Council.

National Council for Building a Better Fiji (NCBBF): Technical and Support Secretariat (n.d.). National Task Team 3 on Social-Cultural Identity and Nation Building, Working Group 7: Poverty, Social Justice and Human Rights - Issues \& discussion paper on poverty alleviation. Suva: National Council for Building a Better Fiji Technical and Support Secretariat. 
National Council for Building a Better Fiji. (2008a). Fiji Peoples Charter for Change, Peace and Progress (Draft). Suva: National Council for Building a Better Fiji.

National Council for Building a Better Fiji: Technical and Support Secretariat (2008b). National Task Team 3: Meeting Basic Needs, Housing, Health and Education, Working Group 8 - Discussion paper and quality homes and sustainable communities. Suva: National Council for Building a Better Fiji Technical and Support Secretariat.

Nayacakalou, R. R. (1971). Fiji: Manipulating the system. In R. Crocombe (Ed.), Land tenure in the Pacific (pp. 206-226). Melbourne: Oxford University Press.

Nomae, V. D., Manepora'a, A., Kumar, S., \& Prasad, B. C. (2004). Poverty amongst minority Melanesians in Fiji: A case study of six settlements in Suva (School of Economics Working Paper 2004/15). Suva: School of Economics, University of the South Pacific. Retrieved from http://www.econ.fbe.usp.ac.fj/fileadmin/files/schools/ssed/economics/working_papers/ 2004/wp2004_15.pdf

No payout for Nasinu squatters. (2009, May 9). Fiji Times. Retrieved from http://www.fijitimes.com

Overton, J. (1987). Fijian land: Pressing problems, possible tenure solutions. Singapore Journal of Tropical Geography, 8(2), 139-151.

Overton, J. (1988). A Fijian peasantry: Galala and villages. Oceania, 58(3), 193-211.

Overton, J. (1992). The limits to accumulation: Changing land tenure in Fiji. The Journal of Peasant Studies, 19(2), 326-342.

Overton, J. (1994). Land tenure and cash cropping in Fiji. In R. Crocombe \& M. Meleisa (Eds.) Land issues in the Pacific (pp. 117-129). Christchurch/Suva: Macmillan Brown Centre for Pacific Studies, University of Canterbury/Institute of Pacific Studies, University of the South Pacific. 
Overton, J. (1999). Vakavanua, vakamatanitū: Discourses of development in Fiji. Asia Pacific Viewpoint, 40(2), 173-186.

Oxfam International. (2005). The Fijian sugar industry: Investing in sustainable technology (Oxfam Briefing Paper 77). Oxford: Oxfam International. Retrieved from http://www.oxfam.org.uk/resources/issues/trade/downloads/bp77_sugar.pdf

Pangerl, M. (2007). Notions of insecurity among contemporary Indo-Fijian Communities. The Asia Pacific Journal of Anthropology, 8(3), 251-264.

Pareti, S. (2007, June). Urban of a crisis: Towns bursting with growing population and limited resources. Islands Business, 16-21.

Payne, G. (2001). Urban land tenure policy options: Titles or rights? Habitat International, $25(3), 415-429$.

Payne, G. (2002a). Introduction. In G. Payne (Ed.), Land, rights \& innovation: Improving tenure security for the urban poor (pp. 3-22). London: ITDG Publishing.

Payne, G. (2002b). Conclusion: The way ahead. In G. Payne (Ed.), Land, rights \& innovation: Improving tenure security for the urban poor (pp. 300-308). London: ITDG Publishing.

Payne, G. (2004). Land tenure and property rights: An introduction. Habitat International, 28(2), 167-179.

Payne, G. (2005). Getting ahead of the game: A twin-track approach to improving existing slums and reducing the need for future slums. Environment \& Urbanization, 17(1), $135-145$.

Payne, G., Durand-Lasserve, A., \& Rakodi, C. (2009). The limits of land titling and home ownership. Environment \& Urbanization, 21 (2), 443-462.

Peattie, L., \& Aldrete-Hass, J. A. (1981). "Marginal" settlements in developing countries: Research, advocacy of policy, and evolution of programs. Annual Review of Sociology, 7, 157-175. 
Perry, M. (2009, 21 May). Fiji sugar still plans growth despite losing EU subsidies. The Dominion Post, pp. C2.

Pinches, M. (1994). Urbanisation in Asia: Development, contradiction and conflict. In L. Jayasuriya and M. Lee (Eds.), Social dimensions of development: Proceedings of the Inaugural Conference of the WA Inter-University Consortium for Development Studies (pp. 114-121). Bentley: Paradigm Books.

Porio, E., \& Crisol, C. (2004). Property rights, security of tenure and the urban poor in Metro Manila. Habitat International, 28(2), 203-219.

Prasad, B. C. (2006). Resolving the agricultural land lease impasse in Fiji. Pacific Economic Bulletin, 21 (2), 177-193.

Prasad, B. C. (2007). Changing trade regimes and Fiji's sugar industry: Has the time runout for reform or is there a plan and political will to sustain it? (School of Economics Working Paper 2007/24). Suva: School of Economics, University of the South Pacific. Retrieved from http://www.econ.fbe.usp.ac.fj/fileadmin/files/schools/ssed/economics/working_papers/ 2007/wp200724.pdf

Prasad, B. C. (2010). Global crisis, domestic crisis and crisis of confidence: Which way forward for Fiji? Pacific Economic Bulletin, 25(2), 1-24.

Prasad, B. C., \& Kumar, S. (2000). Institutional rigidities and economic performance in Fiji. In A. H. Akram-Lodhi (Ed.), Confronting Fiji futures (pp. 111-132). Canberra: Asia Pacific Press.

Prasad, B. C., \& Tisdell, C. (1996). Getting property rights 'right': Land tenure in Fiji. Pacific Economic Bulletin, 11 (1), 31-46.

Prasad, B. C., \& Tisdell, C. (2006). Institutions, economic performance and sustainable development: A case study of the Fiji Islands. New York: Nova Science Publishers, Inc.

Projects on ice. (2009, February 1). Fiji Times. Retrieved from http://www.fijitimes.com.fj 
Pugh, C. (2000). Squatter settlements: Their sustainability, architectural contributions, and socio-economic roles. Cities, 17(5), 325-337.

Rahnema, M. (1992). Poverty. In W. Sachs (Ed.), The development dictionary: A guide to knowledge as power (pp. 158-176). London: Zed Books.

Ratuva, S. (2007). The paradox of multiculturalism: Ethnopolitical conflict in Fiji. In M. A. Brown (Ed.), Security and development in the Pacific Islands: Social resilience in emerging states (pp. 197-224). Boulder: Lynne Rienner Publishers, Inc.

Ravuvu, A. (1983). Vaka i taukei: The Fijian way of life. Suva: Institute of Pacific Studies, University of the South Pacific.

Reddy, K. M. (1976). Some squatters in Suva. Suva: School of Social and Economic Development, University of the South Pacific.

Reddy, M. (2006). Internal migration in Fiji: Causes, issues and challenges (School of Economics Working Paper 2006/23). Suva: School of Economics, University of the South Pacific. Retrieved from

http://www.econ.fbe.usp.ac.fj/fileadmin/files/schools/ssed/economics/working_papers/ 2006/wp200623.pdf

Reddy, M., \& Naidu, V. (2001). Land tenure system in Fiji: The poverty implications of expiring leases. Development Bulletin, 55, 33-35.

Reerink, G., \& van Gelder, J. (2010). Land titling, perceived tenure security, and housing consolidation in the kampongs of Bandung, Indonesia. Habitat International, 34 (1), 7885.

Relocated squatters find no comfort. (2008, August 11). Fiji Times, pp. 11.

Residents fail to heed warnings. (2010, March 9). Fiji Times. Retrieved from http://www.fijitimes.com 
Rina, S. (2010, September 27). Nasinu thriving. Fiji Times. Retrieved from http://www.fijitimes.com

Routledge, D. (1985). Matanitu: The struggle for power in early Fiji. Suva: Institute of Pacific Studies, University of the South Pacific.

Rutz, H. J. (1987). Capitalizing on culture: Moral ironies in urban Fiji. Comparative Studies in Society and History, 29(3), 533-557.

Samy, J. (1973). 'Squatters', insecurity and housing development. In J. Harre (Ed.), Living in town: The problems and priorities in urban planning in the South Pacific (pp. 65-70). Suva: University of the South Pacific.

Satterthwaite, D. (2007). The transition to a predominantly urban world and its underpinnings (Human Settlements Discussion Paper Series - Theme: Urban Change - 4). London: International Institute for Environment and Development. Retrieved from http://www.iied.org/pubs/pdfs/10550IIED.pdf

Savant-Mohit, R. (2004). Security of tenure and the way forward: The case of Samakee Pattana, Bangkok. Habitat International, 28(2), 301-316.

Scheyvens, R., Nowak, B., \& Scheyvens, H. (2003). Ethical issues. In R. Scheyvens \& D. Storey (Eds.) Development fieldwork: A practical guide (pp. 139-166). London: Sage Publications.

Scheyvens, R. \& Storey, D. (2003). Introduction. In R. Scheyvens \& D. Storey (Eds.) Development fieldwork: A practical guide (pp. 1-13). London: Sage Publications.

Seabrook, J. (1996). In the cities of the South: Scenes from a globalising world. London: Verso.

Secretariat of the Pacific Community. (2010). 2010 population and demographic indicators. Retrieved from http://www.spc.int/sdp/index.php?option=com_docman\&task=cat_view\&gid=28\&ltemi $d=42$ 
Sharma, U., \& Lawrence, S. (2005). Public sector reform, global trends vs. local needs: The case of a state rental organisation in Fiji. Journal of Accounting \& Organizational Change, 1 (2), 141-164.

Sims, D. (2002). What is secure tenure in Egypt? In G. Payne (Ed.), Land, rights \& innovation: Improving tenure security for the urban poor (pp. 79-99). London: ITDG Publishing.

Singh, R. D., \& Reddy, M. (2007). Corporate governance in Fiji's Native Land Trust Board. Pacific Economic Bulletin, 22 (2), 36-52.

Small Islands Developing States Network. (2010). Fiji national assessment report. New York: Small Islands Developing States Network. Retrieved from http://www.sidsnet.org/msi_5/docs/nars/Pacific/Fiji-MSI-NAR2009.pdf

Squatter groups forms network. (2007, July 13). Fiji Times. Retrieved from http://www.fijitimes.com

Squatters put on notice. (2010, June 13). Fiji Sun. Retrieved from http://www.fijisun.com.fj

Squatter squeeze. (2010, September 27). Fiji Sun. Retrieved from http://www.fijisun.com.fj

Srinivas, H. (n.d.). Defining squatter settlements. Retrieved from http://www.gdrc.org/vem/squatters/define-squatter.html

Sriskandarajah, D. (2003). Inequality and conflict in Fiji: From purgatory to hell? Asia Pacific Viewpoint, 44(3), 305-324.

Stabile, J. C. (2000). Urban expansion, environmental change, living conditions and development planning in the Pacific: A case study of the Suva-Lami-Nasinu-Nausori conurbation (Unpublished master's thesis). University of the South Pacific, Suva, Fiji.

Stokes, C. J. (1962). A theory of slums. Land Economics, 38(3), 187-197.

Storey, D. (2003). The peri-urban Pacific: From exclusive to inclusive cities. Asia Pacific Viewpoint, 44 (3), 260-279. 
Storey, D. (2005). Urban governance in Pacific island countries: Advancing an overdue agenda (State, Society and Governance in Melanesia, Discussion Paper 2005/7).

Canberra: Research School of Pacific and Asian Studies, Australian National University. Retrieved from

http://rspas.anu.edu.au/papers/melanesia/discussion_papers/05_07_dp_storey.pdf

Storey, D. (2006). Urbanisation in the Pacific. State and Society in Melanesia: Targeted Research Papers. Canberra: Australian National University. Retrieved from http://rspas.anu.edu.au/papers/melanesia/research/SSGM_Urbanisation_in_the_\%20Pac ific_ResearchPaper_06.pdf

Sugar Commission of Fiji. (2002). Sugar in Fiji. Lautoka: Sugar Commission of Fiji.

Suguta, A. (1987). Squatting in Fiji. In L. Mason \& P. Hereniko (Eds.), In search of a home (pp. 131-143). Suva: Institute of Pacific Studies, University of the South Pacific.

Tacoli, C. (2007). Poverty, inequality and the underestimation of rural-urban linkages. Development, 50(2), 90-95.

Taylor, W. E. (2004). Property rights-and responsibilities? The case of Kenya. Habitat International, 28(2), 275-287.

Thomson, P. (1999). Kava in the blood. Auckland: Tandem Press.

Thornton, A. (2009). Garden of Eden? The impact of resettlement on squatters' 'agrihoods' in Fiji. Development in Practice, 19(7), 884-894.

Turner, J. C. (1968a). Housing priorities, settlement patterns, and urban development in modernizing countries. American Institute of Planners Journal, 10(10), 354-363.

Turner, J. C. (1968b). The squatter settlement: An architecture that works. Architectural Design, 38, 355-360. 
Turner, J. C. (1969). Uncontrolled urban settlement: Problems and policies. In G. Breese (Ed.), The city in newly developing countries: Readings on urbanism and urbanization (pp. 507-534). Englewood Cliffs: Prentice-Hall, Inc.

Turner, J. C. (1972). Housing as a verb. In J. C. Turner and R. Fichter (Eds.), Freedom to build: Dweller control of the housing process (pp. 148-175). New York: The Macmillan Company.

United Nations Department of Economic and Social Affairs. (2010). World urbanization prospects: The 2009 revision - Highlights. New York: United Nations Department of Economic and Social Affairs. Retrieved from http://esa.un.org/unpd/wup/Documents/WUP2009_Highlights_Final.pdf

United Nations Economic and Social Commission for Asia and the Pacific (2007). Economic and social survey of Asia and the Pacific 2007: Surging ahead in uncertain times. New York: United Nations Economic and Social Commission for Asia and the Pacific. Retrieved from http://www.unescap.org/survey2007/download/01_Survey_2007.pdf

UN-Habitat. (2004). Global campaign for secure tenure: A tool for advocating the Provision of adequate shelter for the urban poor. Concept paper: 2nd edition. Nairobi: UN-Habitat. Retrieved from http://ww2.unhabitat.org/campaigns/tenure/documents/conceptpaper2.pdf

UN-Habitat. (2006). State of the world's cities 2006/7: The Millennium Development Goals and urban sustainability: 30 years of shaping the habitat agenda. London: Earthscan.

UN-Habitat. (2007). Global report on human settlements 2007: Enhancing urban safety and security. London: Earthscan.

United Nations Development Programme. (2010). International human development indicators. Retrieved from http://hdr.undp.org/en/statistics

United Nations Population Fund (UNFPA). (2007). State of the world population 2007: Unleashing the potential of urban growth. New York: United Nations Population Fund. Retrieved from http://www.unfpa.org/swp/2007/presskit/pdf/sowp2007_eng.pdf 
Ushman, S. (1984). Fiji: Land tenure and productivity. In B. Acquaye \& R. Crocombe (Eds), Land tenure and rural productivity in the Pacific Islands (pp. 97-101). Suva: University of the South Pacific.

Valentine, G. (1997). Tell me about...: Using interviews as a research methodology. In R. Flowerdew \& D. Martin (Eds.), Methods in human geography: A guide for students doing a research project (pp. 110-126). Harlow: Addison Wesley Longman Ltd.

van Gelder, J. (2007). Feeling and thinking: Quantifying the relationship between perceived tenure security and housing improvement in an informal neighbourhood in Buenos Aires. Habitat International, 31 (2), 219-231.

van Gelder, J. (2009). Legal tenure security, perceived tenure security and housing improvement in Buenos Aires: An attempt towards integration. International Journal of Urban and Regional Research, 33(1), 126-146.

van Gelder, J. (2010). What tenure security? The case for a tripartite review. Land Use Policy, 27(2), 449-456.

Varley, A. (1987). The relationship between tenure legalization and housing improvements: Evidence from Mexico City. Development and Change, 18(3), 463-481.

Varley, A. (2002). Private or public: Debating the meaning of tenure legalization. International Journal of Urban and Regional Research, 26(3), 449-461.

Vuetibau, I. K. (1987). Squatting and the California Highway settlement, Suva. In L. Mason \& P. Hereniko (Eds.), In search of a home (pp. 145-154). Suva: Institute of Pacific Studies, University of the South Pacific.

Vula, T. (2010, June 19). PRB and China Railway sign \$20m contract. Fiji Times. Retrieved from http://www.fijitimes.com

Walsh, A. C. (1977). Urbanization in Fiji. Perspective, 14, 1-6. 
Walsh, A. C. (1978). The urban squatter question: Squatting, housing and urbanization in Suva, Fiji (Unpublished doctoral thesis). Massey University, Palmerston North, New Zealand.

Walsh, A. C. (1979a, January). The Fijian and Indian poor: Different strategies for survival. Paper presented at the ANZAAS Congress.

Walsh, A. C. (1979b, January). Traditional and modern behaviour in Suva city: Appropriate urban responses. Paper presented at the ANZAAS Congress.

Walsh, A. C. (1984). The search for an appropriate housing policy in Fiji. Third World Planning Review, 6(2), 185-200.

Walsh, A. C. (1996).1996 Fiji Census of Population and Housing: A Study of the characteristics of housing based on the census data. Suva: Fiji Islands Bureau of Statistics.

Walsh, A. C. (2000). Urban squatting in Fiji. In B. V. Lal \& K. Fortune (Eds.), The Pacific Islands: An encyclopedia (pp. 437-439). Honolulu: University of Hawai'i Press.

Walsh, A. C. (2002). Poverty in Fiji Islands and the Pacific Islands. In Defining and Agenda for Poverty Reduction: Proceedings of the First Asia and Pacific Forum on Poverty (pp. 330-346). Manila: Asian Development Bank. Retrieved from http://www.adb.org/Documents/Books/Defining_Agenda_Poverty_Reduction/Vol_1/ch apter_28.pdf

Walsh, A. C. (2006). Fiji: An encyclopaedic atlas. Suva: University of the South Pacific.

Ward, P. M. (2003). Land regularization in Latin America: lessons in the social construction of public policy. Cambridge, MA: Lincoln Institute of Land Policy. Retrieved from http://66.223.94.76/pubs/819_Land-Regularization-in-Latin-America

Ward, R. G. (1973). Urbanisation in the Pacific - facts and policies. In R. J. May (Ed.), Priorities in Melanesian development (pp. 362-372). Canberra/Port Moresby: The Research School of Pacific Studies, The Australian National University/University of Papua and New Guinea. 
Ward, R. G. (1995). Land, law and custom: Diverging realities in Fiji. In R. G. Ward \& E. Kingdon (Eds.), Land, custom and practice in the South Pacific (pp. 198-249).

Cambridge: Cambridge University Press.

Ward, R. G. (1997a). Changing forms of communal tenure. In P. Larmour (Ed.), The governance of common property in the Pacific region (pp. 19-32). Canberra: National Centre for Development Studies and Research School of Pacific and Asian Studies.

Ward, R. G. (1997b). Land in Fiji. In B. V. Lal \& T. R. Vakatora (Eds.), Fiji in transition (pp. 247-258). Suva: School of Social and Economic Development, University of the South Pacific.

Ward, R. G. (1998). Urban research in the Pacific Islands: A brief review. Development Bulletin, 45, 22-27.

Ward, R. G., \& Kingdon, E. (1995a). Introduction. In R. G. Ward \& E. Kingdon (Eds.), Land, custom and practice in the South Pacific (pp. 1-5). Cambridge: Cambridge University Press.

Ward, R. G., \& Kingdon, E. (1995b). Land tenure in the Pacific Islands. In R. G. Ward \& E. Kingdon (Eds.), Land, custom and practice in the South Pacific (pp. 36-64). Cambridge: Cambridge University Press.

Warning to squatters. (2010, June 21). Fiji Sun. Retrieved from http://www.fijisun.com.fj

Water ill threatens. (2010, February 24). Fiji Times. Retrieved from http://www.fijitimes.com

Wilkinson, A. (2002). Advisory service to Nasinu Town Council: Squatter settlement assessment Nasinu, Phase II - Report. Suva: United Nations Economic and Social Commission for Asia and the Pacific, Pacific Operations Centre.

Winchester, H. P. M. (1996). Ethical issues in interviewing as a research method in human geography. Australian Geographer, 2(1), 117-129. 
World Bank. (1995). Managing urban environmental sanitation services in selected Pacific island countries. Washington D.C.: World Bank, Country Department III, East Asia and Pacific Region.

World Bank. (2000). Volume II: Managing Pacific towns. Cities, Seas, and Storms: Managing Change in Pacific Island Economies. Washington D.C.: World Bank, Papua New Guinea and Pacific Islands Country Unit.

Wratten, E. (1995). Conceptualizing urban poverty. Environment \& Urbanization, 7(1), $11-$ 33.

Young, R. (2000). Gender, mobility and urban place in Fij: From colonial to post-colonial wanderings. Asia-Pacific Population Journal, 15(3), 57-71. 
APPENDICES 


\section{APPENDIX 1: KEY INFORMANTS}

Interviews/Discussions:

\begin{tabular}{|c|c|c|}
\hline Name & Role/Institution (at time of interview/discussion) & Date(s) \\
\hline Ali, Irshad & CEO, Save the Children Fiji & $16 / 6 / 07$ \\
\hline Barr, Kevin & $\begin{array}{l}\text { Consultant to Ecumenical Centre for Research, } \\
\text { Education and Advocacy / Board Member } \\
\text { Housing Authority }\end{array}$ & $\begin{array}{l}\text { 12/2/08; 24/6/08; } \\
5 / 11 / 08\end{array}$ \\
\hline $\begin{array}{l}\text { Canton- } \\
\text { Lamousse, Xavier }\end{array}$ & $\begin{array}{l}\text { Attaché Sugar Protocol Officer, Delegation of } \\
\text { the European Commission for the Pacific }\end{array}$ & $24 / 7 / 08$ \\
\hline Chand, Satish & JP Bayly Trust Fiji (Labasa) & $9 / 7 / 08$ \\
\hline Chandra, Prakesh & $\begin{array}{l}\text { Acting Town Clerk/Health Inspector \& Building } \\
\text { Surveyor, Nausori Town Council }\end{array}$ & $7 / 11 / 08$ \\
\hline Chung, Margaret & Independent consultant & $20 / 6 / 07$ \\
\hline Counts, Richard & National Director, Habitat for Humanity Fiji & $27 / 3 / 08 ; 27 / 6 / 08$ \\
\hline Devi, Premilla & Save the Children Fiji (Labasa) & $9 / 7 / 08$ \\
\hline Dirks, Richard & $\begin{array}{l}\text { Fiji Development Programme Manager, New } \\
\text { Zealand Aid Programme }\end{array}$ & $19 / 8 / 10$ \\
\hline Drysdale, Peter & Rotahomes & 18/7/08; 21/10/08 \\
\hline Fatiaki, Alec & $\begin{array}{l}\text { Director, Housing and Squatter Resettlement } \\
\text { Unit }\end{array}$ & $20 / 6 / 07$ \\
\hline Gaundar, Mahesh & Assistant Registrar, Sugar Industry Tribunal & $27 / 7 / 09$ \\
\hline Hassall, Graham & $\begin{array}{l}\text { Professor and Director of Governance, } \\
\text { University of the South Pacific }\end{array}$ & $20 / 6 / 07$ \\
\hline Khan, Azmut & Secretary, Fiji Local Government Association & $25 / 9 / 08$ \\
\hline Khan, Nasra & Department of Town and Country Planning & 19/6/07 \\
\hline
\end{tabular}




\begin{tabular}{|c|c|c|}
\hline Kiran, Sashi & $\begin{array}{l}\text { Director, Foundation for Rural Integrated } \\
\text { Enterprises 'N' Development }\end{array}$ & $17 / 7 / 08$ \\
\hline Koroisave, Luke & $\begin{array}{l}\text { Senior Economic Planning Officer, Ministry of } \\
\text { Finance and National Planning }\end{array}$ & $6 / 11 / 08$ \\
\hline Lal, Babu & $\begin{array}{l}\text { Principal Land Officer, Housing and Squatter } \\
\text { Resettlement Unit }\end{array}$ & $7 / 11 / 08$ \\
\hline Lingam, Dharam & $\begin{array}{l}\text { Former Director, Housing and Squatter } \\
\text { Resettlement Unit }\end{array}$ & $15 / 6 / 07 ; 7 / 7 / 08$ \\
\hline $\begin{array}{l}\text { Mohanty, } \\
\text { Manoranjan }\end{array}$ & $\begin{array}{l}\text { Senior Lecturer, Development Studies } \\
\text { Programme, University of the South Pacific }\end{array}$ & $14 / 6 / 07$ \\
\hline Naidu, Vijay & $\begin{array}{l}\text { Head of School of Government, Development } \\
\text { and International Affairs, University of the South } \\
\text { Pacific }\end{array}$ & $\begin{array}{l}\text { 14/6/07; 15/6/07; } \\
\text { 29/9/08 }\end{array}$ \\
\hline O'Toole, Ciaran & Project Manager, Citizens' Constitutional Forum & $29 / 7 / 09$ \\
\hline Parker, Terry & $\begin{array}{l}\text { Regional Advisor, Commonwealth Local } \\
\text { Government Pacific Project }\end{array}$ & $23 / 6 / 08$ \\
\hline Qalo, Ropate & $\begin{array}{l}\text { Associate Professor in Sociology, University of } \\
\text { the South Pacific }\end{array}$ & $3 / 11 / 08$ \\
\hline Qalowasa, Semiti & $\begin{array}{l}\text { Coordinator, Economic Justice Programme, } \\
\text { Ecumenical Centre for Research, Education } \\
\text { and Advocacy }\end{array}$ & $\begin{array}{l}\text { 15/6/07; 14/8/07; } \\
2 / 7 / 08 ; 5 / 11 / 08\end{array}$ \\
\hline Rakai, Mele & $\begin{array}{l}\text { Senior Lecturer, Geomatics, University of the } \\
\text { South Pacific }\end{array}$ & $6 / 11 / 08$ \\
\hline Ram, Tulsi & Town Clerk, Ba Town Council & $11 / 8 / 08$ \\
\hline Reddy, Mahendra & $\begin{array}{l}\text { Associate Professor of Economics, University of } \\
\text { the South Pacific }\end{array}$ & $19 / 6 / 07$ \\
\hline Rokosawa, Mere & Director, Housing and Relief Trust & $10 / 11 / 08$ \\
\hline
\end{tabular}




\begin{tabular}{|c|c|c|}
\hline Senibulu, Mesake & General Manager, Public Rental Board & $13 / 11 / 08$ \\
\hline Singh, Pardeep & Mayor of Labasa & $3 / 10 / 08$ \\
\hline Smith, David & $\begin{array}{l}\text { Regional Advisor, Development Policy, United } \\
\text { Nation's Economic and Social Commission for } \\
\text { Asia and the Pacific }\end{array}$ & $14 / 8 / 07$ \\
\hline Tudreu, Apisalome & Board Member, Habitat for Humanity Fiji & $1 / 7 / 08$ \\
\hline Tupua, Mikaele & Land Development Engineer, Housing Authority & $13 / 11 / 08$ \\
\hline Vuniwai, Anare & $\begin{array}{l}\text { Acting Director, Housing and Squatter } \\
\text { Resettlement Unit }\end{array}$ & $31 / 7 / 09$ \\
\hline Wilkinson, Alastair & $\begin{array}{l}\text { Regional Advisor Social Development and } \\
\text { Planning, United Nation's Economic and Social } \\
\text { Commission for Asia and the Pacific }\end{array}$ & $14 / 11 / 08$ \\
\hline $\begin{array}{l}\text { Yakub, } \\
\text { Mohammed }\end{array}$ & Labasa Lions Club & $8 / 7 / 08$ \\
\hline Yates, Kirk & $\begin{array}{l}\text { Fiji Development Programme Manager, New } \\
\text { Zealand Aid Programme }\end{array}$ & $\begin{array}{l}14 / 6 / 07 ; 12 / 2 / 08 ; \\
11 / 7 / 08 ; 6 / 11 / 08\end{array}$ \\
\hline
\end{tabular}

Email Communications:

\begin{tabular}{|l|l|l|}
\hline Name & Role/Institution (at time of communications) & Date \\
\hline Abbott, David & $\begin{array}{l}\text { Pacific Regional Macro Economic \& Poverty } \\
\text { Reduction Advisor, United Nations } \\
\text { Development Programme Pacific Centre }\end{array}$ & $2 / 10 / 09$ \\
\hline Mecartney, Sarah & $\begin{array}{l}\text { Habitat Programme Manager for the Pacific, } \\
\text { UN-Habitat }\end{array}$ & $21 / 7 / 10$ \\
\hline Radford, Chris & Senior Human Settlements Adviser, UN-Habitat & $25 / 7 / 07$ \\
\hline
\end{tabular}




\section{APPENDIX 2: GUIDING INTERVIEW TEMPLATE}

For All Interviews:

\begin{tabular}{|l|l|}
\hline Date: & Household: \\
\hline Time: & \\
\hline Community: & Name: \\
& Age: \\
& Ethnicity: \\
\hline
\end{tabular}

$\underline{\text { General / Migration / Location: }}$

\begin{tabular}{|c|c|}
\hline $\begin{array}{l}\text { 1. Total people in } \\
\text { household: } \\
\text { No. dependents in } \\
\text { household: } \\
\text { Male headed? }\end{array}$ & \\
\hline 2. Length of residence: & \\
\hline $\begin{array}{l}\text { 3. Location of previous } \\
\text { residence: } \\
\text { Previous tenure category: }\end{array}$ & \\
\hline $\begin{array}{l}\text { 4. Reason for move from } \\
\text { previous residence: }\end{array}$ & \\
\hline $\begin{array}{l}\text { 5. Reason for locating } \\
\text { here: }\end{array}$ & \\
\hline 6. Location importance: & $\begin{array}{l}\text { Proximity to employment opportunities } \\
\text { Availability of adequate shelter } \\
\text { Opportunity for continued residence }\end{array}$ \\
\hline
\end{tabular}




\begin{tabular}{|c|c|}
\hline & Proximity to education and other services \\
\hline $\begin{array}{l}\text { 7. How was access to this } \\
\text { land obtained? }\end{array}$ & \\
\hline $\begin{array}{l}\text { 8. Was permission } \\
\text { obtained from anyone? }\end{array}$ & \\
\hline $\begin{array}{l}\text { 9. Was this house built or } \\
\text { obtained? } \\
\text { Cost to obtain/build: }\end{array}$ & \\
\hline $\begin{array}{l}\text { 10. Previous connections } \\
\text { to the community: }\end{array}$ & \\
\hline 11. Own or rent: & \\
\hline $\begin{array}{l}\text { Any documentation of } \\
\text { ownership/rental? }\end{array}$ & \\
\hline $\begin{array}{l}\text { If renting: } \\
\text { Initial deposit: } \\
\text { Deposit repayments: } \\
\text { Amount of rent: } \\
\text { Subleased? } \\
\text { Any other forms of } \\
\text { payment to the land- } \\
\text { owner? }\end{array}$ & \\
\hline $\begin{array}{l}\text { If on native land: } \\
\text { Nature of relationship with } \\
\text { landowner: } \\
\text { Any contribution expected } \\
\text { for community events? } \\
\text { Any other payments } \\
\text { extracted? }\end{array}$ & \\
\hline 12. Subleasing? & \\
\hline
\end{tabular}




\begin{tabular}{|l|l|}
\hline $\begin{array}{l}\text { 13. Own land in home } \\
\text { village or anywhere } \\
\text { else? }\end{array}$ & \\
\hline $\begin{array}{l}\text { 14. Involved in PCN } \\
\text { saving? }\end{array}$ & \\
How long? / How much? & \\
\hline
\end{tabular}

Livelihoods:

\begin{tabular}{|l|l|}
\hline $\begin{array}{l}\text { 15. Main income source: } \\
\text { means? }\end{array}$ & \\
\hline $\begin{array}{l}\text { If cash employment: } \\
\text { Full or part-time: } \\
\text { Permanent, casual or } \\
\text { seasonal: } \\
\text { How travel to work: }\end{array}$ & \\
If bus: Distance to bus \\
stop: \\
$\begin{array}{l}\text { Commuting time: } \\
\text { Monthly cost of travel: }\end{array}$ \\
\hline \begin{tabular}{l} 
16. Monthly Income: \\
\hline $\begin{array}{l}\text { 17. Social welfare: } \\
\text { 18. Other forms of } \\
\text { welfare/donations: }\end{array}$
\end{tabular} \\
\hline $\begin{array}{l}\text { 19. Source of livelihood } \\
\text { prior to moving to this } \\
\text { community: }\end{array}$ \\
\hline $\begin{array}{l}\text { 20. \$ spent on food per } \\
\text { week: }\end{array}$ \\
\hline
\end{tabular}




\begin{tabular}{|l|l|}
\hline $\begin{array}{l}\text { How much has this } \\
\text { increased in the last } 12 \\
\text { months? }\end{array}$ & \\
\hline 21. Have food garden? & \\
\hline $\begin{array}{l}\text { If yes: } \\
\text { Ratio consumed : sold }\end{array}$ & \\
\hline $\begin{array}{l}\text { 22. If you received an extra } \\
\text { \$50 per month, what } \\
\text { would you use this } \\
\text { money for? }\end{array}$ & \\
\hline $\begin{array}{l}\text { 23. Would you like to } \\
\text { move out of this } \\
\text { community? }\end{array}$ & \\
$\begin{array}{l}\text { Where to? } \\
\text { If yes: } \\
\text { How much/What for? }\end{array}$ & \\
\hline $\begin{array}{l}\text { 24. Where could you move } \\
\text { to? }\end{array}$ & \\
\hline $\begin{array}{l}\text { 25. If you were forced to } \\
\text { move what would you } \\
\text { do? }\end{array}$ & \\
\hline $\begin{array}{l}\text { 26. If you had to move } \\
\text { would you expect any } \\
\text { govensation from }\end{array}$ & \\
\hline
\end{tabular}

Services:

Water: Mains___ Spring/creek___ Tank___ Well__ Other

Electricity: $\quad$ Yes___ No__ 
If no: $\quad$ Source of lighting:

Cooking: Gas___ Fire___ Kerosene___ Electric stove

Phone: $\quad$ Yes___ (Landline-----Mobile) No__

Share: $\quad$ Water___ Electricity___ Toilet__

Waste:

Toilet:

Sewer

Septic tank

Pit

Shared

Rubbish:

Council collection

Skip

Buried

Burnt

Amenities:

$\begin{array}{ll}\text { Education: } & \text { School age children } \\ & \text { Distance to primary school___ Distance to secondary }\end{array}$

Health facilities: Where to you go to?

How far is this?

Shopping facilities: Where to you go to?

How far is this?

General (if applicable): How often do you go into town? 
Security of Tenure/Housing Improvement:

Quality of dwelling: Very poor------Poor------Average------Good------Very good

No. rooms

Size

Walls

Roof

Floor

\begin{tabular}{|l|l|}
\hline $\begin{array}{l}\text { 27. What is good about this } \\
\text { community? }\end{array}$ & \\
\hline $\begin{array}{l}\text { 28. What is bad about this } \\
\text { community? }\end{array}$ & \\
\hline $\begin{array}{l}\text { 29. Do you feel threatened by } \\
\text { eviction? }\end{array}$ & \\
\hline $\begin{array}{l}\text { Experience: } \\
\text { move? }\end{array}$ & \\
\hline $\begin{array}{l}\text { 31. Have you had any problems } \\
\text { with the owner of the house or } \\
\text { land? }\end{array}$ & \\
\hline $\begin{array}{l}\text { 32. Do you feel secure or } \\
\text { insecure? }\end{array}$ & \\
this community is threatened \\
in any way?
\end{tabular}




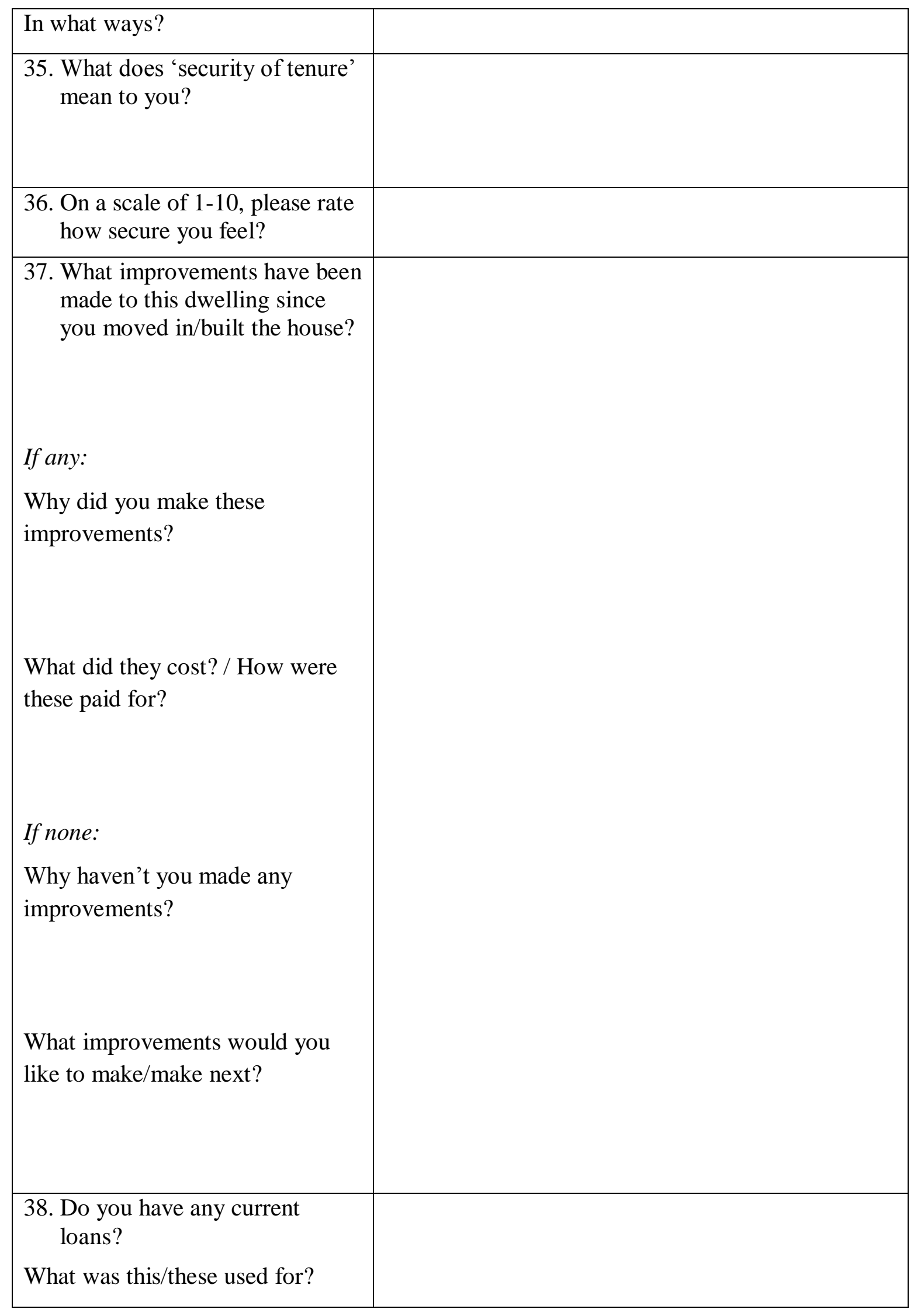




\begin{tabular}{|l|l|}
\hline $\begin{array}{l}\text { Source: } \\
\text { Monthly repayments: }\end{array}$ & \\
\hline $\begin{array}{l}\text { 39. Have you ever tried to get a } \\
\text { loan? }\end{array}$ & \\
$\begin{array}{l}\text { Do you think you could get a } \\
\text { loan? }\end{array}$ & \\
\begin{tabular}{l} 
Source: \\
\hline $\begin{array}{l}\text { 40. Has the community pooled } \\
\text { together and built/paid for any } \\
\text { community level } \\
\text { improvements? }\end{array}$
\end{tabular} \\
\hline $\begin{array}{l}\text { 41. Have politicians ever made } \\
\text { promises to this particular } \\
\text { community? }\end{array}$ & \\
\hline $\begin{array}{l}\text { 42. What could be done to } \\
\text { improve your security of } \\
\text { tenure (protection from } \\
\text { eviction)? }\end{array}$ & \\
\end{tabular}

Notes: 
Additional Questions for Displaced Farmers and Dependents:

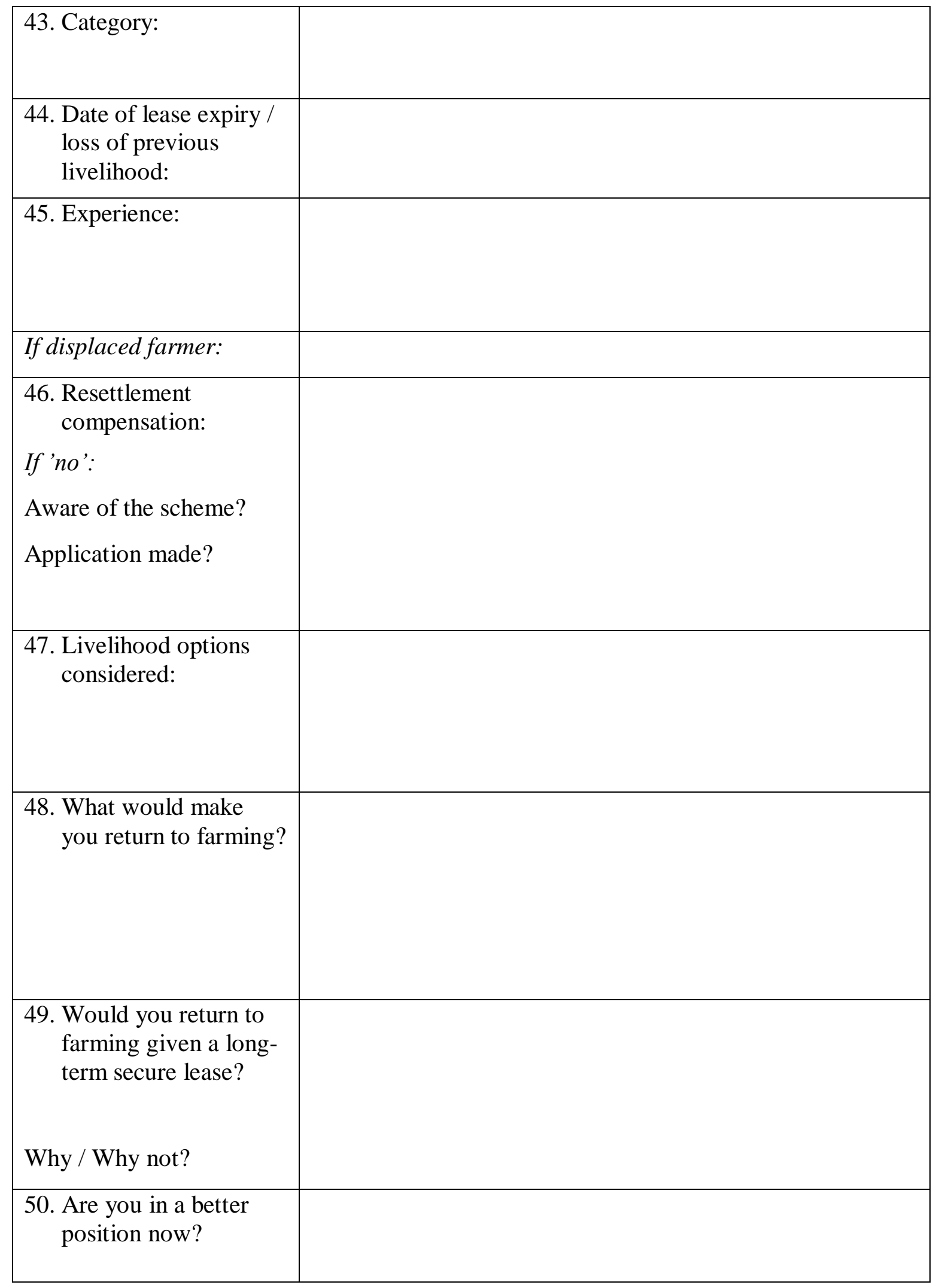




\begin{tabular}{|l|l|}
\hline $\begin{array}{l}\text { 51. Previous income } \\
\text { bracket: }\end{array}$ & \\
\hline 52. Links to old area: & \\
\hline $\begin{array}{l}\text { 53. Know of others that } \\
\text { moved/urbanised: }\end{array}$ & \\
$\begin{array}{l}\text { What of others who } \\
\text { worked for you? }\end{array}$ & \\
\hline $\begin{array}{l}\text { 54. Long-term plans: } \\
\text { Where to? }\end{array}$ & \\
\hline $\begin{array}{l}\text { 55. Are you happy here? } \\
\text { move out of this }\end{array}$ & \\
\hline
\end{tabular}

Notes: 


\title{
APPENDIX 3: INFORMATION SHEET AND CONSENT FORM
}

\author{
VICTORIA UNIVERSITY OF WELLINGTON \\ Te Whare Wananga o te Upoko o te Ika a Mani

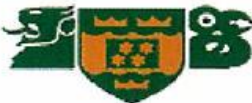

INFORMATION SHEET

Research:

Squatters, Land Tenure, Livelihoods and Intervention: A Case Study from Urban Fiji

June - November 2008

Bula! Namaste! My name is Luke Kiddle, I am a Development Studies PhD student from Victoria University of Wellington in New Zealand. I am undertaking research in Fijian squatter communities, and are currently attached to the Development Studies Program at the University of the South Pacific. The research has 3 key objectives:

1. To document the experience of contemporary urbanisation and squatter community growth in Fiji

2. To explore the dynamics of 'security of tenure' in urban Fiji, and the relationships that this might have to housing consolidation

3. To critically review current government, donor and NGO activity in squatter community development

I am interviewing residents of squatter communities. I will also be interviewing individuals working within various organisations involved in projects and programmes in squatter community development - including from government departments, aid donor agencies, and NGOs.

Interviews will not normally take longer than 45 minutes -1 hour.

The results of my research will be used to prepare and write my own thesis to be submitted around March 2010 and possibly for journal publication. Summary results are also likely to be presented at academic conferences. Research will primarily be for an academic audience - but will also be made available to the New Zealand Agency for International Development (NZAID) who provided some part funding, and also ECREA who have linked me with communities in the Suva-Nausori corridor. Upon request, results will also be made available to interested policy makers and organisations involved in low-income shelter provision/programmes. Please note that:

- Victoria University requires your approval before I ask you any questions. This approval can be written or oral.

Development Studies Department

SCHOOL OF GEGOGRAPHY, ENVIRONMENT AND EARTH SCIENCE

VICTORIA UNIVERSITY OF WELLINGTON

P.O. Box 600 , Wellington, New Zealand

Telephone 64-04-463-5645

Facsimile 64-04-463-5186 
- You have no obligation to participate in this research

- Information will not be tape recorded, but notes will be taken

- Interviews can occur at a time and place of vour choosing

- Interviews will be based around a number of questions around security of land tenure, the community in which you live, and the nature of your dwelling.

- All reporting will be confidential (that is results will be recorded in a way that can not be attributed directly to you), and only the researcher and my supervisors will have access to the information. You also have the option of providing your real name, a false name, or no name. Note that all information will be destroyed two years after the hand in of my thesis, and that no names will be used in reporting.

- On request you can withdraw yourself or any supplied information at any point prior to submission of the thesis (30 March 2010) upon contact with the researcher by (contact details below)

- You can request a summary of the research to be provided on completion

Luke Kiddle, $\mathrm{PhD}$ candidate in Development Studies, Victoria University of Wellington, Email: lukekiddle@gmail.com, Ph: 363 1241, 9074862

Main Supervisor: Professor John Overton, Director of Graduate Programme in Development Studies, School of Geography, Environment and Earth Sciences, Victoria University of Wellington, Email: John.Overton@vuw.ac.nz, Ph: + 6444721000

Co-supervisor: Associate Professor Warwick Murray, Reader in Human Geography and Development Studies, School of Geography, Environment and Earth Sciences, Email: Warwick.Murray@vuw.ac.nz, Ph: + 6444721000

Development Studies Department SCHOOL OF GEGOGRAPHY, ENVIRONMENT AND EARTH SCIENCE

VICTORIA UNIVERSITY OF WELLINGTON

P.O. Box 600 , Wellington, New Zealand

Telephone 64-04-463-5645

Facsimile 64-04-463-5186 


\section{VICTORIA UNIVERSITY OF WELLINGTON \\ Te Whare Wananga o te Upoko o te Ika a Mari

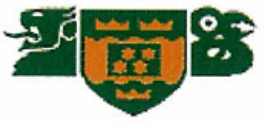

\section{CONSENT FORM}

Research:

Squatters, Land Tenure, Livelihoods and Intervention: A Case Study from Urban Fiji

June - November 2008

- I understand the purpose of this research project.

- I have had an opportunity to ask questions and have them answered to my satisfaction.

- I understand that I can withdraw from this research project without reason before analysis and reporting of results (by 30 March 2010), and in this case interview data will be destroyed.

- I understand that results will be confidential in that they can not be directly attributed to me.

- I understand that $I$ have the option of providing a real name, a false name, or no name at all, and that no names will be used in reporting.

- I am aware that the results will be used to prepare a thesis and possible article for journal publication, and be present at academic conferences.

Signature:

Name: (please provide a real name, a

false name, or no name if you wish)

I would like a summary of the research: YES [ ] NO [ ]

If yes, please provide mail details

Development Studies Department SCHOOL OF GEGOGRAPHY, ENVIRONMENT AND EARTH SCIENCE

VICTORIA UNIVERSITY OF WELLINGTON

P.O. Box 600, Wellington, New Zealand

Telephone 64-04-463-5645

Facsimile 64-04-463-5186 


\section{APPENDIX 4: LEAD INTERVIEWEE GENDER PROFILE}

\begin{tabular}{|l|r|r|r|}
\hline & Male & Female & Both* \\
\hline & & & \\
\hline Lagilagi & 4 & 12 & 4 \\
\hline Caubati Topline & 8 & 9 & 3 \\
\hline Lakena Hill Two & 4 & 15 & 1 \\
\hline Vunato & 5 & 15 & 0 \\
\hline Tomuka & 8 & 11 & 1 \\
\hline Tauvegavega & 10 & 7 & 3 \\
\hline Bouma & 6 & 8 & 1 \\
\hline & & & \\
\hline $\mathbf{n}$ & 45 & 77 & 13 \\
\hline \% Whole Sample & 33.33 & 57 & 9.66 \\
\hline
\end{tabular}

* Interview proceeded with both members of both sexes participating as interviewees 


\section{APPENDIX 5: ADDITIONAL FIELD RESEARCH DATA}

Tenure status:

Table A.1. Household Tenure Status, All Case Studies, Research Sample

\begin{tabular}{|l|r|r|r|}
\hline Community & Occupying Owners & Renting & \multicolumn{1}{l|}{ Other } \\
\hline & & & \\
\hline Lagilagi & 19 & 1 & 0 \\
\hline Caubati Topline & 18 & 2 & 0 \\
\hline Lakena Hill Two & 18 & 0 & 2 \\
\hline Vunato & 17 & 2 & 1 \\
\hline Tomuka & 16 & 2 & 2 \\
\hline Tauvegavega & 19 & 1 & 0 \\
\hline Bouma & 14 & 0 & 1 \\
\hline & & & \\
\hline $\mathbf{n}$ & 121 & 8 & 6 \\
\hline \% Whole Sample & 89.5 & 6 & 4.5 \\
\hline
\end{tabular}

Source: Fieldwork data 
Table A.2. Location of Previous Residence, All Case Studies, Research Sample

\begin{tabular}{|c|c|c|c|c|c|c|c|c|c|c|c|c|c|}
\hline Community & NA & Urbanalatea & Oother urban alea & & & & Rural area & & & & & & \\
\hline & & withinin Province & Central Div. & Nothem Div, & Westem Div. & Esstem Div. & Central Div. & Nothem Div. & & Westem Oiv. & Esstem Oiv. & & shore \\
\hline lagl|agi & & 3 & 5 & 0 & 1. & 0 & 0 & 8 & d & & d & 3 & \\
\hline Caubaiti Topline & & 0 & 17 & 1 & 0 & o & 0 & 1 & 1 & & 0 & 0 & \\
\hline Lakena hill Two & & 1 & 6 & 0 & 2 & 1 & 0 & 7 & 0 & & 1 & 1 & \\
\hline Vunato & & 0 & 9 & 0 & 0 & 2 & 0 & 2 & 1 & & 1 & 5 & \\
\hline Tomkla & & 0 & 12 & 0 & d & d & 0 & 1 & 0 & & 1 & 0 & \\
\hline Taweegalega & & 0 & 10 & 1 & 0 & $d$ & 0 & 0 & 0 & & 9 & 0 & \\
\hline Bouma & & 0 & 1 & 2 & 0 & 0 & 0 & 0 & 12 & & 0 & 0 & \\
\hline & & & & & & $T$ & t & & a & & & 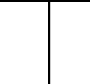 & \\
\hline n & & 4 & 6) & 4 & 3 & 3 & 0 & 19 & 14 & & 18 & 9 & \\
\hline \%Wholesample & & 3 & 45 & 3 & 2 & 2 & 0 & 14 & 10.5 & & 13.5 & 6.5 & \\
\hline
\end{tabular}


Access to informal settlements and payments:

Table A.3. Average Dwelling Purchase Prices, Fijian Dollars, All Case Studies, Research Sample

\begin{tabular}{|l|r|}
\hline Community & \multicolumn{1}{l|}{ lrice } \\
\hline Lagilagi & 590 \\
\hline Caubati Topline & 7,250 \\
\hline Lakena Hill Two & 3,700 \\
\hline Vunato & n.a. \\
\hline Tomuka & 3,500 \\
\hline Tauvegavega & 6,250 \\
\hline Bouma & 500 \\
\hline & \\
\hline Average all & 2,250 \\
\hline
\end{tabular}

Source: Fieldwork data

Livelihoods:

Table A.4. Percentages of Households Earning Supplementary Income, All Case Studies, Research Sample

\begin{tabular}{|l|r|r|}
\hline Community & Yes & No \\
\hline Lagilagi & 10 & 10 \\
\hline Caubati Topline & 4 & 16 \\
\hline Lakena Hill Two & 4 & 16 \\
\hline Vunato & 11 & 9 \\
\hline Tomuka & 4 & 16 \\
\hline Tauvegavega & 5 & 15 \\
\hline Bouma & 2 & 13 \\
\hline & & \\
\hline n & 40 & 95 \\
\hline \% Whole Sample & 29.5 & 70.5 \\
\hline
\end{tabular}

Source: Fieldwork data 
Table A.5. Forms of Supplementary Income, All Case Studies, Research Sample

\begin{tabular}{|c|c|c|c|c|c|c|c|c|c|c|}
\hline Community & Informal sector & Informal sector & & Farming/gardens & Family & Casual labour & Pension & Rental & Other & \\
\hline & retail & services & & & remittances & & & & & \\
\hline Lagilagi & 4 & & 0 & 2 & 1 & 1 & 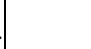 & 1 & 1 & 1 \\
\hline Caubati Topline & 0 & & 1 & 0 & 1 & 0 & 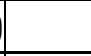 & 1 & 0 & 0 \\
\hline Lakena Hill Two & 0 & & 1 & 0 & 1 & 2 & 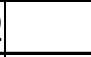 & 0 & 0 & 2 \\
\hline \begin{tabular}{|l|l|} 
Vunato \\
\end{tabular} & 4 & & 0 & 2 & 1 & 0 & 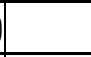 & 2 & 0 & 1 \\
\hline Tomuka & 0 & & 0 & 2 & 1 & 0 & 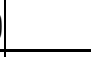 & 0 & 0 & 0 \\
\hline Tauvegavega & 1 & & 0 & 1 & 2 & 1 & 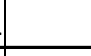 & 0 & 0 & 0 \\
\hline Bouma & 0 & & 0 & 1 & 0 & 0 & 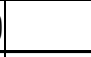 & 0 & 0 & 1 \\
\hline & & & & & & & & & & \\
\hline n & 9 & & 2 & 8 & 7 & 4 & 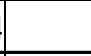 & 4 & 1 & 5 \\
\hline$\%$ & 22.5 & & 5 & 20 & 17.5 & 10 & & 10 & 2.5 & 12.5 \\
\hline
\end{tabular}

Source: Fieldwork data

Services and amenities:

Table A.6. Presence of Piped Water Supply, All Case Studies, Research Sample

\begin{tabular}{|l|r|r|r|}
\hline Commnunity & \multicolumn{2}{l|}{$\begin{array}{l}\text { Yes } \\
\text { (individual meter) }\end{array}$} & \multicolumn{2}{l|}{$\begin{array}{l}\text { (shared meter) } \\
\end{array}$} \\
\hline Lagilagi & 11 & 9 & 0 \\
\hline Caubati Topline & 15 & 5 & 0 \\
\hline Lakena Hill Two & 15 & 4 & 1 \\
\hline Vunato & 18 & 2 & 0 \\
\hline Tomuka & 18 & 2 & 0 \\
\hline Tauvegavega & 17 & 15 & 0 \\
\hline Bouma & 0 & 39 & 2 \\
\hline & 94 & 29 & 1.5 \\
\hline n & 69.5 & & \\
\hline \% Whole Sample & & 29 & 0 \\
\hline
\end{tabular}

Source: Fieldwork data 
Table A.7. Main Water Supply, Lagilagi, Caubati Topline, Lakena Hill Two and Tauvegavega, 2007 Census Information

\begin{tabular}{|l|r|r|r|r|r|}
\hline \multirow{2}{*}{} & \multicolumn{4}{|c|}{ Main Water Supply } \\
\cline { 2 - 7 } & \multicolumn{1}{|c|}{ Total } & \multicolumn{2}{|c|}{ Metered } & \multicolumn{2}{c|}{ Other } \\
\hline & \multicolumn{1}{c|}{$\mathbf{n}$} & $\mathbf{n}$ & \multicolumn{1}{c|}{$\boldsymbol{n}$} & $\mathbf{n}$ & \multicolumn{1}{c|}{} \\
\hline Lagilagi & 98 & 98 & 100 & 0 & 0 \\
\hline Caubati Topline & 148 & 148 & 100 & 0 & 0 \\
\hline Lakena Hill Two & 188 & 181 & 96 & 7 & 4 \\
\hline Tauvegavega & 161 & 151 & 94 & 10 & 6 \\
\hline
\end{tabular}

Source: Fiji 2007 census data made available directly

Table A.8. Electricity Coverage, All Case Studies, Research Sample

\begin{tabular}{|l|r|r|r|r|}
\hline Community & \multicolumn{1}{l|l|}{$\begin{array}{l}\text { Yes } \\
\text { (individual meter) }\end{array}$} & $\begin{array}{l}\text { Generator } \\
\text { (shared meter) }\end{array}$ & \\
\hline Lagilagi & 0 & 18 & 0 & 2 \\
\hline Caubati Topline & 13 & 5 & 0 & 2 \\
\hline Lakena Hill Two & 12 & 3 & 0 & 1 \\
\hline Vunato & 14 & 5 & 0 & 2 \\
\hline Tomuka & 16 & 2 & 0 & 3 \\
\hline Tauvegavega & 16 & 1 & 5 & 10 \\
\hline Bouma & 0 & 0 & 5 & 25 \\
\hline & 71 & 34 & 4 & 18.5 \\
\hline n & 52.5 & 25 & & \\
\hline \% Whole Sample & & & & \\
\hline
\end{tabular}

Source: Fieldwork data

Table A.9. Main Electricity Supply, Lagilagi, Caubati Topline, Lakena Hill Two and Tauvegavega, 2007 Census Information

\begin{tabular}{|l|r|r|r|r|r|}
\hline & \multicolumn{4}{|c|}{ Main Electricity Supply } \\
\cline { 2 - 6 } & \multicolumn{1}{|c|}{ Total } & \multicolumn{2}{|c|}{ FEA } & \multicolumn{2}{c|}{ Other } \\
\hline & \multicolumn{1}{c|}{$\mathbf{n}$} & \multicolumn{1}{c|}{$\mathbf{n}$} & \multicolumn{1}{c|}{$\mathbf{n}$} & \multicolumn{1}{c|}{} \\
\hline Lagilagi & 98 & 98 & 100 & 0 & 0 \\
\hline Caubati Topline & 148 & 148 & 100 & 0 & 0 \\
\hline Lakena Hill Two & 188 & 153 & 81.5 & 35 & 18.5 \\
\hline Tauvegavega & 161 & 149 & 92.5 & 12 & 7.5 \\
\hline
\end{tabular}

\section{* Fiji Electricty Authority}


Table A.10. Telephone Coverage, All Case Studies, Research Sample

\begin{tabular}{|c|c|c|c|c|c|}
\hline Community & \multirow{2}{*}{$\begin{array}{l}\text { Landline } \\
\text { only }\end{array}$} & \multirow{2}{*}{$\begin{array}{l}\text { Mobiles } \\
\text { only }\end{array}$} & \multirow[t]{2}{*}{ Both } & \multirow[t]{2}{*}{ None } & \multirow[t]{2}{*}{ Unsure } \\
\hline & & & & & \\
\hline Lagilagi & 0 & 10 & 9 & 1 & 0 \\
\hline Caubati Topline & 1 & 10 & 9 & 0 & 0 \\
\hline Lakena Hill Two & 1 & 8 & 9 & 2 & 0 \\
\hline Vunato & 2 & 15 & 3 & 0 & 0 \\
\hline Tomuka & 0 & 13 & 6 & 0 & 1 \\
\hline Tauvegavega & 0 & 13 & 7 & 0 & 0 \\
\hline Bouma & 0 & 13 & 2 & 0 & 0 \\
\hline & & & & & \\
\hline n & 4 & 82 & 45 & 3 & 1 \\
\hline \% Whole Sample & 3 & 61 & 33 & 2 & 1 \\
\hline
\end{tabular}

Source: Fieldwork data

Table A.1 1. Toilet Facilities, All Case Studies, Research Sample

\begin{tabular}{|l|r|r|r|r|r|}
\hline & Flush & Waterseal & Pit & None & Unsure \\
\hline Lagilagi & 11 & 5 & 3 & 0 & 1 \\
\hline Caubati Topline & 18 & 0 & 2 & 0 & 0 \\
\hline Lakena Hill Two & 14 & 3 & 3 & 0 & 0 \\
\hline Vunato & 12 & 1 & 7 & 0 & 0 \\
\hline Tomuka & 17 & 0 & 3 & 0 & 0 \\
\hline Tauvegavega & 14 & 0 & 5 & 0 & 1 \\
\hline Bouma & 3 & 3 & 8 & 1 & 0 \\
\hline & & & & & 2 \\
\hline n & 89 & 12 & 31 & 1 & 1.5 \\
\hline \% Whole Sample & 66 & 9 & 23 & 0.5 & \\
\hline
\end{tabular}

Source: Fieldwork data

Table A.12. Toilet Facilities, Lagilagi, Caubati Topline, Lakena Hill Two and Tauvegavega, 2007 Census Information

\begin{tabular}{|c|c|c|c|c|c|c|c|}
\hline & \multicolumn{3}{|c|}{ Toilet Facilities } & \multirow{2}{*}{\multicolumn{2}{|c|}{ Waterseal }} & & \\
\hline & Total & Flu & & & & \multicolumn{2}{|c|}{ Latrine } \\
\hline & $n$ & $\mathbf{n}$ & $\%$ & \begin{tabular}{l|l}
$\mathbf{n}$ \\
\end{tabular} & $\%$ & n & $\%$ \\
\hline Lagilagi & 98 & 64 & 65.5 & 14 & 14 & 20 & 20.5 \\
\hline Caubati Topline & 148 & 148 & 100 & 0 & 0 & 0 & 0 \\
\hline Lakena Hill Two & 188 & 143 & 76 & 13 & 7 & 32 & 17 \\
\hline Tauvegavega & 161 & 108 & 67 & 0 & 0 & 53 & 33 \\
\hline
\end{tabular}

Source: Fiji 2007 census data made available directly 
Table A.13. Principal Method of Rubbish Disposal (Weighted Average), All Case Studies,

Research Sample

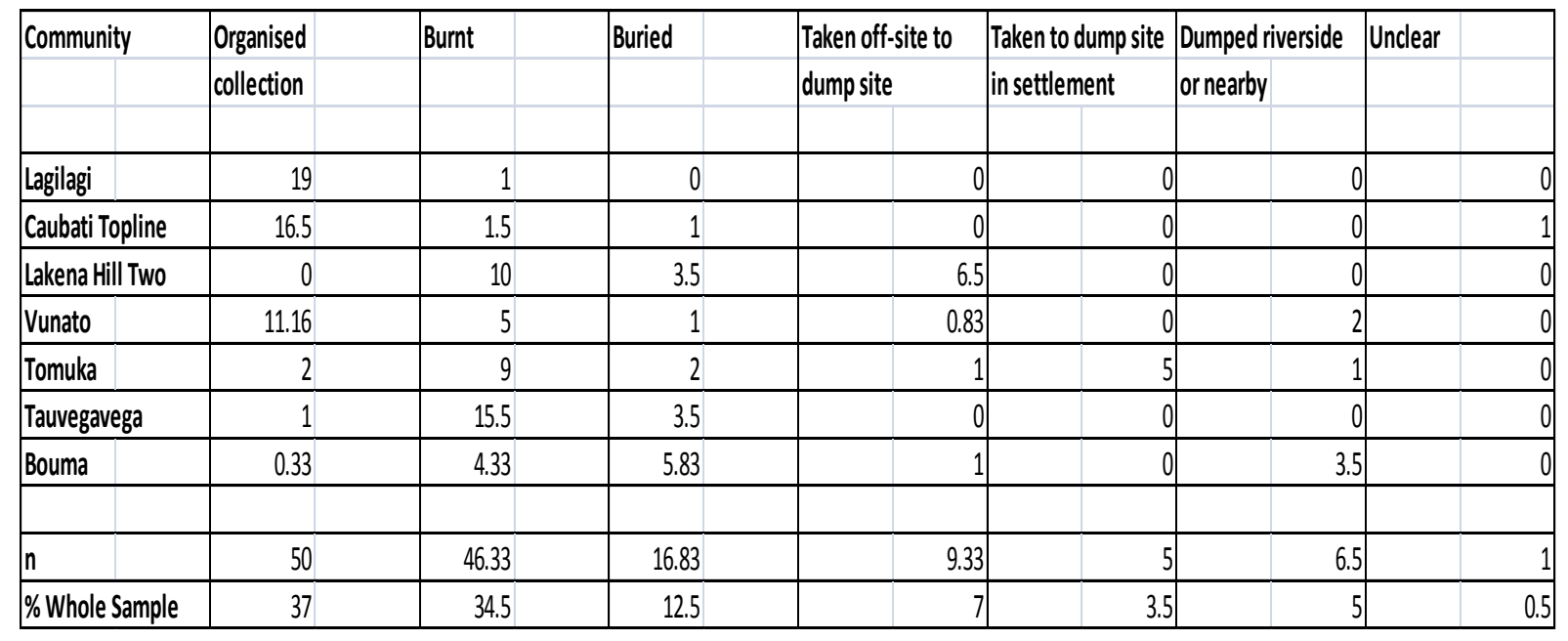

Source: Fieldwork data

Table A.14. Main Cooking Method (Weighted Average), All Case Studies, Research

Sample

\begin{tabular}{|l|r|r|r|r|}
\hline Community & Gas & Fire & \multicolumn{2}{l|}{$\begin{array}{l}\text { Kerosene } \\
\text { stove }\end{array}$} \\
& & & & Unsure \\
& 1 & 11 & 8 & 0 \\
\hline Lagilagi & 4 & 6.5 & 9.5 & 0 \\
\hline Caubati Topline & 0.83 & 8.83 & 9.33 & 1 \\
\hline Lakena Hill Two & 1 & 17 & 2 & 0 \\
\hline Vunato & 1.66 & 9.66 & 8.66 & 0 \\
\hline Tomuka & 0 & 18 & 1 & 1 \\
\hline Tauvegavega & 0 & 14 & 1 & 0 \\
\hline Bouma & & & & \\
\hline & 8.5 & 85 & 39.5 & 2 \\
\hline n & 6.5 & 63 & 29 & 1.5 \\
\hline
\end{tabular}

Source: Fieldwork data 


\section{APPENDIX 6: KEY INTERVIEW PARTICULARS}

Lagilagi:

\begin{tabular}{|c|c|c|c|c|c|c|c|c|}
\hline Interview & Ethnicity & Length of Residence & Average Monthly & House Tenure & Percieved Security & Evidence of Housing & Access to Formal & Date of \\
\hline & & (years) & Income (F\$) & & of Tenure & Consolidation & Credit & Interview \\
\hline LL1 & Indigenous Fijian & 10 & $?$ & Occupying Owner & Positive & Yes & No & $23 / 07 / 2008$ \\
\hline LL2 & Indigenous Fijian & 20 & 480 & Occupying Owner & Positive & Yes & No & $5 / 08 / 2008$ \\
\hline LL3 & Indigenous Fijian & 20 & 600 & Occupying Owner & Positive & Yes & No & $18 / 08 / 2008$ \\
\hline LL4 & Indigenous Fijian & 45 & 100 & Occupying Owner & Positive & Yes & No & $25 / 08 / 2008$ \\
\hline LL5 & Indigenous Fijian & 10 & $?$ & Occupying Owner & Positive & Yes & No & $25 / 08 / 2008$ \\
\hline LL6 & Indigenous Fijian & 36 & 800 & Occupying Owner & Positive & Yes & Yes & $27 / 08 / 2008$ \\
\hline LL7 & Indigenous Fijian & 26 & 400 & Occupying Owner & Positive & Yes & No & $27 / 08 / 2008$ \\
\hline LL8 & Indigenous Fijian & 40 & 320 & Occupying Owner & $?$ & No & No & $30 / 08 / 2008$ \\
\hline LL9 & Indigenous Fijian & 36 & 360 & Occupying Owner & $+/-$ & No & No & $30 / 08 / 2008$ \\
\hline LL10 & Indigenous Fijian & 33 & 480 & Renting & Positive & No & Yes & $1 / 09 / 2008$ \\
\hline LL11 & Indigenous Fijian & 40 & 800 & Occupying Owner & $+/-$ & Yes & No & $1 / 09 / 2008$ \\
\hline LL12 & Indigenous Fijian & 21 & 920 & Occupying Owner & $?$ & No & No & $1 / 09 / 2008$ \\
\hline LL13 & Indigenous Fijian & 40 & 240 & Occupying Owner & $?$ & No & Yes & $23 / 09 / 2008$ \\
\hline LL14 & Indigenous Fijian & 27 & 400 & Occupying Owner & $+/-$ & Yes & No & $23 / 09 / 2008$ \\
\hline LL15 & Indigenous Fijian & 21 & 740 & Occupying Owner & $?$ & No & No & $24 / 09 / 2008$ \\
\hline LL16 & Indigenous Fijian & 21 & 727 & Occupying Owner & $?$ & Yes & No & $25 / 09 / 2008$ \\
\hline LL17 & Indigenous Fijian & 23 & 880 & Occupying Owner & $?$ & Yes & No & $25 / 09 / 2008$ \\
\hline LL18 & Indigenous Fijian & 39 & 868 & Occupying Owner & $+/-$ & Yes & No & $29 / 08 / 2008$ \\
\hline LL19 & Indo-Fijian & 21 & 80 & Occupying Owner & $+/-$ & Yes & No & $24 / 09 / 2008$ \\
\hline LL20 & Indo-Fijian & 60 & 648 & Occupying Owner & Negative & Yes & No & $31 / 08 / 2008$ \\
\hline
\end{tabular}


Caubati Topline:

\begin{tabular}{|c|c|c|c|c|c|c|c|c|}
\hline Interview & Ethnicity & Length of Residence & Average Monthly & House Tenure & Percieved Security & Evidence of Housing & Access to Formal & Date of \\
\hline & & (years) & Income (F\$) & & of Tenure & Consolidation & Credit & Interview \\
\hline TL1 & Indigenous Fijian & 8 & 852 & Occupying Owner & $+/-$ & Yes & No & $8 / 10 / 2008$ \\
\hline TL2 & Indigenous Fijian & 1 & 480 & Renting & $+/-$ & No & Yes & $27 / 09 / 2008$ \\
\hline $\mathrm{TL3}$ & Indigenous Fijian & 5 & 280 & Occupying Owner & Positive & Yes & No & $27 / 09 / 2008$ \\
\hline TL4 & Indigenous Fijian & 1 & 644 & Renting & Positive & No & Yes & $31 / 08 / 2008$ \\
\hline TL5 & Indigenous Fijian & 9 & $?$ & Occupying Owner & $?$ & Yes & No & $27 / 08 / 2008$ \\
\hline TL6 & Indigenous Fijian & 21 & 140 & Occupying Owner & Positive & Yes & No & $16 / 08 / 2008$ \\
\hline TL7 & Indo-Fijian & 14 & 300 & Occupying Owner & Postive & Yes & No & $24 / 08 / 2008$ \\
\hline TL8 & Indo-Fijian & 9 & 450 & Occupying Owner & Positive & No & No & $17 / 08 / 2008$ \\
\hline TL9 & Indo-Fijian & 1 & 1430 & Occupying Owner & Positive & Yes & Yes & $19 / 08 / 2008$ \\
\hline TL10 & Indo-Fijian & 3 & 840 & Occupying Owner & Positive & Yes & No & $24 / 08 / 2008$ \\
\hline TL11 & Indo-Fijian & 8 & 800 & Occupying Owner & Positive & Yes & No & $27 / 08 / 2008$ \\
\hline TL12 & Indo-Fijian & 1 & 335 & Occupying Owner & $?$ & No & No & $28 / 08 / 2008$ \\
\hline TL13 & Indo-Fijian & 2 & 1056 & Occupying Owner & $?$ & Yes & No & $28 / 08 / 2008$ \\
\hline TL14 & Indo-Fijian & 8 & 260 & Occupying Owner & $+/-$ & Yes & No & $31 / 08 / 2008$ \\
\hline TL15 & Indo-Fijian & 10 & 500 & Occupying Owner & Positive & No & No & $2 / 09 / 2008$ \\
\hline TL16 & Indo-Fijian & 8 & 540 & Occupying Owner & $+/-$ & No & No & $3 / 09 / 2008$ \\
\hline TL17 & Indo-Fijian & 6 & 1140 & Occupying Owner & Negative & No & No & $24 / 09 / 2008$ \\
\hline TL18 & Indo-Fijian & 6 & 735 & Occupying Owner & Negative & Yes & Yes & $27 / 09 / 2008$ \\
\hline TL19 & Indo-Fijian & 3 & 225 & Occupying Owner & Negative & No & No & $30 / 09 / 2008$ \\
\hline TL2O & Indo-Fijian & 9 & 320 & Occupying Owner & Positive & No & No & $30 / 09 / 2008$ \\
\hline
\end{tabular}


Lakena Hill Two:

\begin{tabular}{|c|c|c|c|c|c|c|c|c|}
\hline Interview & Ethnicity & Length of Residence & Average Monthly & House Tenure & Percieved Security & Evidence of Housing & Access to Formal & Date of \\
\hline & & (years) & Income (F\$) & & of Tenure & Consolidation & Credit & Interview \\
\hline $\mathrm{L} 1$ & Indigenous Fijian & 5 & 528 & Occupying Owner & $+/-$ & Yes & No & $9 / 10 / 2008$ \\
\hline L2 & Indigenous Fijian & 14 & 910 & Occupier & Positive & No & Yes & $9 / 10 / 2008$ \\
\hline L3 & Indigenous Fijian & 14 & 200 & Occupying Owner & $?$ & Yes & No & 23/07/2008 \\
\hline$\llcorner 4$ & Indigenous Fijian & 17 & $?$ & Occupying Owner & Positive & Yes & No & $4 / 08 / 2008$ \\
\hline $\mathrm{L} 5$ & Indigenous Fijian & 18 & 60 & Occupying Owner & Negative & Yes & No & 23/07/2008 \\
\hline$L 6$ & Indigenous Fijian & 10 & 400 & Occupying Owner & Positive & Yes & No & $4 / 08 / 2008$ \\
\hline L7 & Indigenous Fijian & 16 & 360 & Occupying Owner & Positive & No & No & $20 / 08 / 2008$ \\
\hline 18 & Indigenous Fijian & 4 & 300 & Occupying Owner & $?$ & No & No & $20 / 08 / 2008$ \\
\hline L9 & Indigenous Fijian & 4 & 60 & Occupying Owner & $?$ & Yes & No & $21 / 08 / 2008$ \\
\hline $\mathrm{L} 10$ & Indigenous Fijian & 25 & 400 & Occupying Owner & $+/-$ & No & No & $21 / 08 / 2008$ \\
\hline L11 & Indigenous Fijian & 20 & 1120 & Occupying Owner & Negative & No & No & $26 / 09 / 2008$ \\
\hline $\mathrm{L} 12$ & Indo-Fijian & 28 & 400 & Occupying Owner & Positive & Yes & No & 4/08/2008 \\
\hline $\mathrm{L} 13$ & Indo-Fijian & 8 & 400 & Occupying Owner & Positive & No & No & $20 / 08 / 2008$ \\
\hline $\mathrm{L} 14$ & Indo-Fijian & 26 & 350 & Occupying Owner & Positive & Yes & No & $21 / 08 / 2008$ \\
\hline L15 & Indo-Fijian & 33 & 480 & Occupying Owner & $+1-$ & Yes & No & $29 / 08 / 2008$ \\
\hline L16 & Indo-Fijian & 25 & 600 & Occupying Owner & Positive & Yes & No & $29 / 08 / 2008$ \\
\hline $\mathrm{L} 17$ & Indo-Fijian & 22 & 618 & Occupier & Positive & No & No & $3 / 09 / 2008$ \\
\hline L18 & Indo-Fijian & 26 & 640 & Occupying Owner & $?$ & Yes & Yes & $3 / 09 / 2008$ \\
\hline $\mathrm{L} 19$ & Indo-Fijian & 24 & 480 & Occupying Owner & Positive & Yes & No & $9 / 10 / 2008$ \\
\hline L20 & Other & 16 & 200 & Occupying Owner & $?$ & Yes & No & $26 / 09 / 2008$ \\
\hline
\end{tabular}


Vunato:

\begin{tabular}{|c|c|c|c|c|c|c|c|c|}
\hline Interview & Ethnicity & Length of Residence & Average Monthly & House Tenure & Percieved Security & Evidence of Housing & Access to Formal & Date of \\
\hline & & (years) & Income (F\$) & & of Tenure & Consolidation & Credit & Interview \\
\hline V1 & Indigenous Fijian & 16 & 840 & Occupying Owner & $+/-$ & Yes & No & $17 / 10 / 2008$ \\
\hline V2 & Indigenous Fijian & 9 & 1860 & Occupying Owner & $+/-$ & Yes & No & $17 / 10 / 2008$ \\
\hline V3 & Indigenous Fijian & 10 & 555 & Occupying Owner & $+/-$ & Yes & No & $17 / 10 / 2008$ \\
\hline V4 & Indigenous Fijian & 20 & 800 & Occupying Owner & Negative & Yes & Yes & $10 / 09 / 2008$ \\
\hline V5 & Indigenous Fijian & 7 & 1960 & Renting & Negative & Yes & No & $10 / 09 / 2008$ \\
\hline V6 & Indigenous Fijian & 40 & 1060 & Occupying Owner & Positive & No & No & $10 / 09 / 2008$ \\
\hline V7 & Indigenous Fijian & 6 & $?$ & Occupying Owner & Positive & No & No & $12 / 09 / 2008$ \\
\hline V8 & Indigenous Fijian & 26 & 1120 & Occupying Owner & $?$ & No & Yes & $12 / 09 / 2008$ \\
\hline V9 & Indigenous Fijian & 17 & 1420 & Occupying Owner & $?$ & No & No & $17 / 09 / 2008$ \\
\hline V10 & Indigenous Fijian & 18 & 680 & Occupying Owner & Positive & Yes & No & $16 / 09 / 2008$ \\
\hline V11 & Indigenous Fijian & 23 & 390 & Occupying Owner & Positive & No & Yes & $15 / 09 / 2008$ \\
\hline V12 & Indigenous Fijian & 5 & 600 & Renting & Positive & No & No & $16 / 09 / 2008$ \\
\hline V13 & Indigenous Fijian & 45 & 680 & Occupying Owner & Positive & No & No & $17 / 09 / 2008$ \\
\hline V14 & Indigenous Fijian & 13 & 320 & Occupying Owner & Positive & No & Yes & $17 / 09 / 2008$ \\
\hline V15 & Indigenous Fijian & 9 & 590 & Occupying Owner & Positive & No & No & $17 / 09 / 2008$ \\
\hline V16 & Indigenous Fijian & 5 & 980 & Other & $+/-$ & Yes & Yes & $18 / 09 / 2008$ \\
\hline V17 & Indigenous Fijian & 9 & 2264 & Occupying Owner & $+/-$ & Yes & Yes & $18 / 09 / 2008$ \\
\hline V18 & Indigenous Fijian & 8 & 470 & Occupying Owner & Positive & No & No & $10 / 09 / 2008$ \\
\hline V19 & Indigenous Fijian & 25 & 675 & Occupying Owner & $+/-$ & No & No & $19 / 09 / 2008$ \\
\hline V20 & Indigenous Fijian & 44 & 1080 & Occupying Owner & Positive & Yes & No & $19 / 09 / 2008$ \\
\hline
\end{tabular}


Tomuka:

\begin{tabular}{|c|c|c|c|c|c|c|c|c|}
\hline Interview & Ethnicity & Length of Residence & Average Monthly & House Tenure & Percieved Security & Evidence of Housing & Access to Formal & Date of \\
\hline & & (years) & Income (F\$) & & of Tenure & Consolidation & Credit & Interview \\
\hline To1 & Indigenous Fijian & 13 & 740 & Occupier & $?$ & Yes & No & $17 / 10 / 2008$ \\
\hline T02 & Indigenous Fijian & 5 & 1142 & Renting & Negative & No & No & $16 / 10 / 2008$ \\
\hline T03 & Indigenous Fijian & 9 & 405 & Occupier & Positive & No & No & $16 / 10 / 2008$ \\
\hline To4 & Indigenous Fijian & 1 & 760 & Renting & Negative & No & No & $12 / 09 / 2008$ \\
\hline T05 & Indo-Fijian & 28 & 900 & Occupying Owner & $+/-$ & No & Yes & $18 / 10 / 2008$ \\
\hline To6 & Indo-Fijian & 30 & 600 & Occupying Owner & $+/-$ & No & Yes & $18 / 10 / 2008$ \\
\hline To7 & Indo-Fijian & 27 & 0 & Occupying Owner & $+/-$ & No & No & $18 / 10 / 2008$ \\
\hline T08 & Indo-Fijian & 1 & 340 & Occupying Owner & $+/-$ & No & No & $18 / 10 / 2008$ \\
\hline To9 & Indo-Fijian & 14 & 772 & Occupying Owner & $?$ & Yes & No & $17 / 10 / 2008$ \\
\hline To10 & Indo-Fijian & 9 & 880 & Occupying Owner & $+/-$ & Yes & No & $17 / 10 / 2008$ \\
\hline To11 & Indo-Fijian & 8 & 320 & Occupying Owner & $+/-$ & Yes & No & $19 / 10 / 2008$ \\
\hline To12 & Indo-Fijian & 24 & 1320 & Occupying Owner & Positive & No & No & $20 / 10 / 2008$ \\
\hline To13 & Indo-Fijian & 35 & 800 & Occupying Owner & $+/-$ & No & No & $20 / 10 / 2008$ \\
\hline To14 & Indo-Fijian & 5 & 300 & Occupying Owner & Positive & No & No & $20 / 10 / 2008$ \\
\hline To15 & Indo-Fijian & 31 & 1522 & Occupying Owner & Negative & No & Yes & $21 / 10 / 2008$ \\
\hline To16 & Indo-Fijian & 26 & 425 & Occupying Owner & Negative & No & Yes & $21 / 10 / 2008$ \\
\hline To17 & Indo-Fijian & 17 & 90 & Occupying Owner & Negative & Yes & No & $30 / 10 / 2008$ \\
\hline To18 & Indo-Fijian & 14 & 1720 & Occupying Owner & Negative & Yes & No & $30 / 10 / 2008$ \\
\hline To19 & Indigenous Fijian & 4 & 460 & Occupying Owner & Positive & Yes & No & $20 / 10 / 2008$ \\
\hline To20 & Indigenous Fijian & 48 & 1000 & Occupying Owner & $+/-$ & No & No & $19 / 10 / 2008$ \\
\hline
\end{tabular}


Iauvegavega:

\begin{tabular}{|c|c|c|c|c|c|c|c|c|}
\hline Interview & Ethnicity & Length of Residence & Average Monthly & House Tenure & Percieved Security & Evidence of Housing & Access to Formal & Date of \\
\hline & & (years) & Income (F\$) & & of Tenure & Consolidation & Credit & Interview \\
\hline $\mathrm{T} 1$ & Indigenous Fijian & 5 & 320 & Occupying Owner & $?$ & Yes & No & $9 / 09 / 2008$ \\
\hline $\mathrm{T} 2$ & Indigenous Fijian & 1 & 300 & Renting & +- & No & No & $14 / 10 / 2008$ \\
\hline T3 & Indo-Fijian & 1 & 1790 & Occupying Owner & Positive & Yes & Yes & $10 / 09 / 2008$ \\
\hline T4 & Indo-Fijian & 15 & 760 & Occupying Owner & Positive & Yes & No & $10 / 09 / 2008$ \\
\hline $\mathrm{T} 5$ & Indo-Fijian & 10 & 410 & Occupying Owner & Negative & Yes & No & $11 / 09 / 2008$ \\
\hline T6 & Indo-Fijian & 12 & 340 & Occupying Owner & Positive & No & No & $14 / 09 / 2008$ \\
\hline $\mathrm{T} 7$ & Indo-Fijian & 8 & 260 & Occupying Owner & Positive & Yes & No & $14 / 09 / 2008$ \\
\hline T8 & Indo-Fijian & 13 & 60 & Occupying Owner & Negative & Yes & No & $14 / 09 / 2008$ \\
\hline T9 & Indo-Fijian & 6 & 100 & Occupying Owner & $+/-$ & Yes & No & $18 / 09 / 2008$ \\
\hline $\mathrm{T} 10$ & Indo-Fijian & 24 & 1020 & Occupying Owner & Positive & No & No & $18 / 09 / 2008$ \\
\hline T11 & Indo-Fijian & 34 & 660 & Occupying Owner & Negative & Yes & Yes & $13 / 09 / 2008$ \\
\hline $\mathrm{T} 12$ & Indo-Fijian & 12 & 156 & Occupying Owner & Positive & No & No & $13 / 09 / 2008$ \\
\hline $\mathrm{T} 13$ & Indo-Fijian & 11 & 800 & Occupying Owner & $?$ & Yes & No & $16 / 09 / 2008$ \\
\hline $\mathrm{T} 14$ & Indo-Fijian & 7 & 89 & Occupying Owner & $+/-$ & Yes & No & $16 / 09 / 2008$ \\
\hline $\mathrm{T} 15$ & Indo-Fijian & 12 & 368 & Occupying Owner & Positive & Yes & No & $16 / 09 / 2008$ \\
\hline $\mathrm{T} 16$ & Indo-Fijian & 30 & 840 & Occupying Owner & Negative & Yes & Yes & $15 / 10 / 2008$ \\
\hline $\mathrm{T} 17$ & Indo-Fijian & 8 & 240 & Occupying Owner & Positive & Yes & No & $14 / 10 / 2008$ \\
\hline T18 & Indo-Fijian & 5 & 400 & Occupying Owner & Positive & No & No & $14 / 19 / 08$ \\
\hline $\mathrm{T} 19$ & Indo-Fijian & 8 & 500 & Occupying Owner & Negative & Yes & No & $15 / 10 / 2008$ \\
\hline $\mathrm{T} 20$ & Indo-Fijian & 8 & 240 & Occupying Owner & Negative & No & No & $10 / 09 / 2008$ \\
\hline
\end{tabular}


Bouma:

\begin{tabular}{|c|c|c|c|c|c|c|c|c|}
\hline Interview & Ethnicity & Length of Residence & Average Monthly & House Tenure & Percieved Security & Evidence of Housing & Access to Formal & Date of \\
\hline & & (years) & Income (F\$) & & of Tenure & Consolidation & Credit & Interview \\
\hline B1 & Indigenous Fijian & 15 & 480 & Occupying Owner & Positive & No & No & 2/10/2008 \\
\hline$B 2$ & Indigenous Fijian & 1 & 190 & Occupying Owner & $+/-$ & No & No & $2 / 10 / 2008$ \\
\hline B3 & Indigenous Fijian & 4 & 680 & Occupying Owner & Positive & No & Yes & $3 / 10 / 2008$ \\
\hline B4 & Indigenous Fijian & 1 & 348 & Occupying Owner & $+/-$ & Yes & No & $6 / 10 / 2008$ \\
\hline B5 & Indigenous Fijian & 1 & 85 & Occupier & $+/-$ & No & No & $6 / 10 / 2008$ \\
\hline B6 & Indigenous Fijian & 11 & $?$ & Occupying Owner & Positive & No & No & $6 / 10 / 2008$ \\
\hline B7 & Indigenous Fijian & 2 & 400 & Occupying Owner & Positive & Yes & No & $5 / 10 / 2008$ \\
\hline B8 & Indigenous Fijian & 3 & 512 & Occupying Owner & Positive & Yes & No & $5 / 10 / 2008$ \\
\hline B9 & Indigenous Fijian & 10 & 425 & Occupying Owner & $?$ & No & No & $5 / 10 / 2008$ \\
\hline $\mathrm{B} 10$ & Indigenous Fijian & 8 & $?$ & Occupying Owner & $+/-$ & Yes & Yes & $4 / 10 / 2008$ \\
\hline B11 & Indo-Fijian & 7 & 364 & Occupying Owner & Positive & Yes & No & $4 / 10 / 2008$ \\
\hline B12 & Indo-Fijian & 3 & 150 & Occupying Owner & Positive & No & No & $3 / 10 / 2008$ \\
\hline $\mathrm{B} 13$ & Indo-Fijian & 1 & $?$ & Occupying Owner & Negative & No & No & $2 / 10 / 2008$ \\
\hline B14 & Indo-Fijian & 18 & 360 & Occupying Owner & Negative & Yes & No & $2 / 10 / 2008$ \\
\hline B15 & Other & 13 & 280 & Occupying Owner & Positive & Yes & No & $3 / 10 / 2008$ \\
\hline
\end{tabular}

